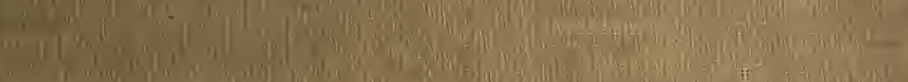

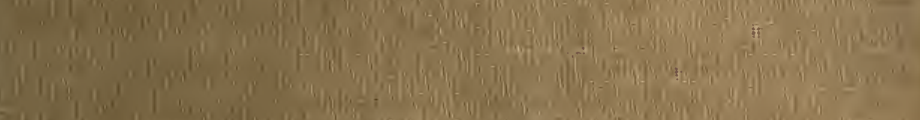

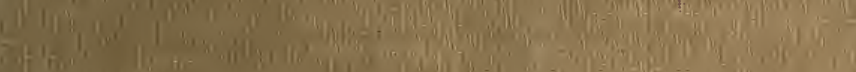
If

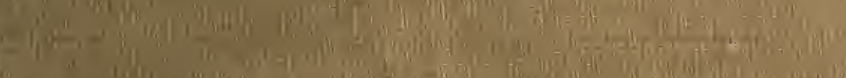

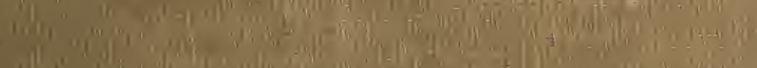
(1)

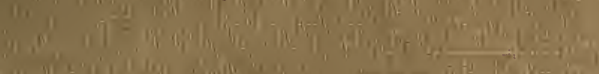

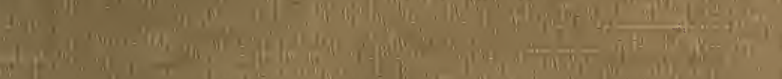
at If

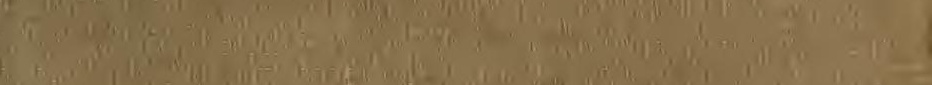

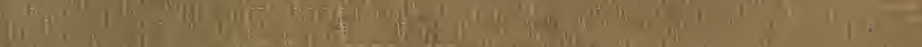

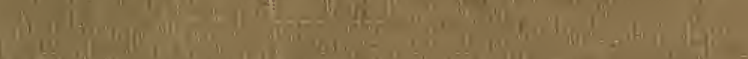




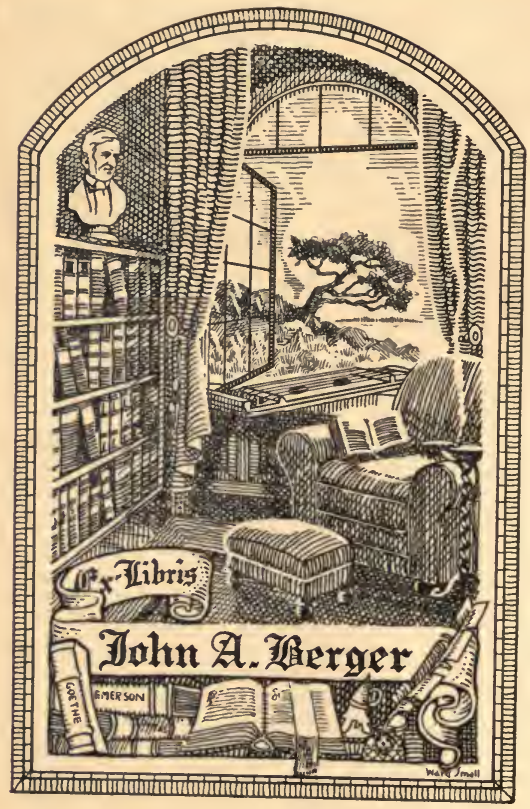




$$
\begin{aligned}
& \text { g. W. Buquer. } \\
& 12 \text { Collegelfs. } \\
& \text { Cthare, } \\
& 1912 \\
& \text { Hy }
\end{aligned}
$$






$$
\text { - }
$$




\section{GENERAL BIOLOGY}

A Book of Outlines and Practical Studies for the General Student

\section{By JAMES G. NEEDHAM, Ph.D.}

ASSISTANT PROFESSOR OF LIMNOLOGY AND GENERAL BIOLOGY IN CORNELL UNIVERSITY

WITH 64 PRACTICAL STUDIES, 287 TEXT FIGURES, AND 9 PORTRAITS

ITHACA, N. Y.

THE COMSTOCK PUBLISHING CO., 1910 
COPYRIGHT, I9Io

BY

Comstock Publishing Co. 
TO THE MEMORY OF

\section{$\begin{array}{llllllll}\mathrm{J} & \mathrm{O} & \mathrm{H} & \mathrm{N} & \mathrm{G} & \mathrm{O} & \mathrm{R} & \mathrm{E}\end{array}$}

- MY TEACHER IN THE DISTRICT SCHOOL, WHO FIRST TAUGHT ME THE USE OF A PRINCIPLE AS A TOOL OF THE MIND. 



\section{PREFACE.}

This book offers a series of practical studies of biological phenomena for the guidance of the general student. It is not a formal text, and not at all a treatise, but only a guide intended to assist the student in acquiring for himself some real knowledge of living nature. It differs chiefly from other books intended for the use of college classes in the wider range of studies it offers, some important phases of biology having hitherto been dismissed with mere didactic instruction. Morphology has dominated-often monopolized-college work in biology in the past; doubtless, because it was first reduced to pedagogic form, and made available for laboratory instruction. A more equable treatment is here attempted, in the hope of leading the student to a practical acquaintance with elementary phenomena in the whole broad field.

The generation of biologists which began its studies with Huxley and Martin's pioneer laboratory manual has witnessed a marvelous expansion of biological knowledge. Departments have sprung up, and teachers as well as practitioners have specialized, and courses have multiplied amazingly. Yet I am persuaded that the reasons given by Huxley and Martin for offering a general course are as valid today as they were in $\mathrm{r} 868$. Indeed I am inclined to think that some added reasons have grown out of the increasing applications of biological knowledge to the practical affairs of life. The conditions of our living make ever increasing demands for knowledge of life phenomena, and some comprehension of biological principles is fast becoming a part of the common intelligence. 
We are organisms; and out of that fact grow the fundamental relations that general biology bears to a whole wide range of special sciences, the threshold of which may, I hope, be reached by those who follow the course here outlined. After Chapter I, which is introductory, the studies of chapter II should lead up to physiology, algology, mycology, bacteriology, protozoology, etc., those of chapter III, to morphology, comparative anatomy, embryology, palæontology and special botany and zoology; those of chapter IV, to cytology and eugenics; those of chapter V, to ecology, and limnology; those of chapter VI, to pathology, experimental biology, etc.; those of chapter VII, to neurology, psychology, sociology and ethnology. And in the broader sense of these terms; many more special sciences are included.

In the preparation of this course I have had in mind the needs of the great majority of college students, who may hardly spend more than a year in this subject. Certainly no other subject touches their lives at so many important points. What will best serve their needs? has been the question constantly before me; not, What has been taught hitherto? Ecological and evolutionary phenomena are just as available for practical studies as are morphological types, and I have introduced them freely, although not without pangs of regret for the good things of former courses that had to be omitted to make room. I have reduced to a minimum the directions for the laboratory study of morphological types, for excellent outlines are everywhere available for work of this sort; and I have given a larger place to outlines for field work and experimental studies. I have arranged the subject-matter to suit the seasons of the college year. I have included more than a year's work in order that selections might be-made. For pedagogic reasons, I have introduced at the first phenomena of some familiarity, postponing more technical matters. Mere 
technique has no part in this course. Facts are neither better nor worse for educational purposes because of technical difficulties that may or may not stand in the way of their acquisition; and therefore, other things being equal I have given preference to such observations as are most likely to be continued after the work of the college course is ended.

The purpose of the introduction given for each subject is to orient the student for the work assigned-not to replace the lecture or the recitation. I have tried to tell what he should know in order to outline what he should do; and I have tried so to shape the conclusion of his work as to invite a little thinking. During the past seven years I have been seeking methods that would facilitate the handling of bodies of facts sufficiently large for satisfactory illustration of general biological principles and phenomena. Many new exercises have been tried by my classes in field and laboratory; the ones that have proved most serviceable are included in the following pages. Herein are detailed the methods I have found most available. The materials used are of less consequence. I have used whatever lay nearest at hand, only seeking to draw my materials from a wide range of groups, in order to extend the acquaintance of the student with the face of nature. In so far as it has been necessary to touch upon theoretical questions, it has been my purpose, not to advance any biological theories but to bring the student into practical contact with the facts underlying all the theories.

The field of biology is so vast that no one can claim expert knowledge in any considerable portion of it. It is very probable, therefore, that in covering so much ground in even so elementary a manner, I have made some mistakes. I can only hope that they may not be of such nature as to seriously mislead or confuse the student and that I may 
have the further aid of generous colleagues toward their early elimination.

Many of my colleagues and former pupils have helpéd me with valuable suggestions and I would be glad if there were space to thank them all; and I cannot refrain from making mention of the special help that has been given me by Professors J. H. Comstock, W. A. Riley, G. F. Atkinson, B. M. Duggar, B. F. Kingsbury, I. M. Bentley, A. Hunter, R. H. McKee and Drs. A. H. Wright and W. A. Hilton on the part of the proofs that they have seen. Others of my colleagues have generously loaned me valuable portraits, concurring in my belief, that it would be worth while to introduce the faces of at least a few of the great pioneers of biology unobtrusively into the students' intellectual environment.

This book exists for the sake of the practical studies contained in it. Mere attendance on a lecture course does not amount to much; for in biology, as in other subjects, it is only those who handle the raw materials and build up with them, who can ever really comprehend the superstructure.

James G. Needham. 


\section{CONTENTS.}

\section{CHAPTER I.}

\section{THE INTERDEPENDENCE OF ORGANISMS.}

I. The Relations Between flowers and Insects, p. 7. i.

The adaptation of flowers to insect visitation, p. II. 2. The adaptation of insects to flower visitation, p. 17. How to know the orders of flower insects, p. 24. 3. The relative fitness of the different visitors to one kind of flower, p. 26.4 . The relative fitness of the different flowers visited by one kind of insect. to profit by its visitation, p. 28 . 5. Precise adaptation between flowers and insects, leading to mutual dependence, p. 29. 6. Specialization miscarried, p. 32 .

II. Galls, p. 35. Animal galls, p. 38. The animals that produce galls, p. 42. Key to the commoner insects larvæ and mites found in galls, p. 45 .

III. The Relations Between Ants and Aphids, p. 47. The chance feeding by ants on the honey dew offered by aphids, p. 48; The habitual guarding of aphid colonies by ants, p. 49. The domestication of aphids by ants, p. 50.

\section{PRACTICAL EXERCISES.}

Study I. Flowers adapted to insect visitation, p. I4.

Study 2. Insects adapted to visiting flowers, p. 24.

Study 3. The relative fitness of the different visitors to one kind of flower, p. 26.

Study 4. An examination of all the flwers visited by some common insect, p. 28.

Study 5. A case of precise adaptation, p. 32.

Study 6. A study of common galls, p. 46 .

Study 7. Observations on ants and aphids, p. 54.

\section{CHAPTER II. \\ THE SIMPLER ORGANISMS.}

I. Some Typical Alge, p. 56. The cell, p. 6r. The form of the plant body in common algæ, p. 64 .

II. Some typical protozoans, p. 68. 
III. The Life Process in Plant and Animal Cell, p. 82 . Matter, p. 82. Energy, p. 83. Protoplasm, p. 88.

IV. Some Intermediate and Undifferentiated Forms, p. 9 I. I. Plants that lack chlorophyl, p. 92. Molds and other fungi, p. 95. Bacteria, p. 97. 2. The slime molds, p. ror. 3. The flagellates, p. ro4.

IV. Reproduction Among the Simpler Organisms, p. iog. Cell division, p. Iog. Sexual reproduction, p. I I 2.

\section{PRACTICAL EXERCISES.}

Study 8. The cell of Spirogyra and the protoplasm of Nitella, p. 60. Study 9. Observations on cell form and growth habit in alga, p. 67. Study IO. The structure and activities of Paramcecium, p. $7^{2}$.

Study II. The specialized cell bodies of Stentor and Vorticella, p. 76. Study I2. Observations on cultures of yeast and molds, p. 96 .

Study I3. A few observations on bacteria, p. Ioo.

Study I4. Observations on slime molds, p. I03.

Study I5. A comparative examination of common flagellates, p. I07. Study 16 . Observations on reproduction among the simpler organisms, p. II5.

\section{CHAPTER III. ORGANIC EVOLUTION.}

I. The Plant Series, p. i 8 . Bryophytes, p. i 8 . Alternation of generations, p. 124. Pteridophytes, p. I28. Speramatophytes, p. I 42 .

II. The Animal Series, p. i56. The hydra, p. i57. The earth worm, p. I63. The salamander, p. I79. Development, p. 193. Types of nurture, p. 214. The life process, p. 217. Common features of development in plants and animals, p. 2 I8. Systematic classification, p. 22 I.

II. General Evolutionary Phenomena as Illustratet in Briefer Series of Organisms, p. 222. i. Divergence and convergence of development, p. 222. Homologies and analogies p. 223. The veins in the wings of insects, p. 225. The serial homology of the higher crustaceans, p. 230. Phvlogeny, p. 236. Convergence, p. 243. 2. Progressive and regressive development, p. 245. Palæontology, p. 246. The persistence of the unspecialized, p. 250 . Regressive development, p. 25I. 3. The correspondence between ontogeny and phylogeny, p. 255: Why evolutionary series? p. 264 . 
III. The Processes of Evolution; Attempted Explanations, p. 266. Natural selection, p. 266. Variation, p. 267. Mutation, p. 273. The struggle for existence, p. 276. Artificial selection, p. 279. Orthogenesis, p. 281. Segregation, p. 283 . The interaction of external and internal forces, $p$. 286 .

\section{PRACTICAL, EXERCISES.}

Study I7. An examination of bryophyte characters, p. I27.

Study I8. Fern development, p. I40.

Study I9. The general structure of the fern sporophyte, p. I4I.

Study 20. A comparison of developmental features of other pteridophytes, p. 141 .

Study 21. Spermatophyte structure, p. 154.

Study 22. Spermatophyte development, p. 154.

Study 23. Observations on the structure of the hydra, p. I62.

Study 24. The general structure of the earth worm, p. 178 .

Study 25. The cellular structure of the earth worm, p. 179.

Study 26. The internal organs of an amphibian, p. 206.

Study 27. The structures of the body wall in an amphibian, p. 207.

Study 28. The cellular structure of an amphibian, pp. 208.

Study 29. The early development of an amphibian, p. 209.

Study 30. Determination of homologies in three series of closely allied insects, p. 229.

Study 3I. Observations on plasticity of form and persistence of type in Malacostraca, p. 233.

Study 32. An attempt at interpreting a possible phylogeny, p. 238.

Study 33. A comparison of convergent species, p. 243.

Study 34. The ontogeny of organs in the frog or salamander, p. $26 I$.

Study 35. Fluctuating numerical variations, p. 272.

Study 36. The struggle for existence among seedlings, p. 278.

\section{CHAPTER IV.}

\section{INHERITANCE.}

I. The Visible Mechanism of Heredity, p. 289. The history of the germ cells, p. 296. Fertilization and maturation, p. 299. Parthenogenesis, p. 204.

II. The Observable Results of Inheritance. Types of inheritance, p. 308 . Alternative inheritance, p. 310.

III. Nature and Nurture, p. 318 . Inheritance of acquired characters, p. $3^{18} 8$. The meaning of nurture, p. $32 \mathrm{I}$. 
Study 37. Observations on cell divisions and on maturation of sex cells, p. 305 .

Study 38. Observations on parthenogenesis, p. 306.

Study 39. Observations on the relation between fecundity and nurture, p. 325 .

\section{CHAPTER V.}

THE LIFE CYCLE.

I. Alternation of Generations, p. 330 .

II. Special Methods of Asexual Reproduction, p. 33 I.

III. Change of Form With Alternation of Host, p. 340.

IV. Metamorphosis, p. 342. The transformations of insects, p. 343. Internal metamorphosis, p. 347 .

V. Artificial Division and Combination of Organisms, p. 353. Regeneration, p. 353. Grafting, p. 360.

\section{PRACTICAL EXERCISES.}

Study 4o. Observations on asexual reproductive methods, p. 337.

Study 41 . External metamorphosis in insects, p. 346.

Siudy 42. Observations on internal metamorphosis, p. $35 I$.

Study 43. Experiments with regeneration in planarians, p. 360 .

Study 44. Grafting practice with plants, p. 363.

\section{CHAPTER VI.}

THE ADJUSTMENT OF ORGANISMS TO ENVIRONMENT.

I. Adjustment in Place and Time, p. 369 . I. Local distribution of green plants 2. Hibernation and xstivation, p. 376. 3. Local distribution of animals, p. 378 . 4. Pond life, $p$ $3^{8} 5$.

II. Adjustment in Manner of Life, p. 390 . I. Symbiosis, p. 390. 2. Parasitism, p. 396. 3. Pollen distribution, p. 400. III. Adjustment in Form and Appearance, p. 404. I. The readaptation of insects to aquatic life, p. 407. 2. Phylogenetic adaptation in diving beetles, p. 4 I 5. 3. Animal coloration, p. 422.

\section{PRACTICAL EXERCISES.}

Study 45. Woodland plant society, p. 373.

Study 46. Observations on the dessication and resustication of rotifers, p. 378 . 
Study 47. The local resident terrestrial vertebrate fauna, p. 383.

Study 48. A laboratory examination of typical pond animals, p. 386 .

Study 49. A field study of pond animals, p. 388 .

Study 5o. The relations of fungus and alga in the lichen, p. 394.

Study 51. A comparative examination of a series of adult parasites, of a single order, p. 400.

Study 52. Pollen production as affected by its mode of distribution, $p$. 402.

Study 53. The principal types of gills found in aquatic insects, p. 4 Io. Study 54. The comparative development of respiratory apparatus in aquatic inesct larvae, p. 413.

Study 55. A comparison of the structure of ground beetle and diving beetle, p. 417 .

Study 56. A comparative study of the size and activities of diving beetles, p. 418 .

Study 57. Field observations on diving beetles, p. 420.

Study 58. The adaptive structures of diving beetles, p. 421 .

Study 59. Examples from the local fauna of the principal types of animal coloration, p. 432 .

\section{CHAPTER VII. \\ THE RESPONSIVE LIFE OF ORGANISMS.}

Introduction, p. 434 .

I. Animal Activities, p. 437 . I. Some typical sensory phe- nomena of the Protozoza, p. 437. Organs of out-reach, p. 438. Some reactions of Paramoecium, p. 4.39. 2. Some general features of the sensory mechanism in the Metazoa, $\mathrm{p}$. 441. Intercommunication withouc nerves, p. 442. Sense. organs p. 444. Nerve and muscle, p. 448. The reflex arc, p. 45o. Control circuits, p. 453. Cephalisation, p. 455 . A mechanism for adaptation of the individual, p. 457. Relations between parts and functions in the vertebrates $p$. 460. 3. Some typical sensory phenomena of the Metazoa, p. 469. Automatic unvarying activities, p. 469. Responses automatically varying, p. 469 . Sequences of automatic activities, p. 473. Learning by experience, p. 479 .

II. The Responsive Life of Man, p. $48_{5}$. I. The natural history of man, p. 485 . Distinguishing human characteristics, p. 486. Language, p. 489 . Tool using, p. 490. Use of fire, p. 491. 2. Unwritten human history', p. 492. Ar- 
chaeology, p. 498. Ethnology, p. 494.' Ontogeny, p. $49^{8}$. 3. The social organism, p. 500 . Animism, p. 502 . Social integration, p. 507 . Social conduct, p. 509 .

\section{PRACTICAL EXERCISES.}

Study 6o. Demonstration of functions of some of the principal parts of the nervous system in the frog, p. $45^{6}$.

Study 6r. Observations on certain activities of caterpillars, $p .472$.

Study 62. The case-building instincts of caddis worms, $p .477$.

Study 63. Experiments with trial and error in chicks, p. $48 \mathrm{r}$.

Study 64. Survivals of animism in our own times, p. 504 .

\section{APPENDIX.}

Preliminary outline and instructions, p. $5{ }^{1} 3$. Lenses, lighting, etc., p. 5 r3. Stage mounts, p. 5 I8. Dissecting, p. 519. Drawings, p. $520 . \quad 2$. Materials for the practical exercises, p. 520.3. Key to the genera of Dytiscide. p. 526 .

\section{INDEX.}

Pages 531-542.

PORTRAITS: Schultze, p. 89; Pasteur, p. 93; Von Baer, p. 174; Linnaeus, p. 220; Agassiz, p. 224; Damwin, p. 277; Leeuwenhoek, p. 298; Mendel, p. 309; Aristotle, p. 470. 


\title{
GENERAL BIOLOGY
}

\author{
CHAPTER I.
}

\section{INTERDEPENDENCE OF ORGANISMS}

The primary demand of individual livelihood is for food. Getting a living is the first business of life, and food is the basis of a living; for the body derives both its substance and its energy from its food.

The gathering of the food for the living world is mainly the work of green plants. These derive carbon from the air and mineral matters from the soil, and build them up into living substance, clothing the earth with verdure and storing up food materials that make animal life possible. Green plants constitute in themselves by far the greater part of the living substance that is in the earth, and support other forms of life out of the excess of their product over what is necessary to maintain their own growth and reproduction.

The primary food of animals is plants and plant products. Animals consume a small part of living plants, a much larger part of plant products (fruits, tubers, wood, etc.) and nearly the whole of plant remains. They use this plant material for building their own bodies and supplying their energy, and excrete it again as simple mineral compounds. Thus they rapidly restore to the soil plant food materials which might otherwise remain long locked up in the bodies of dead plants. Thus the world's available supply of food material is kept in circulation; and thus. green plants and animals are complemental, each preparing food for the other.

That so large a part of living vegetation escapes being eaten is due to the fact that animals, primarily herbivorous, 
have become carnivorous, and have taken to eating each other. The carnivores prevent overproduction of herbivores, and are themselves held in check by parasites within their own ranks. Herbivores and carnivores, parasites and scavengers are everywhere; for they fulfill permanent functions of animal society.

The need of shelter is another large factor in determining the habits of animals, for few can afford to live in the open, and most are so limited that they must find food and shelter in thesame haunts. For both food and shelter animals are dependent primarily upon plants and secondarily upon each other, and the relations that have come to exist between them are so intricate they may fairly be compared to a web with its threads all interwoven.

Interdependence.-The weak are dependent on a few, the strong upon many. The sturdy oak in the woods seems very independent in comparison with the vine that hangs upon its branches or the green mould lodged in a crevice of its bark. But from leaf to root it is beset by enemies and aided by friends.* There are caterpillars feeding upon and within its leaves. On its twigs are aphids sucking the sap out, and within them are beetles boring. Other beetles and caterpillars live in bark and sapwood and heartwood of its trunk, and other aphids attack its roots.

But about its roots there are friendly earthworms working in the soil, mixing it and making it porous; and moulds, assisting in the preparation of its food. Neighboring trees shade its trunk from the scorching rays of the summer sun, and woodpeckers, nuthatches and warblers search its bark and leaves for hidden insect enemies. There are hosts of parasites also, individually insignificant, but collectively, its greatest safeguards, that work wholesale

*In Packard's Forest Insects there are listed 442 species of insects affecting American oaks, and 20 additional that are found in their dead stumps. . 
destruction upon any of its enemies that may become excessively abundant; and even the squirrels that greedily gather its acorns to eat, distribute some of them in just the way to insure another generation of oaks.

Moreover, this complex relation began at its birth, and will continue until it is "resolved to earth again." Weevils devour its acorns; cutworms and lusty smothering weeds imperil its infancy; and the trampling and browsing of quadrupeds are a great menace to its early youth. The storm that scars it, or the disease that weakens it makes the opportunity for attack by beetles or molds that are harmless in its health. When it is dead, its corpse is riddled by borers and softened by molds and speedily reduced to dust.

And of the host of friends and enemies with which it has come in contact, each has its own friends and enemies, ready to help or to devour. There is no living thing that either lives or dies unto itself alone.

Let anyone who would see for himself the complexity of the web of life, study some common plant or animal, observing all the other plants and animals affecting it, and their inter-relationships; or, let him examine the home of some social animal, and find all the inmates of different species, and learn how they manage to live together. There is no plant or animal, no flower or fruit, no nest or burrow, no carcass or $10 \mathrm{~g}$, no product whatsoever of living nature, that will not show a community of life with relations infinitely varied and complex. To see how much we ourselves are continually dependent on the organic life of the world, we need only examine the food on our table, the furnishings of our house or the materials of our wardrobe; however simple these departments of our living may be, each will attest that many kinds of plants and animals from many parts of the earth are tributary to it. 
Balance in Nature.-To the careful observer the face of nature changes little from decade to decade. There are giants and weaklings in every natural community, but every species is strong enough to keep on living. There are shifts of place, but rarely is one lost in the shifting. Casualties may devastate a valley or a hill slope, but, left to itself, it is soon repopulated.

And there is order and progress in the shifting. The

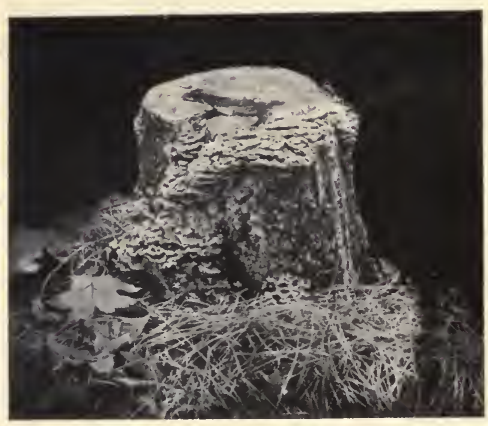

Fig. 1. Oak stump in an early stage of decay; shelf fungi on the bark. fungi growing on this stump (fig. I) and the beetles boring inside it, are not the same species that will feed there when it is half rotted; nor is any one of these the same that will mix its disintegrating fragments with the soil. There will be other stumps with sound wood in them waiting for the descendents of those now at work on this one. The conditions for the life of all are fairly constant, and all are capable of making such shifts as these conditions demand. The balance is maintained by limitations of food and shelter and increase of enemies, serving to prevent the undue multiplication of any species.

Man is the only disturber of the natural balance of any consequence. He plows under the mixed population of the prairie and gives the soil all over to corn. He finds the 
potato a wild, straggling, solitary weed in the hills and propagates it and covers whole acres with it. Thus he disturbs the balance, for the enemies of the corn and potato, with food supply enormously increased, multiply and spread as never before; and to maintain his artificial conditions man must continually put forth his hand to assist his chosen species and to stay their enemies. A few species (such as the bison and the auk) he may by persistent slaughter exterminate; a few (such as cockroaches and some weeds) multiply in spite of his efforts against them; but most are merely held in check, and when his efforts against them cease, they speedily reoccupy their former place.

All economic procedure that deals with plants and animals is based upon the knowledge of their relations to each other. The arts that feed and clothe the human race make progress as such knowledge is advanced.

It is the purpose of the studies of this chapter to give a closer acquaintance with some common phenomena illustrating close interdependence and intricate vital relations between organisms. Three subjects have been selected as especially available and serviceable to this end:

r. The relations between flowers and insects.

2. Galls.

3. The relations between ants and aphids.

THE RELATIONS BETWEEN FLOWERS AND INSECTS.

Inter-relations of mutual advantage are excellently shown by flowers and insects, and may be studied anywhere during the flowering season. The more abundant the flowers, and the more sunshiny the weather, the better will be the opportunities. Two products of the flowers are eagerly sought by insects for food, nectar and pollen: Nectar is the sugary sap of the plant secreted by nectaries 
that are generally located within the flower, and pollen is the product of the stamens. In return for these the insects serve the flowers by transferring the pollen of one flower to the stigma of another, securing cross fertilization.

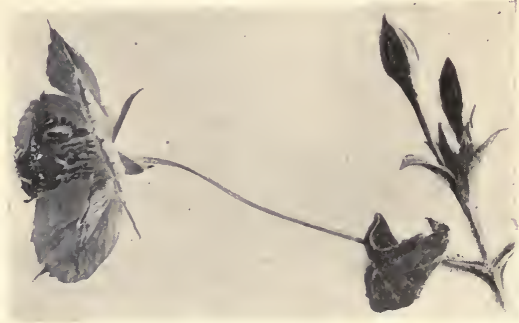

FIG 2. A bee (Macropis ciliata) gathering pollen from the erect stamens of a loosestrife flower (Steironema ciliatum.)

Figure 2 illustrates this relation. The yellow flowers of the fringed loosestrife are not nectar-bearing but they produce abundant pollen. This is much sought for by a little black bee. The bee settles upon the tops of the clustered and protruding stamens, as shown in the figure, and scrapes the pollen out of the pollen cavities of the five long curved anthers. In doing this it turns around several times and gets the hair of its legs and of the under surface of its body filled with closely packed pollen grains. It visits a number of flowers in succession, and is very likely to deposit upon the stigma of each one, some pollen from another flower.

It must be borne in mind that the purpose of the flower is to produce seed. Seeds are ripened ovules: ovules are contained in the ovule case, which is the swollen 
and hollow base of the pistil (see fig. 3 ). This central organ is the most important part of the flower and all the other parts are merely accessory to its seed producing function. A slender style rising from the top of the ovule case serves to hold aloft the stigma in a proper position for the reception of pollen. The stigma is the moist, uncovered spot on the tip, where the tissues of the interior are exposed. Pollen grains lodge there, and

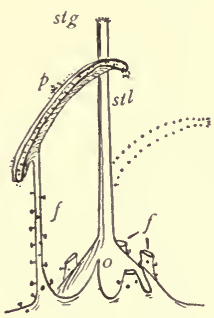

FIG. 3. The essential organs of the loosestrife flower. $p$, pollen-bearing anther; $f$, filament, bearing glandular hairs; 0 , ovule case; stl, style; stg, stigma; $f$, the bases of the filaments of other stamens; the dotted lines indicate the position of style and stigma at the opening of the flower. each one sends out a long. hollow and excessively slender tubular process (the pollen tube), which grows downward through the tissues of the style like a root through soil, until it reaches an ovule. Fertilization consists in the fusion of part of the substance that passes down the pollen tube with that contained in the orule, and will be studied in a subsequent chapter. Suffice it to say here, that fertilization is necessary for the development of seed; and that, in the case of most of the flowers that are risited by insects, it is necessary that pollen be brought to a flower from the flowers of another plant of the same species. This is cross-pollination.

In the loosestrife there are five stamens arranged in a whorl around the pistil. Each consists of a large curved pollen-bearing anther supported on a long, erect filament. The other, accessory parts of the flower (petals, sepals, etc.) while wholly unnecessary to seed production, are often of great aid in securing cross-pollination, being often wonderfully adapted to suit the convenience and to secure the aid of insects. 
See how the loosestrife flower is adapted to small pollen eating bees. Its stamens stand erect with anthers curving inward. The trough-like pollen cavities of the anthers, opening upward, expose their stores to the insect standing on the top. So great is the excess of pollen production over actual needs that the little the bee wastefully and unwittingly scatters over the stigma is enough for setting the seed. This store of choice food the flower reserves for its proper visitors-chiefly for this little bee. Large bees would have great difficulty in collecting pollen from flowers that hang on such slender stalks. Wingless insects, like ants, which, if gathering pollen, could run only from flower to flower upon the same plant, and which would thus be poor agents in cross-pollination, are rigidly excluded. Should they be able to run out along the slender flower stalk, and round the fringed border of the corolla and get inside it, they would still find between themselves and the pollen overhead a barrier of glandular hairs bearing an acrid and offensive secretion with which they would choose to avoid contact.

This flower has a simple and very common device for

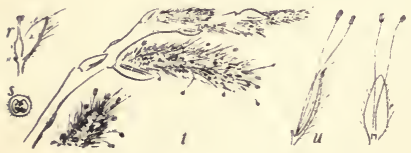

FIG. 4. The flowers of a willow (Salix discolor.) $r$, a single pistillate flower, removed from its cluster; $x$, its covering scale; $n$, nectary, $s$, section of its ovule case; $t$. clusters (catkins) of staminate flowers; $u$ and $v$, single staminate flowers removed from the cluster. preventing self pollination. Its anthers mature in advance of its stigma. When the flower opens the stigma is turned aside (in the position indicated by the dotted lines in fig. 3), but later, usually when its own pollen is removed, the stigma is lifted up into the proper position for receiving that brought by some late visitor from another flower.

This simple illustration of the more general phenomena will serve to introduce the following studies of the subject. 
I. The adaptations of flowers to visitation by insects.

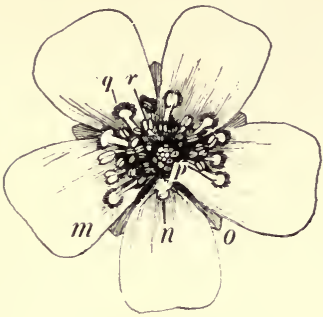

FIG. 5. Diagram of the flower of a buttercup (Ranunculus). $m$, petal; $n$, nectary on the base of the lowermost petal; $o$, a sepal; $p$, acentral gioup of separate pistils: $q$, a mature, and $r$, an immature anther.

Most flowers that profit by insect visitation are composed of the four whorls of organs seen in the loosestrife flower. Two of these sorts of organs, the stamens and the pistils are essential to seed production: the other two sorts, petals and sepals (the floral envelopes or perianth) are merely accessory: they are often highly serviceable, being adapted in manifold ways to secure the visitation of proper insects. These may be wholly absent: and stamens and pistils may be developed in different flowers, or even upon different plants, as in the willows (fig. 4).

The type to which most insect-visited flowers conform finds a simple expression in such a flower as that of the buttercup (fig. 5). There are many separate pistils and stamens: petals and sepals are separate also, and alternate in position: all the parts of these whorls are inserted on a common receptacle at a common level: the nectar, secreted under a little scale upon the base of each petal, is quite exposed and readily accessible to almost all visitors; and the color is nearly uniformly yellow.

These characters are variously modified in adaptation to insect visitors:

a) The flowers may become more showily colored and more attractive to the eye. They may be specially marked with darker or lighter streaks or blotches about the entrance, as if to guide their visitors to the right place. In the iris (fig. 6) there are three separate 
entrances, each with its own guide streaks: and at the center of the flower where there is no entrance there is a convergence of lines that often deceives ill-adapted visitors in quest of the nectar. Not all the markings upon flowers are thus significant: doubtless the deposition of pigment follows structural lines and results from physiological causes, and may often be wholly unrelated to the exigencies of poll-

FIG. 6. Top view of the flower of a wild iris (Iris versicolor).

en transference. But there is no mistaking the meaning of the general fact that flowers adapted to insect visitation are showy, while flowers whose pollen is distributed by wind are generally inconspicuous; or, the fact that hummingbird flowers are scarlet; or, that night blooming flowers are oftenmost white: or, that the points of entrance for visitors are conspicuously marked.

b) The nectar ex-
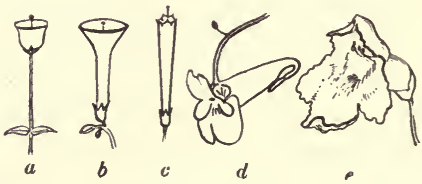

FIG. 7. Diagrams of forms of corollas. $a$, bellform; $b$, funnel-form; $c$, tubular; $d$, spurred; $e$, two-lipped; $a, b, c$ are radial; $d$ and $e$, bilateral. hales a great variety of attractive scents, and the nectaries are sequestered in various ways beyond the reach of ill-adapted visitors- 
hedged about with spines or glandular hairs, or hidden at the bottom of deep or closed passageways - and thus reserved for the use of proper guests.

c) The floral organs may become grown together in various ways. This tendency toward fusion of parts is strongest among the pistils and the petals. In the loosestrife flower (fig. 3) all the petals and stamens are grown together at the base. This stiffens the flower, and makes it better able to support the trampling of a visiting

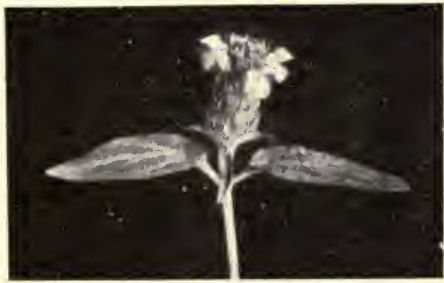

FIg. 8. Typical bilabiate flowers of Prunella. (P. vulgaris L.) insect. Often the fusion of parts is of greatimportance in sequestering nectar (fig. 2 I) and forming the passageways thereto. This is the meaning of the various forms of corollas, the principal types of which are shown in the accompanying diagram (fig. 7).

d) The parts may become unlike in each whorl, making the flowers irregular: or

e) They may lose their symmetrical arrangement, and no longer alternate regularly in each whorl: or,

f) Some of the parts may be lost through atrophy: or

g) The flower may cease to be radial and become bilateral. This point is the concomitant of the three preceding. Bilateral flowers show the completest structural adaptations to insect visitors. They generally face laterally, and are so shaped that the insect enters in one position only. The corolla is usually two-lipped, with the lower lip serving as an alighting place, and the upper as a shelter for the pollen (fig. 8). The stamens are often reduced to one or two pairs, 
and the anthers are so situated that the insect rubs against them at just the right time, entering or leaving: in this consist some of

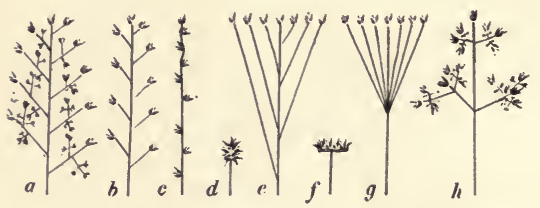

FIg 9. Diagram of types of flower cluster. $a$, panicle; $b$, raceme; $c$, spike; $d$, spike contracted to head; $e$, corymb; $f$, head; $g$, umbel; $h$, cyme. the most wonderful examples of adjustment.

It is one of the delights of the student of floral structures to trace these organs through all their modification of form, position and arrangement, and to be able to recognize them under all their disguises.

The flower cluster.-Two important ends seem to be served by the close grouping of flowers together in clusters. I) Showiness is secured with much less expenditure of vital energy in the production of sterile parts. The single flower of the common elder is very small and insignificant, but the big flat-topped clusters of elder flowers are borne aloft upon the clumps, in such a way that they may readily be seen from afar off: 2) The bringing of the flowers together in compact clusters makes it possible for the insect to pass from one flower to another without taking flight. This greatly economizes labor for the insect. The principal forms of flower cluster are shown in the accompanying diagram (fig. 9). It will be seen that with respect to compactness and rigidity, improvements in arrangement culminate in flat-topped heads.

Study I. Flowers adapted to insect visitation. Apparatus needed: A lens and a forceps. 
Materials needed: Flowers of ten or more species (preferably native), in sufficient abundance so that all stages of flowering from the bud to withering can be found. They must be fresh: if wilted when brought in, they may be revived by being placed under a bell jar with water for a time.

The student will need so to familiarize himself with the parts of the flower as to be able to recognize them under all their disguises. Whatever their form the pollen-bearing parts are the stamens, and the stigmatic surface is upon the pistil. These parts should be examined at first in fresh, full blown, and old flowers of some species of good size in order to determine the appearance of anther and stigma at maturity. And the nectaries, which are in appearance often hardly more than pellucid spots of greenish tissue with minute droplets of nectar exuding from them, should at the first be distinctly recognized. The commoner forms of corolla and of flower cluster should be learned. The foregoing figures may be supplemented by those in any good text book of botany.

Tabulation of observations.-A sheet of paper ruled in tabular form should be prepared with the following column headings (abbreviated as desired):

Name of plant.

Order (or family) to which it belongs.

Form of flower cluster (fig. 9).

Parts of flower that are colored (white is a color, and green is not, in botany).

What colors.

"Guide marks," indicating the entrance to the nectaries. Odor, its strength, character, etc.

Corolla $\left\{\begin{array}{l}\text { form (fig. 7). } \\ \text { symmetry, (radial or bilateral). } \\ \text { open or closed. }\end{array}\right.$ 
Guards against waste of nectar by rain.

Guards against the ingress of ill-adapted visitors.

Position of the nectaries.

Stamens $\left\{\begin{array}{l}\text { number. } \\ \text { arrangement (in pairs, in whorls, etc.) } \\ \text { included or exserted. }\end{array}\right.$

Pollen (dry, sticky, etc.)

$\left.\begin{array}{r}\text { Guards against self- } \\ \text { fertilization in } \\ \text { stigma or anther }\end{array}\right\}\left\{\begin{array}{l}\text { structure, } \\ \text { position, } \\ \text { movements. }\end{array}\right.$

First ready for fertilization, anther or stigma.

The student will use this table for recording his observations on the ten or more species of flowers selected, which should include the following floral types:

I. A simple open solitary flower.

2. A tubular or bellshaped, loosely clustered flower.

3. A spurred or saccate flower.

4. A strongly bilateral mint flower.

5. A papilionaceous flower.

6. An umbelliferous flower.

7. A malvaceous flower.

8. A composite flower (see fig. 236.)

Interpretation of the table.- The student should write out the principal conclusions that can be drawn from the facts included in the completed table. In doing this he should consider the facts of each column by themselves, and afterwards, looking for correlated characters, he should compare the columns together. For example, he will be able to see in the several columns what forms of flowers cluster and of corolla; what colors, guide-marks, scents; what rain guards, etc. prevail: but it is only by carefully comparing columns together he will learn which of the flowers show fewest adaptations to insect visitors, which of the tubular and which of the bilateral flowers show most adaptations, and 
whether there exists any correlations between bilaterality, position of the flower in the cluster, arrangement of the stamens, etc.

2. The adaptation of insects to flower visitatıon.

In the body of an in-

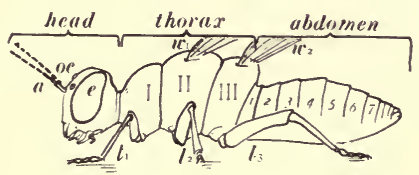

FIG. 10. Diagram of the external parts of an insect. $a$, antenna; $e$, eye; oc, ocelli; $I$, prothorax; $I I$, mesothorax; III, metathorax; $w_{1}$ and $w_{2}$, fore and hind wings; $l_{1}, l_{2}, l_{3}$, fore, middle and hind legs; $1,2,3,4$, etc., segments of the abdomen.

The thorax is divided into three horny rings or segments, each of which bears a pair of legs, and the hindmost two bear each a pair of wings. The abdomen consists of a variable number of segments.

The accompanying diagram (fig. Io) will serve to represent the arrangement of parts for insects in general.

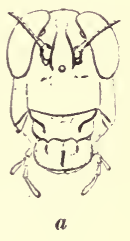
sect there are three prin. cipal divisions: head, thorax and abdomen. The head bears eyes, antennae and mouthparts, the latter consisting of upper and lower lips, with two pairs of jaws working horizontally between them.
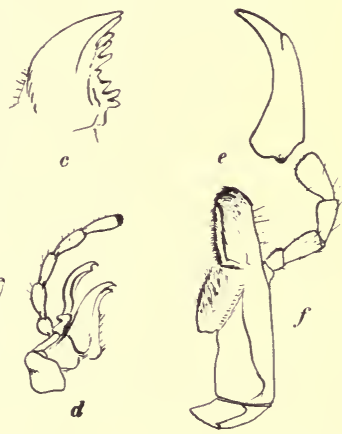

FIg. 11. Mouthparts of grasshopper and beetle. $a$, face view of grasshopper (Melanoplus femur-rubrum) showing at $l$, labrum; $b$, labium of same; $c$, mandible of same; $d$, maxilla of same: $e$, mandible of soldier beetle (Chauliognathus scutellaris); $f$, maxilla of same, showing pollen brushes. 
Since insects visit flowers for food, naturally, it is the parts of their bodies that serve for collecting and carrying the nectar or pollen that are most modified for flower visitation. It is their feeding apparatus, therefore, that most merits our present attention. The nature of the remarkable changes that have fitted insect mouthparts for nectar-gathering will best be understood after comparison with the simple biting mouthparts of a grasshopper. These are shown in fig. II. The upper lip or labrum is a simple transverse membranous flap covering the mouth above. The lower lip or labium is a compound, appendage-bearing flap covering the mouth below. Between the two are two pairs of jaws that swing in and out laterally, and that are toothed on their opposed tips; but one of each pair is shown in the figure. The upper pair (mandibles) lie directly beneath the labrum; each mandible is simple and strongly toothed. The lower pair (maxillae) lie directly below the mandibles, between them and the labium. Each maxilla consists of two basal pieces (cardo and stipes) and three terminal appendages; the innermost, the lacinia, is simple, and toothed internally; the next, the galea, is two jointed and closely fits over the back of the lacinia; and the third, the palpus, is five jointed and is sensitive at its tip. The labium is a compound organ made of a pair of appendages similar to the maxillae, fused together during their development on the middle line. The fused cardines constitute the submentum, the fused stipites, the mentum, and the three terminal parts are easily recognizable, although the lacinia is greatly reduced in size, the galea greatly expanded, and the palpus but three jointed.

Of insects with this simple type of mouthparts, only a few, chiefly beetles, have taken to flower visiting; and these show more or less of narrowing of the front of the head, adapting it for entering corollas, and alteration of the tip of the lacinia to brușhes of stiff pollen-, or nectar-gathering 
hairs, in place of the usual teeth. This is shown in our figure for a pollen-eating soldier beetle (Chauliognathus scutellaris) which swarms upon goldenrod flowers in autumn (fig. I1.)

Proboscides-Most nectar-eating insects have mouthparts prolonged and combined into some sort of a sucking proboscis, with which they are better able to reach sequestered nectaries. In general it may be said that the proboscides are of three types:

I. The hinged and retractile type, variously developed in bees and flies.

2. The coiled type, characteristic of butterflies and moths.

3. The jointed and rigid type, characteristic of bugs (Hemiptera).

The first of these types is well illustrated by the common honey bee, in which the proboscis is made out of maxillae and labium. Labrum and mandibles are much as in the grasshopper: the labrum is narrower, and the mandibles are not toothed at the tip, but scoop-like, adapting them for moulding wax. But the

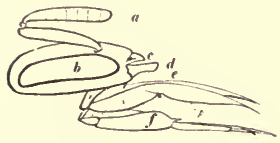

FIG. 12. Diagram of head of honey bee (Apis mellifica, from the side. $a$, antenna; $b$, eye; $c$, labrum; $d$, mandible; $e$, maxilla; $r$, its cardo; $s$, its stipes and $p$, its palpus; $f$, labium, $p$, its palpus. maxillae and the labium are excessively elongated, hollowed out internally and closely applied together to form a sucking tube, the anterior part of the alimentary canal being at the same time modified to form a sucking organ and nectar reservoir. The resultant proboscis is slung beneath the head upon the cardines of the maxillae (fig. I $2 r$ ), and provided with muscles which readily extend or retract it. At thetip of the stipes is another hinge, which allows the long terminal portion to be folded backward under the head when not in use. This terminal composite joint is hollow, and from its tip pro- 
jects a long, slender hairy tongue, that is itself retractile, and that bears a minute membranous nectar-lapping lobe at its tip. These parts seem at first very unlike labium and maxilla of the grasshopper, but it is not difficult by separating them and examining them carefully to recognize their identity. In the accompanying figure (fig. I3) the parts are all indicated by name; and the
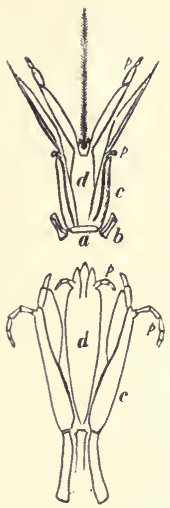

FIG, 13. Comparative diagrams of proboscis of long-tongued and short-tongued bees. Upper figure. the honey bee (Apis). Lower figure (Halictus, from Dr. W. A. Riley); $a$, labrum; $b$, mandibles: $c$, maxilla; $d$, labium; $p$, palpus. proboscis of a short-tongued bee is similarly drawn and lettered to make their recognition easier. It will be observed that in the honey bee the long, tubular terminal joint of the proboscis is composed of the hollowed out laciniae of the maxillae and basal segments of the labial palpi, closely applied together.

In the flies (Diptera) labium and mandibles are rudimentary, the rudiments of the maxillae are intimately combined with the highly specialized labium to form the proboscis, which is hollow, retractile beneath the head, its terminal joint folding downward, much as in the bees: but at its tip, instead of the hairy, decurving, protrusible tongue, there is often developed a pair of up-folding, opposible flaps (labellae) with corrugated inner surfaces (fig. I4). Since investigators are not wholly agreed as to the identity of parts in the fly labium, it will be sufficient if the student note its length, its folding and extension, the action of its labellae, and other characters that have to do with pollen and nectar gathering. 
The coiled proboscis of moths and butterflies is the most specialized of all, and limits its possessors to feeding on

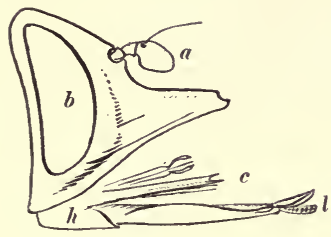

F1G. 14. Diagram of head and proboscis of a syrphus fly (Rhingia nasica). $a$, antenna; $b$, eye; $c$, proboscis, with parts outspread; $h$, its hinge; $l$, its labellæ.

sists of the laciniae of the ing elongated, channelled together to form a tube. that are well developed in the commoner butterflies and moths are the labial palpi, which project forward from beneath the head, and between which the proboscis coils itself up when at rest. So greatly have the mouthparts been modified that the identity of them in their present condition would not be recognized by a beginner; the accompanying diagram (fig I 5), of a specifiliform, coiling compactly like a watch spring beneath the head, and extending when unrolled to a length sometimes exceeding the length of the body, it is adapted for reaching the nectar in the deepes 1 corollas, and for entering the narrowest passageways. Moreover, it is most unique in structure in that it contwo maxillae only, these bewithin and closely applied The only other mouthparts (1) liquids. So slender as to be 
piercing the tissues of plants and sucking out the sap. Only incidentally is it used for gathering nectar. Its very position and direction show it to be

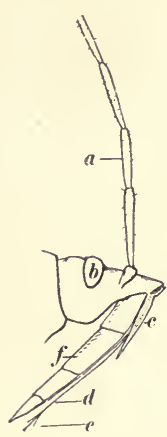

FIG. 16. Diagram of head and proboscis of a bug (Pentato$m a) . \quad a$, antenna; $b$, eve; $c$, labrum; $d$, lancet-like mandibles; $e$. maxilla: $f$, the jointed ensheathing labium. unadapted to probing flowers.

It consists of two pairs of lancet-like organs, the modified mandibles and maxillae, enveloped by the sheathing lower lip, which is practically destitute of palpi, and distinctly jointed: the labrum is rudimentary. The accompanying diagram shows the parts as they appear when somewnat separated (fig. I6).

\section{Vesture.-- \\ The parts thus far considered have to do with} getting food. We will next consider that

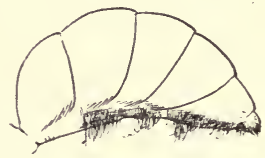

FIG. 17. Side view of abdomen of a bee( Macropis), showing ventral pollen brushes.

which has to do with the distributing of pollen, the vesture, or hairy covering of the body. The horny shell of the insect's body

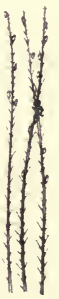
if bare would carry little pollen, but the brushes of hairs with which it is usually clothed carry pollen excellently and serve well for implanting some of it on the surface of the stigna.

F1G. 18. Pollen gathering hairs of the honey tee. 


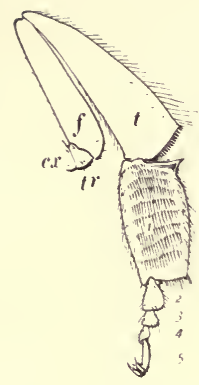

FIg. 19. Hind leg of bee, $c x$, coxa: ir, trochanter; $f$, femur $t$, tibia; $1,2,3,4,5$, segments of $t h e$ tarsus; I, carrying the "pollen basket."

It is a part of the fitness of things that these brushes are usually best developed on the top of the thorax, the under surface of the abdomen (fig. I 7 ) and the outer faces of the legs-the places of most frequent contact with anthers and stigmas: but special tufts of hair or scales are occasionally found in unusual places, serving the needs of some particular flower. The hairs of many bees and syrphus flies bear numerous microscopic lateral branches and hold pollen grains the more securely in the angles of the branchlets (fig. I 8). The hairs may gather of themselves sufficient pollen to be worthy of consideration as food; the bee has a comb developed on his fore legs for removing the stores they gather; furthermore, they may be so arranged as to greatly increase the amount of their load, as in the so called "pollen baskets" of the bee's hind legs (fig. I9).

Other parts. The modifications of other parts of the insect, antennae, wings and legs, have to do chiefly with accommodating it to entering corollas. Obriously the butterfly shown in figure 20 could not enter, and does not need to enter bodily into a flower. The bee will again illustrate by what means the antennae have been made reversible, the legs, closely applicable to the sides of the body, and the wings, close-folding upon the back; the whole insect compacted together, and admirably fitted for getting into, and for getting out again from, the tight places on the road to the nectar in specialized corollas. 


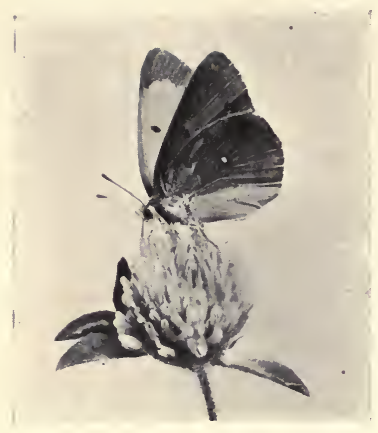

FIG. 20 Butterfly (Colias protodice) on a clover head.
How to know the orders of flower insects.-But five orders* of insects are commonly found upon flowers. The membersof these orders may readily be recognized by the following single distinctive characters:

The Diptera alone have but two wings.

The Lepidoptera alone have the wings covered with dust-like scales that rub off between the thumb and finger: likewise, a coiled proboscis.

The Coleoptera alone have the fore wings (elytra) meeting in a straight line down the middle of the back, not overlapping.

The Hemiptera alone have a jointed proboscis directed backward between the fore legs.

The Hymenoptera alone have a sting; likewise, they lack all the preceding characters: the small hind wings being usually attached to the margin of the fore wings by a series of hooklets, the beginner may overlook them at first.

\section{Study 2. Insects adapted to visiting flowers.}

Apparatus needed: A cyanide bottle, an air net and a lens.

Materials needed: Ten or more species of insects, to be gathered from flowers by the student, who should observe

*Omitting from consideration the minute but ever present thrips (order Physopoda) found hidden within the flowers-insects usually less than a millimeter long, with straight bodies and veinless wings, of slight importance in this connection. 
the while what each insect is doing, in order to be able to interpret the meaning of its peculiarities of structure. The advantage of possessing elbowed and reversible antennae, for example, can only be appreciated after seeing a bee force an entrance into a closed corolla, such as that of Linaria (fig. I69).

The insects should then be studied in the laboratory, not too hastily, and while still fresh. If allowed to become brittle through drying, they may be relaxed again by placing in a moist atmosphere (as, under a bell jar with a wet sponge) for a few hours.

They should include the following types:

I. A long-tongued bee (bumblebee).

2. A short-tongued bee.

3. A wasp.

4. A fly (two winged).

5. A beetle.

6. A bug.

7. A butterfly or moth.

The record of observations should be made in a table prepared with the following column headings (abbreviated as desired):

Name of the insect.

Order to which it belongs.

Flowers on which it was taken.

Seeking pollen or nectar.

Proboscis $\left\{\begin{array}{l}\text { type } \\ \text { length }\end{array}\right.$

Pollen-gathering parts.

Antennae-length, form and position.

Position of wings when at rest.

Relative size and weight (as compared with the others of the table). 


\section{The relative fitness of the different visitors to one kind of flower.}

It will have been observed in the course of the field studies hitherto outlined, that not all the visitors to one kind of flower are equally proficient in obtaining its stores or in transferring its pollen: also, that

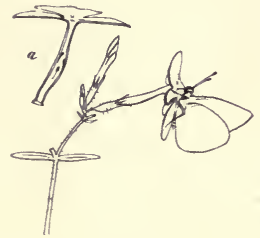

FIG. 21. Diagram of a butterfly on Phlox, and of the position of the stamens within the corolla tube. the manner of visitation is very different in different insects. The butterfly perching atop of a phlox corolla and probing the deep tube only with its long proboscis (fig. $2 \mathrm{I}$ ) could not exchange places with the bee that plunges bodily into the chelone flower (fig. 22): it would meet with difficulties like those of the stork of the fable, attempting to dine with the wolf. A more careful study of this matter will show that the pollination of a flower may be well effected by insects that operate in very different ways.

The following study of all the visitors to one kind of flower is intended to reveal the actual relations existing between a flower and its visitors, and the relative fitness of these visitors. Clearly this fitness consists in two things:
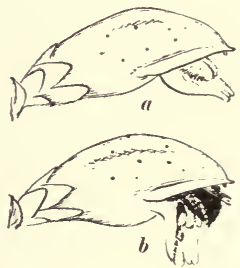

FIg. 22. The flower of turtle heads (Chelone glabra), and its visitor (worker Bombus). ability to get the food store the flower offers, and 2) ability to transfer pollen from anther to stigma.

Study 3. All the visitors to some common flower.

Apparatus needed: insect net, cyanide bottle, lens and note book: use chiefly the two last mentioned. 
First, select a flower that is abundant, and that has pollen and nectar so exposed as to be accessible to a considerable variety of visitors. Before beginning to observe the visitors study the structure of the flower itself, as to I) the position of the pollen and nectar stores, 2) the passageway to the nectar and its guards, 3) the position of anthers and stigmas in relation to this passage at different stages of flowering, and if clustered, 4 ) the form of cluster as likely to affect the convenience of big or little visitors.

The field work of the following outline must of necessity be individual: it cannot be done in a crowd: the student should work quite alone so as to aroid having his observations interrupted by the movement of companions. $\mathrm{He}$ should wear quiet colors, and approach the insects cautiously, avoiding quick motions: thus it will be quite possible to observe many of them at work under a lens. Some degree of warmth and sunshine and dryness of the weather will also be necessary to success.

The record of observations.--From a study of as many kinds of insect visitors as can conveniently be found, fill out a table prepared with the following column headings (abbreviating as desired):

I. Name of the insect.

2. Order to which it belongs.

3. Seeking pollen or nectar.

4. Alights where.

5. Enters how far.

6. Touches stigma or anther first.

7. Carries pollen how.

8. Visits how many flowers in succession without intervening long flight.

9. Visits how many flowers per minute. 
Io. Well or ill-adapted for visiting and pollinating this flower.

4. The relative fitness of the different flowers visited by one kind of insect to profit by its visitation.

A more careful study should now be made of the relations existing between one kind of insect and the many kinds of flowers it visits. This is a study of the relative fitness of the several flowers to avail themselves of its services as an agent of pollen distribution. Clearly fitness in this case consists in I) offering the insect an accessible food supply to win its visits, and 2) having anther and stigma located aright for proper pollen transference.

\section{Study 4. All the flowers visited by some conmon insect.}

Apparatus needed and general directions, as for preceding study. An insect should be selected that is abundant, that is an active flower visitor; it should have a rather long proboscis in order that it may have access to flowers of considerable variety. It should be carefully examined, before the proper work of this outline is undertaken, as to I) its nectar-gathering parts, particularly as to the length and position of its proboscis; 2) the position and structure of its pollen brushes; and 3 ) its size and weight, and 4 ) the position of its appendages when at rest.

The record of observations.-In the field one should examine freshly blooming clumps of as many kinds of flowers as possible, first seeing whether the insect selected for study is visiting them, and if so, watching it carefully and quietly until the points given below as table headings have been determined:

I. Name of flower.

2. Furnishes pollen or nectar. 
3. Offers what alighting place.

4. Is entered how far.

5. Stigma or anther touched first.

6. Pollen carried how.

7. Number of flowers visited in succession without intervening long flight.

8. Number of flowers visited per minute.

9. Well or ill-adapted for pollination by this insect.

5. Precise adaptation between flowers and insects, leading to mutual dependence.

It will have been noticed ere this that the flowers which are very irregular or have closed corollas, or secrete their nectar at the bottom of deep and narrow tubes or spurs, have fewer visitors than those that are open and regular. Only those insects which have long proboscides, or which are endowed with special ability at forcing passageways can obtain their stores. Flowers thus specialized receive the usual good and ills of specialization; they enjoy especially efficient aid when their proper visitors are abundant and lack it when these are scarce. It is in the relations existing between these most highly specialized flowers and their few guests that one sees the most remarkable phenomena of fitness and learns the extent and the precision of mutual adaptation.

Such adaptations are peculiar and special, and no general outline can be given for their study: instead, an example will be detailed and a few suggestions offered, and not a formal outline.

For example, let us consider the pollination of the marsh weed commonly known as turtleheads (Chelone glabra). Its rather large white flowers are arranged in four vertical rows at the top of the leafy stem. They are strongly bilateral and have abundant pollen and nectar, so guarded 
by a nearly closed corolla entrance and by internal barricades of spines, as to be accessible to only one kind of visitors-small worker bumblebees. A side view of a single flower is shown in fig. $22 \mathrm{a}$. The narrowly three-lobed, projecting lower lip offers an alighting place for the bees and the reflexed edges of the corolla mouth offer them footholds. A swóllen palate upon the lower lip blockades the entrance against other insects, but under the weight of the worker bumblebee this is depressed sufficiently to allow the head to be thrust into the median groove that divides the "palate," and thereafter, a little pulling and pushing effects an entrance. The queen bumblebee sometimes tries to enter, but can only get her head inside: she is too big. Other insects that are small enough are too light to "tip the beam," or, entering, are barred from the nectar by a mat of bristling hairs on the floor of the corolla and by dense fringes of spines on the stamens: so that the worker bumblebees have a monopoly.

These bees serve the flower well. They exhibit a maximum of efficiency in effecting cross pollination. The stigma of the flower projects slightly beneath the tip of the upper lip of the corolla. The pollen is carried by the bee in a great quantity amid the hairs on the top of its prothorax. It will be easily understood that in forcing an entrance through the narrow passage, this pollen mass is pushed hard against the stigma. A single visit is sufficient for complete pollination of a flower.

The chief means whereby the flower reserves its sweets for proper visitors are not seen from the outside: and these are its most peculiar and special devices, such as are taken least into account in the preceding studies of this chapter. So let us look within. Looking at the flower from below we can see within the narrow corolla mouth the anthers standing close behind the tip of the pistil and close under the upper 
lip (fig. $23^{a}$ ). Figure $23^{b}$. represents the stamens and pistil
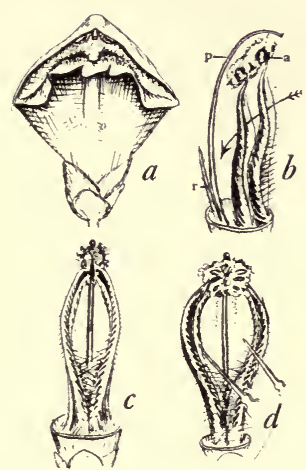

FIG. 23. Diagrams illustrating the structure and mechanism of the turtle heads flower. $a$, anthers; $p$, pistil; $r$, a rudimentary fifth stamen. Other things explained in the text. in side view with the corolla cut away. The stamens are reduced to two pairs and a hairy rudiment of the fifth. The arrow in the figure indicates the position of the bumblebee when it is inside feeding, its body between the paired stamens, its long proboscis reaching downward to the nectaries in the bottom. Only the bee in action could explain the purpose of some of the peculiarities of these stamens. They are laterally flattened so that they will easily bend aside. Their planes are set aslant at an angle opening forward, so that the bee may easily crowd between them. The conspicuous bend forward in their middle portion, being convex toward the entrance, is set in opposition to the pushing of the bee so that they may not be crowded backward out of place. Now turning the stamens so as to see them from the front, as in fig. $23 \mathrm{C}$, we observe that the space between them is much narrower than the bee's body. Separating them a little with our forceps, as at fig. $23 d$ we observe that the anthers, held together by matted hairs above, rotate upon their stalks, separate below, exposing their pollen cavities, out of which a shower of dry pollen falls. Thus it is the bee gets dusted on the back. One may demonstrate this by thrusting a pencil of the thickness of the bees body into the flower and getting a deposit of pollen upon the end of it. Smaller 
insects would not be large enough, and weaker ones would

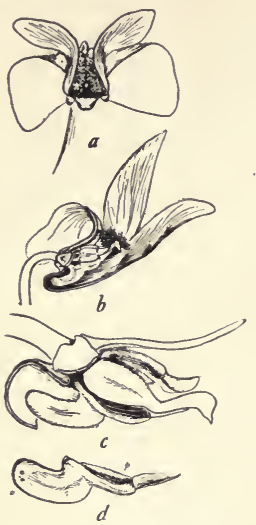

FIg. 24. Diagrams illustrating the structure of the ordinary flower of the violet (Viola cucullata). $a$, a front view of the flower with the tip of the saccate petal cut away. showing the blockade of hairs around and above the stigma; $b$, lateral view with petals and sepals in part removed; $c$, the same more enlarged, and with the lateral stamens removed; $d$, one of the spurred stamens; droplets of nectar on its outer side shown at $o$, and pollen cavities, at $p$. not be strong enough to swing open the heavy doors of the pollen cupboard: so this flower reserves its pollen as well as its nectar for its special guests and affords us a good example of mutual fitness and exclusiveness.

Study 5. A case of precise adaptation.

This is an individual study, to be undertaken only when conditions are right-proper flowers abundant, warm and sunshiny weather, etc. A highly specialized flower with its nectar not easily accessible to flower visitors should be selected, and it should abound in freshly blooming clumps; for the visits to such flowers are often few and far between.

The Record of this study may well consist of a few drawings to illustrate the structure of the flower and the details of the entrance, of the feeding, and of pollen transference by its visitor, with copious explanations thereto.

\section{Specialization miscarried.}

Among our showy flowers are a few possessing the characteristics which elsewhere we find associated with insect aid in pollen distribution, and which are never or rarely visited 
by insects. Such an one is the common blue violet (Viola cucullata). Other species of violets are commonly visited by bees; and this one is apparently finely adapted for such visitation. Yet the bees rarely visit it, and the showy flowers, being incapable of self-pollination, produce no seed.

The accompanying figures show the structure of the flower. It is strongly bilateral, with a saccate lower petal enveloping two spurred stamens: it is blue, with pretty "guide marks" about the entrance: it secretes a little nectar, and

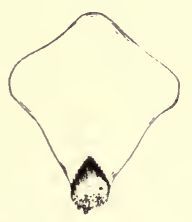

FIG. 25. Tip of pistil of the violet as seen from the front, showing pollen pushed into the hol. low of the stigma. exhales a slight perfume: its entrance is blockaded against improper visitors, but it is narrowed and curved conveniently to admit the proboscis of a bee standing head downward upon its front.

Furthermore, it is well adapted to profit by the bee's visits. A proboscis plying between the spurs of the two lower stamens would dislodge the dry pollen from the anthers, and catch it as it falls, and carry it out, and when probing the sac of the next flower visited, would deposit it on the stigma: for the stigmatic surface is contained in the hollow of the pistil tip, turned toward the entrance (fig. 25); the lower edge of it would scrape up pollen from an entering proboscis, but would only evade pollen that was being withdrawn. What better device could be imagined for securing cross pollination?

The trouble with the mechanism is that it no longer works. The bee stays away. Did it visit the flowers, it would transfer their pollen perfectly and they would be very fertile. This anyone may demonstrate by transferring the pollen with a tooth pick and watching the result in seeds produced. The failure seems to lie farther back in 
the physiology of the plant; it secretes but a little nectar - that little on the outside of the spurs-not enough to run down into the sac where the bee's proboscis can reach it.

There is, however, a small bee-fly (Bombylius major)

that is able to get the nectar

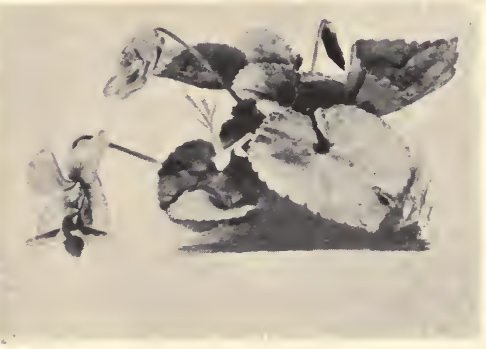

FIg. 26. A beefly (Bombylius major) visiting the violet flower. which hangs in minute droplets on the outside of the spurs (fig. 26). It is often seen poising before a flower, making an oblique thrust at each side of the entrance, pushing its excessively slender proboscis, not down the proper middle passageway at all, but between the spur and the wall of the sac. Thus, it touches neither stigma nor pollen, and gets the nectar without doing the flower any service in return.

But even if this, our commonest violet, has been deserted by its proper visitors, and left to the comradeship of nectar thieves, if its fine adaptations have become useless and its pretty flowers are left to waste their diminished 'sweetness on 'the desert air,' the plant has not been without resource: after the showy flowers of spring cease to appear, it develops at the surface of the soil minute self-fertilizing (clistogamous) flowers, which shun the light, never rise up into view and never open, but which are abundantly fertile, and are produced all summer long* (fig. 27).

*These clistogamous flowers will be examined in Study $5^{\mathrm{r}}$. 
These brief studies of the relations between flowers and insects should have made it apparent that we have with us all grades of association from the most casual contact to mutual dependence, and that we have all grades of fitness on both sides: further that while the adaptations are often wonderfully intricate and fit, they rarely work perfectly, and may even wholly miscarry. And while gratified in observing that they often work with delightful precision,

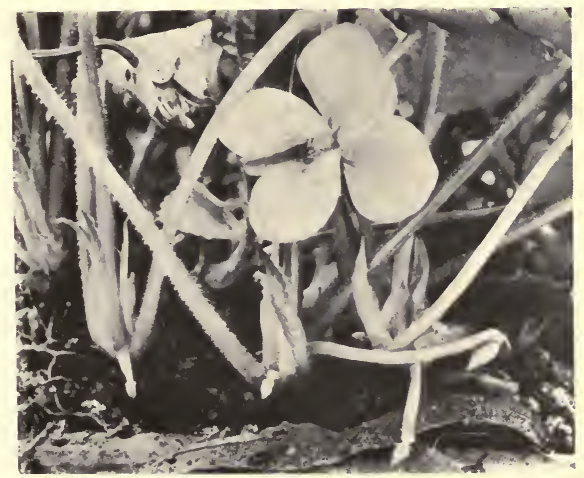

FIG. 27. Flowers and fruit of the violet. The ordinary blue flower and a seed capsule (from a hand pollinated flower) shown above; a row of clistogamus flowers shown below; the lowest one in full bloom.

we should not overlook the fact that the simpler plans suffice for the maintenance of the species that are less specialized.

\section{GALLS.}

Galls are abnormal growths of plant tissues occasioned by stimuli external to the plant itself. The stimuli are furnished by a great variety of insects, by a few parasitic 
fungi, and by a number of other less important and less common agencies. All parts of the plant are subject to these malformations.

As the raking of a wire against a tree trunk that is swayed back and forth by the wind causes great ridges to grow upon the sides of the trunk, so the gnawing or sucking of an insect in the growing tissue of the plant causes a gall to grow. Not all irritations to plant tissues cause such overgrowths, but only such as are applied while the tissue is rapidly developing. There are, for example, a number of moth larvae that work in the stems of goldenrods: those whose attack is made before the stem tissues are fully formed cause galls; the others are merely stem borers. Likewise, in oak leaves the little fly larvae that attack them in the bud cause galls; the later ones make only leaf mines. The stimulus might be the same, but the period of response on the part of the plant being overpast, there is no gall formation. Overgrowth of the plant tissue is, therefore, the criterion of a gall.

So generous is the response of the plant in the production of tissue that serves for both food and shelter, that the habit of attacking young tissues has been biologically profitable. Hence there is developed a large fauna especially and exclusively adapted for exciting galls and living in them-a very favorable subject for the study of interrelations.

We will confine our study here to those malformations that are caused by insects and mites, notwithstanding that there are some common and conspicuous galls, like the one on the sumach top shown in figure 28 , made by fungi. This one belongs to that general class of galls popularly known as "witches' brooms": other common fungus galls appear as knots and swellings upon the trunk or the branches of trees: all consist of more or less solid tissue 
and are readily distinguishable from animal galls which contain distinct cavities for the occupancy of the gall makers.*

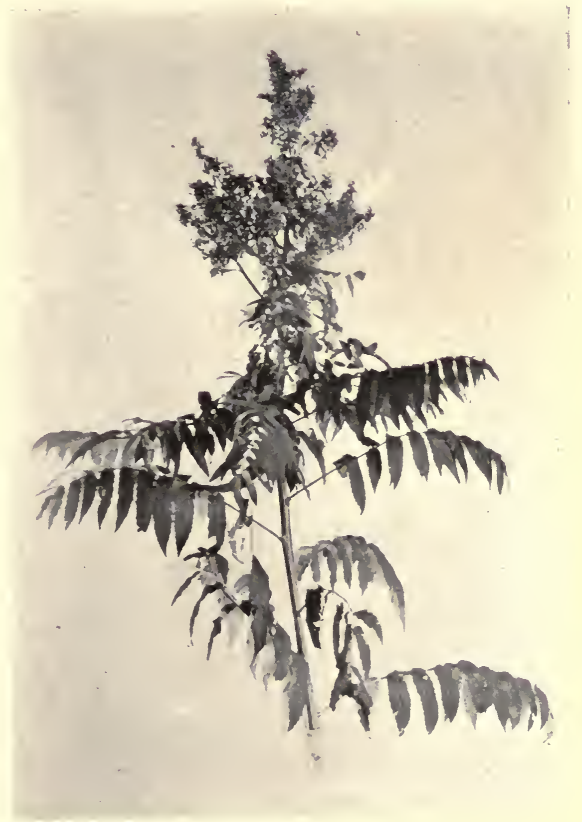

FIG. 28. A fungus gall of the "witches broom" type on the smooth sumac (Rhus glabra)

*While we commonly speak of the gall insect or fungus as a "gall maker," we are not unmindful that it merely furnishes the stimulus to overgrowth on the part of the plant itself. 
Animal galls.-Animal galls are less diffuse. Under the stimulus of the attack of the insect in feeding, the tissue grows rapidly, producing more food: moreover, around the point of attack it grows and shuts in and covers and protects the gall maker. Furthermore, it continues to grow and shape itself into symmetry, its final form often resembling a fruit. More remarkable still, it often developes unpalatable substances (such as tannin) in its walls and sharp spines upon its surface, and thus protects its enemy the gall maker, from being eaten.

Most animal galls are small, but a few of them, such as the aphid gall of the cottonwood shown in figure 29, grow large

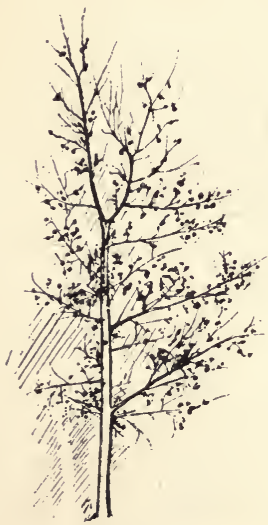

FIG. 29. Winter aspect of aphid galls on a cottonwood tree. enough to become when numerous, a feature of the winter landscape. This one is formed not about a single aphid, but about an aphid colony; and its irregularity is doubtless due in part to the grouping of individuals in the attacking aphid flock.

The commoner forms of animal galls are these:

open $\left\{\begin{array}{l}\text { felted } \\ \text { mantle } \begin{cases}\text { scroll gall } \\ \text { pocket gall } \\ \text { fluted gall } \\ \text { covering gall }\end{cases} \end{array}\right.$

closed $\left\{\begin{array}{l}\text { simple } \\ \text { nucleated. }\end{array}\right.$

The differences between these forms are indicated in the following diagram. (fig. 30). 
The primary distinction between open and closed galls lies in their mode of origin. In the open gall the attack is made from the outside, while in the closed gall the insect enters the tissue bodily and feeds inside: ordinarily, it

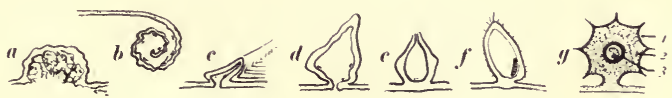

FIG. 30. Diagram of typical form of galls. $a$, felted; $b$, scroll; $c$, fluted; $d$, pocket; $e$, covering; $f$, simple closed; $g$, nucleated. $a$ to $e$ are open galls; $f$ and $g$, closed.

enters in the egg stage, the egg being inserted through a puncture in the epidermis. In the open gall the insect may be covered and inclosed by the overgrowing tissue, but when inside the gall it is still outside the leaf substance, and in feeding, stands upon and punctures the epidermis with its piercing mouthparts.

Felted galls (fig. 3 I) represent a low degree of gall development. They occur mostly upon leaves, and are as a rule made by mites. They usually consist of a slight sacculation of the part of the leaf blade that is subject to attack, and the malformation is mainly confined to the epidermal cells, which develop a wonderful growth of robust plant hairs that are twisted and matted together like felt, whence the name. $\mathrm{T} h \mathrm{e}$ mites clamber around and feed between the bases of these

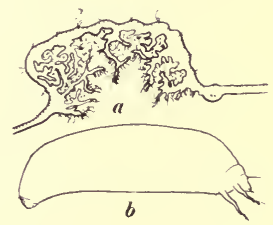

FIG. 31. A felted gall (a, cross-section) from the leaf of button-bush (Cephalanthus occidentalis) and the mite $(b)$ which causes it. plant hairs.

Mantle galls represent a better development of leaf cover for the gall maker: the cavity is deeper 
and more completely inclosed, and, usually, not felted within: the walls often rise and shape themselves with marked symmetry and even beauty. The four names given in the table as types of mantle galls are but convenient designations of the more typical forms which

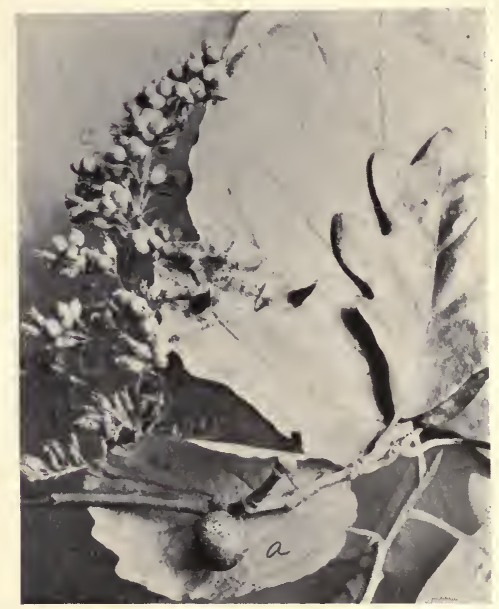

FIG. 32. Stem, leaf and flowe galls. $a$, a nucleated gall on the twigs of white oak (Quercus alba) $b, a$ mantle gall on the leaves of witch-hazel (Hamamelis virginiana); $c$, simple closed galls on the flowers of goldenrod (Solidago nemoralis).

often inter-grade or combine together in a single gall. The scroll gall is formed by the uprolling of the leaf margin: the fluted gall, by the furrowing of the blade (chiefly along veins) in elongate grooves. The pocket gall and the covering gall although much alike in appearance are most unlike in fact, being diametrically opposite in their manner of 
growth. A typical pocket gall is shown on the witch hazel leaf in fig. 32. It is formed by the descent of the tissue attacked to form a pocket upon the leaf blade: the attacking insect is carried into the pocket, which usually dilates, and forms a spacious chamber. The covering gall, on the contrary, rises up around the point of attack, and covers the insect over, leaving only a small aperture at the top. The removal of a pocket gall leaves a hole through the leaf: the removal of a covering gall leaves only a superficial scar.

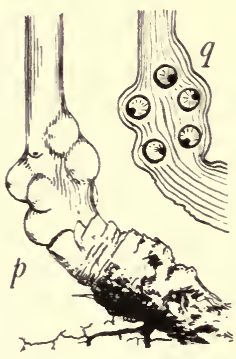

FIG. 33. Compound gall on the root of wild lettuce (Lactuca sp?)

Closed galls, as already stated, result from internal attack: the cavities they contain lie wholly within the plant substance. They likewise differ among themselves in the degree of their derelopment. The simpler ones (fig. $32 \mathrm{c}$ ) have thin walls, of the ordinary tissues of the part bearing them. The nucleated galls (fig. 32( ) show often a high degree of differentiation of parts. There are often three well defined layers in their walls: an inner (when mature) rery hard layer forming the "nucleus" whose cavity contains the gall maker, an intermediate softer and more or less spongy layer. and an outer hard layer, often protected with spines and hairs and ornamented with beautiful colors. The stone-like nucleus in the middle and the form and color of the exterior greatly enhance the superficial resemblance of the gall to a fruit.*

*It is to be noted in passing, that the gall when fruit-like almost invariably resembles the fruit of some kind of plant other than the one that bears it. 
As to their distribution upon the plant, galls are solitary, (as in fig. $32 a$ ) clustered (as in fig. $32 c$ ), or compound (as in fig. 33): they are called compound when they contain separate cavities surrounded by confluent walls.

The animals that produce galls.-With a few unimportant exceptions the animals that cause galls to grow belong to a single family of mites and to five orders of insects, Hemiptera, Coleoptera, lepidoptera, Diptera and Hymenoptera.

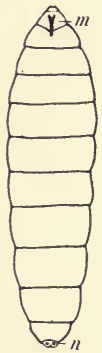

FIG. 34 Diagram of a gall midge larva (family Cecidomyiida of Diptera). $m$, the so-called "breast bone;" $n$, respiratory apertures.

The mites are very minute four- or eightlegged creatures without distinction of head and thorax (fig. $3 x b$ ). They live amid the growth of matted hairs that fills the cavity of felted galls.

Hemipterous gall makers are aphids, psyllids, etc., and they generally live within mantle galls.

Coleopterous and Lepidopterous gall makers are beetle and moth larvae respectively. They are but a few stray members of large families that are not much addicted as a whole to the gall making habit: but these few make comparatively large closed galls, some of which are sure to be encountered in the following field study:

Dipterous gall makers mainly are gall gnats(Cecidomyiidae), with a few scattering representatives of other families. Cecidomyiid galls are very common, and of the utmost diversity of structure and appearance. The larvae within them are often very small, but they are distinguishable by the possession on the under side of the first segment behind the head of the so called "breast bone," a flat, brown horny piece that projects forward toward the mouth and is often notched at its tip (fig. 34). 
Hymenopterous gall makers belong, with a few exceptions to two families, Tenthredinidae, saw flies, and Cynipidae, gall wasps. Sawfly larvae make rather simple closed galls, which they abandon when grown, to find some other place of transformation. Gall wasps are gall makers par excellence. They cause the most perfect nucleated galls: as a family they are most completely adapted to the gall making habit.*

The tenants found in the course of the following study occupying the galls collected, may be identified by the student himself. For the adults, of which few, if any, will be found, use the keys of any good manual of entomology. Pupae if found may easily be reared. Place them uninjured in a glass jar, add a wet sponge, or bunch of cotton to prevent drying up, and tie netting (preferably fine swiss) over the top of the jar, and let them stand till they emerge as adult insects. Larvae, which will generally be found, may be identified as follows:

Key to the commoner insect larvae and mites found in galls.

A. Body short and thick: legs rather long.

B. Head fused with body and not distinct; legs 2 or 4

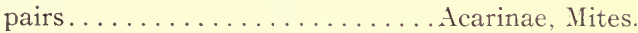

BB. With distinct head: legs 3 pairs (Hemiptera).

C. Wing pads present, projecting at right angles with the body: no cornicles on abdomen. Psyllidae.

CC. Wing pads absent, or if present, laid lengthwise of the body: cornicles often present (see fig. 39). Aphidae AA. Body cylindric, worm-like: legs minute or none.

B. With 3 paris of minute legs under the thoracic seg- . ments.

*It is to be observed that there is not a single family of insects whose members are all gall makers: Cynipida comes nearest. 
C. With a brown shield covering the prothorax above: body armed with stiff bristles............. Lepidoptera, moth larvae.

CC. Without a brown prothoracic shield.

D. With rudimentary legs (pro-legs) underneath some of the abdominal segments.......... .Tenthredinidae, sawfly larvae.

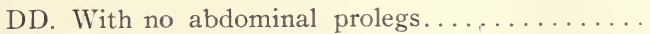
Coleoptera, beetle larvae. BB. Legless.

C. With a distinct head segment: body arcuate, white. D. Body segments deeply wrinkled: head brown: skin dull white,$\ldots \ldots \ldots \ldots \ldots \ldots \ldots \ldots$ Coleoptera, Family Curculionidae, weerils. DD. Body segments smooth, shining, head mostly white......... Cynipidae, gall wasp larvae.

CC. With the head segment greatly reduced, very minute or wanting: body straight.... Diptera.

D. With the ventral piece shown in fig. 34 Color often red or yellow... Cecidomyidae, gall gnats.

DD. Without this structure. Color white...... . Other dipterous larvae

Despite the food, cover, and defense, provided by the plant for the gall maker, the fact must not be lost sight of that the creature is the plant's enemy. The young bur-oak shown in figure 35 gives evidence of this. Cynipid galls, growing too thickly have killed the terminal shoot, and the lateral shoots are taking up the growth. Such positive injury from galls is rarely seen, however, for the gall makers are kept in check by hosts of very efficient parasites. The student following the field work outlined below will be sure to come upon some of these parasites, and it may be with some difficulty that he will distinguish which ị parasite and which is gall maker in 
some cases. The parasites are all Hymenoptera, with larval form very like that of Cynipid larvae (see key).

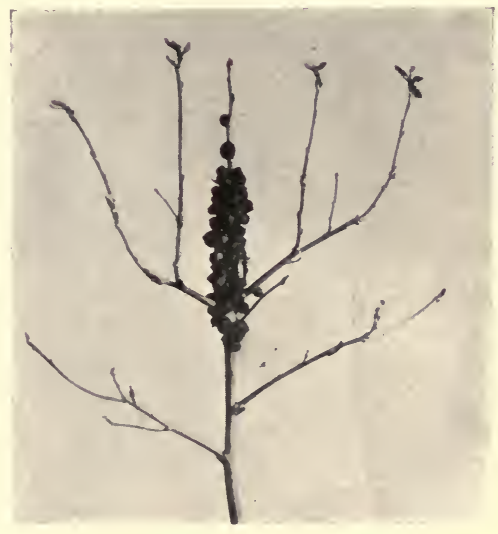

Fig. 35. Clustered galls on a young bur-oak. Observe that the centra! shoot is not putting forth leaves (Quercus macrocarpa.)
$\mathrm{Such}$ larvae found in galls that are made by insects of other orders may of course be set down at once as parasites. In cynipid ga $11 \mathrm{~s}$, which will give the trouble, thesa suggestions may help: The Cynipid larra generally quite fills the central carity of its gall; the parasitic larva is usually consider-
gly arcuate withably smaller: the cynipid larva is very strongly arcuate within the cavity; the parasitic larva is generally not so strongly bent.

The gall when grown offers often a place of shelter and sometimes a place of development to other insects besides the one that caused it to grow. Thus new interrelations are brought about. Some of these are well shown by the cone gall of the willow (fig. 36), whose fleshy scales when green furnish forage for the burrowing larvae of several species of moths and sawflies, and when dry furnish shelter and a place of incubation for meadow-grasshopper eggs. Guest gall-flies, also, develop between the outer scales, 
often in great numbers: and each of these species has its inevitable train of parasites.

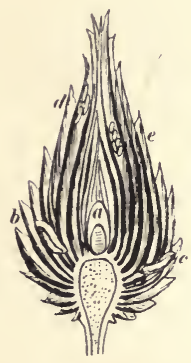

Frg. 36.-Diagram illustrating the distribution of the inhabitants of the cone gall of the willow: $a$, the gall maker. $b$, moth larva. $c$, sawfly larva. $d$, meadow - grasshopper eggs. $e$, guest gallmidge larvae.

All these forms together constitute a miniature animal society, dependent on the overgrowth of willow tissue that results from the attack of the gall midge.

Study 6. A study of common galls.

Apparatus needed: A scalpel, or knife, a lens, and a basket, bag, or very capacious pockets.

Collect afield a large number of galls, bringing into the laboratory enough to fairly represent each kind found. Search such trees as oaks, hickories, lindens, hackberries and willows; such shrubs as sumach, roses, witchhazels and dogwoods and such herbs as goldenrods, ox-eyes, and touch-me-nots.

The record of observations.--Select a dozen or more species that represent best the general phenomena outlined in the preceding pages, and write down their characters in a table prepared with the following column headings:

Name of plant.

Part of plant affected.

Position of gall on this part (upper or lower surface of leaf, etc).

The Gall

Gall type.

Aggregation, solitary clustered or compound.

Cavity of gall (shape, close fitting, etc.).

External coat, armature, etc.

Special structural features, if any.

Defences against foraging animals. 
The Insect $\left\{\begin{array}{l}\text { Order to which it belongs. } \\ \text { Family. } \\ \text { Solitary or gregarious. } \\ \text { Stage found. } \\ \text { Parasites or hyper-parasites. } \\ \text { Inquilines. }\end{array}\right.$

Summarize the results of the preceding study in a table of the orders of the gall makers, prepared with the following column headings.

Order (of insects, or mites)

Mouth parts (biting or sucking)

Habits (solitary or gregarious).

Gall type.

Then state any relation appearing I) between type of mouthparts and type of gall, and 2 ) between order of insect and type of gall.

\section{THE RELATIONS BETWEEN ANTS AND APHIDS.}

Aphids are familiar plant pests which infest our fields and gardens. They are minute Hemiptera, possessed of a slender proboscis, with which they puncture soft plant tissues and suck out the sap. Some aphids. which attack developing plant tissues, will already have been found in the cavities of the galls to which they give rise. All are gregarious in habits, mainly because their great reproductive capacity is coupled with poor power of locomotion. Generation after generation they are wingless: but when the time for their wide dispersal is at hand, a winged generation appears, which flies freely in search of new locations. Autumn is the time of dispersal of most species, because of the general failure of food supply at that time, and the necessity of relocation for winter: but the failure or unfavorable alteration of food supply may occasion the production of a winged generation at any time. 
Individually aphids are insignificant, but collectively their drain upon the plant may be very serious. Each aphis is an animated sap pump. It sits quietly on bark or leaf, with its proboscis immersed in the green tissues, and pumps by the hour, scarcely changing its place or moving by more than an occasional sweep of its long antennae. Its food consisting of sap, contains considerable sugarmuch more indeed than the creature is able to assimilate. This excess of sugar is discharged from time to time, along with the other rejectamenta and excreta of the body, in fluid drops of "honey dew.'

Honey dew is very sweet and palatable. It is gathered from the leaves where it falls by ants, bees, wasps and other animals. Bees store it as honey, and although it is not the best of honey still it is not unwholesome, and men eat it gladly. When aphids are abundant on growing trees honey dew is often secreted in large quantities. A sudden jarring of an aphid covered bough may cause such a sudden and simultaneous discharge by the aphids that the honey dew will fall in a shower of fine spray. It often covers the lower boughs of trees and the bushes beneath them, with a shiny, sticky, sweet coating.

That ants have a "sweet tooth" everyone knows from observations in his own pantry or lunch basket. They like honey dew, and from gathering it at large, they have passed to gathering it at its source-from the aphids themselves. The relations between the two that find their simplest expression in chance visits by ants to aphid colonies, become much more intimate when ants begin to guard and care for the aphid flocks, to build shelters for them, or to share their own homes and fortunes with them.

These relations may be grouped in three categories:

I. The chance feeding by ants on the honey dew offered by aphids.- This is hardly more than accidental associa- 
tion. It may be recognized in an aphid colony that is attended by one kind of an ant on one day, by another

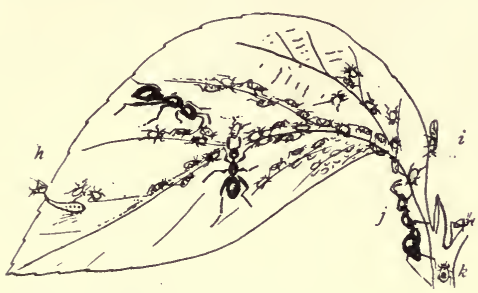

Frg. 37.-Aphid colony on a leaf of Ceanothus, attended by ants seeking honey dew. $h$, a larva of a syrphus fly, feeding on a wingless aphid. $i$, a winged aphid. $j$, an ant patting an aphid with its antennae. $k$, the empty skin of an aphid that has been parasitized. kind on another day, and is part of the time unattended.

2. The habitual guarding of aphid colonies by ants, safeguarding their own supply of honey dew.-This is the commonest type of association, and the one easiest to observe. In summer or autumn, on many a curled dock or thistle or dogwood bush, wherever ants are seen gathered together upon the green foliage, there one may expect to find on closer inspection, an abundance of aphids as well. And if one approach quietly and watch carefully he may see the ants moving about among the aphid herd, fondling them with their antennae, patting or stroking an individual here and there, and obtaining sometimes as a response, the extrusion of a drop of honey dew, which is lapped up as soon as it appears. The ants will often be seen to drive away intruders-chiefly winged parasitic insects, which seek to lay their eggs upon the bodies of the aphids. They will even rush at an intruding finger, and attack it fiercely, though ineffectively, with their jaws. Yet, though they show great dash and courage in dealing with any parasitic syrphus fly or ichneumon that ventures too near the flock, they show a sad lack of insight in allowing the egg, when one has been successfully laid by 
the parasite, to remain where placed, and the fly larva, when hatched, to feed openly (fig. $37 \mathrm{~h}$ ) upon the aphids. That their guardianship is often eluded may be seen on close inspection of almost any aphid flock.

3. The domestication of the aphids by ants. - This covers at least two distinct sorts of activities on the part of the ants: I) the building of shelters and enclosures about the aphid

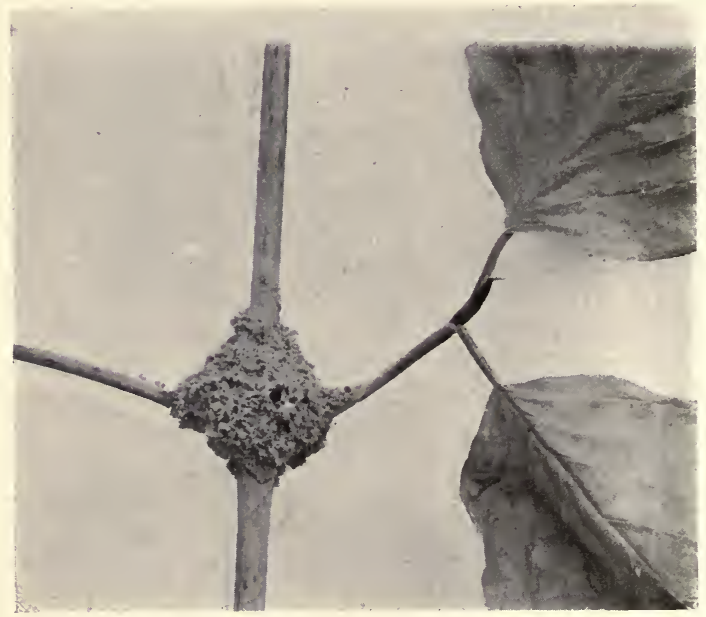

FIG. 38. Aphis shed on twig of dogwood; photo of a specimen in the Cornell University collection.

flocks, and 2) the safeguarding of the development of individual aphids and the establishment of aphid colonies. These are two well recognized functions of all animal husbandry.

Ant sheds are built usually near or on the ground about compact colonies of aphids (or other honey dew secreting 
Hemiptera) so as to completely enclose the flock. With but a few small openings left through the walls for entrance and exit, the guarding of the flock is easier and the security of the flock is greater. The aphids no longer "run the range," but are kept in folds. Excesses of heat and cold are less felt, and the great injury from exposure in rainy weather is largely avoided. The ants probably reap the usual rewards of good husbandry in the larger and more constant secretion of honey dew.

The sheds are of two sorts as regards the materials of which they are made: I) earthen sheds, made of sand grains, etc., stuck together with wet clay, and 2) felted sheds made of interwoven bits of shredded plant tissues. Both sorts are often placed about the stems of bushes (fig. 38) and supported on branches or leaf stalks.

Finally, there is a permanent association, with the ants exercising care and control over the aphids in all stages of their development. This is complete domestication. The best known case of it is that of the little brown ant of the fields and the corn-root aphis. This subterranean aphid lives on the roots of Indian corn, where these roots traverse the branching passageways of the nests of the ants. It is a hapless creature (fig.39), quite incapable of uncovering corn roots for itself, or even of finding them if uncovered: so, the ants excavate the soil, making lateral foraging chambers communicating. with their nest, and carry the aphids in and place them on the roots. There the aphids feed and secrete honey dew through the season, and in the fall, there they lay their eggs. The following account is quoted from a report on corn insects by Professor Forbes, to whom our knowledge of this relation is chiefly due:

"These eggs, which are yellow when first deposited, but soon become shining black, and turn green just before hatching, are at first scattered here and there, as it 
happens, but are finally gathered together by the ants for the winter in little heaps, and stored in their galleries, or sometimes in little chambers made by widening a gallery as if for storage purposes. : If a nest is disturbed, the ants will

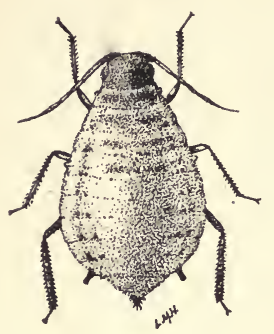

FIG. 39. Corn root aphis (Aphis maidiradicis), wingless female $x$ I4 (from Forbes.) The two black processes at the rear are Cornicles. commonly seize the aphid eggs, often several at a grasp, and carry them away. In winter they are often taken to the deepest parts of the nest. . . as if for some partial protection against frost: but on bright days in spring they are brought up, sometimes, within half an inch or less of the surface, sometimes even scattered about in the sunshine, and carried back again at night-a practice probably to be understood as a means of hastening their hatching. I have repeatedly seen these ants in confinement with a little mass of aphid eggs, turn the eggs about one by one with their mandibles, licking each carefully as if to

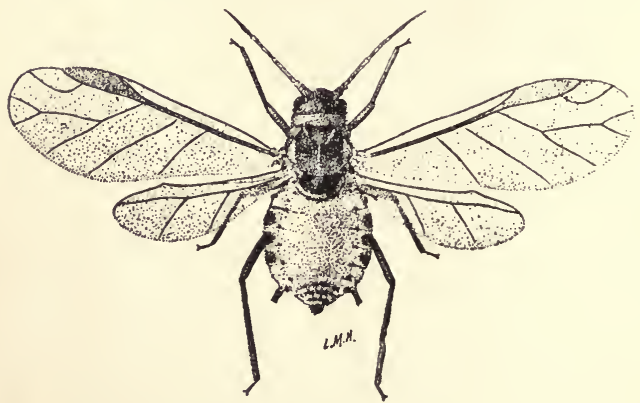

FIG. 40. Corn root aphis, winged female $\mathrm{x}$ i6 (from Forbes). 
clean the surface. These anxious cares are of course explained by the use the ants make of the rootlouse [aphid], whose excreted fluids they lap up greedily as soon as the young lice begin to feed.

"That the young of the first generation are helped by the ants to a favorable position on the roots of the plants they

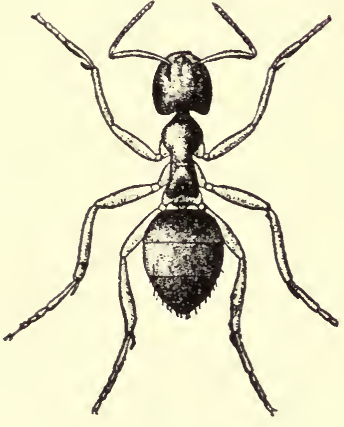

FIG. 41. Small brown ant (Lasius niger alienus) that domesticates the corn root aphis; worker, $\mathrm{x} 8$ (from Forbes). infest is quite beyond question. . . We have repeatedly performed the experiment of starting colonies of ants on the hills of corn in the insectary, and exposing root lice from the field to their attention and in every such instance, if the colony was well established the helpless insects have been seized by the ants, often almost instantly, and conveyed under ground, where we would later find them feeding on the roots of the corn.

"I need hardly say that the relations above described between the corn-root aphis and these ants continue without

cessation throughout the year."

Thus sequestered from parasites, and guarded by the ants and cared for at every turn, this long unknown aphid has flourished inordinately, and has become throughout the great "corn belt" a serious pest. It is another illustration of man's influence in disturbing the natural balance. Corn fields have replaced the native prairies and woodlands over wide areas, and have offered opportunities for almost unlimited increase in numbers of corn insects that were doubtless but sparingly distributed before. 
Study 7. Observations on ants and aphids.

It is not possible to give a hard and fast outline for the study of these phenomena: for, though widespread, they are not equally available at all times and everywhere. It should be possible to find anywhere in summer a number of colonies of aphids with ants in attendance, on such plants as curled dock, milkweed, thistle, dogwood, etc. Ants are easily seen when running about over green vegetation, and almost always there will be found flocks of aphids (or of other honey dew secreting hemiptera with which the ants have similar relations) as the occasion for their assembling.

Such an association being found, the apparatus needed will be a low power magnifier (such as a reading glass is excellent) and a note book, and the things to be observed are:

I) The ordinary behavior of the ants toward the flock.

2) The gentleness of the ants toward individual aphids: the stroking and patting of them first with the antennae and coming closer, with the palpi.

3) The lapping up of the honey dew when an aphid responds by ejecting it.

4) The ferocity of the ants toward intruders: this may be tested with one's own finger.

5) The stupid indifference of the ants toward the eggs and larvae of the parasites.

6) The general inactivity and helplessness of the aphids.

7) The prevalence of (parchment skinned) parasitized individuals.

If aphid sheds can be found, their materials and construction should be noted, their doors, their braces, and their shape as adapted for giving a maximum amount of foraging surface with a minimum of construction. Some advantages to both ants and aphids can readily be seen to accrue from them. 
Root aphids can usually be found in any corn field where burrows of the little brown ant are common. There burrows are easily seen after a rain, when the ants open them up and toss out upon the surface annular mounds of little pellets of earth. The aphids will be found by exposing some of the corn roots where they traverse lateral passageways ramifying outward from the ants' nest. The ants will usually promptly demonstrate their care-taking function in the premises, by seizing any aphids that may be shaken off from the roots and carrying them into their nests. An account of a cage that may be used for rearing such mixed colonies in the laboratory will be found in the appendix.

The record of this study may well consist of brief notes on the things observed. 


\section{CHAPTER II.}

\section{THE SIMPLER ORGANISMS.}

To understand the complex phenomena of life we must seek their simpler expressions. The relations between the higher and more familiar forms of life are very intricate. The bodies of such plants and animals as we have been observing are highly organized-composed of many parts having special functions. How shall we learn what are the primary parts and functions of living things? It will help us to distinguish essentials

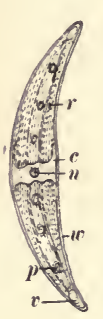

Fig. 42. Closterium if our first quest be made lunula, $c$, cytoplasm;
$n$, nucleus; $w$, celi among organisms of lowly wall; $r$, chlorophylbearing protoplasm; $p$, pyrenoid; $v$, vacuole.

structure. The simpler plants and animals live in the water. We have already learned that the main gatherers of food material for the living world are green plants. The simplest green plants are the algae; so with these we will begin.

\section{SOME TYPICAL ALGAE.}

When we learn to recognize them we can hardly look into the water anywhere without seeing algae. They float in green masses upon the surface; they hang in graceful drapery of verdure on submerged branches; they drip in globules of gelatine from twigs that are lifted out of the water: they rise from the bottom; they lie amid the silt; they trail across the rocks that are swept by the cataract; they cling to wave-beaten piers and boulders; they are free-swimming, and come in our water supply; and they grow and flourish in the bottle of clear water that is long left 
standing on the window sill. It is not hard to find them in great variety of size and form, and in great beauty and delicacy of organization.

Closterium (fig. 42 ) is a very pretty simple alga that is commonly found in the bottom sediment of fresh water ponds. Although very small, its bright green color and crescentic form make it easily recognizable. If we gently lift up from the pond bottom some sticks that have long lain undisturbed, and shake into a white plate filled with water the silt that covers them, spreading it out in a thin layer, we may usually find Closterium scattered about over the plate. It is visible to the unaided eye, and is easily recognized with a pocket lens. It is easily reared indoors in a cool, well-lighted place in a jar of pond water supplied with some mud from the pond bottom, and this is the best way to get a large supply. Enough for class study may usually be obtained by mounting the scrapings of silt from submerged leaves, that have lain long in clear, welllighted water.

A few specimens transferred to a slide and examined with a microscope present at once to the eye some important characteristics of green plants. The crescentic plant body is seen to be encased in a transparent capsule, the cell wall, with a green substance filling the greater part of both ends of the crescent, leaving a transparent, clear band across the middle. In this clear band on closer inspection there is seen a slightly granular substance of such transparency it is at first easily overlooked, and in the centre of it is a round body of slightly denser consistency. Although so inconspicuous, it is well to fix attention at once upon these latter structures, for they represent the essentials of living structure. The granular mass is protoplasm and the round body within it and forming part of it is the mucleus. The green substance filling and obscuring the protoplasm at the 
sides is chlorophyl, and the transparent capsule inclosing the whole is the cell wall. The whole plant thus enveloped is a single cell.

Well down in the angle toward each end of the crescent will be noticed also a round droplet of watery fluid called a vacuole, in which, under high magnification may be seen suspended some minute crystals in continuous (Brownian) movement.

If from a freshly growing Closterium culture a number of individuals be mounted and examined, they will be found to differ considerably in size and in appearance at the transparent middle crossband where the nucleus lies. Some of the larger ones will show a broader clear area there, or an indentation of the cell wall at each side, or a constriction extending entirely across the cell, cutting it more or less deeply into two parts, as indicated in figure 43. Closely examined, this process will be seen to be initiated by the division of the nucleus into two parts, one of which passes

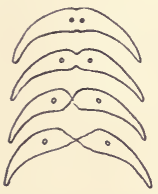

FIG. 43. Division in Closteriums; uccessive stages. to each side of the cross band and into the edge of the chlorophyl. The deepening constriction thus divides the mass of protoplasm, and forms two smaller cells out of one large one. Each of the smaller ones, before the separation, is lacking in the crescentic symmetry of the grown plant, the newly formed end being blunter, lacking chlorophyl and vacuole, and having the cell wall thin and not symmetrical with the other end.

Reflecting on the few readily observable details of this apparently simple process whereby new plants are produced, it is obvious at once that certain of the structures seen are more essential than others. It is the protoplasm that passes on unchanged from mother cell to daughter cells-both the general protoplasm of the cell-body (cytoplasm) and 
the nucleus. About the new end a new cell wall is formed, and in the protoplasm of that end new chlorophyl develops. It is for the sake of the protoplasm that these other parts exist. The normal structure is regained, during the period of growth which ensues. Little is directly observable except the increase in size of the plant.

The two processes of growth and reproduction so simply shown in Closterium, are characteristic of all living organisms, and are their most distinctive phenomena.

Many algae consist, like Closterium, of cells existing singly, while many others consist of numbers of cells aggregated together to form a more complicated plant body. But whether the plant cell exist alone and apart, or whether it live in contact or in combination with other cells, its parts are usually those seen in the cell of Closterium:

I. Protoplasm "the physical basis of life" $\left\{\begin{array}{l}\text { and nucleus } \\ \text { anclosed by, }\end{array}\right.$

2. The cell wall, an investing capsule of transparent cellulose which envelopes, besides the protoplasm, certain diverse substances of greater or less importance that may collectively be designated as:

3. Inclusions, the more important of which are

a) the cell sap; a watery fluid which fills all the spaces (vacuoles) unoccupied by the more solid parts and is the medium of exchange of food and waste materials.

b) chlorophyl, the greenish substance above noted, in the presence of which occur carbon reduction, and the storage of energy of the sun's rays (to be discussed under a subsequent heading), and

c) secretions, excretions, reserve stores of starch and other food materials, precipitations of mineral crystals, (such as oxalate of lime), from the saturated solutions of the cell sap, etc. 
The two studies which immediately follow are intended to give I) an acquaintance with the appearance of the living part of plant substance, and 2) some knowledge at first

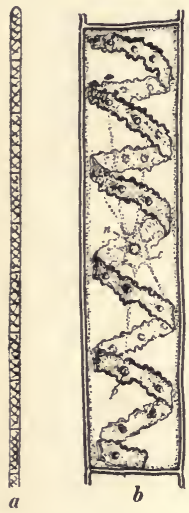

FIG. 44. Spirogyra. $a$, a bit of a filament containing nine cells; $b$, a single cell, more highly magnified; $c$, cytoplasm: $n$, nucleus; $p$, ругеnoids, in the chlorophyl band. hand of the diversity of form of cells and of the manner of their combination together into a plant body among the algae.

Study 8. The cell of Spirogyra and the protoplasm of Nitella.

Materials needed-a supply of fresh Spirogyra and Nitella in clean water.

Apparatus needed-the usual laboratory equipment of simple and compound microscopes, small tools, glassware and reagents.

The student should first examine Spirogyra in mass, as it lies in the water, and then lift out a small tuft of its long filaments for examination in water upona white plate. He will there note their length and their unbranched condition. Examining them with a simple lens, he will be able to distinguish clearly the spiral bands of green that wind about each filament on the inside and make Spirogyra easy of recognition among other algae of similar manner of growth (fig. 44).

If he then mount a few filaments upon a slide, placing a cover-glass upon a favorable portion, and filling up the space beneath the cover glass with water, he may with advantage apply the compound microscope to the examination of them.* Placing the slide thus prepared

*If the student be not familiar with the use of the compound microscope, let him at this point pursue the supplemental study outlined in the opening pages of the appendix, for which Spirogyra is appropriate material. 
upon the stage, and examining the delicate filaments with low power of the microscope, he will at once observe that they are not all alike: different species of Spirogyra often grow together, but the filaments of a single species differ: some are of a richer green, with the chlorophyl bands adjusted closer together about the inner walls of the fibre. Let him select for study a filament with the green bands as far apart as possible (so that the internal parts may not be hidden) and examine it as to the arrangement of its parts.

The cell.-It will be at once apparent that the plant body is composed of elongate cylindric cells placed together end to end: the filament is a simple linear aggregate of cells. Looking at a single cell, it will be seen to have a rather thick cell wall squarely cut at the ends. The chlorophyl is restricted to the spiral band, which is not continuous from cell to cell, and which varies considerably in appearance and in number of turns in the cells of different filaments. Focusing upon the upper surface of the cell, the chlorophyl band will be seen most clearly - a beautiful wavy band of green, marked with a narrow median ridge, and studded here and there along the course of this ridge with round bodies containing the pyrenoids. Focusing downward, the band appears below, inclined in the opposite direction, and less clear because of the parts now intervening. Focusing upon the axis of the cell, and looking between the green bands for the more fundamental parts, there will be seen (and, readily, when one begins to see) at the center of each cell a mass of protoplasm containing the nucleus. As compared with the size of the cell, the amount of cytoplasm is small. It consists in: I). the central mass containing the nucleus, 2) slender strands radiating outward therefrom to various parts of the cell, but chiefly to the pyrenoids, and 3) a thin film next the cell wall. This last fits the cell wall so closely and is so transparent it is hard to see. It may be drawn into view by 
osmotic pressure, if one only replace the water beneath the cover glass with some denser liquid, such as dilute glycerine, or $5 \%$ salt solution. This outer film will then be seen to shrink away from the cell wall, and if the shrinkage continues, to collapse altogether; but if replaced quickly in pure water, it is soon restored to its original condition; clearly the larger part of the cell is occupied with the watery cell sap, easily withdrawn or replaced.

Thus the main features of structure may be seen in the living cell. But the relations of some of the more delicate parts may be made more clear by the two following experiments: If a drop of iodine solution be placed upon the fibres upon the slide, it will stain the protoplasm yellowish brown, making the peripheral parts of it more apparent. It will also stain the minute starch granules that lie about the edges of the pyrenoids dark blue or blackish.

If a few fresh green filaments be placed in

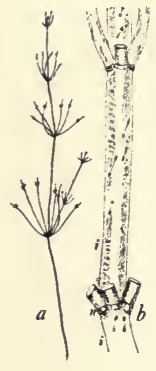

FIG. 45. Nitella. $a$, the tip of a branch; $b$, a bit of the same somewhat magnitied; $n$, node; $i, i$, internodes. strong alcohol, the chlorophyl will be dissolved out by the alcohol (more rapidly with the aid of heat) and the protoplasmic matrix in which the chlorophyl is held will be apparent.

Nitella.-In order to get a large enough single mass of pure protoplasm to see without lenses and to handle, it is necessary to find cells much larger than the ordinary ones, that shall contain it. The common stonewort, Nitella, is an alga with some very large (multinucleate) cells, from which the protoplasmic content is easily removable, and may well be used for a first direct observation on protoplasm. Nitella grows upon submerged limestone rocks in permanent water. It is one of the most highly organized of the algae. It is attached at its base, bears branches arranged 
in whorls along its stem, grows apically from terminal buds, and has more of the aspect of familiar plants of other groups than any of the algae studied hitherto. An examination of its structure (fig. 45) will reveal that its stems and its branches are alike made up of alternating nodes and internodes, the nodes consisting of a ring of short, closely packed cells, the internodes consisting each of a single very large and long cell. The branches arise from the nodes. The internodes are wholly exposed.

It is these very large internodal cells, with their considerable quantity of contained protoplasm that we will study. Since they are wholly exposed to view and have more or less transparent walls, it will be well to observe first the movements of the living protoplasm as seen under low power of the microscope. A fresh green spray may be plucked from the top of the stem, placed upon one slide and held flat under another laid upon it, and thus placed upon the stage for observation. Focusing upon the upper surface of an internodal cell, just beneath the roughness of the cell wall will be seen the numerous oval green chlorophyl bodies. At a slightly lower level, by looking intently for a minute, there may be seen the streaming protoplasm, which, though itself transparent, containsminute granules, by the movement of which it may be recognized. These granules will be observed to have a slow, flowing or gliding motion, and they may be traced in a definite path of circulation round about the wall of the cell. A comparison of different internodal cells will show that the streaming movement varies in rapidity in different ones and is much more clearly seen in some cells than in others. *

*In case Nitella be not obtainable, the closely allied Chara (Fig. 48) may be used for the foregoing study: but for observation of the streaming protoplasm, single internodal cells will usually be found only at the tips of the leaves. 
The protoplasm may be removed from an internodal cell by snipping off one end of it with scissors (after it has been wiped dry) and squeezing the contents out upon a slide. The largest available cells should be selected, for even then the drop of protoplasm obtained is a minute one. Still it is large enough to see and to handle. One may lift it on the point of a needle, and test its viscosity. One may see it with the microscope, wholly uncovered. And if, in looking at it, there is little to be seen, there is enough to reflect upon in the fact that this inert and apparently well-nigh structureless mass is the essential living part of every living thing, much the same in all, and, despite appearances, the builder of all the array of organic life. It is this substance that in the long aeons of the past has reclaimed the earth, and clothed it with verdure and peopled it.

The record of the foregoing study may well consist in drawings of some of the things seen, such as:

A few filaments of Spirogyra, showing their common features and the individual differences between them.

A single Spirogyra cell showing all the parts in detail.

A bit of the chlorophyl band, highly magnified, showing its form, the median ridge upon it, the pyrenoids, and starch granules.

A cell treated with dilute glycerine,showing the shrunken protoplasmic capsule withdrawn from the cell wall.

A diagram of the internodal cell of Nitella, showing the direction of the protoplasmic current.

THE FORM OF THE PLANT BODY IN COMMON ALGAE.

Some hints of the diversity of form in algae will have been gained from the study of Closterium, Spirogyra and Nitella - the first, unicellular; the second, a linear aggregate, its cells all alike; and the third, a branching, well-integrated body of cells of very different sizes, with terminal buds and apical gròwth. 
The form of the plant body is much influenced by the manner of cell division. When

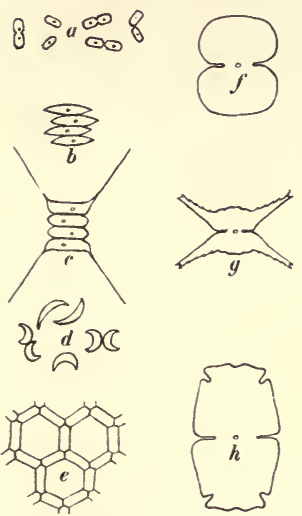

FIG. 46. Miscellaneous algae, further illustrating types of cell form and arrangement. $a$, Clathrocystis, actively dividing; $b$, Scenodesmus acutus; $c$, Scenodesmus caudatus; $d$, Selenastrum; $\varepsilon$, Hydrodictyon. $f$, Cosmarium; $g$, Staurastrum; $h$, Euastrum. the cells separate completely at division, the plant remains permanently unicellular. When elongate cells divide transversely, and remain attached, the linear aggregate results: when they divide lengthwise, such rafts as those of Scenodesmus (fig. 46) and of many diatoms result. When the planes of division of the cells of a linear aggregate become oblique, cutting off from the cells prolonged apical angles, the filaments become branched as in Cladophora (fig. 47). When no division planes are formed, only the nucleus, but not the cytoplasm dividing, overgrown multinucleate cells are formed. One such type, that is enormously overgrown

in long irregular interlacing fibres, is Vaucheria, the green felt-an alga that is found abundantly on wet soil in greenhouses.

One observes in studying the algae that the transition from unicellular to multicellular forms is very gradual. First, there are multitudes of single, completely independent cells. Then there are those algae that consist

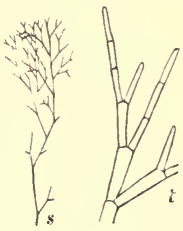

Fig. 47. Cladophora $s$, a branch ; $t$, a tip from the same, to show cell arrangement. 
of practically independent cells that merelyhang together. Then there are those that show some differentiation

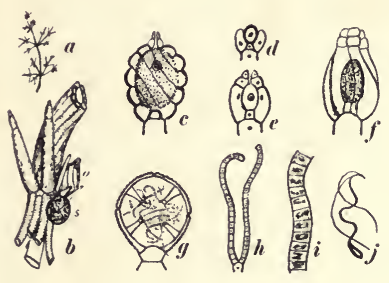

FIG, 48. Chara. $a$, a small branch; $b$, a piece of the stem containing a node and part of two internodes, the lower one having the cortical cells spread apart from the central cell; o, ovary (archegonium); $s$, spermary (antheridium); $c$, the mature ovary more enlarged, showing the egg cell within; $d, e$, and $f$, successive stages in the development of the ovary; $g$, the mature spermary in section; $h$, a pair of spermatic filaments; $i$, a bit of one of the filaments more magnified to show the sperms developing within the cells; $i$, a single sperm, set free.

of parts, and somemutual relations between them. Scenodesmus caudatus (fig. $46 \mathrm{c}$ ) shows a very moderate beginning of differentiation in the modified form of the two end cells. Then we havea differentiation between base and apex, the one end taking up the duty of securing attachment, the other providing for growth as in Cladophora (fig. 47). Finally, we have in Chara, a solid aggregate of greatly differentiated cells. Chara, like Nitella, is made up of a succession of nodes and internodes, but in each of the latter there is one central cell completely surrounded laterally by a layer of slenderer cells. (fig. 48.) Thus the central cell is completely inclosed and removed from the source of supply of food and air; and it is rendered dependent on its neighbors for its living. And in Chara and in many other algae there is a high degree of division of labor, certain cells of the plant body being set apart to serve the reproductive process, while others perform the nutritive functions.

The purpose of the following study is to observe in a variety of representative algae the phenomena of cell aggregation and of cell differentiation. Incidentally there should 
be seen something of the place algae occupy in the world, something of their diversity of form and size, something of their exquisite beauty and delicacy of organization, and the principal differences between them in the manner of their chlorophyl distribution.

Study 9. Observations on cell form and growth habit in
algae.

The materials needed are: r. A few of the larger, more typical green algae (such as Nostoc, Cladophora, Hydrodictyon, Vaucheria and Chara) in water.

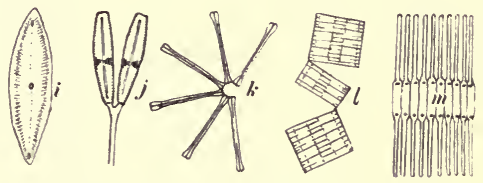

FIg. 49. Some water-supply diatoms. $i$, Navicula; $i$ Cocconema; $k$, Asterionella; $l$. Tabellaria; $m$, Fragilaria.

2. Some submerged or floating leaves of aquatic plants, from which may be scraped a variety of diatoms and desmids. The student will get these for study by mounting and examining the scrapings upon a slide. Stalked diatoms may usually be found upon the filaments of the larger algae, such as Cladophora.

3. Strainings from the water tap, yielding diatoms (fig. 49) and other algae that are common in the water-supply: obtained by tying a sac of fine silk bolting cloth over the tap and letting the water run slowly through for an hour or less.

The study should consist in the examination by the student of these different algae, one by one, observing and recording the points outlined above. He will find it desirable to familiarize himself somewhat with the princi- 
pal groups of algae by reference to any good text book of botany. The identifications of unusual forms that may be found will be facilitated by the use of the plates in such works as Wolle's Fresh Water Algae, Wood's Fresh Water
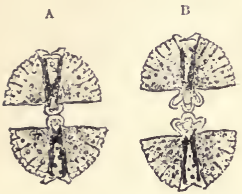

E

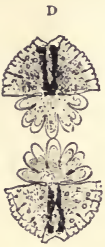

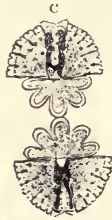

E

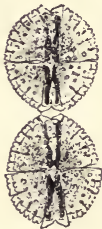

Fig, 50. Micrasterias (after Carpenter.) $A$ to $F$, successive stages in cell formation.

Algae of North America, West's British Fresh Water Algae, and keys in such works as Lampert's Das Leben der Binnengewässer and Stokes' Analytical Key to the Genera and Species of the Fresh Water Algae and Desmidiae of the United States.

The record of the results of this study may be preserved in a few simple outline drawings, showing for the larger forms, a diagram of the manner of growth, and a drawing showing the cell form and the distribution of chlorophyl. Nucleus, protoplasm, cytoplasm, and other internal parts may be taken for granted, and need not be sought out nor represented in this record.

SOME TYPICAL PROTOZOANS.

The simplest animals are the Protozoans. In a much greater proportion than in the algae, the cells exist singly. Like the unicellular algae they consist of few parts, and such of those parts as they have in common are found in every cell-nucleus, cytoplasm, inclusions, etc.

Amoeba (fig. 50) is one of the simplest of animals. We call it an animal because it moves about freely and feeds on other organisms; but at first sight it seems wholly lacking 
in the usual features of animal life. It has no legs, nor even muscles, for moving, no mouth for eating, no nerves for feeling, no organs whatever for any purpose. Since the amoeba lives an essentially animal life without these parts, a careful study of it may enable us to discover what are the essentials of animal existence.

Probably the easiest of the amoebas to obtain for study is the small species that develops in a hay infusion. If a quantity of dry hay be put into a jar of water and left standing uncovered where not exposed to the direct rays of the sun, soon the soluble organic matter in the hay is dissolved by the water. In the course of a day or two the bacteria that feed on this solution, form a soft jelly-like substance which gathers in a film upon the surface of the water in the jar. In the course of about three days amoebas begin to appear commonly in the jelly layer, moving about therein and feeding on the bacteria. In another day or two they generally reach their maximum of abundance; but they may continue much longer, if the conditions of their living be maintained.

They are too small to be seen with the unaided eye, and hence, must be mounted upon a slide and looked for with low power of the compound microscope. Since they inhabit the under part of the surface layer of bacterial jelly, they are best obtained free from it on the slide, by lifting a little patch of the jelly upon the slightly separated tips of a forceps, dabbing it down several times on a slide, thus shaking off the drop of adherent water and the amoebas with it, and then throwing the mass of jelly away. Even thus, so much of the jelly may have fallen into the drop, that one will have to look about the thin edges of it to find a clear field for observation of the animals.

It is very important that the temperature of the animals be not lowered during the process of mounting them or of 
observing them later; else, the following observations will not be possible: for if they be cooled, they will contract into a heap, and remain inactive and scarcely recognizable. Therefore, the air of the room in which they are studied, and the slide and cover and stage of the microscope must not be cooler than the water from which they are taken.

In a few moments after their transfer to the slide (the drop being properly covered, and the space beneath the coverglass entirely filled with water) the amoebas should be-

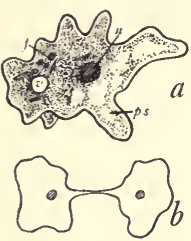

Fig. 51. Amoeba, $a$, ual; $p s$, pseudopodium; $n$, nucleus; $f$, food; $v$, vacuole; $b$, diagrammatic representation of division. an active individ-

gin to creep around freely upon the surface of the glass. Although very minute they will be recognized even under low power by their form (see fig. $5^{\mathrm{I}}$ ) and especially by their slowly changing outlines. The details of internal structure in a single animal are not to be observed except with high magnification, and a sufficient cutting down of the light to allow the more transparent parts of the animal to come into view.

When found and properly lighted, it will be easy to recognize in the body a granular central mass of protoplasm, a clearer exterior layer, with definite, though slowly changing outline that never shows sharp angles, but only rounded lobes.

The granular internal portion of the body of the animal is spoken of as the endosarc. Within it are to be seen I) the round and uniformly translucent nucleus: 2) the very clear contractile vacuole, which disappears at intervals, and which usually shows a tinge of pinkish color, and 3) ingested food particles, usually aggregated more or less into round food balls which may be seen moving about in the endosarc. In these food balls the forms of some of the bacteria more recently eaten may usually be recognized. 
Different individuals will differ much in clearness of these parts, according as they have recently eaten much or little.

The very clear external protoplasmic layer is generally known as ectosarc. It shows no definite cell wall, but only an enveloping film; hardly more of this than may be accounted for by surface tension of the body fluids. It has in amoeba developed no external skeleton, but remains so clear that we may here observe nearly simple naked protoplasm, unobscured by anything, and in action. The movements seen here are quite different from the simple streaming motion in a single current of the internodal cell of Nitella; they are of a higher order of complexity. A portion of the body substance may be pushed out in any direction, but always in the direction of locomotion, forming

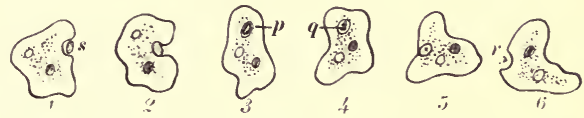

FIG. 52. Amoeba. Diagram illustrating in $1,2,3$, food intake; in $4,5,6$, removal of indigestible residue; $s$, a food organism; $p$, the same occupying a food vacuole, recentlv engulfed; $q$, the same partly digested; $r$, residue of same, discharged.

the broadly rounded lobes called pseudopodia: first the ectosarc pushes out, and then the granular endosarc streams forward into it. Pushing out forward, and pulling up from the rear is the process of locomotion, and it is dependent solely upon the contractility of protoplasm.

By this same power feeding is accomplished. Two pseudopodia (fig. $5^{2} I-3$ ) encircle a suitable bit of food, and press it into the interior of the body, where, engulfed by the protoplasm, it is digested: any indigestible residue, is gotten rid of by the reverse process - the protoplasm flows away from it and leaves it behind (fig. $5^{2} 4^{-6}$ ).

These activities imply volition of some sort or degree, for there appears to be some selection of food and some spontaneity of movement: changes of direction, the taking 
of a circuitous course in avoidance of an obstruction, etc.,indicate this, and since there is only protoplasm present and responsible for the actions, it follows that sensibility, or at least, the capacity for responding to external stimuli, is another property of protoplasm. We tap the slide sharply and the amoebas contract, drawing in their pseudopodia, but soon, after a different interval in different individuals, they resume activity again.

The larger amoebas live in the sediment on the bottom of ponds and ditches, in the slime on the submerged leaves of aquatic plants, etc., and while much more difficult to obtain in sufficient numbers for classuse, they are, on account of their size, much more favorable for studies of some of the phenomena outlined above. One gets specimens for study by mounting the slime upon a slide and searching till amoebas are found. Since these commonly devour diatoms and desmids, which show their characteristic colors for a time after being engulfed, the process of digestion (as evidenced by the disappearance of the normal plant structures) is in these species more easily observed.

Study IO. The structure and activities of Paramoecium.

Materials needed: A hay infusion a week or more old in which the surface layer of the bacterial jelly is breaking up, being largely consumed, and in which Paramoecium has appeared in large numbers: or, an old infusion that has been kept going by occasional feeding with corn meal. The paramoecia will be found about the edges of the culture close to the surface. They are large enough to be seen as minute oblong white specks in rapid motion. They must be present in sufficient numbers for one to get a number in a drop of water taken up by a pipette, and if not so numerous, they should be concentrated, by some such sort of filtering apparatus as that described in the appendix. There will be needed also, besides the usual labora- 
tory apparatus and reagents, a little dry carmine, and a ${ }_{2} \%$ solution of gelatine, or its equivalent.

The student should perform the work of the following outline:

I. Obtain a drop of water containing paramoecia upon a slide. Examine it uncovered with a simple lens to make sure that the animals desired are present. A little trash from the jar included in the drop will be of assistance in preventing the cover glass from coming down too close and crushing the animals. Numerous smaller, but similar infusorians are likely to be associated with Paramoecium, and often the phenomena of division are more commonly found among these.

2. Before applying the cover glass, survey the contents of the drop with low power of the compound microscope, and, by moving the slide, follow some of the paramoecia as they go swimming about. Observe the spiral course of the swimming, and the resultant rapid motion directly forward. Observe also the habit of the animal when it meets an obstruction: note the slight backward motion before the turning aside.

3. Apply the coverglass, with plenty of water under it, so that there will still be room for swimming. Find a place where a paramoecium is repeatedly meeting with obstruction to his swimming, and observe what relation the direction of his turning aside bears to the position of the oblique groove (oral groove) down one side of the anterior end of the body. Observe also, the rolling motion of the body in swimming, and determine what relation the position of the mouth bears to the axis of the spiral course in which the animal swims.

4. Withdraw some of the water from under the coverglass with ablotting paper strip held at the edge, so as to confine some of the animals in close quarters. Find a place 
where several may be observed together, the movements of all somewhat restricted. Note the perfect definiteness of anterior and posterior ends of the body. Note the general pliancy of the body, best seen when turning sharp corners, etc.

5. Observe the presence of a sharply defined layer of ectosarc, thickly covered over its outer surface with minute transparent hair-like processes called illia in constant rapid motion. To the lashings of these cilia, the movements of the animal are due. The cilia are invisible in too strong light, and also when in rapid motion; in the latter case the scattering of such minute particles as come near them will testify to their presence and activity. A few longer cilia at the hinder end of the body, seem to serve as a sort of steering apparatus or rudder, and probably assist in keeping to a true course in swimming.

6. Observe the position and relations of the oral groove, its length, its oblique position, and the funnel-shaped depres sion in which its posterior end terminates. Observe the peristome surrounding the mouth, bearing a continuous line of larger and stouter cilia, which, besides their participation in the spiral swimming, drive food particles into the funnelshaped mouth opening.

7. Mount a small drop of clean water containing paramoecia in a large drop of gelatine solution upon a slide, cover and study the action of the cilia. The movements are restrained more or less by the gelatine, and, with proper lighting, should be easily observed.

8. In a quiescent but living specimen observe the large vacuole near either end of the body. Watch it long enough to observe its contraction and disappearance, and the formation of the circle of radiating clefts through the surrounding protoplasm. Consider the part such movements may play in keeping the contents of the cell in circulation.

9. Observe also the nuclei nearer the centre of the body. The nucleus is differentiated into two parts; a large oval or 
oblong meganucleus and a little round micronucleus close beside it. The former at least should be visible in the live animal.

ı. Mount another drop of clear water containing paramoecia, first adding to it a little finely powdered carmine, stirring the carmine through the drop. Cover, remove excess of water, find a little group of paramoecia in some more or less restricted area, among trash, or at the edge of the cover, and watch them eat the carmine. It is wholly indigestible and may be followed in its entire course through their bodies. Unless the mounting, stirring, covering and finding be done with unusual celerity, bright red food-balls of carmine will already be seen within the protoplasm of the animals when first looked at. Other food-balls may be seen forming in the neck of the funnel-shaped rudimentary esophagus that leads inward from the mouth, and those first formed may be seen in their course of circulation round the body, and may in a little while be followed through their entire circuit.

Ir. Mount another drop containing paramoecia, adding thereto a little methyl green or iodine. Cover and study carefully the details of cellular structure:

a) Ectosarc and endosarc.

b) The peristome and its fringing cilia, and the esophagus.

c) The cilia of the body in general and of the posterior end in particular.

d) The stinging threads which the reagent used caused to be thrown out from the ectosarc. These will be seen among the cilia along the sides of the body, and will be distinguishable therefrom by their irregularity and unevenness of length, and by their different mode of attachment to the ectosarc.

e) Meganucleus and micronucleus.

f) Vacuoles and food-balls. 
I 2. In a fresh mount containing a large number of individuals study the division of Paramoecium (or, if more abundantly evidenced, use any other available infusorian). Observe the division of both mega- and micro-nucleus, and the subsequent division of the protoplasm. Observe the fate of the oral groove. The different stages may often be found simultaneously in different dividing individuals.

The record of this study may well consist in:

1. A diagram to illustrate the spiral course of swimming of Paramoecium.

2. A diagram to illustrate the movements by which an obstruction is avoided. Indicate plainly oral and aboral sides.

3. A detailed drawing of a single animal, showing all its normal structures. This should be begun with the beginning of the study, and details added as they are worked out.

4. A series of outline drawings illustrating the progress of division.

Study II. The specialized cell-body of Stentor and Vorticella.
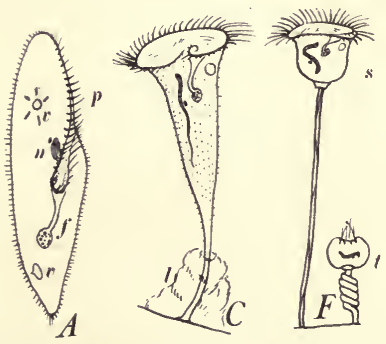

FIG. 53. Three common infusorians. $A$, Paramoecium; $n$, nucleus; $v, v$, vacuoles: $f$, food-ball at the bottom of the rudimentary esophagus; $p$, peristome. $C$, Stentor; $l$, lorica. F, Vorticella; $s$, extended; $t$,
It will now be well to study a few of the higher protozoans, illustrating the great degree of differentiation of parts and of specialization that may occur in the single free-living cell. For this purpose two common protozoan inhabitants of fresh water ponds (fig. 53) are sellected, Stentor and Vorticalla. 
Stentor.-This is a large protozoan that is often found adherent to submerged twigs and leaves, and that is usually obtained by placing the trash from a pond in jars of water and letting it stand a few hours. The stentors, large enough to be seen with the unaided eye, and to be certainly recognized with a pocket lens, will be found extended in the form of a trumpet, the narrow basal end attached to the twigs, etc., or suspended beneath the surface film. If a twig bearing stentors attached be transferred to a slide, covered, and allowed abundance of room and plenty of water beneath the cover, the stentors will soon be ready for observation, and for the work of the following outline:

I. Make a preliminary survey of the contents of the mount, finding:

a) Stentors extended and trumpet shaped (whence their name), and attached by their slender bases to some support.

b) Others contracted into globular or club-shaped form. If possessing a gelatinous cup-shaped receptacle about their bases of the sort known as a lorica (fig. $53 C, e$ ), these will be more or less withdrawn into it.

c) Others detached, more or less contracted, and lying free or swimming about in the water with something of the spiral rolling motion of Paramoecium. These may have been detached in mounting; howerer, Stentor may voluntarily make a change of base.

2. Find a little group that may be brought into the field with the lowest power of the microscope, and take time to study their actions:

a) While watching a fully extended animal through the microscope, tap or jar the slide sharply and see it contract: continue watching until it is again fully extended. 
b) Observe the action of the fringe of strong cilia (peristome) surrounding the rim of the trumpet, and try to see objects free in the water driven by these cilia into the mouth. If not well seen this may be demonstrated, as for Paramoecium, by adding a little finely pulverized carmine to the water.

3. Using an eyepiece of higher magnification, study the extended stentor, observing:

a) The lorica, if present; note its shape, appearance, and consistency.

b) The disc like attachment of the foot.

c) The long tapering body, covered with minute cilia.

d) The flaring distal end, with its encircling peristome, involute at one end to surround the mouth. Compare with the peristome and mouth of Paramoecium.

4. Within the body observe in a specimen having the mouth uppermost:

a) The short esophagus ending blindly in the endosarc.

b) Food-balls moved about in the endosarc.

c) An elongate, moniliform meganucleus, and a micronucleus close beside it. The latter is usually hard to see in the living specimen, but may be demonstrated with iodine as in Paramoecium.

d) A large contractile vacuole, of varying proportions.

e) Fine nearly parallel lines extending from foot to disc in the ectosarc (myonemes).

5. Observe the ordinary reproduction of the animal by division of the single cell into two; note the plane of the division, and the relation it bears to foot, disc, peristome and meganucleus.

The Record of the study of the stentor may well consist in:

I. A sketch in simple outlines of a little group of stentors in various positions.

2. The details of structure of a single animal. 
3. The phenomena of division, in a series of outline sketches.

Vorticella.-This protozoan will usually be found associated with Stentor and specimens for study are readily obtained by the same means. The individuals are smaller, and singly are difficult to see; but they commonly occur in groups, and a little cluster of them about a twig, contracting so strongly as to almost disappear when touched, will be easily recognized. Vorticellas when abundant appear to the unaided eye as a whitish fringe about the edges of submerged twigs. The student should obtain upon a slide a small bit of rootlet or other solid support with vorticellas attached, should mount and cover this, filling up with water all the space beneath the cover, and then should perform the work of the following outline:

I. Survey the mount for:

a) Single vorticellas contracting and extending their stalks.

b) Little groups of individuals, attached to the rootlet separately.

c) Detached heads, broken off from the stalks and swimming free.

2. Study the actions of the vorticellas, observing:

a) The contraction and subsequent extension of the stalk.

b) The closing and opening of the peristome.

c) The action of the cilia and its effects on free particles in the water.

d) The action of the vorticellas toward one another when touched, and toward other free swimming organisms which happen to come into contact with them.

3. Study the differentiation of parts in the body of Vorticella, noting: 
a) The complete differentiation of the body into bellshaped "head" and contractile stalk. What is the distribution of ectosarc and endosarc in each?

b) The great development of the peristome, and the restriction of the cilia thereto. Note the size of the cilia, and the contractility of the ridges that bear them.

c) The band of contractile substance, a highly developed myoneme, extending in an open spiral down the stalk. Observe its position in extended and in contracted specimens.

4. In the body of the cell, observe the usual internal structures:

a) A curved, often horse-shoe-shaped meganucleus near the middle of the body, and a micronucleus lying close beside it. If the latter be not visible in the living specimen it may be demonstrated later with iodine, as in Paramoecium.

b) A clear contractile vacuole, near the nucleus, appearing and disappearing.

c) Food-balls, moved about within the endosarc. The taking of food and the formation of these balls at the end of the rudimentary esophagus, may be demonstrated by feeding with carmine, as in Paramoecium.

5. By surveying a large cluster of vorticellas, a number are likely to be seen in process of division. In such observe the plane of division, and its relation to nucleus, peristome and stalk.

The record of the study of Vorticella may well consist in:

r. A drawing in outline of a little group in various positions.

2. The details of structure of a single cell much enlarged. 
3. An outline drawing illustrating the manner of dividing.

Colonial Vorticellidae.-In a number of protozoans allied to Vorticella, the two cells resulting from a division do not entirely separate,

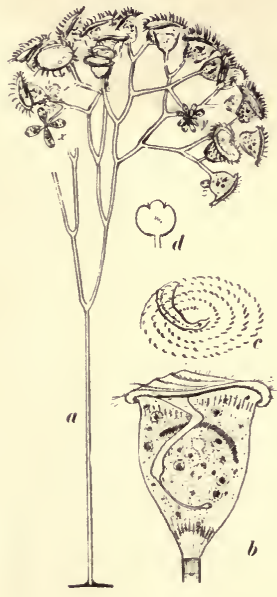

FIG. 54. Epistylis umbellarius. $a$, a portion of a colony; $x$ and $y$, successive divisions producing conjugants of reduced size; $z$, conjugation between one of these reduced cells and a cell of normal size. $b$, a sing!e individual in lateral view, showing the elongated esophagus and peristome; $c$, diagram of the top of the peristome, showing its spiral arrangement; $d$, a normal individual, contracted. but both remain attached basally to the common stalk, each later prolonging the attachment into a stalk of its own. Successive divisions thus give rise to colonies. Such colonies are likely to be found associated with Vorticella, and should be compared therewith. When the colonies are large they are easily distinguished with the unaided eye from clusters of Vorticella by their height, due to their elevation on a common stalk. One of the commonest of these is Epistylis, diagrammatically shown in the accompanying figure (fig. 54). This differs from Vorticella in that the stalk is not contractile, lacking the myoneme: myonemes are restricted to the base of the elongated "head" which, becomestransversely wrinkled when contracted, and to the peristome which becomes enrolled, as in Vorticella.

In Charchesium, however, the individual stalks are contractile and in Zoothamnium, the common stalk of the colony also, in-so-much that when Zoothamnium contracts, the main stalk and all its branches acting synchronously, all the bodies are suddenly brought down into a 
round, berry-like heap. These three genera include all our common allies of Vorticella of colonial habit.

It is not to be overlooked, while studying protozoans, that even in these forms, there is a foreshadowing of the principal organs of the higher animals. The long esophagus of Epistylis is prototype of the alimentary canal; the contractile vacuole, forerunner of a sort of rudimentary circulatory apparatus; and the myonemes constitute a sort of elemental muscular system.

THE LIFE PROCESS IN PLANT AND ANIMAL CELL.

We have seen that in many algae and in most protozoans the cell is an independent organism: all functions of plant or animal are performed by it. Even when such cells are grouped together to form a larger organism, their union is for the most part a loose one, and their physiological independence is little impaired. To the cell, then, we must go to learn what are plant and animal functions, and how they are performed.

How does the cell live and grow? This is a hard question, answered as yet only in part. The answer so far as available is best stated in terms of matter and energy.

Matter.-The bodies of living beings are composed of a few chemical elements, such as are common in soil and water everywhere. This is readily determinable by chemical analysis. In all living substance there are nine chemical elements constantly occurring, three others (the three last named below) that are nearly always present, and a number of others occur here and there. The twelve are: Carbon ..... C Sulphur .... S Magnesium .. Mg Hydrogen ... H Phosphorus . P Sodium .... Na Oxygen ..... O Potassium... K Chlorine .... C1 Nitrogen ... N Iron ...... Fe Calcium.... Ca 
The four in the first column, carbon, hydrogen, oxygen and nitrogen constitute over 99 per cent, of the living substance, the others being present in very small amounts.

In nature these elements are found everywhere in the crust of the earth, combined as simple mineral salts, which, being more or less soluble, are found also in the waters of the earth. That these salts will maintain the life of the green plant cell may readily be determined by supplying them to it as food. The commonly used food solution for green plants has the following composition:

Distilled water $\left(\mathrm{H}_{2} \mathrm{O}\right) \ldots \ldots \ldots \ldots$ I,, 000 . grams

Potassium nitrate $\left(\mathrm{KNO}_{3}\right) \ldots \ldots$. I. ".

Sodium chloride $(\mathrm{NaCl}) \quad \ldots \ldots \ldots . \quad 0.5 \quad$ "

Calcium sulphate $\left(\mathrm{CaSO}_{4}\right) \quad \ldots \ldots . \quad 0.5 \quad$ “

Magnesium sulphate $\left(\mathrm{MgSo}_{4}\right) \ldots . . \quad 0.5$

Potassium phosphate $\left(\mathrm{K}_{2} \mathrm{HPO}_{4}\right) \quad \ldots \quad 0.5$

Ferrous sulphate $\left(\mathrm{Fe}_{2} \mathrm{SO}_{4}\right) \ldots \ldots$ a trace

Here we have all of the twelve elements listed above except carbon, and this the green plant obtains from the carbon dioxide $\left(\mathrm{CO}_{2}\right)$ of the air, either direct, if it be a terrestrial plant, or dissolved in the water, if it be aquatic. On such a solution of the simplest mineral compounds green plants thrive. These elements are recombined in the living body into compounds of very much greater variety and complexity, the more important of which fall into two great classes, according as they possess or lack nitrogen in their composition:

I. Carbohydrates and fats: non-nitrogenous compounds, containing carbon, oxygen and hydrogen, but no nitrogen.

II. Proteins: nitrogenous compounds of great complexity.

These substances, formed in, and constituting the bodies of plants, are the primary food of animals.

Energy.-The forces that operate upon living bodies are those that operate upon the non-living: gravitation, heat, 
light, electricity, magnetism, mechanical energy, molecular energy (cohesion, adhesion, attraction of molecules) and chemical energy (chemical affinity, the attraction of atoms). In the living world, as elsewhere, energy may not be destroyed, but may be endlessly transformed.*

The primary source of energy for living beings is the sun's rays. The radiant energy of the sun, acting on the chlorophyl-bearing protoplasm of the green plant cell, effects the cleavage of carbon-dioxide into its two constituent elements, carbon and oxygen. Then ensues the synthesis of the liberated carbon with water to form sugar, which may be transformed into starch, and stored in the tissues. The chemical statement of the reaction (a statement of the shift of the elements only, that tells nothing of the enormous consumption of energy involved) is, in its simplest form, as follows:
Carbon dioxide
Water Fruit sugar $\dagger$ Oxygen
$6 \mathrm{CO}_{2}+$
$6 \mathrm{H}_{2} \mathrm{O}=\mathrm{C}_{6} \mathrm{H}_{12} \mathrm{O}_{6}+6 \mathrm{O}_{2}$

This equation expresses graphically the primary synthesis of inorganic materials to form an organic compound.

*Energy may be either active (kinetic) or latent (potential.) Kinetic mechanical energy is that of a clock spring, moving by the release of tension the works of the clock: it is potential when the spring is wound up, before the pendulum is started swinging. Or it is that of a pile driver hammer falling and delivering a stroke: it was potential when the hammer was lifted and ready to be let fall. Kinetic chemical energy is that of coal burning in an engine, moving the piston: it was potential in the coal. It is that of powder exploding in a gun: it was potential before the cap was struck. Energy was used to wind the clock, to lift the hammer, to combine the unwilling elements of the powder-it disappeared: it was rendered latent or potential.

tThe simple sugars differ from starch $\left(\mathrm{C}_{6} \mathrm{H}_{\mathrm{ro}} \mathrm{O}_{5}\right)$ mainly in that they contain relatively more water. The complex sugars differ in being multiples of the simple sugar lacking one molecule of water for each molecule of the simple sugar taken (ordinary cane sugar, $\mathrm{C}_{12} \mathrm{H}_{32} \mathrm{O}_{x 1}$ ). Through the series of carbohydrates (sugars, starches, etc.,) carbon is combined with hydrogen and oxygen, the two latter retaining the ratio they have in water. The formula of the series, $\left(\mathrm{C}_{6} \mathrm{H}_{10} \mathrm{O}_{5}\right)_{n}$. : 
In order to understand the energy involved it is necessary to take into account the attraction of the atoms. Carbon and oxygen have strong mutual affinity, and combine together in carbon dioxide to produce a very stable compound. In the above reaction the carbon is separated. from the oxygen, and this requires the expenditure of energy-the energy of the sun. In overcoming the strong affinity of carbon and oxygen for each other, this energy disappears, being rendered potential in the separated atoms: it will reappear in like amount whenever these reunite. It is readily measurable in terms of heat. The heat produced by combining twelve grams of carbon with thirty-two grams of oxygen (an ounce and a half of these two elements) is sufficient to raise the temperature of a kilogram (over two pounds) of water from the freezing to the boiling point, and in the separation of like quantities of these elements whether in the electric furnace or in the green leaf, a like amount of energy is rendered potential.

It is easy to demonstrate that starch is formed by chlorophyl-bearing protoplasm only in the presence of sunlight. It, is not difficult by proper chemical means to determine the composition of the sugar or starch formed, but it is impossible to follow its formation by direct observation: hence it must be borne in mind, the above equation is a theoretical explanation, based on knowledge of the behavior of the chemical elements, of the nature of the compounds in the food and in the products of the plant, and of the observable phenomena of its nutrition. If so great difficulties attend the explanation of the first step in the synthesis of organic substances, it will be readily appreciated why the succeeding steps involving the manufacture of proteins, are little understood. A purely theoretical explanation of the production of asparagin, one of the simplest of organic nitrogen compounds, of wide distribution in green plants is that of the following equation: 
Glucose + Potassium $=$ Asparagin + Potassium + Water + Oxynitrate oxalate gen

$\mathrm{C}_{6} \mathrm{H}_{\mathrm{1}_{2}} \mathrm{O}_{6}+{ }_{2} \mathrm{KNO}_{3}=\mathrm{C}_{4} \mathrm{H}_{8} \mathrm{~N}_{2} \mathrm{O}_{3}+\mathrm{K}_{2} \mathrm{C}_{2} \mathrm{O}_{4}+{ }_{2} \mathrm{H}_{2} \mathrm{O}+3 \mathrm{O}$ The mineral nitrates, sulphates, phosphates, etc., enter into succeeding combinations.

Few proteins have been successfully analyzed; but it is well known that many of them are of exceedingly complex structure. Their molecules are composed of a very large number of atoms, in loose combination. As the size of the molecule increases, the stability decreases, as bricks incline to topple when piled too high. A sample analysis of the molecule of a familiar proteid, hamoglobin, from the blood, gives results corresponding to the following formula:

$$
\mathrm{C}_{600} \mathrm{H}_{960} \mathrm{~N}_{154} \mathrm{Fe}_{1} \mathrm{~S}_{3} \mathrm{O}_{179} \text {. }
$$

The reverse process, whereby these complex and unstable compounds are broken up again into simpler ones with the liberation of their energy for the use of the body, is even less understood in its details: it is chiefly known by its results. The end products of metabolism in animals are water, carbon dioxide, urea $\left(\mathrm{CH}_{4} \mathrm{~N}_{2} \mathrm{O}\right)$ uric acid $\left(\mathrm{C}_{5} \mathrm{H}_{4} \mathrm{~N}_{4} \mathrm{O}_{3}\right)$ and such other simple nitrogen compounds as ammonia, adenin, xanthin, creatin, etc.; and in plants they are the same except that the nitrogen liberated by proteid dissimilation is recombined and does not appear as waste. The accompanying crude diagram is an attempt to represent graphically the relations the more important of these compounds bear to each other in income and outgo of matter for organisms. It is as the map of a country as yet but little explored. 


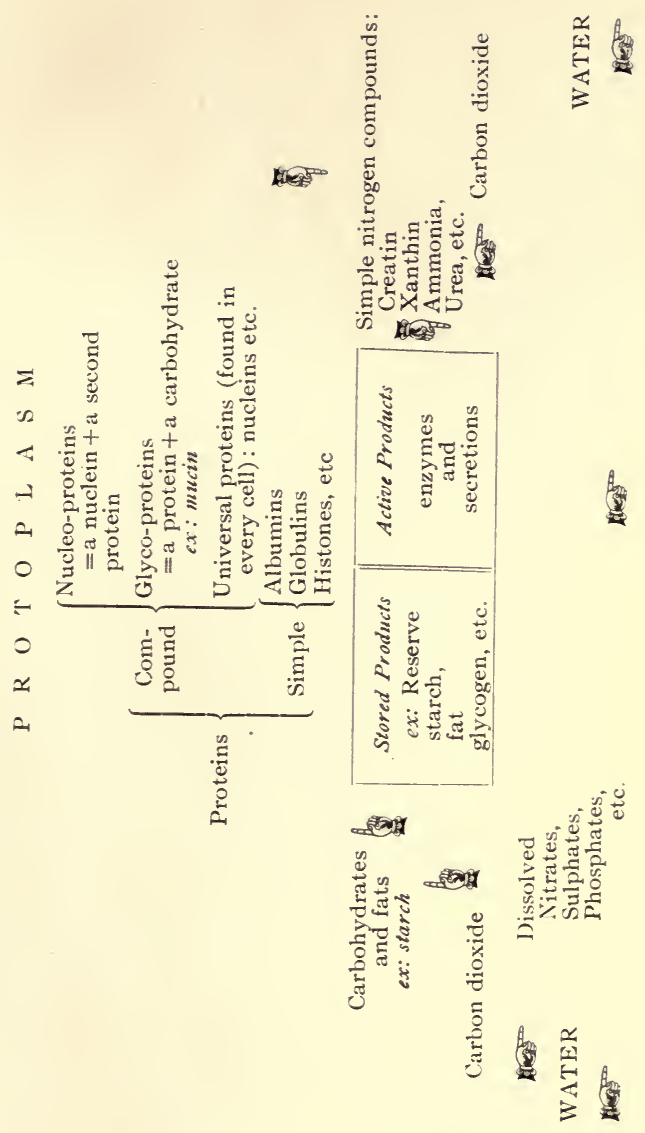


While the analysis of the processes involved in the metabolism of the living substance is difficult, and details are somewhat uncertain and only the beginning and the end steps have hitherto been traced, there is no doubt whatever about a number of the main facts:

I. That the organic life of the world is supported on water, carbon dioxide and simple mineral salts, gathered and assimilated by the green plant cell.

2. That these mineral substances are of simple composition, are composed of but few elements united strongly, and that they are very stable, and devoid of potential energy.

3. That the non-nitrogenous substances first combined under the power of the sun's rays, are compounds of a higher order of complexity of less stability and of much more potential energy.

4. That the nitrogenous substances (proteins) are of great diversity and of exceeding great complexity of structure, very unstable, and of very high potential energy.

5. That protoplasm is a complex substance (not a single chemical compound), probably a mixture or combination of various proteins, water, etc., so unstable it is impossible of analysis for, to analyze it kills it, and death initiates changes altering its composition.

6. That the primary source of energy is the sun, drawn upon by the green plants first; the supply for other organisms is the potential chemical energy of manufactured carbohydrates, proteins, and of free oxygen.

Protoplasm, the physical basis of life, the living part of every living thing, and essentially the same in its general properties and functions in all, possesses in green plants the capacity for developing chlorophyl, through the agency of which the energy of the sun can be utilized in effecting such analysis of simple mineral compounds and such synthesis of more complex organic compounds as result in the storing 
up of a large amount of energy. Then the living substance acts as a chemical engine, using the energy of these same organic compounds, and in that use, reducing them again to simpler ones. Here as elsewhere, neither matter nor energy

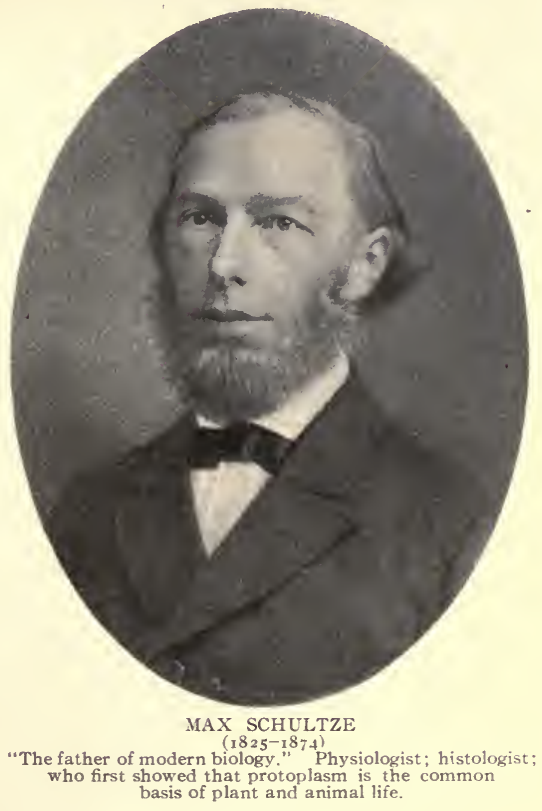

is created or destroyed, but both are endlessly transformed. The living body is constantly changing. It is only the constancy of the stream of income and outgo that allows it to present a semblance of an abiding presence. It is like the chemical engine in that it uses fuel-the food-whose 
transformation into gases and ash liberates energy for its work. It is unlike the engine in that, far from being a mere contrivance of chambers in which transformationsand reactions may occur, it is itself changed constantly, formed and reformed, regularly gathered from and returned to the stream.

The dissimilation process (katabolism), whereby the complex organic compounds are broken up into simpler ones, with the liberation of their energy for use, has not hitherto been traced step by step in detail: indeed, it is even less understood than the assimilative. Its results are well enough known: the end products are simple compounds, $\mathrm{CO}_{2}, \mathrm{H}_{2} \mathrm{O}$, and nitrogen compounds not wholly reduced to the grade of composition they had when first taken up from the water (and therefore, a little energy that they still retain is lost to the body). Their energy has reappeared in various forms, mechanical movement, bodily heat, luminescence, etc.

From the chemical side it therefore appears that assimilation (anabolism) is the process of separating chemical affinities and of storing up chemical energy in complex compounds, and that dissimilation (katabolism) is the process of reuniting affinities in stable compounds with the liberation of energy for use.

Plant and animal differ typically in the nature of their intake and output of matter and energy, and the main features of that difference are expressed graphically in the diagram at the top of the following page.

In this table the facts are of necessity stated broadly. For example oxygen is given off by the green plant only in the light, and among animal foods organic and inorganic materials are set down together. The latter constitutes a very small part of animal food, never-the-less the diagram should aid in forming a definite conception of the fundamental nutritive relations of plants and animals. 


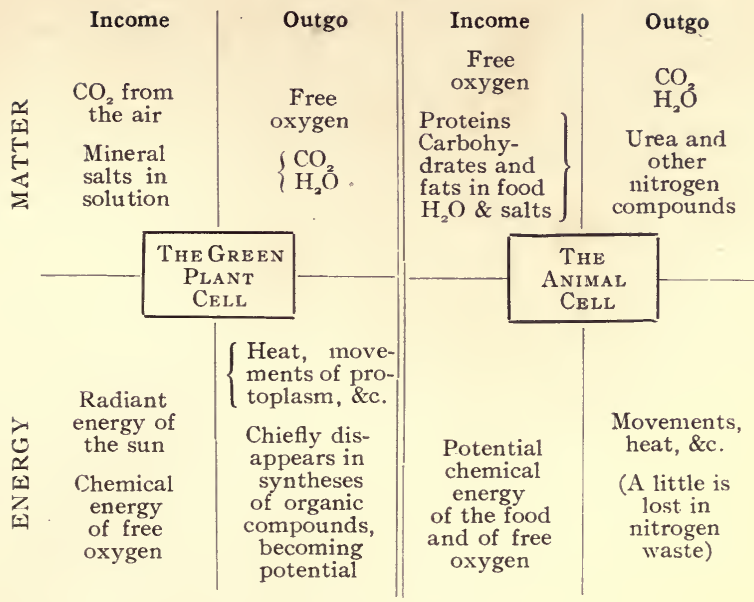

III. SOME INTERMEDIATE AND UNDIFFERENTIATED FORMS.

The typical algae and protozoa studied thus far, conform to our general notion of plant and animal, derived from contact with the higher, familiar forms of life. The green color of the plant and the free movement and foraging habit of the animal seem at first to mark out naturally two distinct groups; among the higher forms there is no difficulty about distinguishing between plant and animal. It is easy to tell a dove from a daffodil; it is not hard to tell a green alga from a free swimming gray protozoan; but there are among the lower organisms some that do not clearly show even the broad distinctions of the preceding diagram, and some that so combine the characters of the two groups that one may not say with assurance whether they are plants or animals. 
We will first consider a large and important ecological group of organisms that we recognize as plants although they do not contain chlorophyl, and they do require much the same food as animals; after that, two other groups with characters so intermediate that they are discussed in text books of both kotany and zoology at the present day.

\section{PLANTS THAT LACK CHLOROPHYL.}

The most important common characteristic of the large ecological group of organisms we now come to consider, is physiological: lacking chlorophyl, they have abandoned the primary plant function of gathering food materials directly from the inorganic world. They must have organic food. They can derive no energy from the sun, and they thrive often quite as well without sunlight. They use the same foodstuffs as animals: yet in structure and growthhabit they are plants very much like green species of parallel development.

Yeasts.-These are unicellular chlorophyless plants of the group of fungi. Isolated cells have, save for their gray color, much the appearance of single cells of protococcoid algae. They have cellulose in their walls; their protoplasm is somewhat more granular, contains minute fat droplets and is without a trace of chlorophyl.

The process of cell multiplication is peculiar. It is called
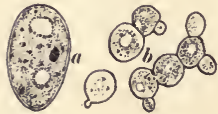

FIg. 55. Yeast. $a$, a single cell showing nucleus (dark colored). two vacuoles, and numerous fat droplets; $b$, clusters of growand budding yeast cells (torulae), in various stages of development; $c$, spores, formed on drying, four within each cell wall.

families of cells (torule), budding (or gemmation). Minute processes are pushed out from the side of the cell, and these grow up gradually to full stature, adhering for a time to the parent cell. Often the new cell starts buds of its own before it is fully grown itself. Thus while growing quietly the cells come to be assembled in little clusters or 
A food solution for yeast that bears the name of the great biologist, whose fame rests in part on discoveries he made of the part yeasts play in fermentation, is the following:

$$
\text { Pasteur's Solution. }
$$

Water $\mathrm{H}_{2} \mathrm{O} \ldots \ldots \ldots \ldots . \ldots \ldots . . \ldots \ldots$

Cane Sugar $\mathrm{C}_{12} \mathrm{H}_{22} \mathrm{O}_{11} \ldots \ldots \ldots \ldots$. 5.00

Ammonium tartrate $\left(\mathrm{NH}_{4}\right)_{2} \mathrm{C}_{4} \mathrm{H}_{4} \mathrm{O}_{6} \ldots . \quad$ I.00

Potassium phosphate $\mathrm{K}_{3} \mathrm{PO}_{4} \ldots \ldots \ldots \ldots . .20$

Calcium phosphate $\mathrm{Ca}_{3}\left(\mathrm{PO}_{4}\right)_{2} \ldots \ldots \ldots .0 .02$

Magnesium sulphate $\mathrm{MgSO}_{4} \ldots \ldots \ldots \ldots .0 .02$

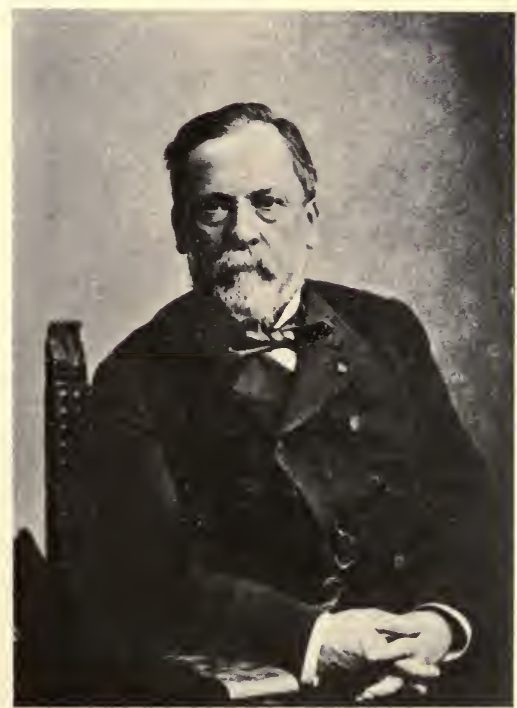

LOUIS PASTEUR

(1822-1895)

"One of the most conspicuous figures of the nineteenth century." Pioneer student of fermentation, of disease germs, etc. His services to his country and to humanity are commemorated by Pasteur Institutes for the treatment of infectious diseases throughout the civilized worid. 
If this formula be studied it will be discerned that the chemical compounds of the food of yeast are intermediate in kind between those of animals and those of green plants. Some of the same mineral salts are used by both green and colorless plants. The nitrogen is obtained from a somewhat more complex compound in the latter. Only the sugar is properly an animal food. Proteids such as animals require are wholly lacking. It will be noted that there is carbon in the formula aside from the sugar: the yeast will live, indeed, in this solution if the sugar be omitted but its growth will then be very slow. It will be noted also that the sugar is present in very great excess of the need of the yeast for carbon. The yeast plant contains a sugar ferment. It utilizes only about one per cent of the sugar, and decomposes the remainder into carbon dioxide and alcohol. The reaction of the fermentative decomposition may be expressed as follows:

$$
\stackrel{\text { Sugar }}{\mathrm{C}_{6} \mathrm{H}_{12} \mathrm{O}_{6}={ }_{2} \mathrm{C}_{2} \mathrm{H}_{6} \mathrm{O}+{ }_{2} \mathrm{CO}_{2}}
$$

It is the production of these two by-products that makes yeast commercially important. Yeast produces the same reaction in the sugars of cider and wines, and in the metamorphosed starches of the cereal grains, that are chiefly used in commerce in the production of alcohol. The carbon dioxide is also utilized in the making of bread. Yeast is mixed with the dough, and, fermenting in it, evolves the carbon dioxide gas, which "raises" it, making it porous, and improving its digestibility and flavor.

If a little fresh yeast be sown in a bottle of Pasteur's solution (or even in a $15 \%$ sugar solution made with tap water, which will be likely to contain enough of the mineral salts for considerable growth), and kept in a moderately warm place, within twenty-four hours abundant growth will be evidenced by the increasing turbidity of the liquid, 
and by the taste of the alcohol in it and by the odor of the escaping carbon dioxide* arising from it. It may be demonstrated by examination of a drop of the fluid with the microscope.

Molds and other fungi.-These are chlorophylless plants of different organization. They parallel the filamentous algae in their structure. The common black mold Mucor, is a much branched, vacuolated and multinucleate cell, of a form recalling the green felt (Vaucheria). Penicillium (figure 56) consists of branching filaments recalling in their form those of Cladophora. Molds live for the most part on a more or less solid substratum of organic matter and reproduce vegetatively by means of spores that are distributed through the air. Therefore, they have differentiated into two parts: the mycelium, the part immersed in the substratum, and concerned with gathering food, a tangle of slender root-like fila-

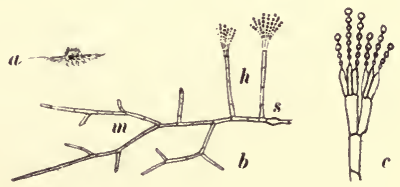

FIG. 56. Penicillium. $a$, a little tuft of the mould, as it appears, growing on the surface of a nutrient medium; $b$, a bit of the same, magnified; $s$, the original spore; $m$, mycelial filaments; $h$, sporophores, with spore clusters; $c$, one of the spore clusters.

ments; and slender aerial sporophores that rise from the mycelium at time of fruiting and bear the spores.

Many molds feed upon the bodies of plants and animals, living and dead, and upon materials extracted therefrom, obtaining both their carbon and their nitrogen

*A simple chemical test of the presence of $\mathrm{CO}_{2}$ in the escaping gas may be made by thrusting a glass rod with a drop of lime water suspended on it into the mouth of the culture bottle. The calcium oxide $(\mathrm{CaO})$ of which lime water is a solution, readily unites with free carbon dioxide to form a white precipitate of calcium carbonate $\mathrm{CaCO}_{3}\left(\mathrm{CaO}+\mathrm{CO}_{2}=\mathrm{CaCO}_{3}\right)$ which may be seen to form in the drop. 
from organic compounds. A few of them make galls upon green plants (fig. 28). Many more (known as rusts, blights, mildews, etc.) are destructive pests of green plants. But most of them are saprophytes, and assist in the circulation of food materials in the earth by hastening the decomposition of the bodies of dead plants.

The fruiting stages of the higher fungi are aggregates or integrates of filaments, that rise collectively from mycelia, and fashion together parts of various forms: spheres in the puffballs, with the spores borne inside: low cup-shaped receptacles in some of the disc fungi, or Ascomycetes (fig. 57), with the spores contained in cylindric spore sacs (asci) in a fruiting layer (hymenium) in the bottom of the cup: umbrella shaped caps in mushrooms, with the spores borne on the vertical surfaces of radiating lamellae underneath the cap.

Study I2. Observations on cultures of yeast and molds.

Materials needed: A good yeast culture in Pasteur's solution. Several plate cultures of molds of different ages on gelatine (directions formaking plate cultures will be found in any good laboratory. manual of mycology or of bacteriology). Young mycelia of Mucor, in which streaming of protoplasm may be observed. One to three day old cul-

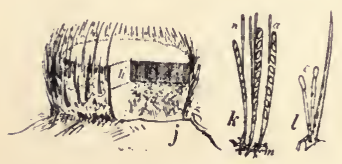

FIG. 57. A disc fungus (Peziza?). j, the aerial part of the fungus, with a quarter section cut out to show $h$, the hymeneum. $k$, a bit of the hymeneum showing, $a$, ascus, containing spores; $n$, sterile paraphyses, and $m$. sub-hymenial tissue. $l$, a bit of the involucre surrounding the hymenium. tures of Penicillium, in which the germination of the spores may be observed. Old Penicillium cultures, in which the spore clusters may be studied.

Study in yeast, I) the evidences of alcoholic fermentation and of the formation of carbon dioxide in the culture jar. 2) The details 
of structure of the single yeast cell. 3) Budding and the aggregation of the yeast cells together into torulae.

Study in the molds: I) The differentiation into mycelium and sporophores; 2) The type of branching, with absence of cell divisions in Mucor. 3) The streaming of the protoplasm in filaments of Mucor. 4) The germination of the spores and the beginning of mycelia in Penicillium. 5) The development of the spore clusters and of the arrangement of the spores in Penicillium, and in any other fruiting molds that may be available.

The record of this study may consist in simple outline drawings, and notes on the things observed.

Bacteria.-These are the smallest of the chlorophylless plants-indeed, they are the smallest of living organisms. They feed upon much the same materials as do other fungi, and while present nearly everywhere, they are sure to abound wherever there are moist organic substances in which they can multiply. Under favorable conditions bacteria increase in numbers with extraordinary rapidity. Their method of increase is already familiar-growth in size, followed by cell division. A division may recur erery half hour, and at this rate something like $\mathrm{I} 7,000,000$ individuals might appear as the offspring of a single one in the course of twenty-four hours. Obviously, such a rate could not long be maintained for want of food. Their reproductive capacity, together with the readiness with which they may be distributed, give them an important place in the economy of nature. They are nature's chief agency of decomposition and decay. They play a large role in restoring spent organic materials to circulation.

Certain bacteria at times develop spores. Usually but a single spore is produced in each cell, the protoplasm of which develops a resistant spore coat within the old cell wall (fig. $58 d$ ). The spores are not injured by drying, and 
may be heated even above the temperature of boiling water without being killed. They are readily distributed everywhere by currents of air.

Bacteria serve their disintegrating function quite without regard to human interests, - spoiling foods, or rotting the compost heap to enrich the soil; souring milk, or ripening cheese; disintegrating living tissues in disease, or aiding the processes of digestion, etc. Although the study of bacteria has been possible only during the brief period that has elapsed since the invention of good microscopes, their effects have always been known, and many empirical methods have been used for combating their growth. They do not thrive in acid solutions, hence acids have long been used as a means of preserving foods, as in the process of pickling meats, fruits, etc. They do not thrive in heavy solutions of sugar, and hence jellies and preserves are composed of large proportions of sugar. They require 25 per cent or more of water in their food substances for normal growth, and hence the reduction of the proportion of water present by the drying of meats and fruits has long been practiced: also, the use of salt to makesuch water as is present unavailable. Then there are many substances whose presence is inimical to their growth, which we now know as antiseptics, and which are the mainstay of modern surgery (bichloride of mercury, etc.), but of old, wounds were forefended against bacteria by the pouring in of oils (such as turpentine) and of alcoholic solutions (strong wines).

All these methods, applied without knowledge of the causes of the evils they sought to cure, have been vastly improved with the development of bacteriology. New processes of treatment by antiseptics, by sterilization, etc., have been developed and old ones have been improved. The bacteriologist has invented transparent culture media, containing suitable food. He sterilizes his culture 
media even as housewives have always sterilized fruit for canning, sealing while hot; but he may allow time for the germination of any spores that are present and then may sterilize again; thus the spores, as well as the active cells of bacteria are killed. This is his method
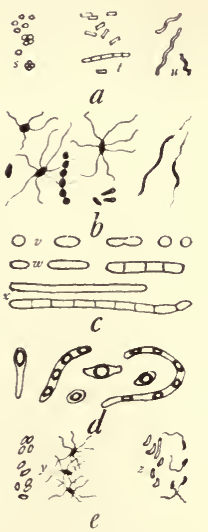

FIG. 58. Bacteria $a$, form types; $s$, coccus, $t$, bacillus; $u$, spirillum types. $\boldsymbol{b}$, these forms stained, some showing flagella, others, none. $c$, types of division; $v$, ordinary cell division; $w$ and $x$, simultaneous division of longer filaments into a number of cells. $\sigma$, spore formation in different forms. $e$, two species of bacteria of the bacillus type, showing differences of appearance, both stained and un$\mathrm{st}$ a in ed; $y, \mathrm{the}$ typhoid bacillus; $z$, the bacillus of Asiatic cholera. of clearing the field: Then he sows in his culture media the sort of bacteria he wishes to study, and observes their habits and manner of growth.

In order to see bacteria, rather high powers of the compound microscope are required, and even with the best instruments little of internal structure is visible in them. There are three formtypes commonly found among them: a) The spherical coccus type, b) the rod like bacillus type, and c) the spirillum type (fig. 58). Under each of these form types many different species occur, which may differ in size and proportions, in manner of grouping, in mode of cell division, etc.; or, different species may appear quite alike to the eye, and may be distinguishable only by their manner of growth in culture media. By proper staining methods some of them show locomotor flagella, that are quite invisible unstained (fig. $58 \mathrm{~b}$ and $e$ ).

Certain soil bacteria, of very great importance to agriculture, cause minute galls (known as tubercles) to grow upon the roots of clover and other leguminous plants. These are important because they are able to derive their nitrogen 
directly from the air. They supply nitrogen to the clover, and thus repay the debt imposed by the parasitic life. They enable the host plants to grow upon soils that are poor in nitrogen, and by their decomposition they leave such soils richer than they found them.

Within the galls, or tubercles, these bacteria grow larger than other forms, the cells becoming irregularly rodshaped, $\mathrm{x}$-shaped, $\mathrm{y}$-shaped, etc. Hence they are easily recognizable with the microscope. Upon examination of the large tubercle) we ordinarily find them filling the interior. Upon the dissolution of their bodies, their nitrogen content is added to the soil, either directly, during the growing season, or indirectly through the intermediary agency of the clover.

Study I3. A few observations on bacteria.

Materials needed: A hay infusion a few days old; some growing clover, or other leguminous plant, bearing root tubercles: a stock of sterilized culture dishes ready for sowing.

Mount a little bit of bacterial jelly from the surface of the hay infusion, and survey it for bacteria of the three formtypes. Look also for species of any type that may be distingushable by size, cell proportions, etc.

Clean some root tubercles, split open; mount scrapings from their interior and study the bacteria in them.

Make a few cultures on plates of agar as follows:

I. Seal one sterilized plate without opening, for a check.

2. Touch all your fingertips to the surface of the agar in a second plate, cover again, and set aside to incubate.

3. Wash the hands carefully and wipe dry on a clean towel, and repeat.

4. Capture a live fly, preferably from a dusty window; put it inside a culture plate and let it walk about a little, over the surface of the gelatine to distribute bacteria from its feet; remove the fly and set the plate aside to incubate. 
Watch the development in the several plates and compare results.

The record of this study may consist of notes and diagrams of the things observed.

\section{THE SLIME MOLDS.}

These are organisms of mixed character. In certain phases of their existence they exhibit animal functions; in other phases, only plant functions. In textbooks of zoology they. are called Mycetozoa; in most texts of botany, Myxomycetes.

Slime molds live during the greater part of their life as spreading masses of naked protoplasm, which slowly creep about through the tissues of rotten logs, stumps, leaves, etc., like giant amoebas. They are soft and slimy to the touch, and are of a consistency about like that of the white of an egg. Their prevailing tints are yellow, brown, ecru or purplish, or almost any color except green: They are usually small, but with plenty of food and moisture, a single plasmodium often grows to be a foot across. They shun the light and are always to be looked for in sequestered places. During nearly the whole of the growing season, from early summer until late autumn, they may be found in deep mossy woods, and in shaded places by permanent springs. On damp, muggy days following warm summer showers the plasmodia may be found, outspread upon the surfaces from which they draw their nourishment. They are saprophytes. They feed on the dissolved organic substances of decaying stems and leaves. They are always found associated with fungi of similar habits, but unlike the fungi they may also take solid food, engulfing it as does an amoeba by surrounding it with outflowing protoplasm.

Each plasmodium is a single multinucleate mass of protoplasm, without separating cell walls. The nuclei 
divide and become very numerous, but there is no distinction of cells. A plasmodium may become divided by the flowing apart of its mass in divergent directions, or two plasmodia may meet and wholly coalesce. They possess little individuality.

Dry weather checks the growth of the plasmodia and often initiates the reproductive phase of the life of the slime molds, in which they re-

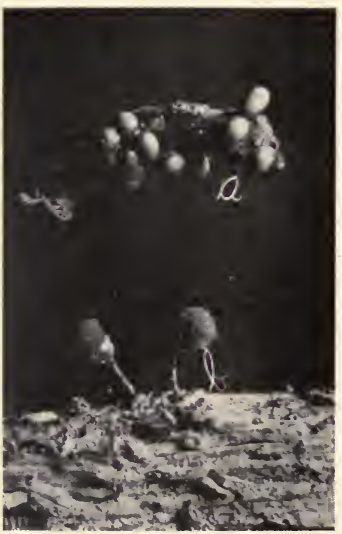

FIG. 59. Slime molds in spore bearing stage. $a$, Trichia; $b$, Stemonitis. semble plants. The plasmodia then abandon the darkness and creep out upon the exposed surfaces of the log or stump, or a little way up the stems of nearby plants. They develop cell walls about all their nuclei and these walls arecomposed of a characteristically vegetable substance, cellulose. Their most elevated portions develop sporangia of various and often beautiful forms. These contain multitudes of spores. This maturing process takes place very quickly-a few days or even hours may be sufficient; it is to be sought on the bright and sunshiny days that follow summer showers.

The spores are scattered with the bursting of the sporangia at maturity. In some of the commoner slime molds (fig. 59), they are assisted in making their exit by the movements of certain spirally twisted threads (capillitial threads: collectively the capillitium) which occur in the 
sporangia with them. These threads, formed from residual shreds of the plasmodium, are very hydroscopic, and when they dry out, twist and turn vigorously, scattering the spores. When favoring wind or water bears a spore to a favorable place for germination, it bursts its cell wall and there creeps out therefrom a minute, naked amoeboid cell, which moves about for a time by means of pseudopodia. - Then it develops a long lash at one end of the body (fig. 60) with the aid of which it swims for a season. Then it settles down, in company with others of like kind, and with the others fuses into a plasmodium of minute size, which has only to absorb food and grow to attain to the size and character of that with which we started.

Thus we see that from the time of germination of the spore

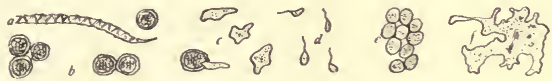

FIG. 60. Reproduction in slime molds. $a$, elater; $b$, spores: $c$, one germinating spore and three amoeboid cells escaped from other spores; $d$, the same cells a little later when free swimming; $e$, convergence of these cells to form a plasmodium; $f$, a small plasmodium.

until the plasmodium is mature, the slime mold exhibits the free locomotion and the feeding habits of the animal, while thereafter it develops cellulose cell walls and produces spores like a plant. Nature has not always established hard and fast boundaries, even between her major groups of organism.

\section{Study I4. Observations on slime molds.}

Materials needed: living plasmodia, and mature sporangia of any common species. Both may be brought into the laboratory on pieces of moist wood. The plasmodia, if broken into fragments with the wood, and placed on slides under a darkened bell jar, will in a few hours creep off the 
wood on to the slides, and, being thus well spread out, and freed from dirt, will show the streaming movements of protoplasm beautifully. One may be fixed on the slide with strong alcohol and stained with safranin to demonstrate the many nuclei. If an inclined slide be placed against the edge of a plasmodium and a gentle current of water made to run down the slide, the plasmodium will creep up the slide in opposition to the current.

Plasmodia may be grown from spores at any season, by sowing the spores upon a proper nutrient surface, and keeping them moist and under a darkened bell jar.

The things that may most profitably be studied are:

I) In the living plasmodium, its movements, its structure, its engulfing of solid bits of food (such as mushroom fragments), its protoplasmic currents and its reactions to stimuli.

2) In its fruiting phase, the form and structure and groupings of the sporangia, the spores and their structure, and the capillitial threads or other sterile parts in the sporangium.

3) In the development of the spores, the first amoeboid stage, the later free-swimming stage, and the fusion of cells to form minute new plasmodia (all of which may be seen in drop cultures, made as directed in the appendix.

The record of this study may consist of sketches and diagrams of the things observed.

\section{THE FLAGELLATES.}

Unlike the slime-molds, the flagellates are minute organisms having considerable definiteness of body structures, yet they have not clearly and uniformly differentiated plant and animal characteristics. Hence these also, or at least a considerable part of them, are treated in books on both botany and zoology; in the former being ranked 
with the protococcoid algae, in the latter with the mastigophorous protozoa.

Euglena is a common flagellate that will serve for introduction to the group. It abounds in sluggish waters, and if a quantity of trash and bottom

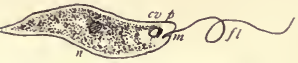

Fig. 61. Euglena. n, nucleus; $m$, mouth; $c v$, contractile vacuole with pigment fleck, $p$, beside it; $f$, flagellum. silt be placed in a large glass jar and allowed to stand awhile, Euglena will usually be found swimming in numbers at the surface on the side next the light. If abundant it will be very evident by its bright green color. It may form a green film on the surface visible to the unaided eye.

If a drop from this film be mounted for the microscope and examined one sees as soon as he finds the organisms that they exhibit the bright green chlorophyl color of the algae along with the active swimming movements of very lively protozoans. The swimming is rapid, and at first it may be difficult to keep a single individual in the field of observation. It is jerky, too; not the regular and orderly progression of a ciliate, but quick movements from side to side, due to the lashing of the long flagellum at the anterior end of the body (see fig. 6r).

In an individual that has settled to creeping about on the slide one may observe the form of the body-oval, blunt in front and pointed at the rear, showing a transparent ectosarc, and an endosarc filled more or less completely with green chlorophyl, and containing near the front end a pigment fleck of more or less orange color. The flagellum may be seen to be as long as, or longer than the body. It may be broken off, however, and if present it is so transparent it can only be seen in very favorable light, or sometimes, only after staining. Beside its base is a cleft-a rudimentary mouth - a receptacle for solid food 
- another animal character. In the midst, more or less hidden by the chlorophyl and by engulfed foods, is the nucleus. Reproduction is by fission, which, also may be observed in fávorable specimens.

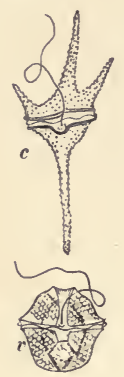

Fig. 62. Two shell-

Ceratium is a free-swimming bearing flagellates; flagellate which secretes a Peridinium.

spinous shell that is probably

a protection against the attack of some of the predaceeous animals of its environment (fig. 62).

Dinobryon is a colonial flagellate which develops an urn-shaped membranous shell open at the anterior end: two flagella of unequal length project from the opening; the chlorophyl is distributed (fig. 63e) in two elongate tracts within the body, and is somewhat obscured, as in many other flagellates, by a yellowish pigment.

Upon division, one of the resulting daughter cells slips out to the rim of the urn-shaped shell, and secretes for itself a new shell of like form, attached at the base within the margin of the old one. Repeated divisions thus give rise to branched colonies. These go swimming about in the water in a most absurd fashion-a contradiction to all the mechanics of submarine navigation - the open end forward, as it must needs be, owing to the position of mouth and flagella.

Gonium is a colonial flagellate of very different form-16-celled when the colony is grown, in a flat raft, four central cells destitute of flagella, and twelve

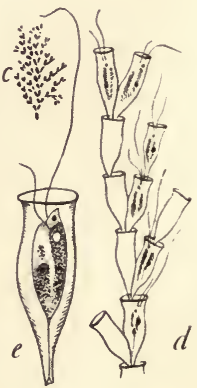

FIG. 63. A colonial flagellate, Dinobry. on. $c$, a colony $t d$, a portion of the same more enlarged: $e$, single individual. 
marginal cells (three on each side) with flagella. The cells all have rather thick cellulose walls, and there is a common gelatinous envelope investing the
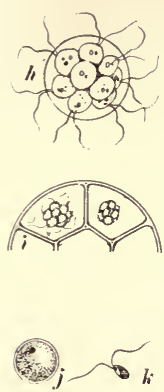

FIG. 64. A colonia 1 flagellate Pandorina. $h$ a normal spherical colony; $i$ daughter colonies developing within the cell walls of the mother colony: $j$, zygote resulting from the fusion of the gametes; $k$,gamete; these are often of unequal size. entire colony. The motion is that of a whirling disk.

Pandorina (fig. 64) is a small spherical colony of bi-flagellate cells. Usually there are sixteen (sometimes only eight, more rarely, thirty-two) of the cells, closely held together in a gelatinous envelope. New colonies are formed in two ways: 1 ) repeated divisions within the old cell wall give rise to new colonies, which escape as colonies and not as single cells (fig. 64 i). each cell of a colony may divide four or five times, giving rise to sixteen or to thirtytwo cells (sex cells, or gametes) which escape singly and fuse in pairs, forming zygotes (fig. $64 j$ ). Each zygote, later, by successive divisions gives rise to the normal colony.

Volvox is a spherical colony of somewhat similar cells (fig. 65). It grows to large size, being easily visible to the unaided eye, and it may contain hundreds or even thousands of constituent cells, all embedded in the common gelatinous matrix, their flagella radially protruded and lashing in unison to produce a rolling motion. Volvox presents a remarkable differentiation into vegetative and reproductive cells, to be discussed under a subsequent heading.

Study 15. A comparative examination of common flagellates.

Materials needed: Living specimens of a variety of simple and colonial flagellates. Some of these will be 
obtained by the method suggested for obtaining Euglena. More may be gotten from the surface plankton of shallow ponds with a towing net of fine silk bolting cloth. It being impossible to say what forms may be found at any time and place, no detailed outline can. be

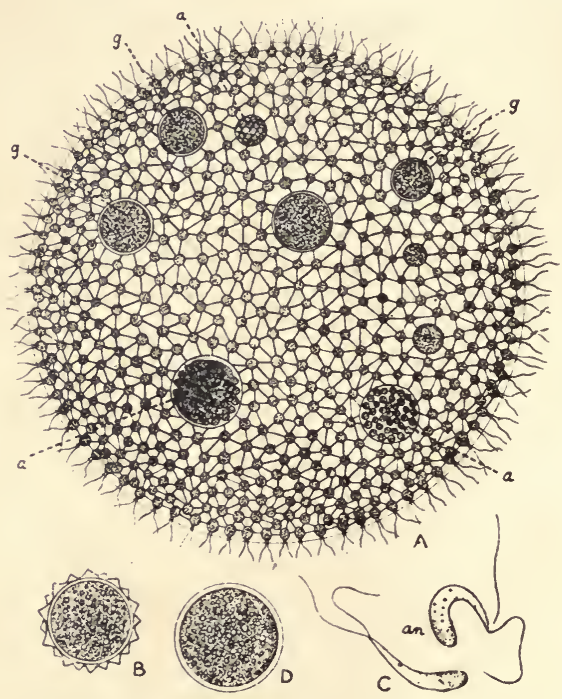

Frg. 65. Volvox (from West, after Klein). The individual cells are united by radiating strands of protoplasm. $A$, a mature colony; $a$, spermaries; $g$, ovaries. $B$, zygote resulting from the fusion of the gametes. $C$, two sperms. $D$, egg.

given for the study of then. Suffice it to say that the flagellates available should be compared as to form and activities, the manner of cell aggregation in colonial forms, and differentiation of cells in the colony. And the individual cell should be studied as to its covering, the number, length 
and insertion of its flagella, the distribution of the chlorophyl and location of the pigment spot, position of the mouth if present, etc., etc.

The record of this study may well consist in sketches, and notes on the things observed.

\section{REPRODUCTION AMONG THE SIMPLER ORGANISMS.}

I. Cell division.-Increase of individuals is brought about among the simpler organisms, as we have already seen, by simple cell division, or fission. This process seems ordinarily to be initiated by the nucleus (which undergoes changes to be described in a subsequent chapter) which separates itself into two parts, about which the other cell constituents become aggregated. The living substance of the mother cell thus lives on in the two daughter cells.

Cell division is an automatic, internal, spontaneous process. It cannot be effected artificially; it cannot be compelled or prevented. If a cell be cut in two, the part of it containing the nucleus and a part of the cytoplasm may live, but the cytoplasm deprived of the nucleus dies, and a wholly isolated nucleus dies also. The cell is the unit of organic structure and function, and in it nucleus and cytoplasm bear relations of mutual dependence. They work together in both nutritive and reproductive processes.

Cell division results from growth, the increase of size disturbing the nutritive relations between the living substance and its food supply: for volume tends to increase faster than surface; the former (if the cell be spherical) as the cube, the latter as the square of the diameter. Therefore, the mass of protoplasm tends to increase more rapidly than the surface through which it derives its nourishment and expels its waste. This is a sufficient reason why cells are small, and why, when a standard maximum size is reached, fission sets in to keep them so. 
For every kind of cell there is a normal size, which being attained, nucleus and cytoplasm act conjointly to bring about a separation of the cell body into two equal parts, and to perpetuate in each of the descandent cells the substance and the characters inherited from past cell generations.

When cells after division remain in contact they tend to form individuals of a higher order. These may be merely colonies of loosely associated and physiologically independent cells-mere aggregates-or, if the cells become intimately associated in relations of mutual dependence, then each aggregate becomes a unit organism. In organisms of this compound sort new individuals may be formed by external agencies. The filament of Spirogyra, for instance, may be broken into a number of parts, and each part, provided it contain an uninjured cell, may become a new fila-

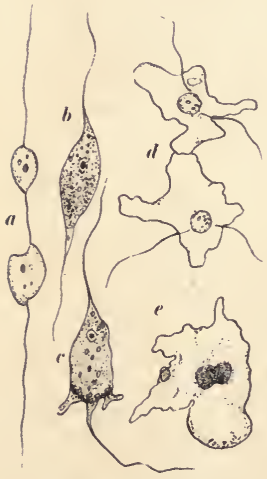

FIG. 66. Cercomonas (in part after Dallinger). $a$, division; $b$, a normal individual; $c$, an individual approaching the time for conjugation; $d$, the beginning of conjugation; $e$, end of conjugation and fusion of nuclei. ment. New individuals of such branching types as Cladophora or Dinobryon are formed when the older parts connecting branches together meet with accident or death and the connection is dissolved. These are negative processes, that do not account for the production of anything new; it should be clearly recognized that cell division is the universal mode of increase among organisms.

2. Sexual reproduction.-In a few minor groups of the smaller organisms, cell division goes on uninterruptedly, and is the only known phenomenon of reproduction; but in all the larger and higher forms of life (and in so many of the simpler ones also that 
it is well nigh universal) another phenomenon known as conjugation or sexual reproduction enters in periodically, alternating with long periods of cell division. This process consists in the fusion of two cells, and so, is the reverse of cell multiplication. Like cell division, it is an automatic spontaneous act of the cells themselves, that cannnot be artificially performed. It occurs after a long period of cell division (after more than soo generations of cells produced by fission in Paramoecium, according to Maupas), and it seems to follow a decline in vegetative vigor. This is indicated by the loose amoeboid form taken on by certain shapely flagellates (fig. 66) just previous to conjugation. It is followed by restoration of the normal form, and by renewed activity in cell division, therefore, it seems to be a sort of rejuvenating process.

It introduces into cell lineage new influences from without, by commingling the substance of two cells that are of diverse ancestry and that have lived apart under different influences.

This fusion may occur among the simpler organisms in a great variety of ways. It may be temporary and partial as in Paramoecium. Two individuals come together and

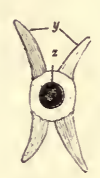

FIG. 67. Diagram i1lustrating conjugation between two cells of Closterium; $y$, the empty and discarded cell walls; $z$, the zygospore, or $z y g \circ t e$, resulting from conjugation. partially fuse at the anterior end. Their meganuclei degenerate; their micronuclei divide; a part of each micronucleus passes over into the other Paramoecium to fuse with a corresponding part of the micronucleus of that animal, the two together forming the new micronucleus. The two paramoecia, after this exchange of substance separate, and enter upon another period of increase by fission.

More often the fusion is total and permanent. It may be between cells that are of normal size and equal activity,(fig. 67) 
as in Closterium. Spirogyra shows the slight difference that one of its conjugating cells is slightly more active, its protoplasm passing over bodily into the other one. In Epistylis (fig. 54) there is greater difference in size and the active cell possesses locomotory apparatus and is free-swimming.

It may occur between cells of reduced size, such as the swarm spores of the Sporozoa, next to be studied (fig. 68). But it usually occurs, even among the simpler organisms, between two specialized reproductive cells (gametes) of opposite character:

SPERM

(or spermatozoan) EGG

(or ovum) small- active - with little cytoplasm and no inclusions.

large-receptive-cytoplasm charged with food materials.

This alone is sexual reproduction, since in absence of this differentiation there is no sex. Sex cells are well illustrated in Volvox. The many generations of cells produced by fission remain in contact and constitute the spherical colony. A few scattered cells in the colony cease their vegetative activity and become differentiated in two ways. Some of them repeatedly divide until very small, develop swimming flagella, and are liberated as free-swimming sperms. The others increase in size and food content by storing up in their cytoplasm food materials derived from neighboring cells, and become eggs. At maturity the sperms break out and swim abroad. The egg remains where produced, and develops only if some wandering sperm find it and fuse with it. After such fusion (fertilization), ordinary cell division begins again; and the little cluster of cells soon formed is set free as a new minute volvox colony.

The case of Volvox is especially significant because Volvox is like all.the higher organisms in the possession of true sex 
cells. The stoneworts, Chara (fig. 48) and Nitella, show the same phenomena, with eggs and sperms developed within much more highly specialized chambers (ovary and spermary respectively). In the other forms we have been considering any cell might enter into conjugation. But here, the greater part of the cells of the body (bodyplasm) eat and grow and die without descendants, and only the few that are relieved of nutritive functions and set apart for reproduction, live on in succeeding generations.

Among the parasitic protozoans (Order Sporozoa) there are many concurrent modifications of life history and of reproductive methods. One of the most instructive of these is the common gregarine that lives parasitically in the stomach of grasshoppers and crickets, where it is usually found abundantly in summer and autumn. It is a large protozoan when grown, easily recognizable with the unaided eye, of a yellowish color, and often so abundant that when a grasshopper's stomach is opened it looks as if lined with a layer of yellow corn meal. Each minute grain of the apparent meal represents a single gregarine, or a pair of gregarines in apposition (fig. 68).

The body of this gregarine shows a constriction across one end which simulates the division between cells; but on closer examination a nucleus is found only in the larger end. The cytoplasm is very densely granular, in so much that the nucleus appears as a clear spot in the midst of it. The ectosarc is thick, and is differentiated into layers, the outermost of which is protective against the digestive fluids with which it is always in contact. There are no locomotor appendages-only some contractile fibres developed in the ectosarc, admitting of slow movements of the body.

These gregarines begin life in the grasshopper's stomach (when swallowed with the food) as exceedingly minute 
bits of hyaline protoplasmic cells. Each develops an organ for the penetration of the wall and attachment to a single digestive cell, from which, during the early part of its (life it draws its nourishment.

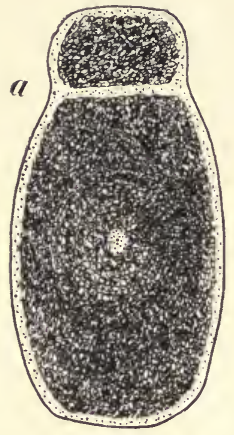
Later it becomes free, and grows enormously, without dividing. As it increases in size its endosarc becomes charged with an abundance of absorbed food materials, and takes on the dark and granular appearance already noted.

This long period of growth and accumulation of food materials is followed by one of rapidand extensive cell division outside the body of the grasshopper. Late in the season, when the grasshoppers and crickets also are old, most of the gregarines are found attached end to end in pairs. This looks like conjugation at first sight and has been so interpreted in the past; but it is only ap-

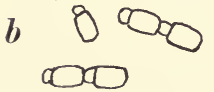
position, preparatory to further development. In such pairs, the protoplasm will often show a different appearance in the two individuals. One cell of the pair divides into a very large number of motile sperm cells, the other into a smaller number of egg cells: the separating walls be-

Fig. 68. Gregarine from the stomach of a grasshopper. $a$, a single individual, showing the dense granularity of the protoplasm; $b$, a group of individuals, apposed mostly in pairs, as they appear previous to sex cell formation. tween become dissolved and eggs and sperms are commingled in the common interior, and fuse in pairs.

Each of the fertilized eggs divides threetimes into eight minute cells which take on an elongate and somewhat boat- 
shaped form (whence they are called psendo-navicellae) and these are liberated by the rupturing of the containing wall. The spores are scattered among the herbage and may readily be eaten by another grasshopper in the spring; and if so fortunate (for therein lies their only chance of further development), they repeat the cycle just outlined.

The deviations from the normal course of protozoan life in gregarines seems to be due to their peculiar parasitic habits. A long period of uninterrupted growth is followed by rapid and extensive cell division, reducing the size again, first to that of normal gametes, and after fertilization, reducing it again to that of the spores.)

Study i6. Observations on reproduction among the simpler organisms.

Materials needed: For fusion between cells of ordinary size, conjugating Spirogyra, or any of the Conjugatae among the algae, fresh or preserved (temporary and partial conjugation may often be seen in Paramoecium and its allies among the ciliate protozoans, but the details are not easily followed by a beginner).

For gametes, one of which is of moderately recluced size and of increased activity, preserved material in Vorticellidae, or, better, in any of the algae, among which this is of frequent occurrence.

For fusion between cells both of which are of greatly reduced size, fresh and preserved gregarine material. For fresh material, up to the beginning of the dividing process, open the stomachs of freshly collected grasshoppers (the head may be snipped off: the body wall slit open; the alimentary canal lifted out entire and freed from extraneous organs and fat, the stomach wall, opened by a longitudinal slit, either with fine scissors or with a very sharp scalpel: the walls will open by the contraction of their own muscles, 
and fully expose the yellow gregarines to view: these may be lifted with a pipette and mounted in normal salt solution for study). For the division, conjugation, and spore forming stages, use prepared slides.

For the ordinary process of sexual reproduction, either fresh or preserved material representing that phase in either Volvox or a stonewort, (Chara or Nitella).

The record of this study may well consist of drawings illustrating such phenomena as have been available for study. 


\section{CHAPTER III}

\section{ORGANIC EVOLUTION}

It is a matter of common observation that the characteristics of plants and animals are plastic, and more or less responsive to conditions about them. We all know this to be true of individuals. One familiar with the breeding of plants and animals knows it is also true of species. How great the changes, that may be wrought in a comparatively short time is shown by every cultivated species of plant or animal. That comparable changes are wrought in nature, only less rapidly, and that the main trend of the change has been toward higher organization, has long been thought, and is now generally believed. This is evolution. It means "descent with modification." Forms now existing differ from their remote progenitors. The complex structures and relations of the present day have dereloped out of the simpler ones that have existed in the past, and the history of that development is a proper subject for investigation, being traceable in the constitution of the living, and in the remains of extinct forms of life.

In this chapter, in taking up for brief consideration the higher plants and animals, we shall study them in series, - beginning with the simpler among them. This is the logical order, the order which we follow in all our studies. It is also the genetic order, the order of departure from primitive conditions, the order of the appearance of the respective groups upon the earth. We shall see the nature of the evidence of their kinship, while seeing the nature of the plants and animals about which we wish to learn. 
There are but two main groups of organisms-plants and animals. If these are not always sharply distinguished among the lower organisms, they are distinct enough among the higher ones. Our study is therefore, of two series of forms, which we shall illustrate in the fewest possible types that will serve to show the more important features of their structure and development. Matters of function and of relation to environment will for the present be left largely in abeyance, while attention is fixed on the form and relations of the types in each series.

\section{THE PLANT SERIES.}

The briefest admissable classification of plants is the familiar one that assembles algæ and fungi into one group, and makes of the remaining plants three groups that are somewhat more homogeneous and consistent, as follows:

I. Thallophytes; algæ and fungi.

2. Bryophytes; liverworts and mosses.

3. Pteridophytes; ferns, etc.

4. Spermatophytes; the seed plants.

We have already studied a few representative Thallophytes; we shall now briefly examine a few representatives of each of the three other groups.

\section{Bryophytes: Liverworts and Mosses:}

This is a group of comparatively small plants, of very great diversity in appearance. Those that live in the drier situations, and that are more familiar to us, are mainly mosses; but liverworts are common also in their proper haunts; in the moist shaded places of deep woods; on wet rocks by stream.

Conocephalus.-Fig. 69 is a good form with which to begin our study of the group. The plant body is a broad flat thallus, which spreads over and attaches itself closely 
to the soil. It is of bright green color, and has a peculiar, and seemingly incongruous musty odor. It grows apically, in a zig-zag course, dichotomously branching alternately to right and to left, the branches and parent stem being of equal breadth.

If we tear up a little strip of the thallus from the soil, we shall observe at once a considerable number of parts not seen among the algæ. First, there is a multitude of slender

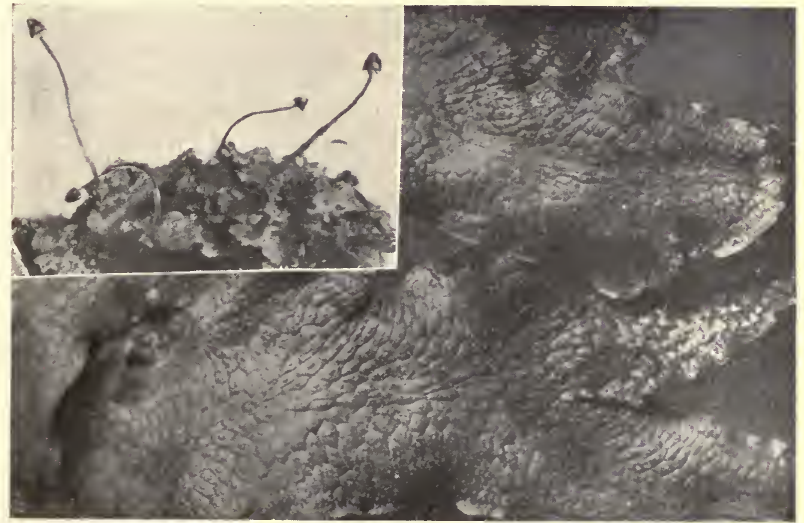

Fig. 69. Photographs of the liverwort Conocephalus; the larger figure is an enlarged top view of the thallus; the smaller one a side view of an old specimen bearing sporophytes. white rhizoids, holding the plant body fast to the soil. These are feeding organs. A number of algæ (for example, Chara, and Nitella) have similar organs for attachment, but they are much less developed and have no feeding function. In the liverwort, as in most of the higher plants, rhizoids are the chief means of taking up dissolved mineral substances out of the soil. The torn end of the thallus will show, also, that the plant body is covered with a dry surface 
layer of cells that is protective to the moist internal tissues. This surface layer is epidermis. Examined with a lens, it will be seen to be marked out in minute polygonal areas all
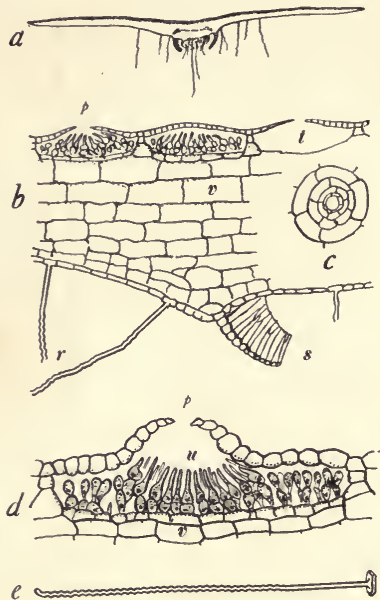

FIG. 70. Conocephalus. a, cross section of the thallus, showing rhizoids and scales beneath; $b$, a bit of the same more enlarged; $p$, breathing pore in the upper epidermis; $r$, rhizoids; $s$, scale; $t$, one of the areas about a pore (empty); $v$, common parenchyma; $c$, a breathing pore, as seen from the surface; $d$, details of a single area; $p$, pore; $u$, assimilatory parenchyma; $v$, common parenchyma. $e$, a single entire rhizoid cell. over the upper surface of the thallus and on close inspection a minute pore will be seen in the middle of each of these areas.

An examination of a cross section of the thallus, fig. $70 a, b$, shows clearly the relation of parts. The thallus is a large aggregate of cells, and the cells are highly differentiated. They form two principal kinds of tissue:-

Epidermis, of flat transparent cells that cover the whole exterior, some of which are modified slightly in shape to form the borders of the breathing pores, and others are modified very greatly, being extended into long filaments, to form the rhizoids (fig. $7 \circ b, e$ ).

Parenchyma, of softer cells, richer in protoplasm, filling the whole interior and differentiated into two principal sorts (fig. $70 d, u$ and $v$ ) - :

I. Assimilatory parenchyma of smaller, thin walled cells, containing abundant .chlorophyl, and situated in an upper 
stratum where they are in communication with the air through the pores, and with sunlight, which penetrates the transparent epidermis. These differ among themselves in form according to their situation.

2. Common parenchyma, of bulky, colorless cells composing the thicker interior stratum, which gives form to the thallus. A few common parenchyma cells rise above the general level, passing between groups of assimilatory cells to mark out the areas already seen from the surface.

These are the primary tissues of all the higher plants.

Such integration of cells into a unit organism of mutually dependent parts, we have not found before. In the algæ we have studied, the cells are more loosely associated together, less differentiated, and physiologically more independent. When every cell is in contact with the water that contains its food, there is no need of special feeding organs.

But with the assumption of terrestrial life, the sort of division of labor that we have just been considering has taken place among the cells of the liverwort. Different plant functions are assumed by different groups of cells; that of getting carbon from the air by the cells of the assimilatory parenchyma; that of getting the mineral matters from the soil, mainly by the rhizoid cells; that of protecting the protoplasm from the new peril of evaporation, by the cells of the epidermis, etc.; each group doubtless improving in capacity for its special work, as it is relieved of the work now performed by other cell groups.

Cell division is localized in the liverworts, and in all the higher plants. It occurs in Conocephalus only at growing points located in the notched tips of the stem and branches. There new cells are formed during the growing season. They are at first minute and rich in protoplasm. They rapidly increase in size and differentiate into the kinds of tissue just described, and take their places, to remain of one form until the death of the stem. 


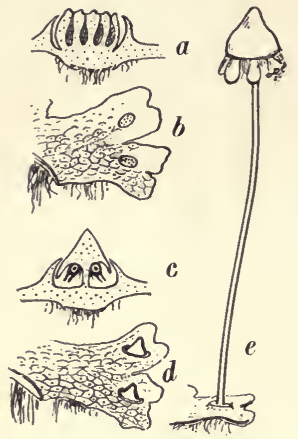

FIg. 71. Conocephalus. $a$, antheridial disc, showing antheridia in vertical section; $b$, the same in surface view; $c$, archegoniophore, showing archegonia in vertical section; $d$, the same in surface view; $e$, the mature archegonial disc, bearing sporophytes (one opened and shedding the spores).

Reproductive cells are produced by another kind of differentiation from the growing points. On some of the branches, sperm cells and egg cells are developed in special receptacles (gonangia), the former in groups, the latter, singly. The container for the sperms is called (as in plants generally) the antheridium.* A number of antheridia are immersed together in the top of a disc-shaped receptacle, (the antheridial disc or antheridiophore, fig. 7 I $a, b)$. The container for the egg is called an archegonium. $\dagger$

Archegonia are developed upon a receptacle (archegoniophore) of a nature similar to, but of a form very different from that which bears the antheridia. It is a conic-capped, mushroomshaped organ (fig. 7 I $c, d$ ). The archegonia are inserted underneath the cap. Each archegonium (fig. $72 \mathrm{~A}$ ), is a hollow, flask-shaped organ; the swollen base of the flask (which contains the single egg cell) is inserted upon the tissues of the disc, and the open neck of the flask is directed downward.

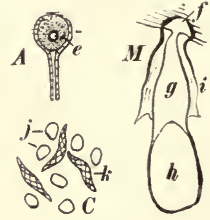

FIG. 72. Conocephalus, $A$, archegonium in vertical section; $e$, egg cell; $M$, the sporophyte; $f$, foot: $g$, stalk; $h$, sporangium; $C$, contents of sporangium; $j$, spores; $k$ elaters.

*This is the equivalent of the better term spermary, which we have used hitherto. It is in almost universal use in botanical text books.

$\dagger$ A special botanical term for one type of ovary. 
During the fall and winter the disc is low and inconspicuous, being contained in a circular pit in the top of the thallus, with only the conic cap projecting. It is surrounded by a circular cleft which admits of access to the archegonia when these are mature. The sperms are free swimming cells of strictly aquatic habit. They can make their egress from the antheridia and swim about to find the egg cells only when rain or dew has supplied sufficient water for the purpose.

In early spring the stalk of the archegonial disc elongates enormously and pushes the cap up in the air to a height of two or three inches (fig. 7 I e). This lengthening is not brought about by the production of new cells, but by the further development of those already present. In the center of the transparent stalk may be seen an axial bundle of cells that have become extraordinarily lengthened, and that form when fully developed and hollow, a bund1 ? of capillary tubes, which facilitate the transport of food materials from the thallus below to the maturing spores above. These capillary cells are the most specialized cells in the body of the liverwort.

Development.-From the fertilized egg cell there develops, not another thallus like the one that produced it, but a plant body of a very different sort, (fig. $72 M$ ), called a sporophyte (or sporogonium). This develops as follows: The egg cell divides repeatedly, forming a mass of cells that distends the walls of the archegonium. This cell mass then differentiates gradually into the three parts of the sporophyte, foot, stalk and sporangium. The sporophyte develops at the expense of the archegoniophore; its foot remains immersed in the tissues surrounding the base of the archegonium, and serves as the food-absorbing organ. The stalk gradually elongates and pushes the sporangium downward toward the outer world. The sporangium develops a 
protective outer wall, and the cell mass contained in it finally develops into a very great number of minute roundish reproductive cells called spores, intermixed with sterile cells called, because of their function, elaters. Upon the drying and bursting of the sporangium wall, the elaters, by their twisting and turning, assist in the scattering of the spores.

Alternation of generations.-From those spores which, when scattered abroad, find suitable lodgment and food for growth, there develop new thalli, like the one with which we started. Thus there are two distinct parts to the life cycle of Conocephalus; a large independently-feeding green plant, which, because it produces the sex cells (gametes) is called the gametophyte, and a small, dependent sporophyte producing the spores. The former is a sexual, the latter an asexual generation. This phenomenon is known as alternation of generations. Because of its importance in the green plant series, gametophyte and-sporophyte should

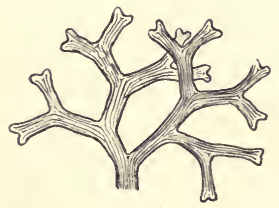
be clearly distinguished at once, the former producing the eggs and sperms, the latter producing the spores; the one regularly developing from the reproductive cells produced by the other.

Other Bryophytes.-Riccia (fig. FIG. 73. A spray of the liver- 73) is a simpler liverwort, that has the wort, Riccia fluitans.

archegonia and antheridia immersed in the upper side of the thallus. Jungermannia (fig. 74) is a liverwort of more highly specialized form, in which the midrib of the thallus has become the plant stem, and the broad margins have become differentiated into leaves. These, however, are rather crude in form and simple in structure, lacking veins and even a mid rib, and consisting of a single layer of chlorophyll bearing cells. But they indicate 
relationship with the simple mosses. The leaves of mosses are better developed, possessing a mid rib, and usually a

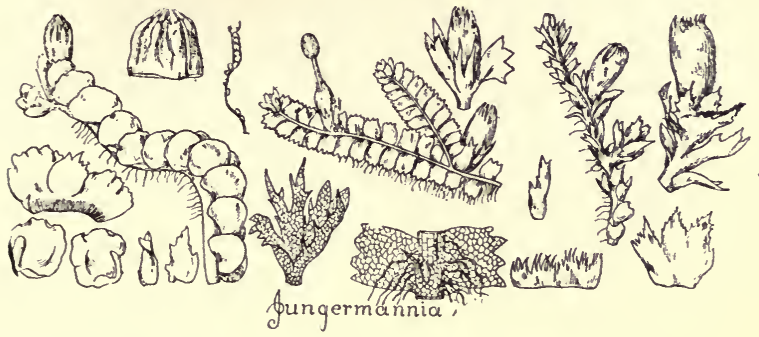

FIG. 74. A "leafy liverwort" Jungermannia, three species. (Copied from Gray's Manual of Botany, a classical work on North American plants).

margin of close knit cells, and are often borne on erect stems.

A comparison of the sporophyte phase in bryophytes

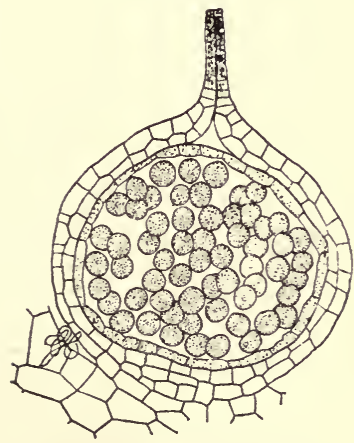

Fig. 75. Section of the simple sporophyte of Riccia narans, inclosed within the distended wall of the archegonium). Note that all the cells of the sporophyte are spores save a single peripheral layer that is dotted in the figure after Chamberlain. will be most instructive. It is in this group we first find alternation of generations fully established with an organized sporophyte. While there is reproduction by means of both sex cells and spores among the thallophytes, there is rarely the regular alternation between them and never such differentiation of a distinct sporophyte phase as we find there. This phase finds a simple expression in Riccia. From the egg there develops a single spherical shell of (ephemeral) sterile cells containing spores (Fig. 75) 
only. No foot nor stalk appear; only sporangium: and in the sporangium, no sterile cells; only spores.

The maximum development of sporophyte phase in the bryophyte group of plants is found in the mosses, in which the archegonia are terminal upon a stem or branch, and, although produced in clus-
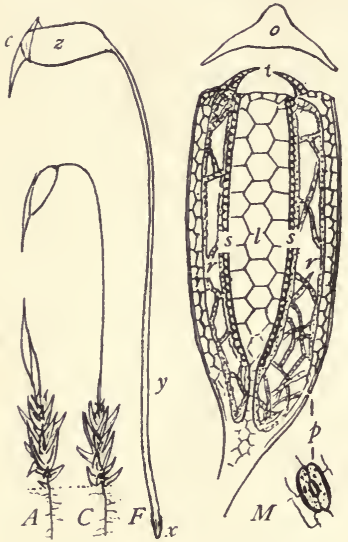

Fig. 76. The moss sporophyte. $A, C, F$ successive stages in its develupment; $c$, calyptra (detached top of archegonium; $x$, foot; $y$, stalk; $z$, sporangium; $M$, longitudinal section of the sporangium; 0 , operculum (detached); $l$, columella; $r$, respiratory parenchyma; $s$, spores; $t$, teeth; $p$, breathing pore (stomate), and the same below in surface view. ters, but a single egg normally develops to maturity. From the fertilized egg there develops a sporophyte of great length which early ruptures the archegonium wall, carrying the upper end of it up into view as the calyptra. This falls away at maturity. Fcot, stalk and sporangium are highly differentiated. The foot is buried in the tissues of the parent gametophyte, whence it draws nourishment for development, as in the liverworts. The stalk is long and pushes the sporangium up conspicuously into view. The sporangium is composed of a number of highly differentiated sterile parts. It contains no elaters, and the spores are situate in a cylindric layer surrounding a central core of parenchyma cells (called the columella), and usually covered over by a detachable cap, the operculum, that grows beneath the calyptra and is a part of the sporangium itself. Underneath the operculum there is often a peripheral 
row of teeth attached at the margin, with free tips that meet at the center of the columella. These regulate the dispersal of the spores, by lifting (as if by hinges at their bases) when dry, and exposing the top of the spore cavity, allowing the spores to be shaken or to fall out, and closing down by hygroscopic movement when wet.

Perhaps the most significant feature is the appearance of a loose layer of chlorophyl bearing parenchyma in the outer wall of the sporangium, and the development in the epidermis covering the base of it, of a few breathing pores (stomates) of a new type. This type that is the prevailing one in the following groups of plants. Thus the sporophyte is able to gather some carbon for itself, though dependent on the gametophyte for other elements of its food.

We have already seen that, as compared with the algæ, the bryophytes have attained to a higher grade of bodily structure, and have acquired an organization that is directly related to terrestrial life. The new features of their life history, also, are related to this changed environment. They brought with them from the water and have one and all retained a strictly aquatic mode of fertilization. All have free-swimming sperm cells: and the distance between the antheridia and the archegonia must be covered by water at the time the sex cells ripen, else fertilization cannot take place. But spores do not require to be fertilized: and the introduction of the spore-producing generation seems to have been the means availed of for securing the production and distribution of a host of new individuals while avoiding the exigencies of fertilization under the changed conditions

Study I6. An examination of bryophyte characters.

Materials needed: Fresh green specimens of Conocephalus or other thalloid liverwort; either fresh or preserved specimens bearing antheridia and archegonia, older specimens bearing sporophytes; also, sets of prepared slides. 
The student should study: I) in the fresh thallus, its form and mode of branching, the location of its growing points, its exposure to light. 2) The areas about the pores of the upper surface (the details of the latter will easily be made out in thin tangential sections cut freehand with a razor from the upper surface).

3) The scales and rhizoids of the lower surface and the attachment to the soil.

4) The details of structure of archegoniophore and antheridiophore. Study vertical sections of these, if such be at hand.

5) The details of structure in cross sections of the thallus (possible in freehand sections from fresh tissues, but prepared sections will be much better, if well prepared).

6) The excessively elongate cells of the axial bundle of the stalk of the mature (easily withdrawn with forceps from the stalks preserved in formalin, and should be mounted outspread in a drop of water or formalin solution). Compare these in form with those of the outer wall of the stalk.

7) The mature sporophyte (easily dissected out with needles under a lens). Study also its development from the egg, if slides are available for this.

8) The form and structure of the spores and of the elaters.

The record of the work done may consist of notes on and drawings of the more important structures studied.

9) The structure of the moss sporangium (easily made out in longitudinal sections: freehand sections will do for this, if permanent slides are not available) identifying the parts mentioned in the explanation to figure 76 .

PTERIDOPHYTES. FERNS, ETC.

This is a group of plants of larger size than bryophytes, and of still greater diversity of appearance. It differs most 
remarkably in the size and predominance to which the sporophyte has attained.

The fern (Pteris).-The gametophyte of the fern will serve well to connect with preceding studies. It is a little heart-
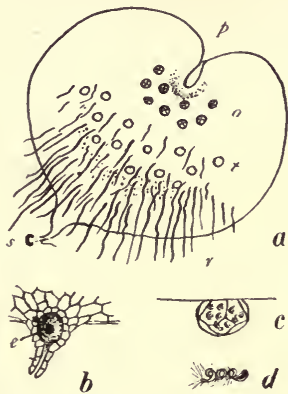

FIG. 77. The fern. a, the gametophyte phase, inverted and seen from lower surface; $s$, the spore from which it grew; $r$, rhizoids; $p$, the growing point in the bottom of the apical notch; $o$, archegonia and $t$, antheridia; $b$, a single archegonium in vertical section; $e$, egg cell; $c$, a single antheridium, with developing sperm cells; $d$, a single mature sperm cell. shaped thallus (called the prothallium), hardly exceeding a quarter of an inch in diameter when grown. Its structure is even more simple than that of the thallus of a liverwort. There is the same copious development of rhizoids, connecting it with the soil, but there is less differentiation of the tissues of the thallus itself, there being no sharp distinction of special assimilatory parenchyma and no pores. The growing point is in the notched tip, protected as before by the lobes extended at either side of it. The archegonia and antheridia are developed on the under side of the thallus, and open downward; the former are arranged in a cluster, nearer the growing point (fig. 77). The sperms are motile and swim about when mature, if favoring rain or dew give them opportunity. Many of them mature in advance of the maturing of the eggs of the same thallus, thus favoring cross-fertilization.

Thus, it will be seen there is quite a general similarity between the prothallium of the fern and the thallus of a simple liverwort. But this phase of the fern is least 
developed, and the sporophyte phase is, save in its origin

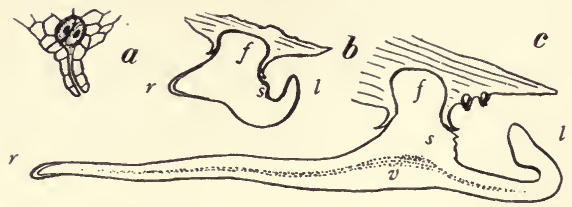

FIG. 78. Fern embryos. a, after the first division into two cells; $b$, an embryo showing the beginnings of root $(r)$, stem $(s)$ and leaf $(l) ; c$, an older embryo, the leaf tip turning upward, vascular bundles $(v)$, developing; $f$, foot.

exceedingly different. The comparison of sporophytes will, therefore, be more readily made if it

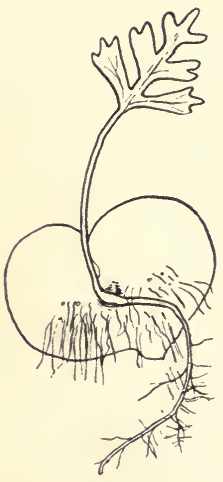

Fig. 79. The fern sporophyte, in the first leaf, but still attached to the parent gametophyte. be a comparison of early stages.

The sporophyte.-The fertilized egg divides (fig. $78 \mathrm{a}$ ) and produces a mass of cells within the walls of the archegonium. From $t$ is cell mass there are early differentiated a nư ber of parts, one of which clearly corresponds to the foot of such sporophytes as we have seen hitherto, it being a food absorbing organ immersed in the tissues of the parent gametophyte (fig. $78 f$ ). From the remainder (which corresponds only in a general way to the stalk) root and leaf develop, the root extending downward into the soil, branching and developing rhizoids for independent foraging there, the leaf passing out between the lobes at the apex of the thallus and turning upward to the light and expanding, taking up its proper work of carbon dioxide reduction (fig. 79). Thus the 


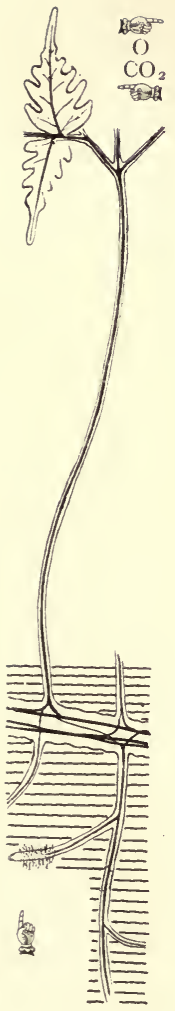

sporophyte early acquires a complete set of foraging organs and becomes independent of the parent gametophyte. The body of the embryo grows out more slowly into the underground horizontal stem (rhizome) of the fern, producing as it grows new leaves that rise to the light, and for a time increase in size and complexity, and new and larger roots that spread through the soil. So, the sporophyte is launched upon its career of independent existence; and not being limited to the supply of food that a small parent thallus can furnish, spore production is long delayed. A long growth

FIG. 80. Diagram i1lustrating the intake of food materials at root and leaf in the fern, and the transportation system of vascular bundles connecting the two sources of supply with all parts of the plant body. period intervenes. A large plant body is produced, which when mature develops sporangia in extraordinary numbers upon the surface of its leaves.

In this plant body the food absorbing organs are those with which we have already become acquainted in the bryophytes. The rhizoids surround the tips of the rootlets in the soil (fig. 80). The assimilatory parenchyma is chiefly located in the leaves, protected by a layer of transparent epidermis, composed of thin flat, curiously interlocking cells (fig. 8I). The oxygen of the air finds ingress through pores (stomates) of the sort already seen in the moss sporophyte(fig. $76 M, p$ ).

The development of a plant body of so greatly increased size is made possible by the development of new structures out of the parenchyma. These are of two sorts:- 
Supporting tissues, necessitated by increasing size and

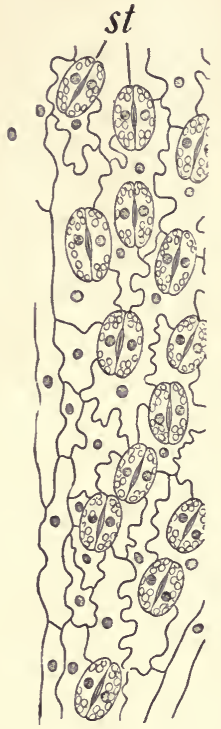

Fig. 81. Leaf epidermis of the fern; $s t$, stomates or leaf pores. weight.

Conducting tissues, necessitated by the increased distance between the two sources of intake of food materials, the rhizoids deep in the soil, and the assimilatory parenchyma of the leaf, lifted high in the air.

The position of these new parts in the plant body can best be learned by an examination of the structure of the mature stem in a cross section of which (fig. 82) they may be seen with the unaided eye. As before, the surface layer of cells is epidermis, and the whole of the soft part of the interior is parenchyma. The new tissues whose function is chiefly or wholly supportive are more or less brownish in color and arranged I) in a peripheral layer just beneath the epidermis, and 2) in two or more broad, darker colored strands of tissue extending through the midst of the parenchyma. These tissues consist of thickened and closely united walls of empty cells. The inner darker strands may readily be traced through the soft parenchyma, and followed where they branch out into the bases of roots and leaves.

The tissues whose most important function is the conduction of food materials (though certain of their elements also serve for support) are found in the vascular bundles, which, also are readily seen in cross section of the stem. They are of various sizes, and not constant in number, but 
are easily recognizable by the finely perforate appearance that the cut end of each bundle presents. These bundles, like the internal strands of supporting tissue, may be traced through the soft parenchyma by dissection, and followed at their branchings out into the base of roots and leaves.

Vascular Bundles.-These bundles constitute the transportation system of the sporophyte, condition its growth, enable it to take possession of larger areas and deeper layers of soil, to rise higher and to

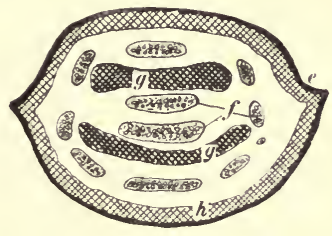

FIG. 82. Diagram of a cross section of the underground stem(rhizome) of the fern (Pteris). $e$, epidermis: $f$, vascular bundle; $g$, inner strands of supporting tissue (sclerenchyma); $h$, peripheral layer of supporting tissue. spread out more widely in the air and light, and are therefore, structures of first importance in the fern. They are compound structures formed out of the common undifferentiated tissue (called the meristem) by the ordinary processes of cell growth and differentiation. They are made up of a variety of tissues serving various purposes. The most important conducting tissues are two: I) tracheids, the tubes of the largest diameter which give the perforate appearance to the cross section of the bundle. These are the lignified walls of elongated and empty cells, and serve chiefly for the conduction of water, with whatever may be dissolved in it. 2) sieve tubes: these are living, greatly elongated, extensively vacuolated, but yet protoplasmic cells, with oblique overlapping ends whose walls exhibit groups of fine perforations. Through the latter there is protoplasmic continuity between adjacent cells. Albuminoid substances are distributed through these cells by diffusion through the continuous protoplasm. The chief supporting tissues of the bundles are two: I) the tracheids already mentioned, 
and 2) the best fibres, situated nearer the periphery of the bundle. The remainder of the bundle is parenchyma, little
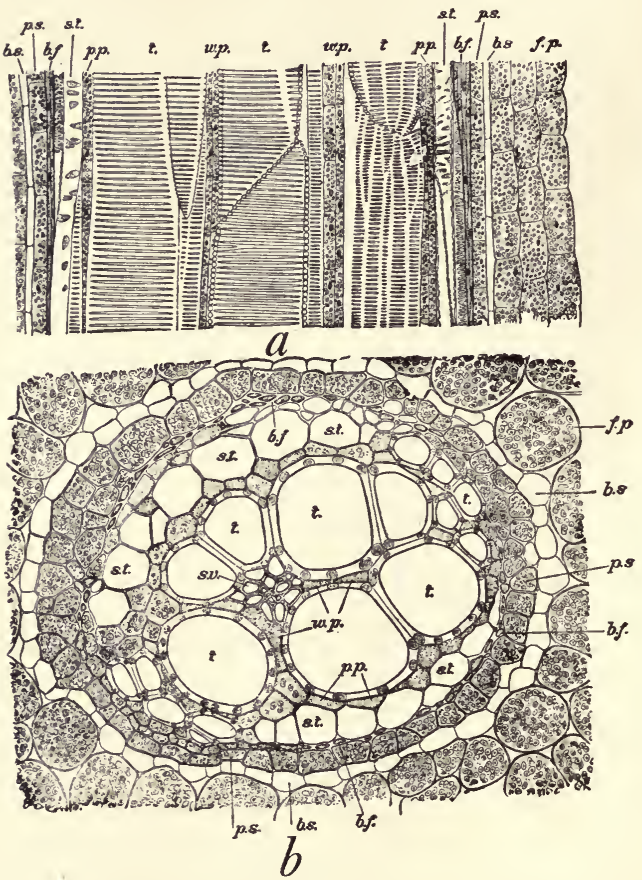

Fig. 83. Vascular bundle of the fern (Pteris) after Sedgwick and Wilson. $a$, longitudinal section; $b$, cross section; $f p$, common parenchyma; $b s$, bundle sheath, $p s$, phloem sheath of parenchyma; $b f$, best fibres; $s t$, sieve tubes; $p p$, phloem parenchyma; $t$, tracheids (wood tubes); $w p$, wood parenchyma; $s v$, spiral vessel.

differentiated. It constitutes the packing, so to speak, 
between the other more specialized parts. The distribution of these tissues in the bundles is indicated in figure 83 .

The distribution of the bundles
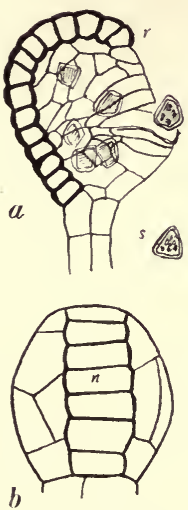

FIG, 84. Sporangium and spores of a fern, . , side view; $b$, rear view; $n$, the annulus; $r$, its front end, which lifts on drying and ruptures the wall below; s. a spore themselves is such that every considerable part of the plant body is put in vascular communication with every other part. The differentiation of vessels follows closely every growing point, down into root and rootlet, up into leafstalk and blade and lobe, through every vein and veinlet. Some branchlet of a vessel ends not far from every group of rhizoids in the soil, not far away from every stomate in the leaf. The venation of the leaf (fig. r63), is the map of the distribution of the vessels therein.

The new organs of the fern are root and leaf, both of them, mere extensions of the plant body, carrying out into new and wider foraging ground the original foraging organs, rhizoids and chlorophyl-bearing cells. The moss has no better circulatory apparatus than a simple axial bundle of slightly elongated parenchyma cells; it develops no roots and can forage in the soil only the length of its rhizoids. Clearly, the structures of the fern we have just noted sufficiently account for the larger size to which the Pteridophytes have attained.

Spore formation is greatly delayed, but in the end it occurs on a much larger scale by reason of the large plant body built up and capable of nourishing spores; moreover, it may be repeated by the same sporophyte year after year. In the bracken fern, sporangia (fig. 84) are developed 
under the rolled margin of the leaf, in small clusters (called sori). Each sporangium is borne on a slender pedicel; its walls are composed of thin epidermal cells; one line of these cells, encircling the top of the sporangium is differentiated into a ring (the annulus) of thick-walled hygroscopic cells, which at maturity burst the capsule by their elasticity, scattering the spores. The spores which fall in suitable place germinate after the manner shown in (fig. 85), and grow into thin, flat heart-shaped prothallia.

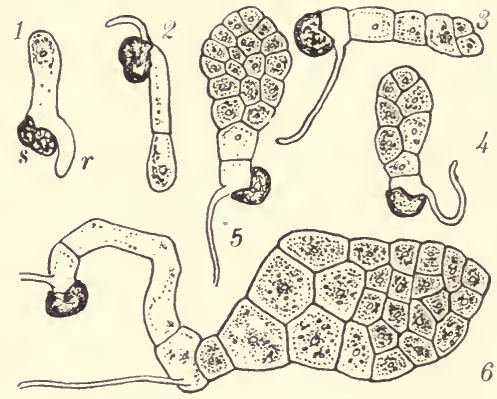

FIG. 85. Development of the fern gametophyte from the spore; figs. 1 to 6 show successive stages; figs. 3 and 4 show the establishment of an apical cell and growing point; fig. 6 shows the second rhizoid.

Comparing fern and liverwort, we see great similarity in reproductive organs and methods, considerable similarity in the gametophyte phase, and great divergence in form, size, structure and manner of life of the sporophyte.

Other pteridophytes.--The common horsetail (Equisetum) will serve to illustrate the kind of differences presented by another group of pteridophytes. The sporophyte phase of the horsetail is leafless, but bears green naked branches which arise from an underground rhizome. The chlorophyl 
bearing parenchyma is located in the furrows of the branches. The furrows extend up and down, and the chlorophyll bearing cells communicate with the air by pores or stomates arranged in two rows in each furrow. The sup-

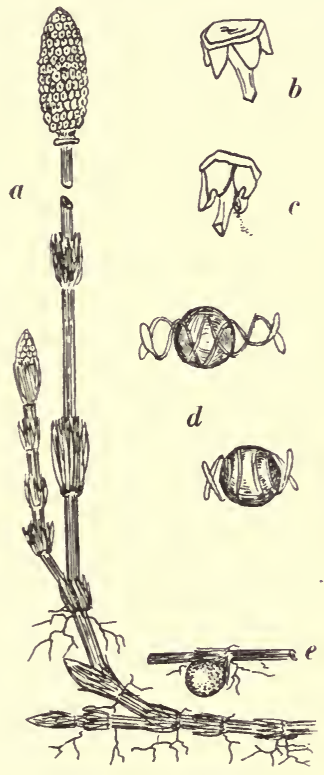

FIG. 86. The common equisetum ( $E$. arvense). $a$, a fruiting spray; $b$ and $c$, two scales from the fruiting cone, showing marginal sporangia ; $d$, two spores, with their hydroscopic elaters partly unrolled; $e_{\text {, a }}$ bit of underground stem, bearing a round tuber.

porting tissues, (aside from the unusualy stiff epidermis), are located in the ridges, which they chiefly compose. The branches are hollow, and the vascular bundles are arranged radially around the main central cavity, opposite the ridges upon the surface. Each branch is divided into segments by a series of nodes (at which it breaks when pulled. whence the popular name. joint-grass"). The arrangement of ridges and valleys, of vascular bundles and carities, of green respiratory parenchyma in the valleys and the broad bands of si pporting tissue in the ridges, are readily seen in cross sectirns of fresh stems. The epidermis is covered with secreted nodules of silica which render the branches rough to the touch (whence the popular name "scouring-rush").

The spores are dereloped in numerous sporangia that grow underneath the scales of a fruiting cone (fig. $87 a, b, c$ ) 
at the top of the stem, as indicated. The outer covering of each spore is split into four long

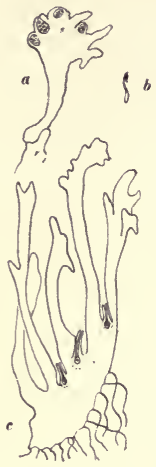

Fig. 87. Male and female prothallia of equisetum (after Goebel). $a$, the male prothallium, with marginal antheridia; $b$, a sperm cell; $c$, the female piothallium bearing three archegonia. involute strips, which serve as elaters, and, being exceedingly hydroscopic, these extend and roll up again with slight changes of moisture and push the spores out of the sporangia.

Two kinds of Gametophytes.-While the spores all look alike, some of them on germination develop into small prothallia which produce only antheridia and others grow into larger prothallia which produce the archegonia.

The prothallia (fig. 87) are therefore unisexual, as in some of the mosses, but each thallus and especially the male, is of very small size. Fertilization occurs with the aid of water for transport of the sperms as in the fern, and the development of the sporophyte from the fertilized egg follows the same general course.

Selaginella (fig. 88) is another pteridophyte with a trailing stem bearing small two-ranked leaves and lesser scales. It is especially interesting on account of the development of its spores. The sporangia are located in the axils of scales aggregated in several terminal laterally flattened spikes and are of two sorts large (macrosporangia), and small (microsporangia). The spores within them are of two sorts, large ones (macrospores), four in number developed in the macrosporangia, and small ones (microspores) developed in large numbers in the microsporanyia. It is less surprising, therefore, that there should develop from them two sorts of prothallia; but the prothallia themselves 
are very different from those we have studied hitherto. The microspore develops, beginning while still within the microsporangium, into a male prothallium of microscopic size. It consists when mature of but few cells, one of these representing the body of the prothallium and the others the antheridial wall, inclosing a considerable number of
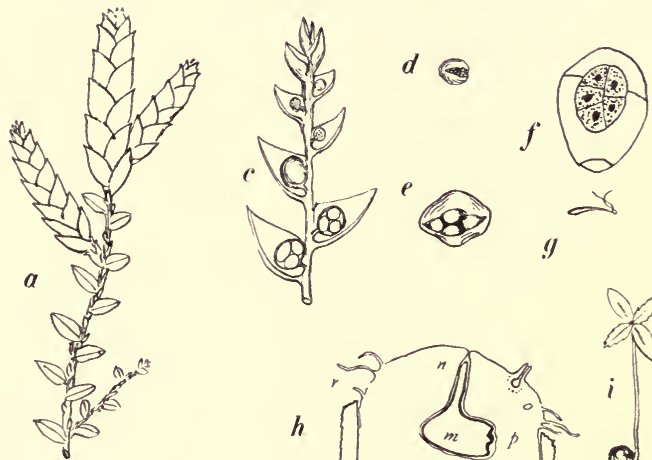

g
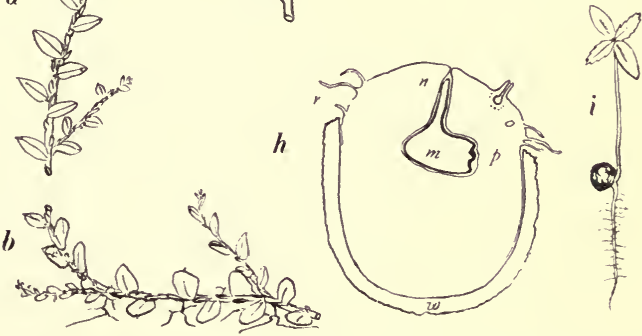

FIG. 88. Selaginella. $a$ and $b$, tip and base of a fruiting spray; $c$, diagram of a fruiting spike, showing macro and micro-sporangia in the axils of scales; $d$, microsporangium; $e$, macrosporangium; $f$, the male prothallium, spore mother cells dotted; $g$, as single sperm cell; $h$, the female prothallium, rupturing the wall $(w)$ of the macrospore; $m$, a new sporophyte embryo; $n$, its suspensor, and $p$ its growing point; $o$, the remains of an old archegonium; $r$, rhizoids.

sperm cells. There are no rhizoids or other nutritive organs developed, and the prothallium is short lived After a few cell divisions it differentiates the sperm cells, which are liberated in the water by the dissolution of the surrounding cells. 
The macrospore likewise begins its development while in the sporangium. It contains, however, within its own wall a store of food material, upon which considerable development is possible. The spore divides repeatedly, and growing at the expense of the stored food, bursts the spore wall, and protrudes as a small prothallium which develops a few rudimentary rhizoids, and later a few archegonia containing egg cells. These are developed and often fertilized before the growth of the prothallium is complete. Since the microspores are developed in the upper part of the fruiting cones they may fall down into the lower scales.

The fertilized egg develops foot, stem, root and leaf as before, and in addition a special embryonic organ the socalled suspensor, whose function it is to keep the embryo pushed down against the prothallial tissue from which it must obtain its food. By the time this supply is exhausted the embryo has developed a root, bearing rhizoids, and one or two pairs of minute leaves at the apex of the stem, and is ready to get food for itself independently.

The predominance of the sporophyte phase is in this plant, very marked. The gametophyte is here not only reduced in size, but wholly dependent on the antecedent sporophyte for food-the reversal of the conditions with which we started.

\section{Study I7. Fern development.}

Materials needed: Fronds, bearing ripe and immature sporangia; prothallia in all stages of development and old ones bearing sporophytes.

Study the grouping of the sporangia in relation to each other and to the veins of the leaf, and their protective covering.

Study the structure of the mature and of the ruptured sporangia. 
Study the spores, and, if material be at hand, their germination also.

Study the prothallia: their form, their parts, their archegonia and antheridia.

Study the young sporophyte, both before and after the acquisition of independent foraging organs. If a few prepared sections of its earlier stages of development are at hand they will be especially instructive.

The record of this study may well consist in a brief account of the life history of the fern, with drawings and diagrams to illustrate it.

Study I8. The general structure of the fern sporophyte.

Materials needed: A growing fern plant; fresh or alcoholic rhizomes of Pteris, and also macerated specimens of same for use in tracing vessels; prepared slides of leaf and root tips; mounted sections and dissociation preparations of vascular bundle elements.

Study the distribution of the vascular system.

Study the leaf: The epidermis in a freshly stripped piece, mounted in alcohol; the air spaces, internal tissues and distribution of vessels in cross sectic ns.

Study the root tips, the arrangement of rhizoids, the location of root cap and vascular bundles.

Study the vascular bundle structure, sufficie tly a least to locate and identify the principal supporting and conducting tissue elements.

The record of this study may consist in notes and drawings of things observed.

Study I9. A comparison of developmental features of other pteridophytes.

Materials needed: Fresh stems of the scouring rush (Equisetum hyemale); fresh fruiting cones of the common horsetail (E. arvense) these may be had in fine condition if 
dug up in winter and placed under a bell jar a week in advance of need): fruiting spikes of Selaginella, andalso if possible, preserved specimens illustrating the development of the male and female gametophytes.

Study the Equisetum stems in sections (which may be cut with a sharp knife, though very damaging to its edge), locating the chief structural features mentioned in preceding pages. Especially note the distribution of the respiratory parenchyma (of bright green color in fresh specimens) and the breathing pores leading thereto; these latter will be better seen if the epidermis be stripped from one of the "valleys," mounted flat, and studied.

Study the fruiting spike of equisetum, its constituent scales, the sporangia these bear, and the spores. Mount some spores uncovered to watch through the microscope their hygroscopic activity; they will respond instantly to the moisture of the breath, let fall upon them while under observation.

Study the fruiting spikes and the macrospores and microspores of Selaginella, and if there be material so available, study also the male and female gametophytes that develop from these spores.

The record of this study may consist in notes and drawings of the things observed.

SPERMATOPHYTES, SEED PLANTS, OR FLOWERING PLANTS.

These are the dominant land plants of our own time. Bryophytes and Pteridophytes we find by searching, but spermatophytes fill the landscape.

Like the preceding group they present utmost diversity in form andappearance and only agree in a few fundamentals of life history. The gametophyte phase is so reduced and difficult of study that we will suit our convenience by 
beginning with the sporophyte phase-the leafy plant, which, as with the preceding group, is the phase we ordinarily see.

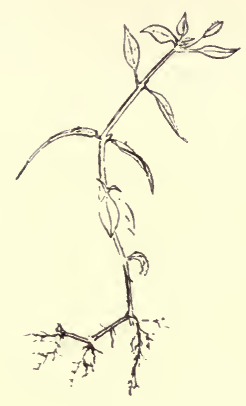

FIg. 89. Chickweed.

Any familiar herb, like the chickweed (fig. 89), will show how much the sporophytes of the two groups have in common. The ordinary differentiation of the plant body into root stem and leaf is already very familiar. The plant body is covered over with epidermis, some of whose cells develop in the air into plant hairs and in the soil into rhizoids. If we strip a bit of epidermis from a leaf we find its constituent cells, and the guard cells of the breathing pores to be of the same type as in the fern leaf. If we section the leaf (fig. 90), we find the same tissues in the same relations. There are stomates in both layers of epidermis and there are intercommunicating air spaces throughout the interior of the leaf and here and there are minute vascular bundles in the midst of the parenchyma.

In a cross section of the stem there appear some differences of importance.

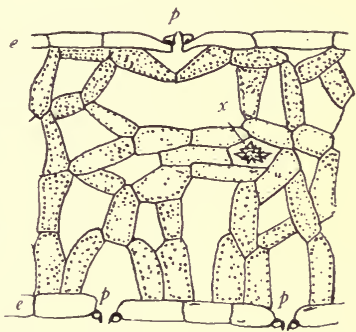

Fig. 90. Cross-section of a bit of chickweed leaf, $p, p, p$, pores; $e$, epidermis; $x$, crystal (probably of oxalate of lime). Epidermis covers it (fig. $9 \mathrm{I} a$ ) and parenchyma fills most of the interior as before, but the arrangement of the vascular bundles is very different. There is hardly any development of supporting tissue outside of the vascular 
bundles, and even these are very weak in a prostrate herb like the chickweed. The bundles are arranged in a ring around a central core of parenchyma (the
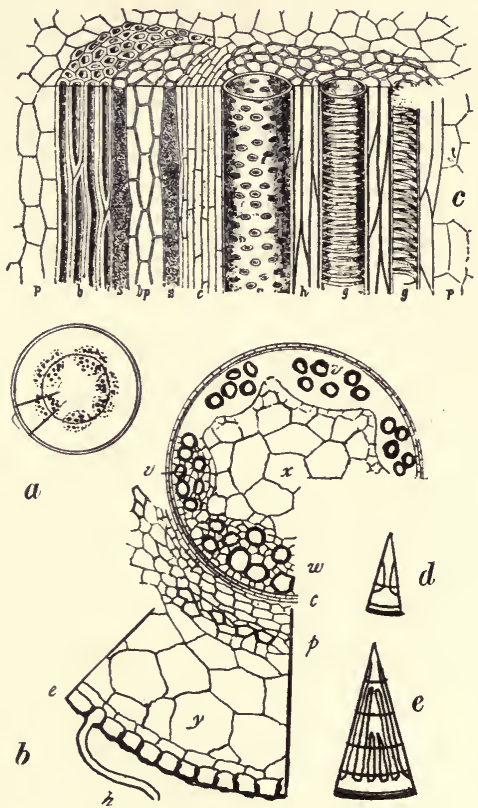

Fig. 91. Diagrams of stem sections (exogens). a, cross-section of chickweed stem, the inner circle representing the cambium ring, the two radial lines indicating the portion enlarged in $b$; $e$, epidermis; $h$, hair; $c$, cambium separating between $p$, phloem and $w$, woody portions of bundles; $v$, spiral vessels in the woody portion; $x$, pith and $y$, common parenchyma of bark; $c$, segment of a sunflower stem; $p$, parenchyma; $b$, bast fibres; $s$, sieve tube; $c$, cambium; $g$, vessels, pitted and spiral; $h$, wood fibres, (from Wettstein); $\boldsymbol{d}$, one year, and $\boldsymbol{e}$, four year old woody stems, illustrating the increase of vascular bundles. 
pith or medulla), and each is divided by a thin sheet of growing tissue known as cambium. Cambium divides the stem as a whole into outer and inner portions that are familiar to every one who has peeled a rod or made a willow whistle; we know them as bark and wood. The cambium divides each bundle into an inner woody portion (xylem), containing the open vessels for conduction of water, and an outer bast portion (phloem). containing the sieve tubes, etc. There is scarcely any development of bast fibres in the chickweed, and the water conducting elements of the xylem are spiral vessels.

Cambium.- The most important new feature is this inconspicuous growth layer that divides the bundles. It forms a sheath of thin cells that are rich in protoplasm and that have retained their capacity for further division. Cell increase in the fern stem may occur only at the stem apex. When the stem is once formed and when its constituent cells are fully grown, no further increase in its diameter is possible, but the cambium makes possible a continuance of stem growth. Hence the plants that dominate the earth by reason of their size, the trees of the forest, all have this means of perennial growth.

The cambium adds new cells during each growing season to each of the layers it separates, and the growth of these cells stretches the bark when it is young, and when it is old and inelastic, cracks it and furrows it, or causes it to shed in strips.

Wood.-Increase of size of aerial plant body necessitates increase of supporting structures, for the long reach of a stem into a position favorable for getting sunlight would be of no use unless the position could be maintained. Rigidity of stem in plants having the manner of growth we have just been describing is secured by further derelopment of the woody elements of the vascular bundles, by increase in 
number of the bundles and by their consolidation in a ring of wood underlying the cambium. This will be understood from a study of the stem of any woody plant, such as the box elder (fig. 92). The cambium is more abundant, and

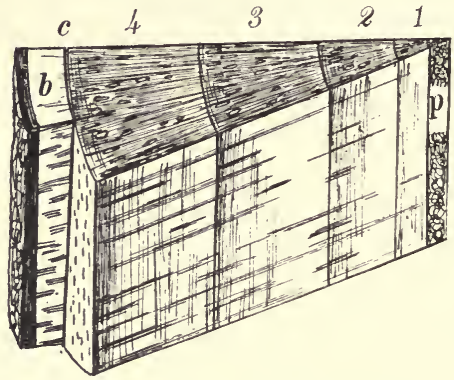

Fig. 92. Segment of a four year old woody stem, with bark in part removed $(b) ; c$, cambium; $p$, pith; $1,2,3,4$, wood of the four years growth; vertical surface shows wood fibres overlaid by transverse fibres of the medullary rays.

clearly delimits bark and wood. In the bark there is a copious development of bast fibres, that protect underlying protoplasmic parts (fig. 9r $\mathrm{c}$ ). The vessels of the wood are pitted vessels, and not spiral; and, most striking of all, the bundles are very numerous and very closely crowded together. Obviously such weak and isolated vessels as those of the chickweed, while capable of conducting water, are of little use for support.

The pitted vessels constitute the frame work around which is built the woody skeleton of the box elder tree. Wood, as we ordinarily know it, is composed of these vessels and of wood fibres, and wood fibres are made out of the parenchyma cells which we have hitherto seen forming the packing around and between the bundles. The cells lying between the vessels become elongated, lignified in their walls 
and consolidated by their over-lapping pointed ends and form the longitudinal wood fibres. The cells lying between the bundles become transversely elongated, and form the wood fibres of the medullary rays. Thus, there is formed beneath the cambium a ring of wood, that owes its solidity to the close adhesion of cells having lignified walls, and the beauty of its grain to the arrangement of the cell groups.

The annual rings of wood are formed by the development of vessels of larger diameter in the "spring wood" formed during the early part of the growing season. As new layers of wood are added outside, those first formed become changed from "sap wood" into "heart wood," losing their capacity for conducting water. That the heart wood is not essential to the life of the tree, every hollow tree testifies. That the outer layers are essential is shown by the fatality of "girdling" the trunks by cutting a groove through the sapwood and bark.

Monocotyledons.-There is, however, one great group of seed plants, known as the Monocotyledons, that has not the mode of growth above described. Structurally these are much more like the pteridophytes. They have no cambium ring, and no axis of solid wood, but their bundles are scattered through a soft internal parenchyma, and the chief support of the stem is a stiffened cortex beneath the epidermis, comparable to the layer similarly situated in the rhizome of the fern (fig. 93).

These are the grasses and sedges, the lilies and irises, and most other plants that have parallel veined leaves. These dominate considerable portions of the earth's surface, in prairies, steppes, savannas, marshes, and other unforested regions. In temperate climes the aerial stems of all of them are of annual growth, and the perenniel roots and 
under ground stems of the dominant species are not injured by fires that would hinder forest growth.

From this very brief sketch of

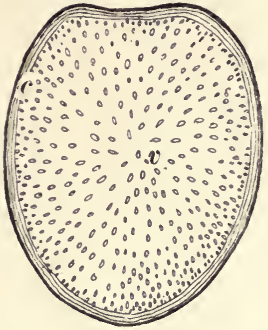

FIG. 93. Cross section of corn stalk, $c$, cortical layer; $v$, vessels scattered through the parenchyma. the seed-plant sporophyte we may learn that the parts of the plant body are much the same as were found in pteridophytes-only modified in form and arrangement. Rhizoids and chlorophyl bearing cells are the foraging agents still, and vascular bundles, the means of communication between them.

Development.-When we turn to the developmental side the differences are much greater. Flowers appear in the spermatophytes, and-what is vastly more important-seeds, also. We have already seen (Chapter I) something of the variety of floral structure. We know that the purpose of the flower is to produce seed. Let us now study the manner in which seeds are developed.

Figure 94 shows at $a$ the flower of the chickweed with its three stigma-tips alternating with three small stamens, and with five small white bifurcated petals wholly encompassed by a like number of big green sepals. At $b$ in the figure, surrounded by the persistent sepals and surmounted by the stigmas, is shown the maturing fruit, within which the seeds are contained.

The differences between flowers of this type and the pteridophyte in reproductive methods are so great, that we will find it easier to study first the conditions found in a more primitive seed plant, and afterward, those found in a highly developed flower. So let us examine first the pine, and after that the violet. 
Reproduction in the pine.- In the pine we again meet with two kinds of spores, microspores and macrospores. With the microspores of the seed plants we have already become acquainted

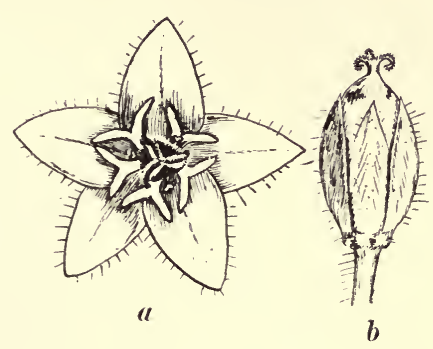

FIG. 94. Chickweed. $a$, flower; $b$, fruit. under their older name of pollen grains, and with the microsporangia, as the pollen sacs of the anthers. The latter are developed in pairs in the lateral margins of scales of the well known little cones, which shower down yellow pollen in early spring. Such cones are remotely comparable to the fruiting spikes of Selaginella and Equisetum.

The microspore or pollen grain develops into a male prothallium or gametophyte of extremely small size, consisting when grown of only a fe'w cells, one of which on division gives rise to two sperm nuclii. These lack locomotor organs and do not swim abroad when mature; instead, the microspore (or the prothallium developed from it) is transported bodily by the wind to the vicinity of the egg cells.

The macrospores (fig. 95) are developed in similar fruiting spikes, which when mature are the familiar cones of the pines (and other conifers). There are but two sporangia upon the base of each scale and in these the macrospores are developed singly. As in selaginella they are of large size, owing to the food stored in them. They differ from 
those of selaginella most markedly in not being discharged at maturity. They remain permanently inclosed in the macrosporangium (usually known in botany by its older name mucellus), and invested closely by a thin layer of integument, the whole structure, being known in botany as the ovule.

The investing integument does not close completely over the macrosporangium, but leaves a little hole at one end, the micropyle. Hither the microspore is brought'by the wind

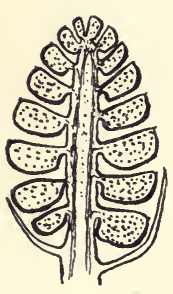

a
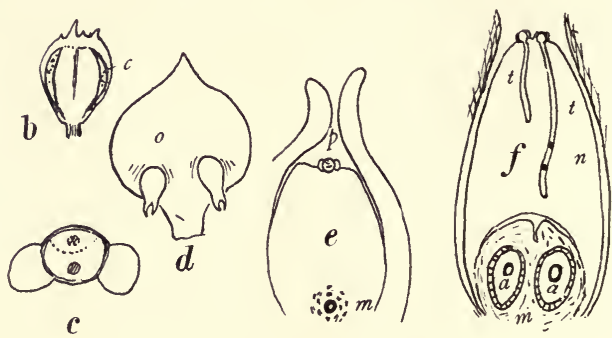

Frg. 95. Diagrams of spore development in the pine, a, longitudinal section of the staminate small cone $b$, one of the scales from the same, showing at $c$, the pollen cavities (microsporangia); $c$, the single pollen grain, divided into two cells, and bearing a pair of thin flat winged processes at its sides; $\boldsymbol{d}$, a scale from the pistillate cone, bearing a pair of macrosporangia: $(o)$ ovules; $e$, a single ovule, in section, with a pollen grain lying inside the pollen cavity at the top; $m$, macrospore: $f$, macrosporangium penetrated by two pollen tubes $(t, t)$; two sperm nuclei $(n)$ shown in one of them; the macrospore $(m)$ is developed into the female prothallium, bearing archegonia $(a, a)$ each containing an egg .

previous to fertilization. The macrospore remains thus in captivity. Within it develops a mass of cells which is the female prothallium, in the apex of which adjacent to the micropyle several reduced archegonia are developed, and in each of these an egg nucleus is produced. The microspore, previously lodged at the micropyle, develops a rhizoid-like process (the pollen tube) from the antheridial cell, and this penetrates to the egg and liberates 
its sperm nuclei through its ruptured tip. One of these unites with the egg cell, effecting fertilization. Then the embryo sporophyte of the new generation begins to develop, also in captivity, within the wall of the old macrospore, and at the expense of the prothallial tissue which now fills it. As with the pteridophytes studied, but one embryo is developed; if several eggs are fertilized, one in developing gains the ascendency and crowds the others out. The form of the embryo is indicated in (fig. $96 h$ ).
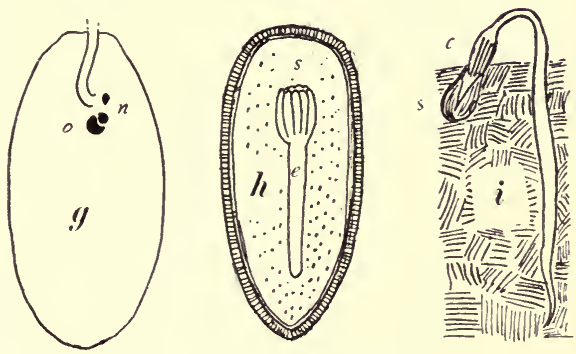

FIG. 96. Diagrams of development of the seed in the pine. $g$, a single archegonium, penetrated by the pollen tube $(t)$ from which the two sperm nuclei are liberated, one of them is uniting with the egg nucleus $(o) ; h$, the seed; $e$, the embryo, which develops from the fertilized egg; $s$, endosperm (remains of the gametophyte): $t$, the germinating seed; the sporophyte slipping off the old seed coat $(s)$ after having consumed the endosperm that was contained in it.

The seed.-After developing a little way the embryo enters upon a resting stage, the integument hardens about it into a seed coat, and the whole becomes a seed, and falls away to resume its development when it finds suitable conditions somewhere in the soil. The seed is thus a composite structure consisting of three parts of very different nature. The seed coat and macrosporangium wall represent and are,"a part of the old sporophyte; the remains of the prothallial tissue within (known as endosperm) is gametophyte, and 
the embryo itself is the new sporophyte. If this seem confusing, the way to make it clear is to inquire what is the
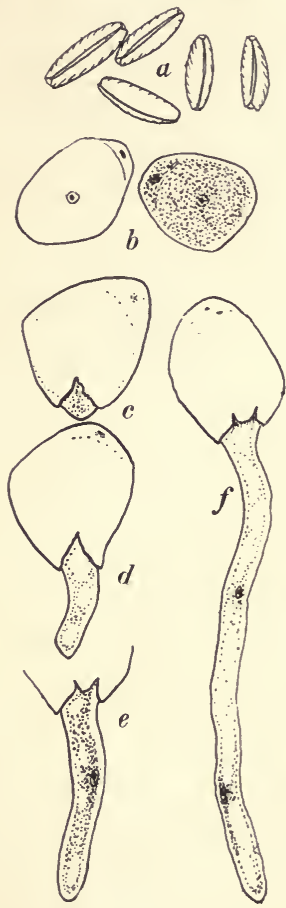

FIG. 97. The microspores of the violet and their development. $a$, dry polien; $b$, the same wet with $15 \%$ sugar solution; $c, d$, $e, f$, development of the pollen tube in sugar solution; $c$, after 15 minutes; $e$, after an hour; one sperm nucleus shows in $f$. origin of each part. To learn what is gametophyte, learn what has developed from the spore.

The pine and the violet represent the two chief groups of seed plants, whose most salient characters are found in flower and fruit. The gymnosperms (gymnos, naked and sperma seed) bear the orules, and later the seeds, uncovered upon the surface of the scales. The angiosperms (angios, a closed vessel, and sperma seed) have the ovules (or the seeds) included within the closed pistil.

Reproduction in the violet. Many signs of specialization are evident in such fowers as violets. Their general structure has already been discussed and illustrated in Chapter I. $\mathrm{We}$ are here concerned only with the phenomena that lead directly to seed development.

The microspore (pollen) develops a male gametophyte of but two cells, and one of these is very small (fig. $97 b$ ); but from it are derived the two sperm nuclei. The other develops when it is carried to the moist stigmatic surface of the violet pistil, 
into a very long pollen tube (fig. 97). This grows down the style and enters the micropyle of the ovule and liberates the two sperm nuclei (that have escaped from their own cell wall) near the egg nucleus.
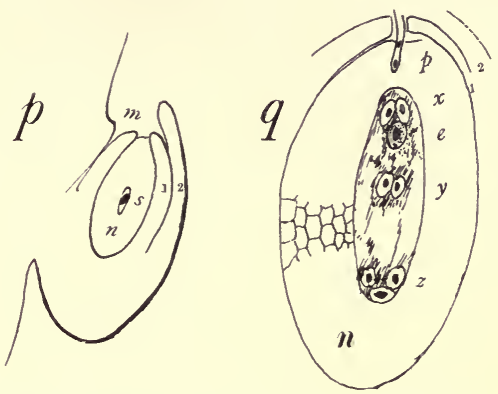

Fig. 98. Diagrams of development of the female gametophyte in the violet. $\boldsymbol{D}$, a young ovile: $\boldsymbol{I}$ and 2 , inner and outer integuments; $m$, micropyle; $n$, macrosporangium (nucellus); $s$, macrospore; $q$, the female gametophyte at the time of fertilization; $p$, pollen tube entering; $e$, egg nucleus; $x$, two synergid nuclei; $y$, two endosperm nuclei; $z$, three antipodal nuclei. Other lettering as in $p$

The macrospore, which is situated (as in the pine) within the nucellus, here surrounded by two investing integuments, derelops by three successive divisions of its nucleus into an aggregation of eight nuclei within a distended cell wall, the whole constituting the so-called embryo sac. The position and names of these are indicated in the accompanying diagram, (fig. $98 q$ ). One of the eight is the egg nucleus, and with it one of the sperm nuclei from the entering pollen tube fuses. There is no archegonial wall. The remaining cells represent the body of the female prothallium, so far as developed at time of fertilization. Among these occur two puzzling phenomena, which render identity of parts somewhat un- 
certain: the antipodal nuclei disintegrate and the endosperm nuclei fuse (and sometimes the second sperm nucleus fuses with them), before undergoing further division to form the endosperm.

Subsequent development is wholly comparable with that of the pine already discussed, save that in many of the higher spermatophytes the endosperm is wholly absorbed, and the matured seeds contain only the embryo, and are without endosperm.

\section{Study 20. Spermatophyte structure.}

Materials needed: Stems and leaves of chickweed or other herbaceous plant. Miscellaneous wood specimens, green and finished. Sections and slide mounts showing vascular bundle elements. Stems and leaves of monocotyledons.

No specific program need be given for a single study of a subject that offers so vast an array of possible materials. Suffice it to suggest that the student use whatever materials are at hand as a means of identifying in the higher plants the tissues already seen in the pteridophytes, and to discover the new features of tissue arrangement presented by exogenous and endogenous growth.

The record of this study may consist in a few diagrams and a complete list of the materials studied and statement of what they illustrate.

\section{Study 2I. Spermatophyte development.}

Materials needed: Flowers and flower buds, from which to obtain ripe pollen; sections of female gametophytes; seeds with and without endosperm.

Study the pollen grains wet, dry, and germinating in drop cultures.

Study the enfolding integuments in sections of young ovules (fig. $98 p$ ); study the mature gametophyte in older 


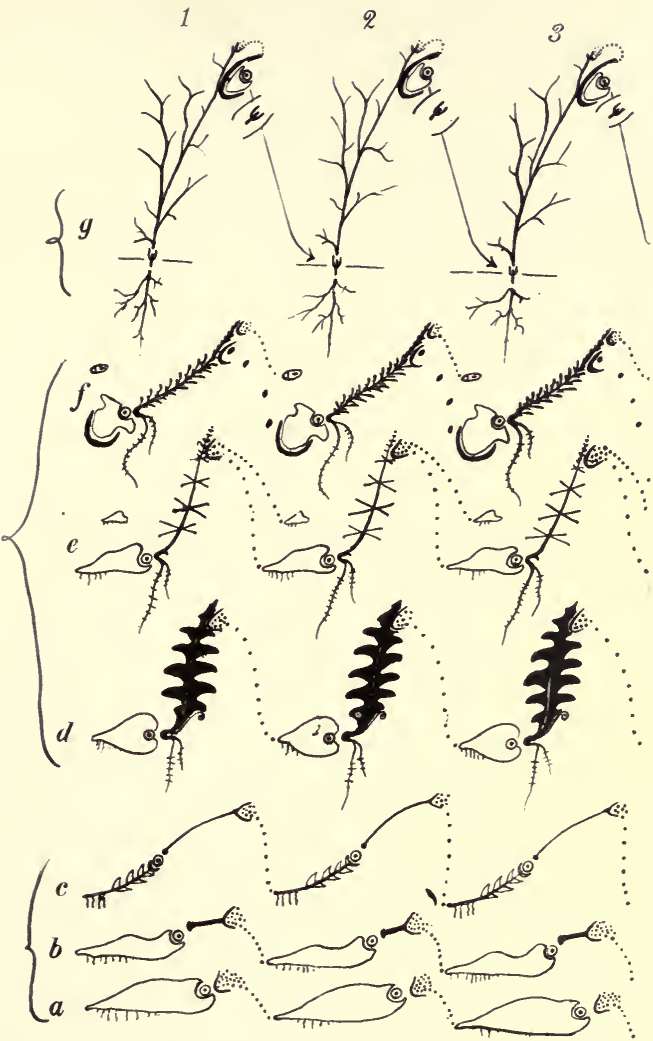

Frg. 99. Diagram, illustrating alternation of generations in the higher green plants. The horizontal lines of figures represent $(I, 2,3)$, successive generations; gametophyte is white and sporophyte is solid black; the egg is represented by circle with central dot, the spores are represented by black dots, of two sizes when differentiated. The types represented are: $a$, a simple liverwort, (Riccia); $b$, a more specialized liverwort, (Conocephalus) : $c$, a moss: $d$, a fern; $e$, a horsetail; $f$, Selaginella and, $g$, a seed plant (seed in ( )-marks, above). 
sections, and also the developing embryo, and diagram. Germinate the seeds and trace the disappearance of the endosperm.

The record of this study may consist in notes on and diagrams of the principal things observed.

The gametophyte phase of the higher seed plant is well nigh suppressed:* why, we cannot say. And sex characters, which primarily must belong to the sexual phase, are gradually extended to the sporophyte: first to the spores alone, then to the sporangia and flower scales and finally, in unisexual (dioecious) species, to the whole organism.

The great advance made by the spermatophytes over the lower groups is in their manner of reproduction. Bryophytes and Pteridophytes, though terrestrial, have retained an aquatic mode of fertilization. Their free swimming sperms are subject to vicissitudes of drouth which the seed plants have largely obviated. The weak point in the life history of the fern is in the development of delicate unprotected prothallia from microscopic spores. The seed plant sets its offspring adrift only when grown to considerable size and supplied with a store of food material for further growth. What chance of a living have fern spores in competition with seeds? A main reason for the dominance of the seed plants upon the earth in our own time therefore lies in the better start in life they furnish to their offspring.

\section{THE ANIMAL SERIES.}

We will choose among the higher animals a series of forms ending with the vertebrates, and will illustrate it with three types:- hydra, the earthworm and salamander, with some supplemental illustrations drawn from the vertebrate group.

*The accompaning diagram (fig. 99) is offered as an aid to the beginning student who may still find difficulty in identifying its remains. 
THE HYDRA.

This is a transparent aquatic animal about half an inch long that lives attached to stems and leaves in ponds and sluggish streams. It has a slender tubular body, provided with a disc-like foot at its basal end for attachment, and a circlet of tentacles surrounding a mouth at the other end. Both body and tentacles are very contractile, and become suddenly drawn down into a heap upon disturbance. On this account, although it is immensely larger than the animals studied hitherto, it is difficult to see while collecting in the field. If stems on which it is sought be placed in a shallow white dish of water, or in a glass vessel to be viewed toward the light, it may be seen when it extends itself again after a few minutes, undisturbed. It is likely to be present on loose trash lying in any pond or slow stream, and a good way to find it is to bring in a pailful of this trash and distribute it in aquarium jars to stand over night. If present in

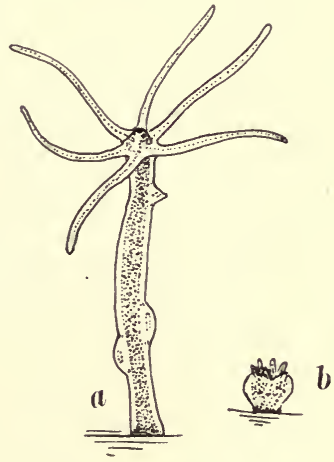

FIG. 100. A hydra. $a$, extended; $b$, contracted; spermary on the body above; 0 , ovaries below. numbers many of the hydras will move out upon the glass on the lighted side of the jar where they may be readily seen on looking toward the light. Too much trash in a single jar will obscure the view, of course. Specimens may be transferred to a watchglass or slide for study by scraping them loose from their support, and taking them up in a pipette, or better in a tube attached to a hand bulb.

In the aquarium hydras may be seen in any position, 
attached to the glass, or to the surface film of the water, as well as to the stems; their bodies extended up or down or sidewise; their tentacles extended radially around the mouth. If fully extended, the tips of the tentacles hang vertically in the water and are excessively slender. These are hydra's fishing lines, set for passing water fleas, minute worms, etc., which they paralyze by contact; contracted, they are its arms, and are used for pushing the paralyzed prey into its mouth. Feeding is so slow a process, however, that if one be so fortunate as to see the prey captured he is likely to have to watch some time to see it swallowed. Often the body is seen to be roundly distended in places by previously ingested food in process of digestion.

The hydra moves from place to place by turning end over end. It bends over in the desired direction, rests its tentacles on its support, lifts its foot and swings it over forward, attaches it and rises again. If the hydra be seen standing on its tentacles with its foot in the air, it is in the midst of one of these turns, which are made, not like hand springs, but with very great slowness. By this means it migrates to the lighted side of the jar. It also moves, but more slowly, by alternate contractions and expansions of its foot: a sort of creeping progression.

When a number of hydras are present in an aquarium, some of them are likely to show buds growing out from the side of the body. If several well grown buds be present on a single individual they make it appear somewhat more "hydra headed," since on the divided body there are then, if not heads, at least divergent tentacled tips. The buds, however, separate before they attain the full size of the parent. Their development may be traced in stages found in different individuals. First, there is an outpushing of the body wall in a little rounded knob; this elongates into tubular form; there it develops a whorl of tentacles that 
first appear as a circle of rounded knobs about the free end, and later elongate. A mouth breaks through at the distal end of the body, and finally, the base constricts itself off, closing communication with the internal food cavity of the parent, and develops a foot for independent attachment. Then the little hydra drifts away to set up in business on its own account. This is obviously an asexual process of reproduction.

The sexual process is not so often observable. The sexual organs, when present appear as minute transparent swellings on the surface of the body; conical and situated above the middle, if spermaries; low and broadly domeshaped and situated nearer the foot, if ovaries.

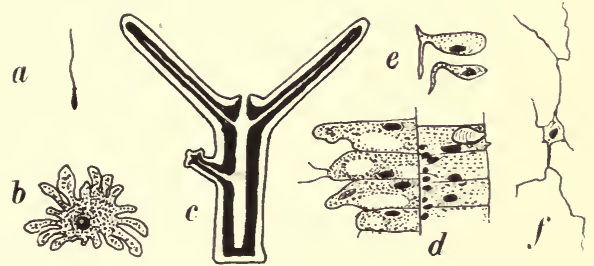

FIG. 101. Hydra. $a$, a sperm cell; $b$, an egg cell; $c$, diagram of a longitudinal section of the body, bearing a lateral bud, ectoderm white, endoderm black; $d$, a bit of the body wall showing tissue layers; $e$, dissociated cells with basal contractile processes; $f$, a rudimental nerve cell.

If a hydra be transferred to a slide or watchglass and examined a little magnified, the two constituent layers of its body wall may readily be made out; a transparent outer ectoderm, and a darker inner endoderm. The endoderm lines the food cavity, which is merely a blind sac having only one opening, the mouth, through which food is taken in and its indigestible residue is thrown out. The tentacles being formed by outgrowth of both layers are hollow, each is a similar smaller blind sac opening into the major cavity. 
This very simple plan of structure is indicated in the accompanying diagram (fig. IOI).

The body of the hydra is too large for the staisfactory study of the form and relations of its constituent cells in the living animal. The two cell layers are easily made out, and, in the slender and transparent tip of an extended tentacle some large nettling cells (nematocytes) are readily observable. These contain transparent ovoid sacs, (nematocysts) (fig. I02) occupying slight elevations of the ectoderm of the tentacle. Inside each nematocyst is a closely coiled stinging filament, which when discharged in contact with a waterflea, paralyzes it and prevents its escape. Close beside each nenatocyst is an erect minute sensory point which when touched by the water-flea, communicates the stimulus that causes the discharge of the filament. This discharge may be caused artificially, while one is watching, if some irritating fluid, like dilute acetic acid, be run under the coverglass that confines the hydra upon a slide. By keeping one's eye at the microscope while the acid is diffusing under the cover until it comes in contact, some of the nematocysts will be seen to be thrown out bodily, while others will throw out only their filaments, which will then hang like long flexuous transparent hairs to the side of the tentacle.

The cellular structure of the hydra is made out by the study of thin sections and of macerated preparations of dissociated cells. In a cross section of the body, ectoderm and endoderm stand out with diagrammatic clearness. Their constituent cells are seen to be considerably differentiated, those of the endoderm being rather larger, and variously shaped at their free internal ends, where some bear flagella, and others pseudopodia. Digestion in the hydra combines the methods of the lower animals hitherto studied, in which the food is engulfed by the protoplasm and digested within 
the cell, with that of the higher animals, in which the food is digested in a stomach through the action of fluids poured out by the cells and afterwards absorbed. Individual cells of the endoderm of the hydra digest minute diatoms, etc., after the former method; the endoderm collectively digests water-fleas and the larger kinds of prey after the latter method.

The ectoderm is a composite layer, especially in the upper part of the body, consisting of larger cells that form the surface layer, and taper down to their inner ends, and smaller interstitial cells that fill the spaces between the bases of larger cells, but do not reach to the outside. These interstitial cells grow up to the surface and some of them develop there into nematocytes by a remarkable differentiation of the cytoplasm of their upper ends. It is probable that after the discharge of the nematocysts, other of the interstitial cells act as replacement cells, growing up and producing new ones.

- There is a significant development of the base of the ectoderm cells that can only be made out well if the tissues be dissociated so that the cells may be viewed singly. In such a preparation, many of the ectodermal cells are seen to have long slender processes extending lengthwise of the body beneath the ectodermal layer in physical contact with many of its cells (fig. IоI e). It is believed that these processes are especially contractile, and that they account for the ability of the body as a whole to shorten so rapidly when disturbed. These foreshadow the muscles of the higher animals. Other cells of the form shown in figure I0I are also present among these processes and appear to be primitive nerve cells, serving to communicate the stimuli and to secure simultaneous contraction of all the cell processes of the whole layer, securing concerted and coordinated action. 
The hydra is a large and fairly well integrated body of cells, among which division of labor is very obvious. Clearly the digestion and absorption of food must fall to the endoderm cells, which alone come into contact with it. Likewise, the protection of the body and responses to stimuli from without must fall to the ectoderm cells. The function of the nettling cells is much more specialized.

Both spermaries and ovaries develop in the ectoderm, each as a little mass of cells covered by a thin, transparent ectodermal film.

In the spermary, each included cell develops a motile sperm which when mature may be seen actively swimming about in the transparent conical tip of the spermary of the living hydra. Of the cell mass which is to be the ovary, one cell gains the ascendency and grows at the expense of the others, absorbing their contents and storing up reserve food materials. This cell which when mature is the egg, has the singular amœboid appearance shown in figure IOI $\mathrm{b}$.

At maturity the top of the ovary

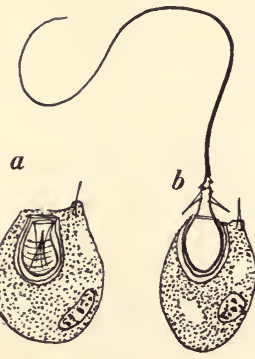

Fig. 102. Nettling cells of the hydra. $a$, charged; $b$, dis-
charged. bursts, making a passage for the ingress of the sperms, and, in fertilization, one of these fuses with the egg cell.

Study 23. Observations on the structure of the hydra.

Materials needed: Living hydras of any species; budding individuals, and also others bearing the sex organs. Mounted cross sections of the body, and dissociation preparations of ectoderm cells.

Study these things in the order mentioned, using the foregoing account of the hydra as a basis of observations. 
The record of the work done may consist in the following figures:

I. Positions of hydra at rest, and form of body extended and contracted.

2. Buds in various stages of development.

3. Sexual organs, if found, and the sex cells if these can be made out.

4. Nematocysts in the tentacle, and the same discharged.

5. Cross section of the body, drawn from section.

6. Diagram of a longitudinal section of body.

THE EARTHWORM.*

To every one who turns the soil in flower bed or garden this animal is very familiar. It assists in tillage by perforating the soil with its burrows, and by carrying subsoil up from below in the "castings" which it strews around the mouth of its burrow, and mixes with the humus. Being nocturnal and blind, its activities may be easily observed with a lantern on a wet night, when it will be found partly extended from its burrow, reaching about over the soil from its doorway, ever ready to make a quick retreat if disturbed. If seized quickly and held for a moment until it releases its hold on the walls of its burrow, it may then be pulled out of it; this is the way to get specimens for study.

External features.-The body of the worm is segmented: i. e., it consists of a series of transverse rings or segments (somites). There is no head and no tail, but there are definite front and hind ends. At the former is the mouth, overhung by a muscular flap or fold, the prostomium, which, in absence of arms or tentacles, assists in getting food into the mouth; at the other end is the anus; and the alimentary canal extends straight through the middle of the body from end to end.

*The following outlines apply especially to the large Lumbricus herculeus, which, on account of its size, is a favorable form for dissection. 
The ventral surface of the worm is somewhat flattened, and at either side of it are two double rows of minute setæ with their tips protruding through the skin. They are short and stiff, and not at all conspicuous-indeed, are easier felt than seen, as one may demonstrate by drawing a worm backward between the thumb and finger. It is by means of these that the worm maintains its footing in crawling, or its hold within its burrow.

The only conspicuous external feature is the broad girdle or" clitellum that surrounds the body between the thirtieth and fortieth segments. Although inconspicuous, the openings of the ducts from the reproductive organs may be seen at the sides of the ventral surface of segments fourteen and fifteen, between the rows of setæ.

Internal Features. - The body of the hydra is tubular in
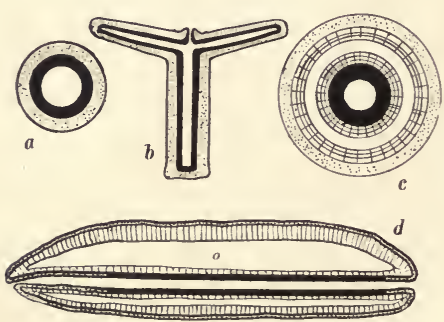

Fig. 103. Diagrams of the structure of hydra and worm. $a$, cross, and $b$, long-sections of hydra; $c$ and $d$, corresponding sections of the worm. The ectoderm is stippled, the endoderm, solid black and the mesoderm of the worm, crosslined; $o$, coelom. plan; that of the worm is compoundtubular - a tube within a tube; the inner tube is the food tube, alimentary canal or enteron; the outer is the body wall; the space between is the body cavity or coelom (see fig. 103).

If a worm be anesthetized with chloroform, and a slit be made through the body wall along the mid-dorsal line, and the cut edges be drawn apart for inspection of the interior, it will at once be seen that the segmentation of the worm extends to the internal organs- 
that segments of the worm are delimited internally by thin transverse membranous partitions or septa, which divide the cœlom into a series of compartments, within which certain structures are serially repeated. At the middle of the body these structures are typically seen. The large enteron occupies the center of the body. A slender vessel of bright red color extends along its dorsal side. This is the dorsal vessel, the central part of a blood vessel system. Its color is due to the contained blood, which it drives forward by evident pulsations of its walls. It is joined in every segment by small lateral paired blood vessels, some of which may be traced to the body wall and some to the walls of the enteron. If the septa be cut for a little way on one side, and the alimentary canal be pushed over to the other side, another smaller longitudinal blood vessel, the sub-intestinal. may be seen extended lengthwise beneath it. In this the flow of the blood is toward the rear. In the serenth to eleventh segments of the body there are large paired strongly contractile vessels, the aortic arches, extending downward each side joining the dorsal vessel to the subintestinal.

Nervous system.- - On the floor of the body carity beneath the sub-intestinal vessel lies the white nerve cord, from which slender branching nerves arise in every segment. In the foremost segment of the body this cord divides into two commissures which pass one on either side of the enteron, and reunite above it in a mass of nervous tissue that is the brain or cerebral ganglion. From the brain arise nerves that pass into the prostomium and into the walis of the enteron.

The food tube or enteron.-This canal is differentiated at its anterior end into a series of organs. Immediately behind the mouth is a muscular pharynx. The circular muscles of tis walls contract it, and the copious radiating fibres that 
extend outward on every side to the body wall, expand it, making it an efficient organ for sucking the food into the mouth. Behind the pharynx, the esophagus extends as a slender passage-way leading to the thin walled and distensible crop, which lies at about the fifteenth segment and this immediately adjoins the thick walled muscular chitin-lined gizzard, which comes nearest to a grinding organ of anything possessed by the worm. The remaining part of the alimentary canal is undifferentiated stomach-intestine. In this the final digestion and absorption of the food occurs. If the alimentary canal be slit open and washed out (it will evert itself in a freshly killed worm by the contraction of the circular muscles of its walls) a sudden change in the color of the lining tissues will be seen at the beginning of the stomach-intestine, the nature of which will be indicated later when development is considered.

Nephridia.-In the colom at either side of the enteron in every typical segment will be seen a delicate whitish organ, at first appearing like a tangle of whitish threads; it is the nephridium, a simple excretory organ, whose principal function is the removal of nitrogen waste from the body. It is a coiled and twisted tube, which opens into the body cavity by a funnel-shaped aperture lined with cilia, and to the outside by an excessively minute pore that is situated near the lower line of setæ. The body of each nephridium lies in one segment, and the funnel aperture and short stalklike beginning of the tube (which perforates the septum low down near the nerve cord) lies in the preceding segment. The relations of the nephridia to the body as a whole, and to the other internal organs, the principal trunks of the circulatory system, the position of the setæ and of the principal muscle bands are indicated in the accompanying diagram of a cross section of the worm (fig. IO4a). The muscle system consists of the broad outer sheet 

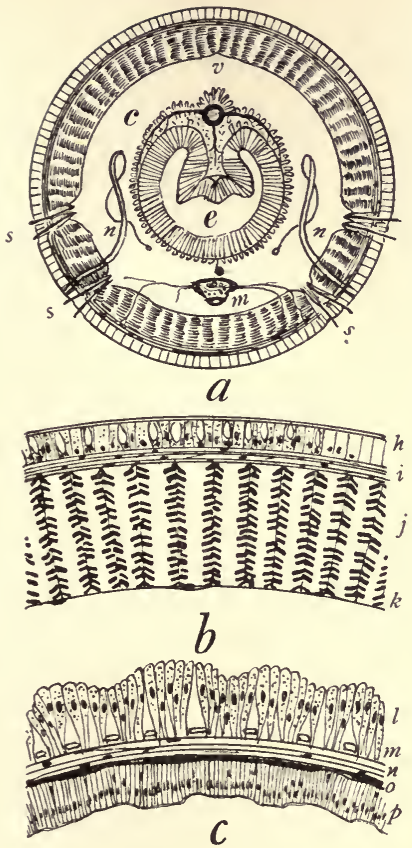

FIG. 104. Diagrams of worm structure. a, cross section of the body; $e$, food tube or enteron; $c$, coelom; $n$, nephridia; $v$, dorsal blood vessels; $m$, ventral nerve cord, with sub intestinal vessel above it and subneural vessel beneath it; $s, s, s, s$ setae. $b$, cross section of the body wall; $h$, hypodermis or epidermis, with covering cuticle; $i$, circular muscle layer; $j$, longitudinal muscle layer; $k$, peritoneum. $c$, cross section of a bit of the wall of the enteron; $l$, chloragogue cells (modified peritoneum); $m$, isolated longitudinal muscle fibres; $n$, circular muscle layer; 0 , blood spaces; $p$, digestive epithelium (endoderm). of circular muscles and the huge tracts of longitudinal fibres shown in this diagram of circular and longitudinal fibres in the walls of the alimentary canal, and of a set of slender fibres attached to the base of each seta.

Organs of reproduction and sex cells.- In the region of the ninth to fifteenth segments of the body, the most conspicuous parts seen are the reproductive organs (fig. I05), which are of remarkable complexity. The largest of these are the sperm receptacles, $\quad t h \mathrm{ree}$ large white paired organs in segments ten to twelve, increasing in size posteriorly, the pair of the twelfth segment extending backward at its free upper end into one or two of the segments behind; these are sep- 
arate only on the sides and above, being united across the median line below the enteron. They contain the spermaries, and usually a large mass of sperm cells in the later stages of development liberated therefrom. If one slit open a vesicle and take from it a drop of its whitish fluid contents and mount this in a drop of normal salt solution for the microscope, he will see abundant sperm cells. They develop in berry-like clusters of ovoid cells, which gradually lengthen out into a flagellum-

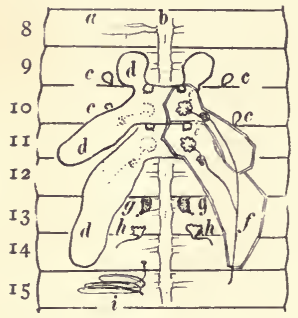

Fig. 105. Diagram of reproductive organs of the earth worm, as viewed from above, the body wall outspread, and the enteron removed. $a$, nerve branches; $b$, nerve cord; $c$, sperm receptacles, $d, d, d$, sperm vesicles; $e, e$, spermaries(two pairs); $f$, sperm duct; $g, g$, ovaries $; h, h$, oviducts; $i$, nephridium. Serial number of segments indicated at left. like tail at their distal ends, and finally break apart and swim free. They pass down the sperm ducts to the external openings already seen on the ventral side of segment fifteen. Their first destination is the sperm receptacles of another worm. These receptacles may be seen on the floor of the body cavity at either side of the foremost sperm vesicle, two pairs of whitish or yellowish sacs, whose outlets are at front and hind margins of segment ten.

The sperms are extruded in copulation, when two worms come together in reversed position, so that the ventral surfaces of segments ten and fifteen are opposed to each other. The sperm cells of each worm are passed out and into the sperm receptacles of the other worm. This is preliminary to fertilization.

The eggs are produced in simple ovaries that lie in the thirteenth segment, attached near the nerve cord to the septum in front. When mature they break away and lie 
free in the body cavity. Later they enter the funnel-shaped end of a short oviduct, that penetrates the septum at the rear of the thirteenth segment, and opens to the exterior on the ventral surface of the fourteenth segment, as before noted.

A preliminary change in the clitellum precedes the discharge of the eggs. The glands, to which the clitellum owes its thickness, secrete a milky fluid within it that loosens it from the body. It breaks its moorings, and is gradually worked forward and finally slipped off over the front end. Its front and rear openings are elastically held close to the sides of the worm, retaining all its fluid content, into which while passing segment fourteen, the eggs are discharged, and while passing segment ten, the sperms, also, stored there previously, derived from another worm. Passing off at the front, the ends close elastically, making a cylindric capsule with pointed ends. Within this fertili-

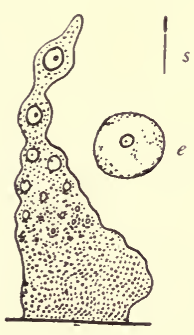

Fig. 106. Ovary and sex cells of the earth worm. $s$, sperm; $e$, egg. zation takes place-cross-fertilization, of necessity, and the eggs pass the early stages of their development in the milky fluid in which they float; it is for the young worms both cradle and food. These capsules are left lying under leaves on damp soil, into which, the little worms on emergence may enter.

Thus the worm, like the hydra and many of the other lower animals is bisexual (hermaphroditic). Cross-fertilization in the hydra, secured by the earlier maturing of the sperm cells than of the eggs, is in the worm secured by the complicated method just described. For the sperm cells are essentially aquatic; in the water they may reach the egg unaided, but in order to fulfill their function in terrestrial animals they require to be transported. 
Early development.-The cellular structure of the earthworm is best understood when considered in the light of its origin. The worm, like all other organisms begins life as a single cell. In a broad sense, two processes make up its physical career; cell multiplication, and cell differentiation. The former necessarily precedes; the latter predominates during the later stages of development, but both take place concurrently throughout life in parts of the body.

The egg (fig. $106 e$ ) when fertilized is potentially a new worm. Whatever characteristics are to appear in the adult are already inherent in it. It is isolated from further parental influence. It develops of itself.
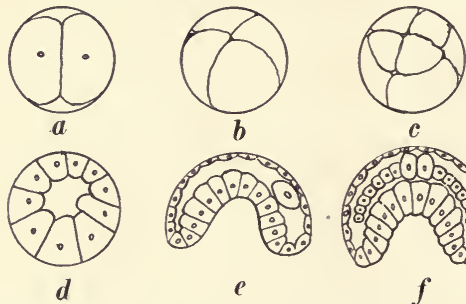

c
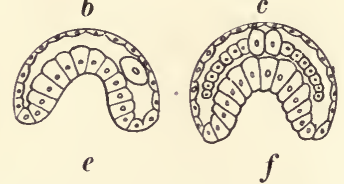

Fig. 107. Diagrams of the development of the earthworm, early $a, b, c, 2$-cell, 4-cell, and 8-cell stages, respectively; $d, e, f$, sections of later stages showing gastrulation. and the formation of the mesoderm. (after Wilson).

There is nothing of the worm structure visible in it; we can see in it only the usual parts of a normal undifferentiated cell-a nucleus, cytoplasm, and inclusions, within the cell wall. Moreover, there is nothing suggestive of a worm in the earlier of the series of remarkable changes through which it passes in development (fig. 107). It divides into two cells, the two divide into four, the four into eight, the eight into sixteen, etc., by a regular and nearly equal division. This process is common to all animals above the protozoans, and is called cleavage or segmentation. It results 
in a hollow sphere of cells (fig. I07 $d$ ) arranged around the now distended wall of the old egg, and called a blastula. Then with the continued increase of cells by fission the wall of the blastula becomes pushed in on one side like a hollow rubber ball indented with the thumb. As the central cavity deepens the walls come closer together, and their convergent edges form a round opening, the blastopore. In this two-

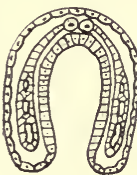

$a$
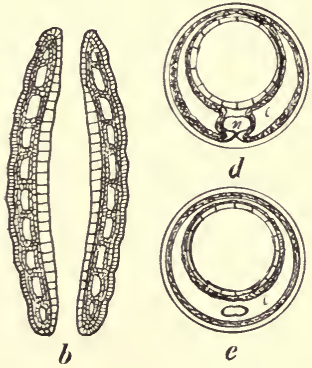

FIG. 108. Diagrams illustrating further development of the earth worm. $a$ and $b$, longitudinal sections of later stages; $c, d$ and $e$, cross sections of the body showing the splitting of the mesoderm and the formation of the ventral nerve cord. The ectoderm is white; the endoderm is crosslined and the mesoderm is hatcheled; $n$, nerve cord.

layered body we may already recognize ectoderm and endoderm, having the same general relations as in the body of the hydra. These are the primary germ layers. Here they are not obviously differentiated at first except by their position. This form of embryonic body is called a gastrula, and the process of invagination by which it is produced is called gastrulation. The cavity which corresponds to the food cavity of the hydra is called the arch-enteron.

A third germ layer, the mesoderm, appears in the worm before gastrulation is completed. It originates as an ingrowth of cells into the narrow segmentation cavity, as indicated in the accompanying diagrams. The diagrams of figure 108 show also how it splits into two layers (joined by rows of cells that later develop into the septa) the 
inner one of which (the splanchnic layer) becomes applied against the endoderm to form the larger part of the wall of the enteron; the other (the somatic layer), applied to the ectoderm, becomes much the greater part of the body wall. The cleft between these layers is the colom. The blastopore in the worm becomes the mouth; the breaking through of the tissues at the opposite end of the body transforms the primitive food sac into an alimentary canal-having the obvious advantage of permitting uninterrupted passage of food,and facilitating also the structural and physiological differentiation of parts along the way.

Thus at a very early stage of its development, the fundamentals of the plan of structure of the earthworm are clearly established.

Later development.-After the completion of the enteron, there occurs along with the rapid elongation of the body, an ingrowth of the ectoderm at both ends (but principally at the front end) which results in the restriction of the endoderm to that part already designated in the adult worm as stomach-intestine. The diagram of figure ro3d indicates roughly the distribution the three germ layers acquire.

The three are unlike in the nature and extent of the differentiation of their cells in the formation of tissues. The embryonic endoderm becomes the adult epithelium-digestive epithelium (and that only) in the worm. The ectoderm differentiates chiefly into two sorts of cells: I) into epidermis, which remains in the original position on the surface of the body and fulfills the primitive function of protection; and 2 ) nerve cells, which are separated off from the ectoderm upon the rentral side as indicated in figure $108 c, d, e$, and pass between the developing masses of mesoderm to lie within the colom and to develop there the nervous tissue (covered, however, by an investment that is of mesodermal origin). 
These nerve cells cease early to divide and develop among themselves intercommunicating processes, and externally, other longer and slenderer unbranched processes which become the nerve fibres, and extend to remote parts of the body. The orig-

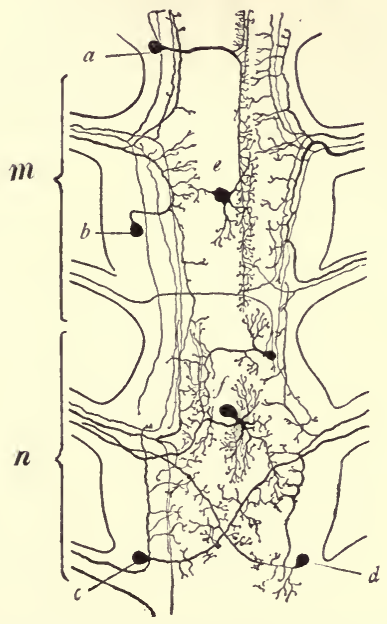

FIg. 109. Diagram of distribution of nerve cells and fibres in the portion of the ventral nerve cord of the worm lying in two segments ( $m$ and $n$ ); cell $a$ sends fibres forward and backward within the cord; $e$ and $f$, are centrally located multipolar cells; all the others are uninipolar; $b$, sends a fibre out on its own side; $c$ and $d$, each sends a fibre out too through a nerve on the opposite side of the cord. inal cell heaps become the ganglia which collectively make up the cord, and each ganglion becomes the centre for the receipt of stimuli and coordination of responses for all the parts of its segment. These cells have no other function than sensory communication between the parts of the body: the accompanying diagram (fig. Iog) shows an arrangement clearly adapted to that office.

Mesoderm we did not find in the hydra, but in the worm it gives rise to the greater part of the adult body. The germ cells remain in the mesoderm unspecialized. The leucocytes, (or white "corpuscles") of the blood, also, retain a singularly primitive amœboid form. They move about freely in the fluids of the cœlom, where they serve the useful function of feeding on bacteria and other foreign substances 
and carrying them out through the tissues of the body wall to the surface and thus, removing them. The nephridia develop from the mesoderm, also, but the greater part of the mesodermal cells develop into muscle fibres. They elongate greatly, and acquire a structure especially fitting

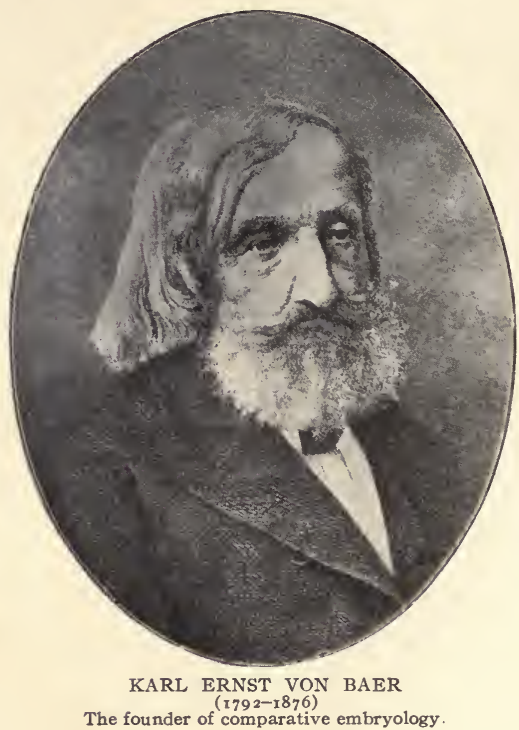

them for contracting in one direction. The tissue that overspreads the walls of the cœlom (formed, as already seen, by the splitting of the mesoderm) is the peritoneum. It consists for the most part of thin flat covering cells, but where these cells overlie the stomach-intestine they become distended with waste assimilation products and take on an 
inverted flask-shaped form, and are then known as chloragogue cells.

These are but the barest outlines of the principal developmental processes. We have not time to enter farther into the field of embryology. We have gone far enough to see that the development of an organism from an egg is a truly wonderful process. We need but go back again and look at the marvelous simplicity of the egg to be convinced of it. Not only do cells differentiate, but cell groups act together like well drilled battalions, cleaving apart here, fusing together there, forming protective coverings or communicating channels, apparently creating out of nothing, a whole set of nutritive and reproductive organs, all in orderly and progressive sequence, producing in the end that orderly disposed cell aggregate, that individual life unit, which we know as an earthworm. Although the forces involved are beyond our ken, the grosser processes are evident, and may be summarized as follows:

I. In respect to development, the general phenomena are: cell multiplication and cell differentiation.

2. The principal changes of form and relations are: segmentation, gastrulation, formation of the mesoderm, splitting of the mesoderm, formation of the anus, origin of the nervous system from the ectoderm, origin of the nephridia and reproductive organs from the mesoderm, ingrowth of the ectoderm to form stomodæum and proctodeum. These are the A, B, C's of embryology.

3. The derivation of the principal tissues from the three germ layers is: From the ectoderm:

epidermis and setæ

lining of stomodæum and proctodeum

the whole nervous system.

From the endoderm: the alimentary epithelium

From the mesoderm: 
muscle and connective tissue blood and blood vessels peritoneum and chloragogue nephridia reproductive organs

Let us now try to get a bird's eye view of the life process in the worm. Both the substance for the building of its body and the energy for its operation are contained in the food. This consists of organic matter (proteins and carbohydrates) and salt solutions mixed with a remarkable large proportion of indigestible materials (sand, clay, etc.), in the earth and rubbish that the worm swallows: also, of the free oxygen absorbed through the skin from the air. The solid food is pulled to pieces by the prostomium, sucked in by the pharynx, passed down the slender esophagus to a temporary storage in the crop and triturated by the gizzard (all purely mechanical treatment), perhaps mixed with some secretions along the way, and then passed on into the stomach-intestine. Here digestion and absorption take place. These are the work of the epithelial cells. But these cells are remote from many parts of the body, and all parts have to be fed, therefore, the food must be transported. Circulatory apparatus exists because the slow process of diffusion is inadequate to the needs of so large and active an organism. Into the blood percolating through the intercellular spaces about the bases of the epithelial cells the dissolved food diffuses, and passes upward through the dorso-intestinal vessels to enter the great dorsal trunk for distribution all over the body to every living cell.

For nutrition is at bottom the work of the cell. One set of cells may attend to the digesting and another to the circulating of the digested material, but every cell must eat for itself. No amount of division of labor can relieve any cell of the necessity of assimilating and excreting. For these 
metabolic processes oxygen is also necessary, and this the worm gets after a very primitive fashion-by direct absorption through the skin. To facilitate this the skin is kept moistened with the watery mucous poured out upon it by numerous secreting cells in the epidermis (fig. 104 $b, h$ ).

The red color of the blood is due to the presence in it of hæmoglobin, a substance that is an excellent agent for the transport of oxygen. It combines loosely with free oxygen, taking it up readily where there is a copious supply, as at the skin, and giving it up easily, where affinities for it are stronger, as in the active and deoxydized tissues. The blood is, therefore, the carrier of both food and oxygen to every cell. It carries the former outward from the stomach wall, the latter inward from the skin.

Income and outgo are not essentially different for any cell in the worm's body from the same process in the protozoan cell as outlined on p. 9r. More food passes through the epithelial cell and more oxygen through the epidermal cell than through the others, as more stores pass through the seaport towns of an importing country than through the interior ones; but the part reserved by each for its own use is used by all in much the same way. The output of matter is therefore, as in the protozoan, mainly water, carbonic acid gas and simple nitrogen compounds.

These waste products must be gotten rid of, and while the cells of the surfaces of the body may excrete them directly to the outside, those of the interior need the circulatory system to carry off their waste. The dispersal of the carbon dioxide and water is as general over the surface of the body as the intake of oxygen. With these doubtless goes a part of the nitrogen waste also. But the nephridia are special agents for disposal of the nitrogen waste. To these the blood goes, laden with the products of proteid dissimilation, and in them these substance are removed and passed to the exterior. 
Another and very peculiar mode of waste disposal occurs in the worm. The cells of the peritoneum, where they cover the parts chiefly concerned with the elaboration of the food, (stomach-intestine and larger blood vessels leading forward therefrom) instead of remaining thin and flat become elevated into high pear-shaped sac-like bodies attached by their slender pointed ends, and filled more or less completely with yellowish-green granules of a substance called chloragogue. It is not quite certain what is the nature of these granules but they are believed to be waste nitrogenous products, and it is certain that they accumulate in the cells until the cells are distended and burst. Then they fall free into the body cavity. A drop of the body fluid taken at random with a pipette from an adult worm is certain to contain numbers of these isolated greenish-yellow granules. They filter posteriorly through the holes in the septa, and finally accumulate in little brownish lumps, intermixed with dislodged setæ, in a few of the hindmost segments. There they are consumed by commensal nematodes. The blood always contains, besides these granules and leucocytes already mentioned, great numbers of bacteria, which the latter feed upon, and occasional parasites.

\section{Study 24. The general structure of the earthworm.}

Materials needed: Live worms of large size; specimens well preserved and hardened: small dissecting trays and tools.

Study the live worm, its movements, its sensibility to touch, the way it uses its setæ. Turn it over and watch it right itself. Note all external features.

In a freshly opened worm make a general survey of the internal organs, guided by the description of the preceding pages in the following order: alimentary canal, circulatory system, nervous system, reproductive organs, excretory organs. Then remove these organs and observe in the body 
wall the distribution of muscle bands and the location of the rows of setæ.

The records of this study may consist in a carefully prepared diagram to show the relation of the organs (except reproductive and excretory) in the median plane of the body. Also, a tabular statement of the parts that are repeated in each segment: a) organs; b) parts of organs.

Study 25. The cellular structure of the earthworm.

Materials needed: Live worms and prepared slides of cross sections.

Examine the blood of the worm (taken with a pipette from the collom of an anesthetized specimen) for leucocytes, bacteria, loose chloragogue granules, etc.

Examine a drop of the fluid from the sperm vesicles for sperm cells in clusters in various stages of development.

Examine a mounted ovary, either fresh or a stained preparation.

Study cross sections of the worm's body and identify all the tissue composing it.

The record for this work may consist in drawings of leucocytes, sperm cells, egg cells in the orary, and a few typical cells from the more important tissues of the body, such as epithelium and hypodermis. Also a tabular statement of the spatial relations of the tissues passing from the outside inward in: a) body wall, and b) enteron wall.

\section{THE SALAMANDER.}

The spotted salamander (Ambystoma tigrinum) is a very common vertebrate, of rather primitive structure. It will serve very well to illustrate that type of animal organization that is found in our own bodies. It is nocturnal and very secretive in its habits, being often seen in cellars and basements, although occasionally dug up in moist garden soil, 
or found by overturning logs, etc., in the woods. It is of elongate form (fig. I ro), with a moist scaleless skin, short legs, that are used more for propulsion than for support, and with a stout laterally flattened tail. It is of greenish-black color, ornamented with irregular and variable yellow spots. Its appearance excites the fears of some superstitious and ignorant people, but it is quite harmless and inoffensive.

Specimens are easiest obtained by taking advantage of their mishaps. They migrate from the fields and woods back toward their native ponds in late fall and early spring, and fall into any hole that lies in their path. In crawling

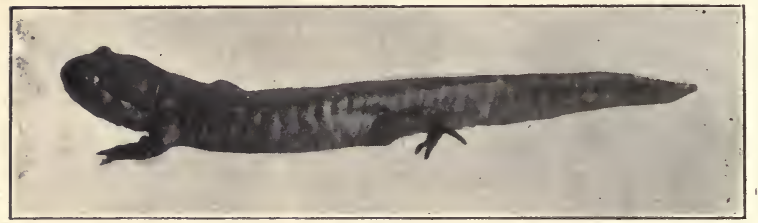

FIG. 110. The spotted salamander, Ambystoma tigrinum.

about the foundations of buildings they get into basements; the walled semicircular pits surrounding old-fashioned basement windows capture many of them. They will fall into any hole that offers, but can crawl out again if the sides be not rather smooth and vertical. Any low barrier interposed between a pond and adjacent hills, such as a long curbing or a railroad track if the rail rest continuously on the ground, will detain them temporarily, where they can be picked up with the aid of a lantern at night. They are easily kept in any cool moist place and need no food in winter.

If a living salamander be examined some of the characters of back boned animals will be readily apparent. First of all, the axis of support (fig. III, spinal column composed of vertebrae) is located in the body wall upon the dorsal side 


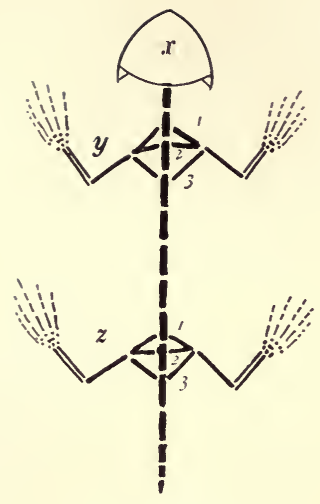

FIG. 111. Diagram of a vertebrate skeleton, $x$, skull; $y$, fore limb; $z$, hind limb; $1,2,3$, in front, clavicle, coracoid, and scapula, composing the shoulder girdle; $1,2,3$, behind, ilium, ischium and pubis, composing the hip girdle.

and in consequence the thick dorsal wall of the body stands in marked contrast with the thin and soft ventral wall. This axis is extended posteriorly into the tail, and expanded anteriorly to form part of the skull, which is the skeleton of the head, and which may readily be felt with the fingers through the soft skin. Two pairs of appendages are quite characteristic of vertebrates. The close correspondence between fore and hind limb will be obvious even in the living specimen. Both have a supporting girdle of bone embedded in the side walls of the body and more or less firmly attached to the axial skeleton.

Upper arm, fore arm, wrist and hand, in the fore limb, correspond to thigh, shank, ankle and foot, respectively, of the hind limb. The divisions between these joints may readily be determined by flexing them between the fingers. Were not this internal jointed skeleton, with its numerous bones united by strong ligaments and moved upon each other by the over lying muscles so familiar to us, its mechanical fitness would be most impressive.

Another small part of the skeleton, located in the rentral wall in the region of the throat, is the hyoid apparatus (fig. I I2). This is mainly cartilaginous, only the part that is stippled in the figure being bony. The anterior fork supports the base of the tongue; the postero-lateral arms curve 
upward about the sides of the neck. These may be felt with

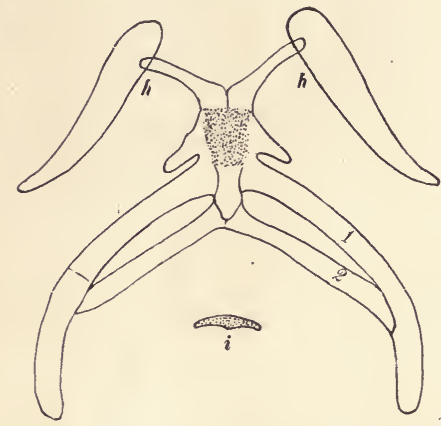

FIG. 112. The branchial skeleton from the throat of the salamander. $h$, the hyoid arch; $I$ and 2 , lateral arms of the first and second branchial arches; $i$, jsolated basal piece corresponding to the missing branchial arches.

the fingers beneath the skin of the throat, or moved about under the skin by moving the tongue with a forceps. This part of the skeleton, though small and weak, is of great historical importance.

These paired cartilaginous arches are landmarks of vertebrate history: to their consideration we shall have occasion to return later.

The eyes of the salamander are prominent and shining and they both wink at once at long intervals. If one of them be touched gently, it will be withdrawn completely into its orbital cavity; thus it gets out of harm's way.

Once in a while the salamander may be seen to gulp down a mouthful of air. It does not inhale; to get air down it has to swallow. The air-swallowing process will often be most clearly seen after the specimen has been handled and put down again. On the under side of the neck the pulse beat may be seen.

On the body there is a mid-dorsal groove extending from the rear of the head to the base of the tail, and there is a series of costal grooves between fore and hind legs traversing the sides of the body vertically. These latter are the external evidence of that segmentation of the body that will be found later in the vertebrae, spinal nerves and ganglia, and 
muscle segments. A number of similar grooves may be seen on the sides of the tail, especially at its base. The surface of the skin is covered with the very minute openings of pores from the large skin glands within it. These pores are visible with a lens. These glands pour out the secretion which keeps the skin moist and enables the salamander to get its oxygen, as the worm does, in a large part by direct absorption. It depends far less on its lungs for air than do the higher vertebrates. Some vestiges of its early aquatic life are preserved in the rudimentary webbing between the bases of the toes, and in the flattening of the tail, which is still put through superfluous sculling motions when the salamander tries to run on land.

At the tip of the snout a pair of small nostrils will be seen, each with a blackish valve-like flap attached to its hind margin within, and if the mouth be held open widely, the inner openings from these nostrils may be seen on its roof at the rear of the palate. On the floor of the mouth lies a fleshy tongue, attached along its middle line, its edges lying free; at the rear of the mouth, the pharynx, with its walls converging to the esophagus, penetrated by abundant minute blood vessels, which give to it something of the character of a respiratory organ. In the lungless salamanders this organ is better developed to serve that function. On the floor of the pharynx is the glottis, the gateway to the lungs, a narrow longitudinal slit with closely appressed cartilaginous lips. Very minute and numerous teeth may be found on the edges of the jaw by scraping it with a finger-nail or with a needle, and two patches of palatine teeth may be found farther back in the roof of the mouth.

Internal features.-Upon looking inside the body of the salamander it is at once apparent that the main general features of structure that were found to characterize the earthworm, are repeated here. There is a compound- 
tubular body, a tube within a tube, and a cœlom or body cavity between; the inner tube is the alimentary canal and the outer one is the body wall as before, but the alimentary canal differs in two important particulars; it is not straight, but greatly coiled and twisted; and it is not simple, but bears conspicuous appendages. And the body wall differs conspicuously in that it bears a differentiated head, and is extended laterally into limbs and backward into a tail.

On comparing the internal organs there are strong contrasts. The central part of the circulatory system is not a

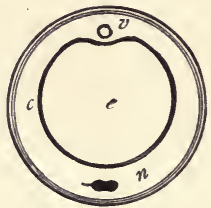

a

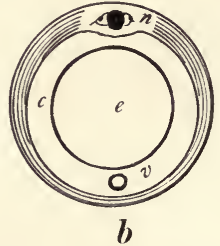

b

Frg. 113. Diagrams illustrating the plan of body in worm and in salamander $(b)$ in cross section; $e$, enteron; $c$, coelom; $n$, central nervous apparatus; $v$, central circulatory apparatus.

long pulsating tube lying on the dorsal side, but a heart, lying upon the ventral side. The central part of the nervous system does not lie within the cœlom on the ventral side, but in the body wall upon the dorsal side. The nephridia are not scattered segmentally in single pairs the whole length of the body, but are aggregated into special paired organs, the kidneys, and in the salamander there are special respiratory organs the lungs, and special supporting structures, the bones.

The food tube, alimentary canal, or enteron, is differentiated into parts the anterior of which bear the same names as parts of like function in the earth worm: mouth, pharynx 
and esophagus, and these are succeeded by stomach, small intestine, large intestine and cloaca. All these, together with the appendages, are indicated in the accompanying diagram (fig. Ir4). Such differentiation of parts bespeaks many separate localized functions along the course of the enteron; and such indeed there are, but we are here concerned with form changes and can note only the more important functions as bound up with the principal organs.

The stomach has become a sharply delimited organ for the reception of food, capacious, distensible, suited to the exigencies of irregular food supply. Its thick muscular walls are filled with small gastric glands, whose secretion initiates digestion. The churning movements of the walls

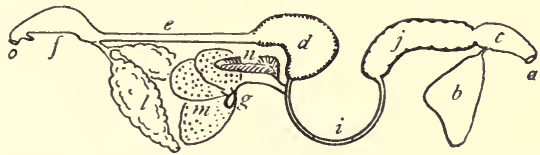

Fig. 114. Diagram of the enteron of the salamander, with its principal appendages. $o$, mouth: $f$, pharynx; $e$, esophagus; $d$, stomach; $i$, small intestine; $j$, large intestine; $c$,cloaca; $a$, anus; $b$, urinary bladder; $g$, gall bladder on $m$, liver; $n$, pancreas; $l$, lung.

aid in the comminution of the food and in the mixing of it with the gastric secretion. At the outlet of the stomach is a guarded passageway called the pylorus, through which the food passes, when reduced to a more or less fluid condition.

The small intestine is a narrow passageway (greatly abbreviated in the diagram), well adapted to the slow passage of the food, to the completion of its digestion, and to the extraction from it of assimilable materials. It is long and tortuous. Its walls are covered internally with folds and processes (villi) which greatly increase the surface in contact with the passing stream. These secure the better mixing of food with the digestive secretions of the liver and the pancreas, and the completer absorption of it after digestion. 
The principal appendages of the enteron.-The lung is here a new feature. As a respiratory sac appended to the alimentary canal, it is peculiar to vertebrates. Among terrestrial animals, most vertebrates are giants, for whom direct absorption of oxygen through the skin would be quite inadequate. Herein is seen the advantage of the lung, which maintains inside the body extensive surfaces that are thin-skinned and always moist.

The liver is the largest gland in the body, a lobed organ of mottled brownish color, its pointed left lobe partially covering the stomach (in the resupinated position in which the salamander is opened). Its secretion is collected in a bluishgreen sac- the gall cyst, which the right lobe overlies. The cyst is connected by a slender bile duct with the snall intestine near the stomach. Compression upon the gall cyst will usually demonstrate that the bile duct opens at this point, by driving the greenish bile down its length, making the duct visible. The pancreas is an elongated thin flat fatty-looking organ, that lies in the loop formed by the junction of the stomach and small intestine and is covered by the liver except at its posterior end where it touches the intestine. The urinary bladder is the hindmost appendage of the alimentary canal. It is a thin, crumpled sac that lies upon the ventral surface of the large intestine, and opens into the cloaca. Its connection with the excretory system will be discussed later. The thin sheet of membrane in which these digestive organs are slung from the dorsal side of the body wall and through which pass numerous branching incoming and outgoing blood vessels, is the mesentery. The elongate oval reddish body suspended in the mesentery behind the stomach is the spleen.

The lungs are the foremost appendages of the alimentary canal. They spring from the ventral side of the pharynx at the glottis, whose location has already been noted, 
by a slender hollow stalk-like trachea, which divides into two bronchial tubes, joining the right and left lungs. By passing a pointed glass tube into the glottis and inflating the lungs, their size, their constituent air cells and the communicating blood vessels in their wall may be clearly seen.

The circulatory system has for its central organ a heart of three chambers, two aur-

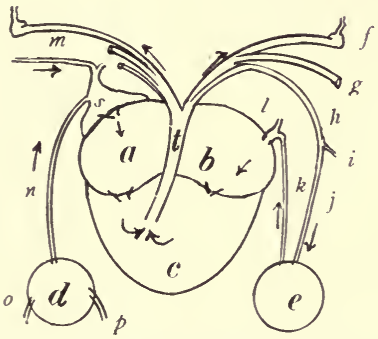

FIG. 115. Diagram of the Amphibian heart, and principal blood vessels. $a$, right auricle; $b$, left auricle; $c$, ventricle; $t$, arterial trunk; $e$, lung; $d$, liver; $f$, carotid arch; $g$, aortic arch; $h$, pulmo-cutaneous arch, with $i$, its cutaneous, and $j$, its pulmonary branch; $k$, pulmonary vein, with the base of the corresponding vein from the missing lung shown at $l, m$, the right precaval vein; $n$, postcava; $o$, anterior abdominal vein and $p$, portal vein. icles and a ventricle (fig. II5). The ventricle has thick muscular walls, and is the chief propelling agent of the blood current. It drives the blood forward through the arterial trunk, and outward through the arches, as indicated in the accompanying diagram. The outward current is called the arterial, the inward, the venous circulation.

The carotid arch carries blood anteriorly to the head, the pulmo-cutaneous inwardly to the lungs and externally to the skin (whence its name), and the aortic arch carries the greatest supply posteriorly and to peripheral parts of the body, and distributes vessels through the mesentery to the internal organs.

The return currents reach the heart separately, entering by the two auricles. That entering the left auricle is returned from the lungs through the pulmonary veins. That entering the right auricle (by way of the venous sinus, a 
vestibule attached to the auricle) is returned from the front by the precava, and from the rear by the postcava. The postcava is the largest bloodvessel coming from the rear. Into the liver the blood returns by two main channels, an anterior abdominal vein that traverses the mid-ventral line of the body wall and jumps across the short intervening space of the cœlom to enter the liver on its ventral side, and a portal vein that comes from the stomach and succeeding portions of the alimentary.canal.

The special organs of excretion in the salamander are the kidneys, a pair of chocolate-colored bodies lying closely applied to the dorsal wall in the posterior end of the body cavity, broader and thicker behind, and tapering to a slender point in front. From their postero-external angles a pair of very short ducts connects with the cloaca, entering just opposite the mouth of the urinary bladder, into which the discharge of their urine passes for temporary storage. A large vein enters each kidney from the rear, breaks up into fine branchlets, and is reformed on the opposite internal side, where, by confluence of emerging branchlets, the postcava is formed.

The reproductive organs lie in the midst of the body cavity, a single pair just ventral to the pointed anterior ends of the kidneys, and they bear usually a considerable development of fat in the form of yellowish finger-like processes (fig. Ir6.). The salamander being unisexual, they are spermaries (testes) in the male and oraries in the female. The spermaries are oval yellowish bodies, which discharge their sperms through a number of fine ducts that penetrate the substance of the kidney and emerge on the opposite side to join the ureter, and thence reach the cloaca. The ovaries are large membranous, crumpled organs in whose walls the eggs may be seen developing, opaque and white at first, acquiring 
blackish pigment as they increase in size, studding the transparent membrane. The eggs are shed from the ovaries into the body cavity and the ducts by which they reach the exterior are not connected to the ovaries at all. The oriducts are long sinuous tubules extending the whole length of the body cavity near the mid-dorsal line, opening
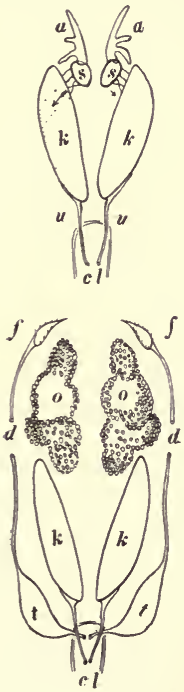

FIG. 116. Diagram of the relations of renal and reproductive organs in amph1bians, male above, female below. $k, k$, kidneys; $u, u$, ureters; $c l$, cloaca; $s$, $s$, spermaries (testes). Arrows indicate the course of the sperm ducts through the kidneys to join the ureter; $a, a$, fat bodv; $o, o$, ovaries; $d$, $d$, oviducts; $f, f$, their funnel shaped openings into the colom: $t, t$, the dilatation(uterus) at the lower end of each.

by a V-shaped slit at the anterior end that is situated between the esophagus and the shoulder, a n d into which the eggs find their way, aided by the lining cilia. As the eggs pass down the tube a gelatinous secretion is added to them by cells along the way, and they find temporary storage in a sacculation (uterus) at the lower end of the duct just before it enters the cloaca.

Nervous system.-As already noted, the central part of the nervous system in the salamander, as in vertebrates generally, is lodged in the body wall upon the dorsal side. It consists of a hollow, but thick walled tube of nervous matter, differentiated into two principal parts: a considerable enlargement, the brain, is lodged in the cranial cavity of the skull, and a long spinal cord occupies the channel formed by the annular vertebræ. The branches it bears, and by which it maintains communication with peripheral parts of the body are paired nerves, which it gives off 
throughout its length. Those nerves issuing through openings in the base of the cranial cavity of the skull are called cranial nerves, and those issuing from the interspaces between the vertebræ are called spinal nerves.

The nervous apparatus of the body is composed of nerve cells and their processes. Where the bodies of the cells predominate, as in the center of the cord and in the surface layer of the fore part of the brain, they give the nervous tissue a pale grayish cast; and where the fibres predominate, the tissue appears white (the so-called "gray matter" and "white matter" of the nerve centers). We have seen a very simple sort of differentiation of nerve cells with processes in the hydra (fig. Ior $f$ ). And in the earth worm (fig. Iog) we have found them very highly differentiated. But in the vertebrates the processes from nerve cells are often very much longer and the interrelations between them often much more complex. Each spinal nerve consists of a bundle of these long processes or fibres, $i$ closed in a common sheath.

Spinal nerves arise in pairs between the vertebræ, as already noted, each by two roots (which are also bundles of fibres), and out upon the dorsal root, just before its confluence with the ventral to form the completed nerve, there occurs a little isolated cluster of nerve cells: that is, a ganglion. There are other nerve cells in the organs of special sense, and at the termini of sensory nerves all over the surface of the body. The apparent branching of the nerves is due to the division of the bundle of fibres into lesser bundles, and finally into single fibres that take different courses to their appropriate endings. The fibres themselves are continuous, and extend from cells in the cord or in ganglia, to other ganglia or to peripheral parts of the body. They are individual lines of nervous communication; they separate as do tele- 
graph lines in passing outward from the commercial centres to the remoter districts.

Within the cœlom of vertebrates there are other ganglia, in part arranged in pairs segmentally and connected with the ventral roots of the spinal nerves, as shown in figure II 7 , and in part variously disposed in the walls of the internal

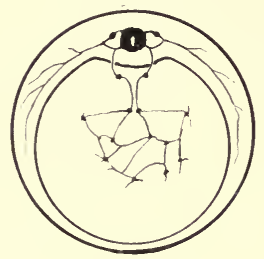

a

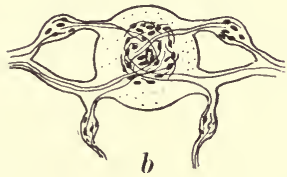

FIG. 117. Diagram illustrating the relation of the neural tube to the ganglia $a$, is a crosssection of the body showing the sympathetic ganglia in the coelom; $b$, is a crosssection of the cord and adjacent ganglia; showing roughly the location of the groups of nerve cells. organs of the cœlom, whose functions they control and coordinate. These are connected with each other by nerve fibres. They together constitute the so-called sympathetic system. The fundamental nutritive processes of the body, that are performed involuntarily, and that are essential to keep life going, are unconsciously controlled through the sympathetic system. Practically all the involuntary muscles of the body, those of the skin, as well as those of the viscera, are controlled through nerve fibres that take their origin from the cells of sympathetic ganglia.

There is another, more direct line of communication between the organs of the coelom and the brain. One pair of cranial nerves (called the vagi; sing. vagus) which descends through the neck into the cœlom, sends branches also to the lungs, the heart, the stomach and part of the intestine.

The movements of the involuntary muscles are comparatively simple and uniform, but those of the voluntary muscles of the body wall and limbs are infinitely 
varied and complex, and are ever effected in new combinations. Hence there is a correspondingly large proportion of the regulative cells of the body, the nerve cells, located in the neural tube. The most significant new feature of cell grouping found among vertebrates is the aggregation of nerve cells at the forward end of the neural tube to form the brain. The cord widens on entering the skull into the medulla. On its dorsal side a thin roofed
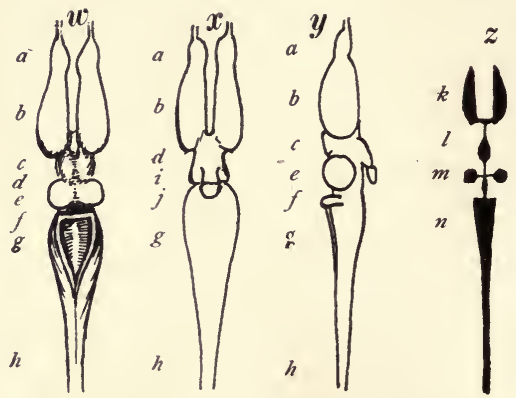

FIG. 118. Diagrams of the brain of the salamander. $v$, dorsal view; $x$, ventral view; $y$, lateral view and $s$, diagram of the continuous internal cavity in dorsal or ventral view; $a$, olfactory lobe; $b$, cerebral hemispheres; $c$, pineal body; $d$, thalamencephalon; $e$, optic lobes; $f$, cerebellum: $g$, medulla, $h$, spinal cord; $i$, infundibulum; $j$, hypophysis; $k$, lateral ventricles; $l$, third ventricle; $m$, optic ventricles; $n$, fourth ventricle.

$\mathrm{V}$-shaped slit, called the fourth ventricle, exposes the central cavity that extends in fact throughout its length. A transverse ridge of nervous tissue at the front of the fourth ventricle upon the dorsal side is the cerebellum. A pair of rounded swellings just in front of the cerebellum are the optic lobes. The pair of large oblong lobes at the front are the cerebral hemispheres. These and other parts externally visible may be located by reference to figure is 8 . Their relations to each other will be considered when their development is studied (p. 198). 
Development.-The way of access to intelligent comprehension of the cellular structure of the salamander lies through the study of its development.

The salamander begins life as a single cell, the result of fusion of egg and sperm. It is a very large cell, because distended with yolk and enveloped by a thick gelatinous envelope; but the protoplasmic part, the living part of it, is very small. The protoplasm is not equally distributed through the egg, but is more abundant on the upper pigmented side. Therefore, the division planes in cleavage start on the upper side, and division is somewhat retarded below by the impeding yolk mass. The cell divides into two cells along a meridional plane and the two divide into four by another meridional plane at right angles to the first; then the four divide into eight by a plane parallel to the equator of the sphere, at right angles to both former planes, not at the equator, but a little nearer the darker upper pole, where it divides the protoplasm more equally. Successive meridional planes, and planes parallel to the equator mark the following divisions into r6-cell, $3^{2-c e l l, ~}$ etc., stages which, however, are not traceable farther because of the retardation of division on the lower side, and because of the planes getting ajog at the joints. The result is clearly a blastula, as before-a hollow sphere of cells of small size. The slipping inward from the surface of some of its cells results in its being more than one layer in thickness over part of the upper side, and the retardation of division owing to excess of yolk on the lower side throws the segmentation cavity above the middle of the sphere. All these facts are indicated in the accompanying figures. Then gastrulation takes place in a manner that is yet more aberrant. An ingrowth from the outer wall gives rise to endoderm surrounding an arch-enteron as before; but the ingrowth, impeded by yolk does not result in a widely open 
blastopore, but, instead, a narrow crescentic slit, the edges of the blastopore being pressed together as shown in figure I $9 i$. Then the edges of the crescent extend downward until they meet below a little circular patch of protruding yolk, the yolk plug. Except upon the upper side where lies the direct entrance to the archenteron, they cut but a shallow circular
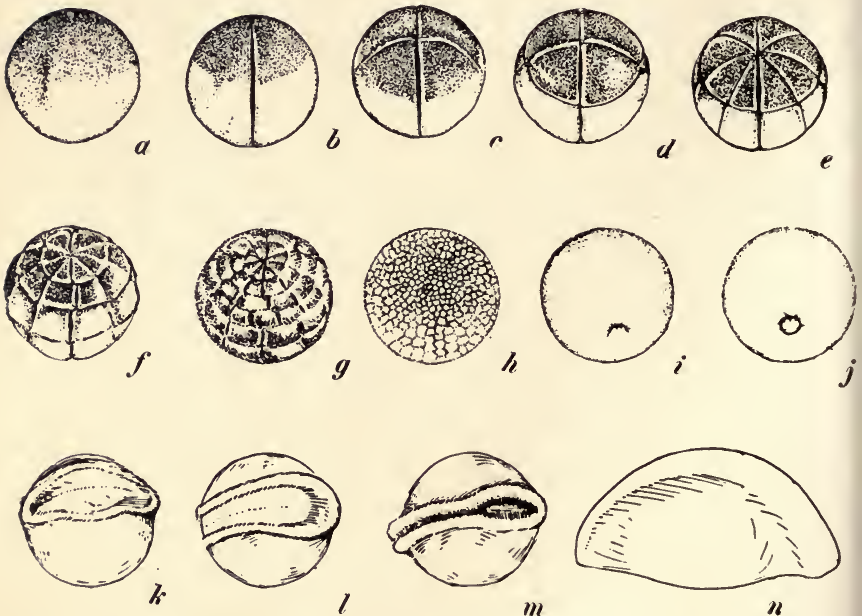

$m$

FIg. 119. Early development of salamander eggs, $a$ to $h, 1-, 2-$, $4-, 8-, x^{-}, 32$-cell and later segmentation or cleavage stages; $i, j$, gastrulation stages; $i$, shows the crescentic blastopore and $j$, the fully formed yolk plug; $k$ to $n$, formation of the neural tube.

groove upon the surface of the yolk. If one conceive of his own head as the sphere of the gastrula salamander, his closed mouth the blastopore, and the corners of his mouth pulled down until they join beneath his chin, he will get a clear conception of the relation of these parts. Figure I 2 I shows in longitudinal sections the formation of the gastrula, 
and the formation and subsequent withdrawal from the surface of the yolk plug. The segmentation cavity is reduced in size as the endodermal sac increases in depth.

Then the mesoderm appears in the space between ectoderm and endoderm at the blastopore on the upper side, and spreads outward and downward in a thin sheet of tissue, and begins to split to form a cœlom. Up to this point in development it will be observed that nothing has appeared to suggest a vertebrate animal. In the one celled stage the embryo is more like a protozoan in structural type; in the blastula stage it has the hollow spherical form of volvox; in the gastrula stage it is more like hydra in plan. As soon as it has acquired a compound tubular body through the
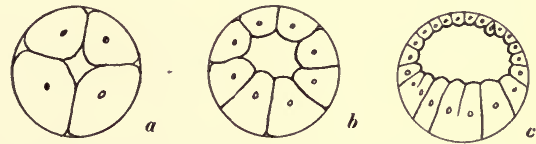

FIG. 120. Sections of salamander eggs in a meridional plane, 8 -cell, 32 -cell and later segmentation stages.

development and splitting of a mesodermal layer, it is more like a worm, and not until the appearance of a central nervous axis upon the dorsal side is there a single structure present that can be pointed out as distinctively characteristic of a backboned animal. Thus the series of embryonic forms assumed by the salamander in its development shows a rough correspondence to the series of adult forms we have been studying. Furthermore, when vertebrate characters appear they are very generalized indeed, and the parts in formation look no more like the adult salamander than like other vertebrate animals.

Vertebrate characters.-Several distinctively vertebrate characters appear now in different parts of the body almost 
simultaneously. The first to appear externally is the nervous axis upon the dorsal side and this and the gill slits
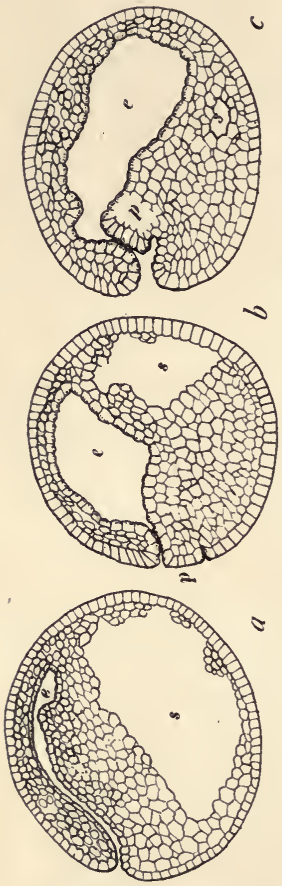
and the notochord are especially worthy of our consideration.

Beside the blastopore an elevation appears which rises in two parallel ridges called the neural folds. These folds at their outgrowing ends are confluent in a loop which marks the head end of the salamander. These folds grow rapidly, and by their increase in length project from the surface of the egg at both ends, spoiling its spherical symmetry. The withdrawal of the yolk plug is accompanied by the outpushing of the tail beyond the end of the neural folds. The folds come together, as indicated in the accompanying figures, the wider anterior end becoming the brain, the remainder, the spinal cord. This then sinks into the interior as indicated in the cross-section diagrams of figure $\mathrm{x} 22$.

Meanwhile the archenteron is elongating in a parallel direction, and a fold from its dorsal wall is cutting off the notochord - the most ancient supporting structure of vertebrates-a larval organ in most of them at the present day. 
The archenteron is converted into an alimentary canal by a
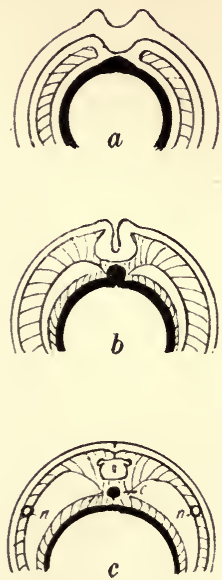

FIG. 122. Diagram of the formation of neuron, notocord and cœlom. The ectoderm is white, the endoderm is solid black and the mesoderm is crosslined; $c c$, notocord; $c n$, pronephric duct.

process somewhat differing from that followed in the worm; it is destined to occupy a reversed position; . the blastopore becomes the anus, and the mouth is formed at the opposite end by an ingrowth from the ectoderm that meets the front end of the archenteron and fuses and then opens a passage through. The anterior end of the archenteron becomes dorsally flattened and laterally expanded into a pharynx, from whose walls sacculations of endoderm grow outward to meet the ectoderm, and then cleave apart on vertical lines, opening gill clefts on the side of the neck. The pillars of tissue left standing between these clefts become the gill arches. By these simple processes, are laid down the main lines of vertebrate structure.

Endodermal differentiation.-The embryonic endoderm becomes epithelium, as before, and is the lining layer of the alimentary canal and of its appendages. It is for the most part a single layer of cells not remarkably modified in form, differing in length according to the extent of their compression. In the pharynx they are short-cylindric and ciliated on their free ends (figure I 34 ). In the intestine they are much more compressed and slender, and certain of their number are differentiated as goblet-shaped mucussecreting cells. In the stomach where the wall is made up of multitudinous pit-like depressions called the gastric 
glands, they are differentiated into bulky cells that secrete the digestive fluids at the bottom, mucus-secreting cells along the sides of the pits and of protective cells about the mouths of the pits where they come in contact with the food. In the lung, where the extension of the walls is very great, the cells are spread out flat and very thin to cover them. This thinness favors the diffusion of gases between the blood and the air, and is characteristic of respiratory epithelium.

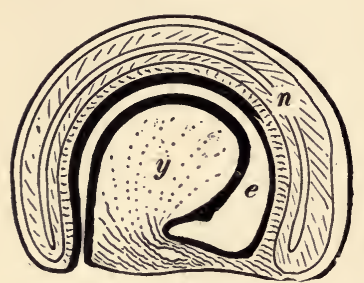

FIG. 123. Diagram of a longitudinal section of a young embryo. $n$, neural tube; $e$, enteron, the black spur from the upper side represents the free part of the notocord. The ventral outgrowth from the front end will form the liver.

The liver arises very early (fig. I23) as a wide sacculation of the archenteron near its anterior end on the ventral side. This outgrowth becomes repeatedly branched, and the resulting glandular blind tubules become convoluted, the basal connection remains as a slender connecting tube, the bile duct, and the distal portion, acquiring through mesodermal additions a system of blood vessels, becomes differentiated into the lobes of the liver. A dilatation on the bile duct becomes the gall cyst (fig. II4). The pancreas arises later but by a simpler and somewhat parallel development arrives at its adult estate, when it consists of a mass of glandular-walled communicating tubes, which secrete the most important single digestive fluid of the body. The urinary bladder arises as a similar but simpler sacculation at the posterior end.

Development of the neural tube.-We havealready seen that the central nervous axis develops into a tube by the 
closure together of two folds about a neural groove, and that the tube thus formed then sinks into the body wall. The

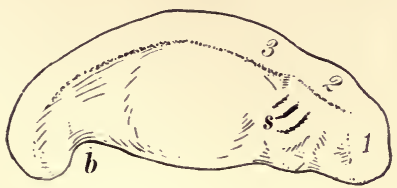

FIg. 124. A young salamander larva, showing gill slits $(s)$. b. blastopore; $I, 2,3$, fore-, mid-and hind-brain, respectively.

diagrams of figure $\mathbf{2} 2$ show how it is overgrown, first by the ectoderm and later by mesoderm, and removed from the surface. The original neural groove thus closed becomes the central canal of the spinal cord. It is lined with a little bit of the epidermal layer of the ectoderm, carried in from the surface. A small ridge of nerve cells that arises each side of the tube dorsally (fig. I 22C) becomes divided with growth into pieces corresponding in pairs to the body segments; and when later, nerves grow out as processes from the cells, these pieces become located upon the dorsal roots of the spinal nerves and become the ganglia (fig. I I 7) hitherto noticed.

Quite early in its development the axis becomes feebly marked off into three successive tracts, which correspond to the fore brain, mid brain and hind brain of the adult salamander (figs. I24 and I25). The fore brain becomes bilobed by a dilatation on either side of the median plane, and by

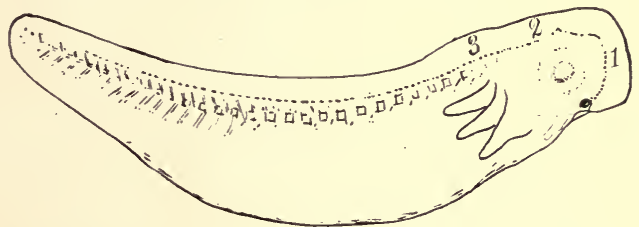

Fig. 125. Older salamander larva, showing gills, $1,2,3$, fore-, mid- and hindbrain. 


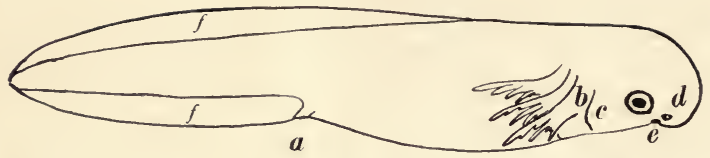

Frg. 126. Older salamander larva, showing further development of the gills.

$a$, anus; $b$, gills; $c$, opercular fold; $d$, nostril; $e$, mouth; $f, f$, caudal fin;

growth of the two lobes forward and extension of the expanded canal into them, the hollow cerebral hemispheres are formed; the small olfactory lobes grow forward from beneath their anterior ends. At the rear of the hemispheres on the middorsal line a small process grows upward to become the pineal body - a vestigial structure, corresponding to the nervous apparatus of a median eye, that is functional in some lizards. A hollow downgrowth on the midventral line develops the infundibulum. This connects with the pituitary body, developed in the roof of the mouth.

Paired upgrowths from the lateral wall of the midbrain become the optic lobes of the brain. The central cavity extends into each of these, the expansions of it within the optic lobes being known as optic ventricles. An axial dila-

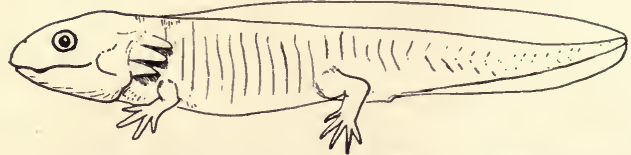

FIG. 127. Older larva of the spotted salamander, with legs developed.

tation of the central canal (fig. I $8 z$ ) is known as the third ventricle. From the front end of the third of the primary brain divisions the cerebellum arises as a transverse solid upgrowing ridge of tissue upon the dorsal side. Just behind this lies the fourth ventricle, as already noted (fig. $\mathrm{I} 8 w)$. It appears from above as a triangular dilatation 
of the central cavity of the medulla, but thinly covered upon the dorsal side.
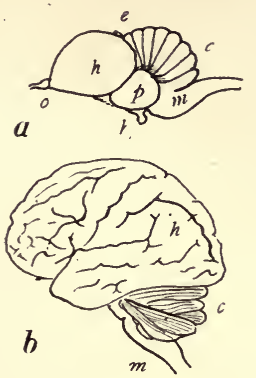

FIG. 128. Brains $a$, of pigeon and $b$, of man; $c$, cerebellum, $e$, pineal body, $h$, hemisphere, $l$, hypophysis, $m$, medulla, $o$, olfactory lobe, $p$, optic lobe.

The elongate brain of the salamander, with its parts outspread almost like a diagram, is very simple in comparison with that of the higher vertebrates (fig. I 28 ). In birds the cerebellum and the optic lobes are relatively larger and in mammals, and especially in man, the cerebral hemispheres attain their maximum development.

Thus a simple tube of undifferentiated nerve cells becomes moulded into a brain. By localized outgrowths of its walls all the principal external features of its form are wrought out. The subsequent development of fibres from all these masses of cells is a matter far too intricate for us to attempt to follow here. A few of the more salient features of the ultimate distribution of these fibres will be considered in chapter VII.

The development of the primary circulation.-In the midst of the mesoderm, tube-like clefts appear, which, extending and becoming confluent, develop into the blood vessels. The most important of these appears as a cleft of sigmoid curvature in the region of the throat, and by the processes diagrammatically represented in figure $\mathrm{I} 29$, it becomes enlarged, strongly flexed, and divided into compartments, it develops muscular walls, and becomes the heart. It becomes two chambered by the differentiation of an auricle and a ventricle, the former being carried to the front of the latter by the flexion undergone during 
development. The passage leading forward from the ventricle, destined to become the arterial trunk, becomes conjoined with other paired passages in the mesoderm of the

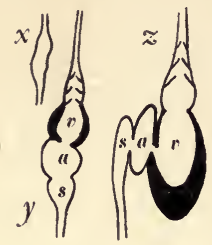

FIG. 129. Diagram of development of the larval two chambered heart. $x$, the primitive cleft of the mesoderm; $y$, the differentiation of chambers and valves; $z$, the completion of the sigmoid flexure; $s$, venus sinus; $a$, auricle; $v$, ventricle. throat leading to the gills, which become the branchial arches. Corresponding vessels develop upon the dorsal side and become conjoined with the great dorsal aorta, leading rearward (see figures I $3 \circ x$, and I.3 I). About the time these vessels are first marked out, gills develop upon the gill arches externally (fig. I 26) and become traversed by a system of capillary vessels, which are at this stage the connecting link between the dorsal and ventral vessels just mentioned. The circulation of the blood through these transparent external gills is easily observed with the microscope, and it is a beautiful sight.

This simple type of circulation is essentially fish-like (fig. I3०x). There are no lungs as yet, and hence there is no pulmonary circulation. The heart is but two chambered. All the blood passes forward from the ventricle through the gills, to be returned rearward through the dorsal aorta. The aortic arches are four, and at first essentially alike.

Development of pulmonary circulation.-Lungs develop as already noted by outgrowth from the ventral pharyngeal wall, and blood vessels to supply them arise from the fourth branchial arch and extend rearward to penetrate their walls. Return channels are developed, joining the lungs directly with the heart. When these vessels become functional, a considerable part of the blood is diverted from the gills to the lungs. This, however, is of late occurrence, being an 
accompaniment of the shift from aquatic to terrestrial life. Before it happens the gills begin to atrophy and new channels begin to be developed. A carotid artery springs from the anterior side of the foremost branchial vessel on each side, to carry blood from the heart into the head. A short cut is developed between the dorsal and ventral portions of the branchial vessels of the second pair, and these become the aortic arches of the adult salamander, forming a con-
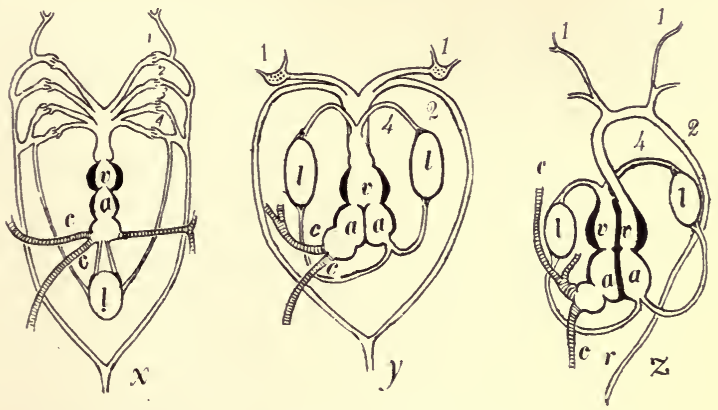

Fig. 130. Diagram of types of circulatory apparatus in vertebrates. $x$, a lung fish (Ceratodus); $y$, a frog and $z$, a mammal. (For the sake of clearness the auricle is turned backward, straightening out the sigmoid flexure.) $\boldsymbol{I}, 2,3,4$, the four branchiallarches, becoming, in $y$ and $z ; 1$, the carotid; 2 , the aortic, and 4 , the pulmonary arches; $a$, auricle; $v$, ventricle: $l$, lung; $c$, cava; $r$, the single root of the? dorsal aorta in mammals.

tinuous uninterrupted channel from the heart to the dorsal aorta, which ultimately becomes the main channel of the circulation. Thus we see that in metamorphosis the fourth arch that springs from the arterial trunk becomes the pulmocutaneous artery; the first arch becomes the carotid, the second becomes the aortic, the third atrophies, or becomes variously connected with adjacent arches, and the branchial circulation first laid down becomes so altered as to be recognizable only by most careful comparison. 
The fate of the gill clefts and skeletal arches is no less interesting. The foremost cleft narrows to a tubular passage way, in connection with the outer end of which the ear is developed, and the cleft in part persists as the eustachian tube leading from the pharynx to the middle ear; this is its fate in most higher vertebrates, and in ourselves. The other clefts close after the atrophy of the gills. The skeletal arches that surround the neck, standing between the clefts have various fates. The mandibular arch that stands in the wall before the first cleft in the salamander, becomes the mandible, or lower jaw of the adult salamander (note that the tadpole has no mandible, and the form of its mouth is entirely changed in metamorphosis). The succeeding skeletal arches of the larval salamander persist in part as the paired members of the hyoid skeleton shown in figure II 2 ; the foremost of these persists as the single hyoid bone in most of the higher vertebrates and in ourselves.

The kidney. - The development of the kidney is no less remarkable. In that part of the cleft mesoderm, which enters into the composition of the body wall (the somatic layer) a cleft appears which develops into a long tube or duct, (fig. $122 c, n$ ) that extends from a point on the ventral wall of the archenteron, where the urinary bladder will later develop, forward along the wall of the cœlom. At its anterior end several short convolute tubes develop, with their open ends abutting against a dilatation of the dorsal aorta in the cœlom (fig. I3 1 a): Thus, they are probably able from the beginning, by reason of this connection, to remove nitrogen waste from the blood. These tubules increase in number, length and complexity of arrangement and form the pronephros, or "head kidney."

The true kidney develops later, and much farther back in the cœlom. It begins as separate and isolated tubules developing against the dorsal wall along side the pronephric 
duct, into which they later find admittance. The tubules (fig. $\mathrm{I} 3 \mathrm{r} c$ ) increase in number and differentiate internally.
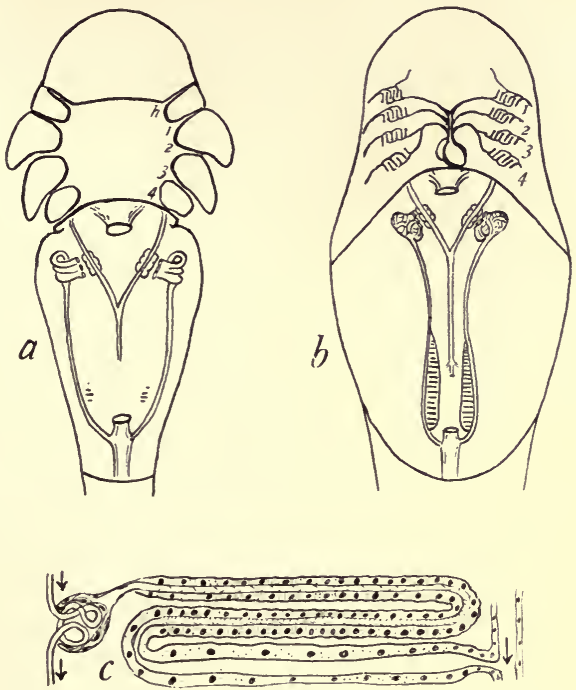

FIG. 131. Diagram of the development of amphibian gill slits, gill arches, pronephros and kidney. $a$, is a horizontal(frontal) section of the body of a young larva, showing the relations of the newly formed pronephros to the dorsal aorta in front and to the cloaca behind; $h$, is the hyo-mandibular gill cleft. $\boldsymbol{r}, 2,3,4$, the succeeding four branchial clefts; $b$, is a dissection of an older larva, showing the branchial blood vessels, and the true kidneys attaching to the pronephric duct; $c$, is a diagram of a single nephridial tubule from the kidney. The arrows at the left indicate the course of the capillary blood circulation through the glomerulus; the arrow at the right indicates the path of excreta to the ureter.

Each acquires connection with one of the capillaries joining the renal artery with the post cava. All of one side become combined together in a single organ, the kidney. The 
rear end of the pronephric duct becomes the ureter; the anterior end, and with it the pronephros, atrophies. These

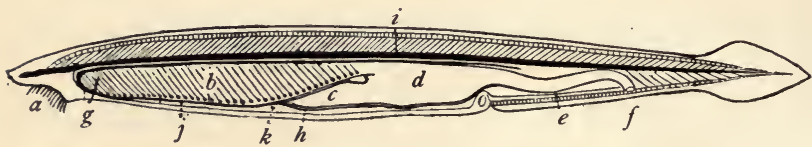

FIG. 132. The lancelet (Amphioxus, or Branchiostoma) after Gegenbaur. $a$, mouth: $b$, gill chamber; $c$, sac of enteron corresponding to the liver; $d$, stomach; $e$, intestine $f$, anus; $g$, aortic arch; $h$, portal vein; $i$, notocord, with dorsal aorta extended beneath it; $j$, post cava (all the main blood vessels have contractile walls); $k$, coelom.

changes are diagrammatically indicated in figure $\mathrm{r} 3 \mathrm{r}$.

The skeleton.-In some very primitive allies of the true vertebrates (as for example, the lancelet, fig. 132), the notocord persists through life as the chief supporting structure of the body, but in the salamander as in vertebrates generally, it is early replaced by a cartilaginous skeleton. Its cells become vacuolated, and are finally resorbed and entirely disappear. The beginnings of the development of the cartilaginous cranium about the front end

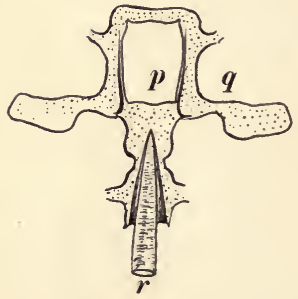

FIG. 133. Front end of notocord in its relations to the cartilaginous base of the cranium in the spotted salamander. $p$, beginnings of cartilaginous cranium; $q$, orbit of eye: $r$, notocord. of it are shown for the salamander in figure 133 . Cartilage constitutes the whole skeleton of many of the lower fishes, but in the higher vertebrates it is more or less replaced by bone.

Study 26. The internal organs of an amphibian (frog or salamander.)

Materials needed: Living specimens to be examined as to external features, appearance 
and actions. Freshly anesthetized specimens for gross dissection.

Study the internal organs in the order outlined in the preceding pages; (if fuller outlines are desired, they may be found in laboratory manuals of vertebrate zoology or of general zoology, nearly all of which deal mainly with comparative anatomy). Trace the alimentary canal and note its differentiation into parts. Identify its appendages and find their channels of communication with the enteron.

Inflate the lungs and note the relation between air tubes, air cells and blood vessels. Identify the chambers of the heart and trace the main channels of circulation. Trace the ureter from the kidneys to the mouth of the urinary.bladder. Compare spermaries and ovaries in male and female specimens and trace the ducts for the exit of the sex cells.

Find the paired spinal nerves issuing from the spinal column and lying against the roof of the body wall, and find the paired sympathetic ganglia in the cœlom attached by commissures, one pair to the roots of each pair of spinal nerves; look also for nerves extending from these ganglia to other sympathetic ganglia in the walls of stomach, heart or lungs.

The record of this study may consist in drawings and diagrams of the form and relations of the principal organs studied.

Study 27. The structures of the body wall of an amphibian.

Materials needed: The specimens from the preceding study, if preserved in two per cent. formalin after the removal of the internal organs. Wash free from the formalin in running water before using. Also skeletons disarticulated, and a few mounted ones for comparison. Also, some forms with cartilaginous crania, such as sharks, or large bull frog tadpoles for the easy examination of the brain. 
Compare the bones with the diagram of the vertebrate skeleton as shown on page 00 and then make a diagram of the skeleton of this amphibian. The skeleton of fore and hind feet will be easily observed if the skin be stripped off, the outside muscles cut off, and the undisturbed skeletal parts then cleared in dilute glycerine. The relations of bone, muscles, nerves and skin will also be seen in the making of the preparations.

To the examination of the main external features of the brain should be devoted the major part of the time alloted to this study. In a shark or a large tadpole the roof and the coverings of the brain are readily cut away, and.the parts shown in figure I 8 will be easily made out.

The record of this study may consist of diagrams of skeleton and brain.

\section{Study 28. The cellular structure of an amphibian.}

Materials needed: A living or freshly anesthetized male specimen; slide mounts of prepared fragments of the ovary showing eggs and egg follicles; sections of the stomach wall, the intestine, the lung, the skin, the kidney, the spinal cord, etc.

The careful study of sections is time consuming, especially for a beginner, and little of it can be done in a single period. To expedite their examination, a number of them may be shown as microscopic projections. The student should at least examine and draw a few living cells from the fresh specimen, such as red and white corpuscles from the blood, living sperm cells, ciliated epithelium scraped from the roof of the mouth, etc. In the sections from the enteron and its appendages, the types of epithelium shown in figure I 34 should be identified, and the subjacent muscle layers, the interpenetrating blood vessels and the covering peritoneal layer of endothelium should be seen. In the skin section 
the thick fibrous dermis should be seen overlaid by the epidermis of several cell layers, and invaded by the large mucus glands that depend from and open through the epidermis. The parts of kidney and spinal cord may perhaps be identified by comparison with figures $\mathrm{I} 3 \mathrm{I} c$ and $\mathrm{I}$ i $7 b$, respectively.
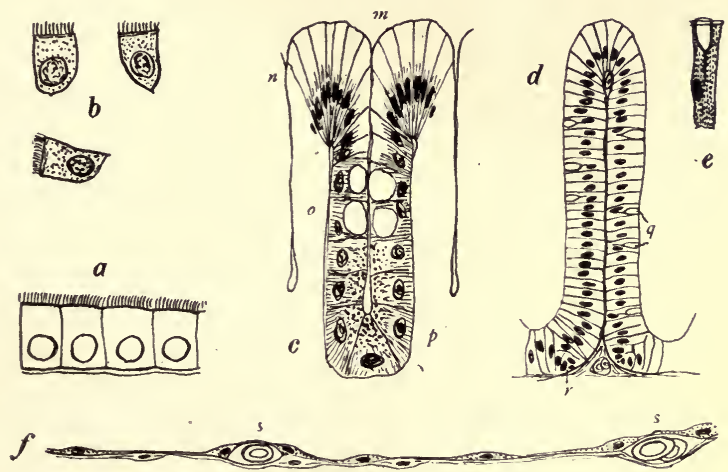

FIG. 134. Diagrams of types of epithelium. $a$, ciliated epithelium of the pharynx; $b$, isolated cells of the same; $c$, a gastric gland from the stomach wall; $m$, its mouth; $n$, the contact layer at the surface; $o$, the middle layer of mucus-secreting cells; $p$, the gland cells of the deepest part (pepsinogen secreting); $d$, a single villus from the wall of the intestine; $q$. goblet cells (mucus-secreting); $r$, a group of replacement cells (center of cell increase); $e$, a single goblet cell; $f$, a bit of the wall of the lung showing the thin respiratory epithelium (stippled); $s, s$, capillaries containing blood corpuscles.

The record of this study may consist in a few drawings and a larger number of diagrams of the things studied.

Study 29. The early development of an amphibian.

Materials needed: Egg masses of various stages of development, preserved in two per cent. formalin; wash out formalin before using. 
Study and diagram segmentation and gastrulation stages and the main features of formation and closure of the neural groove and the development of gill slits and gills as seen in external views of the specimens. The labor of drawing will be lightened if uniform circles be drawn mechanically for the earlier stages, and cut out forms be used for outlines of the later ones; or, if printed or otherwise duplicated outline figures be furnished. This may be supplemented by microscopic projection of egg sections.

The record of the study will consist in the series of diagrams made.

The salamander, a typical vertebrate.-Because of its primitive structure, the salamander serves well for introduction to the study of the vertebrates. The parts we have found in it we would find in all the others, only modified in form. As it develops, so do the others, in the main; in all, the principal organs are laid down in like manner and have like relations to the germ layers, and to each other. Neural tube, notocord and gill arches are formed in all. A two chambered heart and a fish-like circulation develop first, and a pronephros, before the true kidney; but some develop much farther than the salamander, and along very peculiar lines. The salamander ends its improvement of circulatory apparatus with two aortic arches doing precisely the same work; but in the higher groups of vertebrates, birds and mammals, we find one of these arches has been done away with and the other one does the work alone; the right one has been retained in birds, the left one in mammals (fig. I30z). A further improvement in birds and mammals is found in the four chambered heart, which with better developed lungs makes possible a complete double circulation of the blood (fig. I35), all the blood passing through 
the lungs on each circuit of the body. All the blood thus gathers oxygen on each round. Hence, these are the warm blooded animals: these alone are capable of sustained activities in cold climates.

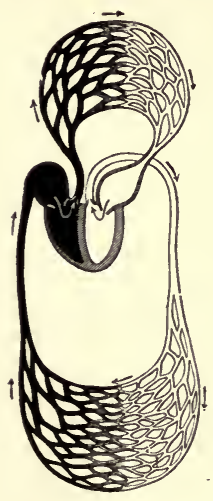

FIG. 135. Diagram of double circulation (from Verworn).

The purpose of circulatory apparatus is to get the food to the points where it is needed for use, and to get the waste to points whence it can be removed from the body. When the animal body is small and no part of it is far removed from food supply, there is little need of circulatory apparatus. The amœba may feed at any point of its body. In the hydra, the food cavity, extending to the tips of the hollow tentacles and out into the buds, is not far removed from any cell. Even in so large an animal as a flat worm the food cavity may, by means of extensive ramifications, reach nearly every part. But in all the higher terrestrial forms of animals, the part of the body wherein food elaboration occurs is small, and the greater part of the body is remote from food supply, and circulation of the food is therefore necessary. Likewise, the more the nephridia become localized in the body, the more necessary becomes circulatory apparatus, with definite blood channels leading to them from every part of the body.

But there is circulation before there are blood vessels. We have seen it in Paramœcium; many of the lower multicellular animals also lack blood vessels. There are body fluids occupying the interstices between the cell layers and bathing all the tissues internally. These are the media through which the internal exchange of food and waste 
materials is effected. These supply the aquatic environment that is necessary for the maintenance of cell life:

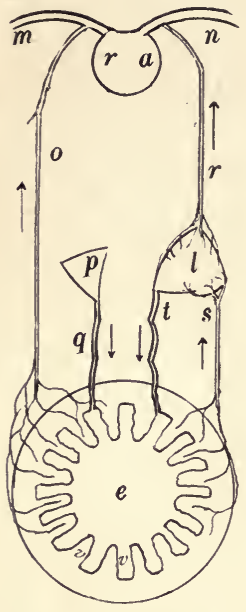

FIG. 136. Diagram of the two main channels by which food enters the general circulation in mammals. $e$ intestine with villi, $v, v$, in its walls $r a$, right auricle of the heart, $m$, post cava; $n$, precava; 0 , thoracic lymph duct; $p$, pancreas: $q$, pancreatic duct; $r$ hepatic vein; $s$, portal vein; $t$, bile duct from $l$, liver: arrows indicate the course of secretions entering the intestine, and of the absorbed food departing therefrom. for cell life, in the beginning aquatic, is in an important sense aquatic still, even in terrestrial organisms. Living protoplasm is a semifluid substance, and metabolism is compatible only with a liquid state.

The fluids of the body are moved about, (that is, circulated) in part by the movements of the tissues which they bathe, and in the higher organisms appear special organs of propulsion. Blood vessels at first appear as short open contractile tubes, that communicate freely with the cœlom, and that merely serve to keep the blood irregularly moving. When, as in the higher vertebrates they have become completely closed channels, capable of retaining the differentiated red corpuscles and carrying them about the body in continuous procession, they are still supplemented by that intercellular circulation that is due to the contraction of the muscles and movements of the organs. The need of this propulsion of body fluids by body movements is convincingly evidenced in ourselves by the benefit of physical exercise (even though performed by proxy, as in massage), and conversely, by the stagnation induced by too exclusively sedentary habits. 
There are more or less definite channels (lymph vessels) developed in all the higher vertebrates, for the circulation of the body fluids aside from the blood vessels. These, in our foregoing hasty survey, we have left out of account. But there is one such vessel (the thoracic duct) of very great importance in mammals; for by it the greater part of the food enters the general circulation, in the manner diagrammatically indicated in figure 136 .

Aquatic and aerial respiration.--In water, the supply of free oxygen is that contained in the air which the water has absorbed. The simpler organisms, being small, readily obtain a supply by direct absorption through the surface of the body. Increase of size, howerer, disturbs the ratio between volume and surface in the body. As compensation for the excessive increase of volume, absorbing surfaces are increased by the outgrowth of gills: and then mechanical arrangements for bringing more water into contact with the gills follow. The gills are lodged in respiratory chambers through which a constant stream of fresh water is maintained, but still the amount of oxygen available is much more limited than in free air. There are no warm blooded animals except air breathers.

In the open air, the oxygen supply is inexhaustible: but air absorbing surfaces, such as are adequate for aquatic respiration, cannot endure exposure to dry air. Some land animals like the earthworm, living in moist places, are able to breathe through the skin, by keeping it moistened with mucus secretion; but if a worm be exposed to a dry atmosphere it quickly dies of evaporation.

The respiratory process, being essentially aquatic, requires moist thin-skinned surfaces for the intake of oxygen, and in organisms that live in dry atmosphere these can only be maintained inside the body; hence, the lungs, reached by long tortuous mucus-moistened passageways and main- 
taining deep cavities next the respiratory epithelium, where a zone of moisture-laden residual air serves as a medium of exchange and as a buffer to the air waves from the outside.

The amphibians make it easy to understand the transition from aquatic to terrestrial life in vertebrates. It would have been hard to imagine all the changes necessary for fitting a fish-like aquatic vertebrate for life on land, but in a salamander these changes, some of which would certainly surpass imagining, are all wrought out in a little while before our eyes; they go forward without a hitch, and most significant of all; they go forward in similar manner, in all the higher terrestrial vertebrates, whether they are to live any part of their lives in the water or not.

As in the salamander, so in vertebrates generally, the sexes are separate and true sexual reproduction is universal. But there is very great diversity among them as to mode of nurture of young, and some of the differences are of profound significance. The lancelet (fig. I32) lays minute eggs containing very little yolk; these segment and gastrulate typically, and the embryos hatch when they reach the gastrula stage, and thereafter shift for themselves, receiving no further parental nurture. But all the dominant groups of vertebrates make better provision for the development of their offspring, and do not turn them adrift in so immature and feeble and defenseless a condition.

Types of nurture.-There are two main types of nurture for the young of vertebrates. I) The storing of additional food supply in the form of yolk in the eggs. We have found a considerable store of yolk in the eggs of salamander; this process reaches its maximum development in the relatively huge eggs of birds.

2) The nurture of the young by means of embryonic membranes. This reaches its maximum development in 
mammals, and it has many features of unique interest and significance, but we can here consider only a few of its more general aspects.

We have already seen in the salamander that a dilatation of the oviduct near its lower end (the uterus) serves for the temporary storage of the ripe eggs, just before their extrusion. In the higher mammals the two oviducts (called also Fallopian tubes) become confluent at this portion of their length into a single uterus, in which the eggs on leaving the ovaries find lodgment. Being fertilized internally they remain here, and undergo segmentation and other early developmental changes while lving against the uterine wall. Almost as soon as the primary germ layers are established the ectoderm of the ventral wall rises up about the embryo in a circular fold all about its body and over its back; the edges of the fold come together and fuse and enclose the embryo (or fœtus) under a double canopy of thin membrane called the amnion (fig. ${ }^{\mathrm{I}} 37 b$ ). Almost simultaneously a food absorbing organ called the allantois develops for attachment of the embryo to the wall of the uterus. This springs from the endoderm near the posterior end of the archenteron. It grows out as a hollow membranous fold posteriorly and then dorsally between the wider folds of the amnion; there is developed within the allantois a complete set of embryonic blood vessels, the principal ones being an allantoic artery that springs from the great dorsal aorta, and an allantoic vein that returns the blood to the post cava. The allantois and the outer layer of the amnion become fused together, and attached to the uterine wall in a series of minute interlocking processes (villi), the whole complex attachment layer being known as the placenta. The processes on the wall of the uterus become permeated by a dense network of capillaries developed from the biood 

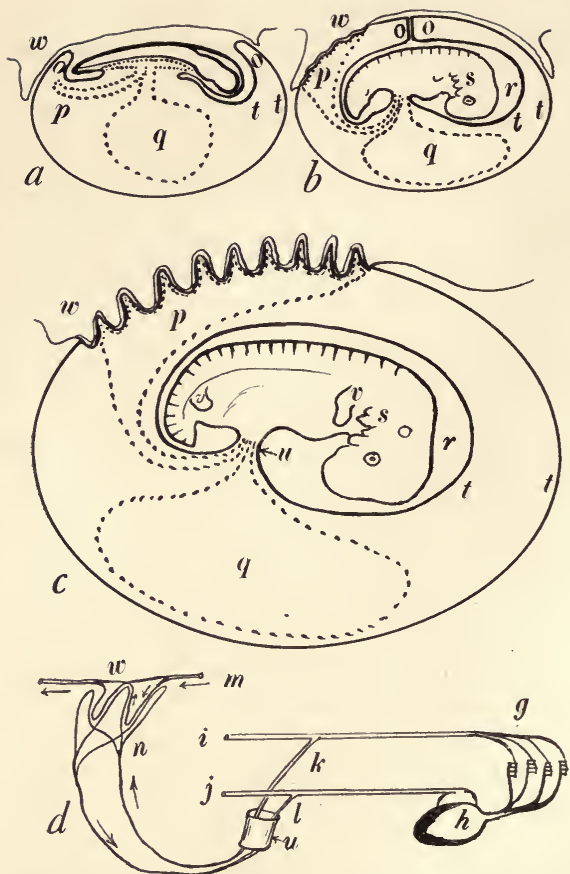

FIG. 137. Diagram of nurture of young through embryonic membranes. $a$, a young embryo with embryonic membranes beginning as folds or outgrowths of ectoderm and endoderm; $b$, an older embryo with the folds extending over the back tc inclose the embryo; $c$, an older embryo with the placental attachment to the uterine wall established; $d$, diagram of the channels of food intake and waste removal in the embryo; $w$. wall of the uterus; 0,0 , folds of the ectoderm which when confluent form the outer and inner amnion; $t, t, p$ fold of the endoderm, outgrowing to form the allantois; $q$, the vestigial yolk sac; $r$, the amniotic cavi sac, in which the embryo floats; $s$, gill slits; , $u$, umbilicus; $v, v$, fore and hind leg buds: $w$, the circulation through the placenta: $m$, indicating the course of the blood of the mother parallel to $n$, that of the embryo; $g$, gill circulation of the embryo; $h$, heart; $i$, dorsal aorta, $j$, post cava; $k$, allantoic artery; $l$, allantoic vein 
vessels of the mother. This becomes the source of food supply for the embryo during its long prenatal existence. In the corresponding villi of the membranes of the embryo copious capillary blood vessels are developed as a part of the embryonic circulation: these are its food taking organs. The process of nutrition is one of exchange of blood content between mother and offspring by diffusion through the thin walls of the villi. It is quite comparable to the exchange of gases which takes place in the gills or lungs. Both food (in solution) and oxygen are withdrawn from the passing currents of the mother's blood, and into the same currents are discharged the carbon dioxide and all other waste from the body of the embryo until its birth.

The body of the embryo immersed within the anmniotic sac, closes to a narrow opening (the umbilicus) on the ventral side of the abdomen and the closure elongates into a long stalk-like umbilical cord through whose vessels nourishment is drawn from the placenta until embryonic growth is ended. The embryo then hangs on the cord, like a ripened fruit upon its stalk. At birth the stalk is severed, and the feeding organs of the embryo, full formed and functional, are called into action.

Such are the means by which the maximum of provision for development of young is attained in mammals, and to these there is added the development of milk from the mammary glands as a further food supply for infancy. What a vast difference exists in bodily equipment between a new born mammal and the microscopic gastrula of a lancelet!

The life process in the salamander and in other vertebrates, is not very different from that in the worm. Indeed, it is much the same in its essentials in all animals, the differences occurring in the ways and means whereby these are accomplished. The essential processes are compre- 
hended in the word metabolism, and their relation to the accessory phenomena are indicated in the following table:

\begin{tabular}{|c|c|c|}
\hline & $\begin{array}{l}\text { Food intake } \\
\text { Digestion } \\
\text { Circulation } \\
\text { of food from the } \\
\text { alimentary canal } \\
\text { of oxygen from } \\
\text { the lungs }\end{array}$ & $\begin{array}{l}\text { Accessory processes, } \\
\text { mechanical and } \\
\text { chemical }\end{array}$ \\
\hline METABOLISM & $\left\{\begin{array}{l}\text { Assimilation (Ana- } \\
\text { bolism) } \\
\text { Dissimilation } \\
\text { (Katabolism) }\end{array}\right.$ & $\begin{array}{l}\text { The essential pro- } \\
\text { cesses: } \\
\text { the work of every } \\
\text { cell }\end{array}$ \\
\hline & $\begin{array}{l}\text { Circulation } \\
\text { of } \mathrm{CO}_{2} \text { and } \mathrm{H}_{2} \mathrm{O} \\
\text { to the lungs } \\
\text { of } \mathrm{H}_{2} \mathrm{O} \text { and } \mathrm{N} \\
\text { waste to kidneys } \\
\text { Discharge of waste }\end{array}$ & $\begin{array}{l}\text { Accessory processes, } \\
\text { mechanical and } \\
\text { chemical }\end{array}$ \\
\hline
\end{tabular}

Common features of organization in plants and animals:

I. Protoplasm is the "physical basis of life," and in nearly all organisms it is definitely organized into cells.

2. Cells, therefore, are the units of organic structure.

3. The method of increase is by cell division.

4. Every organism begins life as a single cell.

5. Aggregates of cells may form individuals of a higher order, with the various parts of the cell complex fitted together in a state of mutual dependence.

6. Two processes are therefore involved in the making of such organisms: I) cell division and 2) cell differentiation. 
7. The fitting of a part of the cells to perform special functions follows the universal law of specialization, that special fitness for one thing involves limitations in respect to other things.

8. The primary differentiation in all the higher organisms is that into germ plasm and body plasm, the former appearing in cells of two complemental sorts, eggs and sperms.

9. Increase in size of the cell complex necessitates supporting structures and circulatory apparatus, but these parts in the different plant and animal groups are exceedingly different in structure.

I0. Exposure to the air in terrestrial organisms necessitates the removal of the organs for intake of oxygen from the surface of the body and the development of epidermal layers to withstand evaporation.

Besides these matters of general organization, there are many other things pertaining to the functions of organisms, to the phenomena of growth and metabolism, to the finer structures of protoplasm and to the behavior of its parts in reproduction, that are common to plants and animals. A few of the better known (cytological) phenomena of the behavior of nuclear parts in reproduction, will be briefly noticed in the next chapter.

The simpler organisms best illustrate the common features of plant and animal organization. The forms we have been considering in Chapter III illustrate rather a few of the main lines of divergence: but beneath their diversity lie the common features just stated. All living things are composed of one kind of substance, that is organized into equivalent structural units, that increases by one method of growth, and that reproduces successive ganerations from a common starting point. 
The principal groups of organisms. - In the foregoin studies we have had before us representatives of a few of the larger groups of plants and animals. We have not time to

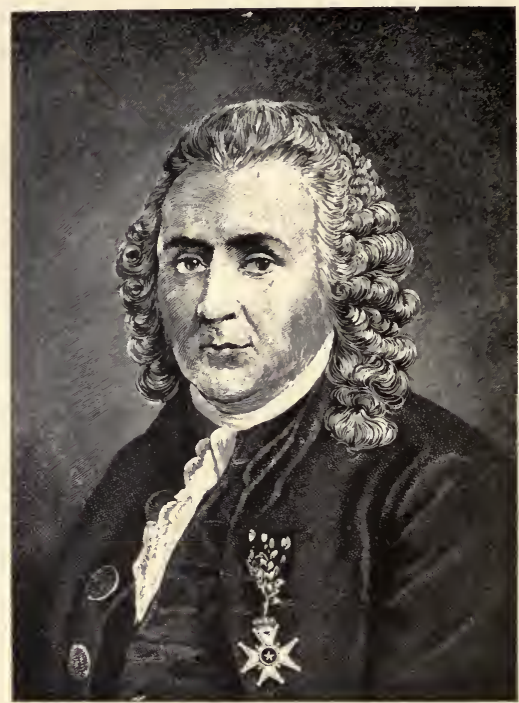

LINNAEUS

(I707-1778)

A great pioneer systematist; founder of the binomial system of nomenclature; author of Systema Naturæ etc.

develop a system of classification, or even to enumerate a the groups, but a tabular statement of a few of the large and more important groups is given on the followin page: 


\section{Plants}

I. Thallophytes, algae and fungi.

II. Bryophytes, liverworts and mosses

I. Hepaticæ, liverworts

2. Musci, mosses.

III. Pteridophytes, the ferns and their allies

I. Filicinæ, the true ferns and the water-ferns (Marsilia, etc).

2. Equisetinæ, the horse-tails

3. Lycopodinæ, the club mosses, etc.

IV. Spermatophytes, The seed plants

I. Gymnospermæ, plants with naked seed; conifers etc.

2. Angiospermæ, plants with seeds developing in closed vessels

a) Monocotyledons

b) Dicotyledons.

\section{Animals}

I. Protozoa, one-celled animals.

II. Metazoa, many celled animals.

I. Porifera, sponges

2. Coelenterata, polyps, jelly-fishes, etc.

3. Vermes (in broad sense) segmented and unsegmented worms, rotifers, bryozoans, etc.

4. Mollusca, clams, snails, squids, etc.

૬. Echinodermata, star-fishes, sea-urchins, holothurians, etc.

6. Arthropoda, insects, spiders, crustaceans, etc.

7. Tunicata, tunicates

8. Vertebrata, backboned animals.

a) Pisces, fishes

b) Amphibia, frogs, salamanders, etc.

c) Reptilia, lizards, snakes, turtles, etc.

d) Aves, birds

e) Mammalia, mammals. 
II. GENERAL EVOLUTIONARY PHENOMENA AS ILLUSTRATED IN BRIEFER SERIES OF ORGANISMS.

In the foregoing studies we have given brief consideration to a very few plants and animals, selected to illustrate the two main lines of organic development, corresponding to the plant and animal "kingdoms"; but the wide gaps between the types studied have left far too much to be bridged in imagination. Hydra and earthworm, or liverwort and fern, stand so far apart in point of structure that it is difficult to conceive of all the forms intervening. Let us now compare together some forms that are more alike in order to see, if possible, the nature of the relations organisms bear to each other. In so doing our attention will be given to typical organic phenomena, rather than to typical organisms. These will be grouped for convenience under three heads:

I. Divergence and convergence of development.

2. Progressive and regressive development.

3. The correspondence between ontogeny and phylogeny.

\section{r. Divergence and convergence of development.}

Whatever our views of relationship, the series in which we arrange organisms are based on the likenesses and differences we find to exist among them. This is classification. We associate organisms together under group names because, being so numerous and so diverse, it is only thus that our minds can deal with them. Classification furnishes the handles by which we move all our intellectual luggage.

We base our groupings on what we know of the organisms. Our system of classification is, therefore, liable to change with every advance of knowledge. The earliest groupings of animals were very simple and obvious; "creeping things," "flying things," "fishes of the waters," etc. How recently, indeed, have bats ceased to be grouped with the 
birds, and whales with the fishes. That the very many different sorts of things living in the water were for a long time merely fishes, is witnessed by the common names they still bear: shell-fish, crayfish, jelly-fish, cuttle-fish, etc. Such classification was based on the recognition of the most superficial characters only. Generally the more fundamental characters are the less obvious ones, and are found in internal organs, and in developmental phenomena.

The earliest anatomical classification of land animals, based on the number of feet--bipeds, quadrupeds, hexapods, octopods, decapods, centipedes and millipedes-was vastly improved when the bipeds and quadrupeds and fishes got together on the basis of the common possession of a spinal column as the group Vertebrata, and all the others were dissociated therefrom as Invertebrata. But the development of embryological knowledge in a later period showed that there are characters more fundamental than the vertebrae; that certain of the invertebrates possess in common with all the vertebrates, pharyngeal gill clefts and a notocord; hence Cordata replaces Vertebrata as the more comprehensive group name.

Homologies and analogies.--Our judgment of the likenesses between organisms, or between the parts of a single organism, is based on that essential identity of parts that we call homology*. Two organs are homologous when composed of like parts in similar relations, each to each. Thus, the hand of a man (fig. 26I) and the fore foot of a salamander (fig. 262) are homologous. since they are composed of the same parts put together in essentially the

*A few exceptional organisms, like certain bacteria, are so simple in structure that differences in their bodily organization are hardly discoverable: and their recognition depends in part at least on their manner of growth in culture media, and in the nature of the by-products of their activity. 
same way. On the other hand, when the likeness is superficial only, and not fundamental; when it is likeness in function or in superficial appearance, it is called analogy. Thus the wing of a bird and the wing of a butterfly are

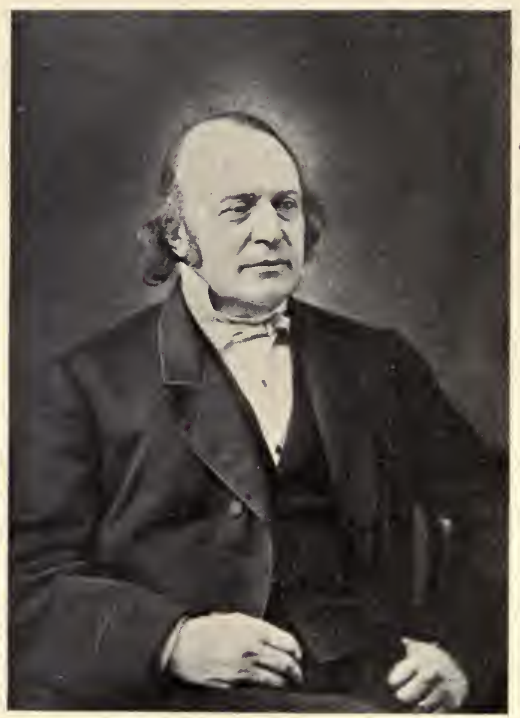

LOUIS AGASSIZ

$(1807-1873$ )

A great teacher of zoology, who did much to promote the development of science in North America.

analogous organs, for though agreeing in form and function they are totally different in structure, and have no component parts that we can recognize as identical.

Homology is, therefore, the ordinary criterion by which we judge of the relationship of organisms. In the neck of 
nearly all mammals there are seven cervical vetebrae, whether the neck be long as a giraffe's or short as a mole's. The foremost is the atlas vertebra, and bears up the skull; the second is the axis vertebra, about which the atlas swings; the other five, although less differentiated, are equally constant in position and relations, and we can not doubt but that these seven are identical. The fore limbs of vertebrates are sufficiently unlike in superficial appearance; we know them as legs in most quadrupeds, as flippers in seals, as wings in birds and bats, and as arms in ourselves; but when we examine their structure we find they are built on a common plan (fig. III), and therefore, homologous. The recognition of homologies often calls for the utmost care in comparison of organs and for discriminating judgment of a high order. It was a dictum of the elder Agassiz that the education of a naturalist consists in learning how to compare.

There is beside this correspondence of parts between different organisms, a similar correspondence between parts that are serially repeated in a single organism. This is called serial homology. It is well represented in the repetition of parts, segment by segment in the earthworm.

The student in this course has already had in Chapter I, a little practice in, identifying homologous parts; first, in flowers (pistils, stamens, corolla, etc.), and later in the parts of the body of insects. A special study of this matter is given here with material more available for critical examination.

The veins in the wings of insects.

The veins that constitute the supporting frame work of an insect wing may bear the following names and designations:

Costa $(C)$ Subcosta $(S c)$ Radius

Media $(M)$ Cubitus (Cu) Anal veins (A) 
The order in which they are named is that of their arrangement from front to rear. Branches of veins are conveniently designated by numerals added in like order to the abbreviation for the vein (as $\mathrm{Sc}_{x}$ and $\mathrm{Sc}_{2}$ for the two branches of the subcostal vein): But there is one large branch so distinctively formed that it has received a special name, the radial sector $(R s)$. All these veins and their usual mode of branching are shown in solid lines in the accompanying diagram of a typical wing. In dotted lines are shown the cross veins of most frequent occurrence. Two of these toward the base of the wing the humeral cross vein $(h)$ and the arculus (ar) have received special names; the others are named in

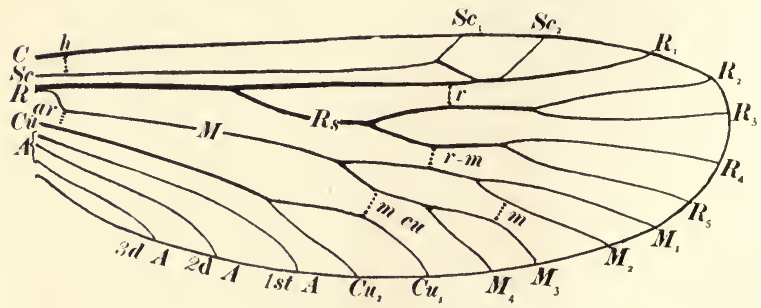

F1G. 138. Diagram of the venation of an insect wing.

accordance with the positions they occupy in relation to the veins. The radial cross vein $(r)$ and the median $(m)$ occupy the principal forks of the radial and median veins respectively, and radio-median $(r-m)$ and medio-cubital $(m-c u)$ connect the veins whose names they bear.

These, then, are the materials with which we have to deal in the following exercise. While they appear simple and distinct enough in the diagram, a glance at the three series of wing figures shows that it is not at once easy to be certain as to their identity. For: 
First, nature has not made the cross veins visibly to differ from the bases of branches, and the angulated and transverse base of a branch may look like a cross vein. It will help in settling their identity to note carefully the type
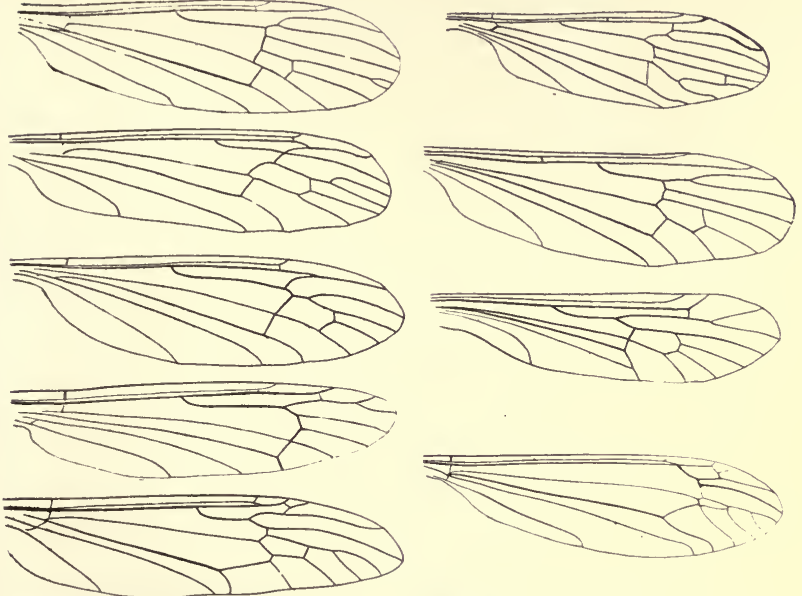

IO
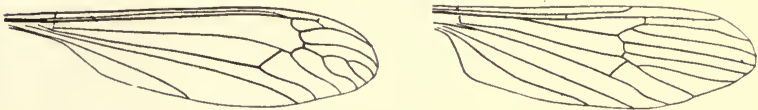

FIg. 139. The venation of the wings of a series of craneflies. $I$, Limnophila; 2, Cylindrotoma; 3 , Liogma; 4, Anisomera; 5, Ctenophora; 6, Dolichopeza;

7. Acyphona; 8, Ula; 9, Mongoma; 10 , Oropeza; 1 r, Erioptera.

of branching of the veins. The radial sector springs from the posterior side of the radial stem, and is typically twice forked, as is also the median vein, while the subcostal and cubital veins are but once forked. 
Second, there are fewer veins in most of the wings figured than in the diagram. Veins may disappear through fusion of two or more branches into one, or, more rarely, by atrophy. Fusions may occur between branches: a) from the tips approximated on the wing margin, proximally to the forks; b) from the forks distally to the wing margin, or $c$ ) by
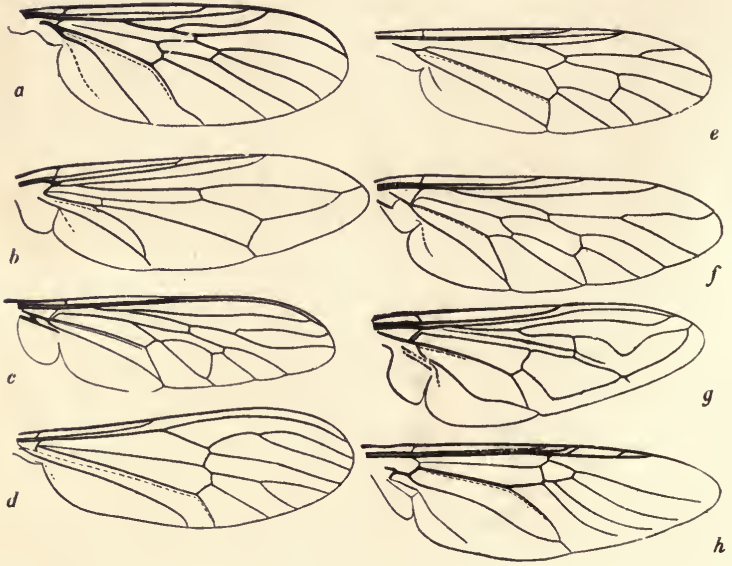

FIG. 140. Venation of the wings of various flies (order Diptera). $a$, Rhyphus; $b$, Conops; $c$, Erax: $d$, Dixa; $e$, Xylophagus; $f$. Thereva; $g$, Eristalis; $h$. Stratiomyia. All from Comstock.

the elimination of a cross vein through confluence of brarches of adjacent veins, and subsequent fusion distally to the wing margin. Various stages of progress in all the methods of disappearance of branches will be found in the wings figured herewith. 
Study 30. Determination of homologies of wing veins in three series of closely allied insects.

Materials needed: Enlarged prints of the wings figured herewith (or of any other series, showing like phenomena), and a single mounted wing of the common cranefly, Tipula, with which to begin.
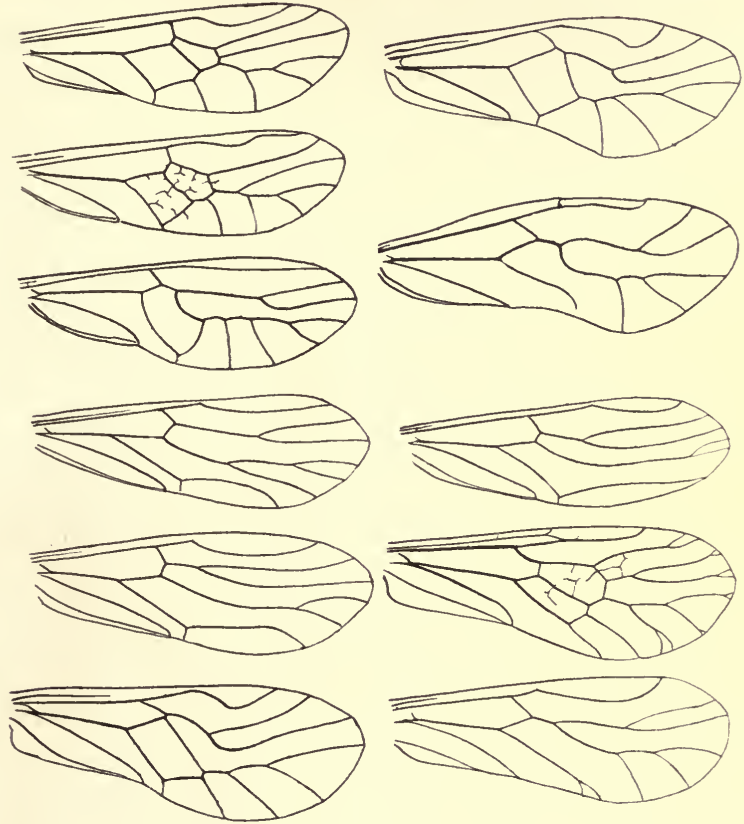

FIg. 141. Venation of the wings of a series ot Psocids. 1, Thyrsopsocus; 2, Dictyo psocus; 3, Taeniostigma; 4, Epipsocus; 5. Ptilopsocus; 6, Myopsocus; 7. Psocus; 8 , Peripsocus; 9. Polypsocus; 10 , Calcpsccus; 11 , Cæcilius. 
First, draw the wing of Tipula, carefully, to see the nature of the material under consideration; for the others, to save time, use the figures, which are reasonably accurate.

Then begin with the cranefly wings series. Carefully label the veins in each wing with the proper abbreviation at base and apex; do this lightly in pencil, subject to later correction. Mark fusions of branches with the plus sign between the numerals of the branches conjoined. Determine homologies carefully. Follow each main vein stem outward and see when and how often it forks. The proof of correctness will consist in having all parts of the typical wing present or accounted for. Omit to name a vein or branch only when it is considered to have disappeared by atrophy; in this series and the next following, veins $\mathrm{M}_{4}$ and $3 \mathrm{~d}$ A may be so treated. Note particularly that the cross veins are all in their proper places, or accounted for. When correctly interpreted the series will be consistent and harmonious, and the correctness of it will be obvious.

Finish the work by coloring the veins alternately in two different colors, and making the cross veins a third color.

Repeat, with the second series of miscellaneous fly wings.

Repeat with the third series, of psocid wings, (fig. I4I) noting here in the beginning that median and cubital veins are fused together in all members of the series from near the base outward well across the wing.

The record of this study will consist in the one drawing and in the coloring and lettering of the veins on the prints, and these are to be preserved as material to be used in a subsequent study.

The serial homology of the higher crustaceans.

Serial homology is characteristic of the group of the higher crustacea known as the sub-class Malacostraca, and this group well illustrates how a single plan of structure may run 
through a series of forms of the utmost diversity in appearance, and how parts essentially alike may be adapted to the most diverse ends.

The Malacostracan body, be it an amphipod, an isopod, a decapod, or what not-is composed of a series of twenty* segments, each of which is essentially of the skeletal plan shown in the diagram (fig. 142 ), except that appendages of the foremost segment are typically unbranched and the hindmost segment (the telson) is rudimentary and bears no appendages at a11. Some of these segments may become

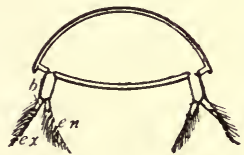

FIG. 142. Diagram of a cross section of the skeleton of a typical body-segment of a malacostracan, with its appendages; $b$, basipodite; $e x$, exopodite; $e n$, endopodite. fused together and consolidated on the dorsal side, only the appendages and ventral margins remaining free. This may occur at either end of the body, but it occurs constantly in the five front segments, these by fusion forming the head. The appendages of these five segments always consist of two pairs of antennæ at the front, one pair of mandibles beside the mouth, and two pairs of maxillæ following the mandibles. These parts and their functions will readily be understood because of their likeness to the parts bearing the sare names in the insects already studied. Immediately following the maxillæ are one or more pairs of maxillipeds, likewise directed forward beneath the mouth to assist in the manipulation of the food. Then follow legs and swimmerets in more or less variety, the terminal joints of some of the legs being modified in many cases into highly specialized grasping organs called chelipeds, and the swimmerets being frequently

*This is not counting a vestigial segment in the head region, that is discoverable only during embryonic life, and with which we have here no concern. 
modified to serve reproductive or respiratory functions. The eight segments following the head constitute the thorax and the seven last segments (counting the rudimentary 20 th segment), the abdomen.

The typical crustacean appendage consists of a single solid basal piece (basipodite) and two jointed branches arising therefrom, one on

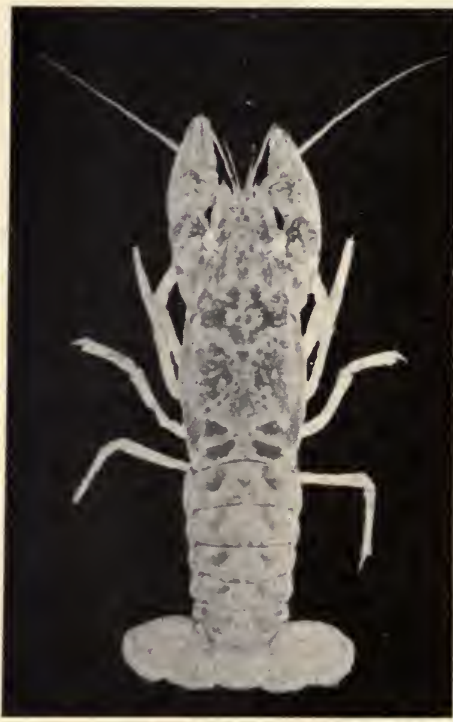

Fig. 143. A common crawfish. (Cambarus). the outer side (exopodite) and one on the inner (endopodite). This typical structure is best shown by the swimmerets of the abdomen. Crustaceans being primitively f r e e-s wi m mi n g aquatic animals, it is their swimming appendages that are least altered by adaptation. The legs are the stoutest of the appendages, and these offer but one branch arising from the basal piece, and that composed of a reduced number of highly differentiated segments. A comparison of a leg with the last maxililpede in the crawfish will show which appendage has been lost and which preserved and specialized. The bestclues 
to interpretation of homologies in any appendage are likely

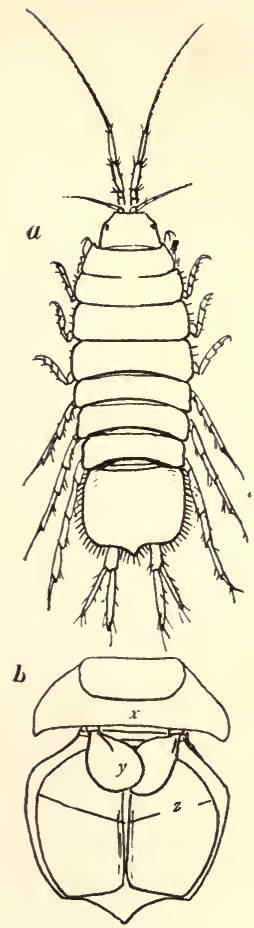

FIg. 144. Asellus aquaticus (after Sars). $a$, dorsal view; $b$, ventral view of abdomen of female; $x$, last segment of thorax; $y$, appendage of abbreviated first abdominal segment (the second segment is without appendages in the female); $z$, gill cover (operculum).

to be found in other adjacent appendages, which , because of proximity, have been subject to somewhat similar influences.

Study 3I. Observations on plasticity of form and persistence of type in Malacostraca.

Materials needed: Specimens preserved in formalin of representative of at least three orders of Malacostraca, Cambarus (fig. I43), Asellus (fig. I 44), and Gammarus (fig. I45): if such marine forms as Mysis (fig. I $58 a$ ) and Squilla and any of the crabs are available, all the better. Also, a few females of each type, bearing eggs, and a few live specimens for use in determining the functions of the appendages. Also, slide mounts of such appendages as are too small to be readily examined in place, or easily removed.

Observe the living specimens, noting especially the different uses to which the appendages are put in locomotion.

Demonstrate the very special water-propelling function of the "gill scoop" that is appended to the outside of the second maxilla in the crawfish, by holding the point of a copying pencil in the water beside 


\section{Table of serial homology.}

ISOPOD

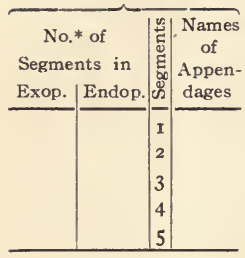

AMPHIPOD

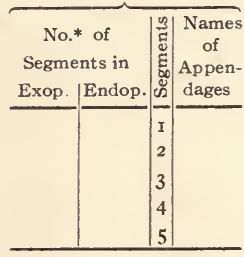

DECAPOD

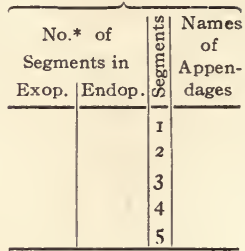

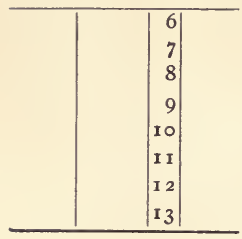
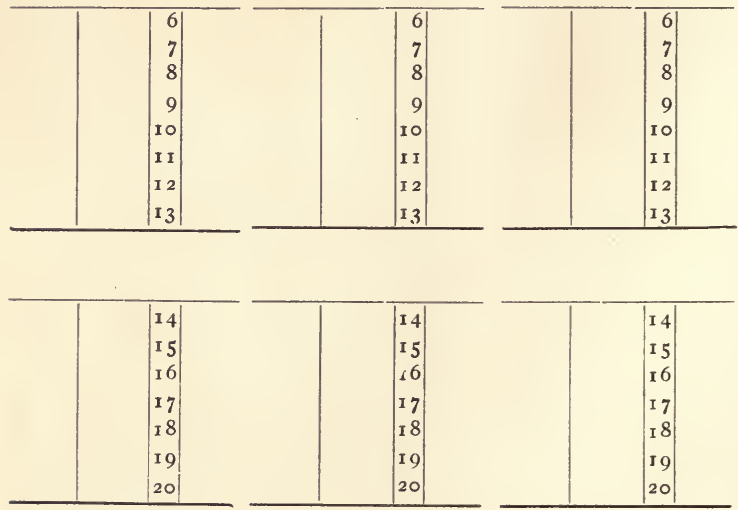

*When more than 10, indicate by the sign for infinity; when in doubt as to number or as to homologies use an interrogation point. Leave space blank only when an appendage is absent.

Bracket together the segments that are consolidated upon the dorsal side.

When different in the two sexes divide the space with a diagonal line and write characters of male and of female in separately.

the base of a hind leg of a living specimen until it dissolves a little, and watching for the colored water to appear at the front of the animal when expelled from the gill cham- 
ber. The passageway through the gill chamber from the rear and outward at the front may be looked up later in a dead specimen.

Study the segmentation of the body and examine the in series, carefully, in the several types, with appendages the aid of the mounted slides where necessary, and fill out a table of homologies prepared as indicated on the preceding page.

Then make out a table of functions for the appendages of the several types, as indicated below, basing it first of all on what you have observed of the uses of the several organs while studying the living specimens. Legitimate inferences as to functions, may be drawn from the form and location of appendages.

Table of functions of malacostracan appendages.

\begin{tabular}{|c|c|c|c|c|c|c|c|c|c|c|}
\hline & 点 & है & 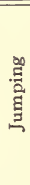 & 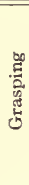 & 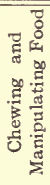 & 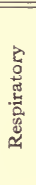 & 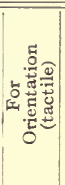 & 岂 & 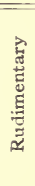 & 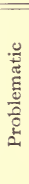 \\
\hline Caml & & & & & & & & & & \\
\hline Gam & & & & & & & & & & \\
\hline Asell & & & & & & & & & & \\
\hline Etc. & & & & & & & & & & \\
\hline
\end{tabular}

*Specify functions in foot notes.

Indicate segments by number only ( $x$ to 20 ), as in preceding table.

Specify characters of male and of female separately, where they differ. 
The record of this study will consist in the two completed tables just outlined, together with a few brief statements as to the relative uniformity or divergence of the appendages of particular segments or particular regions of the body, with possible reasons therefor.

Divergent development has already been illustrated by both the major and the minor series of forms that we have

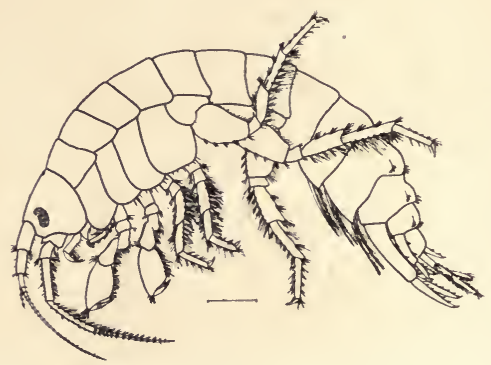

FIG. 145. Gammarus fasciatus (after Paulmier).

been considering. Indeed, in all these, but especially in the two main series, the divergence is greater than has been specifically pointed out; for the lower types in each series represent in themselves the termini of their own lines of development, and not mere passing stages to higher forms. The table of classification on page $22 \mathrm{I}$ is but a statement of the main lines of divergence.

Phylogeny.-The forms of a single line of descent constitute a race, or a phylum. The study of phyla is called phylogeny. A common device for expressing gra phically one's conception of phylogeny is the so-called "genealogic tree." The generalized forms are placed near the base of the tree, the specialized forms, out at the tips of the longest branches, and the intermediates are arranged, according to one's conception of relationship, somewhere in between. The student who has done the work of the last two practical studies will 
understand that the tracing out of natural phyla, even with abundant material, is a matter of great difficulty, and that when forms are insufficient and relationships not clear it admits of great diversity of opinion, and makes errors of interpretation easy.

The divergence of development stated in the systematic table on page 22 I may be more graphically presented to the mind if the groups contained therein be arranged in such a diagram as is shown in figure I46. Such graphic representations of the possible course of evolution have been much used in the past, in spite of their purely hypothetical character; and although less commonly employed now, still they are an excellent aid to the mind in grasping the idea of genetic relationships.

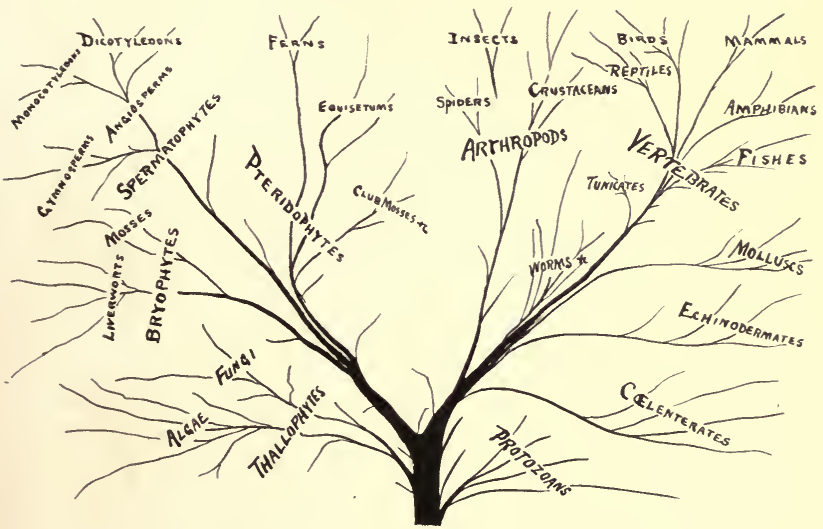

FIG. 146. A genealogic tree; a graphic modc of illustrating possible relationship between organisms. 
Study 32. An attempt at interpreting a possible phylogeny.

Materials needed: The completed drawings from study 30 , with homologies fully determined and verified.

Construct a genealogic tree for each of the three series, that shall show a possible genetic relationship (based only upon the data furnished by the venation of the figures). Assume that the wing of figure ${ }_{1} 38$ is primitive. Pick out the form most like it to go near the foot of each tree. Single out in each series the different ways in which the type has been modified, and make as many principal branches as there are different kinds of divergence. Pick out the most specialized forms for the tips of the longest branches. Arrange the others in position in accordance with their degrees of divergence, and let the branching and the length of the twigs represent this. Derive no form directly from any other that is in any respect morefgeneralized. Compare all wings in each series together with respect to each character, the divergence of the tips of the subcosta, the fusion of the tips of the first fork of the media, etc. Remember that each species is the end of its own special line of development, and place each at the end of a twig.

The record of this study will consist in three genealogic trees (which may be combined into one), drawn without any superfluous branches and with all the forms figured (including Tipula, drawn) located thereon.

It need, perhaps, be stated concerning genealogic trees, that they generally err in being more explicit than the known facts warrant. The figure of a tree does not present a good likeness of evolution as it lies before us at the present time, because the branches of the tree are conjoined in perfectly definite relations. Lines of development are in fact traceable backward only a little way, and are then lost in obscurity. The liverwort shown in figure 147 presents a truer 
picture of evolution as we see it now. Some of the main branches are clearly conjoined; others stand in doubtful relationships. The ultimate origin of all of them is obscure, for many of the older parts have perished. There is a general divergence of the tips, but there is also convergence, and even crossing. But there are enough long stretches of unbroken growth to leave no doubt as to the general course

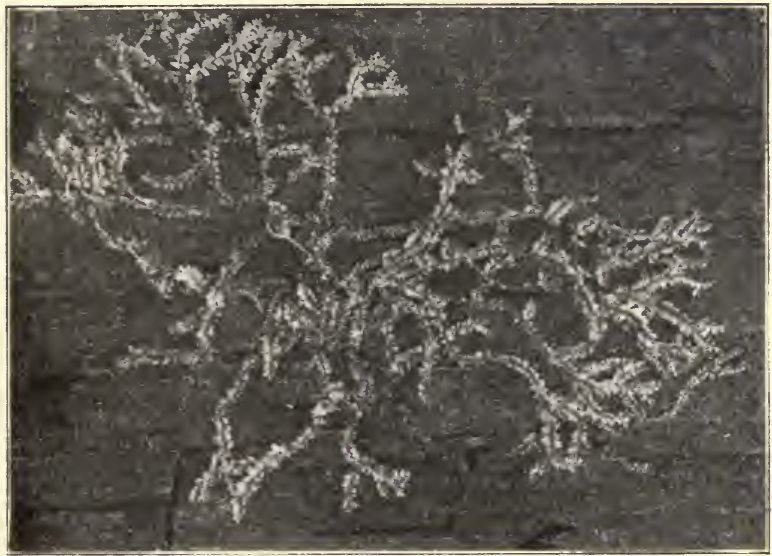

FIG. 147. A leafy liverwort.

of progress, and there is enough convergence of all lines backward to indicate that all the branches may have sprung ultimately from a common source.

Group radiation.-Perhaps the most striking of the phenomena of divergent development is that which has been called adaptive radiation. This name serves to designate that tendency seen in the members of all the larger groups of organisms to become adapted to different natural func- 
tions, and to take on structural peculiarities suited thereto. The phylogenetic lines radiate outward, as it were, from common structural type, into forms adapted to herbiv-
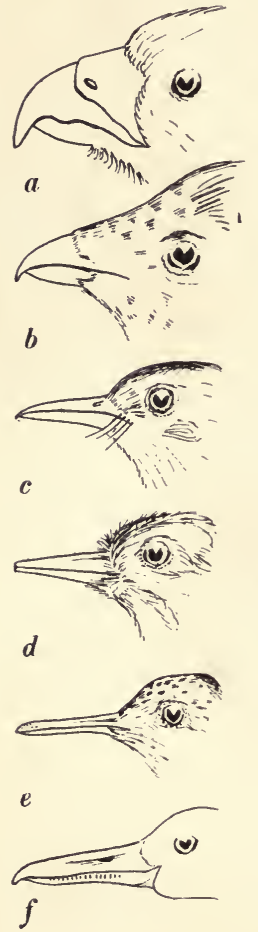

orous or carn i v o r o s aerial or aquatic, or other more special modes of life. Feeding and loc omotion are the two general animal functions that require the most special tools (fig I 48). The accompa n y . ing marginal figures will serve to bring to mind how very diverse are two such organs, beak and feet, in birds. Any dom in a $n t$ major division of the animal king-
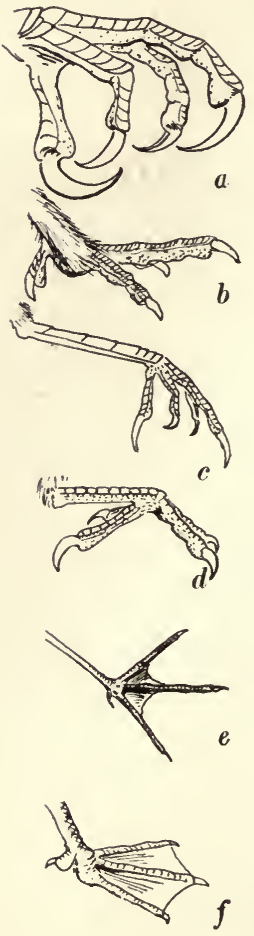

F1G. 148. Beak and feet of common birds, typifying their respective families. $a$, hawk; $b$, grouse; $c$, catbird; $d$, woodpecker; $e$, sandpiper. $f$, duck 
I

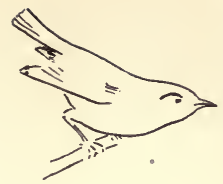

2

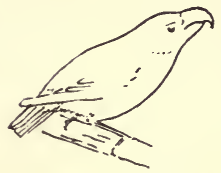

3
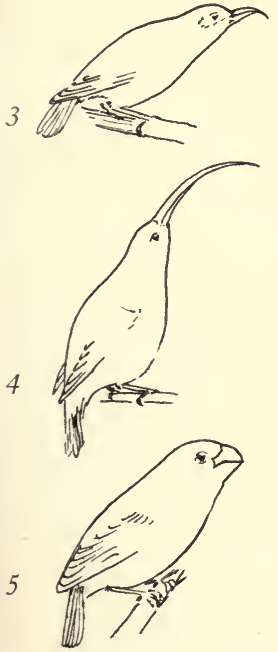

Frg. 149. Hawaiian / birds of the family Drepanida (after Jordan and Kellogg). $\boldsymbol{I}$, Oreomystis; 2, Pseudonestor; 3 , Heterorhynchus; 4 Hemignathus; 5, Chloridops. dom, even single orders when of dominant types (such as the great order Coleoptera of insects, I 50,000 species), will furnish equally striking illustrations. Indeed the best examples of adaptive radiation are furnished by small groups that are dominant within a restricted range. The family Drepanidx of birds in the Hawaiian islands is such an example. The singing birds of these islands are all members of this single family. All are much alike in internal structure, and in all essential family characters, but they differ much among themselves in form of beak (fig. 149) and in other minor characters, as the accompanying outline figure of a few representative selected forms will clearly indicate. These differences are correlated with much greater differences in feeding habits than are usually found among the members of a single family. In our own fauna, for example, this order of birds (Oscines) is represented by a number of families: the families of the thrushes, the finches, the orioles, the warblers, the sparrows, etc., in each of which there is found one form of bill, and a general family resemblance. But the single family Drepanidæ. in exclusive possession 
of the Hawaiian field, without competition except among its own members, appears to have been developed along many divergent lines in adaptation to all the natural functions that are fulfilled by all the families of the order elsewhere; and there are stout seed-cracking finch-like

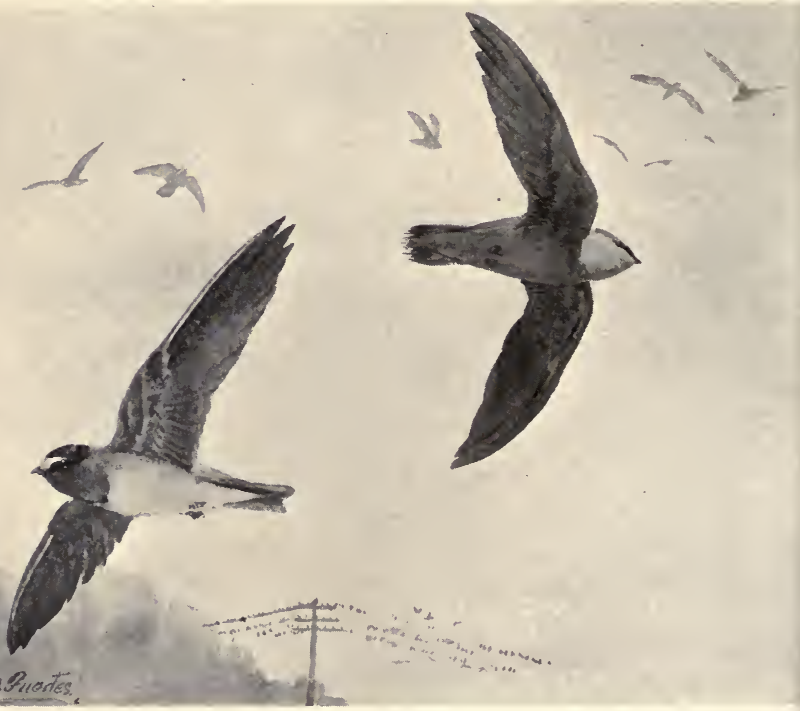

FIG. 150 Swift and swallow (drawn for this book by Mr. L. A. Fuertes).

beaks, and slender leaf-searching warbler-like beaks, and many other forms of beaks possessed by the different members of the one family. A like diversity of group development upon a larger scale is found among the pouched mammals (marsupials) of Australia, and another example among the cat fishes (Siluroids) of South America. 
Convergence.-Convergence of development is less common than divergence, probably because divergent lines, radiating outward from a common starting point, are more likely to enter vacant territory, and thus avoid the stress of competition.

Convergence is manifest in the superficial resemblance of forms that are in essential characters widely different. A familiar example is furnished by the swift and the swallow (fig. I 50 ), birds so similar in appearance and habit as to be readily confused by a novice; indeed, they were long classified together by ornithologists. But they differ in nearly every essential character, and are members of different orders of birds. A comparison of their feet will reveal some of the more obvious external differences. Those of the swallow are of the song-bird type of covering; a series of overlapping scales down the front of the "tarsus" and a single, sharp-edged plate behind. (Compare the tarsus of the catbird figure ${ }_{14} 7 \mathrm{c}$.) And the toes, counting from the hind toe outward are successively 2-, 3-, 4- and 5-jointed. The tarsus of the swift is "rather skinny than scaly," and the toes, taken in the same order, are 2-, 3-, 3- and 3-jointed. Moreover, the tail feathers of the swift are spiny tipped, as in the woodpeckers, with which it has more affinity than with the song birds.

\section{Study 33. A comparison of convergent species.}

Materials: It is perhaps inadvisable to specify particular illustrative material here, since any teacher may have his own "best illustrations" of this phenomenon, which he will regard as most available. The following good examples, will, however, be found readily procurable almost anywhere: I) a bird and a bat, to be compared for the parallel development of organs of flight. 2) Two limpet-shaped insect larvæ common in rapid streams, the "water penny," (larva of a 
beetle Psephemus leconte $i$ ) and the larva of the netwinged midge (Blepharocera) to be compared as to form of body, adapted to clinging to rocks) : or, 3 ) in similar rapid waters. the immature stages of mayflies of the genus Heptagenia

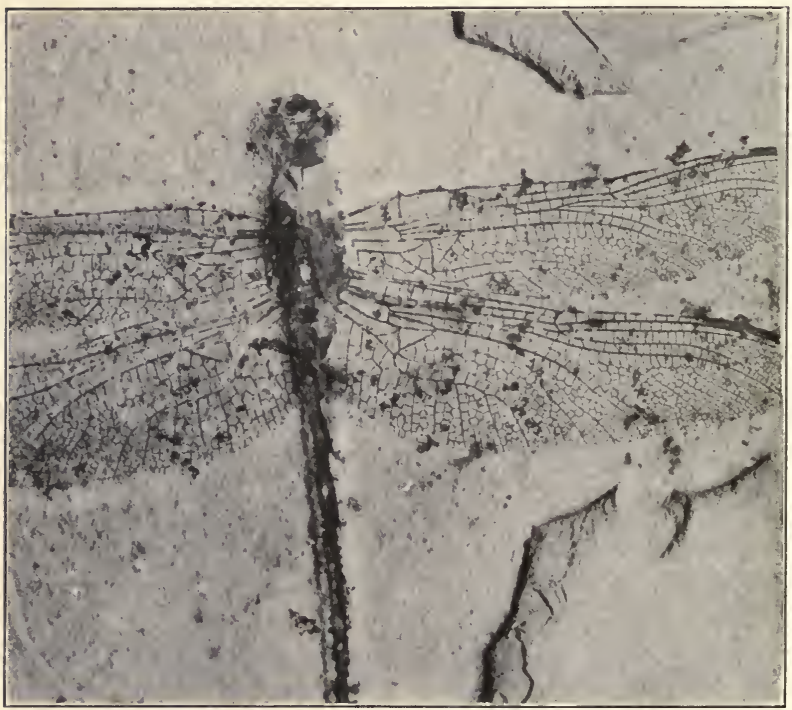

FIG. 151. Photograph of a fossil dragonflv in the Museum of Comparative Zoology at Cambridge, Mass.

and of stoneflies of the genus Perla.

A special phenomenon of parallelism, affecting more superficial characters will be studied in chapter VI under the rame of mimicry. 
The record.-Enumerate carefully the points of similarity in the two forms compared. Then make separate lists of the distinctive group characters of the two which show them to belong to two different lines of development.
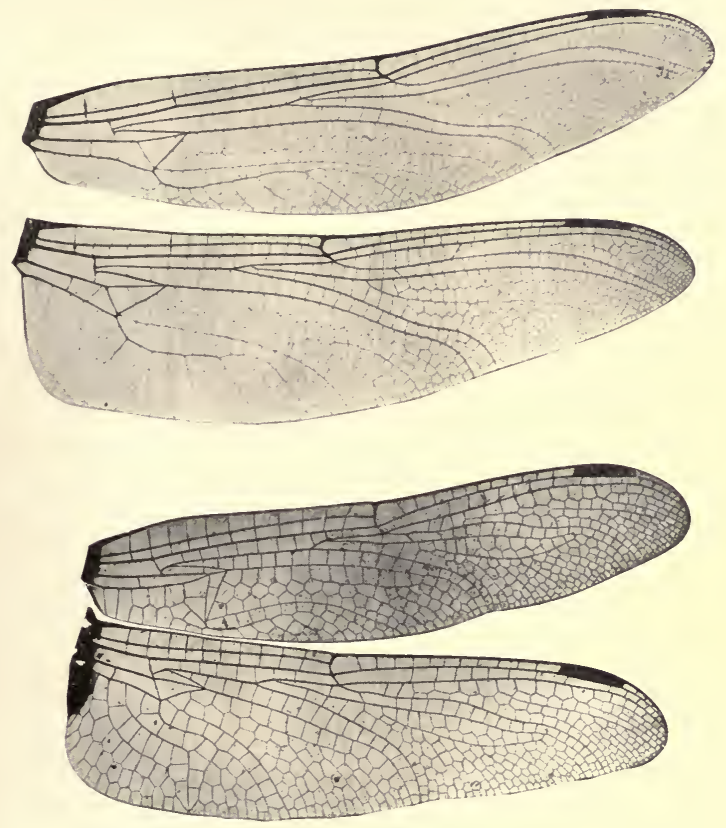

F1G. 152. Wings of two living dragonflies, for comparison with fig. 151. The upper, Anotogaster (family Aeschnidae); the lower, Orthetrum (family Libellulidae).

\section{Progressive and regressive development.}

As a general phenomenon, progressive development needs here no further presentation. It has been illustrated 
by the first section of this chapter, and the figure on page 237 is a map of evolutionary progress. This, however, is hypothetical. It is a conception of what may have happened since life appeared on the earth. How shall we know what actually has happened?

Palæontology offers the actual record of the past history of organisms. This record consists in their fossil remains, buried and preserved in the crust of the earth. It is a very fragmentary and incomplete record; for only the hard parts of organisms are capable of preservation in the rocks. Therefore, the more soft-bodied and primitive forms disappear, and leave no trace. The parts preserved as fossils are fragments, merely, of organisms; shells of molluses; teeth and bones and armor plates of vertebrates; wings and legs of insects, leaf and stem prints of the larger plants. The uncovering of such specimens demands the greatest care, and the study of them demands the greatest knowledge of corresponding parts in living forms. Yet, notwithstanding the necessary defects of the material, the best specimens, and more especially, the best series of specimens, are of the highest scientific value. The degree of perfection seen in the preservation of structures even so delicate as the venation of an insect's wing, is truly remarkable when one considers the long processes of fossilization through embedding in sedimentary rocks. Figure 150 , for example, is from a photograph of a fossil dragonfly. It is a mere impression upon the surface of a slab of lithographic stone from a Bavarian quarry, but how completely are most details of the venation preserved. Even a novice would have no difficulty in determining with which of the two living forms whose wings are figured beside it (fig. ${ }_{5} \mathrm{I}$ ) the fossil form is allied.

Although palæontology has only the hard parts to deal with, every trace of nerve and muscle and every other vital 
part having vanished, yet the case is not so hopeless as might at first appear, for the hard parts, although dead parts, are the permanent defences and supports which the living substance has fashioned, in accordance with its needs and hereditary tendencies. The living substance in every group builds its hard parts on àrchitectural lines of its own, and the parts of organisms are so correlated that missing parts may often be inferred from those that are known. The scattered bones of a fossil vertebrate tend to reassemble themselves in the mind of the palæontologist; there is but one way in which they will go together consonantly to form a possible organism; finding that, a picture of the living organism arises vividly in his mind; and if he draw it on paper, it is what we call a restoration.

It would take us too far from the field of our practical studies of living organisms were we to attempt to consider even briefly the vast wealth of knowledge of extinct forms of life that palæontology has brought to light. For such information recourse must be had to the text books, or to the chapters on palæontology in general treatises of zoology and botany. We may say of organisms, as, in another sense, the poet Bryant said of men,

\section{"All that tread \\ The globe, are but a handful to the tribes \\ That slumber in its bosom".}

Hosts of forms, many of them highly specialized, and some groups once dominant have entirely disappeared from among the living, and the aspect of existing groups has vastly changed during the course of their racial history.

The imperfection of the palæontological record proceeds not so much from its being based on hard parts, as from the fact that the more primitive and more significant organisms lack such parts, and are, therefore, dropped from the record, while the more specialized, although having that degree of hardness which renders them best 
preserved, are the forms that are least instructive as to genetic relationships. But, notwithstanding these things, the record is clearly one of progress in differentiation of parts and in complexity of organization. Seed plants and back-boned animals are absent from the older strata of the

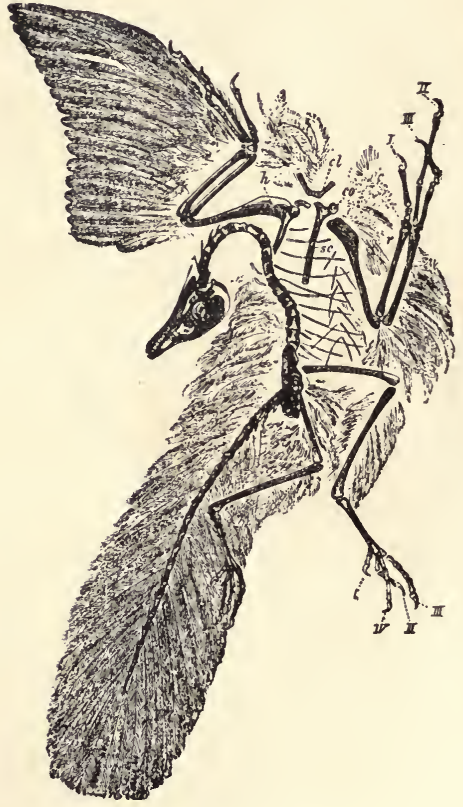

Fig. 153. Archæopteryx (after Zittel). cl, clavicle; $c o$, coracoid; $s c$, scapula; $h$, humerus; $r$, radius; $u$, ulna; $c$, carpus; $I, I I, I I I, I V$, digits. earth's crust. The forms at present living are most $1 \mathrm{ike}$ the later fossils, and the farther we go back among the older strata, the more unlike existing forms do the fossils become. Synthetic types abound: i. e., forms combining characters of two groups that are in their living representatives sharply separated. Such a type is the famous Archeopteryx (fig. I 53) whose discovery brilliantly fulfilled Huxley's prediction (based on com- 
parative anatomy) that the groups of birds and reptiles would be found to be confluent in origin. Archeopteryx is a bird possessed of teeth and a long tail, and other structural characters more like to modern reptiles than to modern birds.

Among fossils there are occasionally found more or less continuous series of forms, successively more primitive, in the successively older geologic formations. To American palæontology belongs the credit of discovery of

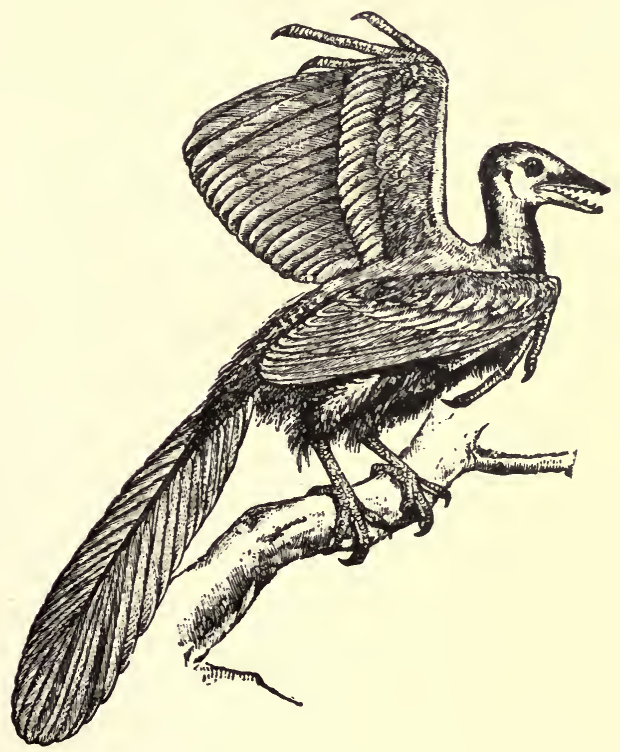

FIG. 154. Archæopteryx: a restoration (after Flower). 


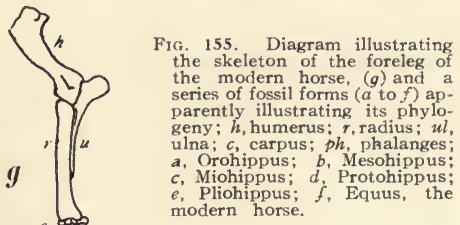

one of the most famous of these, illustrating the phylogeny of the horse. Possible stages in the development of the single toed hoof of the horse as found in fossils are represented in figure I 55. And it may confidently be believed that more such series would be found were the fossils better known. Palæontology is continually filling the gaps between the sundered groups of recent species.

The persistence of the unspecialized.-In spite of the abounding testimony of palæontology that throughout the history of organisms the strong and the well-equipped have frequently dropped out of the race for life, and in spite of the obvious structural advantages of the higher types as we have studied them in the first part of this chapter we still have amœbas and other very simple organisms flourishing in our midst. How have they withstood the stress of competition with forms that appear to be so much better equipped? Why have they not all been exterminated? It may not be possible to say how any particular organism has succeeded, but we do well to remember, first, that size and specialization and organization have their disadvantages as well as their advantages, and second, that most specializations occur in adaptation to removal into new fields 
or into new spheres of activity. Great size may entail great peril in times of scarcity of food. It takes much food to nourish a large organism. A dozen rabbits may fatten where one buffalo would starve. Specialization always means fitness for one set of conditions, and is apt to be disadvantageous when conditions are suddenly altered. Complexity of organization is always a peril. A horse may fall and break its neck, but hardly may a hydra. The mechanism with fewest parts and least complicated adjustments is the one that will best stand rough usage.

This persistence may be further illustrated by an analogy. Reaping machines have had an evolution, almost within our own time. The forms that have successively appeared (and that have successively been dominant) are the sickle, the scythe, the cradle, the reaper and the binder, and these form a series, so to speak, of increasing size, efficiency and complexity of structure. The advent of each new form has only limited the field, has not crowded out, its predecessors. All are in use still. The larger machines are adapted only to broad and open fields; the cradle that once reaped the fields is now restricted to the stump-patch or rocky hill slope; and the sickle finds its place in the edging of the shrubbery or the corner of the garden. All persist together, and the simplest of them is likely to persist longest.

In the second place, these simple aquatic organisms have remained in their primitive haunts of safety, in the ooze of the bottom, or among sheltering stems or rocks, where more or less out of the way of direct competition with stronger forms, and where no sort of cataclasm could well annihilate their whole tribe. These circumstances, combined with a good reproductive capacity, make for persistence.

Regressive development.-This is the phenomenon generally known as degeneration. Retrograde development 
in whole organisms has occurred most frequently as an accompaniment of the parasitic manner of life, and parasites, therefore, furnish its best illustrations. These will be the subject of a special study in a succeeding chapter; but retrograde development in the parts of organisms may be noted here. An excellent example has already been before us in the vestigial fifth stamen of Chelone (fig. $23 r$ ): and the figwort family to which this plant belongs, would furnish a series of forms showing all grades of development of this stamen from normal functional development to complete atrophy. Most functionless organs that are found larger and better developed and functional elsewhere, are vestigial structures. They are developmental heirlooms; useless and unnecessary, but handed down by heredity. There is no other explanation for their existence.

Often the disappearance of their function has accompanied a change of habit or of habitat on the part of their possessor. Thus the abundant stomates of the bladderwort, useless and imperforate, although composed of the two guard cells as in ærial plants, have doubtless been carried over from ærial into aquatic life. The bladder wort (Ltricularia) is descended from terrestrial plants, but now lives wholly submerged beneath the surface of the water. Many such shifts have taken place in the phylogenetic development of the human body. The greatest of them must have been from water to land, from horizontal to erect attitude, and more latterly, from savage to civilized conditions of living; and the vestigial structures are so numerous in man's body that it has been called "a museum of antiquities." The best known of these waning organs of vanished function are the vermiform appendix, the muscles for wagging the ears, the "wisdom teeth," and the hairy covering of the skin. Admirable examples of such organs are the rudimentary lung and pelvic girdle of the snake. 
Retrogression with change of function.-When a waning organ loses its original function, it may be saved by being

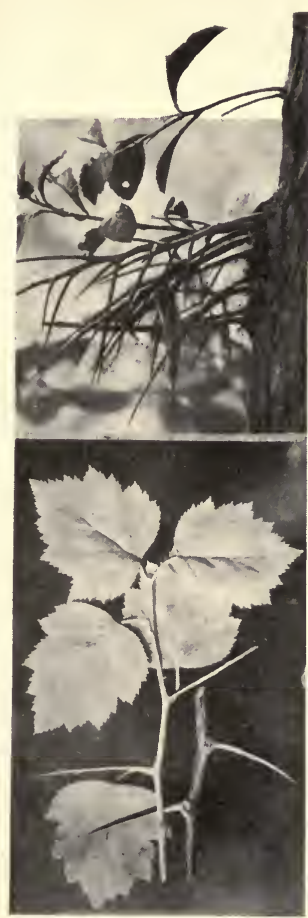

Fig. 156. Hawthorn spines in the making. $a$, compound spines, formed from branches bearing well developed leaves; $b$, simple spines formed from short branches with vestigial leaves. put to a new use. Thus certain of the smallest innermost branches of the our common hawthorns have a brief existence as leafy branches and become transformed into stout defensive spines (fig. I 56) which then serve the tree by opposing the browsing of cattle. The vanishing fifth stamen of Chelone has, in the allied genus Pentstemon, ceased to be a pollen bearing organ, but has become extraordinarily developed to aid in pollen distribution (fig. I 57). It is declined across the base of the other stamens, elongated and protuded in such position that the entering bee walks over its hairy tip, and in so doing shakes the pollen from the anthers of the other stamens down upon its own back.

Specialization by reduction. - It is important to note that the dwindling and loss of parts is generally a gain to their possessors. Organs are of no moment except as they serve the organism. The three series of insects whose wings we have studied all show decided 
improvement in capacity for sustained, speedy and well

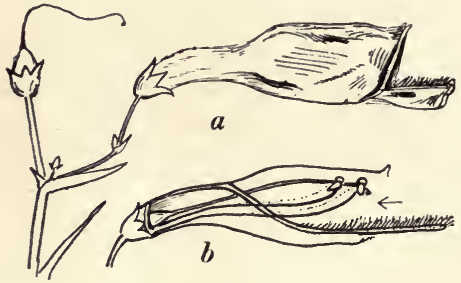

Frg. 157. Beard tongue (Pentstemon pubescens). $a$, a flower viewed from the side; $b$, the same with the side of the corolla cut away, showing the elongated, declined and hairy fifth stamen; arrow indicates the path of the entering bee. directed flight, as the reduction of redundant, and the readjustment of the remaining veins proceeds. It is a sign of a generalized condition when many parts of an organism are found performing similar functions. The earthworm is very generalized in the almost unending repetition of like parts in successive segments. The malacostracan Mysis (fig. 156a)

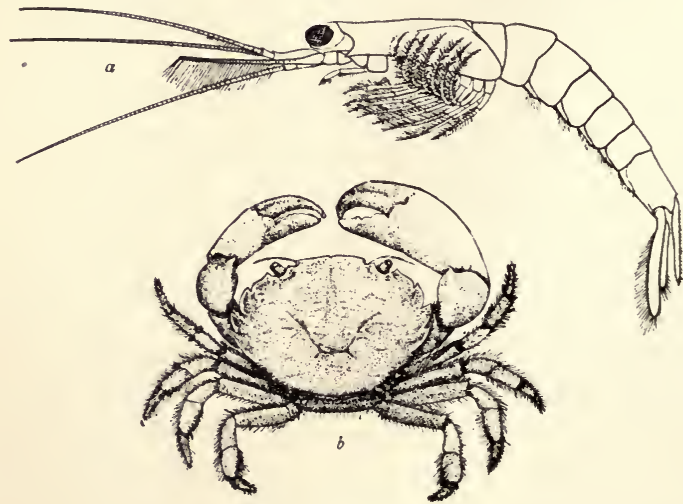

FIG. 158. Mysis stenolepsis (after Paulmier).

$b$, A mud crab. (Panopæus depressus). 
is a crustacean similar to those we had before us in study 3 I, but much more generalized in the possession of a long series of similarswimming appendages, many of which have, in other malacostràcans been modified into legs, nippers, maxillipedes, opercula, stylets, etc., or altogether atrophied (as in the abdomen of the crab, fig. $158 b$ ), with good results. The horse-development series of figure $\mathrm{r}_{55}$ is clearly a reduction series, and quite as clearly a series illustrating the perfecting of the single hoof as an organ for rapid locomotion on land.

\section{The correspondence between ontogeny and phylogeny.}

As phylogeny signifies the development of the race, so ontogeny signifies the development of the individual. The study of ontogeny is the special province of embryology, and investigations in this field have brought to light, in all the great groups of organisms, abounding examples of likeness in plan of structure of developmental stages of higher forms to that of adult organisms lower in the same series. This we have already noted in the salamander. It begins life as a single cell. Its structure roughly corresponds to that of a protozoan. It is, of course, as much a salamander and as little a protozoan at that stage as it ever will be. But its plan of bodily organization is very like that of a spherical single-celled protozoan, and very unlike that of an adult salamander. By segmentation, a blastula is formed, which is very like Volvox in plan, since both consist of a hollow sphere of cells. Then the process of gastrulation makes of it a gastrula, which is much like a hydra, in that there are now two layers of cells surrounding a simple food sac. The correspondence between gastrula and hydra, it must be noted, extends only to general body plan-not at all to the specialized parts of 
the mature hydra; it is rather to a late embryonic form of the hydra, but to one old enough to show the final plan of hydra structure established.

And so the wonderful process goes forward, yielding by the simplest means results that not the boldest imagination could ever have conjectured*. Each new feature reveals some characteristics of a higher type, and each is soon merged with others still newer. The mesoderm appears, and cleaves apart to form the cœlom. Then neural tube and notochord, a heart upon the ventral side and gill slits appear, and it is evidently a vertebrate. But at first it appears to be a vertebrate of very primitive type. It has gills, and a two chambered heart, and a fish-like circulation. Then, more slowly, as we have already seen, these characters are merged into those we call amphibian, and finally it appears in the completed form of a salamander, consonant in general with its species and tribe, and in particular with its immediate ancestors, in form and feature, in proclivities and habits, in faculties and in action.

What a marvel of potentialities is the egg cell! What a marvel of performance is the simple cell-mass we call an embryo, that races down the main travelled road of its phylogenetic history, never going astray though countless paths diverge, and only slackens its speed when nearing its proper destination!

*"Is it the egg which the hen loves?

How should birds know that their eggs contain their young? There is nothing, either in the aspect or in the internal composition of the egg, which could lead even the most daring imagination to conjecture that it was hereafter to turn out from under its shell a living perfect bird. The form of the egg bears not the rudiments of resemblance to that of the bird. Inspecting its contents, we find still less reason, if possible, tolook for the result that actually takes place. If we should go so far, as, from the appearance of order and distinction in the disposition of the liquid substances which we noticed in the egg, to guess that it might be designed for the abode and nutriment of an animal, (which would be of very bold hypothesis), we would expect a tadpole dabbling in the slime, much rather than a dry, winged, feathered creature."-Paley. 
The development of the salamander is but one example of that correspondence between embryonic forms and general plans of adult structure that is exhibited in all the groups. The study of this correspondence by embryologists gave rise to the "biogenetic law" (which is, rather, a rule with many exceptions), that "Every animal in its development tends to repeat in embryonic stages the successive types of structure of animals lower in the series to which it belongs." But this is only a tendency, due to common origin, and a common mode of development. The correspondence is always remote, as we have seen; not to details of adult structure, but to the simplest expression of the structural type, and it may be perverted by any cause, internal or external, that can modify developmental stages independently. It is commonly obscured:

I) By abbreviation of the ontogenetic record. Developmental stages, normal to the higher members of a phylum, may be dropped out of ontogeny. Thus the free-swimming nauplius stage, common to most of the Crustacea, does not appear (as a free-swimming stage) in the development of the crawfish; it is passed over in the egg before hatching.

2) By the coming into predominance in growth of some part of late acquisition in phylogenetic history. The development of the brain in the higher vertebrates is certainly of this precocious sort. The huge brain of the embryo of a bird or a mammal can by no means be regarded as primitive, although it early develops to great size in the embryo.

3) By independent specialization of some of the developmental stages. This is of the commonest occurrence with free living larvæ, which may be specialized in relative independence of adults. The balancers of salamander larvae, present in one species of Ambystoma (A. punctatum) and absent in another closely allied species (A.tigrinum) 
are examples of this. Many others will be seen when a variety of insect larvae illustrating types of metamorphosis are before us in study 40 . The immature stages of mayflies offer a superb example. The adults are much alike in form and in habits, but adult life is very brief and is concerned only with reproduction. But the immature stages are wonderfully unlike, being fitted for life in all sorts of waters. They have specialized independently.

The study of embryology furnished a new criterion of homology. In addition to correspondence in parts and

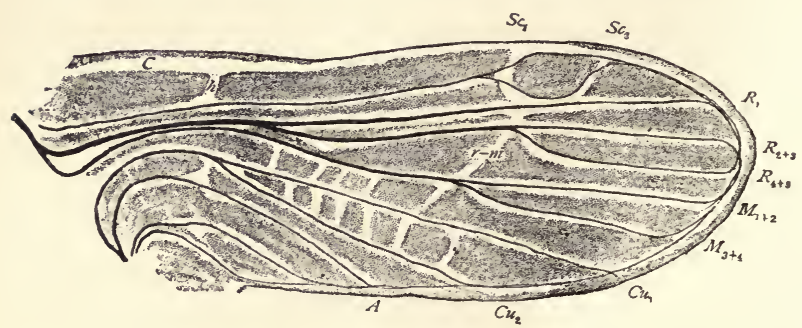

FIg. 159. Wing of the nymph of a stonefly (Nemoura) showing tracheæ, or air tubes, of the wing, with the veins developing about them and between them; note the absence of trachex from cross veins, and the lesser angulation of the tracheæ than of the veins.

relations of parts in adults fundamental likeness has to be judged also by correspondence in development. This is indeed the sort of likeness that shows how deep seated is the homology - the likeness that goes back to correspondence in mode of origin.

Embryology has also vastly extended the field in which homologies may be determined; for, owing to the primitive conditions prevailing in the embryos, their parts may often be readily compared and seen to be identical, when in adult organs all likeness has disappeared. That the coracoid process of the human scapula is in reality the equivalent of 
the separate coracoid bone of the vertebrate shoulder girdle is at once evident when its development is studied; for it arises as a separate bone and has at first the usual position and relations of the coracoid, and later becomes anchylosed with the scapula. Such difficulties as exist in determining what are the principal veins of the wing of an insect, and what is the mode of their branching, disappear when one studies in the immature wing of a primitive insect, such as the stonefly shown in figure $15^{8}$, the arrangement of the tracheæ, about which subsequently the veins are formed.

The correspondence between ontogeny and phylogeny suggests an explanation of hosts of vestigial structures found in embryos. They are inheritances out of the past. Such are the rudimentary incisor teeth of cattle which though present in the embryo never cut the gums, and are wanting in the adult animal. Some of them are useless old heir-looms, of no practical consequence; and many of them are of no value save as they condition the development of other parts. Such, also, are the gill-pouches of bird and mammal embryos; these appear, only to disappear again (save the foremost slit, in connection with which the eustachian tube of the ear is developed), and no gills are formed in connection with them.

Ontogeny often explains the absence in the adult of parts that might be expected. Thus, the carpus of a bird appears to be represented by but two bones, if we study only the bones of the adult bird; but in the young bird an additional row of separate carpal bones is found (fig. I 59) in much the same relations as in other vertebrates.

The tendency of the individual in its development to repeat and reproduce ancestral characters is but the outward sign of that inward force we designate as hereditythe force which tends to make like profuce like. Perhaps it is only a sort of developmental inertia. Racial history 
flows on in the old channels in absence of obstructions sufficient to turn it aside. And the channels are guarded from outside influences by the protection that most living species give to their young during a portion of their develop-

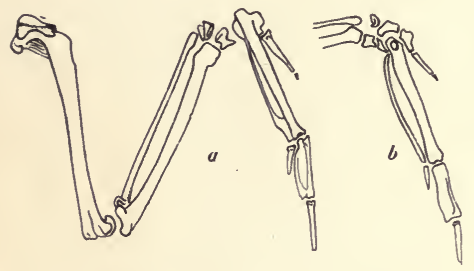

FIG. 159. The wing bones of a fowl. $a$, adult grouse; $b$, young duck (after Coues). ment. We have already seen in both plant and animal series, how the sex organs, especially the ovaries, are developed within the body, out of harm's way. This protection is extended to the embryo.

How much more alike are the archegonia of bryophytes and pteridophytes than any other parts these groups possess! Romanes' classical figures of vertebrate ontogeny, copied on page 262 , show how much more alike are the early embryos of vertebrates than any of their subsequent stages. Wherefore our systems of classification of organisms have tended to be based more and more on developmental phenomena. The bipeds and quadrupeds of old were merged as mammals, animals that suckle their young; and the primary division of mammals became placentals and aplacentals-those that nourish their young before birth through the agency of a placenta and those which do not so. Similar illustrations abound in all the higher groups.

Palæontology makes known to us the life of past ages, by interpreting such fragments of organisms as have actually come down to us. Embryology furnishes historical data of a very different sort-not the organisms of the past, but of the processes of. the past, in so far as preserved in the 
processes of the making of the organisms of the present: Not armor nor bones nor any other finished parts of organs, but the moulding processes of the basic materials out of which all the organs are formed. In these processes embryology gives us evanescent glimpses of the ground lines of phylogeny in so far as they are preserved in the successive stages of development of the individual. That many features of all embryos are ancestral there can be no doubt.

It was the study of embryology that did most to compel the acceptance of the doctrine of evolution in a past generation. And it was this also that stimulated to greater use of the historical method in all fields of investigation. Ontogeny has long been and will ever be one of the most stimulating fields of biological investigation. It is the most synthetic of all. In the bewildering array of forms, it finds a few main types of development, themselves traceable to a commontype in the egg cell. And it shows, withal, how little Nature creates; how much she merely transforms and adapts.

Study 34. The ontogeny of organs in the frog or salamander.

Materials. The results of studies 25 to 28 , together with whatever additional available data reference works may furnish, supplemented by whatever data may be at hand. Ecker's Anatomy of the frog, and Holmes, The Frog, at least should be available for reference.

Tabulate all the organs that show marked ontogenetic changes, under the following headings:

I. Organs peculiar to developmental stages and wanting in adult.

II. Organs functional in young, vestigial in adult.

III. Organs present in both, but serving a changed function in adult. 


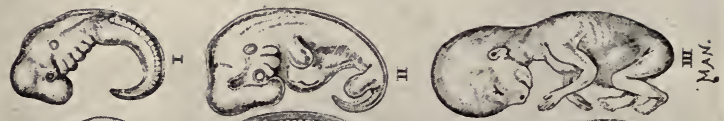

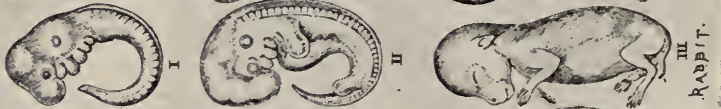
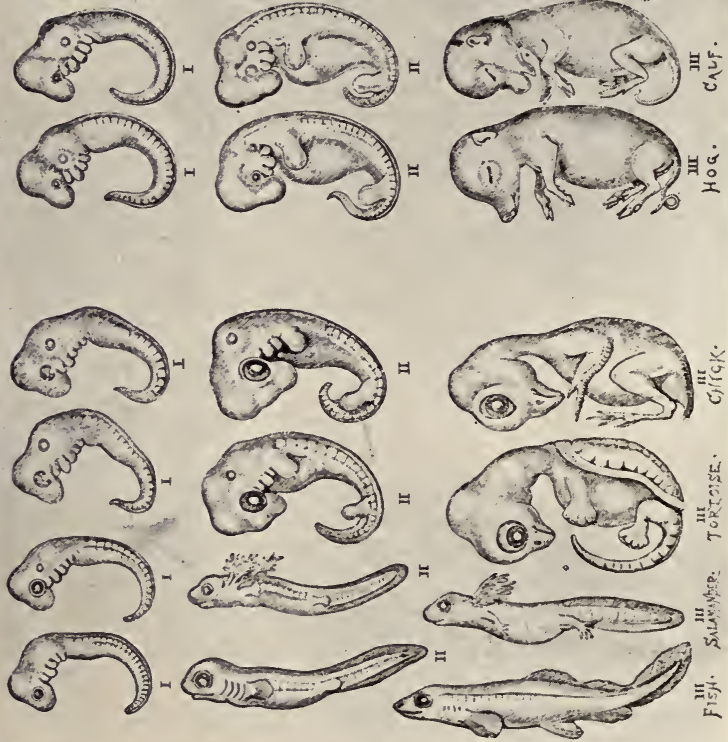

FIG. 160. Ontogeny in vertebrates (after Romanes). 
IV. Organs developed in both, but better developed in adult.

V. Organs rudimentary or absent in young, and functional only in adult.

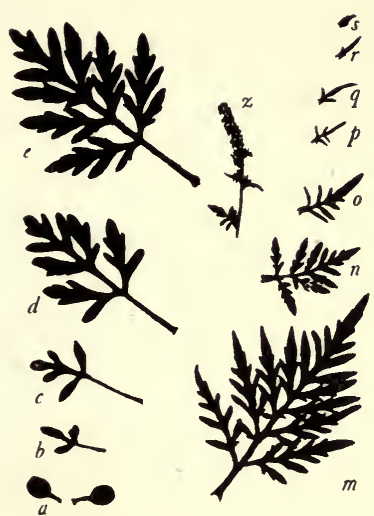

FIg. 161. Leaves of the rag weed (Ambrosia artemisefolia). $a$, cotyledons; $b$ to $e$, leaves successively formed in youth, $m$, the mature leaf form; $n$ to $s$, the diminishing series of leaves successively formed during the period of seed production; $z^{ \pm}$ a fruiting tip.

Progress in regression.-There is an important sense in which all regressive development spells progress. One must take into account the whole manner of life of the organism to comprehend this. Even the most abject parasite, losing all organs for independent existence, is advancing in its own peculiar way of getting on in the world.

There is also a sense in which regressive development is to be considered a part of the normal life of

an individual. As nutritive and reproductive functions come successively into dominence in the lifetime of every organism, so a retrograde development of nutritive organs may begin with the taking up of the labor of reproduction. This is well illustrated by the common rag weed. The leaves shown in figure $\mathrm{r} 6 \mathrm{r}$ were developed at different periods of the life of a single plant. Thry are divided into two series, which parallel the wax and wane of vegetative vigor in the plant. The second series is the one 
of interest here; it begins with the maximum development in size and complexity of leaves at sexual maturity, and, passing through a diminishing series, ends with cessation of leaf production when all the energies of the plant are given over to the ripening of its seeds.

Why evolutionary series?-It has long been the custom of naturalists to arrange organisms in series; such arrangement facilitates dealing with large numbers. The comparative anatomists of the first half of the I 9 th century, who did so much to advance biological knowledge, believed in special creation. and in the fixity of the species. They determined homologies with great conscientiousness and arranged organisms in natural groups; but for them, homology meant likeness in structure merely, and not kinship, and their groups were "natural" in the sense that like had been associated with like in them. The organisms of a series were no more related to each other than a series of one type of vessels made by the same potter. Why then do we consider that natural grouping signifies blood relationship? Why are the series we arrange evolutionary series to us?

It is because evolution alone affords a consistent and satisfactory explanation of the facts now known concerning the structure, the development and the past history of organisms. The student who has done the work hitherto outlined will have felt this explanation. But perhaps it may not be amiss to briefly indicate at this point a few classes of facts that speak especially for evolution, and that seem to stand in the way of any other explanation:

I. The plasticity of species under domestication, and

2. The intergradation of species in nature.

Both these phenomena are well enough known to every observing person and each shows that species are not fixed and immutable. The individuals of a species may, therefore, be arranged in a series with its extremes having very 
different appearance, and the differences between them may sometimes be correlated with their geographic distribution, and sometimes not.

3. The close adherence to structural type in the members of a single group that is modified for great diversity of habit and environment; and, conversely

4. The superficial similarity wrought in different structural types, when they are modified to a common mode of existence.

5. Correlations of structure; when one part of any type is modified for a different sort of life, other parts are modified in harmony therewith. The foot $a$ of figure 148 is never associated with the beak $b$, or with any other beak in the series, except with beak of the type $a$. This is the sort of concordance that makes the interpretations of fossil fragments possible.

6. Vestigial structures; why should these exist at all; except they be ancestral?

7. The tendency of all embryos to recapitulate group characters. Why should such a tendency exist, but for age-lorg heredity?

The palæontologic record is exceedingly fragmentary, and especially lacking in the more simple forms, that would be most significant to us. The phylogenetic record is broken by the absence of connecting forms between the groups, existing organisms being only the twigs of branches that are often widely separated. The ontogenetic record is perverted by marked departures from the original course of development. But, notwithstanding these difficulties, which are so great as to make it easy to err in the interpretation of nature's genealogies, the evidence of descent is thoroughly convincing. It is the more so because of the way in which each of the partial records supplements and corroborates the others, and it is certainly significant that 
the developmental lines traceable backward through both ontogeny and phylogeny are all convergent. They point to a common origin in the remote past, and to "descent with modification."

III. THE PROCESSES OF EVOLUTION; ATTEMPTED EXPLANATIONS.

Facts, such as have been before us in the preceding studies have satisfied biologists generally that evolution has been the method of nature; but the theories that have been advanced in explanation of the processes whereby evolution has been wrought out, have not met with so general acceptance. Yet, if evolution has had a past, it will have a future; and that future is of importance to us, because it must include the destiny of all races, including our own. Nothing could be of more practical importance to us than that we should understand the conditions of evolutionary progress, especially if these conditions should prove amenable to our control.

Many explanations have been offered, and some of them appear in part really to explain. All of them are under scrutiny at the present time. Investigations are in progress to determine their validity. It is well to reserve judgment, but it is also well to know the main features of the current explanations; for such knowledge is part of the common intelligence. Some of the more important explanations will, therefore, be outlined briefly here and in the next chapter.

Natural selection.-The first explanation to receive any general approval (or even to attract much notice) was that of Charles Darwin. He observed how breeders, by selecting and isolating new forms as they arise in domesticated animals and plants, are able to establish new varieties or races. He saw them producing perfectly definite results; 
horses bred for draft or for speed; peas selected for color of flower or for palatability of seed, etc. And in his mind's eye he saw nature producing like results by the removal of the unfit and the preservation of those best suited to her conditions. So, he called the process natural selection.

The theory of natural selection is based on four facts:

1) Organisms vary; 2) In every species more young are produced than can possibly survive; 3 ) Offspring tend to

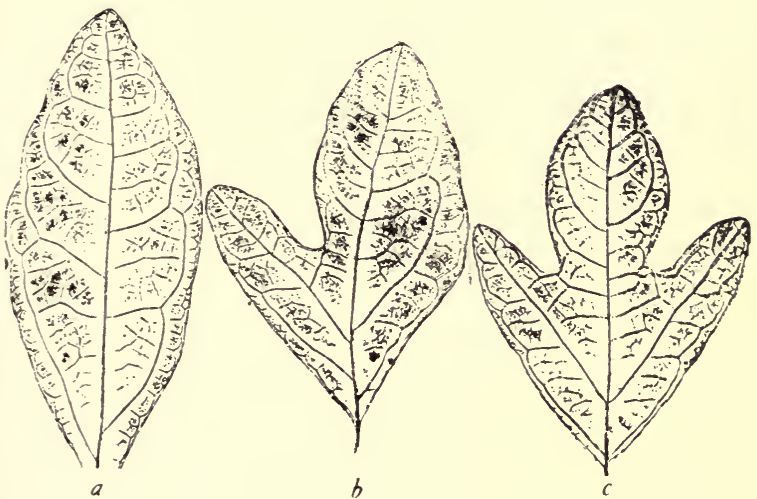

FIG. 162. Three sassafras leaves from the same tree.

resemble parents; and 4) There exists competition between the members of the earth's population.

Inheritance will be considered in the next chapter. Let us here examine the other three classes of facts severally.

Variation.-Animals and plants vary. No two persons look alike, nor do the individuals of any species, on sufficiently close acquaintance. The careful shepherd knows his sheep as individuals, and it is only to the casual observer 
that they look alike. The robins on the lawn may be known personally by any one who will take the trouble to note personal characteristics.

Nature abounds in little refinements of structure, such as we see in the raised lines traversing the cuticle of our finger tips. These lines are never exactly alike in any two persons. So distinct are these differences that finger prints are now-a-days a well recognized aid to the identification of criminals. No two leaves on any tree are exactly alike; indeed those on the same tree may exhibit differences that are very marked (fig. 162).

Fluctuating variations. The differences between the individuals of a species extend to every personal characteristic: stature, streng $t h$, activity, temperament, etc., but they are usually slight, and fluct-

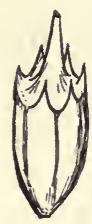

FIG. 163. A six-spined seed uate about a mean that expresses the normal conof the rag weed. dition for the species. This may be simply illus-
trated by the seeds of the common rag weed (fig. r63) each of which bears a long apical point, surrounded by a circle of short spines. The normal number of these spines appears to be six, but many seeds have five or seven of these spines, and a few have even smaller or greater numbers of them. A count of the spines on roo seeds taken at random gives the following results:

No. of spines

No. of times occurring

$$
\begin{array}{rrrrrrrrr}
\text { I } & 2 & 3 & 4 & 5 & 6 & 7 & 8 & 9 \\
\text { I } & 3 & 7 & 9 & 25 & 37 & 25 & \text { r } 2 & \text { г }
\end{array}
$$

If now the seeds of each class be arranged in columns, and a line be drawn joining the tops of the columns, that line will be the curve of variation (fig. I64), a common means of expressing variations of this type.

The class containing the greatest number of seeds (called the mode; the six spined class in this case) may be regarded 


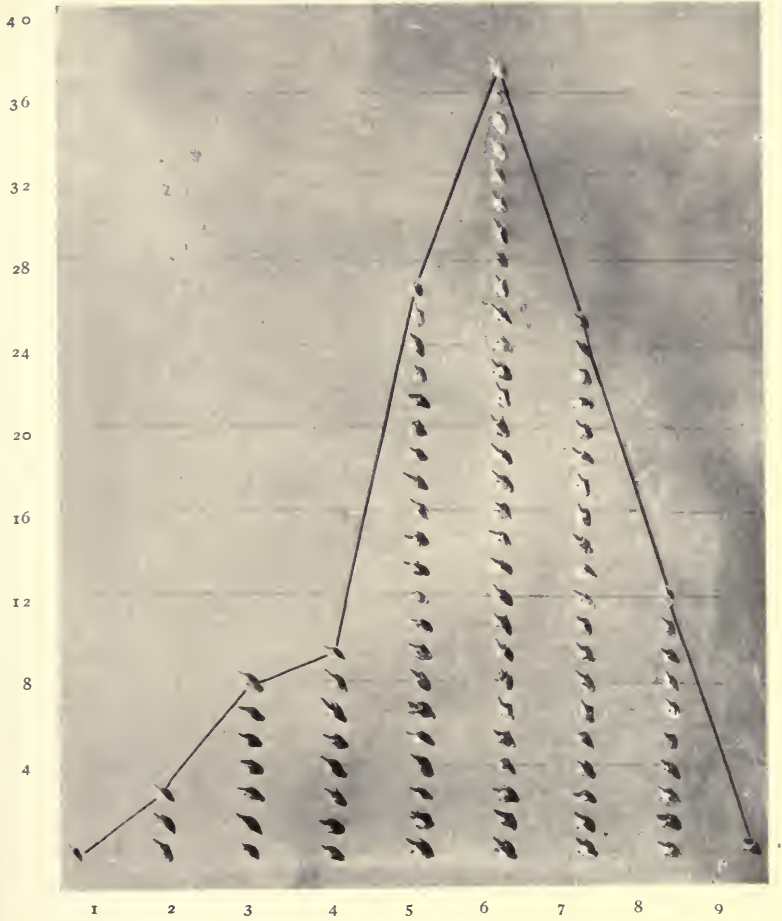

Fig. 164. One hundred rag weed seeds arranged in classes according to the number of their spines. The line represents their curve of variation. 
e

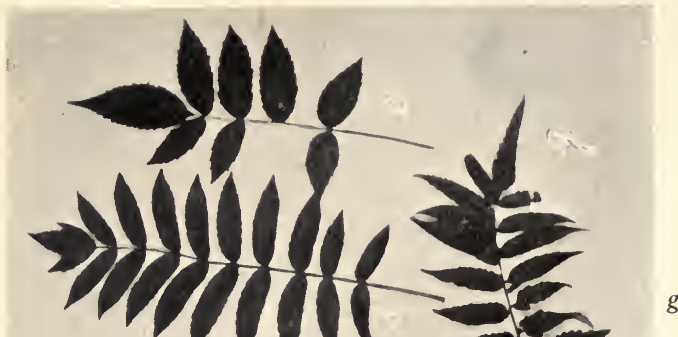

$a$

C
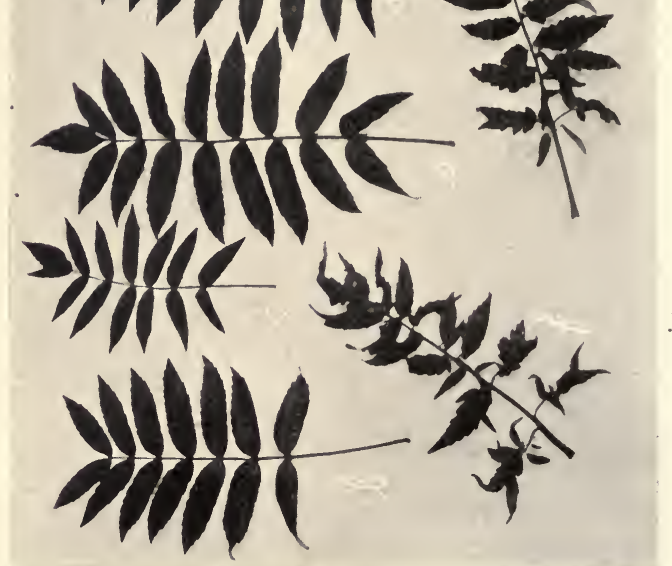

FIG. 165. Leaves of the smooth sumac, showing variation. $a$, the normal odd-pinnate leaf; $b$, an abrupt pinnate leaf; $c$ and $d$, intermediate forms (in the tabulation, sucb were counted for the whole number to which they most nearly approximated); $e$, an oddpinnate leaf with a leaflet of one pair omitted (of rare and probably accidental occurrence); $f$ and $g$, leaves from the base of the fungus gall that is shown in fig. 28 , page 37 , showing a tendency (under the stimulus of the parasite), to be more compound. 
as representing the normal condition for the species. It will be observed that the variations from the normal are here a little more numerous on the side of fewer numbers of spines, but that the curve is nearly symmetrical. It is an approximation to the symmetrical mathematical curve representing the distribution of error. Chance variations fluctuate thus about the normal.

A count of the ray flowers of $3_{5} 5$ heads of the bur marigold, gives, when the results are plotted, a curve that is very much askew:

No. of ray flowers (classes)

$\begin{array}{llllllllll}3 & 4 & 5 & 6 & 7 & 8 & 9 & \text { IO } & \text { I I }\end{array}$

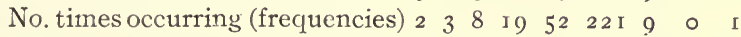

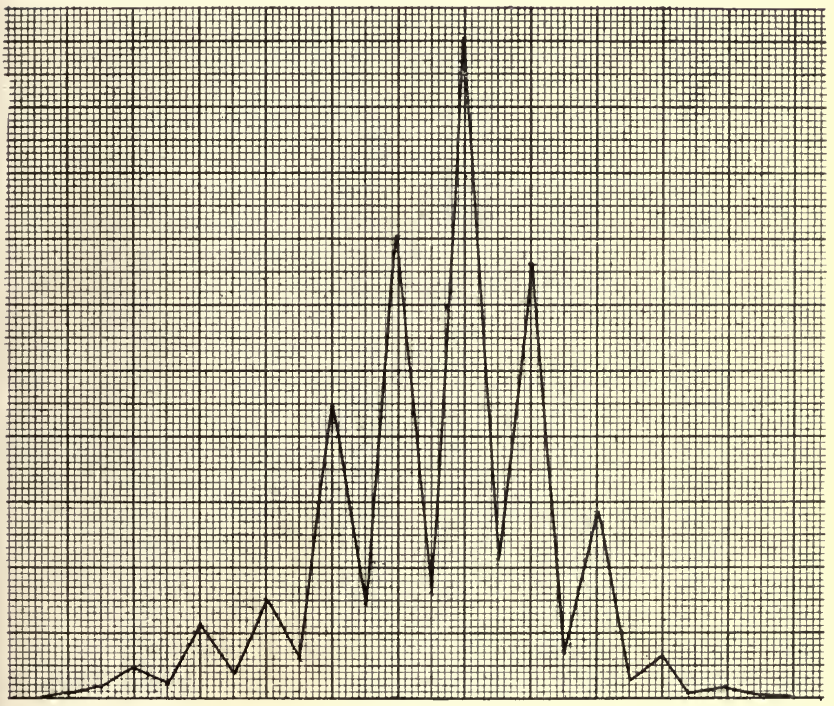

FIG. 166. The curve of numerical variation in leaflets of the smooth sumac, 2730 leaves counted. 
The normal flowering head has eight ray flowers, and the relatively fewer variants are nearly all on the side of the lesser nuinbers.

In the midst of such fluctuating variations there sometimes exists a nuarked tendency toward a definite structural type. Such is the tendency of the compound leaves of the smooth sumac (fig. I65) to be odd-pinnate; that is, to have one terminal unpaired leaflet, with all the other leaflets arranged in pairs. A count of the leaflets of 2730 leaves of this species results as follows:

No. of leaflets (classess)

$\begin{array}{lllllllll}5 & 6 & 7 & 8 & 9 & \text { IO } & \text { I I } & \text { I } 2\end{array}$

No.of times occurring (frequencies) $3 \quad 9 \quad 24$ II $\begin{array}{lllllll}57 & 20 & 75 & 30\end{array}$ $\begin{array}{llllllllllllll}\text { I3 } & 14 & \text { I5 } & \text { I6 I7 } & \text { I8 } & \text { I9 } & 20 & 2 I & 22 & 23 & 24 & 25 & 26\end{array}$ $\begin{array}{llllllllllllll}224 & 7 \text { I } & 352 & 80 & 501 & \text { IO6 } & 33 \text { I } & 35 & \text { I } 43 & \text { I } 4 & 3 \text { I } & 4 & 7 & 2\end{array}$ Here is a total of 1748 odd-pinnate and of 382 abruptpinnate leaves. The broken curve which these figures yield is obviously the equivalent of two similar curves for the two types of compound leaf, and the greater height of the odd-pinnate curve is the index of the tendency toward such leaf type in this species.

Study 35. Fluctuating numerical variations.

Select some common organism or organ having parts that can readily be counted and that vary in number, and study the variation in numbers of these parts. Let the numbers be small ones (for economy of time in counting, preferably not above 20). Such things as the seed spines, ray flowers, or leaflets of a compound leaves just cited in these pages, or leg spines, wing hooks, leaf lobes, etc., etc., are everywhere available in sufficient abundance. Gather the material at random. Count at least roo specimens and record the classes and the number of times occurring, as in the first example cited (see fig. I64). Then plot the curve of variation on a square of cross-section paper, lay- 
ing off the classes-upon the ordinates and the frequencies upon the abscissæ.

Then, if this work be done by a class, let the totals of all the individual

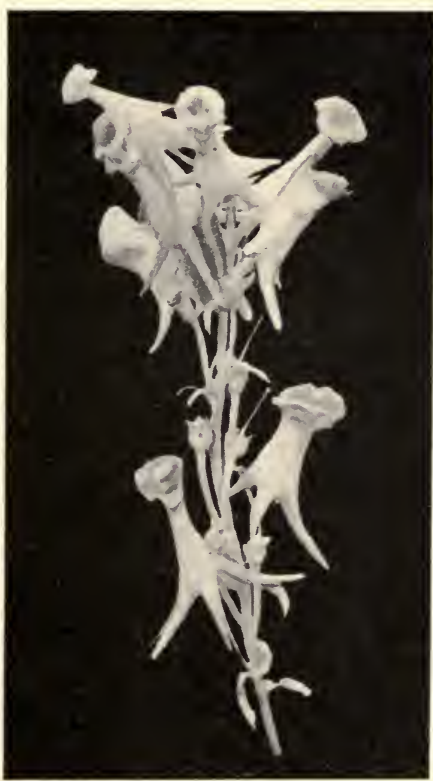

FIG, 167. A probable mutant of Linaria (L. vulgaris), "butter-and-eggs." counts be represented in another curve, plotted in another color upon the same square; this will, on account of the greater numbers, more truly represent the normal variation for the species, and it should be a closer approximation to the symmetrical and balanced curve of distribution of error.

The record of this sturly will consist in:

I) A drawing of a variant showing the normal condition for the species, labelled with the name, and show ing clearly the parts counted and plotted.

2) The individual and collective curves of variation.

Mutation.-Variations are not all so light and inconstant. Figure 167 shows a variant of the common linaria (L. vulgaris, "butter and eggs"), the ordinary flowers of which are 
shown in figure I68. Among the offspring of a single-spurred

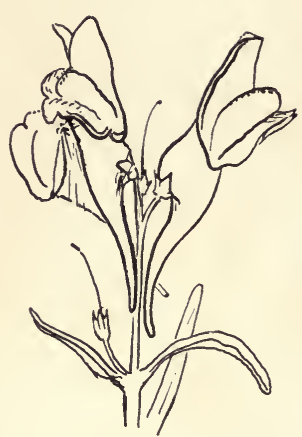

FIG. 168. The normal flowers of Linaria. and strongly bilateral flower appeared this one plant bearing mainly five-spurred and radial flowers. Such larger variations, when they affect a number of correlated characters so as to change the aspect of the organism, and when with self fertilization they are self maintaining (i. e., when they "breed true"), are known as mutations. That mutants establish a new grade of variations is evidenced by the fact that each mutation establishes a new normal, about which ordinary variations fluctuate.

Mutations appear rather rarely, and under conditions that are not at present understood. Their importance as starting points in the development of new races of plants and animals is well recognized by breeders. The long and careful pioneer study of them by Hugo DeVries has madeclear their probable importance as starting points in the evolution of new species. DeVries calls many of the mutants he has found "elementary species." Their significance will again be referred to in the chapter on inheritance.

More young produced than can survive.-The species of organisms differ extraordinarily in the number of young produced, but all agree in the tendency to increase in a geometric ratio. The offspring of a single parent may number millions, or may be but few; but in either case, if all survived to reproduce in like ratio, the earth would soon lack standing room for the progeny. In the edge of the 
pond a single female frog may lay 300 eggs on a spring morning, and she may repeat the performance in successive years. If half of the succeeding generations were females, and were at maturity equally prolific, and if all should survive to reproduce, a simple calculation would show that in a very few years we should have more bulk of frogs than of water in the pond. Three pairs of offspring in one hundred years is said to be the rate of reproduction of the African elephant--a rate phenomenally slow; yet even this is an increase of $300 \%$ in a century-sufficient if maintained without any losses except from old age, to cover the earth with elephants.

It is by excess of births that nature provides for inevitable losses; and the excess is proportioned to the dangers to be encountered in the race of life. A single pike may lay upwards of 80,000 eggs each season, scattering them broadcast in shoal waters, where most of them early fall a prey to other fishes. When hatched, their ranks continue to be thinned, however, in a diminishing ratio, as they become larger and better able to take care of themselves. But if out of all these offspring there remains at maturity for every pair of old pike a single pair of young ones surviving to reproduce each season 80,000 potential offspring, this race of fishes is holding its own; the natural balance is maintained. For more than this proportion to survive persistently would disturb that balance, by depleting the numbers of other fishes on which pike feed. A sunfish that guards its eggs until hatched, need not produce so many of them. But every species, in order to avoid extinction, must produce sufficient excess of offspring to make good the inevitable loss of life during immaturity, and the failures of adult life.

Competition.-For want of food, therefore, and often indeed for want of standing room, the vast majority of organisms born into the world are foredoomed to perish before reaching maturity. Yet the method of nature is not 
more harsh than that we pursue in making a flower bed. For, do we not sow the seed thickly, to insure a good stand, and then thin out rigidly after germination? Among all organisms the vast majority of offspring are swept away by casualties against which they have no power to cope; by exposure to unwonted conditions, to floods, to drouth, to ruthless enemies, to diseases, etc. Here the elimination is wholesale and indiscriminate. But casualties are more or less local and occasional, and they always leave an excess of young to be eliminated by slower methods which allow some play for the powers or merits of the individual, and, therefore, some opportunity for competition.

The struggle for existence.-The thinning out pr cess inevitably goes forward, but it is no longer wholly indiscriminate, for individuals vary. Some are better fitted than others to meet and cope with the perils and exigencies of life. If these be physical agencies, some are better able than others to withstand excess of heat or cold or drouth; if enemies, some are better fitted than others to combat, to escape or to elude; if competitors, some are stronger than others and better able to seize and appropriate to themselves the lion's share of the means of livelihood.

If we did not thin our seedling bed, nature would thin ic for us by the slower, but not less certain methods of competition; and a few of the seedlings of stronger growth, reaching down more deeply with their roots to the food supply in the soil and spreading out their leaves more broadly to the sunlight would prove the better able to maintain themselves.

The survival of the fittest.-Herein lies the efficient principle of natural selection. The fittest survive. Not in the face of casualties; for these sweep out of existence good, bad and indifferent alike. Not in the face of insuperable difficulties; the best'seeds may fall where there is not sufficient 
depth of earth; the best may have no chance of living. And not in times and situations of piping peace and plenty, when there is a living for all, and even weaklings may reach

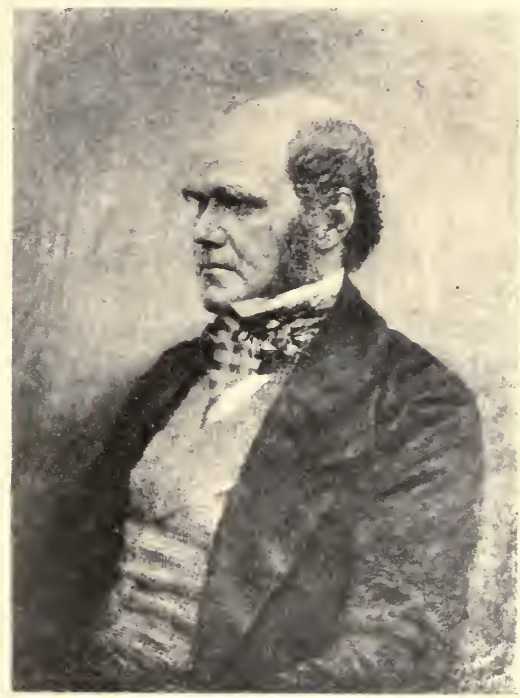

CHARLES DARWIN

(1809-1882)

Prophet of evolution, whose theory of natural selection was founded by almost unexampled industry and patient endeavor: author of "The Origin of Species," the most influential book of the nineteenth century.

maturity. But, casualties and disasters of station aside, and given a stress of competition keen enough to call into requisition all the powers an individual may possess, the fittest survive. They survive to perpetuate their powers in their descendents. This means evolution. 
Fitness.-Fitness for natural selection consists in two things:

I) Ability to get a living and to reach maturity; this is provision for individual needs.

2) Ability to leave well equipped descendents possessed of like good qualities. This is provision for the future of the race. It is not, therefore, the superior excellence of a particular organ, but the balanced excellence of the organism as a whole that is of determinative value. Good leg muscles doubtless make for speed; but speed alone will not avail the hunted hare, if it have not also endurance and instincts of self preservation. "The race is not always to the swift." And all these will be of no moment whatever from the point of view of evolution if it leave no well born descendents. For the sterile variety "carries its own death warrant." What has a chance of survival, therefore, under the most rigid natural selection, will depend on what variation of the several parts of the body appear, and in what combination.

Study 36. The struggle for existence among seedlings.

This study is one that requires time, and observations at repeated intervals; the struggle for existence is not a matter of laboratory periods. Seedling plots of ground, thickly sown by nature to annual weeds are always to be found in the corners of neglected gardens, by roadsides and in fence rows. Other plots in wet, shaded places by streams are overgrown annually by wild touch-me-nots (Impatiens), and in sunny places by smartweeds (Polygonum). If for want of time this study be deemed unarailable for class use, it may be carried out by anyone in his home garden.

Select a plot of ground a few feet square, more or less, free from rooted perennials, in which nature has sowed the seed of annuals and where the seedlings are just beginning to 
crowd one another. Stake it out with markers at the corners. Count the seedlings present and record the number, and note any peculiarities in their distribution.

After allowing time for growth of several additional leaves and a little differentiation in size among the seedlings, count them again, this time in three classes, small, medium and large, and record the numbers.

Watch now the intensification of the struggle for existence and count the survivors of the three classes at longer intervals through the season, and record the results. Count in the end the individuals that are able to mature seed.

Tabulate the results, showing what proportion of each class fruited.

Calculate the area that would have been required if all the plants that germinated from seeds had attained the minimum fruiting size; if all had attained the maximum size of the species.

Artificial selection.-Man selects the variants he finds among his cultivated species of animals and plants, not for the good of the species, but for his own advantage. He selects corn for the starch or for the protein content of the seeds. He selects cattle for beef or for milk production. He selects fowls for egg production or for rapidity of growth, or for form of comb and wattles (fig. I69) or for color or sheen of plumage or for feathers or spurs on the feet; and pigeons and gold fish he selects mainly for qualities that suit his fancy. In the variability of living organisms he finds resources, the value of which he is only just beginning to comprehend.

But, his improved varieties are all weaklings, incapable of maintaining themselves in competition with the wild races from which they are derived, and requiring to be isolated and cared for, in order that the values for which they are selected may be realized. High bred race horses are 

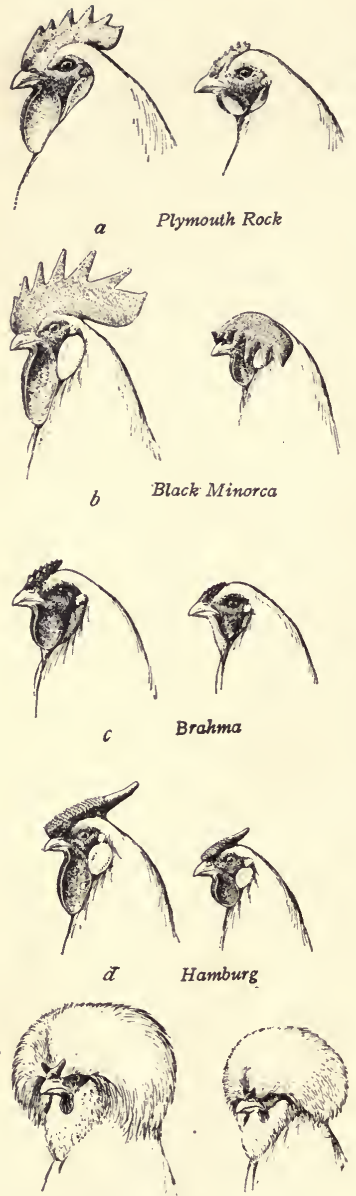

Houdan

short-lived, of nervous temperament and of weak constitution. A bellflower apple is a beautiful fragrant and luscious fruit, but the tree that bears it is quite incapable of entering into open competition with the worthless wild crab apple. Nothing could be more striking in illustration of this point than the certainty with which wild species crowd out the cultivated ones on abandoned farms. Lop-eared rabbits, a nd flightless ducks, and udderencumbered cows, a nd small-boned, small-brained pigs, and hairless, witless, barkless and tailless dogs are all freaks, and nature will have none of them. Her own creations, while often far more curious and extraordinary than any of these, differ from them all in the one essential quality of fitness.

This then in brief is the doctrine of natural selec tion, as a partial explana tion of the process of evo lution. Heritable varia

FIG. 169. Standard varieties of chickens (after Rice). 
tions of whatever sort or origin, furnish the materials of progress, and the competition of life, when of eliminative severity, "selects" the fittest variants for survival, chiefly by the elimination of the less fit. Real selection involves a psychic factor; it may occur if, for example, birds select the most luscious wild cherries or other fruit, whose seeds they carry to a place favorable for growth; or if insects select the showiest of the flowers whose pollen they distribute.

Natural selection is thus seen to be an explanation of the modus operand $\imath$ of those extrinsic forces that tend to make every race conform to conditions of environment. With the intrinsic forces of the living organism, it can only indirectly deal. Natural selection does not, therefore, account for the origin of anything new among organisms, but only for the preservation of such new things as are heritable, advantageous and fit. Nevertheless, it is at this day the one process of evolution whose operations are clearly set forth.

Orthogenesis.-By this name we designate a racial tendency toward some one particular line of development an innate tendency, uncontrolled by external conditions. Such racial development is not fortuitous, but in a single direction, straight ahead, as the name indicates. But orthogenesis is not an explanation of a process; it is merely a name for one.

The orthogenetic tendency is manifest in its incipiency when a group of organisms tends to vary strongly in the direction of some one particular structural type; when the variations are not promiscuous (indeterminate) but show a strongly marked trend. This is illustrated by the inherent odd-pinnateness of the compound leaves of the sumacs; and equally well by the inherent abrupt-pinnateness of the leaves of the cassias (partridge pea, etc.) It is best illustrated by the actual history of races as revealed by the long 
records of palæontology. Many definite lines of specialization, manifestly independent of environing conditions, are traceable among fossils, and some of these lines of specialization may be followed out to their final end. Useful structures, such as in their beginnings natural selection might have favored, have been developed far beyond their optimum, and their possessors have disappeared from the earth. Famous examples are the sabre-toothed tigers and the Irish elk. The canine teeth of the sabre-toothed tiger were so over developed as to be useless, their tips projecting outside the mouth when opened; and the antlers of the Irish elk attained such size and weight as to be a very great encumbrance. Well developed canine teeth are manifestly advantageous for tearing prey, and all carnivorous mammals have them; and strong horns for meeting rivals in combat, are advantageous too, and the males of most social ruminants have them; but in both cases the good thing was overdone; specialization far outran utility.

We need not go so far afield for illustrations of developmental tendencies that have exceeded utilitarian demands. The studies of floral structures in Chapter I should have brought us into contact with numerous examples. What possible use is there for all the complicated apparatus of the milkweed or the orchis flower? or for all the arching, scalloping, and fringing of the lips of a mint flower? Clearly the living substance has inherent powers that manifest themselves in racial tendencies, independently of outward molding forces, and that sometimes are not amenable thereto.

We may perhaps conceive of orthogenesis as a manifestation of a sort of developmental inertia. A genetic tendency, once set going, tends to keep going in a straight line. How it starts we do not know. Natural selection may have something to do with its survival in the beginning, but evidently cannot stop it at the point of optimum develop- 
ment, for we must always remember that there can be no selection of single characters; it is individuals that are selected, with whatever conıbination of characters they may happen to be endowed. If the fittest Irish elk had ever antlers of increasing size, the only possible curb to antler development would lie in the extermination of the line. Natural selection can affect an organ only when that organ causes such manifest unfitness in the organism as is incompatible with the conditions of racial existence.

The phenomena of orthogenesis indicate that the springs of genetic progress lie very deep and that we must look for the origin of species in the origin of variations and of developmental tendencies. This matter will be considered a little further in the next chapter.

Segregation.-The breeder of plants or of animals isolates his choice varieties (except when propagated asexually) in order to obviate the retrogression that would inevitably result from intercrossing with inferior varieties. Biparent ${ }^{\prime} 1$ reproduction necessitates this. Nature also segregates her new forms more or less rigidly, and by a great variety of means, among which may be nientioned both external and internal agencies.

I) Geographic barriers.-Two closely allied species, whose differentiation from one another may have been comparatively recent, are often found on opposite sides of a mountain chain or desert, or other impassible barrier. Thus most of the fishes found on the two sides of the Isthmus of Panama are represented by two clusely allied species, one on one side and the other on the other side. This is held to confirm the opinion of geologists, that the two oceans were once connected across the isthmus by open sea, the assumption being that time enough has elapsed since the emergence of the Isthmus, closing the passage, for the differentia- 
tion of the species from each other and fron the common original stock.

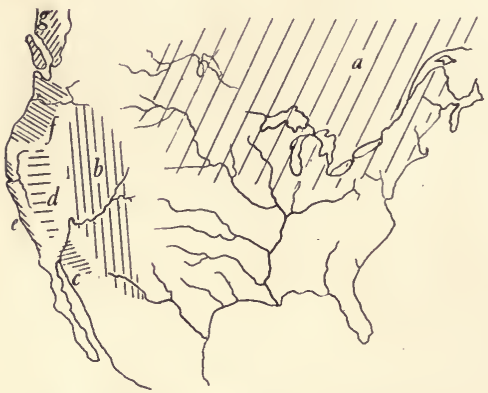

FIG. 170. Diagram of the distribution of the common song sparrows of North America. Shaded areas indicate the range, $a$ of the eastern song sparrow; $b$, of the Rocky Mountain song sparrow; $c$, of the gray song sparrow; $d$, of Samuel's song sparrow; $e$. of Heermann's song sparrow; $f$, of the Oregon song sparrow, and $g$, of the rusty song sparrow.

This is segregation of the most obvious sort. Many a wide ranging species has varieties or sub-species for every distinct faunal area within its $\mathrm{range}$. The accompanying map illustrates the geographic distribution of $t$ he races of the common song sparrow.

Whatever the means employed, nature has practiced segregation on a large scale, even isolating more or less the larger groups of organisms - the palms in the tropics of the world, the marsupials in the Australian region, etc., etc. This is a subject of great biological interest and importance, but it falls outside the scope of our practical studies and therefore, the student is referred for fuller statement to general works on the geographic distribution of plants and animals.

2) Climatic and meteorological conditions.-Temperature and altitude, rainfall and winds, and other similar influences differentiate desert and plain, meadow and forest, and all the host of animal and plant forms that accompany them. This is so familiar a matter, that any one who 
has travelled a few hundred miles away from home should be able to illustrate it by recalling the new form of animals and plants met with in the new environments visited.

3) Physiographic barriers.-We often find two closely allied species in one locality inhabiting haunts that are just a little different topographically. This is illustrated by two of our common dragon flies, one of which (Libellula semifasciata) inhabits the small brooks and the other ( $L$. pul-

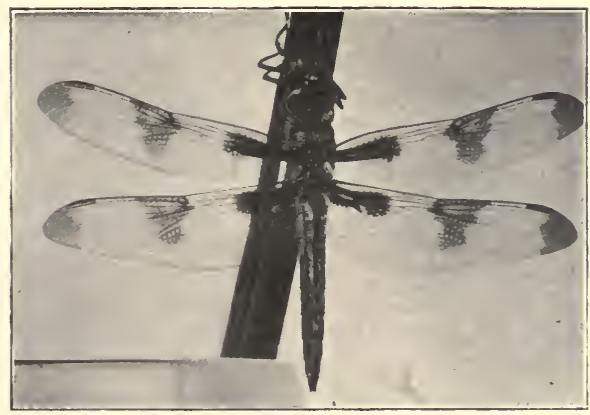

FIG. 171. A common pond inhabiting dragonfly (Libellula pulchella).

chella, fig. I7 I) the small ponds over a considerable part of the United States. This matter will be abundantly illustrated in Chapter VI under the subject of the adjustment of organisms in place.

4) By ecological differences.-Two species niay live eren nearer to each other and yet dwell apart; as in the case of two species of squirrels of the same locality, one of which burrows in the ground, while the other lives and nests in trees. This sort of adjustment in place also will be studied in Chapter VI. 
5) A species might segregate itself into two groups, if among its members there should arise narked differences as to the date of the breeding season. Those maturing early could only mate with others of like early development, and would thus be segregated, (permanently, if this seasonal habit were heritable) from those that mature late. Differences like this would be likely to be correlated with other differences, and thus two races might begin to diverge.

6) A species might be segregated into two, if two of its groups of variants should be mutually sterile. Such variants occur among cultivated species.

7) Two races are developed out of one species when the variants fall apart in two groups, keep together in these groups, develop a "race feeling," and refuse to interbreed. This is reported to have occurred not infrequently when considerable numbers of deer have been kept in private parks. Birds of a feather flock together, even when the feather is distinctive only of a race or a sub-species. This is the kind of segregation known as "preferential mating.'

These are the principal means whereby nature keeps her creatures apart in separate strains, or in groups of higher rank; far apart if the barriers be external agencies of isolation, but still apari even though near together, if there be such internal agencies as prevent intercrossing.

The interaction of external and internal forces.-So there have been and are still two main types of explanation of the process of evolution, typified by natural selection and orthogenesis; the one emphasizing outward conditions, the other, inner tendencies. The contemplation of the environment, and of the fitness of organisms thereto, leads to the over emphasis of adaptation; the study of the spontaneous and automatic activities of the living substance, tends toward confidence in their sufficiency. The two have much too often been treated as though they were mutually exclusive. 
Direct adaptation seems especially to explain such classes of facts as are furnished by geographic distribution, especially of island life, by parallelisms, by mimicry, by degeneration, etc. Let us illustrate by means of the parallelism of the swift and the swallow. How have these birds that are so different structurally, become so very much alike in form, in flight, and in foraging habits that it requires something of an ornithologist to distinguish between them? It is a peculiar field for bird life that they occupy. Above the ponds and lakes there hovers a teeming population of midges and other little insects excellent for food. How have these two, of all the groups of birds, become so finely and so similarly fitted to profit by it? Is it more likely that internal forces automatically produced such external likeness built upon persistent structural unlikeness, or that a common environment, imposing common conditions, has, acting through long ages, shaped to common forn and function those parts with which it came most directly in contact? When we note the numerous details of similarity that are coupled with convincing evidence of diverse origin, we incline to doubt that these likenesses can be wholly due to internal spontaneous developmental tendencies, just as we doubt the originality of two essays that show many points of correspondence. Surely internal forces would modify internal form, as well as external. The impress of environment appears in this that it is the outside of organisms that show all the special fitnesses to the environing conditions. As at distinguished American zoologist has graphically stated it, "The inside of an animal shows what it is; the outside shows where it has been."

Environmental influence comes out most conspicuously where different environments impose very different conditions; as, for example, when part of a group passes over from terrestrial to wrial or to aquatic life. Some such cases will be taken up for special study in Chapter VI. 
Nature has set bounds to which all the living must conform theinselves. This is seen not alone in externals of form, but also in the very fundamentals of organization. Even the types of animal symmetry correspond to evironment. Of the three main types, spherical symmetry, like that of volvox (symmetry about a, point) prevails where uniform conditions exist on all sides of an organism; radial symmetry like that of hydra and most plants (symmetry about a line) prevails when conditions are alike at the sides of the axis of the body but differ at the two ends; and bilateral symmetry like that of the higher animals (symmetry about a plane), prevails when conditions are alike upon two sides but different above and below as well as before and behind, as they must be in all organisms that travel over the surface of solids.

On the other hand, there are phenomena of divergent development, of the persistence of types through the vicissitudes of all environmental changes, of grotesqueries of form, and superfluities of structure and ornamentation, that speak most strongly for the dominance of the inner forces of life, and that negative or minimize external influences.

But it is not wise to exclude the possible action of either inward or outward forces in development when we know that both are ever present. The sightless condition of the fishes that live in the underground streams of caves in total darkness has often been treated as though it were a case of pure adaptation. But when we note that other fishes belonging to the same family (Amblyopsidæ) have weak eyes and incline to stay in the deeper shadows of the shores, we see that a racial tendency toward this sort of development, may have favored the adaptation. Nature may have segregated the fishes best suited to cave life in the environment best suited to them, and then may have gone on perfecting the adaptation, either directly, or by perfecting the tendency, or by both means concurrently. Inherent tendencies and environmental influences are ever present, and development can only be the resultant of their interaction. 


\section{CHAPTER IV.}

INHERITA.NCE.

Nothing is more familiar than the close adherence of offspring to the specific type of their ancestry. Although variations abound, they occur within very narrow limits. The egg of a frog can produce only a frog; never a newt, or a salamander. A hen sitting on duck's eggs can never avail to hatch anything but ducklings out of them; for there is nothing else in them. Moreover, our confident expectation that offspring will resemble not only their race, but their individual ancestors as well is expressed by the proverb, "Like father, like son."

Heredity and variation are two aspects of evolution as riewed from the standpoint of the present, heredity looking toward the past, and variation toward the future. But whether a valuable variation counts for anything or not in racial development depends, as we have seen, upon whether it is heriable or not. Hence we must ask, whether able to answer or not, what is the nature of the bond between the generations? Such facts as have been accumulated bearing on this question may be briefly considered under two heads: I) the visible mechanism, and 2) the observable results of heredity.

\section{THE VISIBLE MECHANISM OF HEREDITY.}

The process of reproduction is one of the chief distinguishing phenomena of living things. We have in the preceding pages considered numerous remarkable structures and developments connected with it. But to distinguish its essentials we must now retrace our steps and consider again the simpler organisms. The yolk accumulation, the embryonic memt-anes, the milk glands, etc., which we have 
been considering are mere accessories of birth and being. Even the primitive vertebrates lack them all; they have only eggs and sperms, and often merely scatter these free in the water, to develop

FIG. 173. Diagram of the division of a paramœeium (after Jennings). $a$ and $b$ show loss of specific characters; $c, d$ and $e$ show division; $f, g$ and $h$ show re-formation of one of the daughter cells. without further parental contact or influence, and when we reach the simplest b

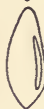

ר

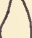

ר

(1)

(

organisms, in some of them we find not even sex cells but only protoplasm; yet there appears to be faithful reproduction of parental characters; and again we are impressed with the fact that the primary functions of life are functions of protoplasm.

In chapter II we traced the origin of separate germ cells. Let us now note certain fundamental likenesses and differences of development with them and without them. First, there is continuity of living substance in either case. A part of the old lives on in the new. The protoplasm out of which new organisms are formed is potentially immortal. Secondly, reproduction is, to a greater or less extent, a new production in either case. Even the two daughter cells of a protozoan are not merely halves of a divided mother cell; for the materials of that cell have been reformed with more or less of change. The unicellular organism undergoes regressive change before division takes place; the specific characters are lost, to be refashioned during the 9 adolescence of the new cell (fig. 173). The process has been aptly likened by analogy to the dissolving of a crystal in its mother liquor, to be subsequently recrystallized out of it.

On the other hand there are very considerable differences, accompanying development by means of germ cells. These 
alone have descendents living on in successive generations. Being protected within the body of a multicellular organism and having no nutritive functions to perform, they are removed from direct contact with environment, and remain unspecialized with reference thereto. The germ cells are developed from the egg along with the body cells, but are set apart therefrom, sooner or later in the course of differentiation. Soon the body cells invest the germ cells with a covering in which they are sheltered and nourished during all their subsequent development. This general relation between germ plasm and body plasm is diagrammatically set forth in figure 174 .

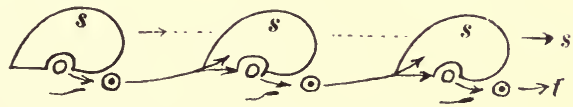

FIG. 174. Diagram of the relation between germ plasm and body plasm. $s$, body plasm (soma), egg and sperm shown below, and zygote (circle inclosing dot) beyond; s, s, s, the line of succession; $t$, the line of descent.

It may well be, therefore, that parent and offspring resemble each other because both are developed from the same stock of germ plasm.

Every organism begins life as a single cell. It behooves us, therefore, to look a little more closely into the structure of the cell. Since the fertilized egg may develop into the complete individual without further parental influence, that new individual must be potentially present, and also the mechanism whereby its parts are wrought out. To the egg cell let us go, therefore, to learn further of the nature of this mechanism. Our task will be easier if we examine the minute transparent, nearly yolkless eggs of such simple marine organisms as sea urchins and starfishes, which if placed alive in sea water under the microscope will go on developing, the divisions succeeding each other in quick 

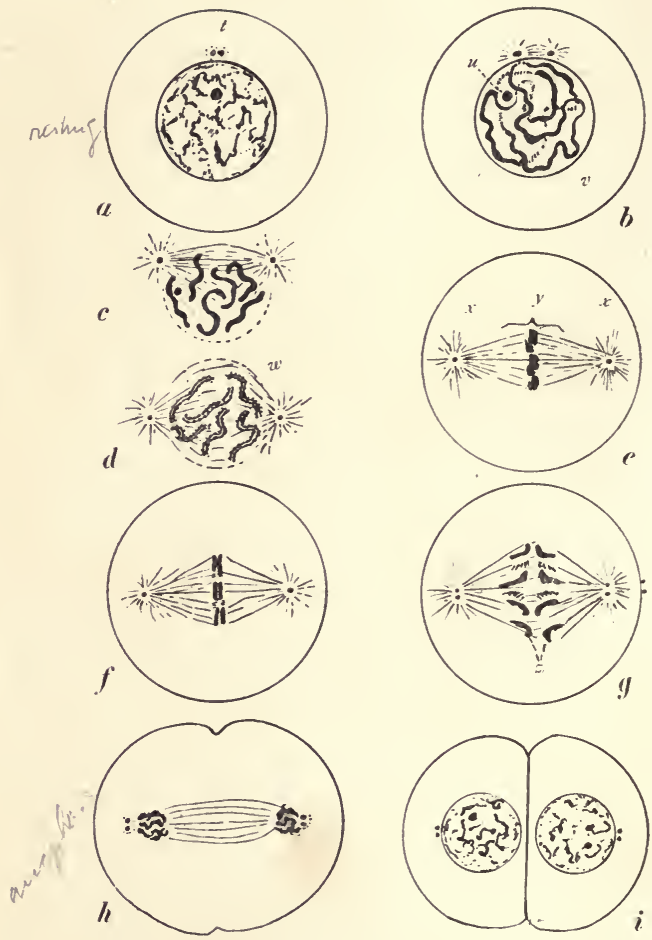

FIG. 175, Diagram of nuclear behavior in cell division (after Wilson). $a$, resting stage between divisions; $b$, beginning of division phenomena; $c$ and $d$, formation of nuclear spindle and fragmentation and splitting of chromosomes; $e$ to $t$, later stages ; $t$, centrosomes; $u$, nucleolus; $v$, spireme; $w$, chromosomes; $x, x$, asters; $y$, chromosomes in equatorial plate; $z$, chromosomes separating. 
succession before our eyes. Nothing could be more convincing of the wonderful refinement of structure of the living substance, or of the precision of its processes, than to watch the behavior of the nucleus in a segmenting egg. And if we supplement what we can see in life by an examination of eggs that have been fixed at different stages, and stained by the precise differential methods of histology, we may discover the chief phenomena of nuclear behavior that regularly recur at every cell division.

Figure 75 is a diagram of ordinary (indirect) cell division. In the resting stage preceding division (a) the nucleus, inclosed by a nuclear membrane is seen to contain an irregularly disposed darker substance (deeply stained in histological preparations) called chromatin. This is deposited in a network of excessively fine and almost invisible threads of a substance called linin. Besides these, the watery fluid in which these lie ("nuclear sap") there is also present, more or less constantly a rounded body, the nucleolus, different in character from chromatin, as shown by its staining reactions. Outside of the nucleus but lying close to it is a minute body, the centrosome.

The first sign of division appears in the division of the centrosome; the resulting daughter centrosomes move apart along the outside of the nuclear wall. The chromatin inside that wall begins to be gathered together in a long convoluted skein called the spireme $(b)$. Before the centrosomes reach opposite sides of the nucleus, the nuclear wall begins to be dissolved. The linin threads take up a position stretched between the two centrosomes and so form the muclear spindle. Corresponding linin threads in the cytoplasm become radiately arranged about the centrosomes to form the two asters. The chromatin of the spireme becomes broken into segments, that are at first irregularly disposed on the linin threads, and that later are shifted to the middle 
of the spindle, as soon as the spindle is fully formed. These are called chromosomes. This completes the first phase (prophase) of division.

Then the chromosomes that have split lengthwise, each into two equal parts, move apart in halves along thelines of the spindle in two equivalent groups. The centrosome also divides. This is the second phase (metaphase) and climax of cell division. Now there is provided the nuclear material for two daughter cells.

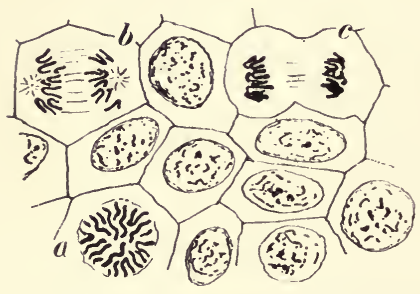

FIG. 176. Cell division in growing tissue (salamander epidermis). A number of resting nuclei, and three in process of dividing. $a$, spireme; $b$, anaphase of division, and $c$, late anaphase.

The two succeeding phases are the reverse of the first two phases.

The chromosomes move in the next phase (anaphase) of division to the ends of the spindle, and form two compact groups, which tend to coalesce more or less into a spireme, and a nuclear wall begins to be developed about them and the spindle begins to disappear. Finally, (telophase of division) the chromatin becomes scattered again upon the finer mesh work of the dispersed linin threads, the cell body divides, and the resting stage with which we began, is resumed. The outcome of these processes is that each daughter nucleus receives half of the nuclear material of the mother cell. However, unequally the cell body may be divided, this process guarantees an equitable distribution of the chromosomes in cell descent.

This is the ordinary indirect process of nuclear division known as mitosis (orkaryokinesis). The figures successively 
formed by chromosomes, aster and spindle, are known as mitotic figures. These regularly appear at every cell division, not only in the embryo, but in almost every growing part of the body, throughout the life of the organisms. They are freely exposed to view in living transparent eggs, but in any developing tissue properly sectioned and stained, nuclei may be seen in some of the division phases above outlined (fig. $\mathrm{r}_{7} 6$ ). These phases follow one another in an inviolable order; each stage conditions the one that is to follow it; and together they seem admirably fitted for the equivalent distribution of those parts of the nucleus which appear most constant.

What role these parts may play in inheritance it is as yet impossible to say. They are all minute, and their study is attended with very great difficulty, The centrosome is usually at the limit of vision with the best microscopes, and, hardly anything is known of its structure. The chromosomes are the nuclear organs most readily followed, and as we have just seen, between spireme and spireme these are scattered in granules on an inconstant linin meshwork, to be reintegrated at each successive division. Only their constituent chromatin persists in our view, and this in particles of such minuteness as to be individually unrecognizable. Yet the chromosomes, as integrates of such particles, show such constant features that we are compelled to attribute considerable importance to them. They appear and reappear in like number and in similar form. The number differs in different groups but it is constant and characteristic for all the individuals of any given species, in all the cells of the body. The number varies from 2 in a species of round worm (Ascaris) to 168 in the crustacean Artemia, ranging in most cases between 12 and 36 . The number appears to be a family characteristic in the grasshoppers, it being 23 in the shorthorned grasshoppers and 33 in the meadow grasshoppers. 
Chromosomes exhibit marked individuality of form, differing in different organisms in length, breadth, curvature, etc., but in a given species, they are fairly constant in form. In certain genera it is claimed that two species may be distinguished as well by the chromosomes of a single cell* as by the external characters of the adult animal.

The history of the germ cells.- Since at the beginning of embryonic life, the egg is already a new organism, charged with the potentiality to develop all the characters of the adult, we must seek the source of these characters farther back. How does the egg come into being? It traces its lineage from an antecedent egg, as we have already seen (fig. I74). That antecedent egg gives rise to both body-plasm and germ-plasm, but the latter is very early set apart from, although surrounded by the former; walls are built up about the germ plasm (spermary or ovary walls), by which it is protected and through which it is nourished. Thus, the germ plasm is removed from direct contact with environment, and also from direct relations with the functional cells of the body, and in this isolation it develops.

The primordial germ cells, thus segregated, pass through a period of rapid divisions which succeed each other in quick succession without much intervening growth, and the result of which is great increase in numbers and great reduction in size. The small germ cells thus produced are called spermatogones or oogones, according as they develop in spermary or ovary. Then follows a growth period, without division, in which the normal size is regained, and much new cytoplasm is formed. The differentiation of the cytoplasm into the different materials that will subsequently be devoted to the production of different parts of the embryo occurs dur-

*They differ among themselves in size and form in the single nucleus; wherefore, it is ordinarily the chromosome complex that offers recognition characters, rather than single chromosomes. 


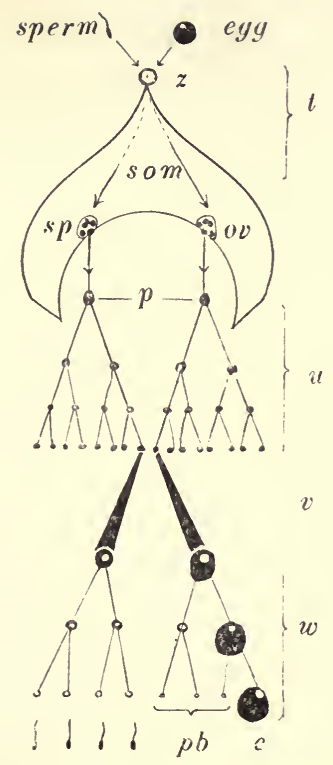

FIG. 177. Diagram of the derivation of the sex cells (after Boveri). $z$, the fertilized egg (zygote); som, the body plasm (soma); $t$, the developmental period during which the germ plasm and the body plasm are indistinguishable; $s p$, spermary; ov, ovary; $p$, primordial germ cells; $u$, the period of rapid increase in number and diminution in size (the number of divisions is much greater than shown); $v$, the period of increase in size with differentiation of cytoplasm; $w$, the two maturation divisions; $p b$, polar bodies; $e$, egg. ing this period. Then follows a period of maturation, or ripening of the sex cells, which involves two successive divisions only, and during which the germ cells are known as spermatocytes or oocytes. The four cells resulting from these two divisions become the sex cells, eggs or sperms, but there is one marked difference, indicated in the accompanying diagram (fig. I77). In the case of spermatocytes, the divisions are equal, and four sperms result; but in the case of the oocytes, the divisions while equal with respect to nuclear parts, are very unequal with respect to cytoplasm,one cell retaining nearly all of it, the others being cast out from it as the so-called polar bodies; therefore, but one functional and perfect egg results.

Such are the form changes undergone by the germ cells during their development, among the higher animals in which they have been most carefully studied. They are not to be considered as occurring at one time only and in a 
direct succession, for many of the primary germ cells remain undeveloped through the life of the individual organism, and in most organisms they develop in cycles, corresponding to

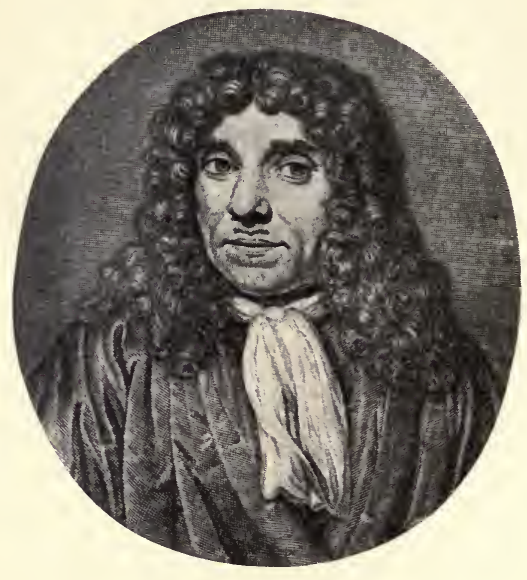

ANTONY VAN LEEUWENHOEK (1632-1723)

Pioneer microscopist and naturalist; maker of his own lenses; discoverer of capillary circulation, of sperm cells, etc.

breeding periods. Division, growth and maturation may often be found side by side in a single reproductive organ. But these external phenomena are mere curiosities of cell behavior, until we inquire what is going on inside the cells. 

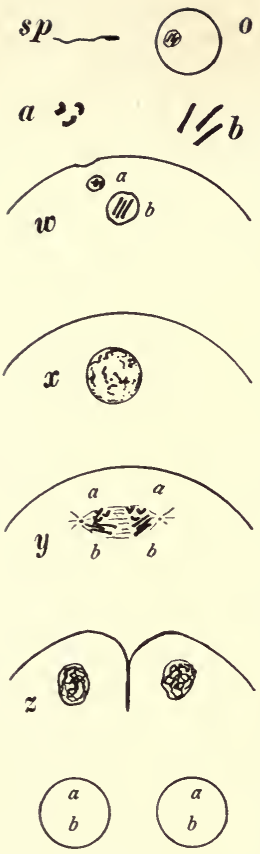

FIG. 178. Diagram of the separate maintenance of paternal and maternal chromosomes as seen in certain hybrids. $s p$, sperm; $o$, egg; $a$, the form of the chromosomes of the sperm; $b$, the form of the chromosomes of the egg; $w$, fertilization about to take place; $x$, the nucleus in its succeeding resting stage; $y$, ing of the two sorts of chromosomes at a subsequent 'division; $z$, division of the cytoplasm: The condition in each nucleus is diagrammatically indicated by the circles below.

\section{Fertilization and maturation.-} The existence of sperm cells has been known ever since the great pioneer Dutch naturalist Leeuwenhoek and his pupils with home made lenses found them in the seminal fluid of animals, but they were long regarded as "wild animalcules." In 1875, Oscar Hertwig established the fact that fertilization consists in the union of one egg and one sperm only, showing that in sexual reproduction each parent contributes one cell of its own body to the formation of the young. Then it became evident that the sexes play an equal, although not necessarily an identical role, in hereditary transmission. This conclusion was strongly reenforced by the important discovery of Van Beneden (1883), that germ cells contain but half the number of chromosomes that is normal to the body cells of their own species. It became evident, therefore, that reduction and fertilization are complemental processes, the one leaving each sex cell with but a half stock of chromosomes, the other restoring to the fertilized egg cell the normal number. At the same time, the sperm introduces new elements into the lineage of the egg cell; 
the new organism must differ in composition from the old.

Every organism, therefore, that is developed from a fertilized egg sets out in life with a material endowment that is derived from two antecedent cells. In its nuclear equipment there are two more or less unlike sets of chromosomes. It is probable that, by the precise mitotic method, the substance of both paternal and maternal chromosomes (fig. I 78 ) is equally divided and distributed at every cell division. We can see that this is so, when paternal and maternal chromosomes are visibly different in form, as is notably the case in certain species that may be hybridized; for in the hybrid embryos two sorts of chromosomes reappear, constant in number and form and grouped by themselves, in successive cell divisions.

Chromosomes.-Protoplasm, the physical basis of life, is of course, the material basis of heredity. Among protoplasmic structures, those of the nucleus maintain the greatest permanence and uniformity of behavior. The chromosomes especially give evidence of continuing individuality of organization. What the chromosomes are we do not know. That they are chemical substances is indicated by their micro-chemical reactions; it is by means of their reactions to specific stains that we are able to bring them clearly into view. Their vital organization is complex. That they play an important role in cell division is sufficiently obvious; mitosis might well have for its object the equitable division of them among the descendent cells. That their role in sexual reproduction is likewise important is indicated by their uniform and parallel behavior in egg and sperm while cytoplasmic parts are undergoing the greatest differentiation.

Naturally, the greatest speculative interest has centered about the chromosomes. They have been assumed to be the bearers. of hereditary characters, and the agents of 
transmission. Imagination has proceeded beyond the limits of vision, and has pictured them composed of "biophores," "ids" "determinants," and other hypothetical structures, capable of handing down unit characters in inheritance. The existence of these, or of any other such mechanism, is not at present capable of either proof or disproof; and need not detain us here. But we may note in passing that some progress has been made in relating characters of the adult organisin to characters of the chromosomes of the germ cells. An excellent example is furnished by the so-called "accessory" or sex-accompanying chromosome of certain Hemiptera and other arthropods. In the squash bug, for instance, in the body cells of the female there are 22 chromosomes; in the male, but $2 \mathrm{x}$. In the cells of this sex one chromosome exists unpaired, all the others are joined in pairs. In the maturation of the sperm mother cells, the division that occurs without the previous splitting of chromosomes, leaves an odd chromosome in half the cells. The resultant sperm cells, odd and even in their chromosome complement, unite with the full-equipped egg cells, as indicated in the accompanying diagram, to produce new male or female organisms, according to the chromosome distribution. This accessory chromosome (fig. I 79), which the female zygote only receives, is sometimes, as in the plant bug (Lygaus) accompanied by a small mate, ( $y$, of the figure), which in fertilization only the male offspring receive. This is a further evidence of the connection between the accessory chromosome and the sex of the adult.

Chromosome reduction occurs, apparently, in all the higher organisms, both plants and animals, but the attendant circumstances appear not always to be the same. It is everywhere a preliminary to fertilization. In the higher plants it occurs at the time of spore formation; and the spores and all the cells of the gametophyte phase, as well as 
eggs and sperms, contain half the number of chromosomes that are found in the cells of the sporophyte. Thus, reduction and fertilization are widely separated in point of time. Two divisions of the spore mother cell with only one splitting of the chromosomes, result in these cells issuing with the half

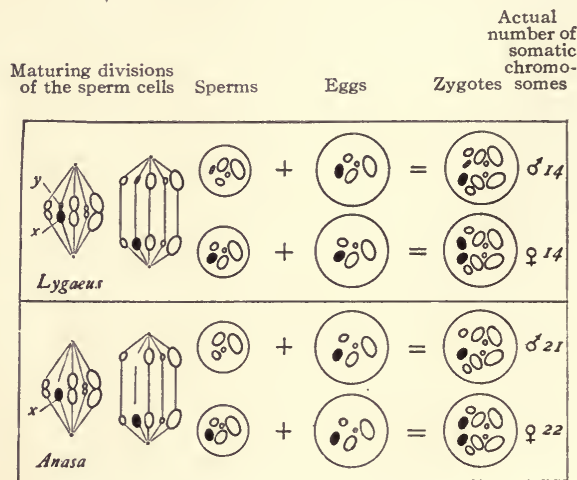

FIG. 179. Diagram illustrating the behavior of the "accessory," sex-accompanying chromosome in fertilization (after Wilson). For the sake of clearness, but four other chromosomes are shown, and these four diagrammatically; accessory $(x)$, solid black.

number in each, just as in the egg and sperm mother cells of the higher animals. If $x$ represent the number of chromosomes in the sex cells, these relations may be expressed by the formula:

The higher $\{$ sperm ( $x)$ Zygote $(2 x)$ The new individual $(2 x) \quad$ sperm ( $x$ ) animals egg $(x)\}$ Gameto- egg (x)

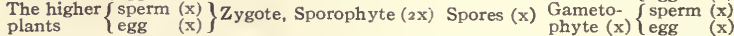

Differentiation of the cytoplasm of the egg.-There is also definiteness of organization in the cytoplasm of the egg. Conklin has shown that in the egg of the ascidian Cynthia there are three kinds of protoplasm that are quite different 
in their appearance and also in their destination in the tissues. I) There is a clear protoplasm that will develop into the ectoderm; 2) there is a gray, yolk-filled protoplasm that will develop into endoderm, and 3 ) there is a yellow protoplasm that will develop into mesoderm. In figure $r 80$ these are imperfectly delimited, the yellow protoplasm being diagrammatically indicated by the heavier stippling, and

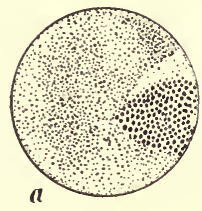

FIG. 180. Eggs of the ascidian Cynthia showing differentiation of organ forming substances in the cytoplasm, lateral views (after Conklin). a. unsegmented, but after fertilization; $b$, in the eightcell stage. the gray by the intermediate stippling; $a$ represents the egg half an hour after the entrance of the sperm cell, but before the first division; the yellow protoplasm has taken up its position in a crescent across one side of the

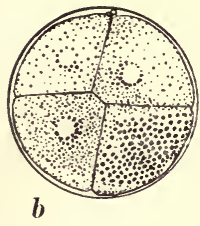
egg, half of it being shown in the figure. The first cleavage plane (median plane of the body to be formed later) will be in the plane of the paper, dividing these substances symmetrically; $b$ is a corresponding view in the 8-cell stage, with the polar bodies still persisting at the upper pole, and the yellow protoplasm occupying a part only of two cells of the lower hemisphere, while most of the gray protoplasm has withdrawn into the other two. The yellow protoplasm will all develop later into the early muscle segments lying alongside the notocord. Here we have definite, predetermined materials for the making of the embryo, which, though differing in kind do not correspond with cell boundaries and which are therefore, clearly unrelated as yet to chromosome behavior.

Synapsis.-There is another process that is believed to intervene in the case of many of the higher animals and 
plants at least. At the beginning of the growth period that precedes the two maturation divisions there occurs a fusion of the chromosomes within the nucleus in pairs, apparently with like paternal and maternal elements in each pair (these elements having, since the preceding fertilization, maintained themselves apart, although in one nucleus). This fusion is called synapsis. It brings into more intimate association the equivalent paternal and maternal units, apparently commingling their substance, and possibly merging the influences they have borne separately since the preceding fertilization brought them together.

Parthenogenesis.-New individuals develop from eggs, and not from sperms alone, but either eggs or sperms alone seem to have the necessary nuclear equipment for the complete development of new individuals; the eggs alone, have the cytoplasmic equipment necessary. In many large and widely separated groups of animals, (aphids and other insects, daphnids and other crustaceans, rotifers, etc.), there occurs habitually the development of eggs without fertilization. This is called parthenogenesis (parthenos, virgin and genesis). In the honey bee, all the drones are believed to be developed from unfertilized eggs. This phenomenon is usually an accompaniment of peculiar conditions of life, and it alternates at longer or shorter intervals with true sexual reproduction.

In the vast majority of organisms, however, the addition of the sperm to the egg is a necessary stimulus that must be supplied before development proceeds. But the eggs of a number of animals that ordinarily require fertilization can be artificially stimulated to develop by temporary inmersion in proper alkaline solutions.

The sperm nucleus also totipotent.-If an egg be deprived of its nucleus, the cytoplasm dies; it has no power to develop alone. But enucleated eggs have been fertilized and caused 
to develop by the experimental addition of sperm cells (fig. 207); the sperm cell enters as it would to fertilize the egg nucleus, but instead, takes the place of that nucleus, and then development proceeds. Evidently the necessary nuclear equipment for development is present in the sperm as well as in the egg, and is duplicated in the zygote in cross fertilization.

The chief facts now before us, regarding the material basis for inheritance are:

r. The continuity of the germ plasm through the generations.

2. In cell division, mitosis, a process apparently well fitted for carrying development forward along the even tenor of its way.

3. In sexual reproduction, fertilization, a process apparently well fitted for introducing new elements into cell lineage.

4. Preliminary to fertilization, synapsis and chromosome reduction.

5. The development of eggs without fertilization in cases of parthenogenesis.

6. The duplication of the chromosome content of the nucleus in fertilization.

Study 37. Observations on cell division, and on the maturation of sex cells.

Materials needed: Prepared slides showing clearly the chief phenomena of cell division, either in growing tissues or in developing egg cells. Freshly laid and living eggs of pond snails showing polar bodies.

The student, duly cautioned as to the damage wrought in tissues in section making, and expedited somewhat in his observations by the guidance of the teacher (a demonstration with projection microscope will for these purposes be 
most serviceable) should study the sections, identifying successive division phases, and should sketch at least the spireme, splitting chromosomes and a complete spindle with the chromosome complex upon it.

Newly laid eggs of pond snails will show the formation of the polar bodies (in external aspect; not chromosome content), and as these persist to the 8-cell stage or later they may be found and sketched in outline in relative proportion to the egg to which they are attached.

The record of this study may consist of notes and sketches of the principal things observed.

\section{Study 38. 'Observations on parthenogenesis.*}

Materials needed: Growing plants of cabbage, turnips or lettuce (or any other green house plant that may be more convenient), infested with viviparous parthenogenetic female aphids; also, small individual plants growing in thumb pots, and covers for them (see appendix).

The student should isolate a newly born, (or, at least, a very young) aphid, transferring it (to avoid injury) on the point of small camel's hair brush to an uninfested lettuce plant in thumb pot, and covering it as in a cage. He should keep the plant growing and watch the reproduction of the aphid from time to time, recording progress at each observation.

Continue through the lifetime of a single individual at least, so that data may be available for calculating possible progeny and rate of increase for a season. Note recurrence of birth of young, and total absence of males during the experiment. Add to your record of this experiment at each time of observation; trust nothing to memory. After the

*This is a running experiment, covering a number of weeks at least, but it will require only a few moments observation each week after it is started. 
isolated aphid begins to bear, remove the young as fast as found to the leaves of the second enclosed plant, leaving the original aphid alone, for certain determination of the number of her progeny. Observe in the other cage the time of beginning of reproduction on the part of the descendent aphids.

The record of this study may consist of diagrams illustrating the method used, and a statement of observations made.

II. THE OBSERVABLE RESULTS OF INHERITANCE.

As bearing on the points just cited, we may note that many facts indicate the uniformity of development, when cell increase proceeds by regular mitotic division, and, on the other hand, that marked changes result from cross fertilization. This is, perhaps, most familiar to the horticulturist, who maintains his choice varieties of fruits by rigid adherence to asexual methods of propagating them, (cuttings, layers, stolons, buds, etc.), well knowing that cross fertilization would introduce new characters to modify (and from his point of view, to deteriorate) his commercially valuable strains. The breeder of domesticated animals has not this advantage. He can increase his flocks only by bisexual reproduction. Hence, he must isolate his pure bred individuals in order to maintain the purity of his stock. This is the key to the efficiency of isolation, as well in nature, as in plant or animal industry.

Pure breeds and hybrids.-In nature, the individuals of a species usually present great uniformity of appearance. They "breed true." But in some wild species there are diverse forms more or less constantly appearing. Sometimes group-differences are correlated with habitat, as in the case of the spermophiles (ground squirrels) of our Pacific slope, where nearly every valley has its own peculiar variety. 
Sometimes they are found side by side, as are the long winged and short winged crickets of the Eastern States, or, they may be related to season, as are three forms of the Ajax butterfly. Species that have been long domesticated always show greater diversity, due to man's influence in selecting and isolating the most divergent types-especially such types as natural selection would ruthlessly eliminate. This is the only way of obtaining new forms. We cannot compel nature to produce anything; we can only wait upon her, and preserve our choice of what she offers, from the swamping effects of intercrossing and from the rigors of a harsh environment. When the breeder of plants or animals wishes to obtain a new strain, he breeds together forms that differ with respect to the characters of which he desires to secure a modification. This is hybridization. If all the offspring of any given variety that is bred inter se, are like in any given character, they may for all practical purposes be considered in respect to that character pure bred.

Types of inheritance.-What the result will be when any two varieties are crossed, what characters the offspring will bear, can only be determined by trial; it will always be the same between the same two pure varieties. Observations on matters of this sort fall outside the possible scope of the practical studies of this course; we will content ourselves, therefore, by noting in passing a few of the more general phenomena of hybridization.

As to heritability of results, the offspring may be sterile, and therefore, self-annihilating. The best known example is the mule, a cross between the horse and the ass. There is no race of mules; other mules are to be obtained only by repeating the crossing of the parent species. Or, the hybrids may be relatively stable, and breed true, as single newformed race from the beginning. The garden sunberry, a cross between two wild inedible species of Solanum, is said 
to be an example, and there are many others among cultivated plants. Or, they may be unstable, as in the great majority of cases, some of which will be illustrated further on. These when bred inter se give offspring of different sorts.

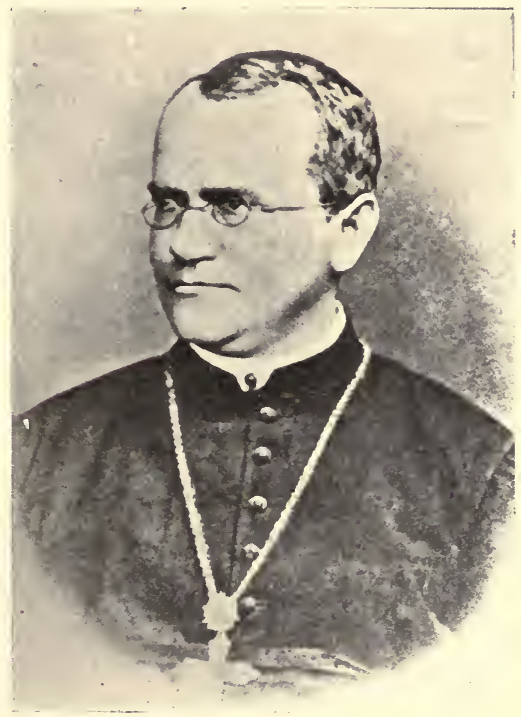

\section{GREGOR MENDEL}

Pioneer student of hybridization; discoverer of the "law of dominance."

The characters that the hybrids bear may be only the characters of their parents, or they may be new characters of their own, the following types of the latter being com. monly recognized: 
I) Blended inheritance. The offspring may possess characters intermediate between those of the parents. If one parent be short and the other tall the offspring may all be of intermediate height.

2) Intensified inheritance. The offspring may be more extreme than either parent. If one parent be dark and the other light, the offspring may be darker than the dark parent.

3) Heterogeneous inheritance. The offspring may exhibit characters differing in kind from those of either parent. Certain races of white and buff pigeons when bred together give slate colored offspring. Possibly, more knowledge of the characters involved in such cases may show them less lawless than has been thought.

Alternative inheritance. When parental characters are preserved in the hybrids, unfixed and unaltered, we have alternative inheritance - the type that has hitherto received most attention, and which in its behavior seems to offer the closest parallel to the behavior of the chromosomes. The offspring of the first generation exhibit the characters of one parent or of the other; but when these hybrids are bred together, in their offspring the characters of both parents reappear. In the first generation hybrids one character appears (is dominant), and the other disappears (is latent or recessive). Both characters are present, but both cannot appear at the same time; a flower cannot at the same time be fragrant and scentless. Both have been inherited, however, along with or by means of the duplicate apparatus for conditioning egg development, and in succeeding generations the parental characters will reappear. This type of behavior among hybrids was first studied carefully by Gregor Mendel, and is often called Mendelian inheritance. 
Mendel's great service lay in a long series of careful hybridizing experiments, from which the principle was deduced that whatever the appearance of the hybrid, it produces germ cells like those of its parents in approximately equal numbers, and the character of its own offspring will be determined by the way in which these germ cells are paired in fertilization. Suppose, for illustration, that D and $R$ of the accompanying diagram (fig. I8I) represent the two parents, which differ in one character only, that of color. $\mathrm{D}$ is black and $\mathrm{R}$ is white. Suppose also black to be the dominant and white the recessive color. Then the offspring in the first generation $\left(F_{\mathrm{r}}\right)$ will all be black. But if they be bred together, their offspring will be both black and white in the proportion of three black to one white. Then, if the

whites be again bred together, all
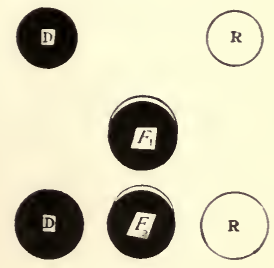

Fig. 181. Diagram of Mendelian inheritance. $D$, the dominant character $R$, the recessive $F_{1}$ and $F_{2}$ the first and second generation hybrids respectively. their offspring will be white. The white character which disappeared in the first hybrids, was obviously still present, and has been sorted out again. This relation between characters in the germ cells has been aptly compared to the putting together in pairs of pieces of glass of two kinds, one transparent, the other opaque; when placed together only the opaque one is visible, but when again separated, both are again apparent.

If, as Mendel supposed, the germ cells possessing the two characters separately, are present in equal numbers in the reproductive organs of the hybrids and are combined in pairs according to the law of chance, there are but four possible combinations of them, giving three classes, as indicated on succeeding page: 
Dand R, germ cells of one hybrid parent

|X | in chance combination with

$\mathrm{D}$ and $\mathrm{R}$, germ cells of the other hybrid parent

$$
\text { give in the second }\left(F_{2}\right) \text { generation, }
$$

$\mathrm{DD}+{ }_{2} \mathrm{DR}+\mathrm{RR}$ in the proportion, (3 black: I white) $n$.

Otherwise stated, if any two of these hybrids be bred together there result the following possible combinations of their characters in their offspring (the characters D and $\mathrm{R}$ of one parent being underscored in order to distinguish sources):

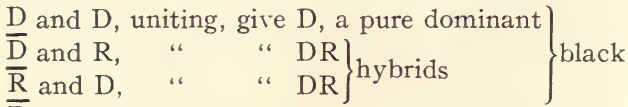

$$
\begin{aligned}
& \underline{\mathrm{R}} \text { and } \mathrm{R} \text {, “ “ } \mathrm{R} \text {, a pure recessive-white. }
\end{aligned}
$$

Of the black individuals it is obvious that there are two classes although all look alike; for one individual out of every three is, like the white, pure bred containing sex cells of one kind only, while the other two are still hybrid in character. The further results of intercrossing of like with like in successive generations is indicated by the following table:

Parents. Offspring, (mated like with like.)

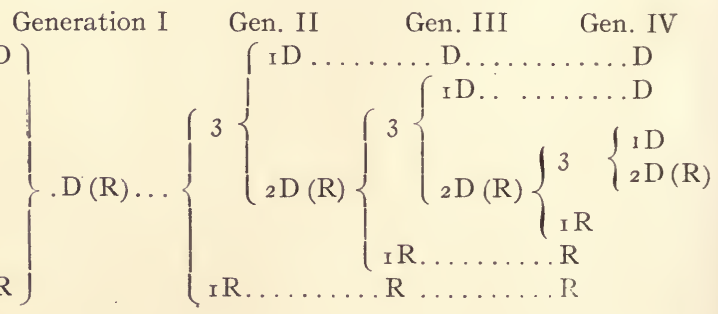


Mendel's law assumes that the gametes bearing the characters of the two parents are produced in equal numbers, and distributed at pairing in accordance with the law of chance; and this assumption is not contradicted by the known facts. And since it offers a simple mathematical basis for calculating the results of a variety of crosses, it may readily be tested, as, for example, by backcrossing a hybrid with an individual of either parent stock. If mated with the recessive stock, the result should be as follows (given, of course, as for any test, a sufficient number of offspring):

D and $R$, germ cells of the hybrid parent

IX I in chance combination with

$\mathrm{R}$ and $\mathrm{R}$, germ cells of the recessive parent, give in the second $\left(F_{2}\right)$ generation,

${ }_{2} \mathrm{D}(\mathrm{R}) *+{ }_{2} \mathrm{RR} \quad i . e ., 50 \%$ of each color.

In the more typical cases of alternative inheritance, all the foregoing proportions have been substantially realized in breeding experiments.

When the parents differ in two or more characters, the hybrids bearing germ cells that bear all these characters severally, will effect new combinations of them, and forms differing from either parent will appear in the second and later generations. If we let $X$ and $Y$ represent the dominant and $x$ and $y$ the recessive phase of two characters (as, for example, eye color and hair length) there will appear in the second generation, besides the unstable hybrid forms, the stable forms $X X Y Y, X X y y, x x Y Y$, and $x x y y$. Whichever two of these represent the combination of characters found in the parents, the other two are new combinations. The law of Mendelian inheritance, substantially as estab-

*The parenthesis is thus used as a convention for indicating the recessive character. 
lished by its founder, is represented in the accompanying table (after Castle).

\begin{tabular}{|c|c|c|c|c|}
\hline $\begin{array}{l}\text { Number of } \\
\text { Differences } \\
\text { between } \\
\text { Parents. }\end{array}$ & $\begin{array}{l}\text { Visibly Differ- } \\
\text { ent Classes, } \\
\text { each contain- } \\
\text { ing one Pure } \\
\text { Individual. }\end{array}$ & $\begin{array}{l}\text { Total } \\
\text { Classes, } \\
\text { Pure and } \\
\text { Hybrid. }\end{array}$ & $\begin{array}{l}\text { Smallest Number } \\
\text { of Off spring } \\
\text { allowing one } \\
\text { Individual to } \\
\text { each Class. }\end{array}$ & \\
\hline$n$ & ${ }_{2} n$ & $3^{n}$ & $4^{n}$ & \\
\hline $\begin{array}{l}\mathbf{I} \\
2 \\
3\end{array}$ & $\begin{array}{l}2 \\
4 \\
8\end{array}$ & $\begin{array}{r}3 \\
9 \\
27\end{array}$ & $\begin{array}{r}4 \\
16 \\
64\end{array}$ & $\left\{\begin{array}{l}\text { Tested by Men- } \\
\text { del for peas and } \\
\text { found correct. }\end{array}\right.$ \\
\hline $\begin{array}{l}4 \\
5 \\
6\end{array}$ & $\begin{array}{l}16 \\
32 \\
64\end{array}$ & $\begin{array}{r}8 I \\
243 \\
729\end{array}$ & $\begin{array}{r}256 \\
1024 \\
+096\end{array}$ & $\{$ Calculated. \\
\hline
\end{tabular}

Castle has proved by breeding experiments that in guinea pigs length, pigmentation and roughness of coat are hair characters that are separately heritable, and that in crossing they follow fairly Mendel's law. And he summarizes his observations as follows:

"This experiment illustrates two important principles in heredity: First, if as regards the hair alone there exists such a variety of characters separately inheritable, how great must be the number of such characters in the body as a whole, and how remote the probability that any animal will in all characters resemble any individual ancestor, provided that in a considerable number of heritable characters a choice is offered between alternative conditions. Secondly, the experiment shows how a variety of new organic forms may quickly be produced by cross-breeding, leading to the combination in one race of characters previously found separately in different races. Thus, in guinea-pigs, one can obtain within two generations any desired combination of the three pairs of alternative coat-characters, if one produces a sufficiently large number of individuals. 
"From what has thus far been said it would appear that in alternative inheritance characters behave as units, and, more than that, as wholly independent units, so that to forecast the outcome of matings is merely a matter of mathematics. While this is in a measure true, it is, fortunately or unfortunately, not the whole truth. In alternative inheritance characters do behave as units independent of one another, but the union of dominant character with recessive in a cross-bred animal is not so simple a process as putting together two pieces of glass, nor is their segregation at the formation of gametes so complete in many cases as the separation of the two glass plates. The union of maternal and paternal substance in the germ-cells of the cross-bred animal is evidently a fairly intimate one, and the segregation which they undergo when the sexual elements are formed is more like cutting apart two kinds of differently colored wax fused in adjacent layers of a common lump. Work carefully as we will, traces of one layer are almost certain to be included in the other, so that while the two strata retain their identity, each is slightly modified by their previous union in a common lump.

"Thus, when we cross short-haired with long-haired guineapigs, we get among the second-generation offspring a certain number of long-haired animals with hair less long than that of the long-haired grand-parent, or with long hair on part of the body only.

"Cross-breeding, accordingly, is a two-edged sword which must be handled carefully. It can be used by the breeder to combine in one race characters found separately in different races, but care must be exercised if it is desired to keep those characters unmodified. If modification of characters is desired at the same time as new combinations, then crossbreeding becomes doubly advantageous, for it is a means of inducing variability in characters, as, for example, in the 
intensity of pigmentation and in the length of hair, quite apart from the formation of new groupings of characters. Sometimes it causes a complex character to break up into simpler units, as the agouti coat of the wild guinea-pig into segregated black and yellow, or total pigmentation into a definite series of pigmented spots. In other cases it operates by bringing into activity characters which have previously been latent in one or other of the parental forms.

"Now, what bearing, we may ask, have these theoretical matters on the practical work of the breeder? They show I) that a race of animals is for practical purposes a group of characters separately heritable, and 2) that the breeder who desires in any way to modify a character found in this group, or to add a new character to the group, should first consider carefully how the character in question is inherited.

"If the character is alternative in heredity to some other character, cross-breeding between the two, followed by selection for pure individuals, will within two generations give the desired combination of characters in individuals which will breed true. This process of selection is simplest when the characters to be combined are recessive in nature, but individual breeding-tests become necessary when dominant characters are included in the combination desired.

"If a character gives blending inheritance, it must be treated in a different way. Suppose, for example, that we desire to combine lop-ears in rabbits with albinism, but that our lop-eared stock consists wholly of pigmented animals. How shall we proceed? First, mate a pigmented lop- with a short-eared albino. The offspring will be pigmented half1ops. If two of these be bred together their young will all be half-lops, and about one in four of them will be albinos. Now these albino half-lops may be mated with pure pigmented lops. The young will again all be pigmented, but will this time be three-quarter lops, and by breeding these 
together albino three-quarter lops may be obtained in the next generation. By continuing this process of back-crossing with the lop-eared stock, and selecting the albino offspring obtained, the lop-eared character may be steadily improved in the albinos until it is practically as good as in the original lop-eared stock. The rate of improvement possible can be readily calculated. The albino young will be:

After 2 generations, one half lops,

After 4 generations, three fourths lops,

After 6 generations, seven eighths lops,

After 8 generations, fifteen sixteenths lops,

After ro generations, thirty-one thirty-seconds lops, etc.

This will be the result on the hypothesis that no secondary variation occurs in the lop-eared character. If, however, variation is induced by the cross-breeding, then it is possible that the desired end may be reached sooner, or that an even better lop may be obtained in the albino cross-breds, than that of the original pigmented stock.

"Latent characters are an important element in practical breeding. Sometimes they greatly aid the breeder's work; sometimes they impede it. If a stock contains undesirable latent characters which are brought into activity by crossbreeding, these latent characters will have to be eliminated, or a new stock tried."

Obviously, without variation no new characters are obtained by such intercrossing, but merely new combinations of characters that previously existed apart. But, when new characters appear among the variants of a species, and especially when a number of new characters appear simultaneously as in typical cases of mutation, then intercrossing may be the means of bringing these characters together in all sorts of combinations, some of which may be of value to man, and some of which may be fit, and may, therefore, furnish a basis for further natural evolution. 


\section{NATURE AND NURTURE.}

The germ cells constitute the bond between the generations. To the egg and the sperm we must look for sources of hereditary characters.

The human species inherits as do the other organisms. Characters of various sorts "run in families;" form characters, such as shape of nose, of chin, of fingers; physiological characters, such as left-handedness, baldness (in males), slenderness or corpulence, etc.; psychological characters, such as emotional or judicial type of mind, phlegmatic or effervescent temperament, etc. But most of these are examples of complexes of characters, that must be analyzed to their component units before their manner of inheritance can be studied. To speak of infectious diseases as being hereditary is wholly inaccurate, for disease germs are not part of the body, but foreign organisms; they can be passed on from one generation to another only by infection, and not by inheritance. There may, however, exist innate physiological weakness that favors the infection in successive generations, and infection may occur before birth as well as after.

However much the young may receive of fostering parental aid in yolk, in shelter within or without the body, in nourishment by means of embryonic membranes, etc., it has already received when egg and sperm have united, its full hereditary endowment; all else is nurture.

Inheritance of acquired characters. In the lifetime of the individual, the body may acquire various characters. The skin may get a coat of $\tan$ in a few days exposure to the sun. The hands become calloused with toil. The muscles strengthen with use. Dexterity results from practice, and by long effort we may acquire an education. But are any of these things which the individual may acquire during his lifetime heritable, or does the offspring start at the common level of its kind, nothing advantaged by whatever his 
individual parents may have gained? This is an exceedingly important question, the answer to which must have something to do with determining our educational policy.

In the long run all characters are acquired characters, if evolution be conceded. The question is, Can the peculiar conditions which cause new characters to develop in the body so affect its germ cells that these will develop the same characters in the next generation, even in absence of the conditions that first called them forth? When we remember the early isolation of the germ cells, their lack of participation in the work of the body, and their remoteness from contact with environment this seems unlikely. How, for example, could the abuse of the eyes, causing partial blindness in the adult, so affect the germ cells that have no eyes, as to cause them to develop in the next generation, with proper use, the same weakness? That new characters are acquired by the individual body needs no proof; that they are at the same time acquired by its germ cells is not proved, although it has been widely believed. Mutilations of the body we know are not inherited. The loss of an eye in one generation does not prevent its perfect development in the next.* The tails of sheep have been docked for centuries, and yet lambs continue to develop tails in apparently undiminished luxuriance.

On the other hand, there are facts showing that the germ cells (or, at least, the sex organs, collectively) do affect the characters of the body of which they are an isolated part. The effects of castration (removal of the spermaries) of young animals are often very marked. The differences between a bull and a steer, for example, are very apparent in the horns and neck muscles, in voice and attitudes, in disposition, in ability to put on fat quickly, and in other

*"Wooden legs do not run in families, but wooden heads do." -Conklin. 
characters that are equally remote from the missing sex organs of the latter. Doubtless the condition of the body does affect the germ cells also (whether well- or ill-nourished; healthy or not, but in what manner and to what extent is not readily determinable at the present day.

The physical basis of racial solidarity.-This we know; that with all the changes of its outward conditions, human nature changes little. Civilization advances, but civilization concerns itself with methods of nurture alone; and its gains, every individual must re-appropriate for himself. Nurture creates many artificial distinctions among men, but their nature is little altered. Good health and good spirits and normal desires for life, liberty and the pursuit of happiness are not the possession of any class or condition of men. Good brains are probably as equitably distributed as are good muscles, although the opportunity for their development may not be. Dynasties may rise and fall, systems come and go, but the racial currents run on serenely. Art and science are not transmitted in the germ; the only part of our education that is inherited is the organic part of it that is common to the race. Fortunately or unfortunately, the springs of racial progress lie very deep; and if they are not readily reached by humanitarian effort, they are at least remote from unskillful meddling. It is the common stock of germ plasm of our race that breeds our common interests and common needs, and makes it possible for us to have common schools and common law. This is the great guarantee of democracy.

Racial differentiation.-Nevertheless, our common stock of germ plasm is not quite homogeneous. It has had a long history. It has developed divergent tendencies. It has lived under different environments. The spirit of one people is not that of another. That the slow methods of nature 
have wrought changes in the constitution of her segregated strains appears in this; their civilizations differ, and though civilization be nurture, the capacity for it, the impulse toward it and the genius to modify it must be inherent. And, if this is true of tribes, it is true within each tribe, on a lesser scale. "Blood does tell." To some extent at least genius does run in families,*. as also do criminal tendencies, the capacity for the development of either being organic. Hitherto human society has taken little account of these springs of future character.

The meaning of nurture.-Most organisms give little nurture to their young. They merely breed. Their innumerable progeny are scattered broadcast in a pitiless environment, and here and there, by chance, one survives. Destruction is the rule; survival the rare exception. We have already seen in our study of the plant and animal series how the dominant organisms have made their advantages secure by better care for their offspring during development; by adding food to the egg or supplying it to the embryo, and then by adding housing and parental care. Ever, there is a lessening of the number of young produced coupled with increase in the care for them. The powers of the body are devoted less and less to starting new individuals in life and more and more to the better equipment for life of those that are produced. The lioness of the fable might well boast that though her offspring were but one at a birth, that one was a lion; and then might well care for it as though there were no lions to spare.

*I have often heard false pride of ancestry condemned, but I have not seen the true pride of ancestry explained and commended. Surely the man who is conscious that he comes of stock sound in body, able in mind, tested in achievement, and who knows that, mating with like stock and maintaining himself in health, he may hand down that heritage to his children, surely such a man may have a legitimate pride in ancestry."-K. PEARSON 
The eggs and sperms of some of the lower organisms may be mixed in a glass of sea water and watched at one sitting

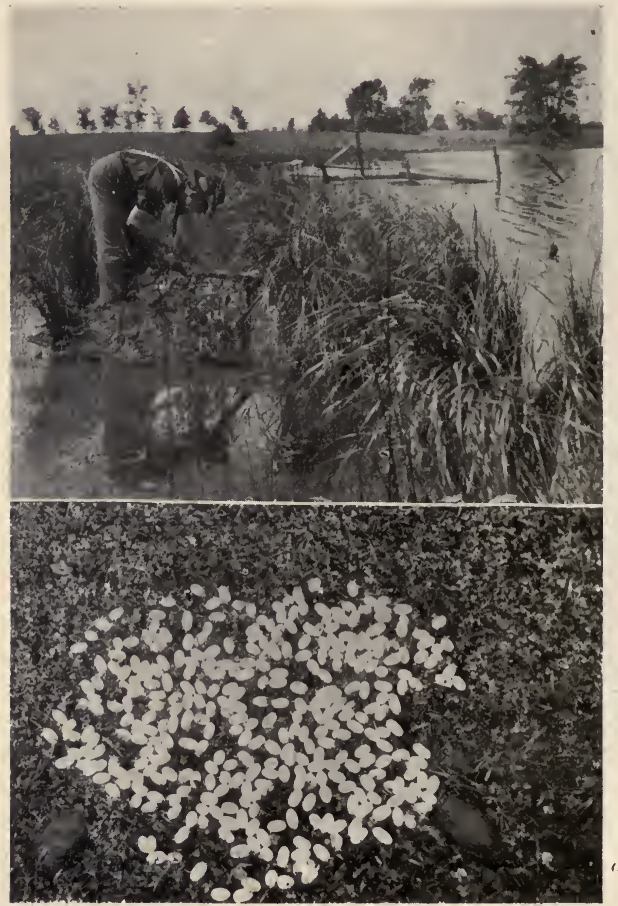

Fig. 182. Nest and eggs of the musk turtle (Eremochelys odoratus). This nest was made in an old muskrat house. The full complement of eggs is shown below. Photos by Hankinson and McDonald.

through fertilization and the early stages of development, until they are ready to enter actively into the struggle for 
life. A few weeks of lying in the sunwarmed marsh suffice for the hatching of the eggs of the musk turtle (fig. 182), which receive no parental care. Three weeks of persistent incubation are necessary to hatch the eggs of the common fowl, and a still longer period of maternal care after hatching is needed to get the chicks well started in their careers.

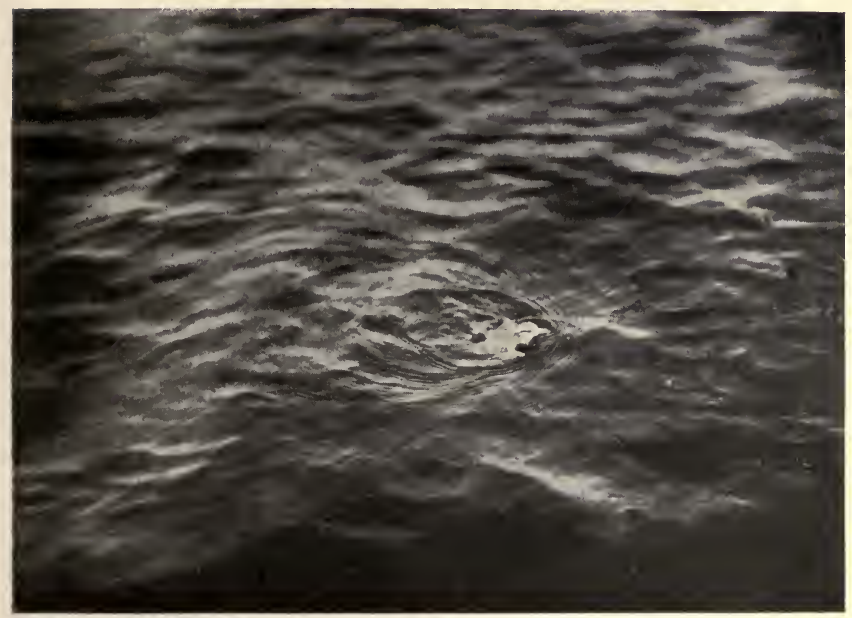

FIG. 183. Sandpiper (precocious) a few days old, swimming. Photo by G. C. Embody.

The young of altricial birds (fig. 184) are fewer, hatch in a more helpless condition, require to have their food brought to them and put in their-mouths and receive the care of both parents for a long time. Months of pre-natal nur ture are required for the development of the young of all the larger mammals, and after birth, other months of nursing, of 
sheltering, of care and assistance. And to all this man adds education, which is only an extension of the original mother

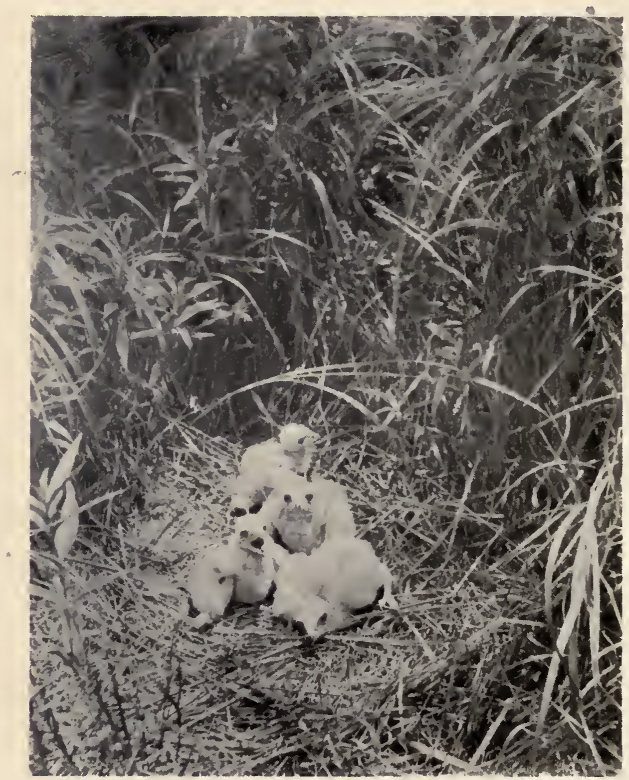

FIg. 184. Young marsh hawks (altricial) some days old, yet hardly able to stand. Photo by E. McDonald.

function.* In the eye of the law it takes twenty-one years to make a man. Thus, human society has learned the first lesson of racial progress.

*"And it was told him, Thy mother and thy brethren stand without, desiring to see thee. But he answered and said unto them, My mother and my brethren are these which hear the word of God, and do it." Luke $8: 20.2$ I 
Study 39. Observations on the relation between fecundity and nurture.

Materials for this study are so diverse and ever present, that instead of a definite outline, the following suggestions of typical illustrations are offered:

I. In order that the enormous numbers of young produced by some species may be realized, study some such thing as the number of spores produced by a flowering fern, or seeds by a cottonwood tree. Count for example in the fern the number of good spores in an average sporangium, the number of sporangia on a sorus, the number of sori on a fruiting frond, the number of fruiting fronds on an average plant, and multiply together for totals, multiplying in the end by the number of years of fruiting for the normal life of the plant; the numbers will be sufficiently significant even though the last point be indeterminable. If done by a class, the averaging of the collective counts will give better approximation to the truth.

2. For observation of the reduction in numbers that goes with a little parental care, compare number of young produced by some nesting fish, such as sunfish, bass or bullhead, with those produced by a pike or a carp; for this, ripe ovaries may be taken and their content counted in part and estimated.

3. The concomitants of more extended care and careful nurture may be studied by comparing the number of young and the care they receive in the precocious and altricial birds, abundant data for which will be found accumulated and ready to hand in many good bird books.

The record of this study may consist of a tabular statement of the data obtained.

The disturbance of the natural balance by conditions of civilized life.-The rate of reproduction established by 
nature for the human species is far too high for civilized conditions. It was adequate to replace the losses bywar, pestilence and famine in primitive society. But now that these agencies of death are in a measure controlled, the natural balance is disturbed. Without these checks the human population of the earth is rapidly increasing.

Many wild species are being exterminated, and most of them are being reduced in numbers. For man must carry with him the few domesticated species on which his livelihood depends, and wherever he spreads, the native population of the earth must be annihilated to make room for his fields and stock pens. The pressure for room has often been felt in "congested districts" throughout human history. With the present excess of birth rate over death rate, the whole habitable earth will be one congested district soon. Every triumph of science over plague or famine or other casualty increases the pressure, so long as the excessive rate of increase continues.

The ideal condition of society is that toward which nature points the way in the series of phenomena we have just been studying: the adjustment permitting the normal well-conditioned development of every individual.

There are biological aspects of our civilization that are not reassuring:

I) The possibilities of the germ are realized only in the individual. Whatever the nature of it, only nurture can bring it to perfection; and nurture is still largely wasted among us in broken lives.

2) The weaklings of our race under existing conditions, not only survive, but they usually survive to perpetuate their weaknesses in descendants.

3) There are processes of civilization that select the best for elimination; wars, which kill off the strong and the brave on the battlefield and leave the weak at home to breed. And economic conditions that take the brightest of 
the children of the poor from their studies and their play, and set them prematurely at grinding toil, thus hindering their normal development.

4) The excess of offspring is mainly coming from the lower ranks of human society. Those classes that are most advanced in arts and education are hardly reproducing themselves, while the earth is being over-populated by the descendants of the less progressive. That the educated classes are not taking a larger share in the building of the future race is not in itself a necessary evil, for education is not always an accompaniment of either physical or moral fitness. Indolence and self gratification and the cultivation of low desires breed degeneracy in rich and poor alike. That the population of the earth in the immediate future will be composed mainly of the sons and daughters of poor and ignorant parents is not so serious a matter as it might at first appear; for, with normal aspirations, property and education may be acquired, and the lack of these things may be due to accidents of birth and station. But the danger of qualitative degeneration lies in the rapidand as yet almost unrestricted breeding of the physically mentally and morally degenerate.

The increase in population, which, if continued at the present rate would certainly bring disaster, is mainly due, strangely enough, to the progress of knowledge and to the extension of humanitarian effort. These have reduced the death rate for all classes of society, while diminishing the birth rate for only the better educated classes. It is thus the natural balance has been disturbed.

In the cities the pressure for room is first manifest; and it is here that the annihilation of the green earth and all the host of living things belonging with it is completest. Even here in times of peace and plenty all men may live in comfort; but when the pinch of famine or disaster comes, then 
men crowd, as do the beasts, for food and standing room. And whenever and wherever they crowd, in good times or bad, they make such use of the earth's resources as means irreparable loss, and insures that the crowding of the future will be of intensified severity.

The greatest problems of man's future upon the earth are connected with better breeding and better nurture. Security for the future undoubtedly lies in having more knowledge, and in making such use of it as will yield better results in racial improvement and in individual development. 


\section{CHAPTER V.}

THE LIFE CYCLE.

Among the simplest organisms, in which each cell may go on growing and dividing indefinitely, the familiar phenomena of youth, maturity, and old age, are not apparent. Every cell is a germ cell, and, therefore, ever young. But with sexual reproduction comes in the dual organism, composed of body plasm and germ plasm, only the latter continuing, the former mortal.

The normal life cycle.-It is the common lot, among all organisms except the lowest, to be developed from an egg, to be supplied in infancy with food, to pass through hereditary changes of form, to grow and reach maturity, to exercise for a longer or shorter period the matured powers of the body, to produce offspring, and then to grow old and die. Youth, maturity, and age follow each other in an orderly progression that is readily definable in terms of metabolism, thus:

I. In youth the building up processes are in the ascendency. Assimilation is greater than dissimilation (juvenescence).

2. In maturity the waste and repair of the body are on a pârity. Assimilation is equal to dissimilation.

3. In age the building up processes are in a state of relative decline. Assimilation is less than dissimilation (senescence).

Although we may thus state in metabolic terms the history of the body, the explanation therefor must be stated in terms of reproduction. It is necessary for the organism to establish itself, before it can do much to provide for posterity; hence, the nutritive apparatus of the body is developed first, and growth precedes reproduction. The 
period of adult life may be long, as in elephants, or short, as in mayflies; it may be reached by a gradual and regular development, or by a series of abrupt form changes; but when it arrives with full maturity of powers, the reproductive process takes the ascendency. Primarily it is the period of making provision for descendants. Whether such provision consist merely in mating and depositing eggs, or whether in addition to this, the substance of the body be transformed into food for the young, or whether, still further, the physical powers of the body be devoted to the care of the young, or whether, finally, as in human society, with long years for individual activity, the labors of life be devoted to securing for posterity the betterment of those conditions that hinder its best development, it is all the same; the primary concern of adult life is provision for the future of the race.

The regularly progressive life cycle is sufficiently familiar, and needs no further illustration. But this undergoes some remarkable changes under natural conditions, and other alterations of it may be caused artificially. Some of the more typical of these phenomena will now be considered, under the following headings: r) Alternation of generations, 2) Special methods of asexual reproduction, 3) Change of form with alternation of hosts, 4) Metamorphosis, 5) Artificial division and combination of organisms.

\section{ALTERNATION OF GENERATIONS.}

This phenomenon consists, as we have already seen, in the establishment of two segregated phases within the life cycle, one sexually, and the other asexually reproducing. We have already traced the development of it in gametophyte and sporophyte of the higher green plants. An equally good example of it is found among animals in the group of marine hydroids. Medusa and hydranth are 


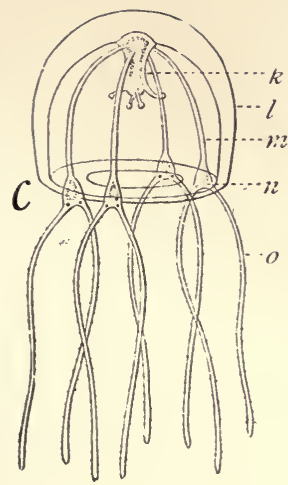

there the sexual a $\mathrm{n} d$ asexual phases of the life cycle respective $1 \mathrm{y}$. The free-swimming medusa (jelly fish, fig. I $85 \mathrm{c}$ ) produces the eggs and sperms and liberates them in the sea. These after fertilization develop into sessile hydranths (more or less similar to the common hydra), which in turn develop medusæ by various modes of ase $\mathrm{x}$ u a 1 budding.

11. SPECIAL METHODS .OF ASEXUAL REPRODUCTION.

Sexual reproduction results in the main in a qualitative increase in a species. Without segregation it tends toward reducing all the forms to a common level, but with segregation, whether external or internal, it is a potent means of effecting species change. Asexual reproduction is quantitative rather than qualitative increase. One individual is

FIG, 185. The Colonial hydroid (Bougainvillea) $a$, the form of a small colony: $b$, a bit from the tip of one of the branches; $w$, tentacles of a single hydranth; $x, y, z$, stages in the development of the buds (medusa). c, The fully formed and free swimming medusa (jelly fish! $k$, the body (manubrium) with the mouth at its tip; $l$, the surrounding bell; $m$, radial canal; $\boldsymbol{n}$, sense organs; $o$, tentacle; $b$ and $c$, after

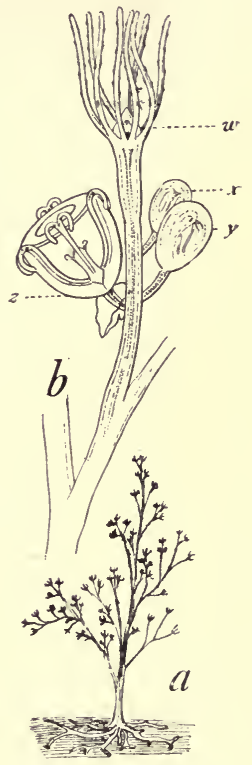
Allman. 
multiplied; the new nnes growing up are separated parts of that one, and are therefore essentially like it.

The parts, however, are not necessarily identical with the parent, or with each other; when separated they may develop slight differences, as in the well known phenomenon of bud variation, and such differences may be increased

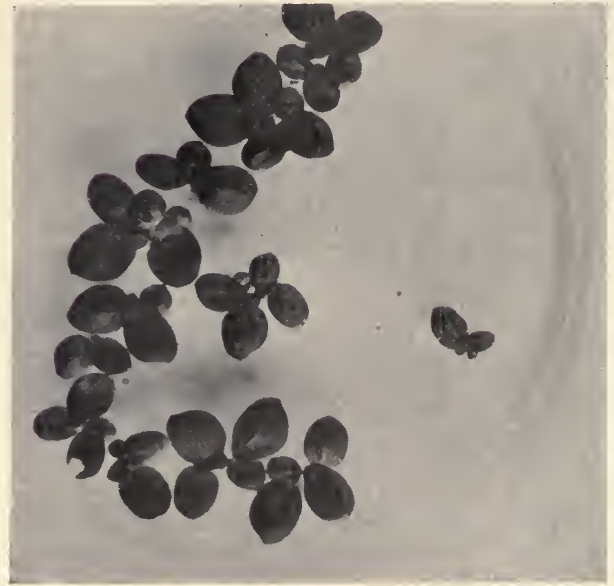

Frg. 186. Duckweed (Spirodela polyrhiza). The growth from a single plant in twelve days. Photo and culture by L. S. Hawkins. Note the grouping in pairs, with small lobes forming between the larger old ones of the dividing individuals.

artificially by selection. One branch of a rose bush may develop finer flowers than any other on the bush. Cuttings of this branch may be selected for growing, and the bestflowered shoots developing from these cuttings may be again selected with some advantage. But there is no probability that these improvements would be inherited. 
The special means by which individuals multiply themselves asexually are far too numerous and diverse for us to attempt to consider them all here. Stools and stolons and runners and tubers and offsets and bulbs and a dozen kinds of detachable buds, are known to every student of plants. Indeed, many of those plants that have been able to advance into and conquer difficult environments and become dominant in them, (such as the pond-weeds on the bottom in shoal waters, and the grasses and sedges in the fire-swept prairies and marshes) increase mainly asexually, by extensions of the plant body. They still produce seeds, but they hold their ground by continuous and exclusive occupancy of it. Budding and fragmentation and other such methods are common also among the lower animals. This we have observed in the hydra. But all such increase has to do with growth as well as with reproduction. Let us here consider some more specialized reproductive parts and methods, that are more exclusively adapted to reproductive ends.

Asexual reproductive cells.-When these are formed for dispersal, they are usually called spores. With ordinary spores,as they are commonly produced upon the aerial parts of plants, we have already become acquainted. These are minute resting cells, usually invested with a protective covering that resists evaporation, and that permits of their being distributed by currents of air.

Among aquatic thallophytes, both alg:e and fungi, there occurs at intervals a breaking up of the cell contents into minute naked unicellular reproductive bodies. These are called zoospores or swarm spores. Each zoospore acquires two or four flagella (or sometimes a circlet of cilia), and, escaping out of the old cell wall, it swims about in the water. Finding a suitable situation it attaches itself and begins to develop a new plant body like that of its parent. 
The alga Draparnaldią, shown in figure 187 , which

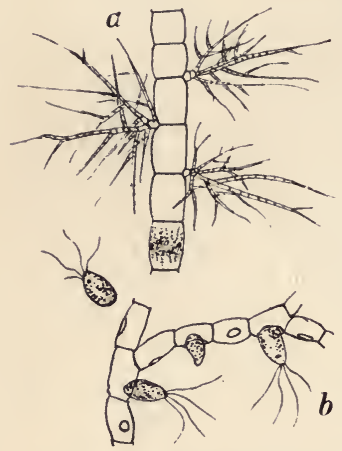

FIG. 187. Draparnaldia, $a$, a bit of the stem, with three branches; $b$, $a$ bit of a branch that is yielding zoospores. grows attached to stones in the riffles of small clear-flowing permanent streams, and is easily seen trailing its long beautifully branching filaments in the current, is a favorable one in which to observe zoospore formation; for it will usually develop zoospores a day or two after being brought out of its native environment into the laboratory. The spores, escaping from the cells singly, will swim to the lighted side of the containing vessel, from the surface of which they may often be obtained in great numbers.

It will be noticed that the figure of the zoospore of Draparnaldia does not differ materially from that of certain of the gametes we had before us in Chapter II. It is highly probable that sex cells were developed out of zoospores. Both are present in certain algæ, and are hardly to be distinguished in form; and the differences between them almost vanish, when, as sometimes happens, the gametes develop without preliminary fusion in pairs.

Multicellular reproductive bodies.-In certain of the lower fresh water animals, notably in sponges and bryozoans, there are special multicellular reproductive bodies called statoblasts (also known as winter buds, and gemmules). These are likespores only infunction, and in having resistant walls which tide them over the dry, hot 
season when the shoal waters in which they grow

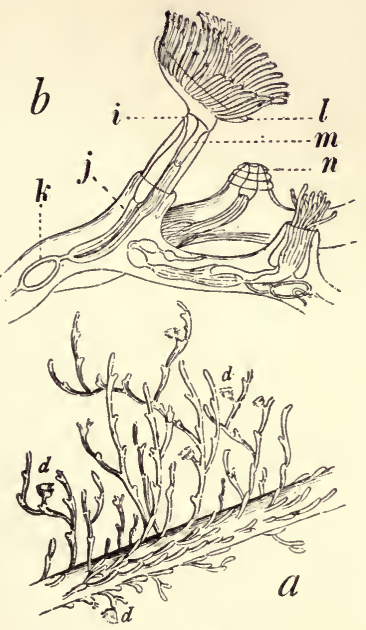

FIG. 188. Plumatella a, a small colony growing on a submerged stick; $b$, a small part of a single branch, with three individuals in different states of contraction; $i$, anus; $j$, intestine (Ushaped) $k$, statoblast developing; $l$. lophopore (crest of tentacles); $m$, esophagus; $n$, the chitinous sheath that shelters an individual. (after Allman)

evaporate. While they are often spoken of as seedlike bodies, they are wholly unlike seeds in that they contain no embryo, and they are entirely different in origin. During the growing season, (spring and early summer), little groups of cells become segregated within the tissues of the parent animal (fig. $188 k$ ), and become invested there with a common protective covering, the statoblast wall, that is often of remarkably complicated and beautiful structure. When the parent dies and its flesh disintegrates, the statoblasts are liberated, to be carried about with the waters, or blown about with the dust of the dessicated bottom mud, or, in the case of statoblasts provided with grappling hooks, such as those of Pectinatella, to be carried and distributed by aquatic animals. In the Spring, those favorably situated germinate and develop new colonies of the parent form.

Statoblasts occur in groups most of whose members are marine. They are probably an adaptation of the life cycle to the conditions imposed by shoal and impermanent 
waters. Not all the sponges and bryozoans that live in fresh waters are known to produce statoblasts, but the

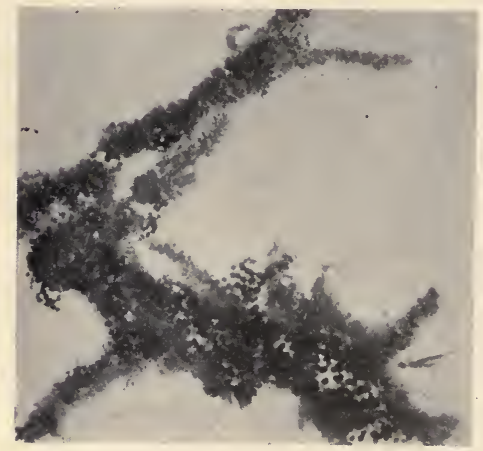

FIG. 189. Freshwater sponge (Spongilla fuviatilis) disintegrating in late summer, showing the abundant seed-like statoblasts. more common shoal-water forms produce them in very great abundance (fig. I89). In early summer the freshly grown sponges may be found by lifting a nd overturning boards, boughs, or almost any solid support that projects into the water, and few if any statoblasts will be found; but in late summer, when the sponge flesh is falling away, the statoblasts will be found in patches scattered thickly over the surface as minute rounded yellow bodies about the size of small mustard seeds. These may be germinated after a resting spell, in a watchglass, the numerous amœboid cells contained in them issuing separately from a side pore in the wall, and then soon coming together to form a delicate chimney-like tube, which is the first of the water channels of the new sponge, and out of the summit of which the water can very early be seen streaming. Doubtless it is in this same way that new sponges are started in the sloughs each spring. Many of them, doubtless, remain attached to the support where they grew, there to develope a new sponge on the old site. 
Study 4o. Observations on asexual reproductive methods.

Materials for this study are almost limitless in number and variety, and those mentioned below are suggested merely as types.

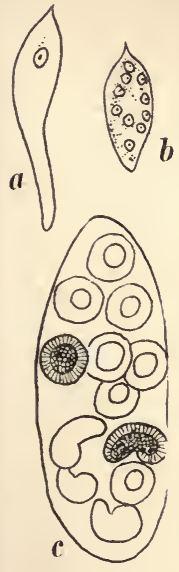

स्मIO G. $190.1 \mathrm{y}-$ embryony in Polygnotus (after Marchal). $a$, the egg; $b$, the same after repeated divisions of its nu. cleus; $c$, the same after the development of separat e embryos from each of the parts (details indicated diagramm a t $\mathrm{i}$ cally in but two, and these at different stages of progress).

Study and compare together a few special reproductive bodies, such as the 'gemmules" of the common greenhouse liverwort, Marchantia, the frond bulbs of the bladder fern (Cystopteris bulbifera), the "bulbils" of the tiger lily, the "sets" of the onion. the tubers of the potato, etc., etc.

Study the swarm spores of Drapernaldia (fig. 187 ), or of Cladophora (in which they are produced in great numbers in single terminal cells), or of any of the water molds.

Study and compare together the statoblasts of such forms as Plumatella and Pectinatella among bryozoans and of Spongilla and Heteromyenia among fresh water sponges; prepared slides will probably be needed for this. If some sponge statoblasts can be germinated under observation, their multicellular nature will be apparent.

The record of this study may consist in notes on and lists of the objects examined, together with sketches of some of them.

Polyembryony.-This is another kind of asexual method of increase, that is even more different in kind from the two preceding than they are from each other. In certain parasitic insects of the order Hymenoptera, the eggs 
which are laid within the soft and richly nourished larvae of other insects, undergo a division which is rather fragmentation, than segmentation; for it results in the development not of a single embryo but of many embryos. The parts into which the nucleus divides develop separately as indicated diagrammatically in figure 190 , each becoming a complete embryo, and growing later to adult estate. A significant feature of development by this method is that all the individuals developed from one egg are of the same sex.

Reproductive methods in general.--Sufficient illustrations have now been before us to show that there is one sexual method of reproduction, fairly uniform and consistent throughout the organic world, but that there are many asexual methods, and that these latter are most diverse. The former is uniform in its fundamentals in all kinds of environment; the latter are uniform in nothing. and they show the most significant relations to conditions of life.

The unity of the organic world is hardly more manifest in the possession of protoplasm, than in the production of gametes, and in the fusion of these in fertilization. The primary differentiation of multicellular bodies is into germ plasm and body plasm. This is even older than the differentiation between plants and animals. But with the secondary sexual characters show as great diversity as do asexual reproductive phenomena: these are the after thoughts of reproduction: these are the special means adopted by special groups. How different are even spermaries and ovaries in the stoneworts and in the liverworts! How lacking in common features are the reproductive organs of an earthworm and a salamander! All these have been more recently developed, along independent lines, in accordance with the tendencies and in adaptation to the needs of the different groups in which they are found. 
The principal relations that the sexual and asexual methods may bear to each other are diagrammatically indicated in figure I9I. Six generations are represented in the six vertical columns. A small circle represents the egg; a dash with a tail, the sperm; a circle inclosing a dot, the zygote; the black dots are spores, and the black
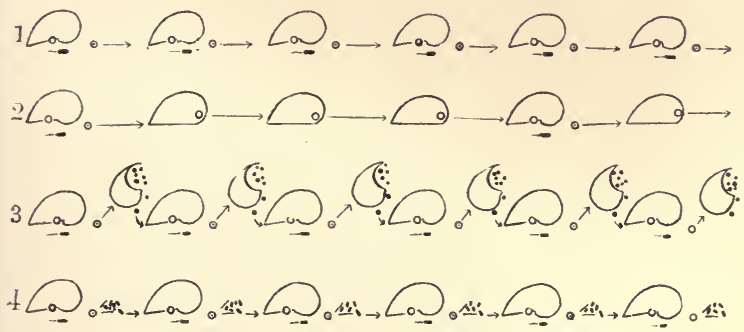

5

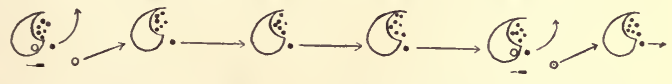

$6 \circlearrowleft$

G.
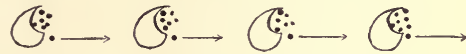

FIG, 191. Diagram of types of reproduction; $I$, normal sexual reproduction; 2 , parthenogenesis; 3 , alternation of generations; 4 , polyembryony, etc.;

5 , occasional production of sex cells in a series of spore forming individuals;

;. 6. continuous spore formation.

dashes are egg fragments. The top line of figures represents ordinary sexual reproduction, occurring alone, substantially as previously shown in figure $\mathrm{I} 74$. The second line represents parthenogenesis (with only three generations of females included between the bisexual generations*).

*In most parthenogenetir species, the sexual generations recur at much greater intervals. In fact, in certain species of rotifers and also in certain gall wasps (Cynipidae) no males are known, and parthenogenetic reproduction appears to be continuous. On the other hand in one genus of gall wasps (Neuroterus) single sexual and parthenogenetic generations regularly alternate; and, strangely enough, the females of the latter differ so much in form and structure from the former that they have been described as a different genus (Spathegaster). 
The third line represents alternation of generations, as we have studied it among the higher plants; substitute buds for the spores, and it would represent equally well alternation of hydranth and medusa in the hydroids. The fourth line represents polyembryony, as just described. It also represents the conditions found in the alga Coleochete, in which the fertilized egg breaks up into eight zoospores, each of which then develops an independent bisexual plant. The fifth line represents the production of sex cells upon occasional members in a series of spore-bearing plants. This occurs in Mucor and other molds. The last line represents continuous spore formation, and entire absence of sexual reproduction-a condition that is believed to prevail in some of the green algæ.

III. CHANGE OF FORM WITH ALTERNATION OF HOSTS.

Among the shifts that organisms make for a place and a living on the earth, none are more remarkable than those

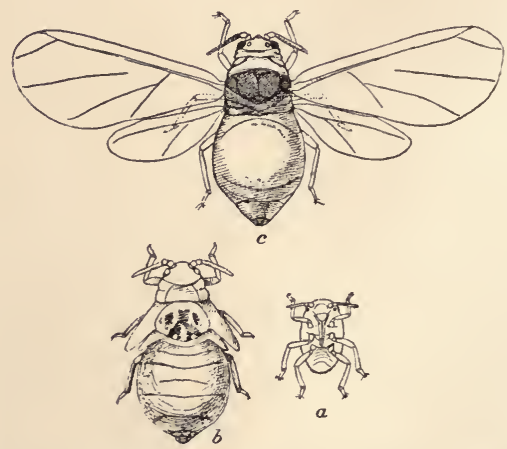

Pig. 192. The witch hazel pocket-gall aphid (Hormaphis hamamelidis) $a$ young larva; $b$, grown larva; $c$, adult (after Pergande). 
of parasites from one host to another; and there are some remarkable changes of form accompanying the shifts. For example, the witch hazel aphid(fig. I92)that causes the conical mantle galls(shown at fig. $32 b$ ) upon the leaves, and that
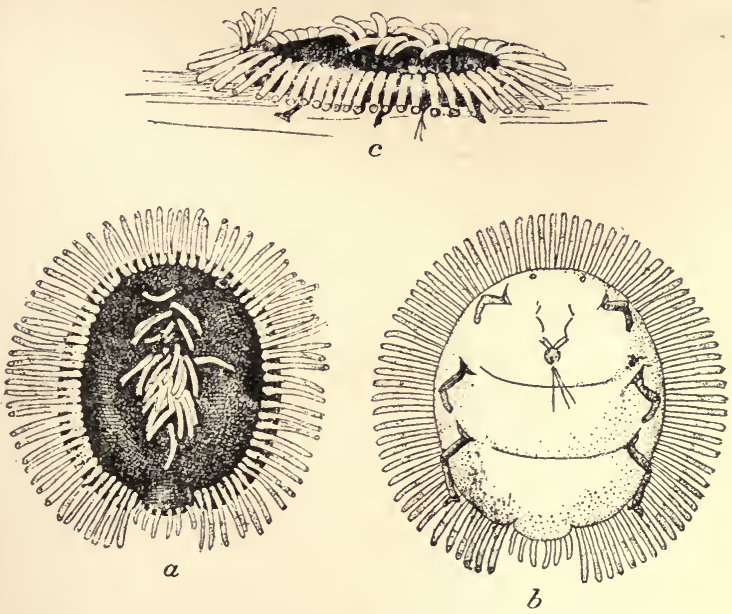

Fig. 193. The same aphid shown in figure 192, in the form assumed aft migration to the birch. $a$, dorsal, $b$, ventral, and $c$, lateral views of t 1 adult (after Pergande).

grows up inside them, is of the ordinary form of the common aphids during its life within these galls (two generations). But in midsummer, when its food supply begins to be cut off by the drying up of the galls, it migrates to a new host plant. It flies through the air in search of birch trees, and finding them, settles upon the under side of the leaves to dwell there the remainder of the season. There it gives birth to numerous young, which will grow up for three successive generations into the adult form shown in figure 193 . 
In autumn the descendants of these will grow into an adult form very like that shown in the first figure (fig. 192), and will fly back to the witch hazel, and the young of these developed upon the witch hazel will be wingless males and females, all the other generations through the year having consisted of females alone. There are other minor differences, none of the seven generations of the season being exactly alike either in adult form or in developmental stages; but the two forms shown in the figures are certainly so different they would not be thought to be one and the same species by any one who did not know their life history.

Other cases of change of form with alternation of host are well known; probably they are more numerous than we now realize, because of the great difficulty of recognizing the identity of the different forms. The best known are porhaps among animals the liver-fluke of the sheep (whose host animals are the sheep and the snail; an account of it may be found in almost any general text book of zoology); and among plants, the wheat rust (whose host plants are wheat and barberry; an account of it may be found in almost any text-book of botany).

We will now leave these cases of heteromorphic adult organisms, which though striking are rather rare and inconsequential, and consider the far more common formchanges that occur in the life time of single individuals.

\section{METAMORPHOSIS.}

This is the name applied to changes of form undergone after the close of embryonic life-ordinarily, after hatching from the egg. These changes may be inconsiderable, as in the earthworm, or the leech (fig. 194), but in a number of the higher groups of animals they are so great that the young of many forms were originally described as independent organisms, and given separate names. Thus 
arose the names still borne by the nauplius and zoaea stages of post-embryonic development in crabs, the

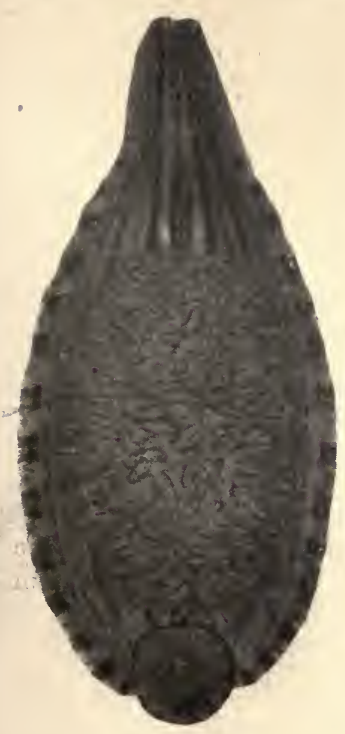

Fig. 194. Leech ( $\mathrm{Cleps}$ ine) overturned, showing the brood of young protected beneath the body. leptocephalus stage of eels, etc. We have seen that there is something of a transformation occurring in the salamander at the beginning of its adult life, and a still greater one in the frog, when gills and tail are lost, new mouth-parts are acquired and the lungs become functional. Indeed, we should not fail to recognize a sort of transformation in ourselves during our earlier years, when our first set of teeth drop out and we develop another and larger one; and in other changes that occur later, in adolescence. But the most remarkable examples of metamorphosis, as well as the most available for study, are found among insects, and these will serve us for illustration of this phenomenon.

The transformations of insects.-In all of the winged insect groups there is a considerable change of form at the time of entrance upon adult life.

When these changes are least, as in the grasshopper (fig. i95), the wings are expanded and the reproductive organs, perfected; when they are greatest, every part of the body is refashioned, and the larva bears hardly any resemblance to 
the adult. In the former case, there are but two stages of metamorphosis, following hatching, the nymph* (fig. 196) and the adult (imago). In the latter, there are three:

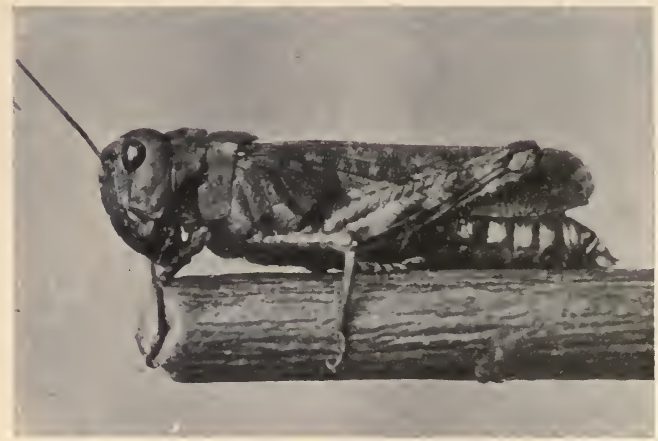

Fig. 195. An adult grasshopper.

larva, pupa and adult. When the differences between the larva and adult become so great that rapid change from

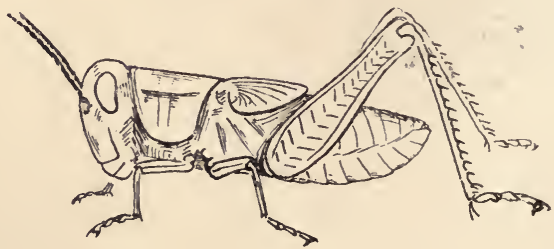

FIG. 196. A grasshopper nymph, well grown.

*Larva is a general term, covering all sorts of immature stages, each of which bears a separate designation in nearly every one of the major groups of animals: $n y m p h$ is the name for one sort of larva in insects-the sort that is most easily recognized by its externally developing wings. 
one to the other is incompatible with the ordinary use of the organs, the quiescent pupal stage comes in as a transition stage, a period of making over, during which the necessary extensive arations of $t$ elhe body are effected. The

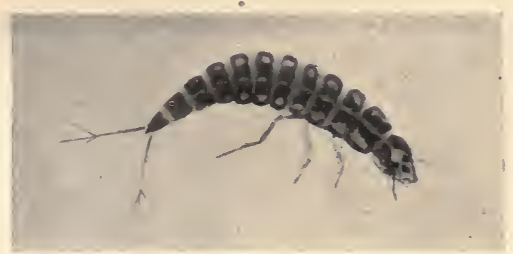

Fig. 197. The larva of a diving beetle (Hydroporus undulatus).

pupal stage is peculiar to insects, and its presence or absence within the group distinguishes between the so-called "complete" and "incomplete" metamorphosis.

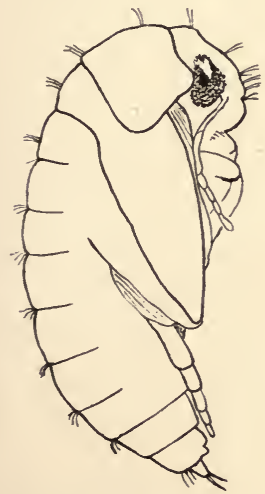

FIG. 198. The pupa of the same diving beetle (draw $n$ by Miss Helen V. Williamson).

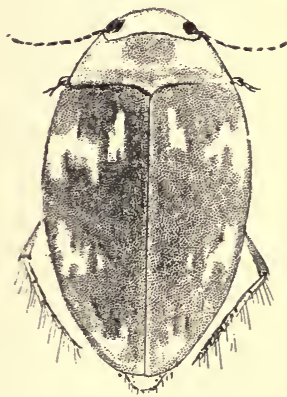

FIG. 199. The adult diving beetle (Hydroporus undulatus). 
Study 40. External metamorphosis in insects.

Materials needed: Two selected examples illustrating the two main types of insect metamorphosis, preferably living and actively transformingin the laboratory; I) nymphs and adults of a grasshopper, a mayfly or a stonefly, and 2) larvæ, pupæ, and adults of mosquitoes, or meal-worms or bean weevils, or any other easily managed forms (see appendix).

Also nymphs and adults of the following in alcohol: grasshoppers, (Orthoptera); psocids, (Corrodentia); stoneflies, (Plecoptera); mayflies', (Ephemerida); dragonflies, (Odonata); bugs, (Hemiptera): and larvæ and adults of any Neuroptera, Trichoptera or Mecoptera, of Lepidoptera, of Coleoptera (a weevil, and a larva with legs), of Hymenoptera (a sawfly and a bee or ant) and of Diptera, (mosquito or cranefly or other nematocerous larva, and one of the degenerate housefly or fleshfly type).

Prepare a table with the following column headings, abbreviated as desired:

r. Name of insect.

2. Order to which it belongs.

3. Relative size of head, thorax and abdomen, expressed in the ratio $I: x: y$.

4. Skin (thick or thin, hairy spiny or naked, etc.)

5. Eyes (well- or ill-developed, large or small).

6. Antennæ (relative development).

7. Mouth parts (adapted for biting or sucking, or vestigial).

8. Wings (externally or internally developing).

9. Legs (relative development).

ro. Peculiar parts (parts found in this larva only).

I . Lives where.

I2. Eats what. 
I I3. Relative size of head, thorax and abdomen, expressed in the ratio, $I: x: y$.

I4. Antennæ (relative development.)

I5. Mouthparts (adapted for biting or sucking, or atrophied).

r6. Legs, (relative development).

I7. Lives where.

I8. Eats what.

Write the forms in this table (by groups) in the order of their departure from primitive similarity between larva and adult. Fill out the table. Then study it, and read out of it the story it contains of the divergence of larval and adult stages, and in the last two columns under both larva and adult, see how this divergence is correlated with change of manner of life.

The internal metamorphosis of insects.-While there is no pupal stage in insects of incomplete metamorphosis, such as the mayfly (fig. 200), there is a corresponding period just before transformation during which the full grown nymph is quiescent for a short time, and during which there is rapid growth of wing muscles and of other internal organs; and some pupæ, like those of the mosquitoes, caddis flies and the true Neuroptera, are not wholly quiescent. But in the pupæ of all the more specialized forms, besides the development of new tissues, there is going on a destruction of old ones that are not suited to the needs of the adult and a reconstruction of their materials in new form. The pupal stage thus becomes one of peculiar helplessness in the life of the insect and it is spent in the shelter and seclusion of a pupal cell or burrow or cocoon. Larval life is abbreviated. The larva stores fat rapidly, and in relatively large quantity, postponing the final elaboration of it into organs. And the amount of fat in its body 
is more or less proportionate to the extent of the changes to be made during transformation. The advantage of this lies in the ability of such an insect to avail itself of a rich but transient food supply. A generation may be "reared

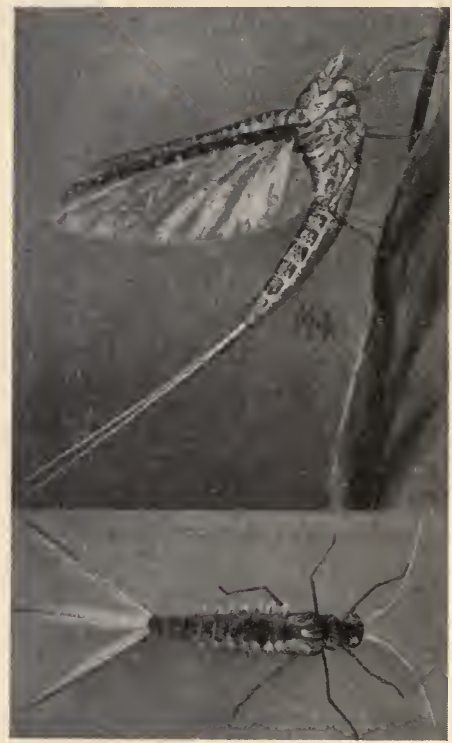

FIG. 200. Adult and nymph of the mayfly Callibaetis skokiana (drawn by Miss Maude $\mathrm{H}$. Anthony).

on the fallen carcass or the ripe fruit before it is decomposed, or in the rich endosperm of the developing seed before it has hardened. 

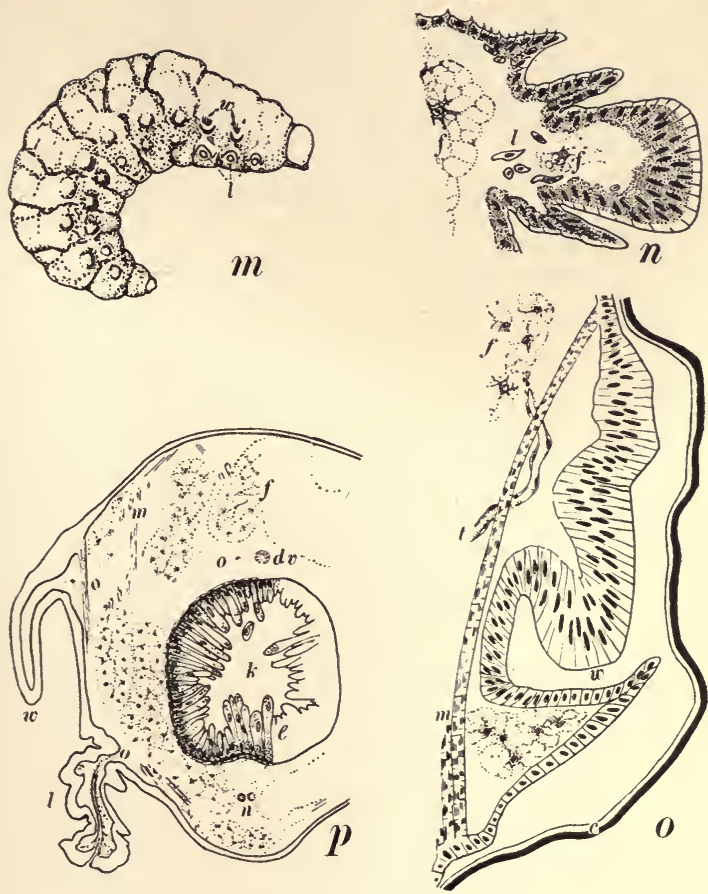

FIG. 201. Metamorphosis in the iris weevil (Mononychus vulpeculus) $m$, the larva at the beginning of transformation: $l$, leg buds and $w$, wing buds, showing through the translucent skin.

$n$, longitudinal section of a leg bud of the larva. showing three principal divisions: $f$, the remains of fat cells; $l$, leucocytes.

0 , vertical section through the wing bud of the larva; $w$, the point of the wing that is to be, with a shelf of epidermis projecting below it; $c$, the loosened cuticle; $f$, fat; $m$, muscle; $t$, air tube (trachea).

$p$. Cross section of a larva just before its final transformation to a pupa: $w$, wing and $l$. leg are now exserted, and the latter, shows differentiation into femur, tibia and tarsus; $k$, stomach; $e$, digestive epithelium; $n$, doublenerve cord; $d v$, dorsal blood vessel; $f$, whole fat and $o, o, o$, dissolving fat; $m$, new muscle fibres forming. 
This destruction of larval tissues during the pupal stage is one of the most remarkable deviations from the ordinary progressive course of the life cycle. Similar processes cccur wherever larval organs are to be made over. The tadpole's tail does not drop off; that would be a waste of valuable organic materials. It is

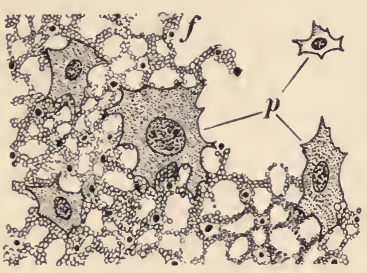

F1G. 202. Phagocytosis in the fat of the abdomen of the iris weevil. $f$, fat; $p$, phagocytes. reabsorbed: i. e., it is dissolved and transported and used again for the building of other parts. The agents of the reabsorption in the tadpole are leucocytes that havc turned temporarily to a diet of muscle fibres (and are called during their tissue-eating period, phagocytes: the phenomenon is called phagocytosis see fig. 202).

Some of the tissues of the insect larvae are eaten and transported by phagocytes. Others appear to be self disintegrating; their nuclei divide extensively and become very small and then gather about themselves the reintegrated remains of the old cytoplasm and of dissolved fat cells, and fashion them into new cell bodies, often constituting organs of very different form in the adult. The process is somewhat like a return to an embryonic condition, followed by a new embryonic development, wherein the fat of the larva stands in the stead of the yolk in the egg. If at the height of metamorphosis one cut open a pupa that has developed from any of the more degenerate larvæ, he finds little semblance of organs, the greater part of the body being reduced to a fluid mass which flows out at every cut. 
Not all of the body is thus destroyed, however; there are preserved little islands of . regenerative cells in all the principal parts of the body, from which their respective continents will be reformed. In the walls of thestomach, for example,there are grouped rings or masses of little cells, rich in protoplasm, by which the new epithelium of the new stomach will be developed. The undeveloped legs and wings exist in the larva as little buds of active cells, attached to the inner face of the body walls. From these legs and wings now grow out, at first beneath the larval skin, to be freed at its last moulting. About the bases of these organs and from other regenerative cell masses in the wall itself, the new body wall is developed. Details of these wonderful processes may not

FIG, 203. Cone galls of the willows caused by the gall midge Rhabdophaga strobiloides. $a$, the pubescent gall produced on Salix discolor; $b$, the crook-necked gall produced on Salix bebbiana. be studied here, but there are some easily observable phe-
nomena, which will help us to understand the main points.

Study 4I. Observations on internal metamorphosis.

Materials needed: Living larvæ and pupæ of some dipterous species having red blood*; preferably of the cone

*The blood of insects is not red, except in a few forms; such as the so-called "blood worms", that are the larvae of midges (Chironomidæ), and in some of the larræ of gall midges (Cecidomyidæ). 
gall midge of the willow, (fig. 203) in abundance (see appendix). Prepared cross-sections of the thorax of old larvæ showing wing and leg buds. Cross sections of the thorax of a damsel fly for comparison of fat development.

The central cavity of the gall may readily be exposed by sinking the end of a knife blade or scalpel lengthwise. through the end of the stem in the base of the gall, and twisting laterally, laying it open. Although the blood is red, the grown larva will appear white, because it is filled with opaque white fat. As the dissolution of the fat proceeds the red color of the blood will reappear. The progress of the pupa in metamorphosis may, therefore, from the first be gauged by the extent of the red color; later, as the end of the pupal period approaches, the black pigmentation of the adult will gradually overspread the surface, beginning with the eyes.

Sketch the pupa in outline, and make several rapid copies of the sketch by tracing. Then color these with red and black pencils (or with water colors, if preferred) to indicate the external evidence of the internal changes. Show thus the place of beginning and the order of progression in fat solution, and later progress in pigmentation.

Place a live pupa that is in the midst of metamorphosis on a hollow ground slide in a drop of normal salt solution, and split it lengthwise with fine scissors. Gently wash away the dissolved interior with a little stream of normal salt solution from a fine pipette and examine carefully the extent and the appearance of the solid organs remaining. A like treatment of a larva would disclose the wing buds and leg buds appended to the interior of the body wall.

Study and diagram a section of the thorax, showing wing and leg buds; show also the proportion of fat and solid tissue; compare this with cross section of thorax of a damselfly.

The record of this study will consist in the drawings and diagrams suggested above. 
V. ARTIFICIAL DIVISION AND COMBINATION OF ORGANISMS.

In the arts of men, artificial division for increase of organisms asexually and artificial combination of the parts of two organisms for the purpose of temporarily combining their characters in one individual, have long been successfully practiced. The former is known in the gardener's art as artificial propagation; the latter, as grafting. The parts of an organism that are to grow up into separate whole organisms must contain cells sufficiently differentiated either to be able to redevelop the missing parts, or to reshape them out of pre-existing tissues. The parts of two organisms that are to be organically joined together must contain cells sufficiently plastic and formulative to beable to effect organic union between the conjoined parts.

Regeneration.--The artificial propagation of the gardener is called, when practiced by the zoologist, regeneration; and this name embodies the essential phenomena involved-the redevelopment of the missing parts of a piece of an organism. The slip cut from the top of an old geranium lacks roots, and when placed in wet sand in a window box, it develops a new root system out of the undifferentiated tissues of its base, and does not proceed much further with leaf development until roots are established.

The capacity for regenerating missing parts varies much in different organisms. It is very great in most plants, and in many of the lower animals; but it is so poor in ourselves, that after we reach adult life we may hardly replace a patch of skin well enough to avoid a permanent scar. If the tentacle of a hydra be cut off, another promptly grows from the base of the old one. If the body be cut in two, two perfect hydras develop from the parts, a new foot being formed on the one and a new head on the other. Indeed, the body may be cut into many pieces, and each piece that 
contains the fundamental tissues, in such relation that food can be taken, may, under favorable con-

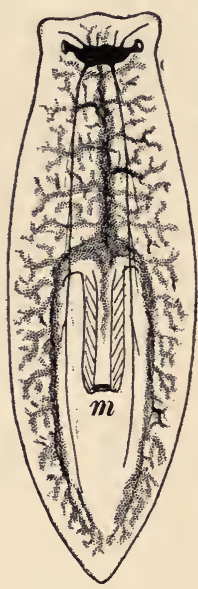

FIv. 204. Diagram of a planarian, showing food cavity in gray and central nervous system in black. $m$, mouth at the end of a cylindric phary nx that is directed downward. ditions, develop into a perfect hydra. A single arm broken from a starfish will regenerate the body and all the other arms. But as we ascend the scale of animal life, the power of regeneration becomes more limited as organization becomes more complex and the adjustment between the organs, more delicate. Herein lies one of the limitations of specialization already mentioned (page 25 I). Blood vessels, for example, are excellent agents of circulation when intact, but when cut, they wonderfully facilitate bleeding to death. Planarians (fig. 204) are classical subjects for regeneration experiments. They may be cut to pieces apparently without very serious inconvenience, and regenerate missing parts with great readiness. They have no parts that can be put entirely out of commission by being severed. They have no blood vessel system, nor organs of respiration. They have a sort of brain, but it is of so little consequence that when the head containing it is cut off, another one is promptly grown. The other organs all appear equally well adapted to withstand mishaps. The extraordinary food canals, branching and ramifying all through the tissues, supply with a food receptacle even the smallest piece of the body that may readily be severed. Figure 206 shows the regeneration of the two halves of a planarian that was cut in two in the median plane of the 
body - a division that, as every one knows, would be instantly fatal to any of the higher animals. Most arthropods regenerate lost appendages readily, but slowly, the new appendage increasing in size a little at every moult. The crawfish (and many of its allies) is so provided against the loss of its legs that a special breaking place is developed across the middle of the second joint in them, a groove across the joint. and folds of membranes within it, that prevent
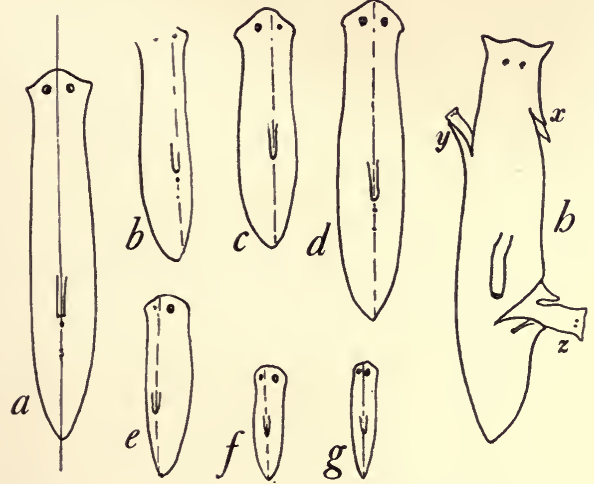

Fig. 205. Regeneration in Planaria ( $a$ to $g$ after Morgan; $h$, after Voigt). $a$, a planaria that was divided as indicated along the median line of the body. $b, c, d$, the regeneration of the left half, that was fed. $e, f, g$, the regeneration of the other half that had no food. $h$, regeneration of pieces obliquely cleft partly free from the body: at $x$ a new tail and at $y$ a new head and at $z$ both a new tail and a new head have appeared.

excess of bleeding when the leg breaks off. Specimens are collected not infrequently, having one of the big claws much smaller than the other, and in process of regeneration; a crawfish, seized by one of the big claws will sometimes automatically cast it off and escape without it. Indeed, so readily are the big claws of the related fiddler crabs cast off, that in handling the crabs one may hardly touch the claws without inviting their loss. 

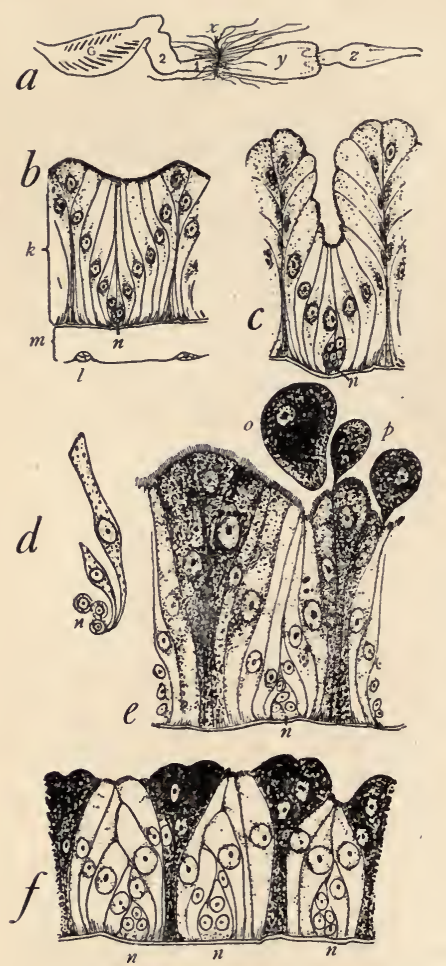

Normal regeneration for the maintenance of the body. - Regeneration of lost parts is but a manifestation of the power of growth applied in abnormal circumstances. It is a very noticeable thing when, by some mishap with tools or machinery, we knock off a finger nail and have to grow a new one; but physiologically it is not very different from getting our hair cut and having it grow out again. Our epidermis is continually being shed from the surface and new cells are continually growing up from below. An excellent example of the renewal of tissues inside the body is

FIG. 206. Growth of digestive epithelium in a dragonfly nymph (Gomphus). $a$, the alimentary canal as a whole; $g$, gill chamber, $I$ and 2 , Main divisions of the intestine. $x$, nephridia (Malpighian tubules) $y$, stomach. $z$, crop.

$\mathrm{b}$, Section of a bit of the stomach wall: $k$, digestive epithelium. $l$, longitudinal muscle fibres; $m$, longitudinal muscle layer; $n$. (as in all the following) a nest of cells for replacement of the functional epithelial cells,

$c$, the same as $b$, after fasting two weeks: note the accumulation of digestive secretion as shown in height of functional cells.

$d$, a dissociation preparation of part of one of the replacement cell nests.

$e$, the discharge of the digestive secretion after feeding. $o$, and $p$, globules of discharge: the oldest of the functional cells are thus thrown off bodily.

$f$, the replacement of the discharged cells with new ones from the cell nests $n, n, n$. Note the new (clear) cells crowding to the surface. 
furnished by the digestive epithelium of the dragonfly shown in figure 206. New cells are constantly being formed in little replacement centres at the base of the epitheliallayer, and the old ones, charged with the digestive secretions, are thrown off at every meal, to be mixed with the food and by their action upon it to dissolve it.

The tissues of the body differ much in their capacity for cell replacement; some cells like those of the lowermost layer of the epidermis, retain this capacity through life, others like nerve cells do all their dividing in embryonic life (hence, the great size to which the brain of the higher vertebrates so early attains), and have no capacity for making good cell losses. But if they have lost the power of produc-

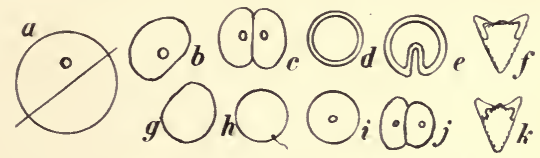

FIG. 207. Diagram of cell regeneration (after Morgan). $a$, an egg of a sea urchin that was divided as shown by the oblique line; $b$ to $f$ its subsequent development; $g$, the enucleate part of the egg; $h$, its fertilization by a sperm cell; $i, j, k$, its subsequent development.

ing new cells, they retain the power of repairing the old ones. If a nerve fibre be severed, a new fibre may grow out from the cell body at the stump of the old one. It is thus that a limb regains sensitiveness after being paralyzed by the cutting of a nerve.

Regeneration in cells and in embryos.-If an egg cell be divided the portion containing the nucleus may reshape itself, and go on developing quite normally, as illustrated in figure $207 b$ to $f$. And if the other part of the cytoplasm be supplied with a nucleus, as by the addition of a sperm cell of the same species (fig. $207 h$ ) it also may develop in the ordinary way. The two cells resulting from the first division of the egg of a sea urchin may develop as indicated 
in figure 208 , producing two individuals of half the usual size. At first they are likely to develop as half embryos, each cell and its descendants behaving

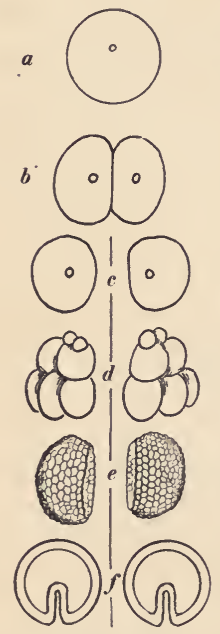

FIG, 208. The development of half embryos in divided $\mathrm{se}-\mathrm{urch}$ in eggs (after Morgan). $a$, the egg, $b$, the same when it was divided: the two cells were isolated as at $c ; d$, two half embryos in the 16 -cell stage: $e$, the same as incomplete blastulas; $f$, the same later in the gastrula stage, complete but of half normal size. as though the other were present. Consequently the blastula when formed is open on one side; but it closes and forms a normal embryo later.

In most bilateral animals the first cleavage plane lies in the medium plane of the body that is to be, and doubtless, when the two cells remain together each develops its own half of the body, left or right; but the above experiment shows that either is capable of developing any part of the body. Frogs eggs, with one cell killed at the two-cell stage, likewise develop at first half embryos, which later become whole ones. Wilson long ago showed that the cells of the egg of the lancelet, isolated at the 4-cell stage are each capable of developing an embryo, but at the 8-cell stage, each cell may develop only as far as the blastula. Apparently differentiation is slight at first, and "ontogeny assumes more and more the character of a mosaic work as it goes forward."

\section{Some aberrancies of regeneration.-} Ordinarily after mutilation, if normal conditions be maintained, regeneration tends toward the production of parts like those removed. When the head is cut off a hydra it produces a new head, and not a foot. What marked 
antero posterior polarity, for example, is shown by the incised planarian of figure $205 \mathrm{~h}$, which is producing new heads where the strips of severed tissue are directed forward, and tails where these are directed backward. But the expected does not always happen in regeneration. In at least one genus of earthworms, if any number from one to five of the front segments of the body be cut off, these will be replaced in like number; but if a dozen or twenty or any number of segments more than five be cut away from the front end, only five will be regenerated in their stead; and if more than the anterior half of the body be cut away, from the front end of the posterior piece there will develop not a new head but a new tail. Apparently, there is a limit to anterior polarity.

The hydroid Antennaria regenerates a new head when the decapitated stem is kept in the upright position, but a new foot when it is kept in inverted position. And stems of the hydroid Pennaria, which regenerate heads under ordinary circumstances, will regenerate roots if the cut ends are held
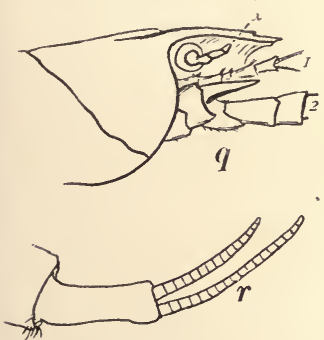

FIG. 209. Regeneration of the stalked eye of the crawfish (after Miss Steele). In $q$ a simple appendage is regenerated in the place of the eye; $r$, a biramous appendage, that regenerated in the place of the eye of another specimen. against a solid support. From the severed eye-stalk of a crawfish (or almost any other decapod crustacean) a new eye never develops, but on the contrary, if there be any regeneration (as there is pretty sure to be if the animal be young, and the conditions favorable for growth), it is usually a jointed appendage, more or less antenna-like, and at its best development distinctly bi-ramous, that grows out in the eye's stead (fig. 209). 
Study 42. Experiments with regeneration in planarians.

Materials needed: Plenty of living planarians, in individual dishes of clean water. This is a running experiment, requiring repeated observations at successive laboratory periods.

Cut small pieces from some of them, cut others in two in the middle, at various planes, and make diagonal clefts in others to observe polarity of the partly severed pieces.

Divide the bodies of a number of the animals. They may be cut with fine and sharp scissors while creeping, fully extended, on a piece of thin wet paper; cut paper and planarian together, at single rapid but careful strokes. Excessive cutting up of the animals may be avoided by apportioning the work among several members of the class. (That need not be a serious consideration, however, since the regenerated pieces may be returned to the waters whence the whole ones were originally taken, and the tribe will have been increased by the operation).

The record of this study should consist of sketches of the animal, one for each operation, and outline drawings of the forms assumed at subsequent examinations.

Grafting.-The parts of two organisms, if brought together by clean cut surfaces, with growing parts apposed, and held in close contact for a time, nuay grow together, and, if complemental parts be taken, they will thereafter function as a single organism. This is grafting. In the higher plants, on which it is most commonly practiced, the piece that is to represent the top of the combined plant is called the cion, the rooting piece is called the stock. These two parts are combined into one in a number of well known ways, three of which are represented in figure 2 IO. The essential things in the practice (with such woody plants as these shown) are I) the bringing of 
the cambium or growth layer of scion and stock into close contact, and 2) protection of the cut surfaces from evaporation and from the weather.

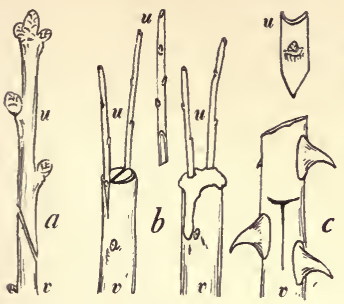

Fig. 210. Grafting methods with plants. $a$, splice grafting; $b$, cleft grafting; $c$, bud grafting (or more commonly called budding). $u, u, u$, $u, u$, cions. $v, v, v, v$, stocks. The second figure oc the cleft graft shows how the grafting wax is applied to cover the wound.

Such combinations of the higher plants are possible only between rather closely related forms (usually, between members of the same genus), and every species has its combination preferences, which can only be learned by trial. Pear cions, for example, will grow well on quince stocks, but quince cions will not thrive on the pear. Potato and tomato will thrive in either combination, and when the tomato is the cion, both potatoes and tomatoes may be produced on one plant (fig. 2 I I).

At its best the union is mainly a co-adjustment of transportation systems, admitting of interchange of food materrials; each part retains its own individuality, and, the results of the combination are not heritable. The objects of grafting are mainly two:

I. To combine the characters of two species in one individual. Thus, in order, to add to the good qualities of certain apples the hardiness of the Siberian crab, apple cions are grown on crab stock. In order to adapt certain plums to southern soils, plum cions are grown on peach stock. When the vineyards of France

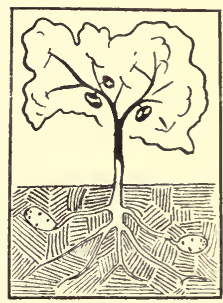

FIG. 211. Diagram of the plant produced by grafting tomato cion on potato stock. 
were being destroyed by the imported American grape phylloxera (a root infesting aphid, Phylloxera vastatrix), the situation was saved largely by grafting wine grape cions on stocks of the hardier and immune American grapes.

2. To perpetuate in the fruiting part of the combination a valuable variety; one that does not breed at all, (as for example, a seedless grape or orange) or one that does not breed true. In such case the kind of stock used is of little consequence, except as it is a good feeder for the cion.

Grafting in animals.-Such combinations of parts are not so readily made in animals. The specialized contractility of the animal body is against it. It is harder to keep the growing parts in close apposition, while being knit together. Advantage may be taken of quiescent periods in the life of the individual when stored food is available for growth, such as the early embryonic stages of frogs (fig. 2 I 2 ) and the pupal

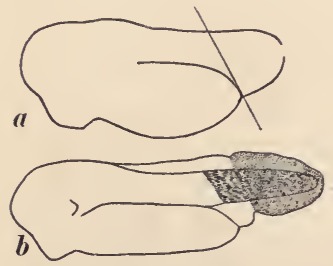

Fig. 212. Diagram of grafting operation on frog larvae (after Harrison). $a$, the larva at suitable age for grafting; $b$, the same larva, older, to which has grafted the tail of a larva of another species.

stages of insects, etc. Thus moth pupæ of the right age carefully cut in two across the base of the abdomen, and carefully handled to prevent loss of blood have been united successfully in cross-combinations, the parts being sealed with paraffine while being knit together. Antennæ, and wings have been cross-grafted in similar manner. By uniting male bodies with female abdomens, females having the appearance of males have been produced. Similarly, male and female wings and antennæ have been combined upon the two sides of one individual. 
Objects. - The purpose of regeneration and grafting experiments on animals has been to obtain new side lights on the nature of the organism. Nature furnished the hints for the first experiments tried. The rooting of detached twigs of the crack willow might have suggested to anyone the possible rooting of cuttings. The finding of regenerating starfishes, broken in the surf, might have suggested regeneration experiments on animals, and if a portion of an animal's body from which the sex organs were removed, were able, as it is in fact in some cases, to reproduce the missing parts with sex organs included, then the experiment would seem to have shown that the distinction between body plasm and germ plasm is not to be too sharply drawn Although the sex cells would normally come from the sex organs removed, they might come from new sources in the body.

\section{Study 43. Grafting practice with plants.}

Materials needed: Selected and over-wintered cions and rooted seedlings or other stocks for their reception; grafting wax (see appendix) and sharp pocket knives.

It will be worth the time of a laboratory period for the student to make with his own hands the combination of parts of two species, and later to see them growing as one. Different types of grafting may be demonstrated also, and the later matured results of previous operations. The work should be directed by someone who has had practical experience.

The record of the study, should be an illustrated account of the student's own operations and observations.

Reserve potentialities of the living substance.-The studies of this chapter should have been convincing of the wide range of methods by which the ends of life--the preservation of races-are accomplished. We began this chapter by speaking of the normal course of life, which is merely the 
more usual course and the more primitive. All the deviations from this course that we have been studying, have become thoroughly normalized in the races that exhibit them; the methods of development are stereotyped alike for all. Whatever the course of life, each individual of a species follows it with the most minute exactness. And yet, when something happens to block the usual course, another may be followed, as regeneration and grafting experiments most plainly show, to reach the same end. There are reserves of power for development that the ordinary circumstances of life do not draw upon; accidents and losses reveal their existence. If a member be maimed and a portion of its tissues be injured beyond repair, the injured part must be removed and new tissue fashioned in its stead. Phagocytes enter a wound to clear away old materials, and the blood brings new materials to be gradually fashioned into the form of the old. This is artificial regeneration; but nature makes use of these same pathologic methods in the removal of old tissues and the building of new in metamorphosis.

That the functional activity of certain parts of organisms may be increased by selection is shown by the increased milk production of the best dairy breeds of cattle, and by the increased egg prodúction of fowls, etc. Selection has made the dairy cow an improved machine for turning hay and ensilage into milk. But nature presents examples of the exaggerated activity of special functions yet more striking. One such has been fittingly described by Lloyd Morgan in the following words:

"There is perhaps, no more wonderful instance of rapid and vigorous growth than the formation of antlers of deer. These splendid weapons and adornments are shed and renewed every year. In the spring when they are growing, they are covered by a dark skin, provided with short, fine, 
close-set hair, and technically termed 'the velvet.' If you lay your hand on a growing antler, you will feel that it is hot with the nutrient blood that is coursing beneath it. It is, too, exceedingly sensitive and tender. An army of tens of thousands of busy living cells is at work beneath that velvet surface, building the bony antlers, preparing for the battles of autumn. Each minute cell knows its work, and does it for the general good, so perfectly is the body knit into an organic whole. It takes up from the nutrient blood the special materials it requires; out of them it elaborates the crude bone-stuff, at first soft as wax, but ere long to be as hard as stone; and then, having done its work, having added its special morsel to the fabric of the antler, it remains embedded and immured, buried beneath the bone products of its successors or descendants. No hive of bees is busier, or more replete with active life than the antler of a stag as it grows beneath the soft, warm velvet. And thus are built up in the course of a few weeks those splendid 'beams' with their 'tynes' and 'snags,' which, in the case of the wapiti, even in the confinement of our Zoological Gardens, may reach a weight of thirty-two pounds, and which in the freedom of the Rocky Mountains, may reach such a size that a man may walk without stooping, beneath the archway made by setting up upon their points the shed antlers. When the antler has reached its full size, a circular ridge makes its appearance a short distance from the base. This is the 'burr' which divides the antler into a short 'pedicel' next the skull, and the 'beam' with its branches above. The circulation in the blood vessels of the beam now begins to languish, and the velvet dies and peels off, leaving the hard, dead bony substance exposed. Then is the time for fighting, when the stags challenge each other to single combat, while the hinds stand timidly by. But when the period of battle is over, and the wars and loves of the 
year are past, the bone beneath the burr begins to be eaten away and absorbed, through the activity of certain large bone-eating cells, and, the base of attachment being thus weakened, the beautiful antlers are shed; the scarred surface skins over and heals, and only the hair-covered pedicel of the antlers is left."

Antler development on the part of the male is no less

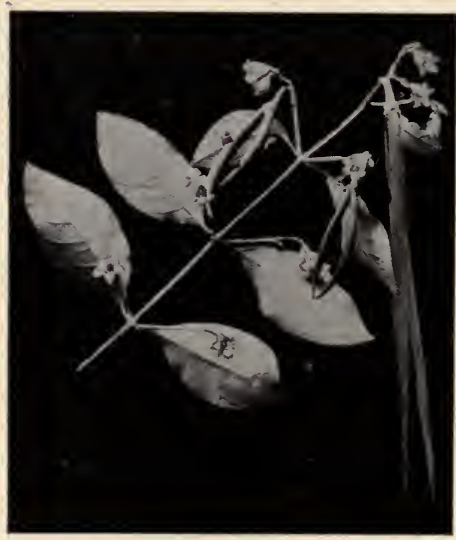

FIg. 213. New seed pods of the spreading dogbane (Apocynum), showing quick response to fertilization. remarkable, a1though far lessimportant, than the organic response on the part of the female that follows upon fertilization of the egg and results in the production and nurture of the young. Figure 2 I 3 is intended to show how quick is this response to fertilization in the common spreading dogbane. If a flower fail of fertilization it dies, but if fertilized, the fruit which then develops from it may reach full size before the last of the flowers on the same peduncle have faded.

These examples of organic activity, suddenly and intermittently recurring, are the results of internal (perhaps orthogenetic) tendencies. But the reserves of developmental power which organisms possess may be tapped by outside agencies as well. Gall insects for example, have 
turned to profit their ability to call forth plant growths in excess of the normal. We have already noted how often galls are fruit-like in form (fig. $2 \times 4$ ). The cone gall of the willow (fig. 203) is not a deformed shoot, but an overgrowth (hypertrophy) of tissue superadded to the normal growth of the shoot.

Organic harmony.-Whether an organism develop out of an egg under normal or under artificially altered circumstances, whether out of a piece of a pre-existing organisms or out of pieces of two put together, if it develop at all it is pretty sure to develop with organic unity, with symmetry and proportion. Its dominant tendency is toward organic wholeness.

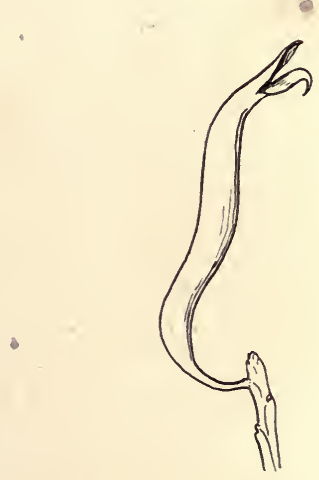

FIG. 214. A pod-like bud gall on Pistachia (after Kerner and Olivier), showing response to external stimulus. 


\section{CHAPTER VI.}

THE ADJUSTMENT OF ORGANISMS TO ENVIRONMENT.

"Life is response to the order of nature."-BRooks.

In this chapter we shall attempt a more careful examination of the phenomena of fitness, selecting arbitrarily for the purpose, out of a world-full of examples, a few that seem fairly illustrative and typical.

Plants and animals, which were primitively much alike and lived under more or less uniform conditions, have multiplied, differentiated, specialized, and spread to every habitable part of the globe, and have become adapted to conditions of utmost diversity and complexity. Fitness to meet these conditions is a necessity of existence under them. Unfitness so pronounced as not to admit of getting a living or of leaving descendants, would mean for any species speedy elimination. That all living things are adjusted to their places in the world is most obvious; how this has come about is a subject of much speculation at the present day. We may not be able to determine whether-the initiative of the variable organism or the impress of environing conditions has been the major factor in producing the results, but we can at least see the sort of facts on which all the theories advanced in their explanation are based. As a matter of convenience we will divide our studies of this subject into three groups, according to the more prominent phenomena involved, as follows:

Adjustment in place and time.

Adjustment in manner of life.

Adjustment in bodily characteristics. 


\section{ADJUSTMENT IN PLACE AND TIME.}

We go to the woods for squirrels, to the marsh for snipe and to the lake for fish. We do not expect to find either in the place of the other; indeed, we know they could not live if they exchanged places. If we likewise go to the beach for sand or to the mine for gold, we know that either might exist as well unchanged if put in the place of the other. The gold or the sand may have lain unchanged for ages; but squirrel and snipe and fish have developed with their environment, and are developing still.

It is not everywhere in the woods that we find squirrels. They have their own particular haunts. They like the nutbearing trees, and shun the thorny locusts. They like certain bird neighbors and dislike others. In the water we find pickerel and top-minnows feeding at the surface, catfishes and mud-minnows feeding on the bottom, and other fishes foraging between; different forms of life at different levels; and likewise, passing out from deep water shoreward we find that every change of forage and shelter brings with it its own peculiar forms of life. The more closely we look into any environment the more we see of small and sequestered species, restricted in range and peculiar in mode of life, segregated into definite and sharply delimited haunts. The physical conditions of life in the water are still simple, but with the multiplication of individuals and differentiation of species, by reason of the stress of competition on every hand, the biological conditions have become severe. Only a few of the stronger and larger species frequent the open water, and these only when they have aitained maturity; the great majority of the lake's inhabitants dwell in some restricted sphere. The great sturgeon may roam the lake at will, but the little darters, and infant sturgeons as well, must keep to shelter. 


\section{Local distribution of green plants.}

The distribution of plants over the larger regions of the earth is determined chiefly by physical and climatic conditions. We can see the effect of temperature by passing from the stunted and scanty vegetation of polar regions to

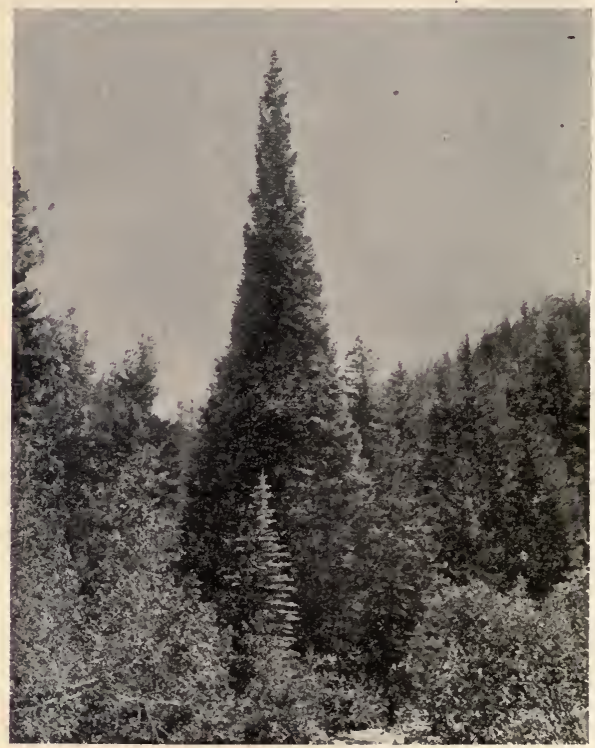

FIG. 215. Engelmann's Spruce from a shelt.red valley (altitude $7600 \mathrm{ft}$.). Photo by D. M. Andrews.

the luxuriant forests of the tropics; of winds (figs. $2 \times 5$ and 216 ) and altitude and drouth, by crossing mountain and desert. We can see the effect of water and sunshine by crossing a narrow ravine, from its moist and shaded north 
slope to its dry and sunny south exposure; or we can see it by walking from the north side of our house around to

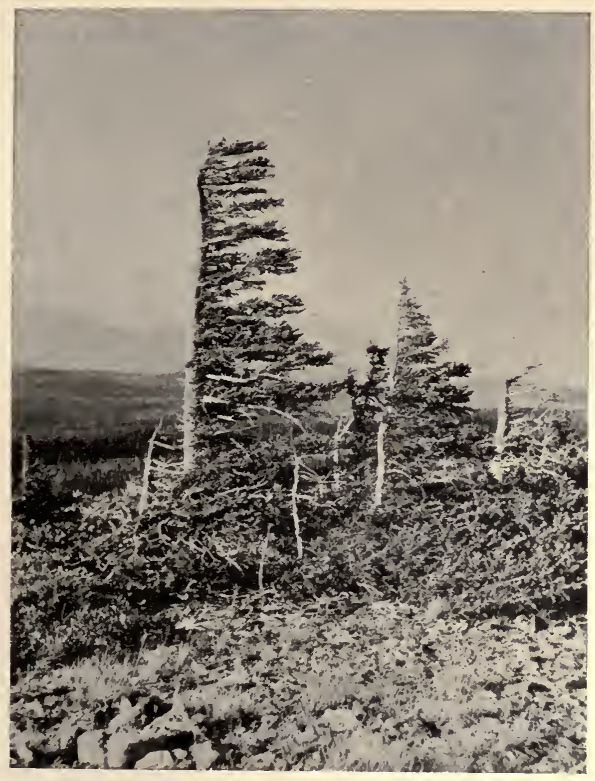

FIG. 216 Engelmann's spruce from an exposed mountain side (altitude ro,800 ft.). Photo by D. M. Andrews.

the south side. Food and water are the primary requisites of plants; but green plant food is nearly everywhere present-the carbon in the air, and the other food materials in the soil; but water is not so uniformly distributed over the surface of the earth. So it has come about that 
the distribution of water has largely determined the grouping of terrestrial plants into natural societies:

Hydrophytes-Plants accustomed to abundant available moisture.

Mesophytes--Plants that live under intermediate conditions.

Xerophytes-Plants that live where the water supply is scanty, and that have deep roots, and many adaptations for conserving the water supply.

Within each of these groups the distribution of the members in relation to each other--their mutual adjustment in place--is determined more largely by exposure to light than by any other single factor. Besides food, green plants must have light, to supply the energy for growth that their simple foods lack. This is especially true of the mesophyte society, with its extraordinary diversity of size and form and habitat. Be it forest, heath, or meadow, we always find it dominated by a few relatively large species of great vegetative vigor. Around and between these, occupying the interstices, and holding what soil and sunshine they can get, are a host of lesser species, scattered, diversified and often highly specialized as to their mode of performing particular functions. It is among these that we find the most special forms of plant-body and the most special devices for securing cross-pollination and seed distribution, etc. A few of these plants of the undergrowth sometimes show a sort of secondary dominance, their crowns forming imperfect foliage strata at successively lower levels. Thus in the hard-wood forests of our northern mountains there is often a top stratum of crowns of maple, beech and birch at high altitude; a secondary stratum of the spreading tops of the hobblebush, a few feet above the ground, and a third stratum of moss, carpeting the floor of the forest. Often in oak woods farther south, there are successively lower strata of 
Study each species as to its more important ecological characters and record these characters briefly in a table prepared with the following headings:

Name.

Duration (annual, biennial, perennial).

- Increase (aside from seeds, by offsets, stolons, tubers, etc.)

Social habit (solitary, commingling, copse forming, cover forming).

Growth habit (scape, rosette, wand, bush, crown. If not erect, trailing, twining, climbing or epiphyte, parasite, subterranean, etc.)

Rooting in (topsoil, subsoil, deep soil, rock crevices, rotten wood, etc.)

Favorite situation.

Favorite exposure.

Season of maximum vegetative activity (spring, early summer, late summer).

Write the names in the first column by groups, as follows:

Spermatophytes $\left\{\begin{array}{l}\text { trees } \\ \text { shrubs } \\ \text { herbs }\end{array}\right.$

Pteridophytes

Bryophytes

Thallophytes.

The record.-After the table is completed (the entire green plant population of the area selected being included therein), then write out briefly your interpretation of the facts, as to the relative dominance of each ecological characteristic, and possible reasons therefor.

Adjustments in place may be further illustrated by the zonal distribution of aquatic seed-plants, indicated at the right in figure 224. This represents an inviolable order; for the shoreward types are capable of shutting out the light 
from those in deep water, except at depths they themselves cannot endure. Adjustments in time are indicated in the last column of the preceding table for the single season.

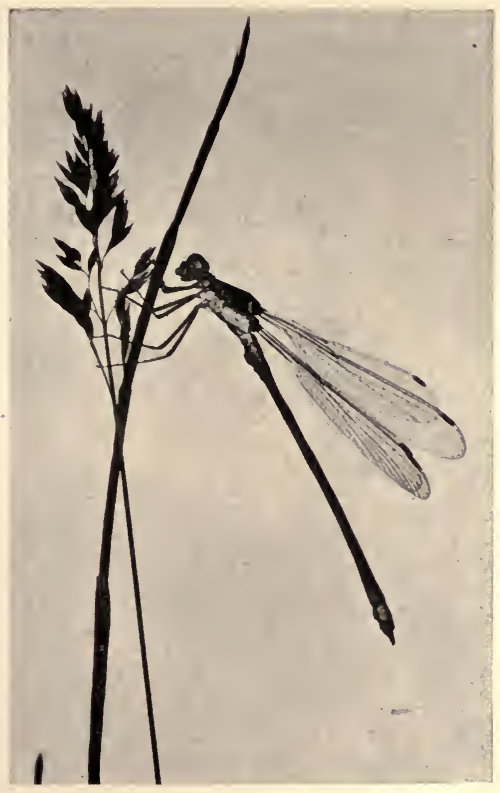

Fig. 218. A damselfly (Lestes uncatus).

These are mutual adjustments and involve succession of periods of vegetative activity. Time adjustments that extend over long periods, and that accompany slow changes 
of environment, and that result in a succession of floras, may be studied if there be available a series of ponds in the various stages of filling, or if

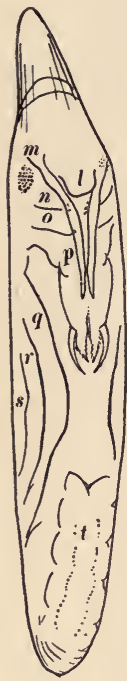
there be burned over tracts or fallow fields in the various stages of reforestation. Suggestions for such studies may be found in a number of modern text books of botany. The adjustment for geologic time is studied in the palæontologic record, and is the history of plant life on the earth from the beginning.

\section{Hibernation and aestivation.}

Corresponding to the seasonal adjustments of early and late plants, just cited, there is seasonal cessation of vital activity among animals. In our temperate climate, many warm blooded mammals, and most other resident animals, disappear on the advent of cold weather, and may be found in a dormant condition, in winter quarters. They are hibernating. Their temperature is barely above freezing point. Their metabolism is well nigh at a stand still. In the spring they emerge in good condition and resume their wonted activities. Nature effects great economy by limiting their foraging operations to the grow-

Fig. 219. The æstivating e mbryo of Lestes, as seen through the translucent e gg shell. $l$, lab r u m; $m$, antenna; $n$, mandible: $o$, maxilla; $p$, labium; $q, r$. $s$, legs of one side; $t$, abdomen. ing season.

On the other hand, in the hot weather of summer, with its accompanying drouth, when there is not enough water to maintain activity on the part of organisms that live in temporary shoals there results another resting stage that is known as astivation. Thus, through the central United States the damselfly shown in 
figure 2 I 8, lays its eggs in the stems of bur-reed and iris, growing in temporary pools. The eggs at first develop rapidly as in other damselflies, and reach the condition shown in figure 2 I9 about the time that these pools nor-
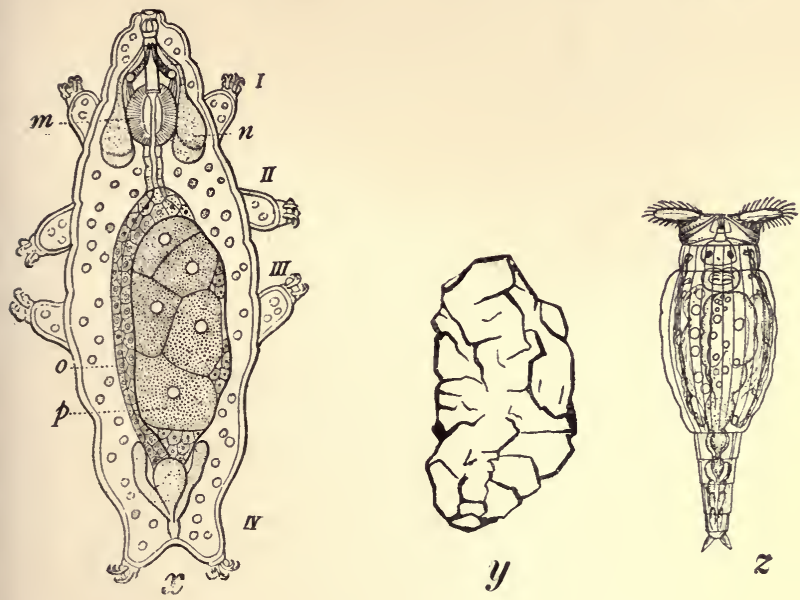

FIG. 220. Animals that withstand dessication. $x$ and $\nu$, a tardigrade (Macrobiotus hufelandi) $x$, extended, creeping; $y$, in a state of apparent death, dried; 8 , a rotifer (Philodina megalotrocha). Internal organs or the tardigrade shown in optic section: $m$, pharynx; $n$, salivary gland; $o$, stomach; $p$, ovary; 1, II, III, IV, legs of one side. ' $x$ and $y$, after Hertwig, $\boldsymbol{s}$, after Jennings.

mally "go dry." There they stop, and in that condition they remain until the rains of autumn refill the pools, when they resume develepment, hatch out and enter the water.

There are many lesser organisms, notably the tardigrades and rotifers (fig. 220), so well adjusted to the exigencies of drouth they can get along and maintain themselves, living 
in rain water spouts, and in stone urns, that are alternately drenched with showers and baked in the sun. With every sun-baking, they are almost completely dessicated, and become contracted and wrinkled into almost unrecognizable shapes; but with the next shower they "soak up" again, and resume normal activity.

Study 46. Observations on the dessication and resuscitation of rotifers.

Materials needed: An abundance of living rotifers, preferably of the genus Philodina, which is commonly found in the dried crust of the bottom in stone urns in cemeteries, etc., and which may be cultivated in little porcelain dishes with rain water in the laboratory. For convenience of handling, cultures are best made on squares of fine-meshed filter paper laid in the hollow of the bottom of the dishes. For methods of handling, of concentrating, of isolating the rotifers see appendix.

The student should obtain specimens at one laboratory period, should isolate some of them in the bottom of a hollow ground slide in the hollow of a piece of filter paper fitted thereto, should set this slide away uncovered to dry by evaporation, and at the next laboratory period, should examine the rotifers dry, and then should cover them with water and watch them resuscitate.

The record of this study should consist of notes on and sketches of the things observed.

\section{Local distribution of animals.}

That food and shelter are the primary factors determining the distribution of animals is almost too obvious to be stated. Where to find a living and establish a home is the great question confronting every animal-even man. Terrestrial plants live where they must; but most animals 
are free to move about within certain, often narrow, limits, to find new pasture or to change their domicile. In a small society of green plants it is comparatively easy to find all the species, for they are fixed in place, and come out into the light, and into view; but so different is the case with animals, so small are many of them and so secretive and elusive of habit, that there is not an acre of the earth's surface of which the entire animal population is known. Even of that class of large animals to which we ourselves belong, there are many mammals living in our own immediate environs that we seldom or never see.

As already stated in the opening chapter, herbivores and carnivores, parasites and scavengers are everywhere, because they fulfill permanent functions in natural society. The herbivores are,

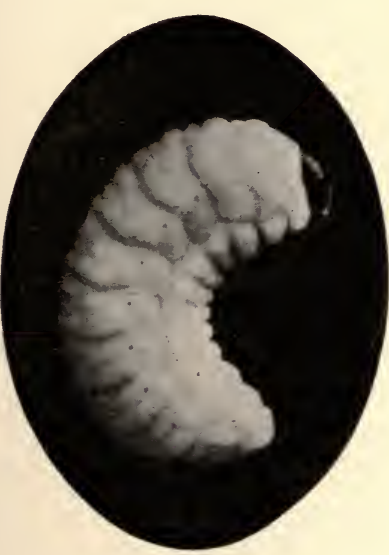

Fig. 221. Photograph from life of a young and active flag weevil larva (Mononychus vulpeculus). among animals, the producing class; all the others are consumers. The food of animals is not to be found everywhere, even that of the most omnivorous species. The deer that roams the forest, cropping the leaves and twigs of a great variety of plants, leaves a much greater number of species untouched. The caterpillars of the gypsy moth will eat the leaves of almost every green tree, but most caterpillars will eat of a single 
genus of plants, and many will eat only of a single species. The result of the competition of the past among animals seems to have been toward greater localization and concentration of food supply - at least for the smaller species. The flag weevil (fig. $22 \mathrm{I}$ ) eats of the seeds of the blue flag (Iris versicolor) but only of the endosperm, and of that only for a few weeks when it is newly formed. Likewise, carnivores, parasites and scavengers all have their peculiar tastes.

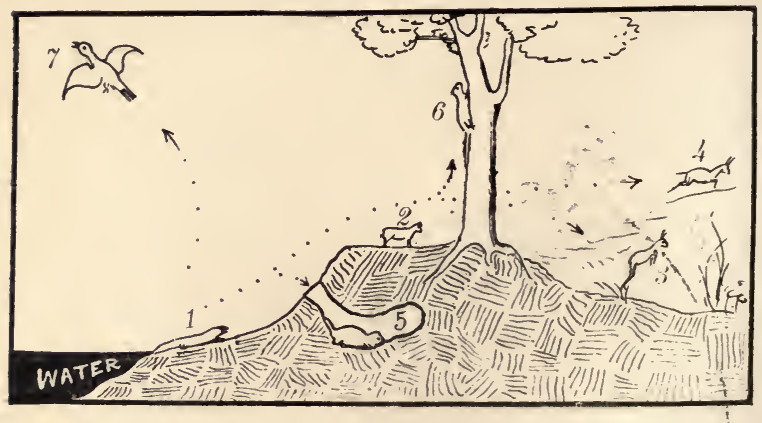

Fig. 222. Diagram illustrating lines of ecological specialization among terrestrial vertebrates.

That these tastes may best be gratified under those conditions that at the same time furnish the best shelter and domicile for each species is a truly wonderful and altogether admirable feature of their adjustment.

Primitive terrestrial animals, recently come up from the water, were doubtless "creeping things," with feet adapted more for propulsion than for the support of the body (fig. I Io, page I80). In time their descendants were able to get up on their feet and walk. With better powers of loco- 
motion they were better able to possess the land, and they multiplied in numbers and competition ensued. Superadded to the stress of competition was the direct onslaught of active enemies. Conditions became hard, and various shifts for a living were resorted to. The main lines these shifts could take were determined, however, by environing conditions. There was room to run in, if speed could be attained. There was soil to hide in, if one could dig; there were trees to climb; there was water to dive in; and if anything could fly the air offered the best of all ways of escape.

So land animals differentiated, somewhat as indicated graphically in the accompanying diagram (fig. 222) into cursorial, fossorial, arboreal, aquatic and aerial groups.

Size.-Owing to the nature of the environment, its limited quantities of food, its limited and irregularly distributed accommodations for shelter, size came early to be a determining factor in the adjustment. For the small animal, while at a disadvantage in point of strength, is at a great advantage when it comes to finding food and shelter. A flag weevil can find a life's provision in one chamber of an iris seed capsule, and leave enough seed untouched to maintain the plant stock, while an ox may browse to the point of extermination all the herbage on half an acre of ground.

The kind of differentiation of habitat possible to the larger vertebrates was possible to terrestrial invertebrates upon a smaller scale. The runners, climbers, burrowers, etc., among the beasts of the forest have their counterparts in groups of like habits among the insects of the meadow. Moreover, among the lesser animals that climbed the tree or that went down into the burrow of the beast, there was a secondary, parallel differentiation; so that on the trunk of the tree, and on the walls of the burrow we find small burrowing, running, jumping and flying forms. Indeed, 
even on the back of the ox there are parallel phenomena of distribution; there are fly larvæ that burrow beneath the skin, there are ticks that cling to the surface, fleas that run and jump about, and flies that take wing.

Thus, the body of the large plant or animal becomes a unit of environment for a host of dependent forms. Miniature units are found in single organic products, such as the ear of

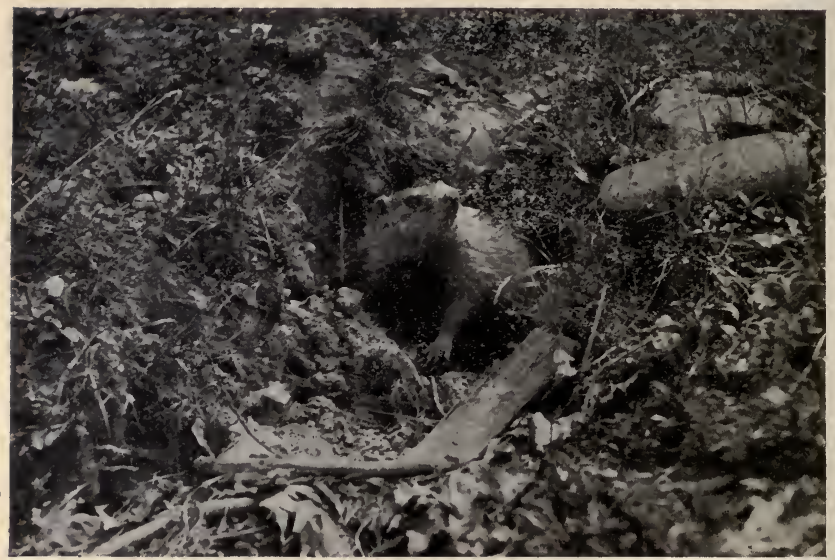

FIG. 223. Young woodchuck (Arctomys monax) in the mothth of his burrow. Photo by T. L. Hankinson.

corn, the head of cabbage, or any of the larger fleshy fruits; how many inhabitants there are dwelling in each of these, and how well they are localized and adjusted in place and time, may be learned from the reports of our agricultural experiment stations. The cone gall of the willow has a considerable population, distributed in place as indicated in figure 36 , (page 46 ). In cases like these the distribution is 
different from that on plane surfaces, as indicated above; but it is always conditioned by and always conforms to the nature of the environment.

It is the terrestrial vertebrates that we know best among animals so we will next attempt a cooperative statistical compilation of facts bearing directly on the mutual adjustments of these.

Study 47. The local resident terrestrial vertebrate fauna: its ecological distribution; a compilation-study.

Prepare a table, leaving a column at the left hand for group names, with the following column headings, abbreviated as desired:

Name.

Inhabits (forest, heath, meadow, marsh, shores, desert place: indicate special habitats in any of these).

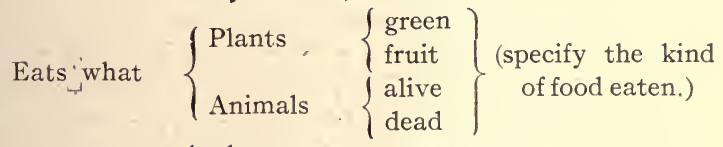

Forages $\quad$ I where
I when, (day, night, etc.)

Special means or apparatus for getting food.

Nests $\quad\left\{\begin{array}{l}\text { where } \\ \text { when (dates) }\end{array}\right.$

Constructs or takes advantage of, what special shelter.

Escapes enemies by $\left\{\begin{array}{l}\text { What sort of activities (running, } \\ \text { jumping, dodging, burrowing, } \\ \text { flying, diving, etc.) } \\ \text { What sort of organic defense (bad } \\ \text { odor, bad flavor, defensive } \\ \text { armor, protective coloration, } \\ \text { etc.) }\end{array}\right.$


Arrange the names by groups at the left hand, mammals, birds, reptiles and amphibians.

Fill out the table as far as possible from personal knowledge and observation. For the balance consult reference literature, or any other source of reliable information. In a class of students this may be facilitated by division of labor. If blanks still remain they should be useful as indicating gaps in the knowledge of the local species.

Such a table as the foregoing kept by the laboratory and added to, year by year, by succeeding classes as knowledge of the fauna increases, may grow into a most useful and reliable ready-reference chart.

The record.-Complete the table so far as possible and then write out briefly your own interpretation of the facts contained in it. These facts should give rise to many legitimate questions. Is there any clear relation between any systematic group and any particular habit of feeding? of locomotion? What kind of habitat has the largest number of species in its population and why? What habits are shown by the smallest number of species and why? .Is there any clear relation between size of the animals and habitat? Between size and feeding habits? Between size and habits of locomotion? etc., etc.

Animal migrations are sudden shifts of place that demand good powers of locomotion. When of irregular occurrence, as is usually the case with the migration of mammals like the lemmings, and of insects like the Rocky Mountain locust, they necessitate biological readjustment in both the localities between which the migration occurs; for the natural balance is disturbed in both places: but when well established as a normal part of a mode of life, as in the regular annual migrations of birds between their summer and winter homes, the adjustment becomes perfected, not only as adjustment in place and time, but also as adjustment between different places and seasons. 
Forms breathing free air

Forms breathing air dissolved in water
(I. Forms running on the surface (water skaters, etc.)

2. Forms lying on the surface (whirligig beetles, etc.)

3. Forms hanging at the surface, tipping the surface film (diving beetles, etc.)

4. Forms far below the surface, connecting therewith by means of a long respiratory tube. (Ranatra, rat-tailed maggot).

5. Free swimming forms, (corethra, etc.)

6. Climbing and clinging forms, (mayfly, nymphs, etc.)

7. Attached forms, (hydras, bryozoans, etc.)

8. Forms that walk or lie upon the bottom, (crawfish, etc.)

9. Forms that burrow in the bottom, (Ephemera, etc.)

Study 48. A laboratoryexamination of typical pond animals.

Materials needed: Plenty of living specimens of the several types of pond animals mentioned in the foregoing table; individual beakers of water in which to examine them.

First compare together representatives of the two main groups; a whirligig (Gyrinus or Dineutes), representing the groups that breathe free air, and a Mayfly or damselfly nymph (fig. 225) representing the groups that breathe the dissolved air. Put both in a large beaker of water and watch them; observe that the beetle carries a bubble of air at its wing-tips as it swims; its respiratory apertures are beneath its wings. Observe the cleavage of the water when 
it rises to the surface; note the water repellent surface; compare with the surface of the nymph. Compare the two as to what happens when they stop swimming; which one rises to the surface like a cork? Compare with one of the free-swimming forms in respect to this. Then examine the whirligig more carefully I) as to the differentiation of its feet; 2) the extreme specialization of its hind feet; 3 ) the form of its body and 4) the differentiation of its divided eyes, into an upper eye to look into the air, and a lower one to look down into the water; all are express adaptations for living on the surface. Then examine the other, as to its

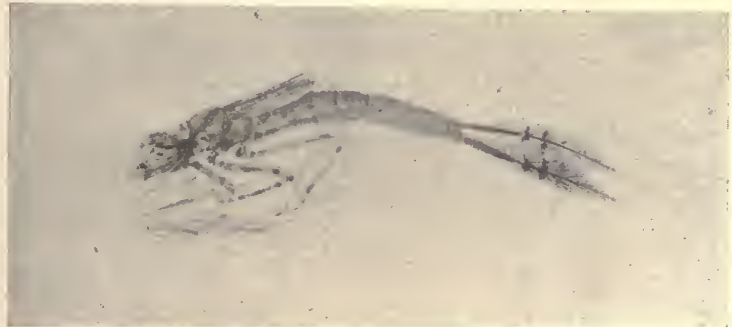

FIG. 225. The nymph of a damselfly (Ischnura verticalis).

climbing feet, the gills upon its abdomen and its protective coloring.

Then compare the representatives of the groups I to 4 as to I) position in the water, and movements; 2) mode, if they have any of carrying air; 3) air repellence of the body surface, and 4) weight. Air carried externally can be recognized by its shine. Push a skater or a water-spider (or even a housefly) under water and see the layer of air enveloping its whole body. 
Then compare together representatives of groups 5 to 9 as to I) diversity of form and habit; 2) resting position in the water. Compare together dragonfly nymphs representing groups 8 (Libellula) and 9 (Gomphus) x) as to form of body, 2) form of front of head, and 3) shape and position of feet.

The record of this study may consist of brief comparative statements of the things personally observed. State briefly the characters of each type that mark its fitness for the ecological situation to which it belongs.

Study 49. A field study of the pond animals in their native haunts.

A pond should be selected that has more or less shore vegetation, and banks dry enough to admit of approach with hand nets. A small pond if permanent is as good as a large one, and if no pond be available, a bay off a lake or river will offer practically the same forms.

Apparatus needed: Individual dip nets, beakers and vials. A plankton towing net, a sieve net and a few pails or bowls for com-
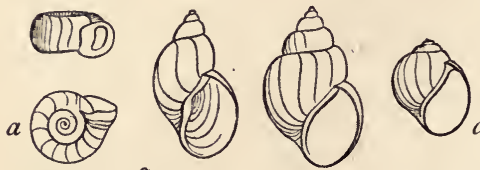

$b$
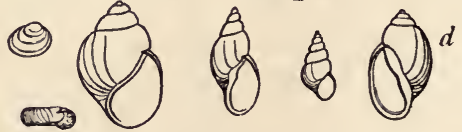

FIg, 226. Shells of fresh water snails. $a$, Planorbis; $b$, Ancylus; $c$, Limnea; $d$. Physa. (From Morse's First Book of Zoology, a pioneer American book of nature-study). mon use will also be advantageous.

Let the collecting and study be individual.

Collect air breathers at the surface with a dip net; such as are foraging or hiding down below may be obtained later. 
Sweep the open water with the dip net for free swimming forms. (Most of these are obtained more readily with a plankton net.)

Sweep the submerged vegetation with the dip net for the climbing and clinging forms; some members of groups 2 and 3 will thus at the same time be obtained.

Scrape the bottom with the dip net for bottom forms; scrape deeper and sift out at the surface, to get the burrowers; for these a sieve net is more efficient.

Take up submerged sticks, stones, leaves, etc., from the water and examine them for attached forms (the examination is very satisfactory by submersion in water in a big white bowl; bryozoan colonies (see fig. I 88a) will, however, be easily seen without this submersion.

Study each species as it is obtained; put a few specimens into a beaker of clean water with a few clean pebbles on the bottom and some stems at one side and watch it. Determine to which of the nine groups it belongs and write its ecological characters in the proper place in a table prepared with the following column headings:

Name.

Stage (larva, pupa or adult, etc.)

Feeding habits.

Takes air how.

Swimming apparatus.

Clinging or climbing apparatus.

Means of locomotion other than swimming.

Means of
escaping $\quad\left\{\begin{array}{l}\text { observation of enemies } \\ \text { attack of enemies }\end{array}\right.$

It should be possible to obtain:

Of group I, water skaters, water spiders, springtails, etc. Of group 2, whirligig beetles. 
Of group 3, diving beetles, water boatmen, back swimmers, water bugs, mosquito pupæ, cranefly larvæ, frogs, snails, etc.

Of group 4, Ranatra and rat-tailed maggot.

Of group 5, Corethra, mosquito larvæ, Daphnia, and a number of other micro-crustaceans.

Of group 6, damselfly, mayfly and some dragonfly nymphs, amphipods, newly hatched amphibian larvæ, etc.)

Of group 7, hydras, vorticellidæ, bryozoans (especially Plumatella), etc.

Of group 8, crawfishes, dragonfly nymphs, Asellus, etc. Of group 9. Tubifex, dragonfly nymphs, small mussels, nymphs of Ephemera, etc.

The record.-Find and include in the table as representative an assemblage of forms as possible. Where many allied forms of closely similar habit are found, use but one example.

\section{ADJUSTMENT IN MANNER OF LIFE.}

We select for study under this heading three subjects only:

I) Symbiosis: the adjustment in mode of life of two different organisms enabling them to live together in union with mutual advantage.

2) Parasitism: adjustment in mode of life between two different organisms for the benefit of the smaller and for the detriment of the larger.

3) Pollen production in flowering plants in relation to its distribution; the adjustment of one special plant function in relation to physical and animal environment.

\section{Symbiosis}

Lichens are the best as well as the commonest illustrations of this phenomenon. Lichens may be gathered at any time from the trunks of trees, from stones and fences, and from 
many other dry and sterile and unpromising situations. The gray encrusting species are commonest, but many forms occur. The well known "reindeer moss" is a lichen. For the purpose of the following study, one of the gray Parmelias (fig. $227 a$ ) and one of the chimney lichens that grow on decaying stumps in damp woods (fig. $229 b$ ) will answer our needs.

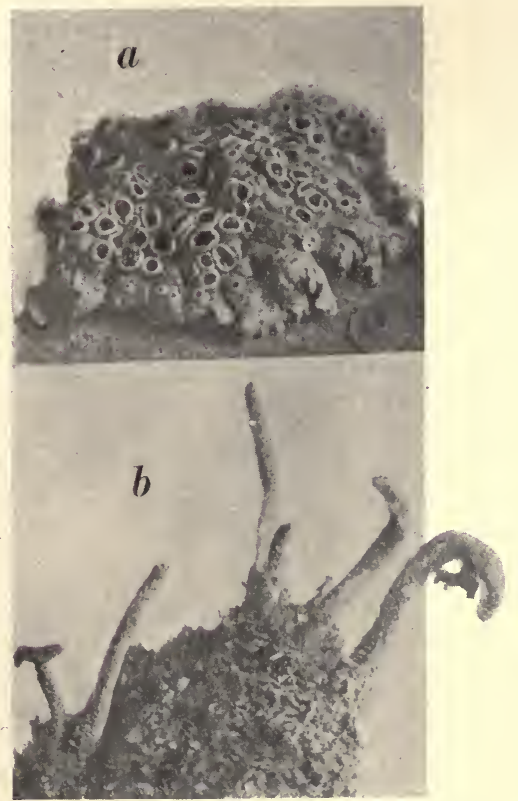

Fig. 227. Lichens. $a$, a common encrusting lichen, showing fruiting cupules; $b$, a "chimney lichen," whose "chimneys" are covered with powdery white lichen buds (soredia). 
Lichens appear as single organisms. They were long so considered. It is convenient to describe them still as single species; for they are such, for all practical purposes. But they are composite species, each consisting of a fungus and an alga, living together in structural and physiological union.

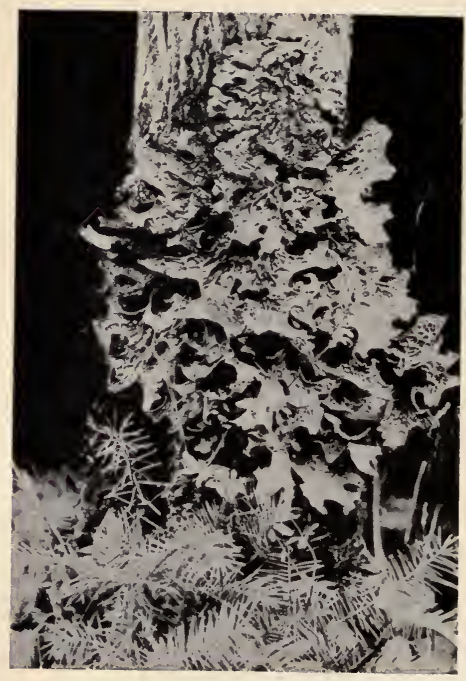

Fig. 228. A strap lichen growing on a tree trunk in damp woods.

The form of the combination is dominated by the fungus, which develops an underlying stratum for attachment to the support, and a covering cortical layer $\mathrm{h}$ aving great capacity for resisting evaporation一 of great advantage in exposed situations: and in ics more porous open fibrous middle layer, shelters a host of algal cells. The color of the latter shows through when the lichen is wet, but the true relations of parts are best made out by cutting vertical sections (fig. 229), through the thallus, and examining them 


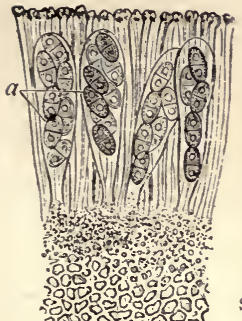

FIG. 229. Vertical section through a lobe of a common $1 \mathrm{ich}$ en (Physcia stellaris), showing fruiting surface above. $a$, spores of the fungus; $b, b$, algal cells, held among the fungous filaments, which are loosely arranged at $c$, but compacted together to form protective surface at $d$. (A fter Bessey).

with a microscope. It will then be at once apparent that the body is mainly a complex of branched fungus filaments and that the algal cells occupying the middle stratum, are in close union with some of these filaments, enwrapped by them, or indented by blunt protuberances from them.

This union is for mutual benefit. We have already learned that a plant like this fungus, lacking chlorophyl, cannot get its carbon directly from the carbon dioxide of the air; and in such situations, there is no other adequate source of supply. Through the agency of the green alga, however, and by means of its close attachment to the algal cells, it gets carbon made up into assimilable form. It furnishes the alga in return shelter and protection and retains about it watery solutions containing the other materials for its food. The algal cells have room for growth and division; alga and fungus grow together, maintaining constant relations, resulting in a growth habit by which lichen species are known. The combination is an efficient one for meeting hard conditions of life in dry and sterile situations. 
Some species that live symbiotically can be cultivated apart; but others appear to have become so fully established in this manner of life that they are no longer able to live apart.

There are other cases of symbiosis in different groups. We have already seen green hydras; the color is due to minute algal cells (zoochlorelle) living within the larger cells of the hydra, doubtless using there the carbon dioxide which the hydra cells excrete, and giving them back again the liberated oxygen for respiration. Attached to the roots of beech trees are moulds that do for the tree the absorbing work ordinarily performed by rhizoids, while the tree supplies them with carbon products. Thus here also the benefit is mutual.

Study 5o. The relations of fungus and alga in the lichen.

Materials needed: Lichens of the two types shown in figure 227 , the foliose one with spore cupules (apothecia) developed, Razor and pith for cutting sections.

Place a cupule-bearing thallus between two wet pieces of pith, and cut vertical sections as thin as possible with a razor. Mount and examine a number of these and select the best for study.

Mark the general arrangement and distribution of fungus and alga. Then study the fungus:

I) The form of its filaments in the several layers.

2) The form of its fructification in the cupule; compare with an account of the Ascomycetes, in any good text-book of botany.

Then study the alga. To do this remove the cover, tease the algal layer of a section to bits on a slide, cover again, and study the alga in the fragments. Determine the relations to the algal cells of the investing fungus filaments. Look for evidences of division in the algal cells. 
Scrape a little of the whitish powdery substance covering the surface of the chimney lichen, and mount it on a slide in water; spread it out thin by pressure (with rotation) upon the cover glass, and study the dissociated fragments. These should be little groups of algal cells intertwined with fungus filaments-lichen buds (soredia): in short, minute lichens, ready for dispersal. Obviously, when the spores of the fungus upon germination have to find and attach themselves to the proper algal cells there are some exigencies to be met that are obviated by this method of starting new plants by means of soredia.

The record of this study may well consist in some diagrams and drawings of the facts demonstrated.

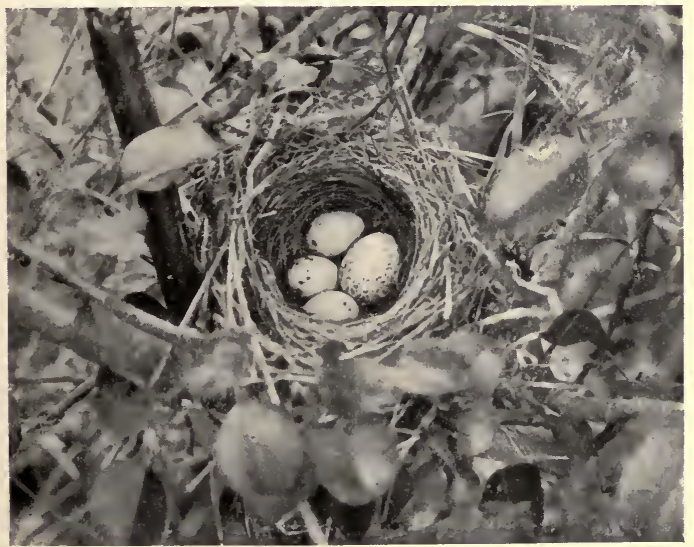

FIG. 230. Nest of song sparrow containing three sparrow eggs and one cow bird egg. Photo kindly loaned by Professor C. H. Eigenmann. 


\section{Parasitism.}

Parasitism is a relation between two species that costs the one its substance and the other its independence; the one species is called host, the other parasite.

The cost to the host species may be light or severe, according to the extent of the parasitism. It is comparatively light in such case as that of the song sparrow that hatches the cow-bird's egg. The
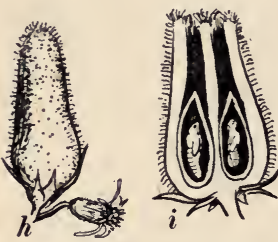

FIg. 231. Downy flower gall of the goldenrod. $h$, a gall and a flower head: $i$, a double gall split open, showing the pupa of the gall midge in one and the pupa of a (braconid) parasite in the other (right hand) chamber.

latter is parasitic only to the extent of the rearing of her brood. She deposits her egg in the nest of the sparrow (as shown in figure 230), supplanting a sparrow egg for the purpose, and leaves it there for the sparrow to hatch, and to feed through the nesting period.

The cost to the host species may amount to personal discomfort merely, as in the case of many small external and internal parasites of the larger mammals-lice, fleas, ticks, worms, etc.-or it may amount to loss of strength or even of life of many individuals. The host may be eaten by degrees by a single large parasite, as is the midge that makes the downy flower gall of goldenrod when parasitized by the braconid shown in fig. $23 \mathrm{I}$; or it may be eaten by a large number of smaller parasites, as is the caterpillar shown in fig. ${ }^{232}$. In any case parasitism is the burden of the host species; but the manner of life of the host is little altered thereby.

Such is not the case, however, with the parasite, which, according to the nature and extent of its dependence upon the host species, .becomes always more or less degenerate. 
The cowbird, relieved of the care of her young, has lost her nesting instincts. The Indian pipe (fig. 233) attached to the roots of trees whence it can draw manufactured carbon products, has lost its green color and its leaves. Sacculina,

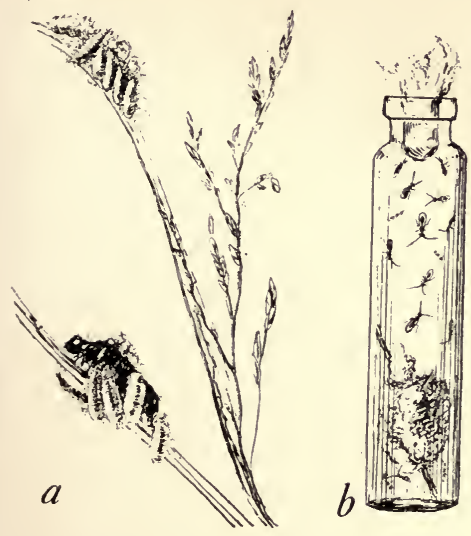

FIG. 232. A parasitized moth larva on blue grass top: some of its parasites have spun their cocoons beside it, others on the grass blade above; $b$, shows an easy method of getting the adult parasites from the cocoons. ihat tamous illustration of the degeneracy that results from the parasitic ha.bit, living in the the perfect nurture and shelter afforded by its crab host, has lost all those structures and capacities by which we recognize its free living kindred.

In general it may be said that in proportion as the conditions of living become simple,easy and secure, the parasite comes to lack those organs and faculties necessary to meet hard conditions, in battling with which they were developed. This loss is not the result of the parasitic habit, but of the sheltered life that goes with it. The series of insect larvæ we have used to illustrate metamorphosis, excellently illustrates degeneracy also, though none of the larvæused was parasitic. It would not be difficult to select parasitic insect larvæ, that would constitute parallel degeneration series. It seems clear that, as in the individual, so in the long run in the race, it is effort that builds; disuse leads to degeneration. 


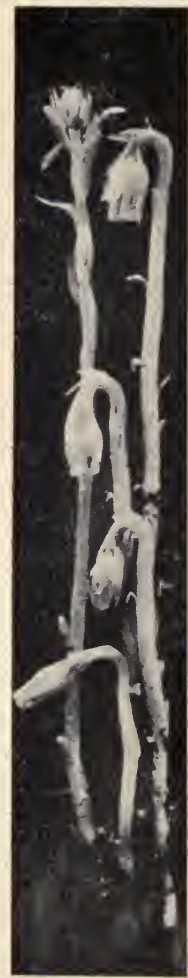

FIG. 233. Indian pipe, a leafless parasitic flow ering plant.

The two primal functions of feeding and reproduction not even the parasite may lose; on the contrary it often develops improved feeding apparatus and increased reproductive capacity; sacculina has done so; and the liver fluke, which is parasitic on two hosts, snail and sheep, at different stages of its existence has developed an extraordinary reproductive capacity to meet the exigencies of shifting from one host to the other.

Parasitism may be either external or internal, temporary or permanent, at one stage, or during the whole life of either host or parasite, on the part of the female only (in its incipiency, the female seeking shelter for her brood) or on the part of both sexes.

Parasitism is one of many possible shifts for a living. The opportunities for it have lain in the accumulation of stores of rich organic products on the part of the larger organisms. These are available only to smaller species. Hence parasitism is a prevalent habit mainly among the smaller organisms. The larger parasites offer like opportunities for smaller ones, and are themselves parasitized. The common bittern has as an external parasite the fly shown in fig. 234, living among its feathers. The fly has its own external parasites - the mites show in the figure, clustered at the joints of the legs, where 
thin connecting membranes offer a point of attack. Escaping from the pressure of competition, and from the attack of enemies, a few of the smaller representatives of many

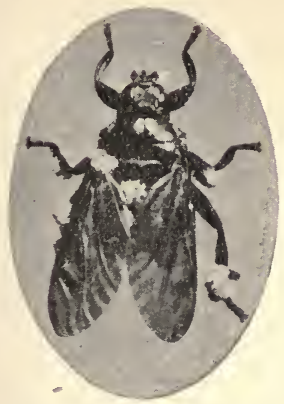

FIG. 234. A parasitic fly (Olfersia) that lives among the feathers of the bittern, bearing clusters of parasitic mites at the joints of its own body and legs. groups have become parasites. In those groups of the Hymenoptera that are most extensively addicted to the parasitic habit, primary parasites are commonly followed by secondary parasites, (hyperparasites), and these occasionally by tertiary parasites, the difference in size between host and parasite, being here at a minimum.

Parasites are nature's agents for regulating the natural balance. They prevent the undue increase of any species. They are themselves self regulating; for with their own undue increase, they eliminate themselves by eliminating their own food supply.

In recent years the aid of parasites has been sought to stay the ravages of noxious species, like the gypsy moth. Sometimes they are imported for this purpose; in which case care is taken to leave their hyper-parasites behind.

A moment's reflection upon the facts that have been before us in this course will make it clear that parasitism is by no means sharply distinguished from other phenomena of dependence of one individual upon another. It is living upon the living, plant upon plant, animal upon animal, one species upon another, that we call parasitism. That the boundary between symbiosis and parasitism is not hard and fast is shown by the case of the nematode that lives in the 
body cavity of the earthworm (cited in chap. III, p. I78). Ordinarily, nematodes found in such situation are parasites, but here they are found clearing up the lumps of waste chloragogue-impedimenta to the worm-accumulated in the hinder segments, and the relation seems to be one of mutual advantage. Were the two species mutually dependent in this function, we should call it symbiosis. As it is we call it commensalism, and say that the nematode is a guest, and not a parasite. Commensalism may well have been at times a transition stage in the development of parasitic habits.

Study 5I. A comparative examination of a series of parasites of a single order.

Materials: As good a series of specimens for comparison as may be had in any favorable group; flowering parasitic plants; copepods, crabs, worms, etc. Hosts may be disregarded.

Compare together as to:

Organs of feeding.

Organs of reproduction.

Organs of locomotion.

Organs of sense perception.

Compare males and females of each parasite if possible as to degree of degeneracy.

Compare together young larval, and adult forms of the more completely parasitic species selected for study.

The record of observations should be preserved in notes and sketches.

\section{Pollen Distribution.}

In our study of the green plant series (Chapter III), we have seen how the otile sperm cells of the primeval aquatic plant gradually lost their opportunity for swimming 
to meet the ovum, as plants became terrestrial and grew to larger size. The distances to be traversed in order to accomplish fertilization became greater and the route lay through the air; transportation became necessary; and it came

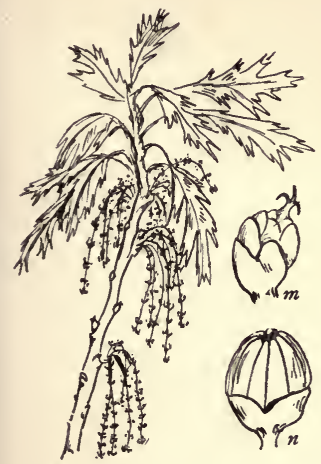

Fig, 235. Black oak flowers. $m$, a single pistillate flower; $n$, a single staminate flower, before the bursting of the anthers. about that the carriage of the microspore, and not of the naked sperm cell, was the plan that successfully met the difficulties of the situation.

Flowering plants were surrounded by various means of transportation for their pollen. Two of these were of prime importance; the wind and winged insects. The wind had certain great advantages. It could be be depended on to blow at all seasons, night and day, and if pollen were light enough, to sift it everywhere, and to deposit some of it in the right place for cross fertilization. But on the other hand, it was quite indiscriminating as to where it should blow, and very wasteful of pollen in consequence. Winged insects on their part, having a liking for the nectar of flowers, would fly from flower to flower with great precision, and if only the flower could adjust itself to profit thereby, would distribute the pollen with far less waste. But their aid was less trustworthy, and might at any time prove inadequate; they were liable to casualties of storm and pestilence. Their very power of selection might lead them to neglect one species for others more attractive. And their aid was most needed by species of sparse dist. 'ution. 
We have learned from the studies in Chapter I to what extent our common plants have become adapted to insect aid in pollen transference, and how greatly they have become modified in special adaptation thereto. We are now to study comparatively the results in pollen production of adaptations to all the various means of securing fertilization including water flotation of the pollen of submerged aquatics that bloom at the surface, and the automatic self pollinating acts of flowers themselves.

Study 52. Pollen production as affected by its mode of distribution.

Materials needed: Flowers of the nine sorts indicated below:

$\begin{aligned} \text { Wind } & \left\{\begin{array}{c}\text { I. Tree, such as oak (fig. 235), hickory, } \\ \text { bollinated. }\end{array}\right. \\ \text { 2. Herb, such as meadow rue, grass or sedge. } & \left\{\begin{array}{c}\text { 3. A large open solitary flower such as } \\ \text { trillium or may-apple. }\end{array}\right.\end{aligned}$

4. An open, loosely clustered flower, such Insect $\quad$ as spring beauty, or buttercup.

pollinated $\{$ 5. A highly specialized bilateral flower, such as the wood betony or sweet pea.

6. A composite flower, such as the dandelion (fig. 236).

Water pollinated. 7. A river weed (Potamogeton).

Self pollinated

(8. Open, chickweed (Stellaria media) or door weed (Polygonum).

9. Clistogamous, the blue violet (Viola (cucullata).

All these will be obtainable anywhere in spring, except numbers 7 and 9 , both of which may be used, preserved in alcohol. The clistogamous flowers of the violet may be found through the whole summer after the blue flowers have 
ceased to appear see figure 27 , on page 35 . The function of these has been discussed on page 34 .

Study these individually, and write their characters with which we are now concerned in a table prepared with the following column headings:

Name.

Sex (male, female or bisexual).

Form of flower cluster.

Number of stamens per flower.

Number of pistils per flower.

Number of pollen grains per stamen.

Number of ovules per carpel.

Ratio for the whole plant of pollen grains to ovules.

The labor of making this table chiefly consists in counting the pollen grains in anthers of the nine species selected. The number of ovules will usually be found stated in the larger works on systematic botany, and these may be used for reference. Since there are some slight difficulties of manipulation to be encountered, it may be well to suggest, how to proceed.

Get anthers for pollen counting from unopened buds, in order that the previous shedding of some of the pollen may not vitiate the count. Select anthers of average size, or, better, count several and average the result.

Large anthers, like those of trillium, should be divided, say into eighths, and a part taken. This is easily done by placing the anther flat on a slide and pressing the edge of a scalpel into it with a rocking motion, being careful to make approximatelk equal successive divisions. Then select an average segment, expose its pollen fully, cover and count, and multiply to get the whole. Very small anthers, like those of the dandelion, are likely to be quite transparent, and need only to be mounted and covered, and their pollen content may be counted at once. It will be necessary to 
split the anther tube of the dandelion, and spread it out flat before covering (fig. 236). When the pollen cavities are so filled that they appear dark, a little pressure on the cover will often burst them and scatter the pollen, so that it may be counted.

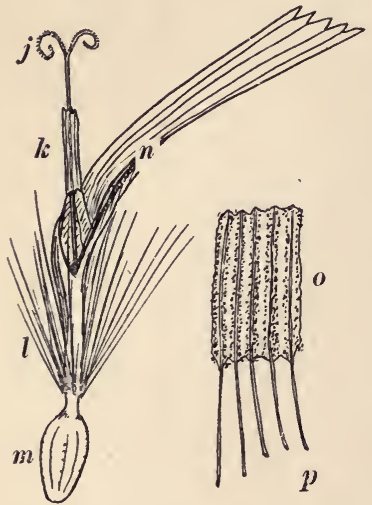

Fig. 236. A single dandelion removed from the flower head. $j$, stigma; $k$, the anther ring, split and unrolled at $o$, the separate filaments shown at $p$ : $n$, strap-shaped corolla; $l$, calyx (pappus) of bristles; $m$, ovule case.

The gist of this study is in the ratios of the last column. For ready comparison they should be reduced to the form $x: I$.

With perfect flowers the ratio of pollen grains to ovules produced will be the same for the whole plant as for the single flower, but with monœcious (fig. 235) and diœecious species it will be necessary to count and estimate for equivalent proportions of the total of male and female inflorescence.

The record.-In conclusion, ascertain from the facts of the completed table whether the form of the cluster or the manner of flower aggregation in it have had any effect on the amount of pollen produced.

\section{ADJUSTMENT IN FORM AND APPEARANCE.}

When we have gotten to this division of our subject, it has already been illustrated in manifold ways by the organisms we have had before us. Nevertheless, it will still repay a more careful examination. 
ADJUSTMENT OF ORGANISMS TO ENVIRONMENT 405

There is the adjustment of the individual to external conditions, and there is the adjustment of the race. The

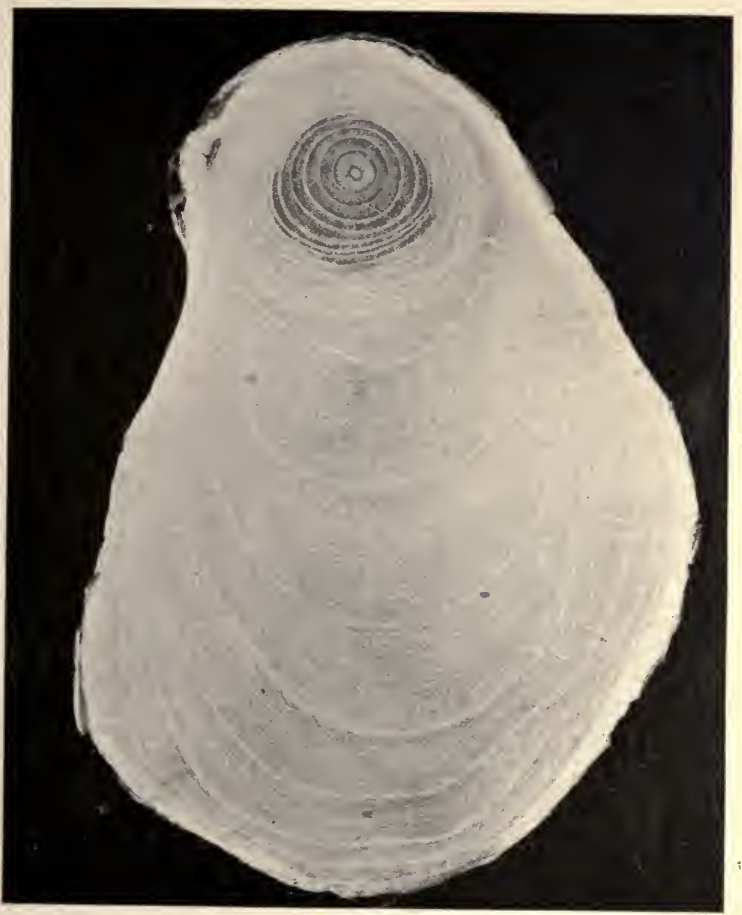

FIG. 237. Cross-section of an elm bough, with its history written in its wood rings.

former is familiar to our experience. The tanning of the skin with exposure to the sun, the strengthening of the 
muscles through use, acclimation, immunisation; these and many others are every day illustrations of the response of the individual to conditions of environment. Figure 237 shows the record in wood of a series of successive responses on the part of the bough of an elm tree during the 25 years of its life. The five dark rings in the center represent the first five years of erect growth (1878-1882), while it was still near the top of the tree; and abundantly and symmetrically lighted. It started in 1878 from a bud formed on the west side of the top shoot of a three year old sapling. The twelve close set rings following represent the scanty growth of the next twelve years (1883-r894), during which it was struggling for light beneath the higher branches that had overtopped it. The larger growth ring for I 888 represents the result of a windy season, when the tossing about of the upper branches allowed this one to get more light. During this time the bough was leaning slightly to westward, as indicated by the greater thickness of the rings on that sidethe lower side in the figure. The ensuing sudden unilateral enlargement of the rings was due to an accident. Some children climbing in the tree bent this bough down, and left it in a somewhat drooping position. Thus, it was brought out from the shadow into the light again, and the rapid growth that followed was, in consequence of its position, on the under side of the bough at the bend where this section was made. It will be observed that for four years (I $895^{-}$ I 898 ) the addition of woody tissue was bilaterally symmetrical upon the lower side. Then another accident changed the stress upon it and caused it to grow obliquely. It chanced to overhang a walk, and in the spring of 1899 to correct its drooping it was hung up lightly on a wire atattached to a fork above and a little to one side. The pull was to the northward during the ensuing four years (1899I902), and this, assisted by prevailing south-west winds, 
caused more woody tissue to be formed on that side. In the winter of 1902 , the bough wascut, and its autobiography was interpreted with the aid of competent testimony that was still available.

Our practical studies shall be of the modifications of form and appearance that belongs to racial, and not to individual history.

\section{The re-adaptation of insects to aquatic life.}

It seems now quite clear that insects were primitively terrestrial. They are covered with a tough chitinized skin, well adapted to resist evaporation. They are provided with a respiratory apparatus of distinctively aerial type. They breathe through open spiracles, that lead to intercommunicating air tubes (tracheæ) within the body. As adults, they all breathe free air, and are adapted only by secondary makeshifts to aquatic life. It is only the larvæ of scattering groups that have become properly aquatic, and able to breathe the air that is dissolved in the water-all the larvæ of a few small groups, and scattering members of most of the larger orders. Among these. therefore, we should be able to see the result of the fitting of diverse forms to the new conditions.

When, with the luxuriant development of the insect group, the press of life on land crowded some insects back into the water, the problem of getting air was the chief one to be encountered. Its full solution lay in the development of suitable respiratory apparatus. An impervious chitinized skin perforated by open air tubes stood in the way of ready re-adaptation. Adult insects merely adopted various devices for carrying or otherwise obtaining free air when in the water, without altering their mode of respiring it: many insect larvæ, also, get their air supply only at the surface (fig. 238). But the softer and more plastic larvæ, 
thin skinned and permeable, are able to get oxygen from the water, and have become strictly aquatic.

Among aquatic insect larvæ (properly so-called) are found three respiratory types:

I. Those without gills.
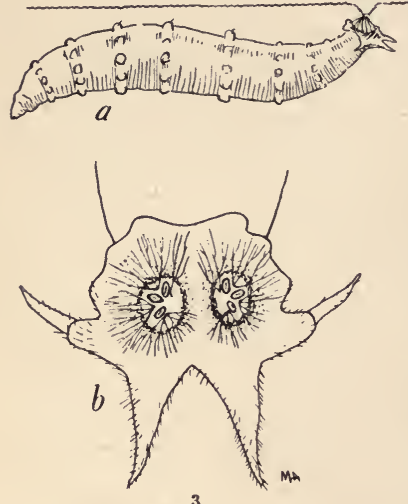

3

FIG. 238. The larva of a swale fly (Sepedon fuscipennis). $a$, Pulling away from the surface film, the guard hairs surrounding the breathing pores convergent at tips; $b$, end of body as seen when resting on the surface, hairs outspread. These are minute larvæ, like those of the biting midges(Ceratopogon, fig. 239) that live in floating masses of filamentous algæ, where liberated oxygen is abundant, or, if of larger size, as in the case of some stoneflies (Perlidæ) they live in rapid and well aerated water. The larger of these although lacking gills have an abundant development of fine air tubes in the thin membranes joining the thoracic segments of the body on the ventral side.

2. Those with blood gills.-These most nearly approximate aquatic vertebrate larvæ in their mode of respiration. Blood gills are protrusions of the body wall through which the blood flows; the exchange of gases in respiration takes place between the blood inside and the water without. Blood gills are developed in many dipterous larvæ, and oftenest, about the posterior end of the alimentary canal (fig $239 g$ ). In dipterous larvæ the tracheae are often somewhat reduced. 
3. Those with tracheal gills.-These, comprising the larger larvæ of all the more generalized orders of aquatic insects, have adhered more strictly to the tracheate type of respiratory apparatus. Tracheal gills are protrusions of the body-wall with fine tracheal tubes grown out into them, and the exchange of gases in respiration is between the air in the tubes and the water outside the gill. The tracheal system, therefore, instead of being reduced, is increased by the outgrowth of the additional parts that penetrate the gills.
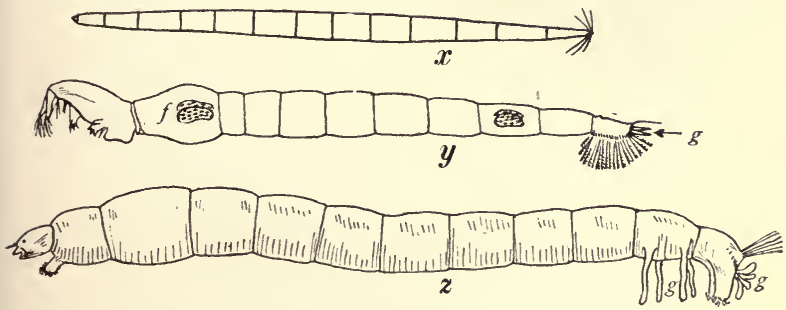

FIG. 239. Larvae of dipterous insects. $x$, the punkie (Ceratopogon). $y$, the phantom larva of Corethra; $z, a$ "blood worm" - the larva of a midge (Chironomus); $f$, floats (expansions of the main air tubes); $g, g . g$, blood gills.

Tracheal gills may be external as in the case of the damselfly nymph shown in fig. 225 , or internal, as in the case of the larger dragonfly nymph shown in figure 240 . Whatever their position number or arrangement, they conform more or less closely in shape to two types, filiform or cylindric, and lamelliform or flat.

Their diversity in form, position, arrangement and number and size will be seen in the series of larvæ selected for study. 
Study 53. A preliminary examination in living specimens of the principal gill types of aquatic insects.

Materials needed: Living larvæ to illustrate:

I. Blood gills (larvæ of Culex, the mosquito, Corethra or Chironomus).

2. Tracheal gills:

External $\left\{\begin{array}{l}\text { Filamentous(larvæ of a caddis fly, etc.): } \\ \text { Lamelliform (nymphs of a damselfy or mayfly). }\end{array}\right.$ Internal (nymphs of the dragonfly, Libellula).

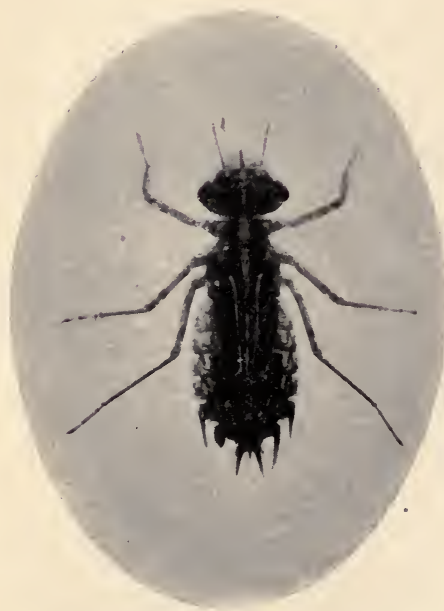

FIG. 240. Dragonfly nymph (Celithems eponina).

Mount a larva having blood gills in a copious supply of water, cover and study the gills directly, noting their number,position and relations. Focus carefully upon one gill to see the outline of its internal cavity, and to see the leucocytes that drift about in it.

To study the external tracheal gills, snip off a few gills with fine scissors and mount them in water; cover and examine at once, to see the tracheoles before the penetration of the water into them has rendered these invisible. While filled with air they appear as sharply defined black lines. They are 
not visible in preserved specimens; hence, living larvæ must be had for this. Study especially the division of the large tracheæ into fine tracheoles and the disposition of the latter and their intercommunications.

The internal gills of a dragonfly (fig. $24 \mathrm{I}$ ) are arranged in rows upon the inner walls of a gill chamber, made out of the posterior third of the alimentary canal. It is so fine a piece of respiratory apparatus, so unique in plan and it exhibits such delicacy and refinement of structure it is well worth a careful examination.

It will be well first to see the external evidences of its operation. Regular respiratory movements of the abdomen can usually be seen in a nymph that lies quietly in a shallow dish of water. They may often be seen intensified if the nymph be turned over on its back. With the expansion of the abdomen water is slowly taken in through the anal aperture to be expelled with its contraction. The currents of the water may be demonstrated by placing some colored fluid in the water close beside the anal opening. This is best done by holding the point of a copying pencil in that position until its color is imparted to the water. The forcible ejection of water from this gill chamber as an aid to propulsion may be seen while the nymphisswimming about. Some idea of the force of the expulsion may be gained by tilting the abdomen of a swimming nymph upward until it touches the surface of the water, when the water in the gill chamber will be shot into the air.

To study the structure of the gill chamber and of the gills themselves, the following method will be found to be expeditious and satisfactory. Kill the nymph by snipping off its head. Then snip off the abdomen at its base; trim off its sharply triangular lateral margins for its whole length; pin it down to the waxed bottom of a dissecting dish that is small enough for use on the stage of a dissecting microscope, 
or under a pocket lens; carefully lift off the roof of the abdomen, (already loosened at the sides by the trim-off of the margins,) by seizing it in front with the forceps.

This will expose the gill chamber, which accupies the greater part of the abdominal cavity, and terminates the alimentary canal. The severed posterior end of the stomach will be seen in the middle in front, terminated in the rear by a dense cluster of nephridia (Malpighian tubules) and followed by a slender, white, ventrally curved and much concealed intestine, joining it to the gill chamber. On either side of the stomach will be seen a large, silvery white air trunk, which breaks up posteriorly into a great brush of lesser branches that penetrate the walls of the gill chamber. This chamber itself, will be somewhat collapsed; it may be distended by injecting air or water through the anal aperture with a fine-pointed pipette; its longitudinal extent may be seen by lifting the stomach with a forceps and drawing it forward. If turned to one side, a ventral longitudinal tracheal trunk may be seen on either side of the body, breaking up in the rear, like the dorsal trunk, into a multitude of branches, and entering the walls of the gill chamber from below.

Through the transparent walls of the gill chamber may be seen lines of the black pigment that occupies the bases of the internal gill plates. Discovering thus the location of the rows of gills, the chamber may be safely opened by inserting the point of a fine scissors and cutting the wall for its entire length between two rows. The circular muscles of the wall will, by their contraction turn the whole organ inside out, and fully expose the rows of beautiful, feathery, purplish tinted gill plates. Then if a row be isolated with scissors and mounted on a slide in water, a few individual gills may readily be isolated with needles under a dissecting lens, covered, and studied with 
a microscope. The accompanying figures (fig. 24I) will assist in identifying all the structures present.

The record for this study may be in the form of sketches and diagrams of the respiratory apparatus studied.
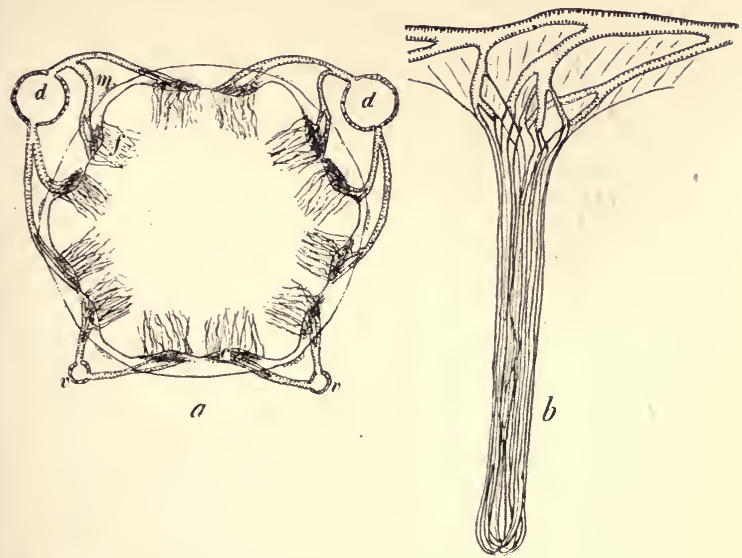

FIG. 241. Diagram of the gill chamber of the nymph of a dragonfly (A nax junius) from drawings by Miss Elizabeth Andrews. a, cross section of the gill chamber; $d, d$, dorsal tracheal trunks; $v$, $v$, ventral trunks; $f$, tuft of filamentous gills; $m$, longitudinal muscle; $b$, a single gill filament, showing tracher and tracheoles.

Study 54. The comparative development of respiratory apparatus in aquatic insect larva.

Materials needed: Either preserved or fresh specimens of larvæ of the following: Ceratopogon, or some other gillless form (perlid or trichopter will do as well).

I. Two or more dipterous larvæ having blood gills of different sort: Chironomus (the larger "blood worms," with ventral abdominal gills) and Simulium will be best, 


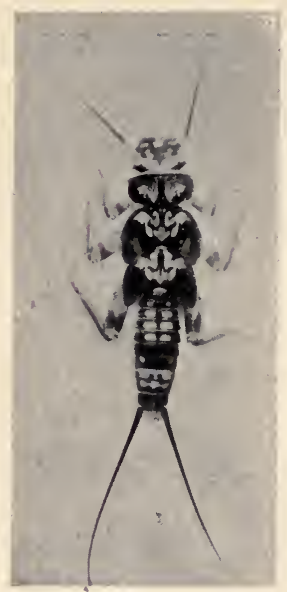

FIG. 242. Nymph of a stonefly (Perla). and easiest obtained, (see appendix).

2. A typical perlid nymph (Perla, Neoperla or Acroneuria).

3. Any of the larger species of mayflies.

4. Any sialid larva (Sialis, Chauliodes, or Corydalis; larvæ of the whirligig beetle would answer the same purpose.

5. A caddis-worm with abundant development of gills.

6 and 7. Damselfly and dragonfly,data for the addition of which were obtained from the preceding study.

Study these seven representative forms individually, and write the characters with which we are here concerned in columns in a table prepared with the following column headings:

Name.

Order (of Hexapoda).

Gill type (blood gill, or tracheal gill).

Number (of individual plates or filaments).

On what segments (use the Roman and Arabic numerals as indicated in fig. 10, p. 17, so far as possible).

Form (filiform or lamelliform).

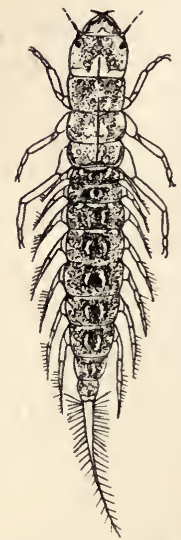

FIG. 243. The larva of an orl fly (Sialis). 
Arrangement (solitary, in clusters, in whorls, etc.; give number).

Water $\left\{\begin{array}{l}\text { as to movement (stagnant, quiet, rapid, torren- } \\ \text { tial, etc.) } \\ \text { as to oxygen content. }\end{array}\right.$

The record of this study will be contained in the completed table.

2. Phylogenetic adaptation in diving beetles.

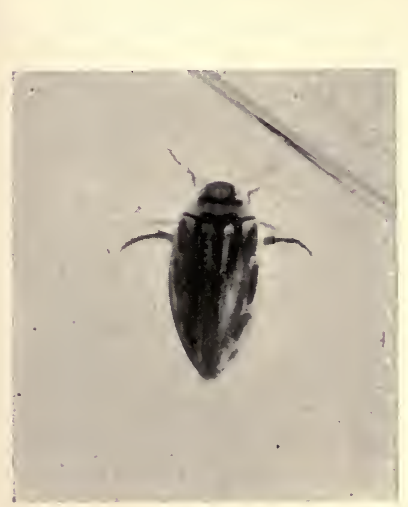

Fig. 244. A diving beetle (Coptotomus interrogatus).

We will now study the adaptation to a changed environment of a series of forms of common origin. For that purpose it would be hard to find better material than that furnished by the family Dytiscidæ of diving beetles (fig. 244). Almost any permanent pond will furnish a number of forms that differ in size and habit, and that exhibit different degrees and kinds of specialization. We will study the adaptation of the adult beetles to pond life.

These beetles have fully retained their terrestrial mode of respiration. They take in air through abdominal spiracles situated on the back of the abdomen, underneath the wing covers. They have merely adopted improved means of carrying air with them when they descend beneath the surface of the water. 
Their chief problem has been locomotion; how to get through the water speedily, in order to capture their prey and to escape from their enemies. Becoming adapted,

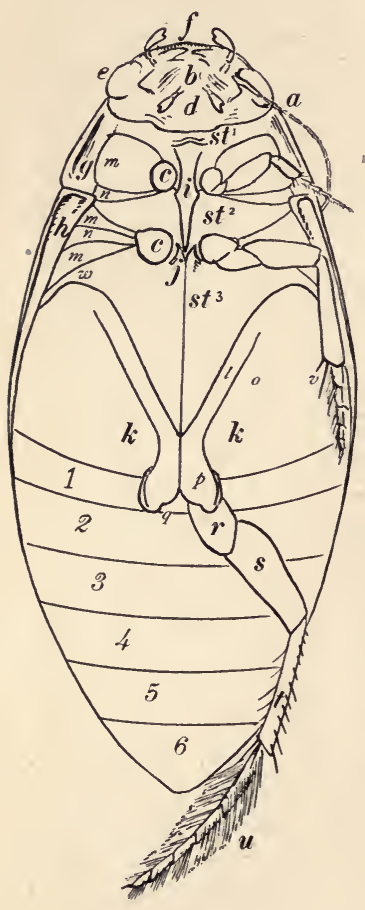

FIG. 245. Diagram of the ventral aspect of a diving beetle (Coptotomus interrogatus) $a$, antenna; $b$, mouth; $c, c$, coxal cavities for the fore and middle legs; $d$. labial palpi; $e$, eye ; $f$, maxillary palpi; $g$, lateral margin of the prothorax; $h$, epipleura of the wing cover (elytron); $i$, prosternal process; $j$ metasternal fork; $k$, hind coxa with $l$, the inner, and $o$, the outer laminae; $p$, the coxal process and $q$, the coxal notch: $r$, trochanter of the hind leg; s, femur; $t$, tibia; $u$, tarsus of five joints; $v$, spurs of the middle tibia. $I, 2,3$. $4,5,6$, ventral abdominal segments $s t^{2}, s t^{2}, s t 3$, sterna pro-, meso-, and meta-thorax, respectively.

therefore, to progression through the water - a medium of sufficient density to offer considerable resistance-they have acquired a remarkable uniformity of appearance. It would be hard to find another large family of organisms all the members of which are of so nearly the same shape. Whether large or small, they are all of one form - that, the form of a submarine boatcompact and evenly contoured and pointed at both ends.

It is 'generally agreed that the ancestors of the Dytiscidæ were ground beetles, more or less like the existing members of the family Carabidæ, of which Calosoma (fig. 246) is a 
representative. We may get some idea of the nature and extent of the adaptative changes that have taken place with the return to aquatic life, if we compare such a form as Calosoma with one of the larger Dytisicidæ (fig. 244). Something of the manner of life of the diving beetle has already been seen in study 48. Calosoma is built for running about on the ground, climbing in and out of depressions, hiding in crevices; hence it is loosely jointed in both body and legs, roughly contoured, with prominent eyes, and large antennæ beset with sensory hairs. In Coptotomus all this is changed . The body is compact, rigid and pointed at

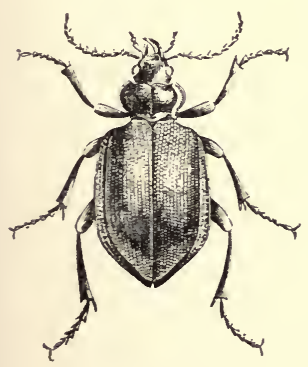

FIG. 246. A ground beetle (Calosoma sycophanta: after Bos). the ends. The contour lines are reduced to smooth curves. The legs, especially the hind ones that are chiefly used in swimming are flat and oar like, compacted and stiffened, limited in variety and specialized in kind of motion. Remote as is the analogy, we may see some like phenomena if we compare vehicles for locomotion on land with boats; especially, if we contrast the great variety of form of land vehicles with the great uniformity in shape of hulls of boats.

Study 55. A comparison of the structure of ground beetle and diving beetle.

Materials needed: A supply of specimens of one of the larger Carabidæ (Calosoma, Galerita, etc.), and of one of the larger Dytiscidæ (Dytiscus, Cybister, Acilius, etc.).

Let this study be a detailed examination of the external structures, first of the ground beetle, and then of the diving 
beetle, omitting mouth parts which are little altered in relation to aquatic life. All the hard parts (sclerites) of the body armor may be identified with the aid of figure 245 .

The purpose of the study is the gaining of some notion of what are primitive and what are specialized conditions in diving beetles.

Study the structure of the diving beetle especially with reference to:

I) That fitting together of the ventral sclerites of the thorax that has to do with increasing the rigidity of the body.

2) That fitting together of wing covers with each other and with the sides of thorax and abdomen that has to do with making a secure enclosure for the retention of air when at the bottom of the pond.

3) That consolidation and alteration in form of the hind coxæ that has to do with increasing the rowing efficiency of the hind legs.

The record of this study may consist of a brief tabular statement of the chief structural differences between the two beetles examined, illustrated with diagrams if desired.

Study 56. A comparative study of size and activities of diving beetles.

Materials needed: Plenty of live specimens representing six or more genera of Dytiscidæ, preferably of different sizes. The specimens should be in normal condition; if not freshly collected, they should have been properly kept, cared for and fed.

Prepare a table with the following column headings abbreviated as desired:

Name (if unknown, use the keys and figures provided in the appendix). 
Size $\left\{\begin{array}{c}\text { Length in millimetres (most easily and quickly } \\ \text { taken with a small caliper rule). }\end{array}\right.$

Weight in grams (weigh each species on a delicate balance; put beetles in envelopes made of filter paper, which will take up the water, a number at a time of the smaller species; weigh in envelope; weigh envelope alone; deduct; divide remainder by number of beetles weighed; quotient should be the average weight).

Swimming $\left\{\begin{array}{c}\text { Strokes per second. (Set a metronome } \\ \text { beating half seconds and count). } \\ \text { Strokes per length of body (measure of } \\ \text { the efficiency of the individual stroke). } \\ \text { Speed per second*. }\end{array}\right.$
Relative
excellence $\dagger$$\left\{\begin{array}{l}\text { Swimming (as determined above). } \\ \text { Walking (judge this not by speed alone, } \\ \text { but by ability to get up on feet and walk. } \\ \text { using the joints of legs and feet). } \\ \text { Jumping. } \\ \text { Taking flight. } \\ \text { Dodging. }\end{array}\right.$

The record of this study will be contained in the completed table, which should show clearly the great differences in the powers of these beetles, that underlie their superficial similarity.

*Place the beetles, one species at a time, in a broad, shallow dish of water, and lay a few pieces of soft wire of measured lengths ( 5 , ro and $20 \mathrm{~cm}$.) on the bottom. With the metronome beating half seconds, watch the beetles as they swim about, and judge by the time it takes them to pass given lengths of wire.

$\dagger$ Expressed numerically: the best swimmer as 1 , second best 2 , etc., written in the columns. All these but the last (which is best seen in the water) may be easily determined by placing beetle of all the species used together on a sheet of paper spread out on as table before a window. Place them on the side remote from the source of light, and they will travel toward the light according to their several abilities, walking, jumping and flying. 
Study 57. Field observations on diving beetles.

Apparatus needed: Dip nets and beakers or other small vessels for individual use. A seine may be useful for obtaining greater numbers of the larger forms that live farther from shore (Dytiscus, etc.)

If the student will carefully gather his own material for the studies of this subject, he will see much that is of interest in the manner of life of these beetles, and some things that will aid in understanding the structural peculiarities of some of them, to be worked out later (in study 58 ). It must not be forgotten for a moment that all peculiarities of vital importance are related to environment.

The best collecting grounds are ponds; small ponds if permanent, even though they be shallow. Few beetles will be seen anywhere without special search for them; a few may be seen rising to the surface to take air, and immediately descending again. It will require careful collecting, and discrimination as to species, to get a goodly variety. Begin by "sweeping" the submerged vegetation at the farthest reach of the net for the larger species, and work gradually toward shore. The smallest species (Bidessus, etc.), will be found right at the edge of the water, and will be obtained by scraping the bottom close up to the bank. Learn careful collecting: for it is a most important part of the education of a naturalist.

Dip up and examine the trash that lies on the bottom; examine also, floating vegetation.

Note the favorite location of each species: the center of its abundance. Observe the relation between size of the species and the depth of the water dwelt in. Observe how the jumping species gather about floating trash, which furnishes a support from which a jump in the air can be made. Such things are best seen before the water has been too much disturbed with nets. 
Separate out the species in suitable receptacles for keeping alive. Rerrember that all are carnivorous, and that the larger ones if pressed by hunger may eat the smaller; remember also that all can climb and fly, and cover vessels accordingly.

The record of this study may consist in a diagram on the plan of the left hand side of fig. 224 on page 385 , with the nares and places of all diving beetles collected indicated therein.

Study 58. The adaptive structures of diving beetles.

Naterials needed: Preserved specimens of the same species used in the preceding study.

Study these species one by one, and record the more obvious characters called for in a table prepared with the following column headings:

Name.

Sculpture (development of furrows or structural ornamentation, especially of the back).

Vesture (development of hair on the body, especially of the back).

Scutellum (visible or hidden).

Relative length $\left\{\begin{array}{l}\text { Femur: } \\ \text { Tibia: } \\ \text { Tarsus. }\end{array}\right\}$ expressed in ratio $I: \mathrm{x}: \mathrm{y}$

Specialized swimming fringes $\{$ On what legs dereloped

Claws $\left\{\begin{array}{l}\text { Number (one or two) } \\ \text { Equality (equal or unequal) } \\ \text { Mobility (fixed or movable) }\end{array}\right.$

Speeial braces (such as the lobe, $x$, of the femur, shown in figure $17 \mathrm{I}$ on page 285 , which serves to steady the action of the tibia, and to keep it moving in one plane: developed where on legs). 
CONCLUDING WORK.

As a conclusion to the foregoing studies, make a tabular statement of the adaptive structures observed (a few are stated, as examples) after the following plan:

Special adaptations of diving beetles.

\begin{tabular}{|c|c|c|c|c|}
\hline & Character & \begin{tabular}{|} 
Best de- \\
veloped \\
in
\end{tabular} & $\begin{array}{l}\text { Of what } \\
\text { advantage }\end{array}$ & $\begin{array}{c}\text { Involving } \\
\text { what } \\
\text { limitations }\end{array}$ \\
\hline $\begin{array}{l}\text { Of head } \\
\text { and body }\end{array}$ & $\begin{array}{l}\text { ex:Flattening } \\
\text { down of the } \\
\text { eyes }\end{array}$ & Cybister & $\begin{array}{l}\text { Dimished } \\
\text { resistance } \\
\text { to water }\end{array}$ & $\begin{array}{l}\text { Dimished } \\
\text { range of } \\
\text { vision }\end{array}$ \\
\hline & $\begin{array}{l}\text { Telescoping } \\
\text { of head by } \\
\text { prothorax, } \\
\text { etc. }\end{array}$ & & & \\
\hline $\begin{array}{l}\text { Of appen- } \\
\text { dages }\end{array}$ & $\begin{array}{l}\text { Upward } \\
\text { bending of } \\
\text { hind legs, etc. }\end{array}$ & Acilius & $\begin{array}{l}\text { Better } \\
\text { rowing } \\
\text { position }\end{array}$ & $\begin{array}{c}\text { Poorer } \\
\text { walking } \\
\text { position }\end{array}$ \\
\hline $\begin{array}{l}\text { Of vesti- } \\
\text { ture }\end{array}$ & $\left\{\begin{array}{l}\text { Loss of sen- } \\
\text { sory antennal } \\
\text { hairs, etc. }\end{array}\right.$ & & & \\
\hline
\end{tabular}

The record of this and the consummation of several preceding studies will appear in the last table.

\section{Animal coloration:}

We come now to the examination of characters that are more superficial, more variable, more plastic, and that ordinarily show the most remarkable fitness to environment. We pass by all that internal coloration, however brilliant, that can have no relation to the external world, because hidden from view; such as the red of blood, the yellow of fat, the iridescent tints of the swim-bladder of fishes, 
and opalescent tints of the inner surface of molluscan shells. We pass also that coloration of purely physiological value, even though it be adaptive, such as the black color of hibernating arctic insects, adapted to absorbing the maximum amount of heat during the short summer season; and the white color of winter animals of the same region, securing them against the too great loss of their own animal heat supply through radiation. We study that adjustment of color and form that has to do with being seen, that doubtless did not exist in the beginning, that came into existence when animals began to hunt with their eyes; that has been developed along with the perfecting of organs of vision.

There are some coloration phenomena so very common and widely distributed that they may be studied in abundant examples anywhere. These are resemblance, flash colors, warning coloration, and mimicry.

Resemblance.-Few animals can afford to be conspicuous -only those possessed of sufficient swiftness or agility to escape their ordinary enemies, or those possessing special means of defense. For most animals, to be conspicuous is to invite destruction. Hence the majority of animals, although conspicuous enough when exhibited in museums, are in their proper environment to be found only by careful searching.

Natural selection furnishes a simple and satisfactory explanation of resemblance. The less fitly colored, being the more conspicuous, are the ones eliminated by enemies, leaving those that are better concealed by their coloration to survive and perpetuate in their descendants their own inconspicuousness.

The most general and fundamental phenomenon of resemblance is the darker pigmentation of the side of the body that is uppermost and the shading off lighter below, to 
counteract the body's own shadow. This is well nigh universal. That it is of primary importance in bringing about inconspicuousness any one may demonstrate by placing two skins of any common gray bird or mammal on the bare ground, one back upward in its normal position, and the other back downward, and then looking at them from a little distance. The conspicuousness of the gray of the body when the shadow of the body is added to it will be most striking, and the advantage of the lighter countershading will be apparent. And if one look carefully at a living or well mounted specimen of a sandpiper or a wild gray rabbit, he will see how delicately this shading and countershading is wrought; each little projecting ledge is overspread with darker pigmentation; and underneath is a lighter area, as under the orbit, under the ear, or under the chin.

That this plan of ground coloration is adaptive, is evidenced by those animals that move habitually in an inverted position, as the sloth, that travels hanging by its claws beneath the boughs of forest trees, and the back swimmer that swims with its back downward in the pond. Such forms have the counter shading of lighter color on the back.

Resemblance is spoken of as protective, helping its possessor to escape its enemies, or aggressive allowing its possessor to approach unobserved nearer its prey; but the difference is not in the coloration, but in the purpose it serves. This finds its analogy in the devices to which men resort. The modern soldier not wishing to offer in himself a good target, wears a khaki uniform; and the hunter, desiring to get closer to his game, adopts outer clothing of similar inconspicuous color. The gray mixed coloration of the rabbit or the roadside grasshopper or the green of the meadow grasshopper, and that of most herbivorous animals is protective; while the same colors in the lynx and the mantis, and in most carnivorous species are aggressive. 
However, in very many species, it may be protective toward a group of stronger species (enemies) and aggressive toward a group of weaker ones

Resemblance is very often a matter of form and attitude, quite as much as of coloration. The moths shown in figure 247 are colored much like the burdock stem on which they rest, but their inconspicuousness is obviously greatly improved by the stub-like attitude in which they hold the body against the side of the stem. Inconspicuousness, may be brought about by loss of color. This is seen in the transparent larva of Corethra, and in many free swimming organisms which are riewed by enemies against the lighted background of the sky.

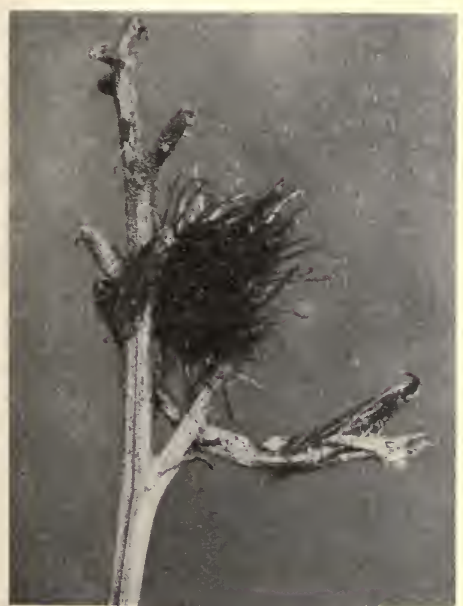

Fig. 247. Burdock moths (Metzneria lapella) on a dead stem: resemblance in form and attitude as well as in color.
It is impossible to judge resemblance except in its proper setting. An animal that appears conspicuous enough in the museum (fig. 248) may be well concealed in its native haunts. Certainly the leopard frog with its green skin covered with black blotches surrounded by yellow rings is conspicuous enough sitting on a white plate in the laboratory, but any one who has collected this frog knows it is 


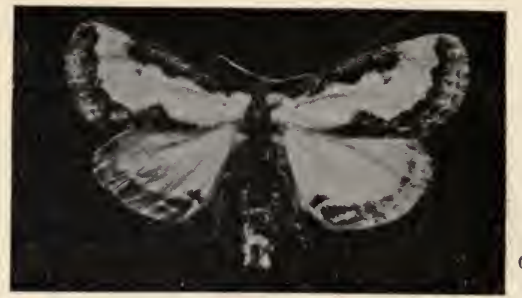

FIG. 248. A moth (Endryas unio) that is a conspicuous museum specimen, but quite inconspicuous in its proper haunts.

very hard to see until it jumps. Sitting amid the mixed vegetation, its blotches fall into places among the leaves as lights and shadows, and tell no tales of its presence. The most conspicuous of cross bands and bars may in nature be fit adjuncts of concealment. For example, the white ring about the neck of the plover, serves outdoors to detach the head from the body, and thus to break the outline of a bird into two less easily recognizable parts.

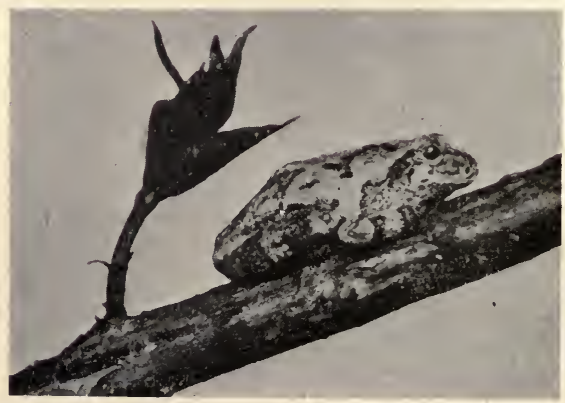

FIG. 249. Tree-frog (Hyla) on gray bark of the buttonbush. 
A few animals have the power to alter their coloration to match their environment. The common tree frog is one such. The specimen shown in figure, (fig. 249) was of a perfect gray color while it sat on the button bush stem, and a short time after being transferred to the leaves, it was equally inconspicuous by reason of its beautiful green color.

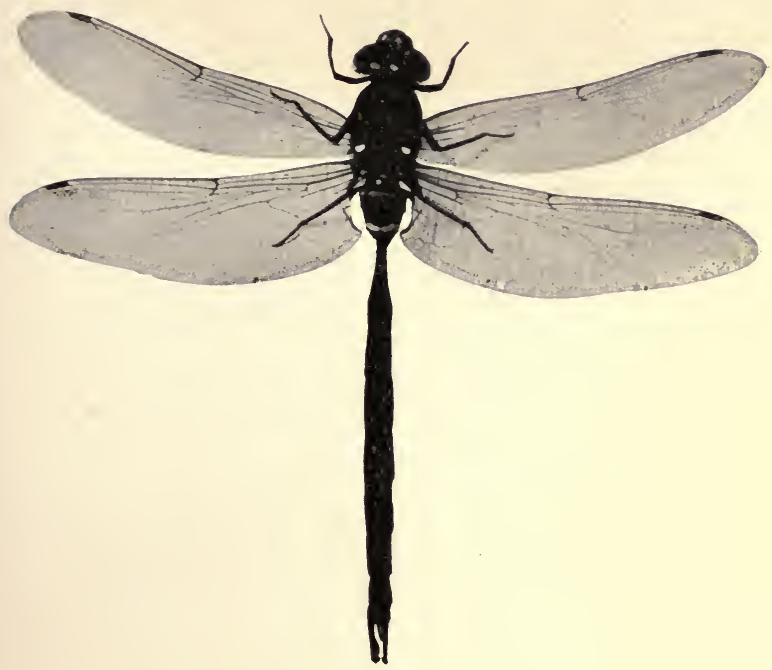

FIG. 250. A draganfly (Aschna constricta).

Flash colors.-There is a class of conspicuous markings upon the bodies of animals that is not for continuous exhibition, and concerning the function of which the greatest diversity of opinion has been held. Since these are usually exposed intermittently in flight, we may use the non-committal name of flash colors for them. Such are the white 
bars of the wings of a night hawk, or the golden shafts of the flicker, or the white side spots of a junco's tail, or the white rump of a. rabbit, exposed only when the tail is lowered in running, or the brilliant reds and blacks of the underwing moths, etc., etc. These are suddenly flashed into view when

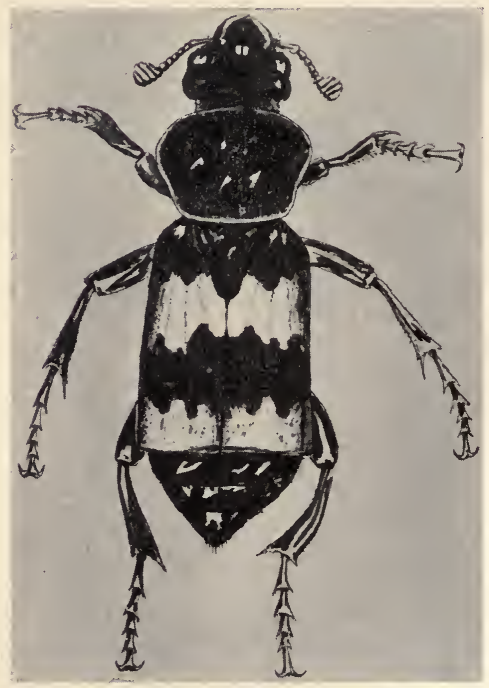

Fig. 251 A carrion beetle (Necrophorus); colors dull red and black.

their possessor takes flight, and as suddenly tucked away again on alighting. They have been called "recognition marks" on the assumption that they enable a fleeing herd of gregarious animals of one species to keep together or help individuals to find one another more readily. But it seems 
in many cases at least as if they serve rather to promote the bewilderment of a pursuing enemy. For the alighting place is usually a little off to one side of the line of flight; the flight is easily followed; so easily, in fact, by reason of the flash colors, that when they suddenly disappear on the alighting of their possessor, pursuit is thrown off the track. Anyone may convince himself of their fitness for such bewildering function by following a flock of juncos to their alighting place in the fence row.

Warning Coloration.-The few animals that everyone sees moving or resting, are either able like the great dragonfly (fig. 250) to escape their enemies by reason of their speed, or else are conspicuous for a purpose-possessed of some bad quality, making them undesirable for food, like the crow, or of some offensive odor, like the carrion

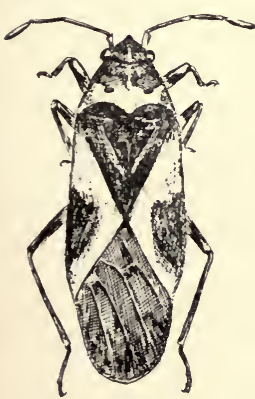

Fig. 252. The milk weed bug (Oncopeltus fasciatus): colors red and black. beetle (fig. $25^{\mathrm{I}}$ ), or of some bad flavor, like the milkweed bug (fig. 252), or of some special defense, like the sting of the bumble bee. It is advantageous to such forms to be conspicuous. They are easily recognized and are for the most part let alone. Unlike the rabbit which runs to hide, the skunk, secure in the possession of an intolerably malodorous secretion, walks along in the open, with his great black and white tail lifted aloft, like a banner in the sky. It is of advantage to the whole group of warningly colored animals that their colors are few and patterns simple. Their enemies, which do make experiments sometimes in youth while learning, and sometimes when greatly pressed by hunger, have fewer combinations to learn to avoid, and both sides are saved unpleasant experi- 
menting. The combinations are (aside from black alone, which is conspicuous enough against green foliage or against the sky) black and yellow, black and white, black and green, and black and red or orange, and the patterns are broad cross bands of alternating colors, or extensive blotches.

Eyespots are the most specialized of warning colors. They are eye pictures (fig. 253), more or less realistically drawn by nature upon some part of the body (usually remote from the true eyes) of their possessor, and where well exposed to the view of an enemy. They are always large enough to belong to some creature many times the size of the one exhibiting them. They thoroughly frighten ignorant people, and it is highly probable that they frighten

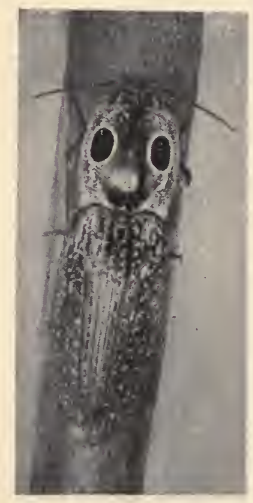

Fig. 253. The owl beetle (Alaus oculatus). such animals as occasionally come upon them in the open. Their efficiency must depend in part on their rather infrequent occurrence, for familiarity would abrogate alarm.

Mimicry.--So well established are the general types of coloration accompanying disagreeable qualities, that some animals, which lack special defense have taken them on. The robber fly shown in figure $254 a$ so closely resembles the bumble bee, (figure $254 b$ ), with which it is associated in nature that an experienced collector may with difficulty distinguish between the two species while in flight. The fly possesses no sting or other special defense; it doubtless secures considerable immunity from molestation by reason of its likeness to the well-armed bumble bee. Most of our commoner mimickers, have taken on more or less of the coloration, form and attitudes of the 
stinging hymenoptera, bees and wasps; a few have mimicked ants which are distasteful by reason of the formic acid they secrete; a few have mimicked unpalatable species in other groups, the best known of which is probably the viceroy butterfly which mimicks the monarch. There are some examples of coloration phenomena so fit, so admirable in every specific detail, of color form and posture, and so well

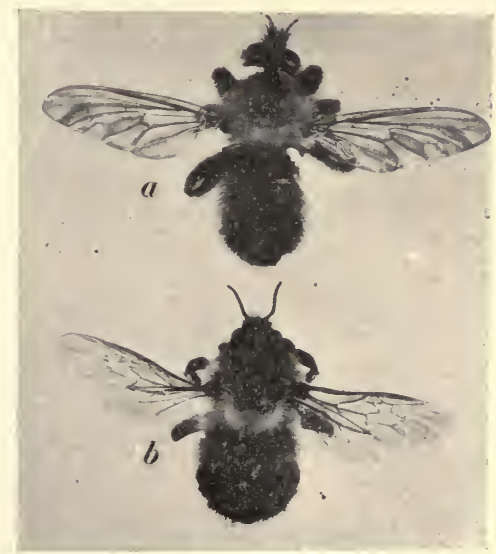

Fig. 254. Mimicry. a, a robber fly (Dasyllis grossa) which mimicks the bumblebee $b$ (Bombus).

adapted to the purpose they seem to serve in nature, that they excite our instant admiration. But of the animals one may gather in an hour's collecting, many will show less fitness, and some will have a coloration that appears to be without adaptive significance. Coloration existed before it became adaptive. There is danger of finding here, as in the case of the coloration of flowers (Chap. I) adaptive signifi- 
cance, where only structural and physiological colors are present. Such furnished the materials out of which adaptation could proceed by natural selection. Feathers, for example, were structurally adaptable to longitudinal streaking,and birds have furnished most of those streaked patterns among animals that fit into a grassy environment. The family Syrphidæ of Diptera, which has furnished our most numerous examples of mimicry of the stinging hymenoptera, was doubtless predisposed toward the colors and forms of that family from the beginning; likewise the crane flies that imitate grass spiders. Doubtless the discerning powers of the predatory species have improved with the disguises of their prey. It would be too much to expect in the nature of the case that the devices always work, and when we examine a series of any adaptive forms, we find such varying degrees of excellence as indicate that the fitting process is still in progress.

Study 59. Examples from the local fauna of the principal types of animal coloration.

Apparatus needed.-Individual insect nets and cyanide bottles, note books and pencils; if coloration of birds is to be specially observed, opera glasses will be of assistance.

The most abundant supply of material will be obtained by "sweeping" the grass with the insect net, for protectively colored forms and collecting from flowers for the other two groups. Hand picking from the trunks of trees, etc., will also be useful.

The record.-It is essential that the record called for below be made in the field, each species being studied in its proper habitat, where alone the significance of its coloration can be seen.

Include in the tables a few well selected examples and omit doubtful cases. 
I. Illustrations of resemblance.

Name | Order | Coloration $\frac{\mid}{\mid \text { general or specific | details }}$

2. Illustrations of flash colors.

Name $\mid$ Order $\mid$ Color $\left|\frac{\text { Exposed to view }}{\text { how } \mid \text { when }}\right| \begin{gathered}\text { Folded away } \\ \text { how }\end{gathered} \mid \begin{gathered}\text { Possible } \\ \text { use? }\end{gathered}$

3. Illustrations of warning coloration.

Name | Order | Colors | Pattern $\mid \begin{gathered}\text { Disagreeable quality } \\ \text { advertised }\end{gathered}$

4. Illustrations of mimicry.

Name | Order | Coloration | Mimicks what $\mid \begin{gathered}\text { whose } \\ \text { defence is } \\ \text { what? }\end{gathered}$ 


\section{CHAPTER VII.}

THE RESPONSIVE LIFE OF ORGANISMS.

It is a long vista the science of biology opens to our imagination. At the farther end is formless protoplasm, moving with the first thrill of responsive adaptiveness to the external world. Along the way are ranged all the form-changes and all the acquired powers of organic life. At this end is the wonderful assemblage of living forms; among them, the human organism, with a mind that contemplates all, and endeavors to understand-all, and withal, itself.

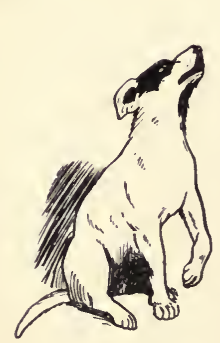

Mind in man is made known in speech and action; the psychic life of animals, in actions alone. If the acts of animals are like those we perform under similar circumstances, we are inclined to infer that animals possess kindred psychic states. Thus, from their behavior, we think we recognize hunger and satiety, anger and fear, pain and pleasure, in the expressions of animals, and, inFIG. 255. Melancholy. deed, some of the less instinctive feelings, such as curiosity in monkeys and jealousy in dogs. The great difficulty in interpreting psychic states in beings other than ourselves lies, of course, in the fact that the mind is directly accessible only to its possessor. One may not know the mind of another being except by inference. Great difficulties attend the interpretation of the psychic states of even those animals that are most like us in bodily organization, and the difficulties become insuperable in the case of animals that lack our 
modes of expression.* How we should express any emotion if we had to do it with a hydroid's tentacles, we cannot conceive.

Nevertheless, there is no living thing that lacks the power of making visible response to the conditions of the external world-such response as no inorganic thing ever manifests. This response may be slow, as in most plants, or rapid, as in most animals possessed of parts having specialized contractility; but it is always in evidence, and in the last analysis it is the most distinctive characteristic of life. Even growth and reproduction are but manifestations of it.

The capacity for responding to stimuli is, as we have already seen, a property of protoplasm. When we watch the streaming of protoplasm in a plant cell we may see it accelerated or retarded with every change of temperature. A little slime-mold plasmodium placed in a half lighted position will move away from the light and into the shadow. It will creep toward a decoction of dead leaves (its proper food), and away from a solution of quinine. Such a bit of naked protoplasm, therefore, although quite destitute of organs, moves freely, and in a fundamental and important sense it both perceives and acts.

The behavior of organisms, which is the visible manifestation of their psychic life, shall be the subject of our study in

* "A bodily structure entirely unlike our own must create a background of organic sensation which renders the whole mental life of an animal foreign and unfamiliar to us. We speak, for example, of an angry wasp. Anger in our own experience is largely composed of sensations of quickened heart-beat, of altered breathing, of muscular tension, and of increased blood-pressure in the head and face. The circulation of a wasp is fundamentally different from that of a vertebrate. A wasp does not breath through lungs, it wears its skeleton on the outside, and it has muscles attached to the inside of the skeleton. What is anger like in the wasp's consciousness? We can form no adequate idea of it."

-Washburn. 
this chapter. Behavior is our only clue. By behavior we judge whether a thing is alive or not. Responses alone can show us whether there is anything within an organism capable of taking cognizance of external conditions. And responses show, also, which of the conditions of the external world an organism perceives. Psychic phenomena are essentially subjective, and our knowledge of them consists (except in ourselves alone) in inferences based on their corresponding objective manifestations. The primary relations existing between the subjective and the objective, may be graphically stated thus:

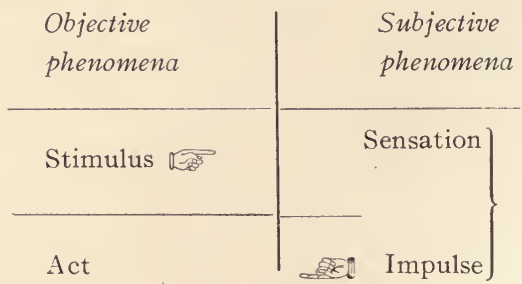

This is merely a graphic statement of the evident facts that environment (external or internal) gives the stimulus, which upon the psychic side, produces the sensation (feeling, taste, sight, etc.), which may be accompanied by an impulse (also subjective), and may eventuate in an act. The act, therefore, is thus the last link in a chain of events: the effect of a succession of causes. However diverse the structure of organisms, their parts that are most directly subservient to the psychic life are of two sorts:

I) Receptive organs, capable of being influenced by stimuli. These are the parts through which the external world makes its impressions upon the sensory mechanism.

2) Active or motor organs, capable of making appropriate responses. These are the parts through the agency of which the psychic states are made manifest. 
I. Animal Activities.

I. Some typical sensory phenomena of the Protozoa.

In such an organism as an amœba, which lacks as we have seen, permanent organs of either of the classes just mentioned, we may observe activities of the same sorts as those above cited for the slime-mold plasmodium. An amœba creeps about freely, manifesting like movements of contact and avoidance. It adjusts the form of its body to getting through narrow passageways, it changes its course of locomotion in avoidance of an obstruction. Now and then it makes a more special response to things in its environment. Coming in contact with a diatom, or other small organism suitable for food, the amøeba moves toward it, extends its pseudopodia and flows about it, and finally completely engulfs it. This is a definite food

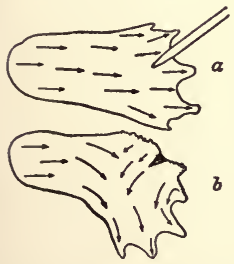

Fig. 256. Diagram of the avoiding reaction in Amoeba. $a$, is the position when stimulated by a glass stylus $b$, cate direction of flow of the
protoplasm. (After Jennings) taking reaction. On the other hand, it withdraws itself promptly from a sharp mechanical stimulus, such as the prick of a glass stylus (fig. 256), a wave of movement in the protoplasm of its body away from the point stimulated, being immediately discernible.

To what sort of psychic states these simple external acts may correspond we cannot say. What the world and the things therein may be like to an animal of this sort we could only know by being amœbas awhile. Indeed, we cannot conceive what it would be like to ourselves if we had never seen or handled things, and if we had no means of knowing objects as such, but only as the obtruding parts of a general environment. Perhaps, there may be some sort of vague 
agreeableness or disagreeableness, some sort of organic sense of comfort or of discomfort, connected with and occasioning the reactions of the two sorts.

Organs of out-reach.-Impermanent pseudopodia are the amœba's only means of exploring its environment, but the higher protozoans possess cilia and flagella. These are permanent organs of out-reach, in which sensory and motor functions are combined. These enable their possessor to reach out and touch an object before coming into bodily contact with it. These give time and opportunity for avoidance of collisions and for escape from approaching "enemies. Indeed, if, with specialized sensibility, these be capable of receiving vibrations, they may give warning of the proximity of an enemy before coming into actual contact with it. These make the course of an animal through the water less groping in proportion to their length or sensitiveness. It is the method of a blind man exploring his pathway with his cane. The long flagellum which Euglena (fig. 6r on p. I05), swings before it as it swims, explores a relatively wide pathway.

But Euglena has also an "eye spot" at the forward end of the body, and is capable at least of discerning between light and darkness; and therefore, if compared with a blind man, the comparison should be with one whose blindness is not total. Euglena swims, as we have seen, habitually into the better lighted areas of its watery environment. In doing this it must be guided not so much by its tactile sense, (which is more directly concerned with the objects of its immediate environment), as by vibrations of light coming from a greater distance. Here, then, is the beginning of another kind of perceptive organ-one whose efficiency - depends, not on the out-reach of a sensitive part of the body, but on specialized sensibility of a part to the inflow of vibratory stimuli coming from a distance. The range of 
perception is by such an organ enormously increased. This fleck of pigment in Euglena is the rudiment of an organ, possessing increased sensibility to light; and it is doubtless no more an accident that it should lie in the front end of the body, than that a vertebrate's eyes should be located in its head.

Some reactions of Paramoecium.-Improvements in the organization of the body of Paramœcium are by no means confined to the development of cilia. These are but specialized parts of the ectoplasm, which depend largely for their efficiency on further differentiation of other parts of it. The general outer surface of the ectoplasm has become thickened, giving permanence of form to the body and solidity of support for the cilia. In the underlying ecto-
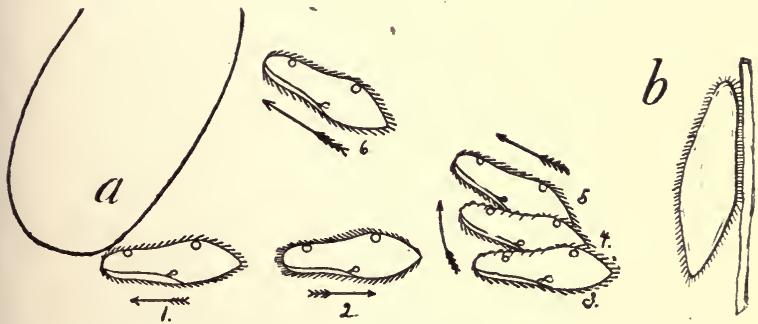

FIG 257. Diagrams of behavior in Paramoecium. $a$, the avoiding reaction; $I$ to $b$, successive positions: arrows indicate directions of movement. $b$ the contact reaction. (After Jennings)

plasm are developed strands of substance for sensory communication between various parts of the cell body; and these doubtless enable the cilia to act in unison, to stop or start or reverse their movements with promptness and efficiency. Therefore, the speed and precision of its locomotions and the promptness and extent of its responses to stimulation are vastly better than in amoeba. 
The specialized activities of Paramœcium have made of it a good deal of an automaton. Aside from the ordinary swimming, in a spiral course, with the oral groove toward the axis of the spiral (see page 73 ), it has one reaction that is prominent above all others-a definite avoiding reaction. Meeting with almost any sort of stimulus it stops, ceases rotation, swims backward a little way, turns a little to the aboral side, and then starts swimming forward again (fig. $257 a$ ). If the change of direction were not sufficient to clear the obstruction (or other source of stimulus), the reaction is repeated; and it continues to be repeated in a perfectly automatic manner until the course is again clear.

Food-taking in paramœcium appears, as we have seen (page 75), to be an equally automatic and undiscriminating performance, digestible and indigestible substances being taken into the body with equal readiness.

There is also a contact reaction observable in Paramœcium. When, in swimming about, one comes into gentle contact with a bit of soft vegetable substance, it may come to rest in the manner shown in figure $257 b$, with a number of its cilia extended in direct contact with the object. Thus, it may remain quietly, as if at a satisfactory anchorage, for a considerable time. Doubtless it is in the neighborhood of such soft substances that its proper food is likely to be found. And when a paramœeium is thus resting it is less responsive than at other times to ordinary stimuli. For example, a slight mechanical stimulus, such as a light touch on the tips of its cilia, may pass unnoticed, whereas the same stimulus if applied to one not thus situated would instantly call forth the avoiding reaction.

In all the Protozoa there are certain activities (and cessations of activity, equally significant) that indicate that the actuating stimuli are of internal origin. Apparent spontaneity of movement may be due to external influences that 
escape our observation; but the constant differences of behavior of a single organism when hungry and when well fed must be due to stimuli arising out of its bodily states. When well fed, it is less active and always less responsive to external stimuli of every sort. A far more striking example is offered by the cyclic conjugating reaction of Paramœcium (see page III), which occurs at long intervals. Two complemental individuals come together for exchange of nuclear substances. These cycles suggest the breeding periods of the higher animals, during which the maturing of the sex cells occasions internal stimuli which call forth a whole train of activities that are collectively known as "breeding habits."

So the protozoa, although their acts are few in kind and simple in performance, exhibit a set of elemental reactions of the most fundamental, wide spread, and comprehensive sort.

\section{Some general features of the sensory mechanism of the Metazoa.}

Protozoan and metazoan are alike organic wholes. Each has developed about itself a protecting outer wall, sequestering itself from the outer world. Each has created an internal world, within which all its vital processes are carried on through the concordant action of part upon part.

Whatever organs a protozoan may develop, it is limited in this; that they must all be developed out of the parts of a single cell. In the metazoans, on the contrary, there are many more or less independent, structural units, that can be differentiated for separate functions. One set of cells may be made to serve as receptors for stimuli (end organs); another may be specialized for doing the contracting (muscle fibers), and another (nerve cells and their processes or fibers), may be fitted for intercommunicating between the 
two sorts first named. The feeble beginnings of this differentiation we have noted in the hydra (page $16 \mathrm{I}$ ), and further development has been briefly traced in the earthworm (especially in the nerve cells, figure I09), and in the salamander.

The cells of a metazoan make common cause of their relation to the outside world, and, with more materials out of which to build, greater progress in differentiation is made. Systems of organs arise; digestive, circulatory, respiratory and excretory systems for performing the nutritive processes of the body, and nervous and muscular systems, for the control and coordination of all, and for maintaining proper relations with the outside world.

Intercommunication without nerves.--Our studies shall be of this specialized apparatus; but we will do well to remember that receptivity and action are older than nerve and musele. These functions are too general and too important to be wholly committed, even in the highest animals, to any particular set of cells. It is the more specialized activities that are taken over by these cells, but there remain other important functions of relation that are yet fulfilled by slower processes in which nerve and muscle take small part. Manifestly, before nerve and muscle were developed interaction had to be brought about by contact of adjacent cells, as is still necessary during early embryonic development. The movement of a stimulus passing from cell to cell was like that of particle upon particle in the body of a pricked amœba (fig. 256). It is like the slow communication by word of mouth from door-yard to door-yard, as compared with the telegraphic communication of news. When nerves develop they take on wholly the function of rapid communication between distant parts; but certain of the other older and slower processes of the bodily economy continue to be performed by older and slower methods. 
Cell still acts upon its neighboring cell directly; and it also acts on all the cells of the body by contributing certain of its products to the fluids that bathe the whole interior. Many organs are known to produce internal secretions, which are circulated about with the blood, and which profoundly affect the well-being of other organs. Thus, the small intestine in vertebrates, when stimulated by contact of the acidulated food entering it from the stomach, produces a substance (known as secretin), which, when carried by the blood to the pancreas, incites that organ to secrete and discharge its own digestive fluid (pancreatic juice). And certain organs, like the thyroid gland (which in us envelops the base of the trachea on the ventral side, and which is the seat of the disease known as goiter), have been found to be of great importance by reason of the internal secretions (hormones) which they contribute to the body fluids. If for example, the thyroid gland be removed, its loss causes both internal and external derangement. The skin thickens and becomes wrinkled, the hair falls out, the nervous balance is disturbed, and finally, death results. But if the extract from the thyroid gland of another animal of the same species be injected periodically underneath the skin, these results will not follow the removal of the gland. Similarly, the sex organs appear to produce hormones that condition the development of secondary sexual characters. For when the spermary of a young cockerel is removed, comb and spurs and the other external signs of his sex are checked in their development; but they can be made to develop by merely grafting into his body a piece of the spermary of another cockerel. So, it appears probable that to this fluid which bathes all the tissues of the body and conditions its metabolism, every cell may contribute something, and the general condition of the body may be largely determined by the totality of this contribution. Internal secretions or 
hormones, therefore, appear to be an important part of the self-regulating mechanism.

Sense organs.-The exigencies of animal existence demand that the functions of relation to the outside world should be performed as speedily as possible - that stimuli should be quickly received and transmitted and translated into useful acts.

Now the stimuli are of various sorts. Some, like the pull of gravity or the change of temperature act constantly or slowly, and there may be no special sense organs for their reception. Others of mechanical, chemical and vibratory nature have caused the development of sense organs of the most specialized sorts.

I. Mechanical stimuli produce the sensation of touch. Special receptors for mechanical stimuli are scattered about over the bodies of all the higher animals. They abound in the tips of outgrowing organs that are specially exposed to contact with external objects. The earlike-lobes at the front end of a planarian, and the prostomium of an earthworm are very sensitive to touch. In our own skin tactile organs are least numerous in the middle of our backs and most abundant in the tips of fingers and tongue.

2. Chemical stimuli give rise to sensations of taste and smell. Some sort of discernment of the difference between edible and inedible substances is well-nigh universal among animals. Since food is limited in quantity and distribution, there is need that it should be recognized. In an aquatic organism doubtless these two classes of sensation are not very different in kind; indeed they are not always sharply distinguished in ourselves. One may bite of an onion and not be very sure whether his impression of the thing is mainly of its taste or its smell. Volatile particles may travel through the air and so may reach the olfactory organ from a distance. Hence the sense of smell is less exclusively subservient tofood 
selection, and may be made to serve other perceptive functions, such as the locating of enemies or the recognition of friends and kindred in terrestrial animals. Dogs, and many wild vertebrates, depend upon this sense apparently for a very large part of the knowledge of the world they live in.

The sense of smell in the human species is not at its best development. Anyone may convince himself of this by the most casual observation of the actions of his own dog. We cannot know, of course, what smells are like to a dog, any more than we may know of any other sense impression of which we have had no experience; but we cannot doubt that they are to him a means of fine discrimination.

Since chemical substances must be in solution, or in gaseous form, in order that they may affect the organs of taste and smell, the receptors of these organs in terrestrial animals are withdrawn into moistened cavities within the body, where they are protected from evaporation.

Since the animal body is a sort of chemical engine, it is not strange that chemical stimuli are frequently the actuating causes that call forth various responses within the body. It is by means of chemical reactions set a-going within the retina of the eye, that the weak stimuli of light vibrations are reinforced and made effective in proportion to their importance.

3. Rays of light produce the sensation of vision. At its beginning, vision is nothing more, perhaps, than a dim awareness of a difference existing between light and darkness. The eye doubtless has had a long line of antecedents. It may have begun as a red "eye spot" like that of Euglena, and may have owed its earliest efficiency as a receptor of vibrations to the greater absorbing power for radiant energy of the lower colors of the spectrum. And it may have been responsive to heat rays rather than to light rays at first. 
Ability to distinguish light from darkness might help an organism to adjust itself in position, but much more than this is necessary in order that it should really see anything. In order that a picture of an external object should be formed in the mind, it must first be pictorially impressed on multiple receptors, so situated that the rays of light coming from different parts of an object may be spatially arranged thereon. Seeing requires eyes. There is no one of the powers of animals in which they differ more profoundly than in their capacity for light perception. Eyes are of the most diverse structural types, and in each of the main types there exist all degrees of perfection. The camera-like eye of vertebrates, with its inverted retinal picture, differs fundamentally from the compound eye of an arthropod, with its mosaic pattern and its fine adaptation for the perception of movement. The development of the vertebrate eye is one of the most fascinating chapters in biology, but far too long a story to be recounted here. Whatever its structure, the eye consists essentially of multiple receptors combined into a single organ, and sheltered behind a transparent protective covering, the whole occupying an exposed position at the forward end of the body and in direct communication with the more important nerve centers.

Taste, smell and hearing give us of themselves hardly any conception of form or of magnitude; nor does touch, for large objects, except in successive impressions as parts are successively explored. But the eye may instantly reveal the whole content of environment, in form, in magnitude, in proportions and in action. Such are the precious powers of this incomparable organ; and so great are the advantages it confers on its possessor that eyeless animals (save when so small as to be beyond the range of ordinary vision) are practically absent from the lighted places of the earth.

4. Vibrations of air or of solids produce the sensation of sound. They also, under certain conditions, produce a 
mechanical effect when they fall upon a sensitive surface. And doubtless tones are perceived as such only by specialized organs of hearing. Sound receptors are variously located about the body, and are wonderfully different in structure in different groups of animals. The antennal hairs of a male midge that vibrate to sound waves of a length corresponding to the pitch of the humming of the female, are freely exposed. But sound receptors are more often sequestered in some part of the body behind a mechanism (such as the tympanum and small bones of the middle ear in ourselves) capable of taking up vibrations and passing them on to appropriate nerve endings. Since sound waves tend to fill all the space they traverse, there is not the same need as in the case of eyes, that ears should be located in a well exposed part of the body. Hence, we find the sound receptors of certain grasshoppers located in the fore legs, and in others, upon the base of the abdomen. These are so different, however, from the ears of vertebrates, that we can form hardly any conception of how they work, nor any at all of the sort of sensations to which they may give rise. The ears of vertebrates, situated on the head, are placed in the direct path of passing sound waves, and trumpet-like external ears are added for concentrating these waves upon the ear drum.

Ears possess the great advantage of giving notice of the presence of friends or enemies in the darkness as well as in the light, and when hidden as well as when in the open. Well developed, they confer great powers of discrimination upon their possessor. For social organisms ears have their value wonderfully enhanced by the development of soundproducing organs. Together, these constitute the fundamental equipment for social intercourse, and for exchange of ideas. Eye and ear are in ourselves the receptors to which we have learned as social organisms to make appeal. 
Nerve and muscle. Pseudopodia, cilia and other organs of outreach in the protozoa fulfill both sensory and motor functions. Separate classes of organs for these functions are not differentiated; and probably they were not differentiated at first in the metazoa. Nerves and muscles must have originated near the surface of the body, for only there could they have been in communication with the outside world. It is there we find them first in the phylogenetic series, underlying the ectoderm in the hydra (fig. IoI, page I 59): It is from the underlying layers of the ectoderm, as we have seen, that the nervous tissues arise in the ontogeny of the vertebrates.

It is the primary function of the nerve cell to develop out of its own cytoplasm such parts of out-reach as shall serve for intercommunication between all of the other tissues and with each other. They must be connected externally with the sense organs of the body and internally with the muscles to the end that the sensing of the things of the external world may bring about prompt and appropriate measures for dealing with them. Muscle cells must therefore be developed in connection with nerves. They are elongate cells of special contractility, connected with whatever solid supports the body may possess. They become aggregated together and integrated into muscles of increasing strength and size as the skeleton develops, giving them points of insertion, and offering strength to resist their pull.

Ganglia.-The possession of long organs of cell out-reach (fibers) made it possible that nerve cells should be removed from the surface where they develop, into the interior of the body, where better protected from injury. The importance of the regulatory function they fulfill made this highly desirable, and intercommunication between the cells themselves was facilitated by the assembling of them together in groups. The simplest of these we know as ganglia. 
Ganglia are local centers, which exercise a regulatory function within a more or less localized portion of the body. Their number and arrangement differs according to the structural plan of the body to which they belong. In segmental animals, like the earthworm, the ganglia are arranged segmentally, each ganglion pair of the ventral chain (nerve cord), controlling primarily its own segment. In all arthropods, as we have seen, they are arranged upon the ventral side; in vertebrates, upon the dorsal side. They are arranged so differently in the different animal phyla as to indicate that they have been brought together on different developmental lines, in accordance with the conditions offered by each structural type.

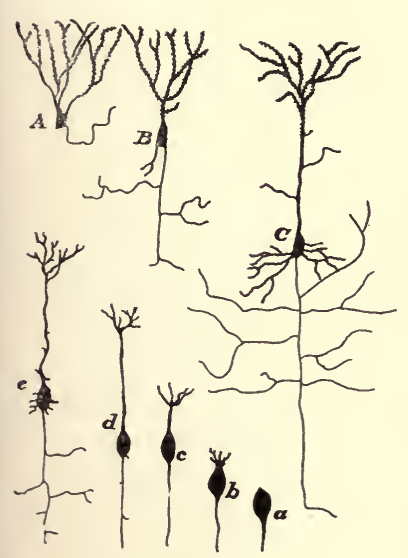

Fig. 258. Ontogeny and phylogeny in neurones of the middle layer of the cerebral cortex. $A, B, C$, corresponding cells from the adult brain in frog, lizard and rat. respectively. $a$, to $e$. successive stages of development of cells of the same sort in a mammal: the axone appears in $a$, den-

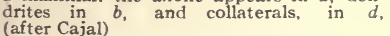

The neurone.-Nerve cells by migration to the centers, have become widely removed from the receptors at the surface of the body. That there are nerve fibers connecting the two together has long been known (the comparison of the fibers to telegraphic lines being a very old and familiar one); but that these fibers are an integral part of the central cells is a matter of recent knowledge, derived from the study of their development. The fiber arises as an outgrowing, process from the cell body (fig. 258). There may be one 
(if a bipolar cell) or more (if multipolar) additional processes arising from the opposite end of the cell and extending in different directions. The cell with all its processes is called a neurone. The process which becomes the fiber is called the axone; if it gives off branches within the nerve center for communication with other neurones, these branches are called collaterals. The processes arising from the other parts of the cell, are typically shorter and much branched and are called dendrites (dendron, a tree).

Division of labor among the neurones has resulted in the development of two complemental sorts of them, one sort being afferent in function, and serving to conduct from the receptors to the centers, and the other being efferent, and serving to carry impulses outward from the center to incite muscle or gland to action. The dendrites are at the receiving end of neurone, while nerve impulses are carried outward from the cell body by the axone, and are distributed to other cells by way of its collaterals.

The reflex arc.-A pair of these complemental neurones, afferent and efferent in function, in contact by their inner ends, and reaching outward the one to a receptor and the other to a muscle or gland, constitute a simple reflex arc. This is the unit of organization within the nervous system. It is a simple mechanism for the functions indicated in our diagram on page 436 . It was called a reflex arc because it appeared to be a pathway over which the effect of a stimulus sent to a center is reflected back in action to our view. Figure $259 a$ shows such an arc for the body of a vertebrate. The afferent cell body $(u)$ lies in the ganglion on the dorsal root of a spinal nerve; its dendrites (not shown) are in the skin; its axone enters the cord. The efferent cell body $(v)$ lies in the gray matter of the spinal cord; its dendrites are in contact with termini of the axone of the other cell, and its axone proceeds outward through the anterior root of a spinal nerve 
to end in a muscle. This is a simple and direct nerve path, sufficing for the reception of a stimulus and the development of an appropriate automatic response.
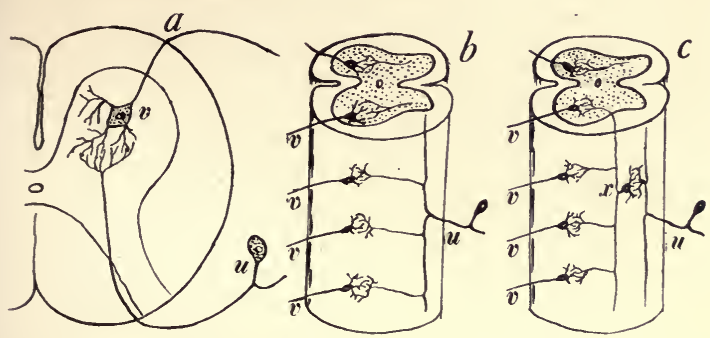

FIG. 259 Diagram of reflex ares in the spinal cord. $a$, a simple reflex arc shown in half the spinal cord in cross section, $b$, a direct connection of one afferent with a number of efferent neurones. $c$, indirect connection through a neurone intercalated in the arc. $u$, afferent, $v$, efferent fibers. $x$, intercalated tract cell in the cord. ( $a$, after Howell, $b$ and $c$ after Kölliker)

But there are no nerve paths quite so simple and independent as indicated by this diagram. There are always bypaths which a stimulus may take to reach other efferent cells and to produce multiple response. These bypaths may be provided by various modes of branching within the nerve centers; by collaterals as indicated in figure $259^{b}$, or by intercalated nerve cells that lie wholly within the nerve centers as indicated in figure $259 \mathrm{c}$. By reason of such connections a stimulus on a single receptor, may according to its strength, give rise to impulses in many motor nerves.

The nervous system is a unit. No reflex arc exists by itself alone. All the circuits of the body are connected, in the first instance by collaterals and dendrites, and in the next, by the arborisations of additional nerve cells intercalated within the nerve centers. Even in so lowly an animal as the earthworm, in whose segments the several ganglia appear to exercise a degree of independence and 
autonomy, there are abundant paths leading to adjoining segments, ultimately connecting all the segments together. If one imagine the two ganglia shown in figure rog (page 173) to be packed (as in fact they are packed) with cells of the several types that are shown singly in that figure, he will readily conceive how numerous are the paths of possible communication by contact between the nerve cells.

But the existence of a bypath does not mean that a nerve impulse must always follow it. There are main-travelled roads, as well as bypaths in the nervous system. A stimulus at any given point has its accustomed path which it always follows; whether it shall overflow into its possible bypaths is apparently determined largely by its intensity. A finger prick if slight enough may merely cause the finger to be lifted in response; thus but a few muscles will be called into action. But a more vigorous stimulus at the same point may cause the arm to be jerked back, involving the action of many muscles: and a deep puncture at the same point may initiate nervous impulses vigorous enough to overflow into most of the motor circuits of the body, calling the whole muscular system into action. This also may ke likened by analogy to the distribution of stimulating news by telegraph. A slight accident excites but a little local interest among the few people who are most directly involved, but a war scare may set the wires going in every important telegraph office in the country. There is a mechanism at hand for communicating with all the motor circuits in the organism; but only so much of it is used as is warranted by the nature of the stimulus.

Doubtless these paths of nervous communication have had a gradual evolution, and have been formed to meet the needs of the organism during its long past history. For they lead in the direction of harmonious and well co-ordinated action. All the muscles that may be called 
into action by a single stimulus, work together concordantly to produce results that are in general beneficial. Differentiation of parts and the development of a mechanism for intercommunication between the parts would be of no use without coordination. Coordination is illustrated by any act that is neatly performed; all the muscles pull at the right tension, at the right time and in the right order. Want of coordination appears when the nervous system "goes to pieces," as in convulsions; or, when some unusual stimulus is applied; something of it is seen even as a result of tickling, which may produce useless and unregulated movements.

Control circuits.-Coordination in the nervous system tends to centralization. So long as the ganglia are of equal potency the effect produced in one by a stimulus at one point of the body may be opposed by the effect produced by another stimulus at a distant point. A homely but familiar experience shows how stimuli may interfere with each other. If a stimulus in our nose (which may be accompanied by a tickling sensation) be impelling us to sneeze, we may start a countervailing stimulus by vigorous pressure upon the upper lip, and thus we may keep from sneezing. Stimuli are not of equal importance, nor is their importance always proportioned to their intensity. A vibratory stimulus of very slight intensity coming in the form of light to the eye may reveal the near approach of a powerful enemy. It is important that the animal heed this stimulus and make its escape, even though appealed to by the presence of food or of other congenial circumstances. It must run now; it may eat again. In other words, it is often important that all the activities of an animal be concentrated on accomplishing a single purpose-be it escape or defense; it is a matter of life or death. Hence some part of the nervous system must dominate the other parts to the extent of determining what 
stimuli shall be needed, and toward what ends all the activities of the body shall be directed. If there can be a headquarters to which all stimuli of this nature shall be referred, and from which the dominating impulses shall go out to the muscles, the resulting action may be more efficient.

The mechanism for such control appears to have been found in the derived circuits within the nerve centers. We have already noted that besides the nerve cells composing the reflex arcs, there are other cells within the centers, that are situated as intermediaries between the primary circuits. These have developed secondary circuits of their own; and we have also noted that these are the media of distribution of stimuli in case of multiple responses. A single reflex arc is sensitive to but one kind of stimulus and tends of itself alone always to give but one kind of response; but these secondary circuits are so situated that they have to respond to varied stimuli coming from every quarter-sometimes augmenting each other, sometimes interfering with each other. We may not be able to say how they control action, but we may well believe that their intermediary position is advantageous in determining what shall be the totality of the organic response.

Among these secondary circuits are innumerable lines of possible communication (through points of mutual contact), and action is determined by the paths the stimuli take. If the stimuli follow paths that lead to useful and beneficial action the animal may live to have the like occur again and again, until a main-travelled road for such stimuli is established, and the action becomes habitual. If on the other hand, the stimulus should follow unprofitable paths, leading up to the wrong action, it might, if the mistake were serious, lead to death (if, for example, a skunk seeing an approaching train, should fail to get off the track). Thus the structure of these secondary circuits is such as to furnish a means 
of controlling and coordinating responses that may be quite as automatic as the action of the reflexes themselves. When varying or conflicting stimuli come in, which shall have the right of way is determined by the availability of the paths these secondary circuits furnish.

Cephalization.- It has come about in the development of all the higher animals that the most specialized of the sense organs have been located at the front end of the body; and doubtless, this fact has determined the location of the control center. The end of an animal that goes ahead first comes into contact with the new features of environment. Here then should be located the organs that are the best agencies of discovery; here, the organs that are responsive to stimuli coming from a distance; the eye, the ear, the nose and the antennae of the arthropods. Such organs as these can give knowledge of the presence of an enemy before their possessor has fallen into its grasp; they can locate food or shelter or kindred, that might be passed by blindly. It is most natural, therefore, that the part of the central nervous system with which these "distance receptors" are most directly connected should gradually assume the regulative function.

The brain is primarily an aggregate of neurones. These consist of the same parts as the other neurones-cell bodies, dendrites at the receiving end, and axones at the other end -and they are combined together in circuits, and connected more or less directly with all the other circuits of the body. They have been from the beginning most directly connected with the organs of special sense in the head; hence they are well used to receiving important stimuli from these organs of outlook, and of discharging impulses to every part of the nervous system. Certain of these stimuli have always been of paramount importance to the organism and well worn paths have been established for them. So, actions that are 
needful, are readily brought about. The nerve impulses that will bring them to pass find established channels through the well integrated mass of neurones comprising the nervous system, and they run through these channels, obliterating the effects of other unimportant stimuli. Thus, we have a mechanism which furnishes the conditions for a great variety of responses, and that may be organized by experience for the ready performance of specific acts.

Such a nervous equipment suffices for the carrying out of reactions that are determined by sense perception automatically, the right of way being given to the kind of stimuli that in the past development of the system have determined its paths. The paths are redeveloped in successive generations. The mechanism is perfected with the survival of the fittest, at least, with the elimination of the unfit, or ill adjusted. Such a mechanism gives reactions that are, therefore, wonderfully adapted to the particular set of circumstances under which they have been developed; but they are inexorably fixed in the structure of the nervous system.

Such reactions characterize the habits of most of the lower animals. The moth that flies to a candle flame is stimulated irresistibly by the light. Its ancestors for ages have flown to white objects (flowers) at night. In a proper environment there is nothing better for a moth to do than this. Thus, it gets its living. But candles being introduced into its environment, it flies to a candle, not being able to distinguish between candle light and the light reflected from a flower, or, at least not being able to respond differently, or even to withhold response. Hence, although it may be merely singed with the first contact, it repeats the act so long as it is able to respond to the light stimulus. Thus it goes down before a peril, new to its racial experience, and not provided for in its nervous organization. If candle lights were to become universal, its race would be doomed to 
extinction, unless, perchance, some line of descent should break away from traditional habits, by developing some new paths of action.

Brain action is not necessarily a whit less automatic than the action of a reflex arc. The moth has a brain, but it does not learn in this instance by experience. If past experience is reproduced at all in memory, the impulses arising from it are powerless to check those that arise from the next perception of light. Control here is based on racial-not at all on individual-experience.

A mechanism for adaptation in the individual.-The growth of the control centers in the nervous system has ever meant a multiplication of new channels of intercommunication between the added neurones in them. It has meant the development of accessory circuits not directly responsible for the ordinary activities of the body. It has meant more and ever more by-paths, which peripheral stimuli might or might not traverse.

The primary function of reflex response not being required of these accessory circuits, they have taken on new functions of their own, and have assumed new powers of control. Especially in the cerebral hemispheres of the vertebrate brain, where they reach their best development, they have come to preside over most of the activities of the body.

The neurones of the body are by no means to be considered merely as mechanical agents of intercommunication; they are all living cells, having their own metabolism, consuming food and developing energy, which may manifest itself in more than one way. They act upon each other as upon the other tissues of the body, in and of themselves, whether stimulated from without or not; and it is natural, therefore, that the masses of neurones that make up the control centers should manifest themselves in new ways. Their dendrites are combined in innumerable paths, and 
although not reached directly by a single external stimulus, they are so connected with the peripheral circuits of the body as to be within the reach of all; and they may be influenced by all. Just how the circuits of the upper brain are influenced, we may not say, but apparently the results of these influences are more lasting here than in other parts of the nervous system. The effect of a given stimulus is no longer an unvarying impulse and action. In the labyrinth of brain paths the stimulus sets off the whole chain of impulses that have followed upon it in the past and the pleasurable or painful results of past experience are recalled in memory along with the stimulus; if pleasurable, the natural impulses that go with the stimulus may be allowed to go on to fulfillment; if painful, the neurones of the new center possess the power to direct action into new channels.

A child on seeing for the first time a pretty bee upon the window pane is impelled to catch it and examine it with his hands. If allowed to do so, he learns something about bees, by the most fundamental of educational methods--by experience. The impulse to touch the bee and the painful impressions that immediately follow become so intimately associated in the accessory circuits of his brain that the next time he sees a bee (or it may be, even a fly), on the window pane the sight of it immediately sets off, along with the impulse to touch it, other countervailing impulses arising out of the memory of the former experience. Thus the new control center steps in and prevents the expected action by initiating new ones.

Perhaps we may be permitted to compare this new control center to the referee at a game. He is not necessary to the progress of regular play; but he may with advantage step in and control the action in case of conflict, or of the appearance of unsolved difficulties. 
The development of the cerebrum as an organ of memory is the last and greatest step in the development of the sensory mechanism in vertebrates. It makes education possible. Modes of action may be altered in the lifetime of the individual, and new modes of action may be tried and if found well approved by results, may, by repetition, be made habitual. And it should be clearly apprehended that the new control center does not replace the old. The individual has his lower reflex apparatus and correlation centers in charge of the ordinary operations of his body that are necessary to keep life going, and, superadded thereto, he has the new part by means of which he may continually be improving his adaptation to environment.

These then are the steps we have tried to trace in the perfecting of the nervous system as a seat of the sentient life:

I) The differentiation among the cells of the primitive metazoan of $a$ ) receptors (sense organs); $b$ ) contracting cells (muscles), and $c$ ) communicating cells (nerves) connecting the other two sorts.

2). The withdrawal of the nerve cells from the surface of the body to protected situations in the interior, and their association together to form ganglia.

3) The differentiation of neurones, bearing axones and dendrites, and the development of polarity in them.

4) The differentiation of neurones into two complemental sorts, and the association of these in pairs, forming reflex arcs, each pair joining sense organ to muscle or gland.

5) The development of intercalary cells in the nerve centers, serving by their own intercommunicating processes to bind together the reflex circuits of the body.

6) The development of specialized sense organs, in connection with some of the ganglia at the front end of the body. 
7) The development of coordination centers (groups of integrated accessory circuits) among the added neurones of the principal centers.

8) The development of control centers in connection with ganglia at the front end of the body, establishing a brain.

9) The development of the upper brain as the chief control center of vertebrates.

Relations between parts and functions in the nervous system of vertebrates.

We have already given very brief consideration to the parts in the nervous system of the salamander, (general structure, pages I88-192; development, pages 19520r). Essentially the same features of both structure and development characterize all the higher vertebrates. The same parts are present and in the same relations, and they come into existence by the same developmental processes. The relatively greater development of the higher centers of the brain has also been suggested (see figure I 28 on page $20 \mathrm{I}$ ). Figure 260 shows roughly the location of the principal parts of the nervous system in the human body. Brain and spinal cord occupy the dorsal axis, and cranial and spinal nerves connect these multiple centers with every part of the surface of the body. The sympathetic ganglia and nerves of the organs of the cœlom are not shown.

As in the salamander so in other vertebrates each spinal nerve has two roots. The ganglion-bearing posterior root is a bundle of afferent or sensory fibers that bring in the effects of stimuli from the surface of the body, and the anterior root is a bundle of efferent (mostly motor fibers,) that carry impulses to muscle or gland (or, through the ventral commissures, to the ganglia of the sympathetic system). The bodies of the afferent neurones, as .we 
have seen, compose the dorsal root ganglion. The bodies of the efferent neurones lie in the gray matter of

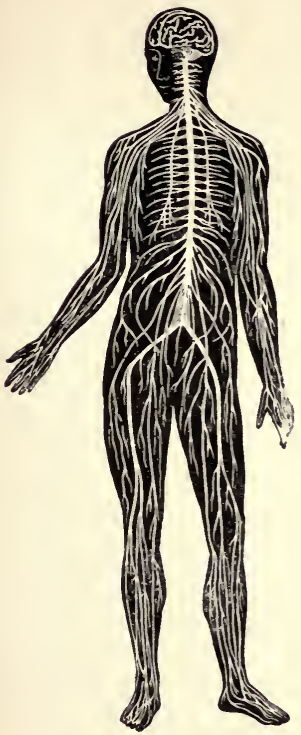

FIg. 260. The nervous system of man. (After Ranke)

the central part of the cord, where they are associated with other intercalary nerve cells. The afferent fibers pass through the white part of the cord up-ward toward the brain by several routes. But the white matter is composed mainly in ourselves of fibers of intermediary neurones, or of efferent fibers descending from the brain. These fibers are arranged in great tracts or "columns," which are the main lines of communication between the brain and outlying ganglia. Even the main fiber tracts are too numerous for us to attempt to give an account of them here.

Lying in the pathway of some of these bundles in the base of the brain are some very important masses of cells, that are centers of control over the most vitally important processes of the body. In the midst of the medulla, for example, lie the centers for the control of heart beat and respiration. But the greater part of the cells of the brain occupy the outer layer of gray matter of the cerebellum and cerebral hemispheres. The cerebellum is connected in an important way with the control and coordination of the involuntary movements of the body, and the cerebrum, or upper brain, 
is the chief control center of the voluntary activities of the body, and the organ of the mind.

The outer cellular layer of the hemisphere is known as the cortex. The chief divisions of its topography as marked out by the convolutions of its surface are called lobes, some of which are named in figure $26 \mathrm{I}$. The distribution of the

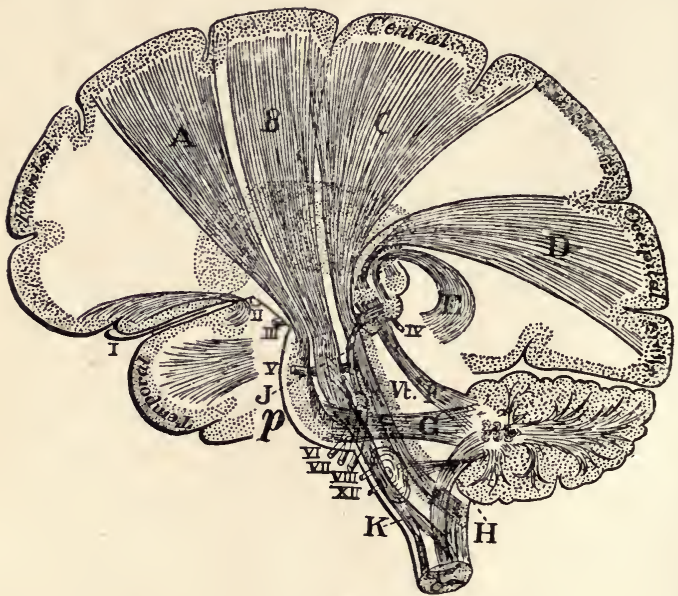

Frg. 261. Diagram of the chief tracts of projection fibers of the brain. Roman numerals designate cranial nerve roots (as in fig. 262) Capital letters designate fiber tracts, as mentioned in text. $p$, pons (From Howell, after Starr)

fibers from the cells that compose the cortex is enormously complicated, and is not fully known, but some of the major features of that distribution are indicated in the figure. This shows some of the main lines of communication between the principal centers within the nervous system. There are three principal sorts of fibres passing out from the cells of the cortex of the hemispheres. I) commissural fibers 
which extend across from one side to the other joining like parts of the two halves of the brain; 2) association fibers, which wholly within the hemispheres and, extending between lobes, connect one part of a hemisphere with another part; and 3) projection fibers, which connect the cortex of the hemispheres with underlying parts of the brain and with the cord. Only the main tracts of projection fibers are indicated in the diagram. Some of these fibers will be seen to extend directly down the cord (as the fibers of the motor tract $\mathrm{B}$, through which the movements of the body are controlled at will), some end in the medulla (tract $\mathrm{C}$ ), others in the mid-brain (tract D), others in the pons (tract A), etc. The diagram also shows the three main tracts that go out from the cerebellum, to the midbrain (tract $F$ ), to the pons (tract $G$ ), and into the cord (tract $\mathrm{H})$.

We have seen in the salamander that the principal "dis-

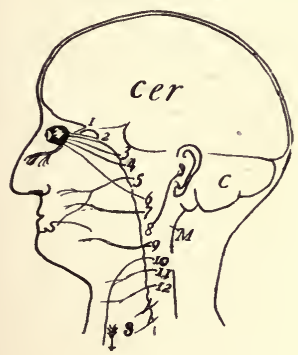

FIG. 262. Diagram of the relations of brain and cranial nerves in man. $M$, medulla, $C$, cerebellum. cer, cerebral hemisphere. 1 , olfactory nerve. 2, optic nerve. 34 , and 6 oculo-motor nerves. 5 sensory nerve of the face, 7 motor nerve of the face. 8 , auditory nerve. 9, the glossopharyngeal nerve. 10 , the vagus nerve. $s$, spinal nerves. tance receptors", eyes and ears and olfactories, are connected directly with the brain. Figure 262 shows the nerves of these organs, and also the other cranial nerves as they occur in ourselves.

The structure of the cortex of the hemispheres is of very great interest to us because this is the highest control-center of the body. An intelligent animal with its cerebral cortex removed becomes a mere automaton, without volition or spontaneity of action. The nutritive process may go on: consciousness is lost.

Five layers of cells are recog- 
nized in the cortex, differing considerably in form and in mode of branching of their cell processes, as well as in position, and all of them, extremely complicated. A single cell from one of the middle layers of the human cortex is

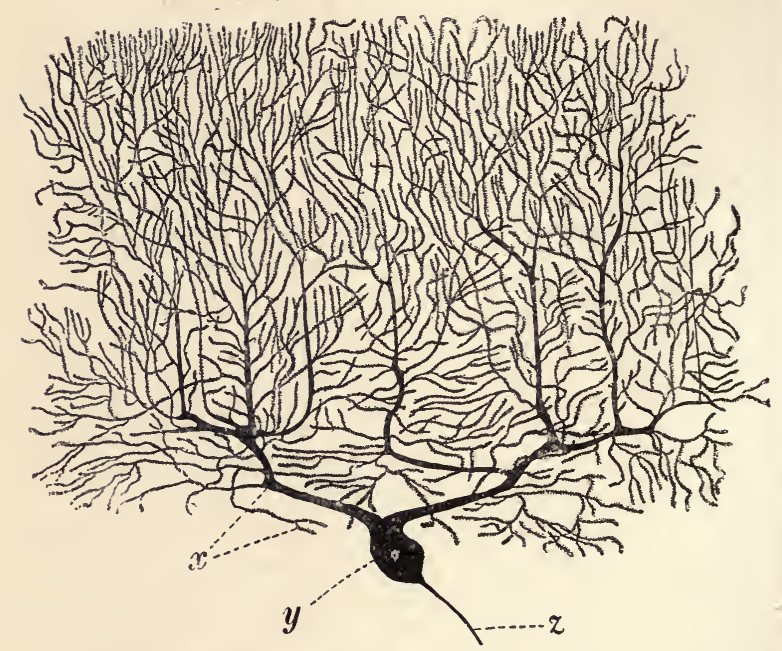

FIt. 263. A single cell from the cerebellar cortex of the human brain. $x$, its dendrites. $y$, the cell body. $z$, the axone or nerve fiber. (From Stöhr)

shown in figure $26_{3}$. The most remarkable feature of it is the extraordinary richness of the branching of the dendrites. These are interlaced and come into contact with the termini of the processes of other cells that lie in other parts of the hemispheres, and in other centers of the brain and cord. In the entire cortex there are said to be millions of such cells.

If here, as elsewhere in the nervous system, nerve cell processes are channels for intercommunication-channels 
for the conveyance of impulses-how manifold are the ways these cells may react upon each other. How inconcrivably numerous are the by-paths of the brain. The mere mechanical complexity of our thinking apparatus is beyond the compass of our thought.

Despite the differences in the mental powers of vertebrates, the anatomical differences of the cortex are not very great. Structurally the cortex of a rodent is very like that of a man. The increase in number of cells is not proportionate to the increase in size in the brains of the higher mammals; the increase appears to be due rather to the more extensive development of cell processes and of intercellular substance, the cell bodies in the cortex of the brains of the higher mammals being thus spaced farther apart. The mechanism is therefore much more alike than we should expect, judging by the great differences in mental capacity. The analogy has been aptly drawn, that the structural difference between a watch that will not keep good time, and a perfect time piece may be very slight indeed.

Such is the arrangement of neurones, that every part of the cortex may receive impressions from other parts of the nervous system and every part may give rise to outgoing impulses. In other words, every point is a center of an arc, with incoming and outgoing paths. The brain is, therefore, essentially an integration of neurones, combined in afferent and efferent intercommunication arcs.

There are no very striking differences in structure in different parts of the cortex, and this in spite of the fact that the functional differences are more or less distinctly localized. But our knowledge of these "centers" in the cortex is very imperfect. Results have been most readily arrived at in, the case of the motor functions, because a stimulus applied to a given part of the cortex may produce a visible response in muscular movement. By this 
means (as well as by the opposite one of observing the paralysis produced by local injuries) the great motor

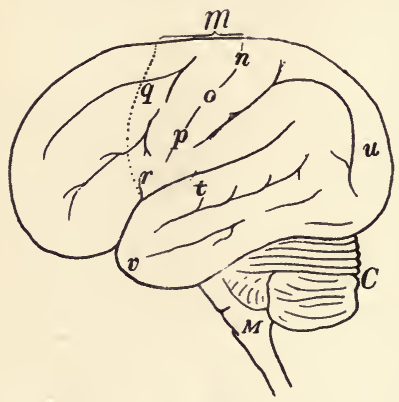
area that traverses both hemispheres ( $m$, of fig. 264), has been carefully explored. The definiteness of the responses to stimulation upon these centers has been aptly compared to that of the tones of a piano that result when certain keys are struck. If, however, the motor center for the leg or arm be stimulated

FIG. 264. Diagram of localization of functions in the cerebrum. $M$, medulla. $C$, cerebellum. $m$, the great motor area of the hemisphere with a few of the control centers approximately indicated: $n$, center for movements of the leg; $o$. for arm; $p$, for face; $q$, for head; $r$, for organs of speech; $t$. center for hearing ("brain deafness" may result from its injury); $u$, for sight; $v$, for smell.

in one hemisphere the limb of the other side of the body will move; for the motor fibers of the great tract $B$ of figure $26 \mathrm{I}$, (the "crossed pyramidal" tract) in the medulla, cross over to the opposite side of the body from the one in which they originate. For this reason, also, great injury to one hemisphere produces paralysis of the opposite side of the body. Conversely, the seat of injury, hemorrhage, etc., within the brain may often be located by observing what portions of the periphery of the body are paralyzed or abnormal in their action.

Study 6o. Demonstration of the functions of some of the principal parts of the nervous system in the frog.

Materials needed: Living frogs, some of them prepared for this study several hours in advance of need (in order to allow time for recovery from the shock of the operations) as 
follows: some, with the cerebral hemispheres carefully removed (other parts of the nervous system being left uninjured); others, with the cerebellum also removed; others, with the spinal cord severed at its junction with the medulla, the purely reflex apparatus thus being isolated. Specimens will require to be properly handled and cared for until used. The specimens may be used by different students in succession, or if preferred, the demonstration may be made by the instructor.

While the preceding account of the nervous system has followed logically the building up of it, these experiments will of necessity follow the reverse order. The student should first of all be familiar with the living normal frog, so as to be able to judge of changes produced in its actions by the loss of brain parts.

I. Observe a frog that has lost its hemispheres only, noting especially its want of volitional activity. Test its power for correlated movement by throwing it into water and making it swim; by tilting the support on which it sits, making it balance itself; by making it jump. Try to determine experimentally whether it can see and hear. See what it will do with a bit of suitable food (such as a fly) placed in its mouth.

2. Try the same experiments with a frog that has lost also its cerebellum, noting especially the effect of this loss upon the coordination of its movements.

3. Observe how the severance of the brain from the cord has affected the tone of the body as a whole. Hang a brainless frog up by its head for convenience in manipulation and test its body at various points for reflex responses to stimulation of the skin. A small brush dipped in dilute acid may be used to touch the skin, and the acid may be immediately removed with a wet sponge. 
A correlation mechanism within the nerve centers that remain may be demonstrated as follows: stimulate one side of the frog in the flank with the acid, and see the foot of the same side lifted and rubbed against the spot as if to wipe it off. Then stimulate the flank again in like manner, but hold the foot of that side by the toes to keep it from repeating the act. After one or more attempts to use this foot, the foot of the other side will be lifted and swung around to the spot stimulated.

With an adjustable induction coil and a small battery, try electrical stimuli of gradually increasing strength, to see the spread of the effect with the increase in intensity of the stimulus.*

Stimulate the cut end of the cord; here are the paths coming down from the brain. Then destroy the cord by thrusting a wire down the vertebral column and twisting it, thus breaking up the reflex arcs and test again for responses.

Then expose the great sciatic nerve (it will appear as a coarse white thread lying between the muscles of the inner side of the thigh, and stimulate it directly to produce muscular response. Then trace this nerve to its forking at the knee, and stimulate each of its main branches separately to see the specifically different responses resulting.

The record of this study will consist of notes and diagrams illustrating the nature of the experiments performed, and their results.

*A little strychnine injected under the skin with a hypodermic syringe will greatly increase the sensitiveness of the spinal cord to cutaneous stimulation: the response, however, soon ceases to be orderly and purposeful, and becomes convulsive. On the other hand a few crystals of salt placed upon the cut end of the cord will check, and after a little time, inhibit altogether the reflex responses: the effect will however soon disappear, upon washing the salt off with normal saline solution. 


\section{Types of sensory phenomena.}

The powers of animals find expression in the responses they make to the external world.* The great differences we have seen in complexity of nervous organization are more or less closely accompanied by differences in mental powers, manifest in behavior. Every step in integration of the nerve paths of the body is doubtless accompanied by improvement in action. Without attempting, however, to draw a close parallel between organization and behavior, we will now examine some types of animal activity, that at least show steps of progress.

Automatic unvarying activities.--Two examples of invarying response have already been before us for consideration. The avoiding reaction of the protozoan Paramœecium as we have seen, constitutes almost the entire stock-in-trade of reactions for that animal. The distance of movement backward upon stimulation and the extent of the swing to the aboral side will depend somewhat on the strength of the stimulus; but the one sort of reaction follows upon almost every sort of vigorous stimulus that the environment of the animal normally offers. And with repetition of the stimulus, the reaction is repeated indefinitely, and in essentially the same manner. The reaction of the moth to the candle flame is essentially of the same invarying type, although it is performed by the aid of a complicated nervous system. The moth, however, has other less inflexible responses that it makes to other less dominating stimuli.

Responses automatically varying.-The repetition of a stimulus usually brings about a change in the behavior of an organism, sometimes an augmentation of the reaction, sometimes the entire cessation of it. A stentor, for example, if stimulated by mechanical contact with the cilia of its

*The essence of an a nimal is in what it does.-. A ristotle. 
peristome, will, for a time, merely withdraw its body by direct contraction. If at each extension the stimulus be repeated, the stentor will swing its body first to one side and then to the other. If this be unavailing and the stimulus be continued, the animal will free itself from its support,

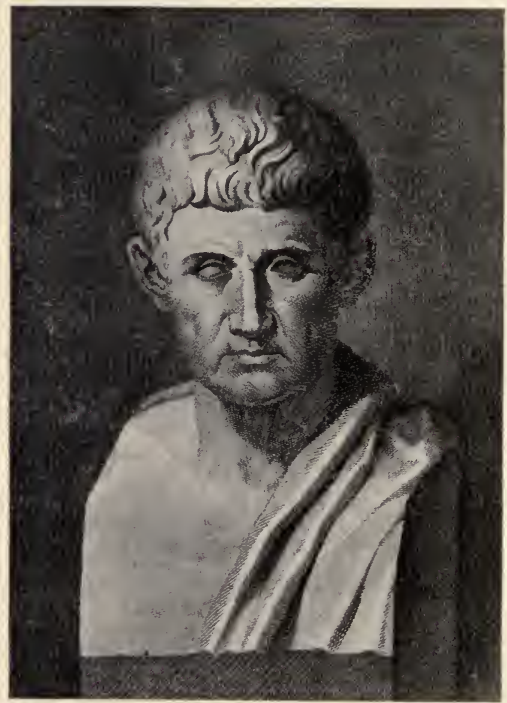

ARISTOTLE

$[384-3222$ B. C. $]$

Naturalist and Yhilosopher.

and swim away. This method of avoidance is, however, quite automatic. If the stentor be again stimulated when it has attached itself in a new place it will go again through the entire series of varying responses under the same stimulation. It learns nothing by the repetition. 
On the other hand a stentor will soon cease altogether to react to light touches rapidly repeated. A hydra also will react to touch by contracting its body, and if allowed time between stimulations for complete extension of its length, it will contract again when touched, every time; but if the touch is repeated before a full extension of the body, the animal will soon cease to notice it altogether. In such an organism the stimuli must follow each other in quick succession if they are to modify action. Certain spiders habitually drop from their webs to the ground when disturbed. This is their avoidance reaction, and it doubtless carries them often out of an exposed situation into one of less danger, and at times enables them to escape capture by enemies. A certain spider will respond, when a large tuning fork is struck near at hand, by drooping from its web. But it will cease to do this (and to put itself to the trouble of climbing up again) after the experiment has been repeated half a dozen times.

Moreover, the spider unlike the hydra and the stentor and many others of the lower animals, may after daily repetition of this experience become used to the stimulus of the tuning fork and cease to react to it at all after a considerable time. This would seem to indicate growth in power of discrimination between stimuli; for only an animal with some such power could afford to suspend the reaction by means of which it escapes its ordinary enemies.

Cessation of response to continued but harmless stimulation is a wide spread phenomenon in the reactions of animals. It is too familiar for much notice in ourselves. We are not long conscious of contact with our clothing after it is put on, notwithstanding that by contact we get it adjusted properly. And even admonitions of the worthiest sort, too oft repeated, we let "go in at one ear and out at the other;" that is, they go unheeded. The better the organization of the 
psychic mechanism, the more lasting appears to be the result of getting used to a stimulus.

Study 6I. Observations on certain reactions of caterpillars.

Materials needed: Living caterpillars in normal and healthy condition, and a supply of their appropriate food. Silk worms (and mulberry leaves) will do for this, or almost any of the larvæ of the larger butterflies or moths. The larvæ of the common milkweed butterfly have been used successfully.

I. Study the creeping reactions of an active caterpillar. Observe first its method of locomotion. Then place the specimen on a reversible cord (as, for example, a bow cord and note the persistence of its almost unvarying reaction to the pull of gravity. It crawls upward. Reverse the cord betimes, and observe the result.

2. Then test the variability of reactions to stimuli such as will stopits crawling; a puff of breath, or a sharp rap on a table on which its support is resting. Most caterpillars have a characteristic habit when stopped of turning the head either up or down. Determine by trial (using a watch for timing) how often it is necessary to repeat the puffs of air or the raps on the table in order that they may fail to elicit the reaction.

3. Test the time it takes to inhibit the feeding reaction by substitution of unsuitable food. Get a hungry caterpillar to feeding on the margin of the leaf of its proper food stuff, and slip up beside the leaf a sheet of some thin substance unsuitable for food (such as a leaf of some other plant which the larva of itself will not eat, or a sheet of paper or of tinfoil). Note any evidence of dissatisfaction with the substitute food. Then, allowing the caterpillar to resume eating the right leaf, determine by trial what interval must intervene before it will again bite of the substitute. Ob- 
serve whether this interval grows greater with repetition. Observe whether the number of bites taken of the substitute grow fewer after repeated trials. If the caterpillar has a memory for the sort of experiences tried, how long can it remember?

4. Observe the effects of bodily states on the activities of the caterpillars by comparing their reactions when hungry and when well fed; when cold and when warm.

The record of this study may consist of an account (with diagrams) of the experiments tried, and a brief statement of the results.

Sequences of automatic activities.-We come now to the consideration of a class of phenomena commonly known as instincts. These are automatic activities, amplified and serially arranged and extended until they cover often a large part of the life of the individual. They are not essentially different from the simpler automatic acts we have just been considering. A caterpillar instinctively moves upward on its food plant; but creeping is itself a sequence of events. The participation of many sets of muscles is necessary, and these must act successively and in progressive order. Each movement is prepared for by the one that went before it. The stimulus acts through the control centers. Not the stimulus, but the state (position) of the body determines which foot shall first be lifted and swung forward.

Instincts proper are sequences of such actions the events of the series being unlike in kind and unrepeated. The preparation of the caterpillar for its transformations is a performance of this type. When fully grown it ceases feeding, crawls to a place of security (usually away from the plant that has nourished it), spins a silken cocoon about its body and changes into a pupa. But before these things can occur it must be full-fed, it must have a store of material for further development, the rudiments of the adult organs 
must have reached a proper stage of development, and the silk glands, now nearing the climax and the end of their usefulness, must be charged with the secretion that is to form the cocoon, and a host of other physical (somatic) conditions must be fulfilled. When fulfilled, we may say, speaking in figures, the ship of instinct is laden and tugging at its cables; its course is laid out from beginning to end, the points of call, the discharges of cargo, the bells that shall be rung and the whistles that shall blow are all pre-arranged, and only the signal to start is needed, to initiate all the events of the voyage. Nothing could more plainly show the essentially autogenetic nature of responses.

The bird builds her nest when the condition of body and brain impels to it. No stimulus has any effect whatever until body and brain are ready. Maturity must be reached, and eggs must grow, and mating must take place; and when all is ready, the simplest sort of stimulus, the sight of suitable materials (straw or fiber or hair, not conspicuously different from a thousand other things the eye might fall upon), serves to set the complex activities of nest building going. The stimulus is but the spark that sets off the

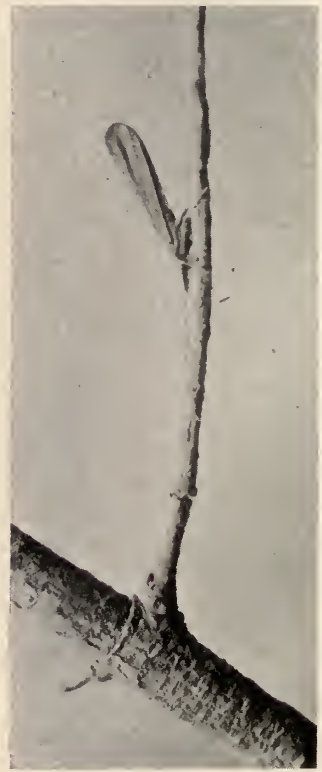

FIg. 265. A caddisfly (Molanna cinerea) with a highly specialized (and highly protective) sitting posture. (Photo by C. Betten). 
powder in the mine. In itself it may be insignificant, but in its relations to the organism it is all important; for it determines the very conditions of existence. Nest building must wait on the finding of suitable materials-materials not too different from those the sight of which has elicited the nest building responses in the past, and all the subsequent acts of rearing young wait on nest building. This means

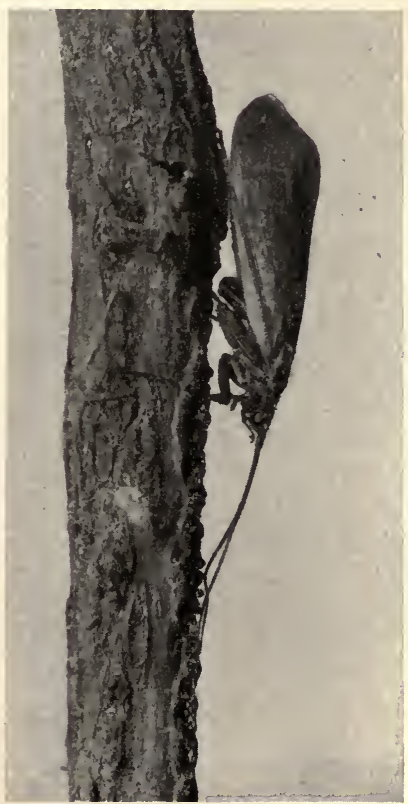

FIg. 266. A caddisfly (Halesus sp?) whose sitting posture suggests a half way stage in the development ot the posture of Molanna. that the want at any point of a stimulus that can set off an appropriate action, blocks the remaining acts ct the series and leads to failure.

The perfection of instinct at its best is marvellous. Sequences of acts, that, like nest building and web spinning, are worthy to be ranked as fine arts, are performed perfectly without instruction, example or experience; performed, perhaps but once in a life time. The method of a caterpillar in spinning is as much a product of its organization as is the silk in its spinning glands. Glands and nerve cells are alike charged during development. They 
are alike the end results of a long evolution, with endless adaptations to conditions of life.

The caddisfly Molanna (fig. 265) "sits close" on a twig, its wings up-rolled about its lifted abdomen, and all the other appendages outspread against the side of a supporting twig or trunk. So situated on jagged bark or amid the stubs of a twig, it is well nigh undiscoverable. The flying Molanna, settling instantly to this attitude, vanishes, ghost-like, from view. It makes no superfluous motions to hold the eye; actions, attitude and color are in protective accord. But perfected actions, like structures, have to be evolved. Halesus, (fig. 266) sits in a position intermediate between that of Molanna and the more ordinary resting attitude of such insects; and its posture suggests possible stages in the development of Molanna's perfected habit. An ingrained habit may persist, also, like a vestigial organ after it has ceased to be of any use. Perhaps the most familiar illustration of this is the turning round and round of a dog before it lies down. The primitive dog presumably made its lair in the grass, where this was an eminently useful performance.

Instincts illustrate extreme specialization in the neural mechanism. It is fitted finely to one set of conditions, and is apt to be found wanting when conditions are altered. The moth that flies to the candle flame has left the beaten track of its ancestry, through want of discrimination between stimuli. Another example is furnished by the kinglet (fig. 267) which, being racially unacquainted with the dangerous hooks on the burdock (an imported weed), endeavors to get the seed-eating larvæ from the heads for food. Fatal want of discrimination is sometimes displayed toward objects of the normal environment. Thus the flesh fly is stimulated by the odor of the carrion flower and lays 'eggs upon the plant, where her young on hatching will 
find no food. The fly does not possess even such perceptive faculties as would enable it to distinguish between a flower and a dead carcass. The fly knows neither carcass nor flower, but only a certain kind of olfactory stimulus that may come from either.

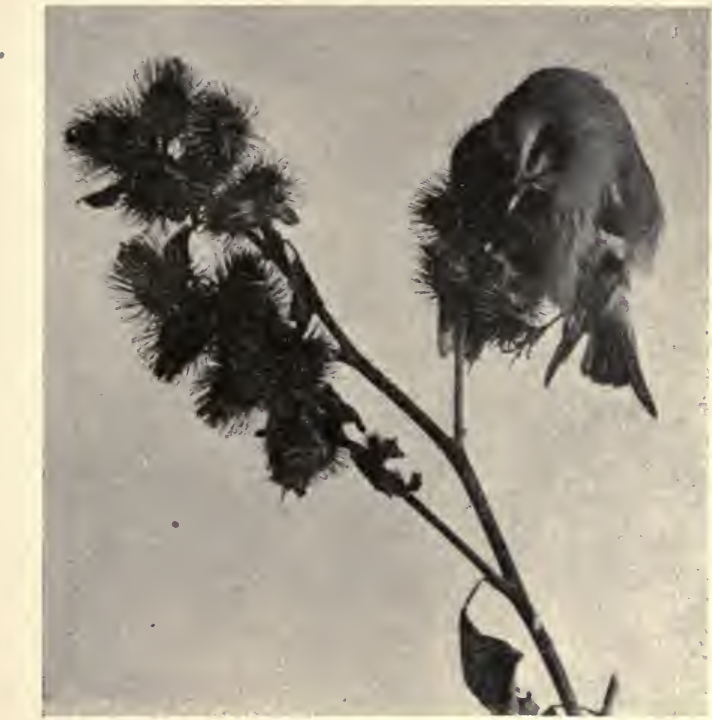

Fig. 267. A mistake of instinct. The kinglet, seeking the larvæ of the burdock moth (see fig. 247 on page 425 ) is ensnared by the hoods of the burdock heads.

Study 62. Experiments on the case building instincts of caddis-worms.

Materials needed: A supply of living caddis-worms, that may be kept in proper receptacles at proper temperature 
and in good condition for at least a week. Almost any species that makes its cases of pieces of wood (fig. 268), or stones, with or without ballast-pieces attached to the side, will do. For the following experiments, handle the larvæ gently, with care not to do them any physical injury, and leave them in clean water and comfortable conditions while waiting the results of the experiments. While cutting cases the larvæ may be temporarily removed from them, if this be. deemed necessary.

Observe the fitness of the cases for protection of the body

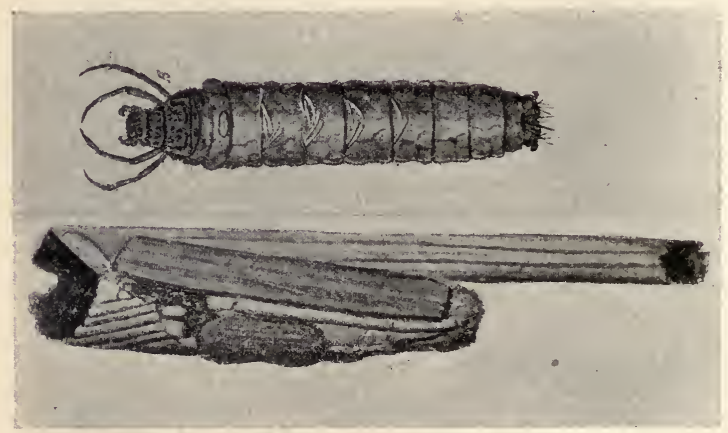

F1G. 268. A caddis-worm (Halesus sp?) and the case from which it was removed. (Drawings by Mrs. J. H. Comstock).

and for escaping observation when in the natural environment. Observe the ordinary activities of the caddis-worms; the manner in which they drag their cases about, or retreat into them when disturbed. Drive a worm out of its case (by poking it gently from the rear), and observe the form and structures of the body and its need of protection.

Study the case of the species selected for experiment, its materials and construction. Observe the cement-substance 
which binds the other materials together; this is the hardened secretion from glands that open through the labium of the larva, which exudes as a fluid, and hardens after contact with the water. This secretion is all the equipment the larva needs for building or repairing its cases.

I. To test the adaptability of case building present physical needs:

I.) Cut a hole in the side of the case, exposing a vulnerable part of the body, and see if it will be repaired.

2.) Slit a case lengthwise, in a narrow opening from end to end and leave it to be repaired.

3.) Cut a case in two crosswise, and leave one part of it only on the larva for repair.

II. To test the adaptability of case building to conditions of environment.

4). Provide a background of a different color from the natural one, (background may be placed under the bottom of a glass dish), and materials for case building of suitable size and of a color to match the background (strips and bits of mica, glass, colored celluloid, whitewood, etc.), Provide also the materials ordinarily used, but which are unsuited to the new background, being there conspicuous when viewed against it. See what materials a larva, removed from its case, uses for making a new one.

5). Leave a larva, removed from its case, upon the old background, but provide it only with case-building materials that will be conspicuous against that background, and note the result.

The record of this study will consist of an illustrated account of the experiment, setting forth their results.

Learning by experience.-Many of the lower animals are born educated almost to the full extent of their capacity, the possible lines of action of their whole lives being pro- 
vided for and predetermined in their organization. The acts most fundamental to the preservation of races, feeding, reproduction, etc., are thus provided for in the main in all animals. A kitten is instantly thrown into a paroxysm of defensive movements and attitudes at the first sight or smell of a dog. A chicken flees at the first cry of a hawk, although it may be quite unresponsive to the (to us apparently) similar cry of a catbird. Nature has developed this nice discrimination by the elimination of the unresponsive. Racial experience has thus been incorporated into the organism in such manner that vitally important stimuli dominate all the activities of the body and enable it automatically to meet the chief exigencies of life. There is, however, especially in the higher animals, a field of activity in which reactions are less stereotyped; more variable; and here lies the opportunity for learning by individual experience. This is so large a part of our own life that we have difficulty realizing how limited it is in many of the lower animals.

The sight of food that is not within reach may stimulate to activities that are predetermined only for the act of feeding, and the processes of nutrition; not at all for the method of getting at the food. A horse confined in a bare lot, is stimulated to a great variety of activities by the sight of the green grass on the other side of the fence. He does many things that yield no satisfactory results; he pushes, he whinnies, he stamps, he tugs at the toprail with his teeth, he rears, etc. But by chance he lifts the latch of the gate with his teeth, and this act is accompanied by pleasurable results; he sees the gate open. Another time he is likely to concentrate his efforts at the gate, and to lift the latch sooner, with fewer ineffective efforts. Every repetition of an act makes its subsequent performance easier, especially when accompanied by pleasurable experiences accompanying successful performances of it. Soon he is able to eliminate all the un- 
profitable acts, and to lift the latch at once; he has learned by trial and error.

So we learn in infancy to walk, to talk, to play; and in later life, to acquire any wholly new accomplishment without instruction or example.

Such learning is conditioned upon the possession of a nervous mechanism that is capable of retaining the impressions accompanying a former act until the stimulus is repeated. Such a mechanism is, as we have seen, the upper brain in the vertebrates. It is an agency for reviving alongside every important stimulus the impressions that have accompanied former responses to the same kind of stimulus, action then being determined in accordance with whether these have been pleasurable or painful, whether they have been successful or unsuccessful in attaining a desired end. The details of the process will be made much clearer by the study of a concrete example.

Study 63. Learning by trial and error in chicks.

Materials needed: Healthy young chickens, a week to ten days old; food and water for the chickens. A labyrinth made on the plan shown in figure $269^{*}$ (one for each group of eight or ten observers).

This study consists in observations on the details of the method of a chick in learning the route through the box from one end of it to the other. Place the chicks as indicated in figure 269; several of them with plate of food in one end of the box, and one chick (the subject of the experiment) alone and without food in the other end. The group will feed and chirp contentedly, and the other one, moved by the sound of their social converse and by his

*This may readily be constructed out of an ordinary wooden cracker box, by adding partial partitions to make the passageway, $\mathrm{I}, \mathbf{2}, \mathbf{3}, 4$. 
gregarious instincts, will (if not too full-fed) try to get to the others. Observe in detail his methods. Let one person of the group of observers be time keeper, and let the others record impartially all the efforts of the chick. These efforts will follow each other, sometimes in such quick succession that some short-hand method will be required for recording them. The following, as inclosed in parentheses after the acts named, are suggested: walking about (w; repeat the sign for each start with change of direction): calling to mates or peeping $(\mathrm{p})$ : peering through crevices or holes in the sides of the box (o): flying against the sides of the compartment $(\checkmark-$ mark, or checkmark of any sort quickly made): after return entering the passage, from points of record ( 1,2 or 3 ;

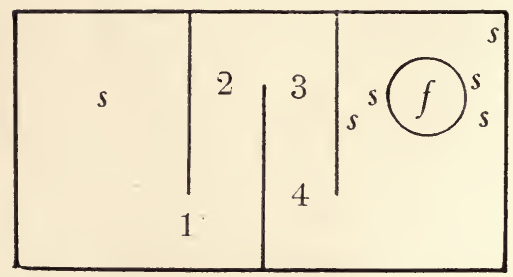

Fig. 269. Diagram of a simple box labyrinth, arranged for testing trial and error in young chicks. $s s s s s s$, the chicks at the start, one isolated from the company. $f$, a plate of food. $1,2,3,4$, points of record in the passageway.

there will be no return from 4 , where the mates are sighted).

Mark the chicken that is to be the first subject of the experiment in some way (or note its personal characteristics) so that the same one may be taken again for repetition of the trial. Record all its acts and the time it takes to find the way to its mates. Return it to the starting point and record again; and repeat until it has learned the passage, and is able to traverse it without much hesitation or delay, and 
without any misdirected efforts.* When learned thoroughly, make a tabular record of the time and efforts expended in the process, by successive trials, as follows:

\begin{tabular}{c|c|c|c|c|c|c|c|}
\hline $\begin{array}{c}\text { Number } \\
\text { of } \\
\text { Trial }\end{array}$ & $\begin{array}{c}\text { Spells of } \\
\text { peeping }\end{array}$ & $\begin{array}{c}\text { Walks with } \\
\text { change of } \\
\text { direction }\end{array}$ & $\begin{array}{c}\text { Peer'gs } \\
\text { through } \\
\text { walls }\end{array}$ & Flights & \multicolumn{2}{|c|}{ Returns from } & Time \\
\hline Ist trial & & & & & &
\end{tabular}

Etc.

If any considerable part of the laboratory period remains after one chicken is educated to the act, another may be tried; or the labyrinth may be altered or complicated and the same one re-tried.

The record of this study will consist of a diagram of the experiment, together with a summary of the results appearing in the table.

Further progress. - As the chick has mastered one performance so it may master another. With repetition the signs of effort disappear and those of habit take their place.

It is a long step forward toward intelligence when brain circuits are able to retain impressions arising from one stimulus long enough to influence the action that shall result from the next stimulus of the same kind; for then the responses may begin to take on individual variations. It is a still longer step when the central circuits through previous stimulation and mutual interaction become able to originate like acts in absence of the original stimuli; for here initiative comes in. Then, the trial of a performance need not wait

*It is best that the chicken should be quite unmolested by the observers during the experiment, but if unfortunate conditions should have made it sluggish in action (so that it inclines to squat and do nothing), results may still be had by applying any sort of gentle stimulus that does not tend to urge it in any particular direction, such as dropping the end of a cane against the bottom of the box. 
upon an outside stimulus; an autogenetic one may be substituted. Practice may go forward. Experiments may be tried. The individual may of himself learn new modes of action.

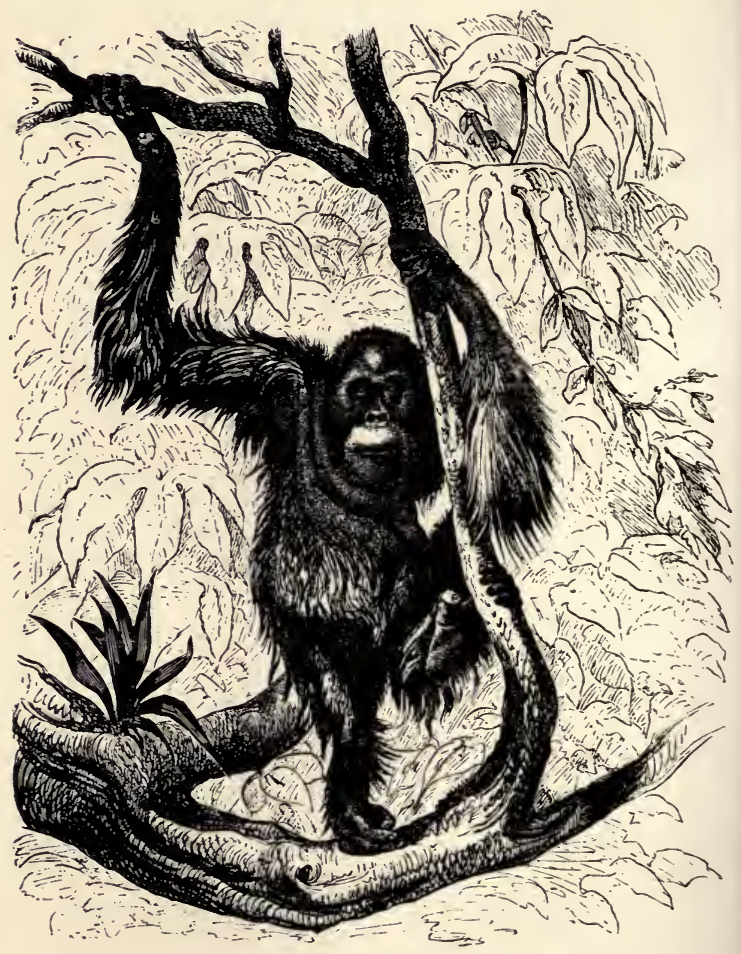

FIG. 270. The Orang (after Bos). 
II. THE RESPONSIVE LIFE OF THE HUMAN SPECIES.

Man in the organization of his body is a vertebrate animal. So great is his likeness in structure to other vertebrates, we should have no trouble identifying every organ in his body from the study of the organs of the others. The functions of the parts, too, are so similar that our knowledge of human physiology has largely been derived from the study of other vertebrates-much of it even from the study of one so distantly related as the frog. But the slight physical differences existing between man and even the highest mammals are accompanied by menta! differences so profound that our account of the responsive life of organisms would be most inadequate without brief notice of mental development in the human species.

\section{The natural history of man.}

We have not time to review the physical history of the human body, its development from an egg, its segmentation, its development of gill clefts and a fish-like circulation that is subsequently altered to the mammalian type, its nurture through embryonic membranes, its birth, like that of any other mammal. These do not need to be repeated. And we will not make mention of his mammalian affinities, for these are sufficiently apparent. We will only remark in passing that man's nearest zoological allies are found among the anthropoid apes. The mammalian order Bimana, (two handed animals), which a distinguished zoologist of a past generation once erected as a pigeon-hole in which man might be kept apart from the higher apes (Quadrumana; four handed animals), has long been merged in the great mammalian order Primates, which includes, besides man and the apes, also the monkeys and the lemurs. The zoological differences between man and the higher apes, such as the orang, the chimpanzee and the gorilla, are far less than the differences between these and the lemurs. 
Distinguishing human characters.-The chief features of man's body that distinguish him from his nearest allies are

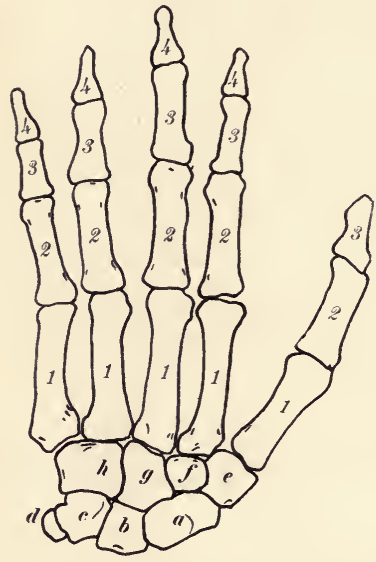

FIG. 271. The framework of the human hand. $a$ to $h$. carpal bones; $x$ to 3 , bones of the thumb; $I$ to 4 , bones of the several fingers. precisely those that have favored his great psychic development; his erect attitude, his hand and his brain.

Man is the only mammal that stands erect. His legs are longer and stronger and his pelvic bonesare stouter and better consolidated together for bearing the entire weight of the body. His arms are shorter and have more freedom of motion at the wrist, and his cranium is better balanced at the top of the vertebral column than in the apes. These (fig. 270) shuffle along, using the arms as well as the legs for locomotion. The chief advantage of the erect attitude is that it sets the hands free for other uses.

The human hand is generalized in structure; its skeleton is very like that of the foot of a salamander and not far removed from that of the typical vertebrate (compare figures $27 \mathrm{I}, 272$ and III). It is much like the ape's hand in its opposable thumb and its freedom of rotation at the wrist. These two features make it adaptable to a great variety of uses. Its readiness at grasping and turning make it a splendid servant of the brain; for it can be used in examining objects, in exploring surfaces and in moving things 
about. Thus things may be known as objects, and not as mere obtruding features of the general environment. It is hardly conceivable that the specialized hand of a bird or of a fish could be of much use in the educating of its possessor; the variety of sense impressions it could furnish would be very limited. Doubtless the possession of so adaptable a grasping organ has been a large factor in human development. It has made man a tool-using animal. It is the recognition of this service that has made hand-training (manual training) an integral part of our educational system.

The human brain is distinguished by a very great development of the cerebral hemispheres. These, as we have seen, are relatively small in the salamander. They increase in size with improvement in mental power in all the higher vertebrates. They overspread first the olfactory and then the optic lobes and the upper side of the cerebellum, and in the higher mammals their cortex becomes thrown into foldsincreasing thus its superficial area. They reach their maximum development in the human species, exceeding many times in weight all other parts of the nervous system put

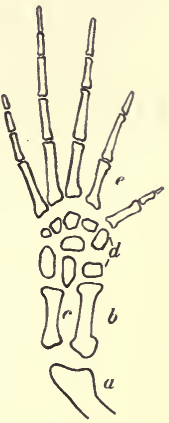

FIG. 272. Bones of the foot of a spotted salamander. $a$, femur; $b$, tibia; $c$. fibula; $d$, tarsal bones; $e$ phalanges. together.

The hemispheres constitute, as we have seen, the chief control center of the vertebrate nervous system. This added mass of nervous matter, which was not, in the beginning of development, necessary to the organism, and which is still unconcerned with the ordinary performance of the most vital processes of the body (although connected with all), may be conceived of as containing innumerable possible nerve paths, formed by the association together of its ex- 
ceedingly complicated cell-arborisations. In them are possible channels of intercommunication in number far and away beyond the needs of an organism for the performance of the acts that are connected with the inherited instincts of the species. The potential nerve paths of the brain, are at first of equal resistance; through them sense perceptions may find their way and responses may wear their channels until all the main highways become established in experrience.

The external world rains down its innumerable stimuli upon the organism. Those stimuli that are related to experience have the

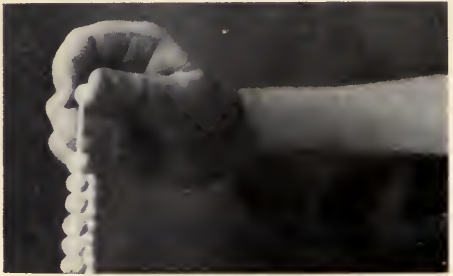

FIG. 273. The hand of a little girl. right of way, and determine action. The experiences that accompany action are retained in the organism to augment or modify or inhibit further action. Discrimination between stimuli improves with the varying of experience. Discernment of the relation between cause and effect follows, and this may determine choice of action; at first the choice is based on the expected immediate good or ill results; later, on the more far-reaching consequences of the act. Morality comes in here.

In both body and brain man is at birth far more poorly equipped for the struggle for existence than any other animal. He has no defensive armor to ward off attacks of enemies. He has no formidable bodily weapons, teeth, fangs, claws or horns, to make them fear him. He has no equipment of inherited behavior sufficient to insure his safety. His new born spontaneity of movement is confined 
to two acts both of which are directed toward self preservation and not toward defense; these are sucking and grasping. He has, however, a brain, that, when rightly developed, is capable of supplying all these deficiencies. And he has a long period of infancy-far longer than that of any other animal-during which to develop it . Relieved by parental care from the necessity of immediately entering upon the struggle for existence, he has time to learn, to feel and to do, to discriminate and to act, to sift and to try an endless variety of experiences and to learn both wisdom and discretion. Infancy, although it be playtime, is in man and animals alike, a time of preparation for the serious business of life. Play is but practice for the game of life.

Language.-Man is the only animal that talks. Birds chatter and sing; insects chirp and hum; fiddler crabs gesticulate, and dogs have many ways, familiar to every one, of expressing their feelings; and the rudiments of language are doubtless in the signs and calls which are a part of the social habits of animals. "Actions speak louder than words." By many sense impressions of an object or an act man may gain a conception of its qualities, and then he is able to conceive of the qualities severally, and,apart from the thing possessing or manifesting them. From seeing swiftly moving objects, he may conceive of swiftness in the abstract, and then he may use a word to symbolize that conception. Whether a dog or any other animal may conceive of swiftness apart from a swiftly moving object seems highly improbable.

The first words used may have been such calls to companions as two persons unacquainted with each other's language, might today agree upon. Or, they might well have been vocal signals such as men use when acting in companies to secure co-operation. "All together-hee-o!" is such a combination of words and verbal rudiments as we 
often hear on the streets, spoken by the leader of a group of laborers. The efficiency of such symbols depends upon their being understood; there must be general acquiescence in their use.

How words, as condensed and convenient symbols of experience, have aided mental development has recently been well expressed by a British physiologist, Professor Starling, as follows:

"A word is a fairly simple motor act, and produces a correspondingly simple sensory impression. Every word, however, is a shorthand expression of a vast sum of experience, and by using words as counters it becomes possible to increase enormously the power of the nervous system to deal with its own experience. Education now involves the learning of these counters and of their significance in sense experience; and the reactions of the highest animal, man, are for the most part carried out in response to words, and are governed by past education of the experience-content involved in each word."

Without language one may profit by the experience of others only to the extent that he is an observer of that experience; but experience symbolized in words may be dissociated from the individual and told abroad.

Tool using.-Man is the only animal that uses tools. Monkeys will throw down cocoanuts from trees in imitation of or response to stones thrown up at them; and a little wasp Ammophila uses a pebble held by her jaws to pound down the soft earth over her completed nest. But even so simple an idea as the using of a club for defense appears not to have emerged in the mind of any animal. Man, however, had both more need to supplement his weak powers, and more range for adaptive action provided in the accessory circuits of his brain. 
The earliest human tools were very simple; a club, a flint stone; such things as might be selected from nature already fitted to the hand. Better tools followed when a little labor was added to their preparation. A split stick lashed to the flint gave a stone ax; and splitting and sharpening of the flint yielded stone knives. A great variety of tools of stone and wood and bone and horn followed; and, later, tools of bronze and of iron. Indeed, the kinds of tools mankind has used furnish a fair index of the progress of the race. Cutting tools especially have been made the basis of ethnological classifications.

The use of fire.-Man is the only animal that uses fire. Many animals undoubtedly enjoy the glow of its warmth; and some of our domesticated animals appear to be sensible of the improvement it makes in the cooking of food. But no animal has attained to the idea of adding a stick of wood to keep a fire burning.

Fire was the first of nature's resources to be pressed into human service. Its use appears to have. been known to all races and tribes of

FIg, 274. Primitive tools. $a$ a chipped flint of very ancient form. $b, c, d$, flint knives of improved design. e. a flint arrow head. $f$, a flint spear head $g$, a bone fish hook. $h, i$, bone needles. $j$. a wooden bowl $k$, a wooden comb. $l$. a necklace of teeth and claws.
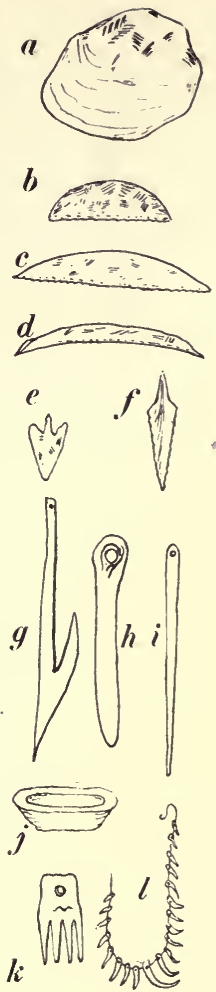
mankind, throughout human history. It served primeval man in many ways. It increased his physical comfort. 
It bettered his rough food. It warded off the beasts by night. It aided in the preparation of his crude tools-the shaping of his club and spear, the splitting of his flints, etc. It hollowed the log that was thereby transformed into a canoe-his first conveyance.

The physical comfort of the fireside glow man shares with his animal friends; he differs from them in the foresight that anticipates future needs, and provides the means to gratify them. Even with all our modern improvements in heating appliances we cling to the open blaze with a love that is born of primeval experience.

The use of fire for cooking may have been first learned by the accidental discovery of the greater palatability of flesh or of tubers that had been roasted in wild fires. Doubtless the earliest modes of cooking were roasting over the open fire and roasting in hot ashes. Water was first heated for the boiling of food by the addition of hot stones to the vessels containing it; it is still so heated by certain North American Indians. The earliest water vessels were shells, as of cocoanut or gourd, and the crania of vanquished enemies; and the boiling of food over a fire had to wait on the invention of fire-proof vessels. The first of these were earthen vessels, which were later succeeded by pots of bronze and of iron.

\section{Unwritten human history}

The sources of our knowledge of the evolution of the human species are the three "great historical documents" already familiar; palæontology, phylogeny and ontogeny; but for these as applied to man there are special names to be used. There is in the case of men and animals an actual record of the past, incomplete but indisputable. It is preserved in the bones and teeth and armor of animals and its study is known as palæontology. It is 
preserved in the weapons and defenses that man has substituted for fangs and claws and armor, and in the imperishable products of his hands, and its study is known as archeology. There is also the same opportunity for comparative study of developmental attainments in men and animals, and for arranging genetic series and deducing history therefrom; for different races of men exist in very different cultural stages. The study of these is called ethnology. The development of the individual is of some historical value also even here, for the corroborative evidence that it may furnish.

Archaeology.-Written history goes back but a few thousand years, but the records of archæology extend back hundreds of thousands of years further. The oldest extensive series of human remains have been found in the interglacial deposits of the ice age. These consist of man's own skeleton, his tools and the charred remnants and ashes from his fires. They are found mainly in caves, associated with the bones of cave-dwelling animals. The extinct cave bear and the mammoth were his contemporaries, the former being his competitor for such shelter as caves afforded. His tools at this period were few, and of the simplest sort; chipped flints, a club, a sharpened bone, etc.

The objects of his home environment were such as bestrew the lair of the wild beast in similar situations - chiefly the remains of his feasts, the most imperishable things being the bones of his victims. Among these are found human bones, split ingeniously for the ready extraction of the marrow-a choice morsel of his diet. It is not an attractive picture of the life he lived that these facts suggest. It differed from that of the cave dwelling beasts chiefly in the use he made of tools and of fire. There is a faint promise of his later attainments in the marks of scanty workmanship found upon his tools. 
We can not go into the fascinating story that is written in the remains of later date; the slight changes of his skeleton, and increase of cranial capacity; the improvement and diversification of his tools of flint and wood and bone during the Age of Stone. (when the use of metals was as yet unknown); the development of implements, and of articles for personal adornment, and the beginnings of art; the vast changes in his material equipment during the succeeding ages of bronze and of iron. No written account of these records of human progress can be equal in value to a thoughtful visit to any good museum of antiquities, in which the archæological exhibits are arranged in evolutionary sequence. The cruder materials with which archæology deals, although much neglected in the past, have come to be appreciated as among the rarest of human treasures.

Ethnology.-As amœbas continue to exist on the earth along with men, so savagery and all intermediate conditions persist, along with the most modern types of civilization. And as the primitive forms of life are restricted to the places that are left unoccupied by the dominant types, so the more

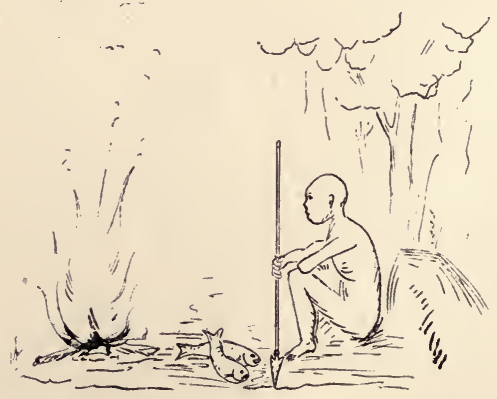

Fig. 275. Man 
primitive types of culture are relegated to the out-of-theway places of the earth. Comparative ethnology, therefore, has had the same kind of opportunities as comparative anatomy, and has made use of them with similar results; i. e., cultural types have been described and classified. Similarly, also, the different systems of classification have not always been in agreement. A simple grouping based on the main features of man's methods of getting a living from the earth, will answer our present purpose. It recognizes four principal stages in human progress: I) the hunter stage; 2) the shepherd stage; 3) the artisan stage, and 4 ) the inventor stage.

The earliest of these is the hunter stage. It comprises that long period during which primitive man lived upon the products of nature, lived as a freebooter, picking from the wild, cultivating nothing for food. He was less provident than the squirrel or the ant, and far less industrious. He was satisfied when present needs were met, and accumulated nothing. He built only the rudest shelter, at the first wore no clothing, and had no society. His food was doubtless not very different from that of the cave bear, with which he was a competitor; the flesh of animals and the fruits and roots of plants; perhaps, also, with an occasional feast of wild honey. His early home was by the waterside, and fish were a most dependable part of his living. Fish he could catch by hand, or, better, with a bone hook, or with a spear. It was easier to spear

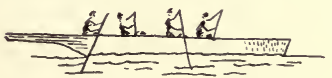

FIG. 276. Co-operation. fish from a floating $\log$, and a hollowed log with a pole for propulsion was probably his earliest conveyance. Larger canoes demanded more hands to propel them: and in the propelling of these, and in the driving of the fish upon the shoals may have begun cooperative labor. Cereal grains, 
especially rice and barley, early becamc important food stuffs, and with the stone mortar for grinding grains household arts may be said to have begun.

The pastoral stage is ushered in with the beginning of the domestication of animals and the cultivation of plants. When man tamed the wild things, some of them rewarded his care by furnishing him with a larger and more dependable food supply. Thus foresight grew, and agri-

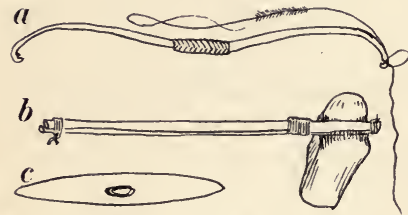
culture began. The possession of fields and folds made for settled homes and for social organization. An abundant food supply could support a larger popula-

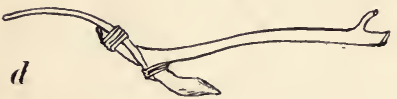
tion. The history of nations begins here.

The first agricultural implements were crude

FIG. 277. Primitive implements. $a$, a bow (California Indians). $b, a$ stone $a x$, with enough. The first mill split wood handle. $c$, a wooden shuttle. $d$, a wooden plow.

was a stone mortar; the first plow was a crooked stick, the first apparatus for weaving of fibres or hair into cloth was a wooden shuttle. With better food supply, less time was required for obtaining a livelihood and the energies thus set free were available in some measure to be devoted to the perfecting of the finish of manufactured products and the development of the fine arts.

The artisan stage naturally followed upon the development of increased food supplies; for exchange of products began, and commerce demanded wheels and keels. Improved tools of metal were needed, and artisans, of various sorts, to use them. Money came to be used as a medium of 
exchange, replacing the barter of products that was characteristic of the pastoral stage. Men began to gather into cities. In preceding stages all men were engaged in much the same pursuits, but now they differentiated, one man producing articles for the use of the others, and receiving the products of the others in exchange.

Finally, came the inventor stage. The forces of nature were harnessed to do men's work. Artisans largely gave place to operators of machines. Production was vastly increased; population grew apace. The exigencies of commerce demand the centralization of lines of communication and of transportation and thus cities grow. And the end of this is not yet.

Doubtless the earliest of these periods was most extensive; the night of savagery was long and the dawn broke slowly. But it was a period of physical perfecting and of sound beginnings of mental improvement. During the long struggle with animals, better equipped by nature for fighting, man had to match their strength and cunning with his wit. Thus he gained good eyes and ears, a supple frame, quick muscles and strong sinews, hands that could control weapons with deftness and precision, and above all, a brain that could turn to advantage the circumstances of his environment. The elimination of the unfit was then most rigorous. The savages of all dominant tribes are fine physical specimens, and it is not too much to say that on this basis of physical fitness all subsequent history is built. The foresight that would put a stick of wood on a fire to keep it going, that would shape a stone for hitting, or that would improve its efficiency by the addition of a handle, marked an enormous psychological departure from the status of the brute. The native taste that shaped an arrow head with symmetry and beauty, or that traced with flint its crude fancy in a picture on bone, had in it the germ of art. Given these, all language, all subsequent history was possible. 
Ontogeny.-From birth onward the developmental phases in man do not help greatly with the unravelling of his history, for they are much altered by environmental influences. But there are many things that are suggestive of a sort of correspondence with phylogeny. The infant is born with hands that are fitted for grasping, and capable of sustaining, his weight. When he begins to travel he goes on "all fours," and it is not until he assumes the erect position

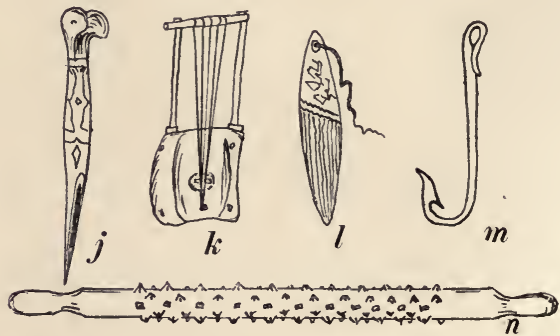

FIG, 278. The beginnings of the arts. $l$, a carved dagger made frum a human bone. $k$, a stringed instrument (Upper Nile). $l$, an instrument to be used against evil spirits (S. Australia). $m$, a bronze fish hook (Lake-dwellers of Switzerland). $n$, an instrument for correcting heterodox opinion, (known as a "spiked roller"; the infidel was t1sually stretched naked upon a rack and rolled vigorously with this instrument, as a means of correcting his beliefs: Germany; Middle Ages). (All after Brinton).

on his feet that he advances in action beyond his four-footed relatives. Relieved of the function of support, his arms learn throwing and striking and pulling. He imitates all sorts of movements, and engages endlessly in play that is imitative of the work of his elders, and that is essentially like the play of other young mammals. At about the age of twelve he appears to arrive at consciousness that he is a part of a community; for he begins to play with his fellows at cooperative games and organized sports; he enters upon team work. 
Ethnic culture stages are rapidly passed through in the experience of his earliest years. At the beginning he is a freebooter, taking what he likes of what he sees, recognizing no rights of property, and doing nothing to produce what he consumes. Then he enters upon the domestication of animals and the cultivation of plants quite naturally and on his own account. He cultivates the good will of his pets and feeds them, and makes them work for him. He plants flowers and vegetables and clearly recognizes ownership in these things. Then he comes to be interested most keenly in tools and in the things he can make with them. At this age he is vastly more benefited by the gift of a jack knife or a hammer than of more complicated toys. An indian's bow and arrow is more to be desired than a repeating shot gun. But soon 'he will aspire to have the complicated toys and the engines and the hand organs. The inventor stage is upon him even before he is entered in school.

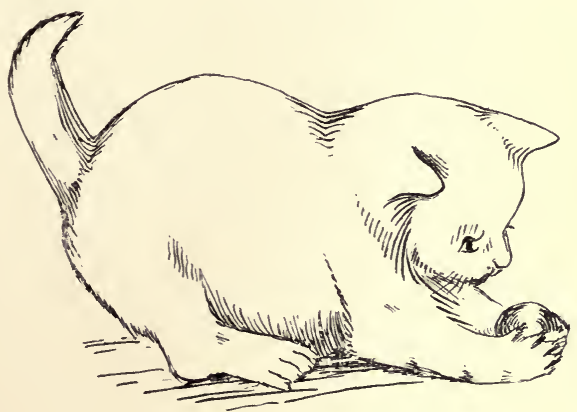

FIc. 279. Play is preparation for business 


\section{The social organism.}

Human history begins in isolation and not in society. Primitive man was a barbarian, and the life of a barbarian is essentially solitary. Probably he made a friend of his dog earlier than of any person outside his own household; for strangers were enemies. And the reason for this is not far to seek. He must have room, or starve. He could not live on grass or any other plant product of unlimited abundance, as do the mammals, that nature had made gregarious

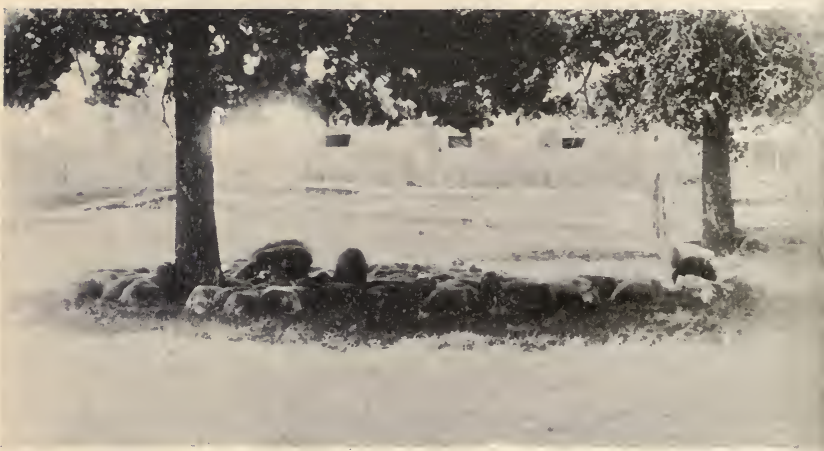

FIG. 280, Typical gregarious herbivores.

(fig. 280); nor had he superior powers of locomotion that would enable him to get about and find widely scattered food products as do the social birds. The households of cave-dwellers were therefore, few and far between*.

Nor are the habits of a barbarian favorable to social life. He eats like an animal when hungry, and waits until hungry

\footnotetext{
*Ethnologists estimate that without any agriculture, it requires sixteen square miles of territory in temperate regions to furnish sufficient available food for one person.
} 
again before setting out to find more food. He is quarrelsome when hungry and lazy when fed, and, being perfectly satisfied with himself, lacks the main spring of progress. The narrow sympathy that in primitive man was born of his parental and conjugal instincts, and that was limited to his family, may have been widened through his dealings with animals when he had domesticated them. The man who will bind up the broken leg of his dog, or pull his ox out of a ditch is more likely to help his fellow man when found in distress. Tolerance of fellow men led to the formation of tribes, which at first were composed of a few allied families. Primitive tribes retain the characters of the individual barbarian; they kill outsiders, and often eat them, and not infrequently they similarly dispose of a part of their own female infants, in order to keep the birth-rate down; the tribe, also, must have room. Tribal societies are ever at war; and wars, besides preventing increase, block progress, destroy property, and curtail desire to do or to build. The beasts were man's first enemies, but since he learned to make efficient fighting weapons, his own kind have been his worst enemies.

The growth of nations may be said to begin with the culti-

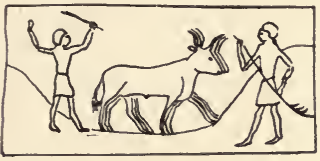

FIg. 281. Threshing scene. From a
painting on the wall of an ancient Egyptian tomb (after Brinton). vation of plants in fields. This made for settled homes, for the establishment of property rights, and of law and order (within narrow limits), for the development of knowledge, and for the accummulation of the means of livelihood that should set men's hands free to do something besides meeting the needs of the hour, and their minds free to forecast future needs. Unfortunately these needs were too largely needs 
of defence against other nations. For, in the beginning the savage characteristics of their constituent tribes were passed on to the new formed nation. Nations initiate wars to annihilate other nations. Most of the migrations of the human race have been migrations of conquest. Hence, the earlier civilizations of the earth could only grow where a nation could exist in comparative isolation. Such places were the desert-bordered valley of the Nile in Egypt, the mountain-fringed table lands of Mexico and Peru, etc. They did not grow in the earth's exposed areas, such as the Mississippi Valley, although the works of the mound-builders show that great constructive efforts once started there. There was security only in isolation until the growth of a broader sympathy and the dawn of a more constructive social spirit.

Socially, primitive man was unspecialized. Aside from differences of the sexes, there was nothing preformed in his bodily organization determining what should be his relations to other individuals of his kind. There was no preformed division of labor as in bees; there were no castes, as in the ants and the termites. He came into possession of no particular modes of social activity by inheritance. If he attained to social co-operation he had to acquire it for himself. But he possessed speech; and speech wondrously facilitated cooperation and the exchange of experience and the comparison of old ways and the development of new ones, and conditioned further development. And he possessed laughter - a fountain of social responsiveness, and a means of extending sympathy and developing comradeship surpassing speech. And the primary demand of social progress is sympathy, and good will toward men.

Animism. Animals live in a world of sense perception, but man has always lived to a greater or less extent, in a super-sensual world-a world of ideas. In language man 


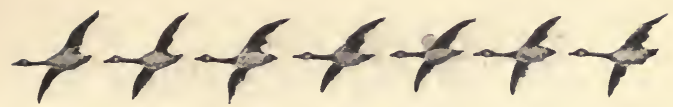

Frg. 282. Social co-ordination.

crystallized his concepts and gave them currency. They were concepts first of the things he saw and then of their properties; also, of the things he imagined, and then of their imagined properties. Having attained to a discernment of the relation between cause and effect, his mind demanded explanations of the things in the world. Any explanations were better than none. When he had gained ascendency over the powers of the animal world and, by the establishment of the rudiments of agriculture and household arts, had forefended himself against immediate want, he took to thinking the great problems of birth and death, of times and seasons, and of the heaven and the earth were before him.

He was interested in the relation between his own body and the breath or spirit that animates it; and out of the consideration of this problem, he evolved ideas that, more than any other, have dominated all the intratribal social intercourse of subsequent history. He conceived of a spirit of like form with the body but impalpable and separable from the body, that goes a-wandering from it in dreams and trances, but returns again; and that leaves the body at death to wander elsewhere as a disembodied spirit, or to take up a new abode. He conceived that animals also possess kindred spirits and he wore the teeth and claws of

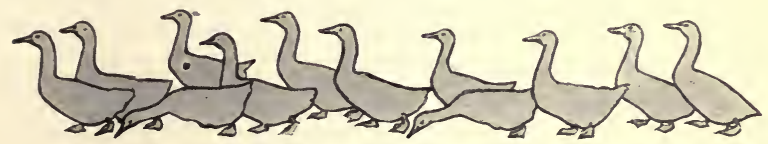

FIG. 283. General sociability. 
ferocious beasts in the belief that thus he assumed their powers. His imagination peopled the world with spirits; mostly evil ones, with fearful powers for harm, demanding to be propitiated by sacrifices, offerings or worship, or controlled by magic. These spirits might enter in to human bodies, producing demoniacal possession, witchcraft, disease, or death. This, in brief, is animism. It appears to have been the earliest form of both philosophy and religion of all savage tribes. It has practically no moral purpose or effect. It appeals mainly to men's fears; for although it peoples the world with both good and evil spirits, the evil ones are mainly worshipped, because fear is a more powerful emotion than reverence.

Some of the specialized manifestations of animism are, I) Spiritism, the belief in the existence of free spirits: ghosts, etc. 2) Fetichism, the belief that the spirit resides in an object, which then becomes a fetish, and is treasured for the magic power it possesses; charms, etc., such as the rabbit's foot, the old horse-shoe, and the four-leaved clover. 3) Magic, the belief that the spirit is controlled (or that some supernatural result is wrought) through the performance of some act. 4) Ancestor worship, the belief in the presence and supernatural power of the good spirits of dead ancestors, etc. A little study of the harmless survivals (psychic vestigial relicta) of these things should be convincing that animism has left its permanent records with us, and that these records are of interest and value as landmarks of an evolving culture.

\section{Study 64. The survivals of animism in our own times.}

The materials for this study will be furnished out of our experience, and out of the behavior of the people we have known. Illustrations of fetishism and of magic will be most available. A dozen or more examples of each of these 
should be subject to recall in the memory of any observant person. Perhaps a comparative statement will bring into relief their main characters. The following form is suggested:

FETISHES.

\begin{tabular}{c|c|c|c}
\hline $\begin{array}{c}\text { Potency } \\
\text { resident in what }\end{array}$ & $\begin{array}{c}\text { Conditions of } \\
\text { its efficiency }\end{array}$ & Effects & $\begin{array}{c}\text { Attendant } \\
\text { manifestations }\end{array}$ \\
\hline Ex., a mad stone & $\begin{array}{ll}\text { laid upon the } \\
\text { wound caused } \\
\text { by mad dog }\end{array}$ & $\begin{array}{l}\text { cures } \\
\text { rabies }\end{array}$ & $\begin{array}{l}\text { sticks a longer or } \\
\text { shorter time to the } \\
\text { flesh, according to } \\
\text { the extent of the } \\
\text { evil influence to be } \\
\text { overcome. }\end{array}$ \\
\hline
\end{tabular}

MAGIC.

\begin{tabular}{|c|c|c|c|}
\hline The act & Conditions & Effects & $\begin{array}{c}\text { Belief of what } \\
\text { people }\end{array}$ \\
\hline $\begin{array}{l}\text { Ex., crow- } \\
\text { ing of a cock }\end{array}$ & $\begin{array}{l}\text { at the front } \\
\text { door in the } \\
\text { morning }\end{array}$ & $\begin{array}{l}\text { will bring com- } \\
\text { pany d uring } \\
\text { the day }\end{array}$ & $\begin{array}{c}\text { Scotch, } \\
\text { English, etc }\end{array}$ \\
\hline
\end{tabular}

Nowadays we hold magic and charms in so light esteem, that we are apt to overlook the tremendous importance they have had in the past. Our language and literature and history are full of them. Our clothing drips with them, for it grew out of them. Is there not a place for a charm on a watch chain? and what is a locket but a case for some sweet magical thing like a lock of hair, that may be worn next the believer's palpitating heart? Betimes, we lay aside our seriousness and have a little romp of childhood in this intellectual haymow of stored primeval experiences. Especially do we this at holiday seasons, when the emotions rule and when dormant racial instincts waken easily. We hang the mistletoe at Christmas tide, and at Hallow-e'en we indulge 
in all sorts of absurd divinations. We tell fortunes. We consider signs. We give birthstones. We tell ghost stories in the dark - the primeval setting, and the condition that stimulates the latent racial emotions which we wish to recall in diluted and enjoyable form.

But these are matters serious enough to many of our own population; witness the advertising columns of the necromancers and magicians in any of the Sunday newspapers. And we do well not to forget with what tyranny such ideas have held sway over our entire race during most of its history. Selfish and vainglorious magicians and sorcerers and healers have been able, through appeals to fear, to practice great oppression, and to add a grievous burden to the sins and miseries of all savage peoples. The earliest records of all races are full of this. Happily, they tell also of prophets and seers who have risen to point out truer relations between cause and effect, and of great leaders who have sought to free men from the bondage of superstition, and of teachers who have labored to dispel ignorance-its cause.

Besides wars and superstitions, there are yet other troubles of his own creation that have vexed man throughout his history. He has never been satisfied with food, but has always and everywhere wanted something added to his diet to excite or modify the action of his nervous system. Opium and alcohol are typical of these; and the use of stimulants and narcotics has added and is still adding enormously to the vast sum of human misery in all naticns.

Nor has he ever anywhere been clothed with the utmost possible comfort and convenience. Dress was originally for charm bearing, for ornamentation, or for sign of rank or station; and it is little modified from its traditional functions by considerations of comfort. Every improvement in methods of getting a livelihood that has set men's hands free from constant toil and given time for thought, has 
made opportunity also for the growth of social habits without thought. In the social organism, as well as in the physical, things have run their course unchecked by environing conditions. Traditions are usually cherished quite irrespective of their usefulness.

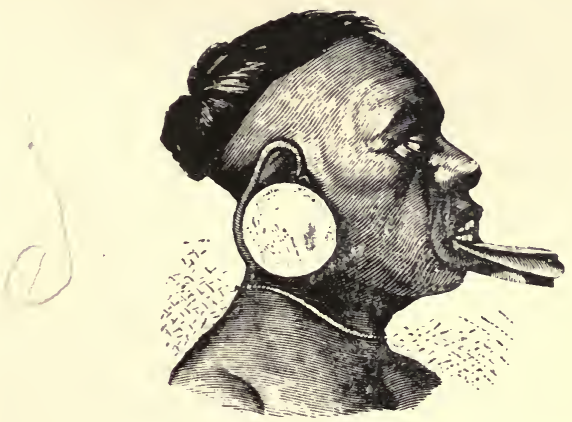

FIG. 284. A stylish young Botocudo Indian (Brazil). Psychological orthogenesis. (After Brinton).

Social integration.- Society is first an aggregate and afterwards an integrate of human beings. The social organism has followed the same developmental methods that have perfected the multi-cellular body, and made of it an integrate organism. Ancient history is filled with endless experiments at social integration. The parts brought together at first lacked the essential bond of mutual dependence. They were alike save for the differentiation of the sexes, and each man, or at least each family, was. capable of getting along alone. Differentiation and division of labor was necessary here as in the physical organisms to create the need of one part for the complemental parts that should bind all indissolubly together. 
Differentiation occurred in strict accordance with the physical needs of men, which are the same as those of animals - needs of food and shelter and defense against enemies. Hence the earliest of callings are those of hunter and fishermen, soldier and scout, shepherd and husbandman, builder and weaver, etc. Precise fitness of any of these callings involved loss of fitness for the others, and made the specialist in one more or less dependent on all the others for that part of his living that he could not so well provide for himself. The primary condition of social integration is mutual dependence.

Social stability demands coordination. The parts must function harmoniously, so that the actions of any or of all shall be made subservient to the welfare of all. This demands r) intercommunication between parts, and 2) the development of centers of control. Intercommunication is primarily needed for exchange of products. Therefore, as the physical organism develops circulatory apparatus, so the social organism develops channels of trade. Are they not popularly characterized as "arteries of commerce"? Means of sensory communication are next needed; and as the physical organism develops nerves so the social organisms develops postal and telegraphic lines. And do we not hear these fitly spoken of as "nerves of intelligence"? Control centers in the physical organism arise, as we have seen, where nerve cells are gathered together to form ganglia; and similarly in a nation they develop just as naturally wherever those individuals live who assume the function of coordinating and directing the activities of the whole body politic, (councils, directorates, congresses etc.). And are not these also with some propriety often called "centers of trade, of culture, or of government"?

When organization has proceeded to the point of establishing control centers its efficiency depends on the concurrent 
development of such organs of outlook as are capable of giving knowledge of the outside world, and the maintenance of such mutual responsiveness and adaptability of parts within as will admit appropriate actions in response to the things discerned. The watchman in the tower is as the eye of primitive society; and equally so are the explorer and the investigator in later times. As the body is profited by its distance receptors, so society is profited by its seers and prophets of truth. It is natural, therefore, that with later specialization, groups of individuals should have been set apart. from the ordinary avocations to serve scciety as watchmen, devoting their energies to scanning the face of nature and to the discovery of the principles of science. The scientific centers are as the eyes of a nation.

But eyes are merely receptors; the effectors or rulers are elsewhere in the body. Given good eyes, fitness of reaction yet depends on the discriminative powers and the capacity for correct coordinated responsiveness of the organism as a whole. It is possible that the worst of actions may follow upon the best of vision. Society is not bound to progress. It may go forward, or it may halt, like a salamander that stands blinking at the light, and then runs back to its hole. So in our own time it seems to be blinking at the question of international peace.

Society makes progress as its constituent units become clear in perception united and correct in discrimination and inference, and concordant in action. The parts must not only act together (harmony is not all that is necessary); they must act together in profitable ways.

Social conduct. The individual begins life as a single cell, and has first of all to run over in ontogeny a course in phylogenetic history that is enormously long. This, however, is quickly passed. A sound body and well organized animal instincts are his by right of birth. He has yet to 
retrace the course of human development; and this though comparatively short, is beset with difficulties; for his art and science he must for himself acquire. Nature will make of him only a barbarian; nurture must make of him a citizen.

He must first of all acquire the methods of education. He begins with trial and error; but this method is too slow, too uncertain in its results, and too apt to cultivate ways of going elaborately wrong, alongside of those which go right. He must learn to imitate, and must learn by initiation. He must learn to do, or not to do, as others do. By these means he lays a broad basis of personal experience. By these means he is made fit for social intercourse. For so he learns the signs in which racial experience is expressed: gestures and attitudes, manners and customs, and, most of all, words. The circumstances of his nurture compel imitiation. Only the same signs that others use will be understood. And by continual imitation he establishes automatic habits like those of other members of society. His social conduct takes on forms that are like to the instincts of animals in their fixity, and he becomes a fit and acceptable member of society. The moral person is he whose acts are in accord with the accepted rules of conduct for the community.

But society is an organism, and therefore adaptable. Just as there are common emotions, ruling as with an iron hand the general conduct of the people, so also there is a common intelligence that may find better modes of action. It may seem at times to exert but little influence. Appeals to instinctive habits always bring tumultuous responses; for racial nerve paths are thoroughly well broken for stimuli to eat, to drink, to fight and to indulgence of the baser passions; and the plea for better things, may often seem to fall on deaf ears. The prophets and seers who 
have sought to extend public vision may at times seem to have labored in vain. But in the social as in the physical organism, in the long run, intelligence wins.

Trial and error was at first the sole method of progress; but society learned to imitate and has improved by imitation; and it has learned to initate new activities and to inhibit old ones by reason of clearer discernment of the truth. We no longer piously burn witches, or beat lunatics to drive the devils out of them.

Society, therefore, having taken stock of its experiences, has instituted some integrating forces of its own. Education is the chief of these: universal education; for organic health is impossible unless all the parts of the organism be properly responsive to common needs. Instruction now brings within reach of the individual the best things of racial experience, both past and present; and if there be discernment, practice develops in him the appropriate modes of action. 



\section{APPENDIX.}

I. Preliminary outline on lenses, lighting, focusing, covering, finding, etc.

I. The crystalline lens of the eye is adjusted by change of shape, effected by voluntary muscles. Hold a pencil between the eye and a distant window and try to see pencil and window sash at the same time, Note the distinct muscular effort within the eye at each shift of vision from one object to the other. Repeat with the window sash and a tree on the horizon.

2. Artificial lenses, being of permanent shape, are adjusted or focused by change of position, altering the distance from the object. Move a large simple lens forward and backward between the eye and the letters of a printed page until a clear and enlarged image of the letters is obtained. Note that there is but one place of clear vision: at this place the lens in in focus. Observe whether two lenses of different size focus at the same distance from the page.

3. Catch the nearly parallel rays of light from a distant window in the larger lens, and focus them on a sheet of white paper held behind the lens. When focused, a clear miniature picture of the window will appear upon the paper. Measure the distance from the optic centre of the lens to the paper; this is the focal distance of the lens. Try the other lens and determine its focal distance. The curvature of the surface of a lens mainly determines its focal distance, and also its magnifying power. The magnifying power of any simple lens is easily computed by the following formula: $\frac{10}{f}=M$, wherein 10 is ten inches, the focal distance of the normal, unaided eye, when viewing small objects, $f$ equals the focal distance of the lens in question (measured as above), 
and $M$ equals the magnification. Substituting the values you have found $f$ to have for your two lenses, determine their magnification.

4. The objective of the compound microscope is practically a simple lens. Take the shorter of the two objectives in hand and examine with it the stippled background of a printed halftone figure (such as figure 2, on page 8 in this book). Then try the longer objective, and observe the shortening of focal distance with increasing magnification. Obviously, we soon reach the limits of practicability of simple lenses.

5. Hence, the compound microscope, with its eyepiece for magnifying the already enlarged image produced by the objective. Examine again the half-tone stippling with the low power objective used as a simple lens and note the apparent size of the stipple marks; (Better use for this and the following a detached slip of paper printed in halftone, for convenience in placing under microscope) then attach this objective to the microscope, insert the longer (if there be two) of the eyepieces in the top of the microscope tube; place the stippling on the stage directly under the objective, focus and again note the apparent size of the stippling. The magnification of the compound microscope is determined by multiplying that of the objective by that of the eyepiece. Suppose that your objectives are of two-thirds inch and onefifth inch equivalent focus, and your eyepieces, of one inch and one-and-one-half inch, respectively: what will be the magnifying powers of the four poisible combinations?

6. Observe the effect of pushing in and pulling out the draw tube of the micruscope on the apparent size of the object. The lenses of the usual laboratory microscope are corrected for (and so, will give the best results with) a tube length of 160 millimetres. 
Uncontrolled refraction of light rays, producing distortion of image.

I. Dip the front of a simple lens in water, and, without wiping it, look through it in the letters of a printed page. You have altered the curvature of the surface first met by the rays of light coming from the print, deflecting them out of their proper course.

2. With the low power objective in place on the microscope and clean, the eyepiece in place, and some object clearly in focus, touch the front of the objective lightly with the moist finger, and observe how the appearance of the object is altered. The fingers are never optically clean. The slightest deposit on the surface of a lens disturbs its refracting harmony. Do not touch the glass of your lenses with the finger again, nor with anything else, except on the occasions (which will then be rare) when it necessary to clean them.

3. To clean a lens, moisten it with the breath and wipe dry with soft lens paper (or with a very soft old linen handkerchief); when more than this is needed, take it to the instructor.

4. Place a little tuft of green algæ upon a slide, wet, and examine it with a lens. Then lower a cover glass upon it, fill up beneath the cover with water and examine again. The cover gives the flat upper surface that is necessary to prevent uncontrolled refraction and distortion of image. Complete immersion in a watchglass of water would give a similar result. You cannot well examine an object half wet and half dry. Dry objects may be examined with low power lenses uncovered, but you must always use a cover glass with the high power objective.

5. Air entangled under the cover glass is a frequent source of trouble. The air may cling to the cover-will be likely to do so if the cover be dropped flat upon the object. 
Breathe upon one side of the cover to moisten it, and let down with one edge in advance of the other.

6. The air may cling to the object. For exampl mount a dry thread in a drop of water, cover and examir with low power. Alcohol may be used to remove the ai Remount the thread in alcohol; cover, allow a little time soak, and observe the disappearance of the air. Air bul bles are generally present in freshly mounted slides, an must be recognized, and not confused with structure Note the peculiarities of their refraction at different foci, an learn to recognize an air bubble instantly.

\section{On locating dirt that is in the field of vision.}

I. It may be on eyepiece, objective, slide, condenser mirror. To tell whether it is on the eyepiece, rotate the ey piece while looking through it; if there, the dirt will rota with the eyepiece.

2. To tell whether it be on the objective, change focu if there, it will give the same obscurity at all foci.

3. If it be on the slide, it may be located by moving th slide or cover; it will move with the slide, and may readi be focused upon; the two sides each of slide and cov offer four levels at which it may be found. There is $n$ excuse for using dirty slides or covers, or for allowing di upon condenser or mirror, where it may be directly observe and whence it is easily removed.

\section{On the use of mirror and diaphragm.}

I. Learn the use of the mirror: I) by trying both side of it; 2) by trying it in different positions of the swingin mirror bar; and 3 ) by taking light from various sources, a the wall, the ceiling, the curtain, the sky. Then keep th mirror bar vertical, and use the flat side with, the concav side without, a condenser. 
2. Using a slide of algal filaments, mounted and covered as before, examine some favorably exposed green filaments, using all the sizes of diaphragm you have available in succession, and finally using no diaphragm at all, observing the while the relative distinctness of the green chlorophyl, and of the clear transparent cell wall. Thus you should learn the advantage of stopping out the excess of light.

\section{Cn the use of the higher power lenses.}

I. In rapid focusing, while finding an object under the compound microscope, never run the objectives downward while looking through the tube: for thus you would sooner or later jam an objective into the cover glass, possibly breaking both. The objectives as well as being the most expensive part of the instrument, are the parts most easily abused. While looking from the side, push the objective down close to the object (close enough to be within the focal distance of the objective, previously determined); then place your eye to the eyepiece and draw up slowly till the object is somewhat visible; then finish focusing with the fine adjustment.

2. Determine the actual size of the field with the different combinations of lenses available, by examining a mounted strip of paper printed with fine and regular halftone stippling (better mounted in glycerine and covered) with them successively, and observing the extent of the stippling included in the field with each. Thus you may determine what combination will be available for the examination of objects of different size.

3. Learn once for all how to find an object speedily and certainly under the high power objective; proceed as follows: find the object or the part of it desired, first with the low power objective; then place the part of it to be examined with the high power in the centre of the field, change 
objectives by turning the nose piece, and focus, observing whether the lens must go up or down, and how many turns of the fine adjustment screw. If the two objectives are exactly concentered, nothing further will be necessary. If not, an object placed in the centre of the field with the low power may not be in the field at all with the high. To find where it is reverse the process. Pick out some easily recognizable part seen under high power; change objectives again, and see where it lies in the low power field. Here will be the place to put an object, in order to find it again under high power. Always begin hunting it with the low power. If your objectives do not happen to be concentered, the above process may have to be repeated every time an objective is loosened and its position changed. Practice finding things with high power until you can do it quickly and certainly.

Practical points in the use of miscroscope and of stage mounts.

I. Save your eyes, by proper use of them. First focus; then look.

2. Look through the centre of a lens, not through its edges.

3. Look with both eyes open, concentrating attention on what is before the one, disregarding what is before the other; this will save much weariness of many facial muscles, when once an acquired habit.

4. Never rack the microscope tube downward while looking through it.

5. Always use a coverglass with a high power objective.

6. Wet objects should be completely immersed for examination.

7. A cover glass has several mechanical uses: a) Mounted objects of some kinds (such, for example, as fully 
mature spermaries of Chara) may be crushed beneath it and their parts scattered, and dissociated for study. b) Many objects not too flat may be turned over, or rolled into new positions for observation, by pushing on the edge of the cover.

8. Drop Cultures for germinating spores, etc., are made upon cover glasses. A drop of culture fluid is placed on the middle of a cover which is then inverted and laid over the open well in a hollow ground slide, or over a ring of thick wet blotting paper, where it hangs suspended in the center. The slide is then kept under proper conditions in a moist chamber of some sort, and is replaced on the stage of the microscope for examination at any time without disturbance of the culture.

\section{On the dissecting of any of the larger animals.}

r. Learn to handle your tools, forceps, scissors, scalpel and needles, and to depend on them for results; hacking to pieces is not dissecting.

2. Open the body cavity where access is easiest and damage to internal significant parts is least likely to occur. This will be the dorsal side in worms and arthropods, and the ventral, in vertebrates.

3. If delicate parts are to be seen, immerse under water, which will float them into better view.

4. Be careful not to cut into any organ whose contents will roil the water and hinder observation.

5. Fully expose the organs to be observed by pinning the flaps of the body wall out of the way as by pinning them to the bottom of the dissecting tray.

6. Know what you are looking for, but do not be too easily convinced that you have seen it. 


\section{Concerning laboratory drawings.}

Draw the thing as you see it, but first be sure:

I. That you see the right thing; don't draw dirt or air bubbles.

2. That you see it in normal condition; look your material over, and make sure what is normal; and then don't draw distortions or freaks.

3. That you see the significant things; and then don't draw endless repetitions, such as whole sections of similar cells-but represent those things that mean something to you.

4. Don't draw what you can't see.

5. Draw with as few lines as possible (smearing with a pencil is not drawing); shading is usually unnecessary.

6. In starting a drawing, look to proportions; usually there are a few main structural lines discoverable, and if these are first laid down with a little care, a well proportioned drawing is easily built upon them.

7. Use mechanical means, especially for diagrams, when the subject admits of it; forms, or a compass for making circles, and a ruler for parallel lines, etc.

\section{Materials for practical studies.}

A few suggestions are here made as to useful ways of handling the materials that are less familiar to the experience of the average laboratory student at the present time.

On collecting and concentrating aquatic organisms. A very simple and inexpensive outfit will procure these organisms in very great variety and abundance, and with little expenditure of time.

I. A cone-shaped dip net, some four inches in diameter, on a long light handle. The cone may be made of fine swiss, of China silk, or, better of no. I 2 silk bolting cloth. Swept through the water the plankton is swept into the point of the 
cone, and is easily transferred therefrom to a beaker of clean water by everting the cone on the tip of one's finger and washing it off in the beaker.

If a more expensive net is allowable, a plankton towing net a yard long of silk bolting cloth, that may be drawn from the end of a long pole, will gather the material faster and will be better for use in open water, but not for use in the little openings along the shores.

2. A few small strainers of different mesh, for sorting organisms according to size.

3. Some sort of concentrating apparatus for getting the organisms together so that a number of specimens may be obtained with each drop of water taken up with a pipette. An excellent one may be made as follows: Fold a piece of fine-meshed cloth (bolting cloth, preferably) filter paperfashion, and place it in a small funnel. Set the funnel in a jar level full of water with a mouth wide enough so that the point of the cloth in the funnel will be immersed half an inch. Set the jar in a larger vessel to catch the overflow, and then pour the water containing the organisms into the funnel until the desired concentration has been reached. A rubber hand bulb on a glass tube will be of assistance in transferring. Some such apparatus will be useful for gathering the material needed for. studies IO, I I, I 5, I 6, 20 , 46 and 49 .

Collecting of the larger organisms will require a dip net of the ordinary shallow sort, so shaped that things can be examined outspread upon it as lifted from the water. Dip nets will be most useful for gathering the material needed in studies $37,4 \mathrm{I}, 43,48,49,53$ to 58 , and 62 . Here, also, a collecting seine will be more efficient for collecting larger organisms in open water.

A cyanide bottle for collecting insects is easily made from any wide mouthed bottle by placing some cyanide of 
potassium (one fourth ounce more or less for a pint bottle) in the bottom, covering it with dry sawdust (or other good absorbent) and fastening it in the bottom with several discs of thick blotting paper. Gum the edges of the blotting paper discs before pressing them into place. After the gum dries, cork tightly, affix a POISON label, and keep it out of the way of small children. An insect net is a valuable adjunct to the cyanide bottle, but the collecting required for studies $2,3,4,5$, and 59 may all be done with the bottle alone if it be dexterously used.

Swarms and occasions of special abundance should be taken advantage of by one who has to keep a laboratory supplied. It is often possible to get enough of certain kinds of material to last for years at a few strokes of a net, but the opportunity may be a brief one, and not regularly recurring, as in the autumnal swarming of the milkweed butterfly. Such studies as no. 4I may seem to demand a lot of preliminary collecting of material; but with the wide range of material allowed, and the remarkable abundance of all of the types, it may, with foresight, be had with remarkably little time and labor spent in getting it together. For example, one can go to the ledges of stone in the bed of almost any rapid creek in early autumn and sweep up in a few minutes enough black-fly larvæ to last a laboratory a life time.

Permanent cultures of the insects needed for study $4 \mathrm{I}$, and for some of those of study 48 , may be easily maintained in the laboratory. Meal worms or bean weevils may be raised in a closed bin of shorts or of beans, respectively, needing only the occasional removal of the excess of animals and the renewal of their provender. Mosquitoes and midges and certain mayflies from pools may be raised in covered vessels of rain water. 
Eggs of pond snails (Physa, etc.) for study 37 may usually be obtained in late winter by bringing the snails in from the ponds, where they may easily be picked from bottom trash or from floating boards, and placing them in bowls of clean water. Provide them with bits of cress or cabbage or other fresh leaves to eat. Within twenty-four hours the elongated and transparent egg masses will begin to appear, sticking to the sides of the vessel. The vessel should be kept clean, for silt adhering to the gelatinous covering will hinder observation. The egg masses may be divided into small parts and distributed for study.

Planarians for study 42 may be picked from stones lifted out of a clean creek bed or out of the surf on the shore of a lake, or often from the trash in a spring pool.

Carriers for handling the numerous plants in thumb pots needed in study 38 may be made by partly filling any shallow tray with wet sand, and soldering stretched poultry netting of suitable mesh across the top. Set the pots in the sand. The wires will prevent their toppling over, and they may easily be carried back and forth as may be necessary between laboratory and greenhouse (or lighted window).

Grafting wax (for study 44):

Rendered tallow I part.

Beeswax 2 parts.

Resin 4 parts.

Melt together with heat; pour into a pail of cold water; pull (like taffy) until light colored; and put away for use. The heat of the hands will soften it sufficiently for application.

Grafting is to be attempted in spring just before growth starts. Scions are better kept over winter in a cool cellar in moist (not wet) sand, but can be cut, if still dormant for immediate use. Seedlings to be grafted can readily be grown in a garden, but large trees are often available, and wild crab apples, in the woods. The operation of bud 
grafting (budding) is available for late summer, where mature buds are selected for immediate transplantation.

Cone galls needed for study 42 , abound on the tips of the

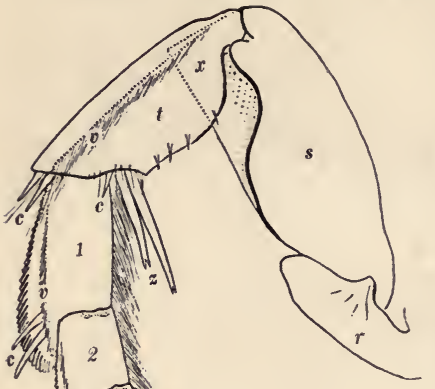
twigs of our common glaucous willows, along streams and in sunny wet places generally. The gall midge larvæ spend the winter in the galls, fully grown, and transform in early spring. If brought into the laboratory any time after Christmas (or after heavy freezing has occurred) they will enter the pupa stage in a few weeks or less and adults will appear two weeks thereafter. Individual lots collected
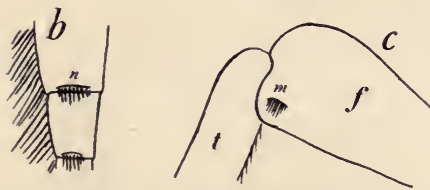
by students may by them be tied up in squares of cheesecloth, and the midges will develop normally

FIG. 285. Diagrams of the leg structures of diving beetles. $A$ the hind leg of Laccophilus. $r$, trochanter. $s$, femur, $t$, tibia. $x$, the overlapping lobe or brace of the femur that lim ts and guides the action of the tibia 1, 2, 3, 4, 5, the segments of the tarsus. $e$, the single claw $c, c, c, c, c, c, c$, jumping spines. $v, v$, swimming fringes, $z$, tibial spurs.

$b$, two segments from the middle of the tarsus, showing at $n$ the little transverse group of apical bristles characteristic of Acilius and its allies.

$c$, the knee joint, showing at $m$ the linear group of setae that is characteristic of Agabus and its allies, $f$, femur. $t$, tibia. 
if the galls be wetted about once a week, (as by holding them under the water tap, or by immersing them for a minute in a bowl of clean water). Data given in chapter I, (pages 44 and 45), will suffice for distinguishing the midge larvæ from their parasites (which are sure to be numerous) and from the other occupants of the galls. (See figure 36 on page 46 .)

A biological garden, while not absolutely required, is the best possible equipment for the sort of a course this book proposes. It need be a little more than a pond or a brook, and a few little border plantings. There should be enough of it for supplying stores of fresh materials for class use, and enough for connecting the work of the student upon living things with the world of which they are a part.

If time can be taken for but one of the introductory studies on the relations between flowers and insects, Study 5 is the one that should te chosen. Full blooming clumps of flowers (preferably of some specialized bumble-bee flower, such as the snap-dragon, the great blue lobelia, butter and eggs, or turtle-heads) will be needed. If not. accessible in nature, they may be easily provided with a little forethought at planting time: all give handsome landscape effects in border plantings.

For the series of ecological studies on diving beetles (studies 55 to $5^{8}$ inclusive), some means of determining the beetles being needed, a key to the North American genera in the family Dytiscidæ is presented on the following pages. The number of our species in each genus is indicated by the arabic numeral standing before the name of the genus (in parenthesis): and limited distribution is indicated by abbreviations for the name of the region in which it is known to occur. 


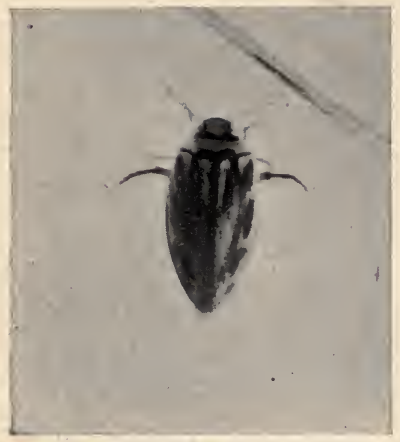

FIG. 286. A diving beetle (Coptotomus inverrogatus). The scutellum is the small triangular piece lying between the bases of the wing-covers, or eleytra.

FIG. 287. Diagram of the venural aspect of a diving beetle (Coptotomus interrogatus) $a$, antenna; $b$, mouth; $c, c$, coxal cavities for the fore and middle legs; $d$, labial palpi; $e$, eye; $f$, maxillary palpi; $g$, lateral margin of the prothorax; $h$, epipleura of the wing cover (elytron); $i$, prosternal process; 1 , metasternal fork; $k$, hind coxa with $l$, the inner and $o$, the outer laminae; $p$, the coxal process and $q$, the coxal notch; $r$, trochanter of the hind leg; $s$, femur; $t$, tibia; $u$, hind tarsus of five joints; $v$, spu $s$ of the middle tibia. $x, 2,3,4,5,6$, ventral abdominal segments, $s t^{1}, s t^{2}, s t 3$, sterna of pro-, meso-, and meta-thorax, respectively; $w$, wing of the metasternum. $m$, episternum, and $n$, epimercn of the successive thoracic segments. The coxal line is the line ex.ending between $l$ and $o$ in the figure, and the coxal border is the part of the coxal by the posterior end of the coxal line.

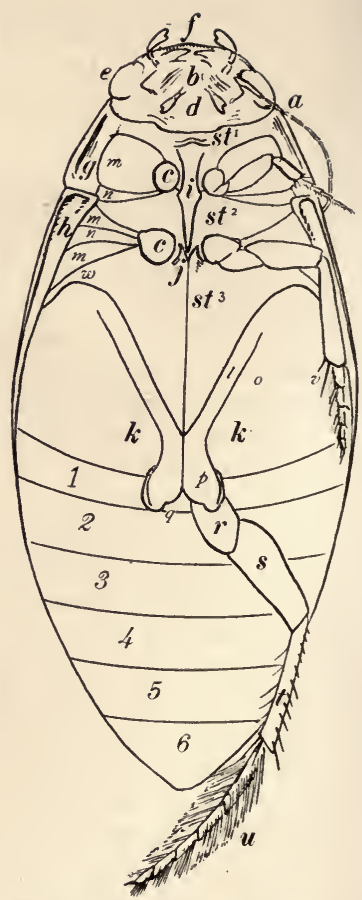

process, $p$, that is marked off laterally 
3. KEY TO THE GENERA OF ADULT DYTISCIDAE-DIVING BEETLES.

I. Third joint of the fore and middle tarsi deeply bilobed, the fourth joint rudimentary or wanting. 2 Third and fourth joints not greatly different from the others.................. 8

2. Scutellum visible (S. U. S.). (2)......... Celina

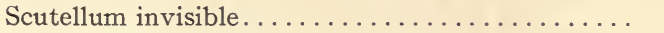

3. Hind coxal processes each divided by a deep posterior notch, the inner ramus oppressed against the first abdominal segment (6)....Hydrovatus Hind coxal processes not so formed .............

4. Hind-margin of outer lamina of hind coxa grown solidly coherent by its margin with the first ventral segment of the abdomen ............. 5

Hind margin of hind coxa overlapping but not coherent with the first ventral segment of

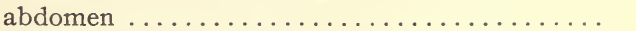

5. Prosternal process broad and short with obtuse hind margin; middle coxæ conspicuously separate

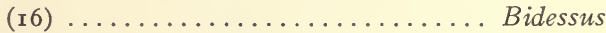

Hind end of prosternal process rhomboidal; middle coxæ more approximate (4)..... Desmopachria

6. A thin flat angulate process springing from the longitudinal ridge that extends along the under side of the wing covers near their side margins (visible only if the wing covers are lifted and viewed from beneath) (18) ............... Coelambus No such free process beneath the wing covers.... . 7

7. The mesosternal fork connected with the intercoxal process of the metasternum (72)....Hydroporus. The mesosternal fork not connected with the intercoxal process of the metasternum(4)..Deronectes. 
8. Scutellum invisible................. 9

Scutellum visible ................. I 3

9. Prosternal process broadly dilated and truncated behind; joints of the hind tarsi simple, without broadly over-lapping lobes ............ ro

Prosternal process compressed and pointed behind; joints of the hind tarsi with broad over-lapping external lobes (fig. $28_{5} A$ ) (13)...... Laccophilus

Io. A more or less conspicuous curved spur or hook on the apex of the front tibiæ. . . . . . . . . I I

No such hook present on front tibiæ (S. U. S.) (I)

Notomicrus

I I. Prosternum strongly angulate in the middle; body nearly globose; last joint of palpi emarginate at tip; hind coxal cavities separate; length $3.5 \mathrm{~mm}$. (S. U. S.) (I) ..................... Colpius

Prosternum flat; hind coxal cavities contiguous.. I 2

1 2. Prosternal process very broad behind; hind tibiæ very broad; length 4 to $7 \mathrm{~mm}$.(E. U.S.) Hydrocanthus

Prosternal process moderately broad behind; hind tibiæ rather slender; length less than $4 \mathrm{~mm}$. (5) Canthydrus

13. Inferior spur of hind tibiæ dilated, much broader than the other spur $(5) \ldots \ldots \ldots \ldots \ldots$ Cybister The two spurs of hind tibiæ of equal or nearly equal breadth

I4. Distal margin of the segments of the hind tarsi beset on the outer side with a transverse row of minute appressed bristles (Fig. $285 b$ ).

No such row of appressed bristles across the ends of the tarsal segments

15. Front margin of the eye circular; the last two pairs of abdominal stigmata greatly enlarged, each 
attaining a diameter equal to one fourth the width of the abdomen (I I)............. Dytiscus

Front margin of the eye more or less deeply notched, by the intruding margin of the front of the head; stigmata nearly uniform in diameter ........ I6

I6. A linear group of minute setæ present upon the postero-external angle of the hind femur (fig. $285 \mathrm{c}$ ). . I 7 No such linear group of setæ present......... 2 I

I 7. Claws of the hind tarsus equal, and joints simple. . I 8 Hind tarsus with its claws unequal, and its joints produced posteriorly in overlapping lobes (I6) Ilybius.

18. Palpi with the terminal joint dilated, that of the labial palpi sub-quadrate (Calif.) (I) Hydrotrupes Palpi with the terminal joint not conspicuously dilated ..................... I

I 9. Wing of the metasternum wedge-shaped ....... 20

Wing of the metasternum linear, and deflexed around the front border of the external lamina of the hind coxa (8)................ Ilybiosoma

20. Coxal lines very deep and nearly straight (Calif.) (I) Agabinus

Coxal lines fine and sinuous $(48) \ldots \ldots$.... Agabus

2 I. Last joint of palpi emarginate at tip (3) Coptotomus Last joint of palpi rounded or truncate at tip. . . . . .

22. Prosternum with a deep median longitudinal

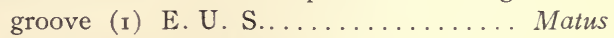

Prosternum not grooved :............... 23

23. Claws of the hind tarsi equal, movable......... 24

Claws of the hind tarsi unequal, the outer one fixed 25

24. The coxal border very broad (I).........Agabetes The coxal border very narrow (2) Copelatus

25. Upper surface of the body conspicuously reticulate (2) ................... Scutopterus 
Upper surface, if sculptured, not reticulate. . . . . 26 26. Metasternal groove broad and definite; length not over $\mathrm{r}_{5} \mathrm{~mm}$. (Io) . . . . . . . . . Rhantus

Metasternal groove narrow and indistinct ${ }^{\circ}$ (8) Colymbetes

27. Prothorax with a narrow lateral raised margin

Eretes

Prothorax without such a margin......... 28

28. Spurs of hind tibiæ acutely pointed at tip (4)

Hydatıcus

Spurs of hind tibiæ emarginate at tip........ 29

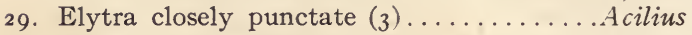

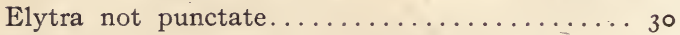

30. Middle femora beset with elongate setae (7)

Thermonectes

Middle femora beset with short and stout setae (3)

Graphoderes

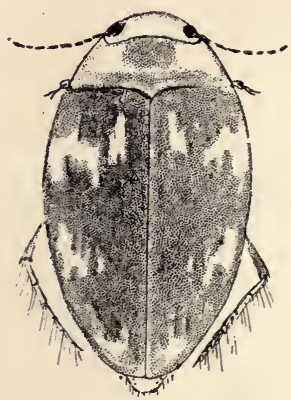

Hydroporus undulatus. 


\section{INDEX}

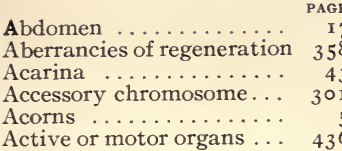

Adaptation ........287,459

Adaptation in the individual

Adaptations of flowers ...

Adaptations of insects....

Adaptive radiation ......

Adjustment ........ 14, 368

Adjustment in form and appearance

404

Aeschna.

427

Aestivation

376

Age of Stone

494

Agassiz

224

Air-swallowing

I 82

308

Ajax butterfly

429

Alaus

316

Algæ .......56, 105, I I 9, 334

Alimentary canal . I 64, I 86, i 97

Alternation of hosts..... 340

Allantoic artery ......... 215

Allantoic vein........... 2 I 5

Allantois

Alternation of generations

2 I 5

... I 24, 330

Alternative inheritance... 3 Io

Altricial birds......... 323

Amblyopsidæ ......... 288

Ambystoma ....... 1 79, 257

Amœba .......... 68, 437

Ammophila.......... 490

Amnion ............ 2 I 5

Amphibian .......... 214

Anabolism ......... 90

Analogy ............ 224

Anaphase ........... 294

Anax junius .......... 4I

Angiosperms.......... $\mathrm{I}_{52}$
PAGE

Animal coloration $\ldots \ldots, \quad 422$

Animal galls .......... $\quad 38$

Animal series ......... $\quad$ I 56

Animism .......... 502

Annual rings......... 147

Annulus ............ $\quad \mathbf{3} 35$

Antennae ........... I 7

Antennal hairs ........ 447

Antennaria ........ 359

Anterior abdominal vein . . $\quad$ I 88

Anther............. 9

Antheridium......... I 22

Antler .............. 365

Antipodal nuclei ....... I 53

Antiseptics .......... 98

Ants............. ro, 48

Ant sheds ........... 50

Aortic arches ........ I6 5

Apes ............. 485

Aphids........... $38,47,306$

Aphidæ............ 43

Aphid eggs ......... $\quad 52$

Aphid gall .......... 38

Apocynum .......... 366

Appendages ........ I8I, 23 I

Apposition ........... I I 4

Aquatic insects....... 407

Archæology .......... 493

Archæopteryx ........ 248

Archegonial disc........ I 23

Archegoniophore ....... I 22

Archegonium........ I 2 2, I 29

Arch-enteron ........ I 7 I, 197

Arcs $\ldots \ldots \ldots \ldots \ldots{ }_{46}$

Aristotle .......... 470

Artificial fertilization .... 304

Artificial division....... 353

Artificial selection ....... 279

Artisan stage $\ldots \ldots \ldots \ldots . \quad 496$

Asellus............ 233

Ascomycetes.......... 96

Asexual reproduction .... $33 \mathrm{I}$

Asexual reproductive cells 333

Asparagin .......... 85

Assimilation ........ 329 
PAGE

Assimilatory parenchyma. I20

Association fibers....... $46_{3}$

Aster............... 293

Atrophy ........... 252

Attitude ............ 425

Auditory nerve........ $46_{3}$

Auk .............. 7

Auricle ............ 187

Autogenetic responses ... 474

Avoiding reaction .....73,440

Axial skeleton ......... I8 I

Axone ............. 450

Back boned animals...... . I 80

Bacteria ......6.69, 97, I 73

Balance in nature......6, 325

Barbarian .......... 500

Beak ...........240, 242

Bee ........... $8,45^{8}$

Behavior of organisms... . 435

Bilateral symmetry ..... 288

Bile duct .......... I 86

Bimana .......... 485

Binder ........... $25 \mathrm{I}$

Biogenetic law ........ 257

Biophores .......... 3 이

Birch ............. $34 \mathrm{I}$

Bird's brain ......... 20I

Birth ........... 217

Birth rate $\ldots \ldots \cdots \cdots 3_{27}, 501$

Bison $\ldots \ldots \ldots \ldots \ldots \ldots$. 7

Bittern ........... 398

Bladderwort ......... ${ }^{252}$

Blastopore $\ldots \ldots \ldots \ldots$ I 7 I

Blastula ....... 17 1, 255, 358

Blended inheritance $\cdots 3$ 10, 3 I 6

Blood gills........... 408

Blood vessels ........ 201

Blue flag .............. 380

Body cavity . . . . . . ${ }_{\mathrm{I}} 6_{4}$

Bodyplasm ... I I 3, 29 I, 296, 363

Bones .............. ${ }_{184}$

Bombus........... 43 I

Bombylius major...... 34

Brain ... I89, 196, 257,455, 486

Brain paths............ $45^{8}$

Bread making......... 94

Breast bone .......... 42

Breeding habits ....... $44 \mathrm{I}$

Bronchial tubes ........ 187
PAGE

Brooks quoted ....... $\quad 368$

Blepharocera .......... 244

Bryophytes........... I I 8

Bryozoans........... 336

Budding $\ldots \ldots \ldots \ldots \ldots 92,33$ I

Buds ............. ${ }_{15} 8$

Bud variation $\ldots \ldots \ldots \ldots, 332$

Bumblebee ..........30, 429

Burdock ........... 476

Burdock moths ....... 425

Bur marigold ......... 271

Butter and eggs ........ 273

Buttercup .......... II

Butterfly .........2 I, 24

By-paths in the nervous system ......... $45^{2}$

By-paths of the brain .... 465

Caddisfly ......... 475

Caddis-worms........ 477

Callings ............ 505

Calosoma ........... $4 \mathrm{I}_{7}$

Calyptra .......... I 26

Cambarus ............ 233

Cambium ......... 145, $36 \mathrm{I}$

Canoe ............. 492

Capillitium .......... ${ }_{102}$

Carbohydrates ......... 83

Carbon ............ ${ }_{3} 3^{\circ}$

Carbon dioxide........ 83

Cardo............. I 8

Carmine ........... 73

Carpus ............ 259

Carriers ........... 523

Carrion beetle........ 420

Carrion flower.......... $47^{6}$

Case building ........ 479

Castle quoted ............ $3^{14}$

Castration $\ldots \ldots \ldots \cdots 3$ I9, 443

Casualties ..........6, 276

Caterpillars ......... $47^{2}$

Cat fishes........... 242

Cave bear ........... 495

Cave dwellers ......... 500

Cecidomyidæ $\ldots \ldots \ldots \ldots \quad 44$

Celithemis .......... 4 ro

Cell differentiation...... I 70

Cell division ...... I09, I 2 I, 293

Cell multiplication...... 170

Cell wall $\ldots \ldots \ldots \ldots \ldots 5^{8,59}$ 
Centralization PAGE

Centralization ........ 497

Centrosome.........293, 295

Cephalization ........ 455

Ceratium ............ I06

Ceratopogon ......... 409

Cercomonas ........... I Io

Cerebellum ....... 192, 200, 46I

Cerebral hemispheres .... 192, I $98,200,201,487$

Cerebrum .........459,46 I

Cervical vertebræ...... 225

Change of function ...... 253

Chara...........663,66, I1 3

Characters in germ cells. . 3 II

Charchesium......... 8 I

Charms ........... 505

Chauliognathus scutellaris 19

Chelipeds ........... 231

Chelone .......26, 252, 253

Chelone glabra ........ 29

Chemical elements ..... 82

Chemical engine ...... 89

Chemical stimuli . . . . 444, 445

Chickweed .......... I43, I48

Chicks ............. 48 I

Chironomus .......... 409

Chloragogue ........ I 75 , I 78

Chlorophyl, 58, 85, 92, 105, I 75

Chordata .......... 223

Chromosomes …294, 295, 299

Chromosome reduction .. 30I

Chromatin .......... 293

Cilia $\ldots \ldots \ldots \ldots \ldots \ldots 74,438$

Circulation ........ 202

Circulatory apparatus ... 2 II

Circulatory system ..... 187

Civilization $\ldots \ldots \ldots \ldots \ldots, 320$

Civilized life ........ 325

Cladophora .......... 65

Classification ......... $22 \mathrm{I}$

Clathrocystis ......... $6_{5}$

Cleavage .......... 193, 303

Climatic and metereological conditions

Coleochete

PAGE

Coleoptera ...

Colipta......24,42,44

Colias protodice ........ 24

Collaterals........... 450

Collecting .......... 520

Colony............ 8 1, I06

Coloration ........ 422

Closterium .......... 112

Columella ........... 126

Columns .......... $46 \mathrm{r}$

Combination of organisms 353

Commensalism ........ 400

Commensal nematodes ... $\quad 178$

Commissural fibres ..... $46_{2}$

Common parenchyma ... I 2 I

Competition .......... 275

Compound microscope ... $\quad 5^{\mathrm{I} 4}$

Concentrating apparatus . $\quad 5^{2} \mathrm{I}$

Conducting tissues ...... I I $_{32}$

Cone gall $\ldots \ldots \ldots 45,367,5^{24}$

Conifers ............ 149

Conjugating reaction .... 44 I

Conjugation ......... I I I , I 13

Conocephalus ........ I i 8

Conklin quoted........ 319

Contractile processes .... I 6 I

Contractility ......... 435

Control centers ....... 508

Control circuits ....... 453

Convergence ......... 243

Convulsions ......... 453

Cooking $\ldots \ldots \ldots \ldots \ldots$ 49

Co-operation......... 495

Coordination $\ldots \ldots \ldots 453,502$

Coptotomus .......... $4 \mathrm{I}_{7}$

Copulation .......... I 68

Copying pencil....... 4 I I

Coracoid bone ........ 259

Cord............ 46 I

Corethra ........ ;09, 425

Corn........... 6

Corpuscles, white ..... 173

Correlation ......... 459

Clistogamous flowers..... 284

Clitellum ........... I64, 169

Closed galls ......... 40

Closterium .......... 57

Cockroaches ........ 7

Cœlom .......... r64, 184

Correspondence between

ontogeny and phylogeny 255

Cortex .. I 47, $462,46_{3}, 465,487$

Correlation ............ 265

Costal grooves ........ $\mathrm{r}_{2}$

Cottonwood .......... 38

Countershading ...... 424 
PAGE

Cover glass .......... 518

Covering gall ......... 40

Cow-bird ........... 396

Cradle .............. 25 I

Cranial nerves ........ I90, 463

Crawfish ........... 355

Crickets ............ I $1_{3}, 308$

Crop ............. I 66

Cross-breeding ......... 3 I 5

Cross-fertilization ....... 129

Cross-pollination ....... 9

Crossed pyramidal tract .. $\quad 466$

Cross-section elm bough .. 405

Crustacea ...........230, 232

Crystalline lens.......... $55^{1} 3$

Culture stages.......... 499

Curculionidae ........ 44

Cutting tools........... 49

Cyanide bottle ....... 24, 52 I

Cynipidae ........434,44, 339

Cynipid galls.......... 44

Cynipid larva .......... 45

Cynthia .............. 312

Cytoplasm .......... $5_{58}^{8}$

Cytoplasmof the egg ... 302

Damselfly ............ 376

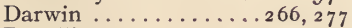

Dasyllis ............ 431

Death rate .......... 327

Degeneracy ............. 327

Degeneration ......... $25 \mathrm{I}$

Democracy ............ 320

Dendrites . . . . . 450, 457, 464

Derivation of tissues ..... I 75

Derived circuits ....... 454

Dessication .......... 378

Determinants ......... 301

Development . . . . . 148, I 70, 290

De Vries ............. 274

Differentiation .......... 442

Differentiation of habitat . $\quad 38 \mathrm{I}$

Dinobryon ........... 106

Diptera ..........20, 24,42, 44

Dipterous gall makers ... 42

Dissecting .......... 519

Dissimilation ............. 90,329

Distance receptors ...... 455

Distribution .......... 1 27,378

Divergent development 236,237
Diving beetles

PAGE

Division of l....4 I 5,527

Domestication ....... 7 76, 508

Domestication ..........5 I, 499

Domestication of aphids . 50

Dominant characters .... 3 10

Dorsal vessel........... I $6_{5}$

Dragonfly ............ 4ro

Draparnaldia ......... 334

Drawing ........... 520

Drepanidæ ........... 24 I

Dress ............. 506

Drop Cultures ....... I04, 5 I 9

Duckweed ................. $33^{2}$

Dytiscidæ..........4 I 5, 527

Ear. . . . . . . . . . 259, 447

Earthworm .......... I6 63,359

Ecological differences .... ${ }_{2} 8_{5}$

Economic procedure .... 7

Ectoderm ........ I 59, I 7 I , 448

Ectosarc ........... 7 r, 105

Education,

318, 324,459,490,511

Eels .............. 343

Egg .... I 22, I62, I 75, 193, 291

Elaters ........... I 24

Elder ............ I 4

Elementary species ..... 274

Elytra ............. 24

Embryo............ I30, I 5 I

Embryology . I 75, 255, 258,260

Endoderm........ I 59, I60, I 7 I

Endopodite.......... 232

End organs ......... 44 I

Endryas ............ 426

Endosarc............ 10 5

Endosperm .......... I 5 I

Endosperm nuclei .... . I 53, I 54

Energy ............ 83 , 90

Enteron......... 164, 1 85, 1 86

Environment . . . . . 1 27, 291

Epidermis,

I 20, I32, I37, I43, 356

Epistylis ............ 82 , I I 2

Epithelium ........ I72, I97

Equisetum ............ I 36

Erect attitude ........ 486

Eremochelys odoratus . . 322

Esophagus ....78, 82, I 66, I 83

Ethnological classification $49 \mathrm{I}$ 
PAGB

Ethnology. . . . . . . . 493, 494

Euglena.

Evaporation

I०5, 438

Evolution I I 7, 239, $264,277,3$ I 7

Excess of offspring

327.

Excess pollen production 10,402

Excess of young ....274, 325

Excretions .......... 59

Exopodite .......... 232

Experience .......... 490

Exposure ........... 2 I9

Expression of animals ... 434

Eyes ............ 1 82, 446

Eyespot. . ......429,438,445

Eye-stalk .......... 359

Fallopian tubes

2 I 5

Fat

Feathers

347

Fecundity

432

Felted galls

325

Fern.

39

129

Fertilization,

9, I I 2, I 27, I 38, I 50, I 69, 299

Fetishism .......... 504

Figwort family ....... 252

Filament ............. 9, $6_{I}$

Fire ............. 49

Fishes, blind ......... 288

Fish ............. 495

Fission............. 109

Fitness .................... 278

Flagellates ........... 104

Flagellum ........... 105,438

Flag weevil ......... 38 I

Flash colors ......... 427

Flat worm ......... 2 I I

Floral envelopes ....... I I

Flowers ............ I 48

Flower cluster ......... I4

Fluctuating variations ... 268

Fly wings .......... 230

Focal distance ......... $5^{\mathrm{I}_{3}}$

Fotus .............. 2 I 5

Food cavity .......... I 7 I

Food solution ......... $8_{3}$

Food-taking .......... 440

Food tube ........... I I $_{5}$

Foot. . . . . 78, I $23,126,130,157$

Forbes quoted
Fore brain

PAGB

I 99

Fore limbs of vertebrates . 225

Foresight .......... 496

Formic acid .......... 43

Fourth ventricle....... I92, 200

Fragmentation ....... 338

Frog . . . 275, 358, 362, 466, 485

Fruit ............ 148

Funnel............ I6 6

Galea ........... I 8

Galls... . . . . . 7, 96, 35 1, 524

Gall cyst . . . . . . . . 1 86, 198

Gall midge ........ 4 42, 352

Gall wasps..........443, 339

Gallery ............. 52

Gamete ......... I 24, I38, I42

Gametophyte ..... 1 24, I 38 , I 52

Gammarus ........... 233

Ganglion ........ I 90, I 99, 448

Gastric glands . . . . . . I 85, I 9 I

Gastrula ........ I 7 I, I 94, 255

Gastrulation ............ I 7 I

Gelatine solution ....... 74

Gemmules .......... 334

Genealogic tree......... 236

Genius in families....... $32 \mathrm{I}$

Geographic barriers ..... ${ }_{28} 8_{3}$

Geographic distribution .. $\quad 284$

Geranium ................. 353

Germ cells .......... 299

Germ plasm .....291,320,363

Germination .................. 336

Ghost stories. . . . . . . . 505

Gill arches .......... 197

Gill chamber ......... 4 I I

Gill clefts........... 197

Gill-pouches ......... 259

Gill scoop ........... 233

Gills ............. 4 I I

Gizzard ............ I66

Glands ........... I 69

Glottis .......... 183,186

Glosso-pharyngeal nerve. . ${ }_{4} 6_{3}$

Goldenrods ............... 36

Gomphus ............. 356

Gonangia ........... 122

Gonium ....................... 106

Grafting ............ 360-523

Grafting in animals ..... $36_{2}$ 
PAGB

Grafting wax ........ 523

Grasshopper ......... I I 3, 343

Grasshopper eggs ...... 45

Green plants ......... 370

Gregarine ............ I I 3

Group development .... 242

Groups of organisms .... 220

Group radiation ...... 239

Growing point ........ I 29

Growth habit ......... 373

Guard cells ............ I 43

Guest gall-flies ......... 45

Guide marks ......... 33

Guide streaks .......... I 2

Guinea pigs ......... 3 I 4

Gymnosperms ......... I $5^{2}$

Gypsy moth ......... 399

Gyrinus ............ 386

Habit $\ldots \ldots \ldots \ldots \ldots .483$

Hæmoglobin ........ I 77

Hairs of bees ........ 23

Halesus ......475, 476, 478

Half embryos ......... 358

Hand ............ 486

Harmony ......... 509

Hawk ............ 480

Head ............. I 7

Head Kidney ......... 204

Heart............ 187

Heat ............ 85

Hemiptera $\ldots \ldots \ldots 21,42,43$, 5 I

Hemipterous gall makers . 42

Hemispheres of brain $\ldots 457,462$

Heptagenia .......... 244

Herbivores ......... 379

Hereditary diseases .... 318

Heredity .........259, 289

Hermaphroditism ....... I 69

Heterogeneous inheritance 3 10

Hertwig............. 299

Hibernation ........... 376

Historical documents .... 492

History of germ cells . .... 296

Homology ....223, 233, 258, 264

Honey bee........... I9

Honey dew .......... $4^{8}$, $5^{\text {I }}$

Hormones .......... 443

Horse............... 250

Horsetail

PAGE

Host .............. 396

Human brain . . . . . . 487

Human hand $\ldots \ldots \ldots \ldots .486$

Human population ..... 326

Human species ........ 485

Humming-bird flowers ... I 2

Hunter stage $\ldots \ldots \ldots \ldots, 495$

Husbandry ......... 51,496

Hybrids........... 307, 3 I I

Hydra ....... 157, 164, 354, 47 I

Hydranth ............ 330

Hydroid ........... 330

Hydrophytes .......... 372

Hydroscopic cells .... I $36,1_{3} 8$

Hyla ........... 426

Hymenium .......... 96

Hymenoptera ........24, 42

Hymenopterous gall makers 43

Hyoid apparatus ....... I8I

Hyoid bone .......... 204

Hyper-parasites ...... 399

Hypertrophy ........ 367

Ideal condition of society 326 Ids ............ 3 or

Imago ............ 344

Imitation .......... 5 I 9

Implements ......... 496

Incisor teeth $\ldots \ldots \ldots \ldots .259$

Inclusions $\ldots \ldots \ldots \ldots \ldots . \quad 59$

Income $\ldots \ldots \ldots \ldots \ldots$ 9I

Indian corn. . . . . . . . 5 I

Indian pipe $\ldots \ldots \ldots \ldots . \quad 397$

Infancy $\ldots \ldots \ldots \ldots \ldots .489$

Infundibulum........ 200

Inheritance $\ldots \ldots \ldots \ldots, \quad 295$

Inheritance of acquired characters ......... 318

Insects........... I $7_{7}$

Instincts $\ldots \ldots \ldots \ldots \ldots .473$

Integuments $\ldots \ldots \ldots \ldots$ I 53

Intensified inheritance ... 3 I0

Intercommunication ... 442

Interdependence $\ldots \ldots 4,7,368$

Intergradation $\ldots \ldots \ldots \ldots \quad 264$

Intermediate forms ..... $9 \mathrm{I}$

Internal gills ......... 4 I 1

Internal secretions $\ldots \ldots .443$

Intestine $\ldots \ldots \ldots \ldots \ldots$ I 97

Inventor stage $\ldots \ldots \ldots \ldots \quad 497$ 
Iris

Iris weevil

Ischnura

Isolation - Th

Jelly fish

Joint-grass

Juncos

Jungermannia

Juvenescence

Karyokinesis

Katabolism

Kidney .......... I 84 , I 88

Kinetic energy ........ $\quad 84$

Kinglet ........... 476

Kitten ........... 480

Labella

20

Labium

I 8

Labrum

18

Lacinia

I 8

Lack of insight ....... 49

Lactuca ........... 40

Lancelet .........206, 214

Language ...........489, 490

Laughter .......... 502

Law of specialization . .2 I 9,422

Leaf ......... r $30, \mathrm{r}_{3} 8, \mathrm{I}_{43}$

Learning by experience... 479

Leaves of mosses ....... $\quad 125$

Leeuwenhoek ........ 299

Legs $\ldots \ldots \ldots \ldots \ldots \ldots$ I 7

Lemurs ............ 485

Leopard frog......... 425

Lepidoptera $\ldots \ldots 24,42,44,426$

Leptocephalus ......... 343

Lestes ............. 376

Leucocytes ......... I 73, $35^{\circ}$

Libellula ............ ${ }_{28}$

Lichen............ 390

Lichen buds ......... 395

Life cycle .......... 329

Life process.......8 $82, I_{7} 6,2$ I 7

Line of descent ...... 29 I

Line of succession ...... 291

Linin ............ 293

Linnæus ........... 220

Lioness ............ $32 \mathrm{I}$

Liver ......... I 86, 198
PAGE

238

Lloyd Morgan quoted .... 364

Loosestrife .......... I I $_{3}$

Lop-ears in rabbits .......

Lorica ............ 37

Loss of color ......... 425

Lost appendages ....... $\quad 355$

Lungless salamanders .... $\quad$ I $_{3}$

Lymph vessels .......... $2 \mathrm{I}_{3}$

Macrobiotus ......... 377

Macropis ciliata ........ 8

Macrosporangium ..... 138, I 50

Macrospore ...138, I40, I49, I 53

Mad stone $\ldots \ldots \ldots \ldots \ldots 505$

Magic.............. 504

Magnifying power $\ldots \ldots \ldots \quad 5^{1} 3$

Malacostraca ......... 230

Malpighian tubules ...... 4 I I

Mammoth .......... 493

Man .............. 207

Mandibles .......... I 8

Mantle galls .......... 39

Manual training $\ldots \ldots \ldots \quad 487$

Marsh hawks ........ 324

Marsupials ........... 242

Matter ........... $88_{2}$

Maturation ......297, 299

Maxilla .......... I8, 23 I

Maxillipeds ......... $23 \mathrm{I}$

Mayflies....... 244, 258, 347

Meaning of nurture ...... $32 \mathrm{I}$

Mechanical stimuli...... 444

Medulla ..... I45, 192, 201, 461

Medusa ............. 330

Meganucleus ........ 75, 80

Mendel ........... 310

Mendelian inheritance ... 310

Meristem ........... I I3 $_{33}$

Mesentery .......... 186

Mesoderm ....... I7 I, I73, r95

Mesophytes.......... $37^{2}$

Metabolism,

86,2 I $8,329,443,457$

Metamorphosis ...342, 345, 352

Metaphase ........... 294

Metazoa ............ $44 \mathrm{I}$

Metzneria .......... 425

Micrasterias ......... 68

Micronucleus .......75, 80 


\begin{tabular}{|c|c|c|}
\hline & & \\
\hline Micropyle. & I 50 & Nauplius \\
\hline Microscope & 517 & Necrophorus \\
\hline Microsporangia $\ldots \ldots \ldots 138$, & 149 & Nectar \\
\hline Microspore ..... 1 38,149 , & & Nematocysts . \\
\hline$\ldots \ldots \ldots \ldots$ & $35 \mathrm{I}$ & Nematocytes ... \\
\hline Milkweed bug $\ldots \ldots \ldots$. & 429 & Nematode.... \\
\hline Mineral salts .......... & 88 & Nephridium ....... 66, I 74, I84 \\
\hline$\ldots \ldots \ldots \ldots$ & 429 & Nerve and muscle...$\ldots$. \\
\hline$\ldots \ldots \ldots \ldots$ & $5 \circ 5$ & Nerve cells $\ldots \ldots \ldots$ I61, I 72, 44 I \\
\hline$\ldots \ldots \ldots \ldots$ & 39 & Nerve cord ........ \\
\hline $\begin{array}{l}\text { Mitosis. . . . . . . . . . . . . . . } \\
\text { Mitotic figures . }\end{array}$ & $\begin{array}{l}294 \\
205\end{array}$ & $\begin{array}{l}\text { Nervous system, } \\
\qquad \mathrm{I} 65, \mathrm{I} 89,45 \mathrm{I}, 459,460,487\end{array}$ \\
\hline Iode ................. & 268 & Nest building ......... 475 \\
\hline$\ldots \ldots \ldots$ & 476 & Net \\
\hline$\ldots \ldots \ldots \ldots$ & 95 & Neural.folds . . . . . . . . \\
\hline$\ldots$ & 496 & Neural tube. \\
\hline$\ldots \ldots, 4_{48}$ & 490 & $\ldots \ldots \ldots \cdots \cdots$ \\
\hline edons $\ldots \ldots \ldots$ & 147 & $\because \ldots \ldots \cdots \cdots$ \\
\hline is $\ldots \ldots \ldots \ldots$. & 379 & Night blooming flowers ... \\
\hline$\ldots \ldots \ldots \ldots$ & 488 & $\ldots \ldots \ldots 60,62$, II $3_{3}$ \\
\hline $1 \ldots \ldots \ldots \cdots$ & 510 & Nitrogen waste $\ldots \ldots \ldots$ \\
\hline$\ldots \ldots \ldots \ldots$ & $35^{8}$ & 67 \\
\hline es & I 25 & 183 \\
\hline $.21,3^{6}, 4^{26}, 45^{6}, 4^{6} 9$ & 476 & spindle $\ldots \ldots \ldots$ \\
\hline ........ & 466 & ...... \\
\hline rts $\ldots \ldots \ldots \ldots$ & I 7 & ed galls.......... \\
\hline$\ldots \ldots \ldots \ldots$ & 95 & $\ldots \ldots$ \\
\hline$\ldots \ldots \ldots$ & 308 & cal variation ..... \\
\hline reproductive & & 318 \\
\hline .. & 3 & 76 \\
\hline ptors $\ldots \ldots \ldots$ & 446 & 344 \\
\hline s...m. & & 5,36 \\
\hline$\ldots \ldots \ldots$ го & 167 & mena.... \\
\hline$\ldots \ldots$ & 322 & nerves \\
\hline ...273 & 317 & bes $\ldots \ldots \ldots$. \\
\hline ... & 286 & nerve $\ldots \ldots \ldots$ \\
\hline$\ldots \ldots \ldots \ldots$ & 95 & us $\ldots \ldots \ldots \ldots$ \\
\hline$\cdots$ & IOI & Ontogeny $\ldots \ldots \ldots 255,358,498$ \\
\hline$\cdots 78,80$ & 0,82 & 297 \\
\hline & 254 & 296 \\
\hline Myxomycetes & IOI & dlum $\ldots \ldots \ldots \ldots$ \\
\hline $\operatorname{arcotics} \ldots \ldots \ldots \ldots$ & 506 & Optic nerve $\ldots \ldots \ldots \ldots$ \\
\hline Native population . & $5 \circ 2$ & $\begin{array}{l}\text { Optic lobes } \ldots \ldots \ldots \ldots \text { 192, } 200 \\
\text { Optic ventricles } \ldots \ldots \ldots{ }_{200}\end{array}$ \\
\hline $\begin{array}{l}\text { Native population } . \dot{ } \\
\text { Natural balance } .6 \text {, }\end{array}$ & 326 & Oral groove $\ldots . . . \ldots \ldots \ldots$ \\
\hline & & 484,485 \\
\hline & & 367 \\
\hline & 379 & Organism, the social \\
\hline & & Organization . \\
\hline
\end{tabular}


Organs of out-reach $\ldots \ldots \quad \begin{array}{r}\text { PAGR } \\ 438\end{array}$

Origin of species ....... 277

Orthogenesis.......281, 507

Outgo .............. 9 I

Outlook ..........509, 5 I I

Ovary .......1 22, I62, I 88

Overspecialization .... 282

Oviducts ......... I89, 2 I 5

Ovule........... 8 , r 50

Ovule case......... 8

Ovum ........... II

Palæontology ....246, 260, 492

Palatine teeth ........ I $8_{3}$

Palpus

18

Pancreas ...... 86, I 98, 443

Pandorina $\ldots \ldots \ldots \ldots \ldots$ 10 7

Parallelism .......... 287

Paralysis .......... 466

Paramoecium . 72, I I I , 439, 469

Parasite...45, 50, 252, 263, $35^{6}$

Parasitic protozoans ..... I I 3

Parasitism ........... 396

Parenchyma ........ I20, I 32

Parthenogenesis . 304, 306, 339

Pasteur............ 93

Pasteur's Solution ....... 93

Pastoral stage......... 496

Pectinatella ......... 335

Penicillium ......... 95

Pennaria ........... 359

Pentstemon .......... ${ }_{253}$

Perianth ........... II

Peristome.......... 78

Peritoneum.......... I 74

Perla ............. 244

Persistence of the unspecialized ........ 250

Petals ............ 7-9

Phagocytes ......... 350

Pharynx ....... I65, I8 8,197

Philodina ......... 378,379

Phloem ............ 134, I45

Phlox............ 26

Phylloxera ......... $36_{2}$

Phylogenetic adaptation. . 415

Phylogeny $\ldots \ldots \ldots \ldots 236,255$

Phylum ........... 236

Physical basis of racial solidarity
PAGE

Physcia $\ldots \ldots \ldots \ldots \ldots \ldots .393$

Physiog raphic barriers ... $\quad 285$

Pickling............ 98

Pike ............ 275

Pine $\ldots \ldots \ldots \ldots \ldots \ldots$ r 49

Pineal body ........ r98, 200

Pistachia .......... 367

Pistil ............ 9

Pituitary body ....... 200

Pith ............ 145

Pitted vessels .......... 146

Placenta ........... 215

Planarian ........... 354, 523

Plankton net. . . . . . . $52 \mathrm{I}$

Plasticity ........... 264

Plasmodium ......... IOI

Play ............. 499

Plover............ 426

Pocket gall .......... 40

Polar bodies ......... 297

Polarity............ 359

Pollen $\ldots \ldots \ldots \ldots, 7,9,2$ I, 402

Pollen basket .......... 23

Pollen distribution..... 400

Pollen sacs .......... 149

Pollen tube ......9, 150, 153

Pollination ......... 402

Polyembryony ....... 337

Pond animals . . . . . . . 386

Pond life .......... 385

Pond snails ........ 523

Pons ............ 463

Pores ............ 120

Post-embryonic development ............ 343

Potato ..........., $36 \mathrm{I}$

Potential energy ...... 84

Pouched mammals ..... 242

Prairie ........... 6

Precava .......... $\quad{ }_{1} 88$

Preserves .......... 98

Pride of ancestry ...... 321

Primary differentiation .. 219

Primary food of animals . $\quad 3$

Primary germ layers ..... I 77 I

Primates .......... 485

Primitive haunts ....... 25 I

Proboscides ......... I9

Process of evolution..... $\quad 266$

Progress in regression .... $\quad 263$ 
Progressive development

Projection fibers.........

Pronephric duct .......

Pronephros ..........

Prophase ...........

Prostomium .......... I 63

Proteins $\ldots \ldots \ldots \ldots \ldots 83,86$

Prothallium ...... 129, I 38 , I 53

Protoplasm, $57,59,88$, 10 I, I 5 I, 2 I $8,290,299,435$

Protozoa.. 68, 105, 22 I, 437, 44 I Psephenus lecontei ...... 244

Pseudo-navicellae ..... I I 5

Pseudopodia......7 7 I, I03, 438

Psocid wings ........ 230

Psychic phenomena $\ldots . .4436$

Psychic states.......434, 437

Psyllidae .......... 43

Pteridophytes ........ I 28

Pteris.

I 29

Pulmonary circulation ... 202

Pupa .......344, 347,352, 362

Pylorus .............. ${ }^{1} 85$

Pyrenoids ............ $6_{2}$

Quadrumana ......... 485

Quercus macrocarpa ..... 45

Race feeling ........ 286

Racia'l differentiation .... 320

Racial improvement ..... 328

Radial symmetry ...... $\quad 288$

Radiant energy ........ 84

Rag weed ............ 268

Rag weed seeds ....... 269

Reaping machines ...... 257

Recapitulation ........ 265

Receptacle ........... I 22

Receptors ......436, 44 I, 445

Recessive characters ..... 310

Reflex arc .......... 450

Reflex response ....... 457

Refraction ......... 5 I 5

Regeneration ....3 353, 356, $36_{3}$

Regeneration in cells … 357

Regenerative cells ...... $35 \mathrm{I}$

Regressive development . $25 \mathrm{I}$

Reindeer moss ........ $39 \mathrm{I}$

Relations between ants and aphids
47
PAGB

Reproduction ....109, 289, 329

Reproductive cells ..... I 22

Reproductive methods ... 338

Reproductive organs $\ldots 167$, i 88

Resemblance ......... 423

Reserve potentialities.... 363

Respiration aquatic ..... $2 \mathrm{II}_{3}$

Retrogression ......... 283

Robber fly.......... 429

Rhizoids .......... I 19, I 20

Rhizome .......... I3 I, I36

Rhus glabra ......... 37

Riccia ............ I I 24

Root .............. $x_{30}$

Root louse........... 53

Root tubercles ......... 99

Rotifers .........339, 378

Sacculina.......... 397

Salamander .. I 79, 255,460, 487

Sandpiper ................. 323

Savages $\ldots \ldots \ldots \ldots \ldots .497$

Scenodesmus ......... 66

Schultze........... 89

Scion ............ 360

Scouring-rush $\ldots \ldots \ldots \ldots$ I 37

Scroll gall ........... 40

Sea urchin egg $\ldots \ldots \ldots 291,357$

Secondary circuits $\ldots \ldots \quad 454$

Secretin .......... 443

Secretions....... 59, 87, 443

Seed ............ 148, I5 I

Seedlings ........... ${ }_{27} 8$

Seed plants ........ I $42,{ }^{2} 5^{2}$

Seers ............ 509

Segmentation cavity .... I 70

Segments ........ I 7, 231

Segregation........28 3,331

Selaginella .......... ${ }_{13} 8$

Selection $\ldots \ldots \ldots \ldots \ldots .339$

Self pollination ........ I0

Senescence ........... 329

Sense organs $\ldots \ldots \ldots \ldots \quad 444$

Sepals ............. 9

Sepedon ............ 408

Septa $\ldots \ldots \ldots \ldots \ldots$ I $_{5}$, I $_{7}$ I

Sequences of activities ... 473

Serial homology $\ldots 225,230,234$

Seta .............. 164

Sex cells ........ $66_{7}, 290$ 
Sexual reproduction,

Sporoganium

Sickle

I I O, I I 2,2 I 4, 33 I

Sieve tube

Silica

I 33

Silk bolting cloth

Silk glands

Size

474

$\ldots \ldots \ldots \ldots 2$ I9, 38 I

Skeleton .......... 448

Skin glands $\ldots \ldots \ldots \ldots \ldots \quad{ }_{1} 8_{3}$

Skunk ............ 429

Slime molds ......... IO

Slime-mold plasmodium . 435

Small intestine ....... $\quad$ I 85

Smell

444

Snails

388

Social conduct ........ 509

Social integration....... 507

Social organism ....... 507

Society …....379, 507,509

Song Sparrow .......284, 395

Somatic layer ......... ${ }_{172}$

Soredia ........... 395

Sori ............ I 36

Sound receptors $\ldots \ldots \ldots \quad 447$

Sparrow ........... 396

Spathegaster . . . . . . . 339

Special creation ........ 264

Specializatian....... 282

Specialization by reduction 253

Speech ............. $55^{\circ 2}$

Sperm .........11 $2, \mathrm{I}_{2}$

Spermary ...122, I62, 168, I 88

Spermatogones......... 296

Spermatophytes...... I42,297

Spermatozoan ......... II 2

Sperm cells ......... I 68

Sperm nuclei........ I 49, I 53

Sperm receptacles ...... I ${ }^{6} 7$

Spiders ............ 471

Spinal column ........ 180

Spinal cord ...... I89, I96, 45 I

Spinal nerves ......... 190

Spinning glands ....... 475

Spireme ........... 293

Spirogyra .........6. 6 , I 10

Splanchnic layer ....... I 72

Spleen ............. I 86

Sporangium . . 1 23, I 26, I 35, I 38

Spores....97, 102, I I 5, I 24 , I 26

Sporophores ......... 95

Sporophyte, .. I23, I26, I30, I35

Sporozoa ........... I I 2

Spotted salamander..... I 79

Spreading dogbane $\ldots \ldots . \quad 366$

Squilla .................. 233

Shelter........... 4

Smooth sumac ........ 271

Stalk ........... I23, I 26

Starch ............ 85

Starfishes .......... 291

Starling quoted $\ldots \ldots \ldots \ldots .490$

Statoblasts ......... 334

Steironema ........ 8

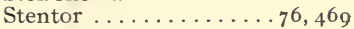

Stem borers .......... ${ }_{36}$

Sterilization ......... $\quad 9_{98}$

Stigma............ 9

Stigmatic surface ...... 33

Stimulants ......... 506

Stimulus ......4 435, 444, $45^{2}$

Stipes ........... I8

Stock ............ 360

Stomach ........... I 85

Stomach-intestine ..... I 66

Stomates ...... I27, I3 I, I43

Stone ax .......... 490

Stoneflies ........... 244

Stone knives ........ $49 \mathrm{I}$

Stoneworts . . . . . . . II

Strap lichen $\ldots \ldots \ldots \ldots . \quad 392$

Stratification ........ 373

Struggle for existence ... $\quad 276$

Strychnine .......... 468

Style ........... 9

Sub-intestinal vessel .... I ${ }^{6} 65$

Sugar ............ 94

Sumac............36, 270

Sunfish ........... 275

Supporting tissues $\ldots \ldots$ I32 $^{2}$

Survival of the fittest $\ldots 276,456$

Swallow............ 243

Swift ............ 243

Swarming ......... 522

Swarm spores $\ldots \ldots \ldots \ldots .333$

Symbiosis . . . . . . . 390, 400

Symbols ............ 490

Symmetry.......... 288 
Sympathetic system .... I00, 460

Synapsis ............ 303

Synergid nuclei ........ I 53

Synthesis ........... 84

Synthetic types ........ 248

Syrphidæ .......... 432

System of classification $\therefore \quad 222$

Systems of organs ..... 442

Tails of sheep ........ 3 I9

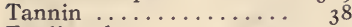

Tardigrades .......... 377

Tarsus ............. 243

Teeth ............ 27,183

Telophase........... 294

Telson ............. 23 I

Tentacles ........... 157

Tenthredinidae ....... 44

Terrestrial life ......... I 2 I

Testes ............. I 88

Thallophytes ......... I 18

Thallus .......... I 19, I 29

Third ventricle ....... 200

Thoracic duct ........ 213

Thorax ............... 7,232

Thyroid gland ....... 443

Time adjustments ..... 375

Tipula............. 229

Tongue ............ 183

Tools .............. 49

Tool using $\ldots \ldots \ldots \ldots 487,490$

Torulæ............. 92

Toti-potent sperm nucleus 304

Touch ...........444, 446

Tracheae ...... $87,259,408$

Tracheal gills ........ 409

Tracheid ............ I 33

Transformation of insects 343,347

Tree frog ........4 426,427

Trial and error ........ $48 \mathrm{I}$

Tribal societies ....... 50 I

Types of inheritance .... 308

Types of nurture ....... 214

Types of symmetry ..... 288

Upper brain .......... 48 I

Ureter ............. I88, 206

Urinary bladder ...... 186, 1 98

Uterus . . . . . . . . . I 89,2 I 5

Utricularia .......... 252

Vacuole ............ $5^{8}$

Vagus ............. I 9 I, $46_{3}$

Van Beneden
Variation ......267, 268, 289

PAGE

Vascular bundles ...... 132, 143

Vaucheria .......... 65

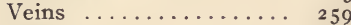

Velvet ............. ${ }_{36} 65$

Venation of leaf ........ 135

Venous sinus.......... 187

Ventricle ........... 187

Vertebra ............ I 80

Vertebrate characters .... I95

Vestigial structures . . 259, 265

Vesture ............. 2 I

Vibrations............ 446

Vibratory stimulus ..... 453

Villi ............. I $8_{5}, 2$ I 5

Viola cucullata ....... 33

Violet ................ I3 52

Vision ............ 445

Vital relations ........ 7

Volvox .............. 107, 112

Von Baer ............ 174

Vorticella . . . . . . . . 76, 79

Vorticellidae ........ 8 I

Wars ............. 326

Warning coloration ..... 449

Wasp ............. 490

Water and distribution .. 372

Water penny ......... 245

Water vessels ........ 492

Weaklings .......... 279

Web .............. 4

Weevil ............ 5, 379

Whirligig.......... 387

Willow........... I I 45,352

Wind, effects of ...... $40 \mathrm{I}$

Wings $\ldots \ldots \ldots \ldots 17,225,258$

Wing veins $\ldots \ldots 225,229,258$

Winter buds ......... 334

Witch hazel aphid ...... 341

Witches' broom ........ 37

Wood.............. I45, 146

Woodland plant society .. 373

Xerophytes ......... 372

Xylem ............ 145

Yeast .............. 92

Yolk plug ............ I 94

Zoaea.............. 343

Zoochlorellæ.......... 394

Zoospore ..........333, 340

Zoothamnium ........ 8 I

Zygote ............ 297 

QH

308

$\mathrm{N}_{4}$

\section{THE LIBRARY \\ UNIVERSITY OF CALIFORNIA \\ Santa Barbara}

THIS BOOK IS DUE ON THE LAST DATE STAMPED BELOW. 
UC SOUTHERN REGIONAL LIBRARY FACUITY

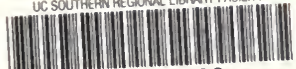

A 0012448890 


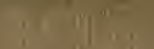

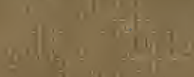

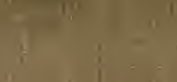

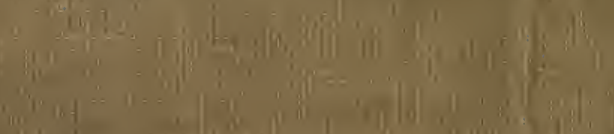

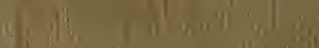

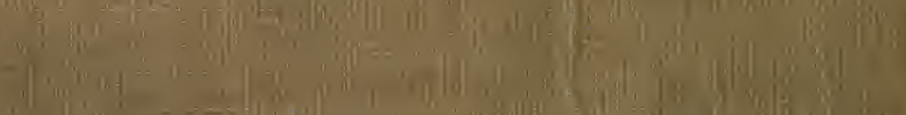

(1) a

1. 10, lint

and rem

and

Sint all ly I.t.

(n) Sin.

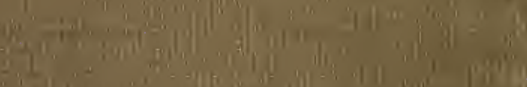

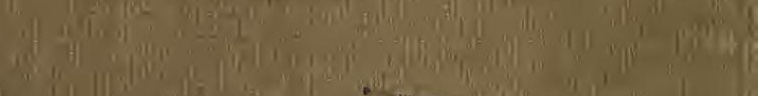

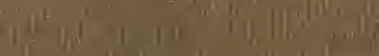
(14)

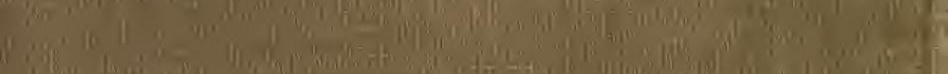
(1) Don $x_{n=1}$ (and (1)

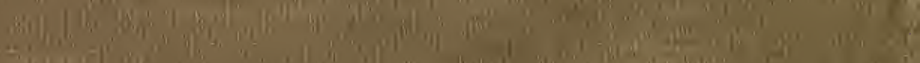

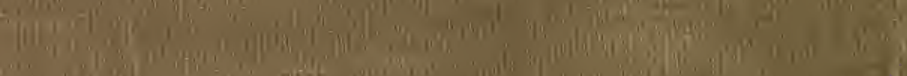

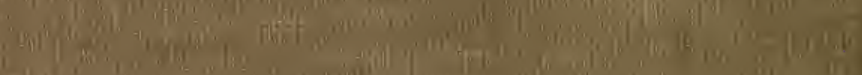

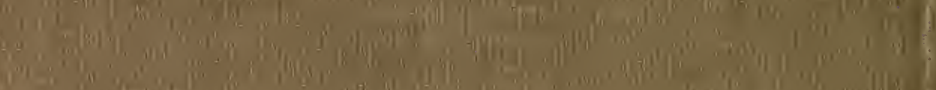

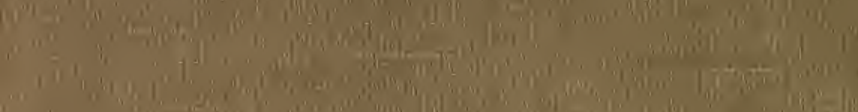

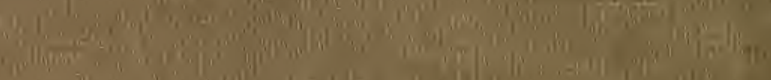

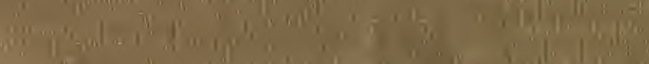
20. 